\title{
Synthesis Report on Thermally Driven Coupled Processes
}

\author{
Ernest L. Hardin \\ Dwayne A. Chesnut \\ Lawrence Livermore National Laboratory \\ with contributions from \\ Timothy J. Kneafsey \\ Karsten Pruess \\ Lawrence Berkeley National Laboratory \\ and \\ Jeffery J. Roberts \\ Wunan Lin \\ Lawrence Livermore National Laboratory
}

October 15, 1997

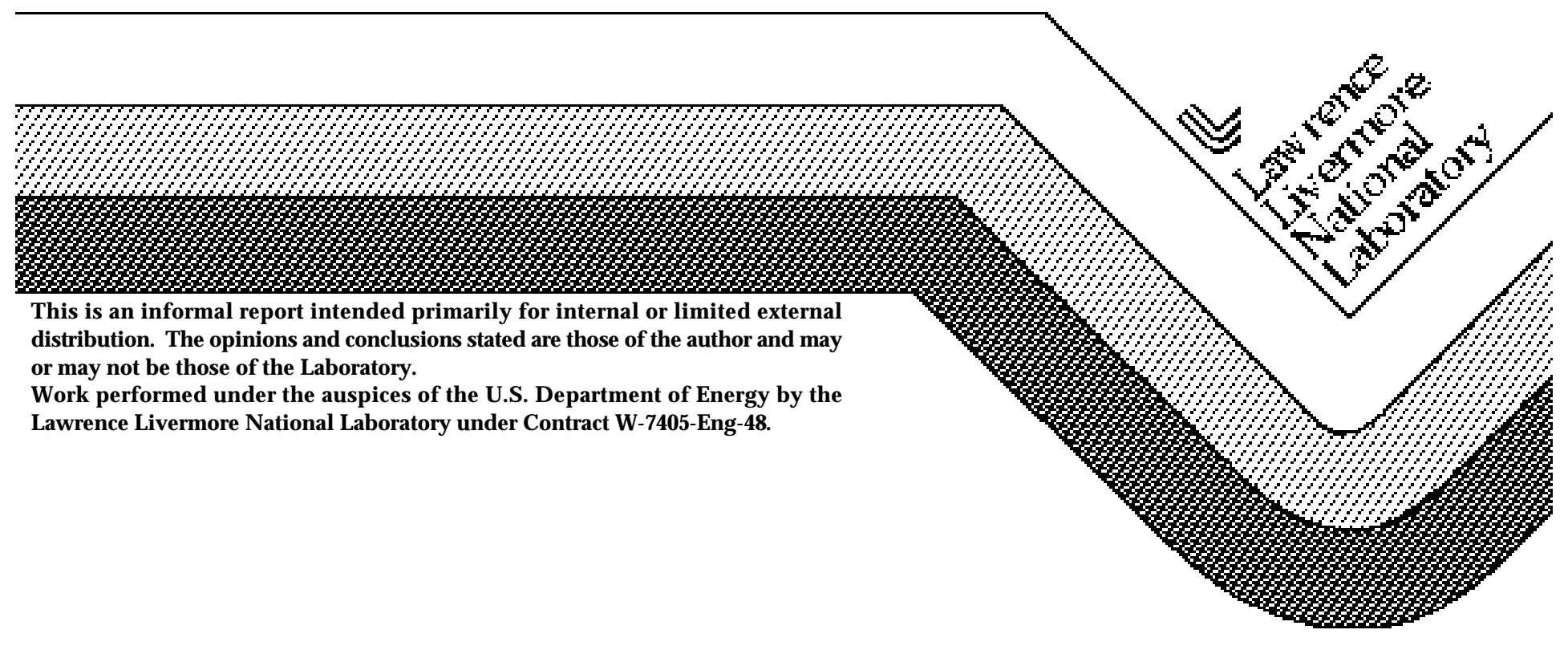




\section{DISCLAIMER}

This document was prepared as an account of work sponsored by an agency of the United States Government. Neither the United States Government nor the University of California nor any of their employees, makes any warranty, express or implied, or assumes any legal liability or responsibility for the accuracy, completeness, or usefulness of any information, apparatus, product, or process disclosed, or represents that its use would not infringe privately owned rights. Reference herein to any specific commercial product, process, or service by trade name, trademark, manufacturer, or otherwise, does not necessarily constitute or imply its endorsement, recommendation, or favoring by the United States Government or the University of California. The views and opinions of authors expressed herein do not necessarily state or reflect those of the United States Government or the University of California, and shall not be used for advertising or product endorsement purposes.

This report has been reproduced directly from the best available copy.

Available to DOE and DOE contractors from the Office of Scientific and Technical Information P.O. Box 62, Oak Ridge, TN 37831

Prices available from (615) 576-8401, FTS 626-8401

Available to the public from the National Technical Information Service

U.S. Department of Commerce 5285 Port Royal Rd., Springfield, VA 22161 


\section{Contents}

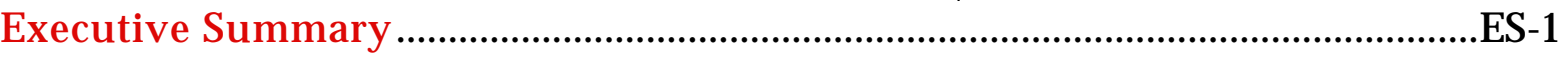

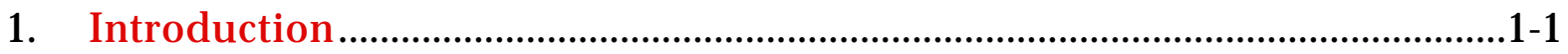

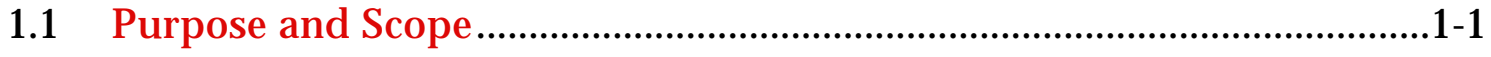

1.2 Types of Coupled Processes.........................................................................1-1

1.3 Thermodynamics of Coupled Processes …….............................................1-3

1.4 Onsager Processes......................................................................................1-5

1.5 Transient vs. Residual Effects ................................................................1-6

2. Laboratory Property Measurements......................................................................2-1

2.1 Purposes of Measurements...................................................................2-1

2.1.1 Support for Test Design and Analysis...............................................2-1

2.1.2 Support for Repository Design, System Studies, Performance Assessment, and Related Purposes.........................2-2

2.1.3 Types of Measurements....................................................................

2.2 Physical Properties (Dry Bulk Density, Grain Density, and Porosity) ……….................................................................................... 2-5

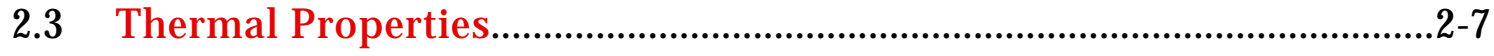

2.3.1 Thermal Conductivity ………….......................................................

2.3.2 Heat Capacitance .........................................................................2-10

2.3.3 Thermal Diffusivity.....................................................................2-12

2.4 Thermal Expansion .................................................................................... 2-13

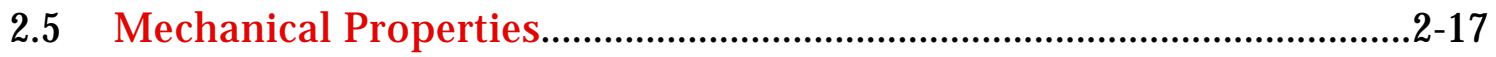

2.5.1 Strength and Deformability.........................................................2-17

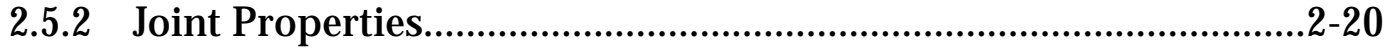

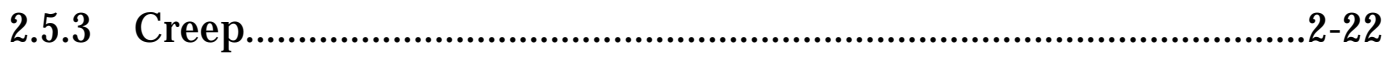

2.5.4 Ultrasonic Velocity......................................................................2-23 


\section{Contents (continued)}

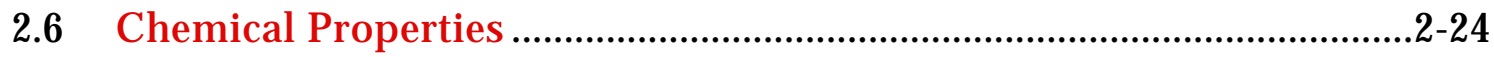

2.6.1 Tuff Minerals Important to Near Field Performance.................2-24

2.6.2 Thermodynamic Properties of Minerals Important

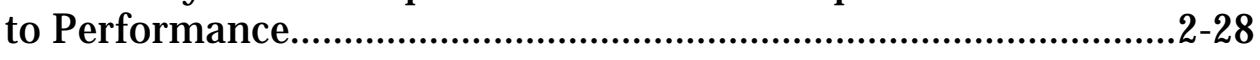

2.6.3 Thermochemical Properties of Selected Aqueous Species.......2-31

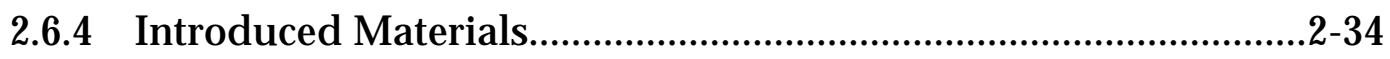

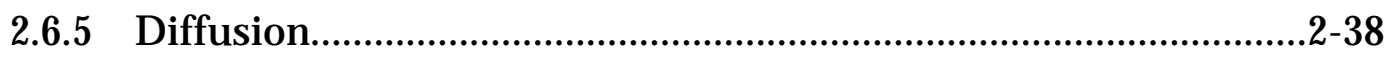

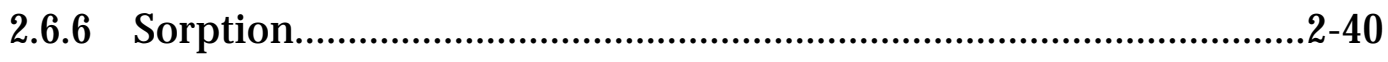

2.6.7 Variation of Reaction Rates with Temperature..........................2-44

2.7 Hydrological Properties ............................................................................2-50

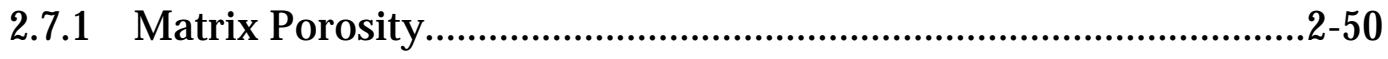

2.7.2 Matrix Permeability (Hydraulic Conductivity).............................2-50

2.7.3 Enhanced Vapor Diffusion.............................................................2-53

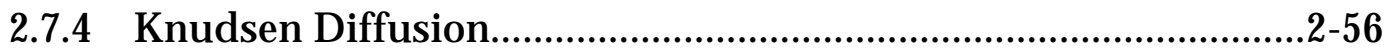

2.7.5 Water-Retention Characteristics...............................................2-57

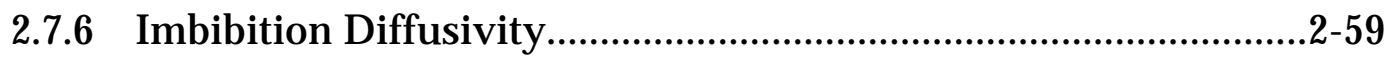

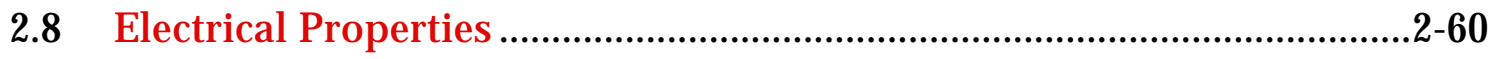

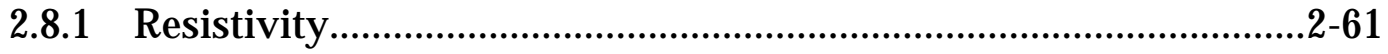

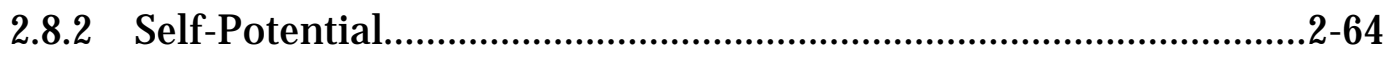

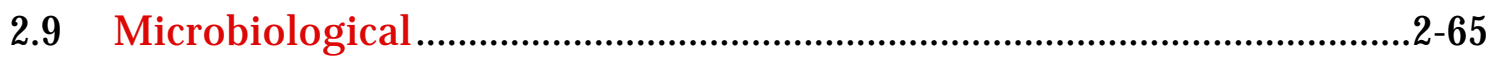

2.9.1 Indigenous and Introduced Microbial Species.............................2-66

2.9.2 Behavior of Microbes Under Anticipated Repository Conditions.................................................................. $2-68$

2.9.3 Significance to Yucca Mountain.......................................................2-69

2.10 Summary of Laboratory Properties Measurements ................................2-70 


\section{Contents (continued)}

3. Laboratory-Scale Process Studies ......................................................................

3.1 Drying and Rewetting ................................................................................

3.2 Permeability Reduction .........................................................................

3.2.1 Matrix Permeability of Yucca Mountain Tuff and Other Rocks......................................................................................

3.2.2 Laboratory Studies of Fracture Permeability in Tuff.....................3-4

3.3 Fracture-Matrix Flow Coupling ...................................................................

3.3.1 X-Ray Radiography of Fracture Flow and Matrix Imbibition in Topopah Spring Tuff Under a Thermal Gradient....................3-9

3.3.2 Fracture Coatings...........................................................................

3.4 Flow Channeling ...................................................................................

3.5 Creation of Heat Pipes and Refluxing Zones...........................................3-20

3.5.1 Preferential Flow Paths and Heat Pipes: Results from Laboratory Experiments on Heat-Driven Flow in Natural and Artificial Rock Fractures..........................................................3-20

3.6 Alteration of Minerals and their Distribution ........................................3-39

3.6.1 Fracture Healing............................................................................3-39

3.6.2 Changes in Water Chemistry.........................................................3-40

3.6.3 Flow-Reactor Experiments.............................................................

3.7 Near-Field Radionuclide Transport .......................................................3-45

3.7.1 Waste Package/Waste Form Releases..............................................3-45

3.7.2 Radionuclide Retardation...............................................................

3.8 Multiply Coupled Processes.....................................................................3-46

3.8.1 Nominal 0.5-m Scale Laboratory Experiments..............................3-47

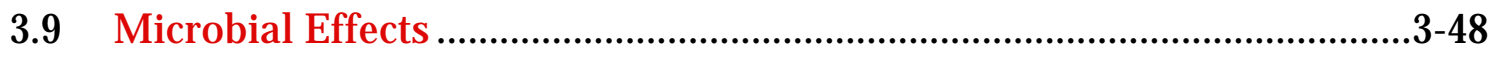

3.9.1 Biofouling of Fracture Flow ............................................................

3.10 Summary of Laboratory-Scale Study of Thermally

Coupled Processes...... 


\section{Contents (continued)}

3A Figures for Section 3.3.1 and Section 3.5.1 …...................................................A-1

4. Field-Scale Experiments and Observations of Thermally Driven

Coupled Processes ......................................................................................................4-1

4.1 Yucca Mountain Project.................................................................................4-1

4.1.1 Spent-Fuel Test-Climax..................................................................4-1

4.1.2 Edgar Mine, Colorado School of Mines............................................4-3

4.1.3 G-Tunnel, Nevada Test Site...............................................................4-4

4.1.4 Large Block Test.................................................................................4-11

4.1.5 Yucca Mountain Exploratory Studies Facility..............................4-16

4.2 International High-Level Nuclear Waste Programs................................4-26

4.2.1 Tests in the Boom Clay near Mol, Belgium.................................4-26

4.2.2 Underground Tests at Stripa, Sweden..........................................4-27

4.2.3 Berfeforsen Power Dam, Sweden....................................................4-28

4.2.4 Underground Tests at Grimsel, Switzerland...............................4-29

4.2.5 Russia and FSU............................................................................. $4-31$

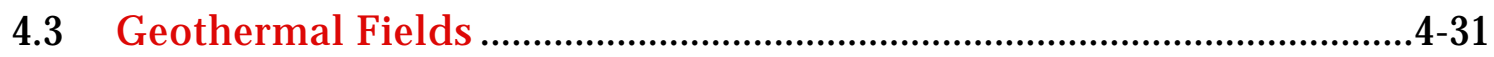

4.3.1 The Geysers.....................................................................................4-33

4.3.2 New Zealand................................................................................. $4-34$

4.4 Thermal Oil Recovery ..............................................................................4-38

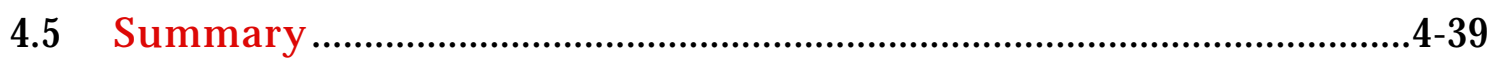

5. Summary and Conclusions ................................................................................... 5-1

5.1 Summary of Laboratory Property Measurements .....................................5-1

5.2 Summary of Laboratory-Scale Process Studies .............................................5-3

5.3 Summary of Field-Scale Experiments .........................................................5-4

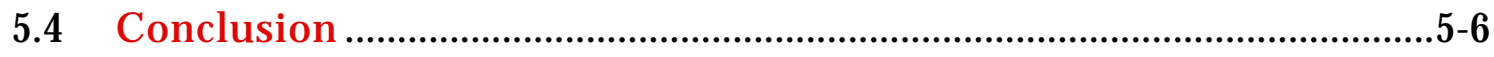

Acknowledgments and References........................................................................ 


\section{Tables}

Table 1-1 List of coupled processes potentially relevant to performance of a repository in the unsaturated zone at Yucca Mountain

Table 1-2 Direct and coupled Onsager-type transport processes $1-4$

Table 2-1 Laboratory tests performed in support of ongoing field-scale testing for the Yucca Mountain Project..

Table 2-2 Selected design assumptions that relate to properties of the host rock

Table 2-3 Physical properties of lithophysae-poor Topopah Spring member-welded tuff

Table 2-4 Thermal conductivity of lithophysae-poor Topopah Spring member-welded tuff

Table 2-5 Comparison of temperature-dependent heat-capacitance values measured on seven samples of TSw 2 welded tuff

Table 2-6 Average coefficients of linear thermal expansion for vacuum saturated, air-dried, and oven-dried TSw2 welded tuff

Table 2-7 Mechanical properties for intact TSw2 welded tuff

Table 2-8 Kinetic data for dissolution of various phases important to near-field performance ................................................................ 2-45

Table 2-9 Quality assurance status of conclusions reported in Chapter 2....2-78

Table 3-1 Experimental Parameters....................................................................3-11

Table 3-2 Summary of experiments and major observations..........................3-23

Table 3-3 Laboratory experiments and video recordings...................................3-38

Table 3-4 Concentrations ( $\mathrm{mg} / \mathrm{l}$ ) of selected elements analyzed in effluent splits from selected flow tests.

Table 3-5 Quality assurance status of conclusions reported in Chapter 3.....3-53

Table 4-1 Chemical analyses of water samples collected from borehole SHT-16-4

Table 4-2 Quality assurance status of conclusions reported in Chapter 4....4-43 


\section{Figures}

Figure 2-1 Comparison of porosity measured

Figure 2-2 Average heat capacitance for 7 samples of TSw2 welded tuff .......2-12

Figure 2-3 Linear thermal expansion coefficients vs. temperature .................2-16

Figure 2-4 Stress-strain showing typical linear elastic stress-strain behavior

Figure 2-5 Stress-strain curve for deformation of a fracture …………............2-22

Figure 2-6 Gibbs free energy of Na-clinoptilolite determined ..........................2-30

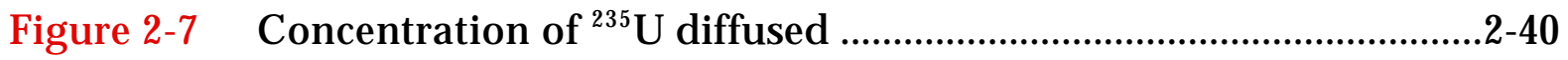

Figure 2-8 Comparison of urayl sorption to tuff in suspension ......................2-43

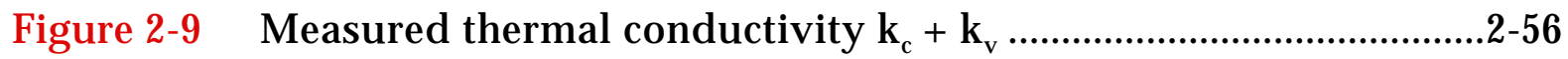

Figure 2-10 Moisture-retention curves developed by Flint ................................2-58

Figure 2-11 Plot of measured resistivity vs. saturation .......................................2-62

Figure 2-12 Resistivity values measured ……......................................................2-63

Figure 3-1 Experimentally determined moisture-retention curves ...................3-2

Figure 3-2 Permeability of a naturally fractured core sample …..........................3-5

Figure 3-3 Permeability of a single fracture in a core sample ..............................3-8

Figure 3-4 Schematic of X-ray radiograph system..............................................A-1

Figure 3-5 Radiograph of sample and assembly................................................A-1

Figure 3-6 Saturation as a function of normalized $\mathrm{x}$-ray attenuation.............3A-2

Figure 3-7 Difference radiographs of FR5..........................................................

Figure 3-8 Difference images of FR6 …………................................................

Figure 3-9 Conceptual fracture aperture model...................................................3-18

Figure 3-10 Physical model of water flow.............................................................3-19

Figure 3-11 Glass fracture model.........................................................................

Figure 3-12 Water and pentane properties..........................................................

Figure 3-13 Experiment setup...........................................................................

Figure 3-14 Condensation halo forming ........................................................... 


\section{Figures (continued)}

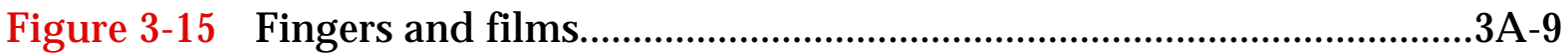

Figure 3-16 Fingers and rapid evaporation event............................................ A-10

Figure 3-17 Finger between and through warmed circles..................................A-11

Figure 3-18 Infiltration and condensation halo formation............................... A-12

Figure 3-19 Finger length and width................................................................

Figure 3-20 Fingers forming in model..............................................................

Figure 3-21 Finger length altered by heterogeneous heat transfer.....................A-15

Figure 3-22 Film development and hindered flow........................................... A-16

Figure 3-23 Seepage through model.................................................................

Figure 3-24 Longer fingers through model center............................................A-18

Figure 3-25 Pentane films...............................................................................

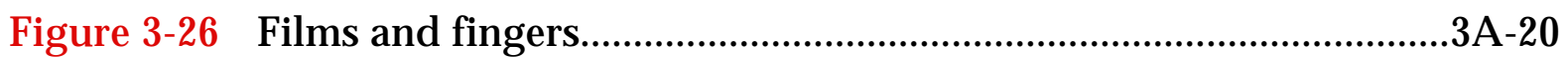

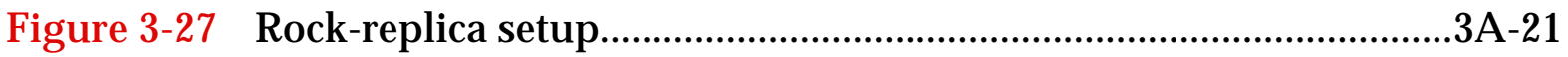

Figure 3-28 Initial model condition and temperature distribution.................3A-22

Figure 3-29 Pentane and temperature distribution............................................ A-23

Figure 3-30 Pentane and temperature distributions............................................A-24

Figure 3-31 Pentane and temperature distribution ………………….............. A-25

Figure 3-32 Pentane and temperature distributions showing heat pipe........3A-26

Figure 3-33 Pentane and temperature distribution...........................................A-27

Figure 3-34 Pentane and temperature distributions......................................... A-28

Figure 3-35 Film penetration depth vs. temperature..........................................A-29

Figure 3-36 Finger length vs. temperature......................................................

Figure 3-37 Finger length vs. temperature ………...........................................

Figure 3-38 Partial chemical analyses of major constituents................................3-41

Figure 4-1 Schematic of G-Tunnel heated-block test ............................................4-6

Figure 4-2 Plan view schematic of the PEBSFT ....................................................4-8

Figure 4-3 Temperature vs. time at six thermocouples .......................................4-9 


\section{Figures (continued)}

Figure 4-4 Changes in moisture content ……......................................................4-9

Figure 4-5 Schematic of LBT borehole array ………..........................................4-12

Figure 4-6 Time series temperature fluctuations in the LBT ..........................4-14

Figure 4-7 Vertical temperature profiles through the large block ...................4-15

Figure 4-8 Single Heater Test layout .................................................................4-17

Figure 4-9 ERT changes during heating phase of SHT ......................................4-19

Figure 4-10 Schematic plan view of DST layout ....................................................4-23

Figure 4-11 Concentration of aqueous silica vs. time ….......................................4-37 


\section{Executive Summary}

Thermally driven coupled processes may have beneficial or adverse effects on the performance of a potential repository at Yucca Mountain. Significant effects from thermally coupled processes are very likely to occur because, near the hot waste packages, large amounts of water will be redistributed by evaporation and condensation. Even with the lowest practical thermal power density in the repository, this thermally mobilized water will dominate seepage into emplacement drifts for thousands of years and control the environmental conditions at the waste packages. If seepage is reduced or temporarily eliminated by drying out a volume of rock around the emplacement drifts, as predicted by thermohydrologic model calculations, then the waste-package lifetime will be increased, and the contact of waste by water can be postponed for thousands of years after emplacement. After the decay of the thermal pulse, drift seepage may be reduced or eliminated by the permanent plugging of fracture pathways by thermally coupled alteration and deposition of minerals. On the other hand, either transient or permanent changes in flow pathways resulting from thermally coupled processes could result in diverting condensate flow toward waste packages. These considerations suggest that thermally coupled processes must be thoroughly evaluated and bounded in order to support a credible assessment of total system performance. To support selection among alternative designs and operating strategies, it is also important to understand how these processes interact with engineered components and operational controls.

The types of coupled processes are briefly described in Section A of this summary. Processes described by the formalism of irreversible thermodynamics (Onsager type), with the possible exception of electrical potentials arising from some coupled processes, are not believed to be important for Yucca Mountain repository performance. If these potentials occur, and if they can support significant current flow, the corrosion rate of waste-package materials could be increased. It may be possible to bound these effects in future underground heater tests.

Section B of this summary provides descriptions of laboratory measured changes in physical and chemical properties with temperature; these range from simple physical properties (e.g., porosity) to changes in mineralogy, groundwater chemistry, and permeability.

The supporting laboratory data for evaluating thermally coupled processes are adequate in some topical areas and sparse in others. Variation of thermal and thermomechanical properties with temperature are relatively well understood, and qualified data are available. The dependence of the matrix and fracture rheology on temperature, including deformation modulus and creep properties, is less well known, and there are few qualified data at elevated temperatures. However, at present it is not clear how important this information would be for long-term repository performance assessment. Further work should carefully delineate what, if any, additional measurements are required. 
For hydrologic matrix properties, there are fundamental temperature-dependent responses that may be important to thermohydrologic models but that have not been investigated experimentally; these include the temperature effect on hysteresis of wetting and drying characteristic curves, and the magnitude of enhanced vapor diffusion. These parameters may be important in determining the time that rewetting occurs after the thermal pulse decays.

Chemical reactions are strongly temperature-dependent, but the effects of elevated temperature on chemical kinetics have not been determined experimentally for many important reactions. However, experimental kinetic data are not generally needed for reactions that can be satisfactorily modeled using qualified thermodynamic equilibrium and reaction-path models such as EQ3/ 6 and its associated chemical databases. In preparation for use with qualified models, thermodynamic data for many aqueous and mineral species have been measured or estimated and reviewed for accuracy and consistency.

For certain other types of reactions (e.g., surface complexation), equilibrium conditions at elevated temperatures are unknown and must be estimated, relying chiefly on ambient-temperature data not collected under a quality assurance (QA) program approved by the current Yucca Mountain Site Characterization Project. These data and similar data are called "non- $Q$ " data, as contrasted with "qualified data." Most surface complexation experiments reported in the literature involved simple chemical systems that may not be representative of conditions along transport pathways from the repository. Rates of reaction are even less well understood except for a few systems (e.g., the dissolution and precipitation of silica polymorphs), and directly applicable, qualified data are rare. Such data are needed to more fully assess the distribution and magnitude of altered flow pathways above and below the repository.

Section $C$ of this summary provides a brief description of phenomena associated with thermally-coupled processes observed at the laboratory scale. The experiments include comparison of vapor phase and liquid phase rewetting, fracture healing, fracture-matrix coupling with flow into heated tuff, heat-pipe formation, and rock-water interaction studies.

These laboratory-scale simulations of thermally coupled processes have advanced conceptual understanding and provided tests for mathematical model development. The available data have been used to identify conditions for fracture-permeability reduction. Additional experiments have been suggested to isolate mechanical and chemical effects on fracture healing. Investigation of tuff dissolution and alteration in batch reactor studies and preliminary flow-through studies has indicated that the nature and rates of predominant reactions will depend on the local thermohydrology. Planned prediction of changes in the altered zone will incorporate chemical and thermohydrologic constraints. Flowvisualization experiments have shown that episodic fracture flow occurs, particularly in heat pipes. Prediction of the effects of episodic flow on fracturematrix interaction and movement of refluxing water into the dryout zone has not been attempted. Laboratory hydrologic experiments have revealed 
drying/wetting hysteresis effects at elevated temperature; these effects have not been evaluated for impact on thermohydrologic simulations. A preliminary laboratory experiment designed to investigate matrix diffusion indicates that this effect is diminished at elevated temperature; this result has not been addressed by additional experimentation. Finally, preliminary experiments have shown that soluble salts are leached from the tuff matrix and fracture-lining minerals and are likely to accumulate in heat-pipe zones where they can be mobilized during rewetting; the deposition of salts on the waste packages will potentially have adverse effects on their lifetime. Concentration of chloride and sulfate ions would be particularly detrimental to the performance of the corrosion-resistant inner barrier in the waste packages and could require the use of more expensive materials.

Section D provides a brief discussion of field tests and geothermal reservoir investigations relevant to thermally coupled processes. An important conclusion of this report is that thermohydrologic processes are difficult to simulate with the available numerical models and hydrologic parameters. Laboratory- and fieldscale experiments have shown that heat-pipe effects in fractured rock are inherently episodic and sensitive to spatial heterogeneity of material properties. Thermohydrologic simulators, on the other hand, tend to produce temporally as well as spatially smooth results because of continuum approximations and the damping inherent to solution methods. To evaluate whether physical model results have significant implications for near-field performance, there is a need for further experimentation and model development, particularly regarding expanding to field scale. Additional analysis of information in the geothermal and thermal oil-recovery literature is expected to provide better methods of predicting large-scale and long-term behavior of the repository during the thermal pulse.

\section{A. Types of Coupled Processes}

Coupled processes can generally be classified as the Onsager-type, driven by gradients of thermodynamic state variables, or another type in which processes are affected indirectly by the magnitudes of thermodynamic state variables (Carnahan, 1987). Thermally coupled processes in the latter category occur solely because of temperature-dependent changes in medium, fluid, or reactive properties. These are the major focus of investigation into coupled processes that could affect a repository at Yucca Mountain, and these are the topic of this report.

The Onsager-type processes (Table 1-2) are fundamental and occur even if the associated physical or chemical properties of the medium are temporally invariant. Direct processes lie along the main diagonal of the table, and coupled processes are off-diagonal. Phenomenological coefficients relating forces and fluxes for coupled processes have not generally been derived or measured for porous geologic media. Most of the coupled processes shown in Table 1-2including thermal osmosis and thermal filtration, Soret and Dufour effects, reverse osmosis, Seebeck and Peltier effects, and electro-osmosis-are probably 
not significant to repository performance. Coupled processes can be insignificant when the gradients of temperature, pressure, or electric potential are small or if the effects of the processes are overwhelmed by direct processes such as Darcy flow, Fickian diffusion, and electrical conduction.

Given present knowledge about the near field environment, a few of the Onsager coupled processes listed in Table 1-2 cannot be eliminated from consideration and are discussed in appropriate sections of this report:

- Chemical osmosis refers to fluid flux, from less concentrated to more concentrated conditions, in response to gradients of chemical potential. Osmotic activity is well known in swelling clays and contributes significantly to the matric potential of pore water in some media. In welded tuff, the differences in solute activity required for significant chemical osmosis may occur only on a small scale or in secondary minerals such as zeolites and smectites.

- Electrophoresis is likely to occur to some minor extent in the near-field environment where ions and charge-carrying particles move in the presence of electric fields. The reciprocal effect is represented by the sedimentation current, in which an electric current flows in response to a gradient of chemical potential. Neither effect has yet been identified in the course of field testing.

- Streaming current is caused by differential mobility of electric charges in an advective flow and makes up a net current. Advective flow velocities may not be sufficiently greater than migration velocities associated with other phenomena, such as thermal diffusion, to produce a measurable current at Yucca Mountain.

Thermally driven coupled processes at a Yucca Mountain repository can also be categorized based on duration of the effects:

- Transient Effects - Processes that produce reversible effects (e.g., drying and rewetting) and that recover to pre-emplacement conditions after the thermal pulse decays to zero. For these processes, ultimate postclosure repository performance can be adequately assessed using models calibrated to existing site characteristics, with boundary conditions modified to represent future conditions. However, the transient period may span tens to hundreds of thousands of years.

- Residual Effects - Processes that result in permanent changes to flow and transport pathways and that remain in effect after cooling of the host rock. An important example is thermohydrochemical (THC) coupling caused by the dissolution and precipitation of minerals, especially along fractures. Another example is thermohydromechanical (THM) coupling, in which permanent deformation occurs in response to thermomechanical stress. 


\section{B. Laboratory Measured Property Variation with Temperature}

The following comments summarize some of the findings on the temperature dependence of laboratory measured properties found in the reports reviewed for this compilation. Further detail is provided in Chapter 2, especially in Section 2.10, Summary of Laboratory Properties Measurements.

- Porosity and grain density-For the Topopah Spring welded tuff host rock (TSw2), these properties change little from ambient temperature up to at least $180^{\circ} \mathrm{C}$. Changes expected for the welded, devitrified tuff matrix in the altered zone are minor and will be caused by mineral-phase transitions (e.g., cristobalite) and dehydration of minor hydrous phases such as clinoptilolite and smectites. Dehydration of hydrous fracture-lining minerals has the potential for much greater effects on altered zone performance than does the dehydration of constituent minerals in the tuff matrix.

- Thermal conductivity-There is a slight increase in thermal conductivity with increasing temperature of the repository host rock. A small pressure effect in other rock types, whereby conductivity increases with confining stress has been observed and is likely caused by closing of microcracks. Laboratory measurements of thermal conductivity have been performed on samples from the Exploratory Studies Facility (ESF) in conjunction with field scale thermal testing (Brodsky et al., 1996). These qualified data are summarized by values in the Reference Information Base (RIB, Rev. 0; [DOE, 1995]).

- Heat capacitance-The heat capacitance of the TSw2 welded tuff increases about $20 \%$ from ambient temperature to $200^{\circ} \mathrm{C}$, when measured on dried samples (Brodsky et al., 1996). These qualified data values are summarized in the RIB (Rev. 0; [DOE, 1995]). Behavior at temperatures greater than $150^{\circ} \mathrm{C}$ is affected by transitions of mineral phases, notably that of cristobalite.

- Thermal expansion-The coefficient of thermal expansion for TSw2 welded tuff increases with temperature because of mineral-phase transitions and dilation caused by differential thermal expansion. Brodsky et al. (1996) reported many measurements conducted at ambient pressure, temperatures to $300^{\circ} \mathrm{C}$, and several saturation states. Average values summarizing the qualified data from this study are used in the RIB (Rev. 0; [DOE, 1995]).

- Mechanical properties-Few data are available, for the TSw2 welded tuff, for evaluating the variation of laboratory-measured compressive strength or Young's modulus with temperature or saturation. Laboratory measurements reported by Board et al. (1984) for the Grouse Canyon welded tuff, indicated that such variations were small compared to variations between samples. Blacic et al. (1986) reached a similar conclusion: any effects on mechanical properties were smaller than 
between-sample variability of those properties. More recently, Blair and Berge (1997) subjected a 0.5-m scale block of Topopah Spring welded tuff to uniaxial loading at temperatures as great as $93^{\circ} \mathrm{C}$. Young's modulus for the tuff matrix at several locations in the block decreased significantly as temperature increased. These results indicate that, although the tuff matrix has ample compressive strength, there may be a tendency for joints to close in response to heating while loaded by in situ stress.

- Compressive strength vs. saturation-It has been reported that a significant decrease in compressive strength could be associated with increased saturation (Nimick and Schwartz, 1987). This observation was based on early studies that may have been affected by different methods used to control sample saturation (Boyd et al., 1994).

- Rock creep- Just as in other materials, rheological properties of Topopah Spring welded tuff depend on stress level and sample size. A principal source for qualified creep-properties data on Yucca Mountain tuffs is Martin et al. (1995c). There was some evidence that the ultimate strength at a given strain rate decreased with increased temperature. Significant creep occurred only when samples were stressed to at least $50 \%$, and in some cases more than $90 \%$, of their ultimate strength. Such stress conditions may be uncommon in the near-field environment, but there may be a tendency for fractures in the host rock to close in response to heating and subsequently to open in response to cooling.

- Temperature Dependence of Water Chemistry-Groundwater from well $\mathrm{J}-13$ is widely believed to be representative of the chemical composition of water in equilibrium with the Topopah Spring welded tuff. Changes in the chemistry of J-13 water in contact with welded tuff on heating from $25^{\circ}$ to $100^{\circ} \mathrm{C}$ were calculated using EQ3/6 (Wolery, 1992a; Wolery and Daveler, 1992) and found to be minor (Glassley, 1995). The major differences calculated to result from heating were increased concentrations of dissolved Si and precipitation of minor amounts of carbonates. Model results depend strongly on the assumed chemical potential of volatile constituents such as $\mathrm{CO}_{2}$.

- Behavior of radionuclides in J-13 water-Investigation of spiked J-13 water at temperatures as great as $100^{\circ} \mathrm{C}$ indicated that $\mathrm{Pu}$ solubility decreased with increasing temperature, while the solubility of $\mathrm{U}, \mathrm{Np}$, and Am remained constant or increased (Nitsche, 1991). Carbonate complexes appeared to be important to the solubility of $\mathrm{U}, \mathrm{Np}$, and Am at elevated temperature. A recent review of what is known about complexation and solubility of $\mathrm{Ni}, \mathrm{Zr}, \mathrm{Tc}, \mathrm{U}, \mathrm{Np}, \mathrm{Pu}$, and $\mathrm{Am}$ in J-13 water at elevated temperatures was published by Wruck and Palmer (1997). Additional review of solubility data for radionuclides of interest was published by Rard (1996). 
- General vs. analog approaches to chemical systems-Although experimental studies with J-13 water summarize the effects of various chemical reactions that are likely to be important to repository performance, there is an important limitation to the approach. The complexes or precipitates that determine the total solubility of each radioelement are not exhaustively determined, and the results tend to be specific to the chemical system (i.e., J-13 water). The experiments are therefore analogs, and the results are not generally applicable to repository performance if actual aqueous chemistry deviates much from that used in the experiments. For more generality, measurements of thermochemical data and qualification of existing data are preferred for use in conjunction with models such as EQ3/6.

- Hydrothermal tuff alteration-Batch studies of hydrothermal alteration of wafers of Topopah Spring welded, devitrified tuff have been performed at temperatures as great as $250^{\circ} \mathrm{C}$, and duration of as many as 120 days (Knauss, 1987; Knauss and Beiriger, 1984; Knauss et al., 1985a, 1987, 1985b; Knauss and Peifer, 1986; Oversby, 1984a, 1984b, 1985). These studies showed only minor changes in the composition of water in contact with the tuff at temperatures as great as $150^{\circ} \mathrm{C}$, with slight alteration of the tuff over a few months. At higher temperatures, reaction rates increased significantly. Accelerated experiments on crushed tuff at temperatures greater than $150^{\circ} \mathrm{C}$ produced the most extensive alteration, including the production of metastable phases. The temperature of matrix pore water in the "dryout zone" of the near-field environment could approach $150^{\circ} \mathrm{C}$ if the permeability of the tuff matrix is low enough to produce "throttling" (Buscheck, 1996b). These batch studies indicate that, at lower temperatures, hydrothermal alteration will be slow relative to the laboratory time scale.

- Alteration of vitric and zeolitized tuff-The upper and basal Topopah Spring vitrophyres contain glass and secondary minerals that are reactive, and these strata are potentially important to repository performance. Knauss and Copenhaver (1995) reported an experiment that examined alteration of polished wafers of the unaltered, densely welded Topopah Spring vitrophyre. At temperatures of $150^{\circ} \mathrm{C}$ and less, only glass

dissolution was observed. Another experiment examined the alteration of naturally zeolitized samples from the same vitrophyre (Knauss and Copenhaver, 1995), which appeared stable to alteration. From these qualified data, it may be inferred that the reaction of water with glass will be slow (compared to the experimental time scale) at temperatures as great as $150^{\circ} \mathrm{C}$. Alteration minerals that already seal fractures appear to be stable with respect to further alteration.

- Zeolite dehydration- Because zeolite dehydration requires more energy per mole of water than does evaporation of free water and because the water content per unit bulk volume is relatively high (Bish, 1995; Bish et al., 1996; Carey and Bish, 1996b), zeolites could have a significant effect on the heat and water balance where they are abundant. Zeolite hydration is 
apparently reversible; thus complementary effects will occur during repository cool down. Altered units above and below the repository horizon contain a large fraction of zeolites, and the qualified data from these studies indicate that dehydration will cause some amount of shrinkage that increases porosity and probably also increases permeability. This could affect the water perching behavior at altered zones associated with the upper and lower Topopah Spring vitrophyres.

- Effect of steam on fracture lining alteration minerals-Hydrous minerals, including zeolites and smectites, are common in fractures, and their dehydration behavior is important for transport of moisture and released radionuclides. In particular, hydrous phases could exhibit behavior similar to that of a bentonite-sand mixture that was shown to shrink dramatically when exposed to steam (Couture, 1985). The behavior of actual fracturelining mineral assemblages at conditions anticipated for the near-field environment has not been directly investigated.

- Effect of hydrothermal alteration on flowpaths-Plug-flow reactor studies involving flow-through reaction of J-13 water with crushed tuff at $240^{\circ} \mathrm{C}$, resulted in significant dissolution of alkali feldspar and cristobalite (DeLoach et al., 1997). The data from this experiment are significantly different from batch reactor studies at similar temperature (i.e., predominantly dissolution instead of alteration). The two approaches span the range of conditions likely to exist in the near-field environment: stagnant vs. flowing water in the tuff matrix or fractures. Future plug-flow experiments will extend the temperature ranges and types of samples investigated.

- Limitations of available kinetic data-The available kinetic data for dissolution of mineral phases that may be important to repository performance are limited. Comparison between experiments is difficult because various physical conditions have been used. Different investigators have used various interpretation strategies, and there is apparent lack of agreement between measurements made with batch methods and those made with flow-through methods.

- Kinetics of silicate dissolution and precipitation-Reaction rates for dissolution of quartz, silica polymorphs, and feldspars and precipitation of amorphous silica are important for understanding thermochemical effects in heat-pipe zones. According to one conceptual model, condensate at $\sim 100^{\circ} \mathrm{C}$ dissolves silica, refluxes along fractures, and evaporates, thus precipitating amorphous silica. Reaction rates control the concentration of silica in refluxing water and the manner of deposition in fractures near the dryout front.

- Experimental kinetic data-In a classic study, the dissolution rate for silica polymorphs increased by a factor of 300 between $25^{\circ}$ and $70^{\circ} \mathrm{C}$ (Rimstidt and Barnes, 1980). Upon cooling a supersaturated silica solution, the rate constant for precipitation decreased, producing a maximum precipitation rate at a temperature $25^{\circ}$ to $50^{\circ} \mathrm{C}$ below the saturation temperature. More 
recent investigations of albite (feldspar) and quartz dissolution kinetics at $70^{\circ} \mathrm{C}$ were reported by Knauss and Wolery $(1986,1988)$ and produced results that were comparable to Rimstidt and Barnes (1980). These results have not been integrated with thermohydrology simulations in a mechanistic analysis to assess the dependence on these effects of repository performance predictions.

- Cement alteration-The $\mathrm{Ca}-\mathrm{Si}-\mathrm{H}_{2} \mathrm{O}$ constituents of cement will dehydrate on exposure to elevated temperatures and will transform to more crystalline minerals (Meike, 1996). Chemical reactions involving these recrystallized phases can affect not only water chemistry, but also the relative humidity of the near-field environment. Also, water in contact with Portland cement typically develops high $\mathrm{pH}$. Various degradation mechanisms are known to occur in cementitious materials over time and they will increase the surface area available for chemical alteration. As indicated by laboratory comparison with crushed tuff, degraded concrete in the near-field environment could be beneficial to radionuclide retardation. Preliminary studies on chemical interactions for various candidate cementitious materials are underway.

- Interaction of radionuclides with alteration products of introduced materials-Surface complexation reactions will be important for retardation of actinides, and possibly pertechnetate, in the near-field environment (Meike, 1996). Introduced materials, including the wastepackage corrosion-allowance material, will be important potential sources for high-affinity sorbents, which may form pseudo-colloidal particles on which radionuclides can be transported. Sorption on these materials (e.g., goethite, silica polymorphs, thermally transformed $\mathrm{Ca}-\mathrm{Si}-\mathrm{H}_{2} \mathrm{O}$ minerals) has not been evaluated at elevated temperatures nor generally in chemical systems that represent the near-field environment and include $\mathrm{CO}_{2}$ and silica.

- Matrix diffusion effects-Diffusion of radionuclides into minerals and into the tuff matrix is a potentially important temperature-dependent retardation mechanism. The tuff matrix contains ubiquitous nanopores that support slow diffusion along with a few connected paths through which diffusion is orders of magnitude faster, but of limited extent. Experimental evaluation of diffusion in the tuff matrix and in clinoptilolite (Buchholtz-ten Brink et al., 1991; Roberts et al., 1996; Viani, 1996a) generally indicates that the rate of diffusion in the tuff matrix and potential sorbents is significantly enhanced at elevated temperatures. The performance implications of increased diffusivity at elevated temperatures in the host rock have not been established.

- Matrix permeability-Variations associated with temperature changes have been found to be much less than variations between samples in matrix permeability of the Topopah Spring welded tuff. This conclusion was reached in several studies, including a long-term flow test lasting three months (Lin and Daily, 1984; Lin and Roberts, 1996; Moore et al., 1985 
and 1986; Morrow et al., 1984; Reda, 1985a). Permeability of the welded tuff matrix to steam was also investigated by Lin and Daily (1984) and found to be comparable to the water permeability.

- Unsaturated hydraulic conductivity-Virtually no measurements have been made of unsaturated conductivity in Yucca Mountain tuffs. Only a few measurements for samples of Yucca Mountain tuff have been reported (Conca and Triay, 1994; Conca and Wright, 1992). This important parameter is estimated for thermohydrologic models using semi-empirical methods such as that of van Genuchten (1980). Between-sample variability is likely to be such that many measurements will be needed to develop a qualified, empirical basis for this parameter. Changes in the properties of water at elevated temperatures suggest that unsaturated conductivity may increase by as much as an order of magnitude from $20^{\circ}$ to $100^{\circ} \mathrm{C}$. The viscosity effect is taken into account in thermohydrologic simulations, but the surface tension effect is not. In addition, changes in the water-rock-air contact angle at elevated temperatures are difficult to predict and probably influence unsaturated conductivity.

- Enhanced vapor diffusion-This effect has been observed in soils (Cass et al., 1984) and is potentially significant in Topopah Spring welded tuff for the saturation range in which contiguous gas-phase pathways are partially blocked by islands of pore water. In thermohydrologic simulations, it has the effect of equalizing the rates of rewetting in certain parts of the repository, as determined by spatial heterogeneity and geometry (Buscheck, 1996a). In soils, diffusion of water vapor under a temperature gradient has been observed to vary several-fold, depending on saturation, but there are no known measurements in rocks. An experiment to evaluate vapor diffusion in tuff is underway.

- Knudsen diffusion-This effect could mean that gas permeability is several times greater than water permeability. Enhanced gas permeability results when the size of pores is comparable to the molecular mean free path. Reda (1985b) measured the gas permeability to nitrogen, which varied by more than an order of magnitude over a range of average pressure from 0.1 to $13.1 \mathrm{MPa}$ (corresponding to a mean free path ranging from 70 to $0.5 \mathrm{~nm}$ ), of a single sample of Topopah Spring welded tuff at ambient temperature. Knudsen diffusion by definition does not vary with temperature, but the effect could be large enough to impact thermohydrologic model predictions.

- Self-potential-Naturally occurring electrical potentials are associated with geologic contacts where there are temperature or fluid pressure gradients (thermoelectric and streaming potentials) or gradients in electrolyte concentrations (electrochemical potential). Potential differences observed in the Single Heater Test (SHT) in the ESF are large enough to be considered as a factor in electrochemical corrosion analysis, but the source of these potentials and their current generating capacity have not been investigated. 
- Microbiology-Investigations have established that a variety of subsurface microbes exists in the Topopah Spring host rock; these include natural organisms and those introduced during construction. Survival of some species at elevated temperatures has been observed. Some species produce metabolic products that could be important in determining the rates of corrosion processes and radionuclide transport in the near-field environment. Further testing is required to predict the effects of microbial processes in the repository.

\section{Laboratory Scale Studies of Thermally Coupled Processes}

The following comments summarize some of the findings on the laboratory investigation of thermally coupled processes found in the reports compiled for this review. Further detail is provided in Chapter 3, especially Section 3.10, Summary of Laboratory Scale Study of Thermally Coupled Processes.

- Rewetting behavior-Testing wafers of welded tuff has indicated that water-retention hysteresis varies at elevated temperature (Lin and Roberts, 1996). Wetting/drying hysteresis that is typically observed in measurement of saturation vs. water potential at ambient temperature was nearly zero at $78^{\circ} \mathrm{C}$, and negative at $94^{\circ} \mathrm{C}$. Daily and Lin (1991) reported similar results. The effect is probably related to changes in surface tension and the rockwater-air contact angle at elevated temperatures. This effect is important for thermohydrologic modeling, although hysteresis behavior has been generally ignored in models and the effects of negative hysteresis have not been considered. Rewetting hysteresis at elevated temperatures has not been explained or further investigated.

- Vapor resaturation-Tuff matrix rewetting due to the presence of saturated water vapor $(100 \%$ relative humidity $[\mathrm{RH}])$ has a different result from rewetting by liquid at the same zero potential. Experiments described by Lin and Roberts (1996) showed that rewetting of dry tuff in the presence of water vapor occurs much more slowly than does rewetting by imbibition of liquid water. This effect is incorporated in thermohydrologic models by adjusting the matric potential vs. saturation relationship for the equivalent continuum so that matrix saturation of $30 \%$ to $40 \%$ corresponds to relative humidity close to $100 \%$. Vapor resaturation strongly affects the timing of rewetting in the repository host rock (Buscheck, 1996a), but is unlikely to affect the relative humidity calculated at waste packages until the waste-package temperature is well below boiling.

- Fracture healing-An understanding of permeability reduction has been developed and several mechanisms have been identified: 1) dissolution of fracture asperities by flowing water combined with aperture reduction under the influence of confining stress, 2) dissolution/precipitation reactions that clog porosity by redistributing silica or by creating secondary minerals with greater molar volume, and 3) heating of the rock mass, 
which causes flow of matrix pore water toward fractures where it evaporates or boils, leaving the solute behind to clog fractures or matrix porosity near the fracture walls. Experiments have shown that flowing water or steam is required for permeability reduction, and the effect is strongest at temperatures greater than $90^{\circ} \mathrm{C}$ (Lin and Daily, 1985; Lin et al., 1995). Additional studies are needed in which fracture aperture change is measured directly and the mass and distribution of fracture precipitates are evaluated.

- Permeability reduction by steam-Permeability reduction by flowing steam has been investigated in laboratory experiments by Lin (1990) but not evaluated to determine the mechanism or the potential effect on fracture permeability in the near-field environment. Flowing steam and flowing water had similar effects on fracture permeability. If the observed permeability reduction is attributable to precipitation, a mechanism for silica transport by steam must exist. Observations from geothermal development may be useful for evaluating silica transport by steam.

- Fracture-matrix coupled flow visualization-Studies by Roberts and Lin (1997b) have physically demonstrated the relationship between fracturematrix coupling in welded tuff and the fracture pressure gradient or flow velocity. When the experiment was repeated with a thermal gradient, a different flow regime, with localized precipitation of the solute tracer, resulted. These experiments can be simulated using equivalent continuum models (ECM) and dual permeability models (DKM) to evaluate whether the flow phenomenology and thermal coupling are handled appropriately by both approaches. Additional experiments are needed to relate saturation data to the accumulation of fracture precipitates and to examine the distribution of solute that results when the matrix is initially saturated and then dehydrates through the fracture.

- Flow channelization-Visualization experiments reported by Geller et al. (1996) showed, among other findings, that fracture transport in response to constant boundary conditions can be unsteady and associated with intermittent rivulets that "snap off" and reform periodically. These were ambient-temperature experiments that demonstrated that both parallel plate fractures and epoxy casts of natural fractures can produce episodic flow behavior in response to constant upstream boundary conditions. This is applicable to thermohydrologic studies because similar flow can be expected in the fractures of a heat-pipe zone. There are important implications for fracture-matrix interaction, especially in areas of the fracture traversed by the unsteady flow and where the contact time available for matrix imbibition is limited. The average periodicity for episodic flow appears to be related to fracture aperture, wetting properties, and the inclination of the models from the vertical. 
- Physical models of heat pipes-Fracture thermohydrology visualization studies by Kneafsey and Pruess (1997) examined conditions (e.g., liquid saturation, temperature difference, and fracture dimensions) that support heat-pipe development. Heat pipes were observed in parallel plate fractures containing obstacles, heat sources, and vents. Film flow and meniscal flow were observed to produce heat pipes. Unsteady rivulet flow behavior, analogous to fracture flow at ambient temperature reported by Geller et al. (1996), was observed. Rapid evaporation events occurred when "islands" of fluid became superheated and suddenly boiled, constituting another mechanism for unsteady flow with the potential to rapidly disperse solute. Some of these observations were repeated with a half-cast model incorporating welded tuff as one fracture wall. Ongoing investigations will evaluate other types of models and compare the physical model observations with numerical simulations.

- Potential for episodic reflux-Flow visualization results of Kneafsey and Pruess (1997) show that there is the potential for large-scale episodic reflux flow into emplacement drifts. Condensate islands, held stationary in fractures, could coalesce in a stream analogous to the "intermittentrivulet" behavior observed in the physical model. Fracture water could be transported well within the dryout zone and possibly into the emplacement drifts, depending on the velocity, flow rate, and thermal response. The unsteady behavior observed in simulated fractures could be enhanced with stronger wetting behavior (e.g., water in natural fractures). Alternatively, fracture surface heterogeneity and matrix imbibition may moderate the unsteady behavior. These issues can be addressed through further testing of the type described by Kneafsey and Pruess (1997).

- Water-rock interaction-Chemical analyses of effluent water from matrix and fracture flow experiments indicated that water-rock interaction occurs. When J-13 water was flowed through an intact core sample, the concentration of most major anions and cations first increased, then approached influent concentrations (Moore et al., 1985). Anions such as chloride and sulfate were leached in concentrations that may be significant to waste package degradation. Roberts and Lin (1994b) reported chemical analyses for water that flowed through a healed, natural fracture at elevated temperatures. Leaching of soluble salts from the tuff matrix and fracture-lining minerals could be an important factor in the chemistry of waters that eventually reenter the waste-emplacement drifts. Accumulation of soluble salts in a heat-pipe zone has not been evaluated physically or numerically.

- Alteration of flow paths-Plug-flow reactor experiments have produced results that compare with reactive transport calculations (DeLoach et al., 1997). Additional experiments will evaluate sensitivity to test conditions, such as flow rate and temperature, and will test more reactive materials, such as vitric tuff. The same modeling approach will be used to predict 
mineral alteration along potential waste-migration pathways through the altered zone. Comparison to observations obtained from field-scale testing is planned for model validation purposes.

- Matrix diffusion-Matrix diffusion was investigated using conservative tracer transport through a core sample with a saw-cut fracture (Viani and Carman, 1996). Complete recovery of chloride and bromide tracers was achieved, but the breakthrough time and tailing behavior were sensitive to temperature. Indications from the test series were that matrix diffusion is less effective at elevated temperatures. This is the only investigation of matrix diffusion behavior at elevated temperatures in tuff, and the results are contrary to the expectation that diffusion increases at elevated temperatures. Replication of the experiment with direct measurement of the fracture aperture changes and measurement of changes in fracture wall permeability has not been undertaken.

- Laboratory scale block test-Uniaxial loading of a fractured $0.5-\mathrm{m}$ scale block at elevated temperatures has shown that fractured tuff becomes more deformable at elevated temperatures (Blair and Berge, 1997). Also, permanent deformation occurred as the block temperature was elevated to $\sim 85^{\circ} \mathrm{C}$ while under compressive load. Much of the deformation of the block occurred at the fractures. These results indicate that fractures in the host rock will close in response to thermal loading and will reopen in response to cooling. Test results were also interpreted to indicate that fractures will develop in the host rock proximal and parallel to the drift walls. Additional testing of the block will examine transport behavior under similar temperature and loading conditions.

\section{Field-Scale Studies of Thermally Coupled Processes}

Field-scale thermohydrologic coupling has been observed in several experiments including G-Tunnel heater tests, the Large Block Test (LBT), and SHT. Field-scale tests have mobilized significant amounts of water as fracture flow.

Thermohydrologic coupling was apparent from the first heater test in G-Tunnel (Johnstone et al., 1985), in which a prodigious amount of condensate was collected in a short time. The Prototype Engineered Barrier System Test (PEBSFT) in G-Tunnel also produced thermohydrologic coupling, redistributing moisture in a manner consistent with predictive models. In the PEBSFT, drying fronts were reported to proceed along fractures during heating, and rewetting occurred near fractures during cooling.

In the LBT, after a region of the block centered on the heater plane attained a temperature greater than $100^{\circ} \mathrm{C}$, a heat-pipe zone was created (Lin, 1997a). The block heated conductively at first, then a reflux event occurred in response to boundary temperature fluctuations. The event lasted less than one hour and involved sufficient water to change the temperature of much of the block by a few degrees. This was followed by repeated, smaller reflux events, which were rapid and can only have occurred by fracture flow. 
In the SHT, water was collected in borehole \#16-4 at a rate that exceeded, by nearly an order of magnitude, the permeability of the tuff matrix (Glassley and DeLoach, 1997). The water was flowing in fractures and became trapped in the borehole. Moisture was redistributed in a manner consistent with predictive models. Small temperature fluctuations were observed that may provide evidence for heat-pipe activity.

Dimensionality is an important determinant of heat-pipe behavior in field-scale tests. Single-heater experiments have permitted "shedding" of condensate around the heater so that much of the condensate has not flowed back to the boiling zone. This has resulted in larger dryout zones and tended to suppress heat-pipe effects. The LBT is designed to investigate heat-pipe effects by restricting dimensionality. Indications of heat-pipe behavior observed so far in the LBT have been spatially and temporally heterogeneous, behavior similar to the intermittent behavior identified in laboratory physical model studies. Both laboratory and field studies have shown that water reflux is intermittent; when it occurs, a strong flow forms from coalescing liquid islands. The enhanced flow rate and velocity caused liquid flow to penetrate the boiling zone and contact the heated region of the LBT. The implication for a Yucca Mountain repository is that reflux events will be episodic and may be capable of penetrating to the emplacement drifts.

Review of the geothermal literature suggests that heat pipes are possible on a large or small scale and are associated with surface-measured heat flow as low as 5 to $10 \mathrm{HFU}$. The maximum rate of repository heating will be about $250 \mathrm{HFU}$ (100 $\mathrm{kW} / \mathrm{ac}$ ). The duration of repository heating will be intermediate between previous human-caused perturbations, such as thermal oil recovery, and geothermal systems.

Heat pipes at a Yucca Mountain repository will bear some resemblance to vapordominated geothermal systems such as The Geysers, a geothermal reservoir in California. Vapor-dominated geothermal systems are naturally sealed on the top and sides; otherwise the steam would escape or the vapor zone would be flooded by groundwater. A cap of liquid condensate forms lower, at the top of the vapor dominated zone. Condensate in this zone must tend to flow laterally, and similar flow will probably occur above the heat-pipe zone at Yucca Mountain. Shedding of condensate around emplacement drifts has been predicted in thermohydrologic simulations (Buscheck, 1996b), and similar behavior has been observed in borehole heater tests (Ramirez et al., 1991b).

Silica precipitation in a heat-pipe zone at Yucca Mountain is likely to exhibit rate behavior covering the range rates observed in laboratory and field experiments. If liquid water travel time is on the order of minutes or hours, experimental precipitation-rate data can be interpreted to mean that precipitation will be ratelimited in heat-pipe zones. It should be noted that kinetic experiments were performed at isothermal conditions, whereas water reflux in a heat pipe zone travels up a thermal gradient. 
Another potentially important geothermal effect that has been observed is the stability of geothermal wells that have been quenched by the accumulation of water (i.e., once a steam well inadvertently fills with water, it tends to remain filled). Coupling between heat and mass flow, caused by permeability changes associated with saturation, means that wet pathways receive less heat and therefore tend to remain wet. This implies that some waste packages in a Yucca Mountain repository may be exposed to refluxing water or higher humidity, while others will remain dry. 


\section{Introduction}

\subsection{Purpose and Scope}

The main purpose of this report is to document observations and data on thermally coupled processes for conditions that are expected to occur within and around a repository at Yucca Mountain. Some attempt is made to summarize values of properties (e.g., thermal properties, hydrologic properties) that can be measured in the laboratory on intact samples of the rock matrix. Variation of these properties with temperature, or with conditions likely to be encountered at elevated temperature in the host rock, is of particular interest. However, the main emphasis of this report is on direct observation of thermally coupled processes at various scales.

Direct phenomenological observations are vitally important in developing and testing conceptual models. If the mathematical implementation of a conceptual model predicts a consequence that is not observed, either (1) the parameters or the boundary conditions used in the calculation are incorrect or (2) the conceptual basis of the model does not fit the experiment; in either case, the model must be revised. For example, the effective continuum model that has been used in thermohydrology studies combines matrix and fracture flow in a way that is equivalent to an assumption that water is imbibed instantaneously from fractures into adjacent, partially saturated matrix. Based on this approximation, the continuum-flow response that is analogous to fracture flow will not occur until the effective continuum is almost completely saturated. This approximation is not entirely consistent with some of the experimental data presented in this report.

This report documents laboratory work and field studies undertaken in FY96 and FY97 to investigate thermally coupled processes such as heat pipes and fracturematrix coupling. In addition, relevant activities from past years, and work undertaken outside the Yucca Mountain project are summarized and discussed. Natural and artificial analogs are also discussed to provide a convenient source of material documenting the conceptual and mathematical basis for modeling coupled phenomena. The actual models and codes, and their specific empirical and theoretical bases, will be documented in a separate report to be delivered in FY99.

\subsection{Types of Coupled Processes}

Thermally driven coupled processes may have either beneficial or adverse effects on the performance of a high-level nuclear waste repository at Yucca Mountain. Some effects from thermally coupled processes are very likely to occur, based on the knowledge that large amounts of water will be redistributed due to vaporization by radioactive decay heat and condensation in cooler regions of the 
host rock. This redistributed water will probably dominate seepage into emplacement drifts for thousands of years and control the temperature and humidity at the waste packages. The adverse effects of seepage could be mitigated by decreased fracture permeability in regions of the rock mass where mineral dissolution and precipitation occur after repository closure.

Thermally coupled processes must be thoroughly evaluated and bounded to support credible assessment of total system performance. To support selection among alternative design options and operating strategies, it is also important to understand how these processes interact with design features and operating variables.

A list of coupled processes potentially important to a repository in the unsaturated zone at Yucca Mountain is presented in Table 1-1. This list was modified from one in Tsang and Mangold (1984) and, for completeness, includes some processes that are not thermally driven.

Processes in Table 1-1 can be classified in two categories:

- The Onsager-type driven by gradients of thermodynamic state variables

- Another type in which processes are affected indirectly by the magnitudes of thermodynamic state variables (Carnahan, 1987)

Thermally coupled processes in the latter category occur solely because of temperature-dependent changes in medium, fluid, or reactive properties. The Onsager-type processes are fundamental and occur in response to potential gradients, even if the associated physical or chemical properties are invariant.

Table 1-1 List of coupled processes potentially relevant to performance of a repository in the unsaturated zone at Yucca Mountain (modified from Tsang and Mangold, 1984)

\begin{tabular}{|l|l|}
\hline \multicolumn{1}{|c|}{ Type of Coupling } & \multicolumn{1}{|c|}{ Processes } \\
\hline \hline A. Thermohydrologic $(\mathrm{TH} \leftrightarrow \mathrm{HT})$ & $\begin{array}{l}\text { Thermal osmosis } \leftrightarrow \text { thermal filtration } \\
\text { Thermally driven gas diffusion } \\
\text { Thermal convection and buoyancy flow } \\
\text { Heat pipes } \\
\text { Phase changes and flow interference } \\
\end{array}$ \\
\hline B. Thermochemical $(\mathrm{TC} \leftrightarrow \mathrm{CT})$ & $\begin{array}{l}\text { Soret effect } \leftrightarrow \text { Dufour effect } \\
\text { Phase changes and solid solution } \\
\end{array}$ \\
& Metastable phases \\
\hline C. Thermoelectrical $(\mathrm{TE} \leftrightarrow \mathrm{ET})$ & $\begin{array}{l}\text { Seebeck effect } \leftrightarrow \text { Peltier effect } \\
\text { Thermal-electrical property changes }\end{array}$ \\
\hline
\end{tabular}




\begin{tabular}{|c|c|}
\hline Type of Coupling & Processes \\
\hline D. Thermomechanical (TM) & $\begin{array}{l}\text { Thermal expansion } \\
\text { Thermal creep } \\
\text { Thermal stress (can induce cracking and } \\
\text { spalling) }\end{array}$ \\
\hline E. Hydrochemical $(\mathrm{HC} \leftrightarrow \mathrm{CH})$ & $\begin{array}{l}\text { Ultrafiltration } \leftrightarrow \text { chemical osmosis } \\
\text { Formation and transport of particles }\end{array}$ \\
\hline F. Hydroelectrical $(\mathrm{HE} \leftrightarrow \mathrm{EH})$ & Streaming current $\leftrightarrow$ electro-osmosis \\
\hline G. Electrochemical $(\mathrm{EC} \leftrightarrow \mathrm{CE})$ & Sedimentation current $\leftrightarrow$ electrophoresis \\
\hline H. Hydromechanical (HM) & $\begin{array}{l}\text { Pore pressure change and effective stress } \\
\text { Hydraulic fracturing } \\
\text { Erosion of fractures } \\
\text { Sedimentation and filtration of particles } \\
\text { Flow distortion of contact angles ("raindrop } \\
\text { effect") }\end{array}$ \\
\hline I. Thermohydromechanical (THM) & Stress redistribution (hydrologic properties) \\
\hline J. Thermohydrochemical (THC) & $\begin{array}{l}\text { Thermal osmosis } \\
\text { Dissolution/precipitation } \\
\text { Thermohydrochemical property changes } \\
\text { (diffusion, adsorption, aqueous speciation, and } \\
\text { capillarity) }\end{array}$ \\
\hline K. Thermomechanical-Chemical (TMC) & $\begin{array}{l}\text { Hydration/dehydration } \\
\text { Hydrolytic weakening } \\
\text { Stress corrosion (creep) } \\
\text { Mineral phase changes (physical/mechanical } \\
\text { properties) }\end{array}$ \\
\hline L. Thermohydromechanical-Chemical (THMC) & $\begin{array}{l}\text { Flow channeling (selective dissolution and } \\
\text { leaching) } \\
\text { Dissolution/precipitation (pressure solution) } \\
\text { Hydrothermal alteration } \\
\text { Heat pipes with dissolution/precipitation }\end{array}$ \\
\hline
\end{tabular}

\subsection{Thermodynamics of Coupled Processes}

The following presentation of nonequilibrium thermodynamics applied to coupled processes was given by Jamet et al. (1991). They wrote an expression for entropy production per unit volume in a fluid with multiple chemical components:

$$
\left.\sigma=\mathrm{J}_{\mathrm{q}} \cdot \nabla\left(\frac{1}{\mathrm{~T}}\right)+\sum_{\mathrm{i}} \mathrm{J}_{\mathrm{i}} \cdot\left(\frac{\mathrm{F}_{\mathrm{i}}}{\mathrm{T}}-\nabla \frac{\mu_{\mathrm{i}}}{\mathrm{T}}\right]\right)+\sum_{\alpha} \frac{\mathrm{A}_{\alpha} \chi_{\alpha}}{\mathrm{T}}+\frac{\mathrm{V}}{\mathrm{T}} \nabla \cdot \omega
$$


where $\mathrm{T}$ is temperature, $\mathrm{J}_{\mathrm{q}}$ is the heat flux, $\mathrm{J}_{\mathrm{i}}$ is the diffusion flux of the $\mathrm{i}^{\text {th }}$ component, $F_{i}$ represents external long-range forces acting on the $i^{\text {th }}$ component, $\mu_{\mathrm{i}}$ is the chemical potential of the $\mathrm{i}^{\text {th }}$ component, $\mathrm{A}_{\alpha}$ is the chemical affinity of the $\alpha^{\text {th }}$ chemical reaction, $\chi_{\alpha}$ is the volumetric reaction rate of the $\alpha^{\text {th }}$ chemical reaction, $\mathrm{V}$ is the viscosity tensor, and $\omega$ is the Lagrangian velocity. Changes in $\sigma$ are always positive for an irreversible process (from the $2^{\text {nd }} \mathrm{Law}$ ). The above expression is general but simplifies if fluxes vanish as the forces vanish, such that near-equilibrium behavior is represented by:

$$
\mathrm{J}_{\alpha}=\sum_{\alpha} \mathrm{L}_{\alpha \beta} \chi_{\beta}
$$

where the $\mathrm{J}_{\alpha}$ are fluxes, and the $\chi_{\beta}$ are thermodynamic forces. Onsager-type processes are described in this manner in Table 1-2. Direct processes lie along the main diagonal, and coupled processes are off-diagonal. The forces and fluxes in Table 1-2 are related by the coefficients $\mathrm{L}_{\mathrm{ij}}$, which have not generally been derived or measured for phenomena in porous geologic media. Reciprocal processes are found in symmetrical positions with respect to the main diagonal. The forces and fluxes can be defined in such a way that the matrix $\mathrm{L}_{\mathrm{ij}}$ is symmetric, which can be important in assigning values to unknown coefficients.

Table 1-2 Direct and coupled Onsager-type transport processes (after Carnahan, 1987). Fluxes are driven by gradients of temperature $(T)$, pressure $(P)$, chemical potential $(\mu)$, and electrical potential $(V)$.

\begin{tabular}{|l|c|c|c|c|}
\hline \multicolumn{1}{|c|}{ Flux $\downarrow$ Force $\rightarrow$} & $\nabla \mathbf{T}$ & $\nabla \mathbf{P}$ & $\nabla \mu$ & $\nabla \mathbf{V}$ \\
\hline \hline Heat & Fourier's Law & Thermal filtration & Dufour effect & Peltier effect \\
\hline Volume & $\begin{array}{c}\text { Thermal } \\
\text { osmosis }\end{array}$ & Darcy's Law & $\begin{array}{c}\text { Chemical } \\
\text { osmosis }\end{array}$ & Electro-osmosis \\
\hline Mass diffusion & Soret effect & $\begin{array}{c}\text { Reverse } \\
\text { osmosis }\end{array}$ & Fick's Law & $\begin{array}{c}\text { Electro- } \\
\text { phoresis }\end{array}$ \\
\hline Electrical current & Seebeck effect & $\begin{array}{c}\text { Streaming } \\
\text { current }\end{array}$ & $\begin{array}{c}\text { Sedimentation } \\
\text { current }\end{array}$ & Ohm's Law \\
\hline
\end{tabular}

It should be stated that the linear phenomenological relationships of Table 1-2 represent only behavior, in response to small perturbations, for a particular location and state of the medium. In addition, the coefficients are not generally scalar, and the directional dependence of transport phenomena in solid phases is typically described by second-order tensors. Geologic media are considered continua for purposes of applying these relationships. Hydrodynamic dispersion is not incorporated in this framework; if it were merged with the theory, some of the $\mathrm{L}_{\mathrm{ij}}$ would depend on the fluid velocity, and some of the fluxes would depend on the velocity and other state variables. 


\subsection{Onsager Processes}

Most of the indirect Onsager processes shown in Table 1-2 are probably not significant to near-field performance. The following discussion describes each process and possible constraints on the significance, in the absence of buoyancy, to performance of the near-field environment.

Thermal osmosis refers to a flux of water driven by temperature differences through a porous medium, from regions of higher to those of lower temperature. It has been observed in clays and has the potential to drive a flux of $500 \mathrm{~mm} / \mathrm{yr}$ under a temperature gradient of $20^{\circ} \mathrm{C} / \mathrm{m}$ (Srivastava and Avasthi, 1975). Clays are relatively impermeable to water, and the thermal osmotic effect in other media is relatively insignificant because of greater Darcy permeability. The reciprocal effect (i.e., thermal filtration) corresponds to a heat flow that, for pressure differences present in the near-field environment, will be insignificant compared with Fourier heat conduction.

The Soret effect is the solute flux driven by temperature differences and has been measured in pelagic sediments (Thornton and Seyfried, 1985). On the basis of experiments, the Soret effect has been shown to be potentially significant in clay materials subject to temperature gradients on the order of $10^{\circ} \mathrm{C} / \mathrm{m}$ or greater. As with thermal osmosis, the effect is relatively insignificant in media with greater permeability to advective transport, and the reciprocal Dufour effect is a heat flux that will be insignificant compared with Fourier conduction.

Chemical osmosis is an indirect (off-diagonal in Table 1-2) Onsager process and refers to fluid flux in response to gradients of chemical potential, from lessconcentrated to more-concentrated conditions. Osmotic activity is well known in swelling clays and contributes significantly to the matric potential of pore water in some media. In welded tuff, the differences in solute activity required for significant chemical osmosis may occur only on a small scale. Matric and suction potentials are often assumed to be equivalent (Roberts and Lin, 1995). The reciprocal reverse-osmosis effect can be achieved in semipermeable media but requires large pressure gradients that are unlikely in the near-field environment.

The Seebeck effect corresponds to production of an electric current in response to variations in temperature. There is the possibility for electrical current flow between regions of different temperature in the near-field environment, but the phenomenon may be indistinguishable from electrochemical effects. The reciprocal Peltier effect is the physical basis for thermoelectric cooling devices, but may be insignificant, given the weak electric fields likely to be present and the magnitude of heat flow associated with Fourier conduction.

Electro-osmosis refers to fluid flux between regions with different electrical potential, the direction of which depends on fluid and medium properties. The effect has been used for dewatering of clay soils in an applied electric field but is likely to be insignificant in the near-field environment because electric potential gradients are small. The reciprocal effect is the streaming current, which is caused by differential mobility of electric charges in an advective flow, producing 
a net current. This effect will be limited by advective flow velocities, which are small in the rock matrix, but may produce significant streaming potentials associated with fracture flow.

Electrophoresis is likely to occur to some small extent in the near-field environment, where ions and charge-carrying particles move in the presence of electric fields. Experimental observations indicate that field magnitudes are small, thus electrophoresis of fracture and matrix pore water constituents may be insignificant. The reciprocal effect is represented by the sedimentation current effect, in which an electric current flows in response to a gradient of chemical potential. Neither effect has been identified in the course of field testing, but electric fields have been measured in association with heater tests, and the source mechanism is unknown.

It should be noted that be none of the phenomenological coefficients for the aforementioned Onsager coupled processes has been measured or investigated in welded tuff media. Carnahan (1987) applied the Onsager relationships to modeling of solute transport in clays and compared the results to observations from controlled experiments. His focus was clay media for which the osmotic processes and ultrafiltration are important, but indirect processes that produce gradients of temperature or electric potential are not important because of Fourier and Ohmic conduction, respectively.

\subsection{Transient vs. Residual Effects}

Thermally driven coupled processes at a Yucca Mountain repository can also be categorized based on longevity of the effects:

- Transient Effects-These effects are processes that produce reversible changes (e.g., drying and rewetting) that eventually return to preemplacement conditions. Without changing the spatial distribution of porosity and intrinsic permeability, the rock mass eventually returns to its pre-emplacement condition (perhaps altered by hysteresis or changing boundary conditions, such as the climate). For this category of processes, postclosure repository performance can be adequately assessed using models calibrated to existing site characteristics, with boundary conditions modified to represent future conditions.

- Residual Effects-These effects are processes that result in permanent changes to flow and transport pathways, which remain after cooling of the host rock. An important example is thermohydrochemical (THC) coupling caused by the dissolution and precipitation of minerals, especially along fractures. Other examples include thermohydromechanical (THM) coupling, in which permanent (inelastic) deformation in response to thermomechanical stress could open or close fractures and change the fracture permeability within a large volume of rock; and microbiological activity, which may be considered as biologically mediated THC coupling. 


\section{Laboratory Property Measurements}

\subsection{Purposes of Measurements}

Laboratory properties generally comprise the most extensive set of data available to support model calculations. Physical, thermal, and hydrologic properties of the rock matrix used as input to numerical simulations are based on descriptions of the variations of laboratory-measured properties within functional units. Characterizing the variations of properties with temperature (and other thermodynamic-state variables) requires additional testing and experimental controls that are more readily achievable in the laboratory than the field.

Measured values for many properties of interest are scale-dependent, which limits the applicability of laboratory-scale data to field-scale problems. One example is the hydraulic conductivity of the Topopah Spring welded tuff, which varies over approximately five orders of magnitude, depending whether matrix flow is observed at a small scale or fracture flow is viewed at a larger scale. A similar principle applies to rate processes: the time scale of laboratory measurement limits the applicability of laboratory data to field problems.

Based partly on laboratory-measured matrix properties and their variations with temperature, field experiments have been designed to measure the same properties and to investigate coupled processes at scales that incorporate fractures. Laboratory property measurements form the basis for design of these tests and analysis of the results.

\subsubsection{Support for Test Design and Analysis}

Laboratory properties measurements have been integrated with in situ tests performed at G-Tunnel, at the Large Block Test (LBT) at Fran Ridge, and in the Exploratory Studies Facility. The extent of laboratory effort has varied according to the information available from other investigations. Laboratory tests supporting the LBT, the Single Heater Test (SHT), and the Drift Scale Test (DST) are summarized in Table 2-1. 
Table 2-1 Laboratory tests performed in support of ongoing field-scale testing for the Yucca Mountain Project

\begin{tabular}{|c|c|c|}
\hline Test & Parameter Descriptions & Reference \\
\hline Large Block Test & $\begin{array}{l}\text { Moisture content and water } \\
\text { permeability } \\
\text { Moisture-retention characteristics } \\
\text { Mercury porosimetry } \\
\text { Electrical resistivity } \\
\text { Mechanical properties } \\
\text { Microbiological reconnaissance }\end{array}$ & $\begin{array}{l}\text { Roberts and Lin (1994b; } \\
\text { 1996b) Roberts et al. (1995) } \\
\text { Lin (1994; 1996) } \\
\text { Roberts et al. (1996b) } \\
\text { Lin (1995) } \\
\text { Roberts (1995; 1996) } \\
\text { Blair (1996) } \\
\text { Horn and Meike (1995); Meike } \\
\text { (1996) }\end{array}$ \\
\hline Single Heater Test & $\begin{array}{l}\text { Porosity } \\
\text { Moisture content } \\
\text { Particle density } \\
\text { Heat capacitance } \\
\text { Thermal conductivity } \\
\text { Thermal expansion } \\
\text { Porosity } \\
\text { Moisture content } \\
\text { Deformability } \\
\text { Saturated hydraulic conductivity } \\
\text { Thermal conductivity }\end{array}$ & $\begin{array}{l}\text { Wang and Suarez-Rivera } \\
\text { (1997) } \\
\text { Sobolik (1997) }\end{array}$ \\
\hline Drift Scale Test & $\begin{array}{l}\text { Porosity } \\
\text { Moisture content } \\
\text { Particle density } \\
\text { Thermal conductivity } \\
\text { Thermal expansion } \\
\text { Compressive strength } \\
\text { Mineral abundance }\end{array}$ & $\begin{array}{l}\text { Wang and Suarex-Rivera } \\
\text { (1997) } \\
\text { Brodsky (1997a; 1997b) } \\
\text { Viani (1996b; 1996c; 1997a; } \\
\text { and 1997b) }\end{array}$ \\
\hline
\end{tabular}

\subsubsection{Support for Repository Design, System Studies, Performance Assessment, and Related Purposes}

Support for design can be shown by examining design assumptions that relate to properties of the repository host rock. Table 2.2 presents design assumptions that have been extracted from the Controlled Design Assumptions (CDA) document and that are related to rock properties. Laboratory-measured properties have been used directly, or in analytical and numerical model calculations, to develop the CDA document.

Many assumptions refer to rock characteristics (e.g., mechanical properties) at ambient temperature although the design features (e.g., underground openings) to which they pertain will also perform at elevated temperatures. Repository performance under disturbed conditions such as elevated temperature is 
addressed by the more general system performance assumptions (e.g., waste containment) and service life for other engineered barrier system (EBS) structures and components. To verify such assumptions requires analyses that incorporate laboratory-measured properties for disturbed conditions.

The CDA results from applying a systems approach to design. Other system studies, such as the Calico Hills System Study (TRW, 1995) and the Exploratory Studies Facility (ESF) Alternative Study (Dennis, 1991), have also incorporated information from laboratory property measurements.

Table 2-2 Selected design assumptions that relate to properties of the host rock (extracted from the CDA document)

\begin{tabular}{|c|c|}
\hline Assumption & Types of Properties \\
\hline $\begin{array}{l}\text { A. Design assumption: } 150-y r \text { maintainable, } \\
\text { preclosure service life for EBS structures, } \\
\text { systems, and components (CDA EBDRD 3.2.5.4) }\end{array}$ & $\begin{array}{l}\text { Thermal, thermomechanical, } \\
\text { mechanical, chemical, mineralogical, } \\
\text { hydrologic }\end{array}$ \\
\hline $\begin{array}{l}\text { B. Design assumption: Substantially complete } \\
\text { waste-package containment for } 3000 \mathrm{yr} \text { (no more } \\
\text { than } 10 \text { failed packages in this time) after } \\
\text { permanent closure (CDA EBDRD 3.7.D) }\end{array}$ & $\begin{array}{l}\text { Thermal, thermomechanical, } \\
\text { mechanical, chemical, mineralogical, } \\
\text { hydrologic }\end{array}$ \\
\hline $\begin{array}{l}\text { C. Design assumption: Ground surface temperature } \\
\text { rise limited to } 2^{\circ} \mathrm{C}(\mathrm{CDA} \text { EBDRD 3.7.G.4) }\end{array}$ & Thermal, hydrologic \\
\hline $\begin{array}{l}\text { D. Design assumption: Access-drift temperature limit } \\
\text { of } 50^{\circ} \mathrm{C} \text { during repository operation (CDA EBDRD } \\
\text { 3.7.G.6) }\end{array}$ & $\begin{array}{l}\text { Thermal, thermomechanical, } \\
\text { mechanical, chemical, mineralogical, } \\
\text { hydrologic }\end{array}$ \\
\hline $\begin{array}{l}\text { E. Design assumption: Container design to limit the } \\
\text { amount of liquid water contacting the waste form, } \\
\text { consistent with the requirement that } 1 \% \text {, at most, } \\
\text { of the waste packages will be breached at } 1000 \mathrm{yr} \text {, } \\
\text { and the mean time to breaching is well in excess } \\
\text { of } 1000 \mathrm{yr} \text { (CDA EBDRD 3.7.1.2.D) }\end{array}$ & $\begin{array}{l}\text { Thermal, thermomechanical, } \\
\text { mechanical, chemical, mineralogical, } \\
\text { hydrologic }\end{array}$ \\
\hline $\begin{array}{l}\text { F. Design assumption: Maximum underground air } \\
\text { temperatures in emplacement drifts; limits given } \\
\text { for specified functions, including } 50^{\circ} \mathrm{C} \text { (dry bulb) } \\
\text { in portions of emplacement drifts requiring access } \\
\text { for waste retrieval (CDA DCSS 019) }\end{array}$ & $\begin{array}{l}\text { Thermal, thermomechanical, } \\
\text { mechanical, chemical, mineralogical, } \\
\text { hydrologic }\end{array}$ \\
\hline $\begin{array}{l}\text { G. Design assumption: Temperature at the average } \\
\text { top of the zeolite layer beneath the potential } \\
\text { emplacement area not exceeding } 93^{\circ} \mathrm{C} \text { (CDA } \\
\text { DCSS 025) }\end{array}$ & $\begin{array}{l}\text { Thermal, thermomechanical, } \\
\text { mechanical, chemical, mineralogical, } \\
\text { hydrologic }\end{array}$ \\
\hline $\begin{array}{l}\text { H. Design assumption: Concrete and steel as } \\
\text { candidate ground-support materials for use in } \\
\text { emplacement drifts (CDA DCSS 034) }\end{array}$ & $\begin{array}{l}\text { Thermal, thermomechanical, } \\
\text { mechanical, chemical, mineralogical, } \\
\text { hydrologic }\end{array}$ \\
\hline $\begin{array}{l}\text { I. Design assumption: Temperatures in the } \\
\text { nonwelded Paintbrush tuff (PTn) unit limited to } \\
\text { less than } 115^{\circ} \mathrm{C}(\mathrm{CDA} \text { DCSS 031) }\end{array}$ & $\begin{array}{l}\text { Thermal, thermomechanical, } \\
\text { mechanical, chemical, mineralogical, } \\
\text { hydrologic }\end{array}$ \\
\hline
\end{tabular}




\begin{tabular}{|c|c|}
\hline Assumption & Types of Properties \\
\hline $\begin{array}{l}\text { J. Design assumption: Invert material of } \\
\text { concrete/crushed tuff material combination; } \\
\text { other material additives used as necessary (CDA } \\
\text { DCSS 037) }\end{array}$ & $\begin{array}{l}\text { Thermal, thermomechanical, } \\
\text { mechanical, chemical, mineralogical, } \\
\text { hydrologic }\end{array}$ \\
\hline $\begin{array}{l}\text { K. Design assumption: Fuel-cladding temperature } \\
\text { limited to less than } 350^{\circ} \mathrm{C} \text { (CDA DCWP 001) }\end{array}$ & $\begin{array}{l}\text { Thermal, thermomechanical, } \\
\text { mechanical, chemical, mineralogical, } \\
\text { hydrologic }\end{array}$ \\
\hline $\begin{array}{l}\text { L. Design assumption: TSw2 saturation in situ of } \\
65 \% \text { (CDA TDSS 003) }\end{array}$ & Hydrologic \\
\hline $\begin{array}{l}\text { M. Design assumption: TSw2 rock density of } 2274 \\
\mathrm{~kg} / \mathrm{m}^{3} \text { (CDA TDSS 004) }\end{array}$ & Hydrologic \\
\hline $\begin{array}{l}\text { N. Design assumption: TSw2 thermal conductivity, } \\
\text { dry and at in situ saturation, } 2.1 \mathrm{~W} / \mathrm{mK} \text { (CDA TDSS } \\
\text { 005) }\end{array}$ & Thermal, hydrologic \\
\hline $\begin{array}{l}\text { O. Design assumption: TSw2 heat capacitance varies } \\
\text { according to temperature (CDA TDSS 006): } \\
2.0324 @ 25^{\circ} \mathrm{C} \quad 2.1280 \quad @ 50^{\circ} \mathrm{C} \\
2.2638 @ 94^{\circ} \mathrm{C} \quad 10.7683 \quad @ 95^{\circ} \mathrm{C} \\
10.4690 @ 105^{\circ} \mathrm{C} 10.1984 \quad @ 114^{\circ} \mathrm{C} \\
2.0065 @ 115^{\circ} \mathrm{C} 2.1114 \quad @ 155^{\circ} \mathrm{C} \\
2.1912 @ 195^{\circ} \mathrm{C} 2.2692 \quad @ 235^{\circ} \mathrm{C} \\
\left.2.3410 @ 275^{\circ} \mathrm{C} \text { (in } 10^{6} \mathrm{~J} / \mathrm{m}^{3} \mathrm{~K}\right) \\
\end{array}$ & Thermal, hydrologic \\
\hline $\begin{array}{l}\text { P. Design assumption: TSw2 thermal expansion } \\
\text { coefficient during heating (CDA TDSS 007): } \\
\begin{array}{ll}5.07 \times 10^{-6} \mathrm{C}^{-1} & 25^{\circ} \mathrm{C} \text { to } 50^{\circ} \mathrm{C} \\
7.03 & 50^{\circ} \mathrm{C} \text { to } 100^{\circ} \mathrm{C} \\
8.19 & 100^{\circ} \mathrm{C} \text { to } 150^{\circ} \mathrm{C} \\
8.97 & 150^{\circ} \mathrm{C} \text { to } 200^{\circ} \mathrm{C}\end{array}\end{array}$ & Thermomechanical \\
\hline 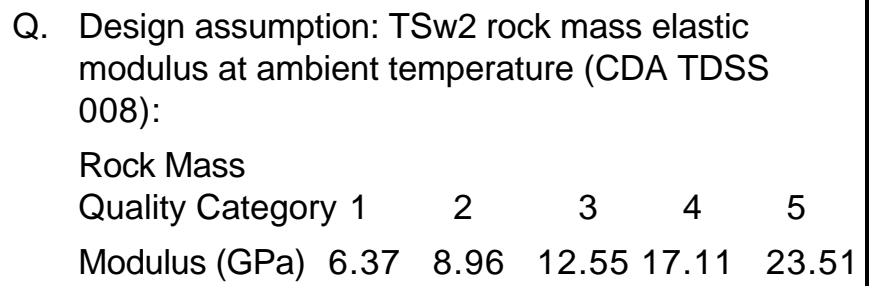 & Mechanical \\
\hline $\begin{array}{l}\text { R. Design assumption: TSw2 Poisson's ratio at } \\
\text { ambient temperature (CDA TDSS 009) } 0.21 \text { for } \\
\text { intact rock and } 0.21 \text { for the rock mass }\end{array}$ & Mechanical \\
\hline $\begin{array}{l}\text { S. Design assumption: TSw2 uniaxial compressive } \\
\text { strength of intact rock: } 155 \mathrm{MPa} \text { at ambient } \\
\text { temperature (CDA TDSS 010) }\end{array}$ & Mechanical \\
\hline
\end{tabular}




\begin{tabular}{|c|c|c|c|c|c|}
\hline \multicolumn{5}{|c|}{ Assumption } & Types of Properties \\
\hline \multicolumn{5}{|c|}{$\begin{array}{l}\text { T. Design assumption: Mohr-Coloumb strength } \\
\text { parameters for the TSw2 intact rock at ambient } \\
\text { temperature (CDA TDSS 011) vary as follows: } \\
\text { Rock Mass }\end{array}$} & \multirow[t]{4}{*}{ Mechanical } \\
\hline Quality Category 1 & 2 & 3 & 4 & 5 & \\
\hline Cohesion (MPa) 1.3 & 1.6 & 2.2 & 2.8 & 3.8 & \\
\hline Modulus (GPa) 49 & 49 & 50 & 50 & 50 & \\
\hline \multicolumn{5}{|c|}{$\begin{array}{l}\text { U. Design assumption: Porosity of intact TSw2 } \\
\text { 12.1\% (CDA TDSS 012) }\end{array}$} & Hydrologic \\
\hline \multicolumn{5}{|c|}{$\begin{array}{l}\text { V. Design assumption: Seepage into the repository } \\
\text { has } \mathrm{pH} 7.4 \text { (J-13 water). Effects of microbial } \\
\text { activity or other acidic conditions could change } \mathrm{pH} \\
\text { to as low as } 4.5 \text {. Alkaline conditions could range } \\
\text { from } 7 \text { to } 10.5 \text {. Dynamic heating and cooling could } \\
\text { concentrate solutes by a factor of } 10 \text { relative to } \mathrm{J} \text { - } \\
13 \text { composition. The ionic concentration of } \\
\text { episodic percolation, and of refluxing } \\
\text { condensate, is assumed to be one-tenth that of } \mathrm{J} \text { - } \\
13 \text { water. (CDA TDSS } 025)\end{array}$} & $\begin{array}{l}\text { Thermal, hydrologic, chemical, } \\
\text { mineralogical }\end{array}$ \\
\hline
\end{tabular}

\subsubsection{Types of Measurements}

The following is a survey of laboratory property measurements and analysis relevant to thermally coupled processes in the candidate repository host rock (TSw2). The discussion emphasizes the variation of rock properties with temperature and related environmental conditions such as relative humidity. For further discussion of laboratory-measured properties, the reader is referred to the Near Field Environment Report (Wilder, 1996a). Selection of properties for discussion is based on the available literature for Yucca Mountain, with special attention to the variations of laboratory-measured properties with temperature.

\subsection{Physical Properties (Dry Bulk Density, Grain Density, and Porosity)}

Physical properties, including porosity and grain density, have been measured on a large number of samples taken from rock core and outcrops. Borehole samples were analyzed most recently by Boyd et al. (1996), Martin et al. (1994, 1995b), and Roberts et al. (1995). The greatest number of measurements from borehole and outcrop samples is given by Flint (1996). Additional, unqualified data were reported by Price et al. (1985). Representative values for the host rock are given in Table 2.3, taken from Flint (1996), and from the Reference Information Base (RIB Version 4). 
Table 2-3 Physical properties of lithophysae-poor Topopah Spring welded tuff, candidate host rock for a Yucca Mountain repository

\begin{tabular}{|l|c|c|}
\hline \multicolumn{1}{|c|}{ Parameter } & Flint (1996) & RIB $^{\mathrm{a}}$ \\
\hline \hline Porosity & $0.11 \pm 0.02(\mathrm{~N}=266)$ & $0.12 \pm 0.03^{\mathrm{b}}$ \\
\hline Grain density $\left(\mathrm{g} / \mathrm{cm}^{3}\right)$ & $2.53 \pm 0.03(\mathrm{~N}=266)$ & $2.55 \pm 0.03^{\mathrm{b}}$ \\
\hline Dry bulk density $\left(\mathrm{g} / \mathrm{cm}^{3}\right)$ & $2.25 \pm 0.05(\mathrm{~N}=266)$ & $2.22 \pm 0.10^{\mathrm{c}}$ \\
\hline Bulk density at in situ saturation $\left(\mathrm{g} / \mathrm{cm}^{3}\right)$ & $2.34^{\mathrm{d}}$ & $2.30 \pm 0.09^{\mathrm{e}}$ \\
\hline
\end{tabular}

${ }^{a}$ Properties for the TMN hydrostratigraphic unit

${ }^{\mathrm{b}}$ Reference Information Base (1.1325, Rev. 3; [DOE, 1995])

${ }^{\mathrm{c}}$ Based on porosity and grain density

${ }^{\mathrm{d}}$ Based on porosity, grain density, and in situ saturation of $0.85 \pm 0.12(\mathrm{~N}=266)$

${ }^{\mathrm{e}}$ Based on porosity and in situ saturation of $0.65 \pm 0.19$

Porosity and grain density can vary with temperature through the effects of dehydration, thermal expansion, and mineral phase changes. Dehydration produces alteration of clays and zeolites that is generally associated with shrinkage, but which may be reversible by rehydration. Reversibility is related to factors that include the maximum temperature, the mechanical compaction, and the duration of dehydration.

The limiting temperature to prevent irreversible alteration may be substantially less than $100^{\circ} \mathrm{C}$. Sample preparation procedures developed by Flint (1996) called for drying in two steps to distinguish the effects of desaturation from alteration at temperatures greater than $100^{\circ} \mathrm{C}$. After $48 \mathrm{hr}$ at $60^{\circ} \mathrm{C}$ and $65 \% \mathrm{RH}$, "free" pore water was removed, leaving bound water and residual saturation in the finest pores. To obtain "dry" conditions, drying at $105^{\circ} \mathrm{C}$ was continued until constant weight was achieved. Once a sample was dried at $105^{\circ} \mathrm{C}$, the initial volumetric water content could not be reproduced at the same value of water potential. Flint (1996) qualitatively related the difference between same-sample moisture content values to the abundance of clay and zeolites (Figure 2-1). 


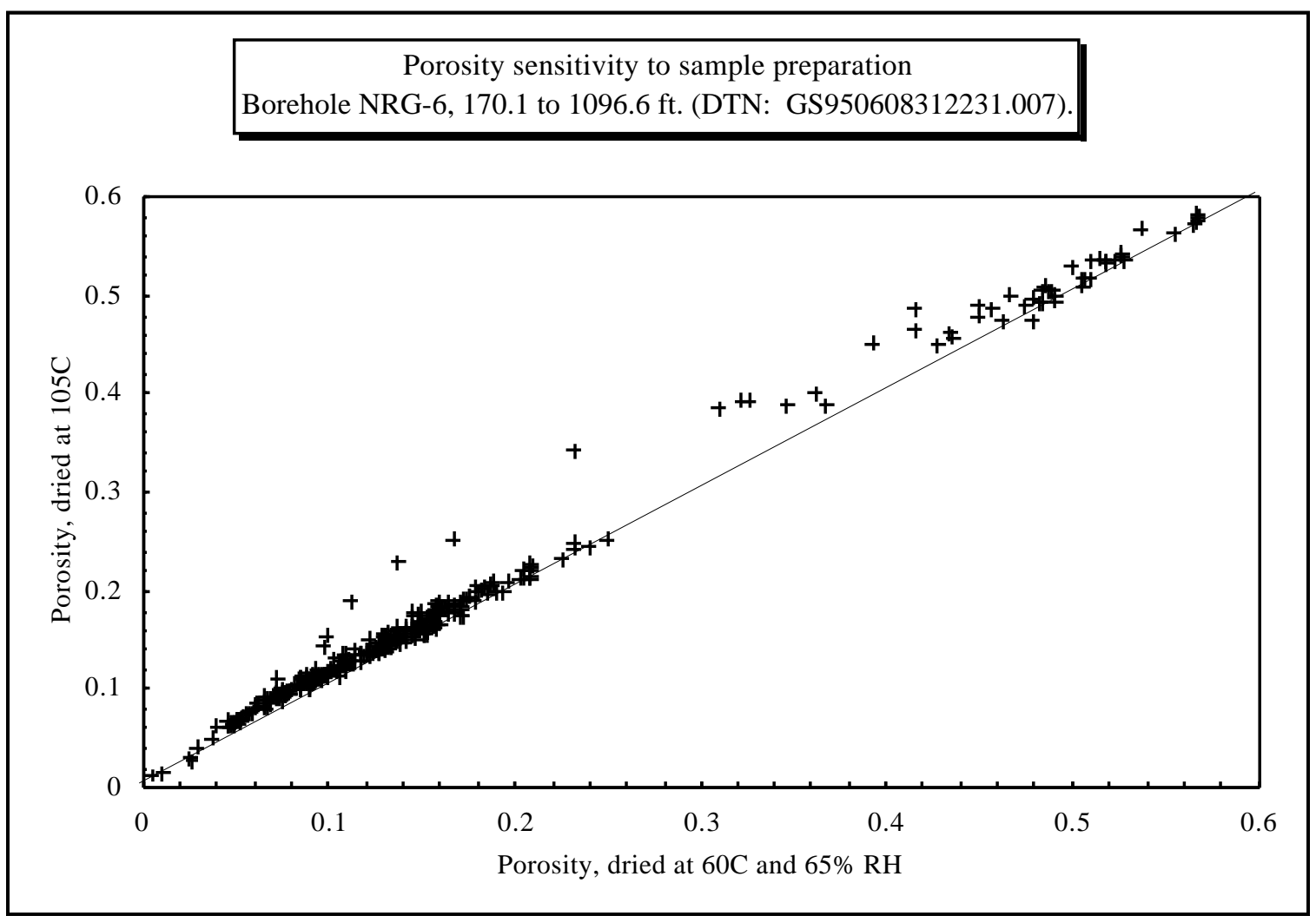

Figure 2-1 Comparison of porosity measured, using different drying procedures, for each of a series of samples from borehole NRG-6. Porosity measurements using the "relative humidity" oven $\left(60^{\circ} \mathrm{C}\right.$ and $\left.65 \% \mathrm{RH}\right)$ are plotted against subsequent same-sample measurements using oven drying at $105^{\circ} \mathrm{C}$ (after Flint, 1996).

The porosity of the host rock varies with temperature because of volumetric thermal expansion on the order of $3 \times 10^{-6} /{ }^{\circ} \mathrm{C}$. The change in porosity for a $100^{\circ} \mathrm{C}$ temperature increase is much smaller than the natural variability of porosity from sample to sample. As discussed subsequently, the coefficient of thermal expansion increases with temperature, which is interpreted to represent opening of microcracks by differential thermal expansion of a heterogeneous solid.

Mineral phase changes have the potential to increase or decrease porosity through grain density changes and differential expansion. Among nonhydrous phases present in the host rock, cristobalite probably has the greatest potential for phase change, as discussed subsequently. Blacic et al. (1986) reported that porosity and grain density of Topopah Spring welded tuff were unaffected by heating at temperatures as great as $180^{\circ} \mathrm{C}$ for as long as 3.5 months under hydrostatic confinement (non-Q). 


\subsection{Thermal Properties}

Measured thermal properties are strongly influenced by sample moisture conditions and are weakly influenced by the direct effects of temperature. Transport of heat is enhanced by conduction in pore water and by the transport of water vapor containing latent heat. Under certain conditions, heat transport may also be sensitive to mechanical stress. The heat capacity of pore water adds to the heat capacity of mineral phases, whereas the apparent heat capacity associated with evaporation or condensation can dominate rock response to heating. The following discussion focuses on laboratory measurement of the thermal properties of Topopah Spring welded tuff and emphasizes property variation with temperature, without explicit treatment of simultaneous heat and moisture transport. The enhanced vapor diffusion effect is addressed in a later section of this report.

\subsubsection{Thermal Conductivity}

Brodsky et al. (1996) conducted a total of 143 thermal conductivity tests on 95 test specimens of Topopah Spring welded tuff. Core samples were tested at ambient pressure and several saturation states, including air-dried, oven-dried, partially saturated, and vacuum-saturated. Sample dimensions were nominally $1.27 \mathrm{~cm}$ length and $5.08 \mathrm{~cm}$ diameter. Thermal conductivity was computed from the measured steady temperature gradient in the axial direction while samples were subjected to known heat flux in a temperature-controlled environment.

Thermal conductivities, averaged over all boreholes from which samples were obtained, ranged from 1.5 to $2.3 \mathrm{~W} / \mathrm{m} \cdot \mathrm{K}$, depending on temperature and saturation state. Thermal conductivity is generally greatest for saturated conditions and smallest for dried samples. Table 2-4 shows a comparison of the mean values reported by Brodsky et al. for the TSw2 thermomechanical stratigraphic unit with values from the RIB. Brodsky et al. (1996) pointed out that the tabulated mean values obscure the observation that thermal conductivity of the tuff matrix (i.e., oven-dried samples) is slightly sensitive to temperature and exhibits some variability among the four boreholes from which samples were obtained. 
Table 2-4

Thermal conductivity of lithophysae-poor Topopah Spring welded tuff (TSw2)

\begin{tabular}{|l|c|c|}
\hline \multicolumn{1}{|c|}{ Parameter } & $\begin{array}{c}\text { Mean values, } \\
\text { Brodsky et al. }(\mathbf{1 9 9 6})^{\mathrm{a}}\end{array}$ & $\begin{array}{c}\text { Nimick } \\
(\mathbf{1 9 9 0 a})^{\mathbf{b}}\end{array}$ \\
\hline \hline \multicolumn{3}{|c|}{ Low Temperature $\left(<\mathbf{1 0 0 ^ { \circ } \mathbf { C } )}\right.$ Thermal Conductivity $(\mathbf{W} / \mathbf{m} \cdot \mathbf{K}):$} \\
\hline Dry matrix thermal conductivity & $1.49 \pm 0.44$ & $2.51 \pm 0.17$ \\
\hline Saturated matrix thermal conductivity & $2.29 \pm 0.42$ & - \\
\hline Matrix thermal conductivity at in situ saturation & - & $2.18 \pm 0.17^{\mathrm{c}}$ \\
\hline Dry in situ thermal conductivity & - & $2.07 \pm 0.18$ \\
\hline In situ thermal conductivity at in situ saturation & - & $2.14 \pm 0.18^{\mathrm{c}}$ \\
\hline \multicolumn{2}{|c|}{ High Temperature $\left(>\mathbf{1 0 0}^{\circ} \mathbf{C}\right)$} & Thermal Conductivity $(\mathbf{W} / \mathbf{m} \cdot \mathbf{K}):$ \\
\hline Dry matrix thermal conductivity & $1.59 \pm 0.10$ & - \\
\hline
\end{tabular}

${ }^{a}$ Reference Information Base (1.1326, Rev. 0; [DOE, 1995]); also see Brodsky et al. (1996)

${ }^{b}$ Source: Nimick (1990b); not performed under an approved QA program

${ }^{c}$ Assuming $0.65 \pm 0.19$ in situ saturation fractures and lithophysae dry)

Experimental control of moisture conditions was identified by Nimick (1990a, $1990 b)$ as a source of error in thermal conductivity data reported up to that time. Methods used to "dry" core samples produced actual saturations as high as 50\%, while methods to "saturate" samples produced saturations of only $95 \%$.

Reinterpretation of previously acquired measurements at sample temperatures greater than $100^{\circ} \mathrm{C}$ was shown to be unfeasible.

For samples that were systematically oven-dried at $110^{\circ} \mathrm{C}$, thermal conductivity remained constant or increased slightly with temperature from 25 to $300^{\circ} \mathrm{C}$. This is consistent with general properties of the constituent minerals: plagioclase is the major mineral constituent, and its thermal conductivity is reported to increase with temperature (Brodsky et al., 1996).

These results contrast with other reports of rock thermal conductivity decreasing with temperature. Durham and Abey (1981) observed a 20\% decrease in thermal conductivity of Climax quartz monzonite from 40 to $200^{\circ} \mathrm{C}$ at confining pressure of $50 \mathrm{MPa}$. This rock is approximately $65 \%$ feldspar and $28 \%$ quartz (similar to Topopah Spring welded tuff, except that cristobalite is the major form of silica). The decrease of thermal conductivity was interpreted to be consistent with the reciprocal dependence on absolute temperature, suggested on physical grounds by Touloukian and Ho (1981). Further, the thermal conductivity of quartz is reported to decrease at elevated temperatures (Brodsky et al., 1996). A small increase in thermal conductivity was observed with increasing hydrostatic confining pressure from 3 to $50 \mathrm{MPa}$, but was within the estimated measurement error $( \pm 0.25 \mathrm{~W} / \mathrm{m} \cdot \mathrm{K})$. 
Another set of experiments, which was reported by Moss et al. (1982), examined the isotropy of thermal conductivity in samples from the Grouse Canyon Member welded, devitrified tuff. Samples were tested over the temperature range of 37 to $150^{\circ} \mathrm{C}$; thermal conductivity was insensitive to orientation with respect to the rock fabric, within the limits of experimental precision. This is an important observation in relation to thermal conductivity of Yucca Mountain tuffs, which are usually assumed to be thermally isotropic. A related experiment tested the thermal response of a saw cut in Grouse Canyon tuff. Thermal resistance of a composite formed by rejoining a saw-cut core sample, was within $1 \%$ of the sum of the separate resistances: from 27 to $100^{\circ} \mathrm{C}$ and at axial stress from 0.4 to $6.9 \mathrm{MPa}$.

\subsubsection{Heat Capacitance}

Heat capacitance is defined as the product of specific heat and density, both scalars, and represents the rate at which heat must be supplied to achieve temperature increase. It includes sensible heat plus any latent heat absorbed in phase changes and is expressed on a volumetric basis. Phase changes typically occur within specific ranges of temperature, hence heat capacitance is temperature-dependent.

Brodsky et al. (1996) reported 10 measurements of heat capacity on 10 samples of rock core. Measurements were made in an adiabatic pulse calorimeter in a way that limited the change in temperature of the bulk sample during a measurement. Specimens were initially air dried and allowed to equilibrate at successively higher temperatures prior to calorimetry. Tests were conducted at ambient pressure and at temperatures as great as $300^{\circ} \mathrm{C}$. Experimental data for the TSw2 unit are reported in Table 2-5, as are estimates based on tuff mineralogy and physical properties. Figure 2-2 presents a plot of the average heat capacitance for seven samples of TSw2 welded tuff from borehole NRG-5. The irregular slope of the heat capacitance versus temperature curve is probably related to mineral phase changes (Brodsky et al., 1996). 
Table 2-5 Comparison of temperature-dependent heat-capacitance values measured on seven samples of TSw 2 welded tuff, with estimates based on mineralogy

\begin{tabular}{|c|c|c|c|}
\hline $\begin{array}{c}\text { Temperature } \\
\left({ }^{\circ} \mathbf{C}\right)\end{array}$ & $\begin{array}{c}\text { Experimental }^{\mathbf{a}} \\
\left(\mathbf{J} \cdot \mathbf{c m}^{-\mathbf{3}} \cdot \mathbf{K}^{-\mathbf{}} \mathbf{)}\right.\end{array}$ & $\begin{array}{c}\text { Temperature } \\
\left({ }^{\circ} \mathbf{C}\right)\end{array}$ & $\begin{array}{c}\text { Estimated }^{\mathbf{b}} \\
\left(\mathbf{J} \cdot \mathbf{c m}^{-3}-\mathbf{K}^{-1} \mathbf{)}\right.\end{array}$ \\
\hline 25 & 1.79 & 25 & 2.03 \\
\hline 50 & 1.88 & 50 & 2.13 \\
\hline 75 & 1.97 & 94 & 2.26 \\
\hline 100 & 2.16 & 95 & 10.77 \\
\hline 125 & 2.32 & 105 & 10.47 \\
\hline 150 & 2.45 & 114 & 10.20 \\
\hline 175 & 2.43 & 115 & 2.01 \\
\hline 200 & 2.40 & 155 & 2.11 \\
\hline 225 & 2.39 & 195 & 2.19 \\
\hline 250 & 2.39 & 235 & 2.27 \\
\hline 275 & 2.39 & 275 & 2.34 \\
\hline 300 & 2.43 & & \\
\hline
\end{tabular}

a Brodsky et al. (1996); values used in Reference Information Base (1.1326, Rev. 0; [DOE, 1995])

b Nimick and Connolly (1991); not performed under an approved QA program

Nimick and Connolly (1991) used bulk chemical analyses of 20 samples of Yucca Mountain tuffs to estimate heat capacities of the solid components of tuff over a range of temperature. In Table 2-5, estimated heat capacitance values for the TSw2 unit are compared with experimental data. For estimation purposes, Nimick and Connolly assumed that the dehydration of pore water, from the initial saturation of $65 \%$, occurred uniformly and completely in the temperature range of 95 to $115^{\circ} \mathrm{C}$, producing an effective heat capacity approximately 5 times the background value. The tridymite phase transition $\left(163^{\circ} \mathrm{C}\right.$ in synthetic pure phase; [Meike and Glassley, 1989]) was assumed to occur over a temperature range of $20^{\circ} \mathrm{C}$ centered on $163^{\circ} \mathrm{C}$. Similarly, the cristobalite transition $\left(272^{\circ} \mathrm{C}\right.$ in synthetic pure phase; [Papike and Cameron, 1976]) was assumed to occur over a $20^{\circ} \mathrm{C}$ range centered on $225^{\circ} \mathrm{C}$. Based on mineral abundance data for the TSw2 unit, the cristobalite transition produced a $20 \%$ increase in heat capacitance, and the contribution from the tridymite transition was negligible.

Phase changes of pore water are accounted for separately from heat conduction in numerical thermohydrologic simulators, therefore the experimental values in Table 2-5 are appropriate input to models such as NUFT (Nitao, 1993), and the estimates of Nimick and Connolly (1991) are not. Mineral phase transitions are reflected in the experimental heat capacitance data, to the extent that the transitions occur over a range of temperature and that the range is sampled. The $\alpha \Rightarrow \beta$ cristobalite transition is evidently reversible, although with significant hysteresis in the transition temperatures $\left(\beta \Rightarrow \alpha\right.$ transition at $\sim 170^{\circ} \mathrm{C}$; [Meike and 
Glassley, 1989]). In addition, the effects of drying/rewetting hysteresis on the enthalpy of moisture loss / gain have not been investigated (Nimick and Connolly, 1991).

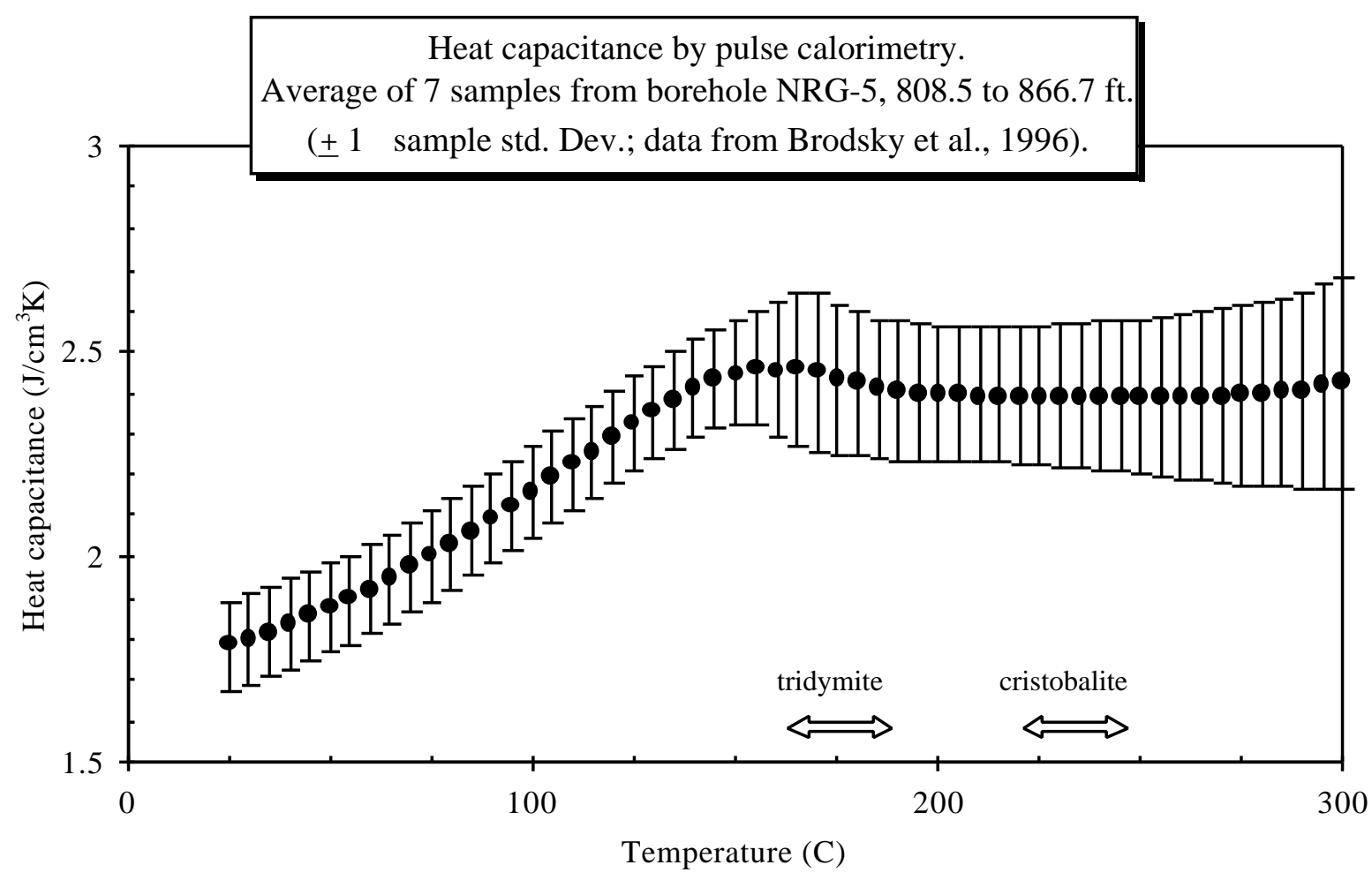

Figure 2-2 Average heat capacitance for 7 samples of TSw2 welded tuff, as a function of temperature, measured by adiabatic pulse calorimetry (data from Brodsky et al., [1996])

\subsubsection{Thermal Diffusivity}

Thermal diffusivity is the ratio of thermal conductivity to heat capacitance and is therefore temperature-dependent. Thermal diffusivity describes transient behavior, and direct measurement requires a transient method. The methods used to measure thermal conductivity and heat capacitance involve steady-state temperature measurements that are inherently more stable and precise than are transient measurements. These methods include thermal line-probe methods for measuring conductivity, which measure the pseudo-steady-state rate of temperature increase in response to constant heating (Marovelli and Vieth, 1964; Nimick, 1989). All documented efforts to measure laboratory thermal properties of Yucca Mountain tuffs have reported thermal conductivity and heat capacitance, from which thermal diffusivity is calculated as a function of temperature (Brodsky et al., 1996; Nimick, 1989, 1990a, and 1990b; Nimick and Schwartz, 1987). 


\subsection{Thermal Expansion}

In repository emplacement drifts, rock strain due to thermal expansion will be similar in magnitude to the deformation response to excavation. Thus the magnitude of thermal stresses that develops at confined conditions in the host rock will be comparable to that from other causes. Thermal stress will affect the mechanical stability of openings if resultant stresses exceed rock strength at key locations such as open boreholes or at the drift crown.

Porous geologic materials would have the same coefficient of linear thermal expansion as do the solid minerals from which they are composed, except for the effects of constitutive heterogeneity and the presence of fractures (Cook, 1985). The thermal stress at a specific location depends on deformability, which is strongly affected by fractures, and on the nature of mechanical confinement. Laboratory measurements of thermal expansivity are essential to understanding variability in the magnitude of thermal expansion and its effects throughout the rock mass.

Brodsky et al. (1996) reported 132 thermal expansion tests conducted on 120 samples. Tests were conducted at ambient pressure, at temperatures to $300^{\circ} \mathrm{C}$, and in several saturation states, including oven-dried, air-dried, partially saturated, and vacuum-saturated. Coefficients of linear thermal expansion were temperature-dependent, and values for the TSw2 unit, averaged over all boreholes, ranged from 6.7 to $37 \times 10^{-6} \mathrm{C}^{-1}$. Average values for the TSw2 and other thermomechanical units from Brodsky et al. (1996) are used in the RIB (1.1326, Rev. 0; [DOE, 1995]). Table 2-6 shows average values for the instantaneous coefficient of thermal expansion (local slope of thermal strain vs. temperature) for borehole NRG-6 from the same source. Thermal expansion of welded tuff was generally independent of saturation state. 
Table 2-6

Average coefficients of linear thermal expansion for vacuum saturated, air-dried, and oven-dried TSw2 welded tuff from borehole NRG-6. Posted values are averages over 16 to 19 samples of the slope of the strain vs. temperature plot at each temperature $( \pm 1 \sigma$ standard deviations reported).

\begin{tabular}{|c|c|c|c|}
\hline Temperature $\left({ }^{\circ} \mathrm{C}\right)$ & $\begin{array}{l}\text { Vacuum Saturated } \\
\qquad\left(\times 10^{-6} \mathrm{C}^{\circ-1}\right)\end{array}$ & $\begin{array}{c}\text { Air Dried } \\
\left(\times 10^{-6} \mathrm{C}^{\circ-1}\right)\end{array}$ & $\begin{array}{l}\text { Oven Dried } \\
\left(\times 10^{-6} \mathrm{C}^{\circ-1}\right)\end{array}$ \\
\hline 50 & $7.58 \pm 1.22$ & $7.91 \pm 0.76$ & $8.15 \pm 0.71$ \\
\hline 75 & $7.82 \pm 1.16$ & $8.16 \pm 0.86$ & $9.04 \pm 0.61$ \\
\hline 100 & $6.45 \pm 5.38$ & $9.16 \pm 0.84$ & $8.60 \pm 0.72$ \\
\hline 125 & $9.72 \pm 2.51$ & $9.54 \pm 1.15$ & $7.96 \pm 0.84$ \\
\hline 150 & $10.55 \pm 1.11$ & $10.32 \pm 1.74$ & $10.94 \pm 1.41$ \\
\hline 175 & $12.69 \pm 2.09$ & $11.05 \pm 1.98$ & $10.57 \pm 1.25$ \\
\hline 200 & $14.20 \pm 1.48$ & $12.95 \pm 2.24$ & $13.86 \pm 2.51$ \\
\hline 225 & $17.18 \pm 2.94$ & $14.90 \pm 3.07$ & $20.29 \pm 10.54$ \\
\hline 250 & $21.50 \pm 4.04$ & $17.31 \pm 3.65$ & $25.03 \pm 13.55$ \\
\hline 275 & $31.02 \pm 9.98$ & $21.57 \pm 7.83$ & $33.40 \pm 12.64$ \\
\hline 300 & $41.58 \pm 16.39$ & $27.82 \pm 12.58$ & $42.58 \pm 17.35$ \\
\hline 300 & $18.51 \pm 4.97$ & $15.30 \pm 3.49$ & $17.15 \pm 4.05$ \\
\hline 275 & $25.86 \pm 8.67$ & $19.32 \pm 6.76$ & $22.33 \pm 7.31$ \\
\hline 250 & $28.55 \pm 11.00$ & $19.6 \pm 7.25$ & $27.01 \pm 11.26$ \\
\hline 225 & $23.50 \pm 8.29$ & $18.54 \pm 4.35$ & $25.45 \pm 11.73$ \\
\hline 200 & $18.64 \pm 4.06$ & $17.01 \pm 2.92$ & $20.19 \pm 7.27$ \\
\hline 175 & $15.27 \pm 1.92$ & $13.95 \pm 2.56$ & $19.19 \pm 14.79$ \\
\hline 150 & $13.42 \pm 1.24$ & $12.68 \pm 2.24$ & $13.88 \pm 7.86$ \\
\hline 125 & $11.93 \pm 1.43$ & $11.49 \pm 1.68$ & $10.82 \pm 5.19$ \\
\hline 100 & $11.00 \pm 1.11$ & $10.07 \pm 1.17$ & $10.07 \pm 3.91$ \\
\hline 75 & $9.70 \pm 0.63$ & $9.34 \pm 0.73$ & $9.40 \pm 3.35$ \\
\hline 50 & $9.03 \pm 0.61$ & $8.53 \pm 0.57$ & $7.98 \pm 3.11$ \\
\hline
\end{tabular}

The expansion coefficient values in Table 2-6 represent expansion of samples that, during heating, measure $5.1 \mathrm{~cm}$ long by $2.54 \mathrm{~cm}$ diameter. The values may not fully describe the contribution of thermal expansion to effects such as spalling in very near-field locations (Blair and Berge, 1996a). In addition, the available thermal expansion data are biased toward nonlithophysal tuff, which tends to crumble when cored (Nimick and Schwartz, 1987). 
At temperatures near $200^{\circ} \mathrm{C}$, hysteresis in the strain-versus-temperature curves became apparent in most tests, probably because of phase changes in tridymite and cristobalite (Brodsky et al., 1996). At a transition temperature of approximately 175 to $225^{\circ} \mathrm{C}$, strain-versus-temperature curves for many samples of welded tuff became increasingly nonlinear, indicating a phase transition, with increasing expansion coefficients (Figure 2-3). Unconfined thermal expansion of silicate rocks generally increases with temperature. This probably results from nonuniform expansion of constituent grains, which causes the formation of new microcracks or the opening of pre-existing microcracks (Cooper and Simmons, 1977). In most of the tests reported by Brodsky et al. (1996), expansion reversed on cooling, but permanent elongations of as much as $0.4 \%$ were observed for some samples.

The $\alpha \Rightarrow \beta$ cristobalite transition occurs at approximately $225^{\circ} \mathrm{C}$ (pure phase) and produces a volume change of $+5 \%$ (Meike and Glassley, 1989; Peacor, 1973). Cristobalite and tridymite make up as much as $30 \%$, by volume, of Topopah Spring tuff groundmass in some locations (Bish et al., 1984). For example, differences in measured thermal expansion coefficients between boreholes $\mathrm{G}-2$ and GU-3 for the temperature range 150 to $200^{\circ} \mathrm{C}$ are attributed to cristobalite abundance (Bish and Vaniman, 1985; Nimick and Schwartz, 1987).

Brodsky et al. (1996) indicated that the connection between thermal expansion and mineralogy was not entirely clear from close comparison of available data. They stated that additional data and correlation between mineralogy and thermal behavior would support better understanding of observed variations, particularly the causes for expansion hysteresis and peaks in the heat capacitance vs. temperature curves. In addition, they recognized that mineralogical phase changes are pressure-sensitive and that transition temperatures increase with pressure. 


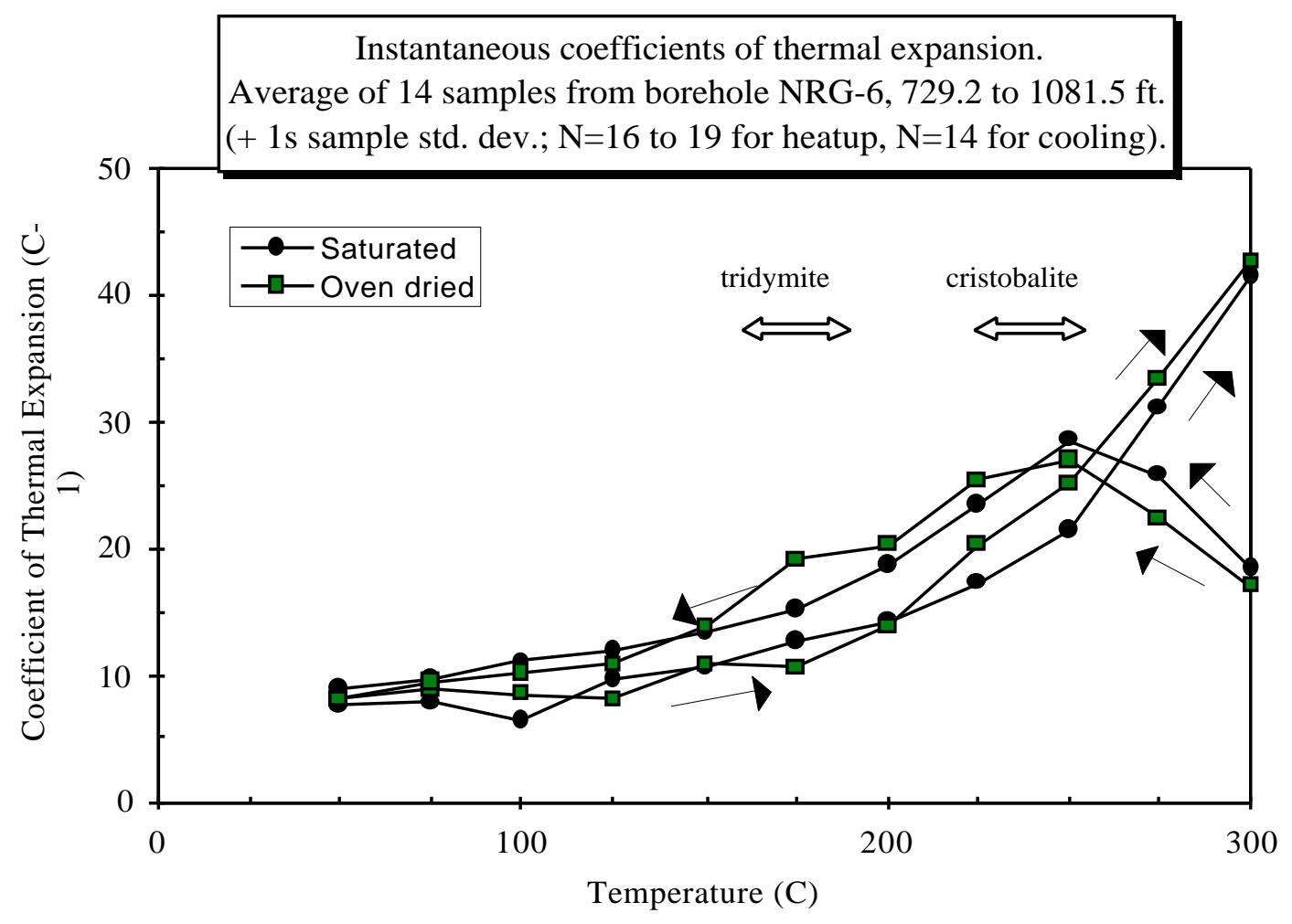

Figure 2-3 Linear thermal expansion coefficients vs. temperature for saturated and oven-dried samples of TSw2 tuff from borehole NRG-6 (data from Brodsky et al., [1996])

Martin et al. (1996) conducted thermal expansion measurements, as a function of confining pressure and at temperatures to $250^{\circ} \mathrm{C}$, on core samples of Topopah Spring tuff. They found that the coefficient of thermal expansion for welded tuff increased with temperature. At temperatures less than $100^{\circ} \mathrm{C}$, the value of this parameter was in the range 7.7 to $10.8 \times 10^{-6}{ }^{\circ} \mathrm{C}^{-1}$; as temperature was increased to near $250^{\circ} \mathrm{C}$, values of the coefficient of thermal expansion increased to between $14.2 \times$ and $20.6 \times 10^{-6}{ }^{\circ} \mathrm{C}^{-1}$. The authors concluded that confining pressure had a small effect of the coefficient of thermal expansion.

Schwartz and Chocas (1992) also reported TSw2 thermal expansion coefficients measured under confined and unconfined conditions. Using a comparator method, unconfined measurements were made on 78 samples with dimensions of approximately $2.5 \times 0.5 \times 0.5 \mathrm{~cm}$. Saturation was not controlled during tests up to $250^{\circ} \mathrm{C}$, and loss of water probably occurred. There was a significant trend toward higher expansion coefficients at higher temperatures. Confined measurements were made using 4.7- $\mathrm{cm}$ diameter drill core, under hydrostatic confinement at $10 \mathrm{MPa}$ and heating at a rate of 0.1 to $0.7^{\circ} \mathrm{C} / \mathrm{min}$. The samples were saturated prior to testing and were drained during testing. Expansion coefficients for welded tuff were similar to unconfined values. (For nonwelded tuffs, negative expansion coefficients were sometimes obtained, probably from alteration associated with dewatering combined with compressive stress.) 


\subsection{Mechanical Properties}

Changes in rock matrix strength and deformability caused by temperature and the effects of moisture are important to investigation of the near-field environment because of the potential for mechanical instability and for altered hydrology. The role of fractures in geomechanical near-field response was summarized by Cook (1985):

The strengths of even hard rocks are time dependent and decrease also with temperature and in the presence of water. Therefore, even where breakouts and spalling are not a problem in the short term of repository construction, they may become so in the longer term. Thermally exacerbated spalling in emplacement boreholes could produce a local region of decreased thermal conductivity and increased hydraulic permeability.

Increases in the temperature of the rock around a repository will produce thermal expansions that result in changes in stress. In general, within the volume of rock through which temperatures increase, there will be an increase in compressive stress. In order to maintain overall equilibrium, it follows that outside the heated volume there must be exactly compensatory decreases in compressive stress....

Anomalously low values for thermally induced displacements and stresses were measured in the Stripa heater experiment, which have been shown to result from the deformation across fractures. It can be seen that thermally induced displacements are altered so much by fractures that no predictions about stress or displacements can be made without at least knowing fracture stiffness and location relative to the temperature field and measurement points.

Rock mass deformability depends critically on the deformation of fractures, and fracture flow will be affected to some degree by rock mass deformation. Field scale measurement of fracture deformation and hydromechanical coupling are discussed in a later section of this report. Laboratory measured mechanical properties are used to interpret observations from such tests. The following sections describe the available laboratory scale measurements of mechanical properties of TSw2 welded tuff, substantially all of which have been made at ambient temperature.

\subsubsection{Strength and Deformability}

Laboratory data reported in the RIB (1.1322, Rev. 3;[DOE, 1995]) indicates that the intact TSw2 welded tuff has uniaxial compressive strength of $155 \pm 59 \mathrm{MPa}$, which is many times greater than the overburden stress. Parameters of internal friction show that strength increases significantly with confinement (Table 2-7). Unfractured samples from the TSw2 unit typically exhibit nearly linear and 
elastic stress-strain behavior until failure, and samples with fractures exhibit nonlinear behavior when stress is greater than approximately $50 \%$ of the unconfined compressive strength (Blair and Berge, 1996a).

Table 2-7 Mechanical properties for intact TSw2 welded tuff (RIB, 1.1322, Rev. 3)

\begin{tabular}{|l|c|}
\hline \multicolumn{1}{|c|}{ Mechanical property } & Value \\
\hline \hline Unconfined compressive strength (MPa) & $155 \pm 59$ \\
\hline Young's modulus (GPa) & $32.7 \pm 4.6$ \\
\hline Poisson's ratio & $0.22 \pm 0.03$ \\
USW G-1, USW GU-3 & $0.30 \pm 0.05$ \\
USW G-4 & \\
\hline Cohesion (MPa) & $18.3 \pm 5.2$ \\
USW G-2 & $37.8 \pm 12.4$ \\
UE-25a\#1, USW G-4, USW GU-3 & \\
\hline Angle of internal friction & $19.7^{\circ} \pm 5.2^{\circ}$ \\
USW G-2 & $36.5^{\circ} \pm 9.0^{\circ}$ \\
UE-25a\#1, USW G-4, USW GU-3 & \\
\hline
\end{tabular}

Mechanical properties for intact rock of the potential repository horizon have been extensively studied via tests on core samples (Martin et al., 1994 and 1995b; Boyd et al., 1996; Nimick et al., 1987; Price, 1983 and 1986; Price et al., 1987).

The following mechanical properties of Yucca Mountain tuffs have recently been extensively measured at ambient temperature in association with construction activities: unconfined compressive strength, static Young's modulus, Poisson's ratio, and elastic wave velocities (Boyd et al., 1996; Martin et al., 1994 and 1995b). In addition, a number of earlier studies were performed, but not under an approved QA program (Nimick et al., 1987; Price, 1983 and 1986; Price et al., 1987). Recent measurements were made with tuff samples taken from outcrops on Busted Butte and from boreholes NRG-4, -5, -6, and -7/7A.

Recent measurements were generally conducted at room temperature on watersaturated samples. The nominal strain rate for strength measurements was $10^{-5} \mathrm{sec}^{-1}$. Confined compressive strength and indirect tensile strength were also measured for some samples. Samples were first dried at $110 \pm 5^{\circ} \mathrm{C}$ before saturation, using laboratory procedures that were evaluated to determine that this temperature did not produce measurable microfracturing. Ultrasonic compressional and shear-wave velocities were used to evaluate sample damage.

The recent measurements of unconfined compressive strength, and static Young's modulus and Poisson's ratio (e.g., NRG-6, for which data are shown in Figure 2-4) exhibited more scatter than did TSw2 data reported in the RIB (Table 2-7). The recent samples were apparently more heterogeneous, representing a wide range of porosity, and some samples were much weaker than strength values given in the RIB. In particular, some samples from the NRG-boreholes failed at stress levels well below $100 \mathrm{MPa}$ (Boyd et al., 1996; Martin et al., 1994 and 1995b). Because saturation tends to lower the compressive strength (Nimick and 
Schwartz, 1987) any discrepancy between the recent data and the RIB data may have been caused by the different methods used for sample preservation and preparation (Boyd et al., 1994).

The static Poisson's ratio for the borehole samples was mostly within the range 0.15 to 0.25 , with a few measurements in the range 0.10 to 0.40 . One explanation for scatter in Poisson's ratio is that some samples may have contained more abundant $\alpha$-cristobalite, which has a negative Poisson's ratio for crystals and polycrystalline composites (Yehaneh-Hari et al., 1992). In this case, the Poisson behavior could be expected to change at elevated temperatures. Another possible explanation for scatter in Poisson's ratio measurements is material heterogeneity.

Martin et al. (1992) measured anisotropy of the TSw2 welded tuff using both static linear compressibility and ultrasonic compressional wave velocity. They reported that the deformation properties of the tuff are transversely isotropic, with the symmetry axis perpendicular to the bedding plane. This is reasonable because the rock fabric is strongly influenced by flattened pumice fragments, which form lamellae and contain inclusions with properties different from those of the bulk tuff. Static compressibility is $20 \%$ greater parallel to the symmetry axis (i.e., perpendicular to the bedding). Compressional wave velocity is $6 \%$ greater in directions parallel to the bedding plane than it is in directions perpendicular to the bedding plane.

Few data are available for interpreting the variation, with temperature and saturation, of compressive strength and Young's modulus of the TSw2 welded tuff. Laboratory measurements reported by Board et al. (1984) for the Grouse Canyon welded tuff indicated that variations in compressive strength due to temperature and saturation were smaller than those between samples. Blacic et al. (1986) investigated long-term (3.5- to 6-month) changes in mechanical properties of three samples of Topopah Spring welded tuff at temperatures of $80^{\circ}$, $120^{\circ}$, and $180^{\circ} \mathrm{C}$. They reached a similar conclusion: any effects on mechanical properties were smaller than between-sample variability.

Karakouzian and Hudyma (1996) found a statistical basis for the statement that saturation lowers the average compressive strength and average Young's modulus and that it increases between-sample variability in these properties. Nimick and Schwartz (1987) predicted that compressive strength would be $20 \%$ to $40 \%$ lower for saturated than for dry conditions. Based on data from the Grouse Canyon tuff and other rock types, they predicted no significant variation, relative to between-sample variability, of compressive strength with temperature and no significant variation of Young's modulus with either saturation or temperature. 


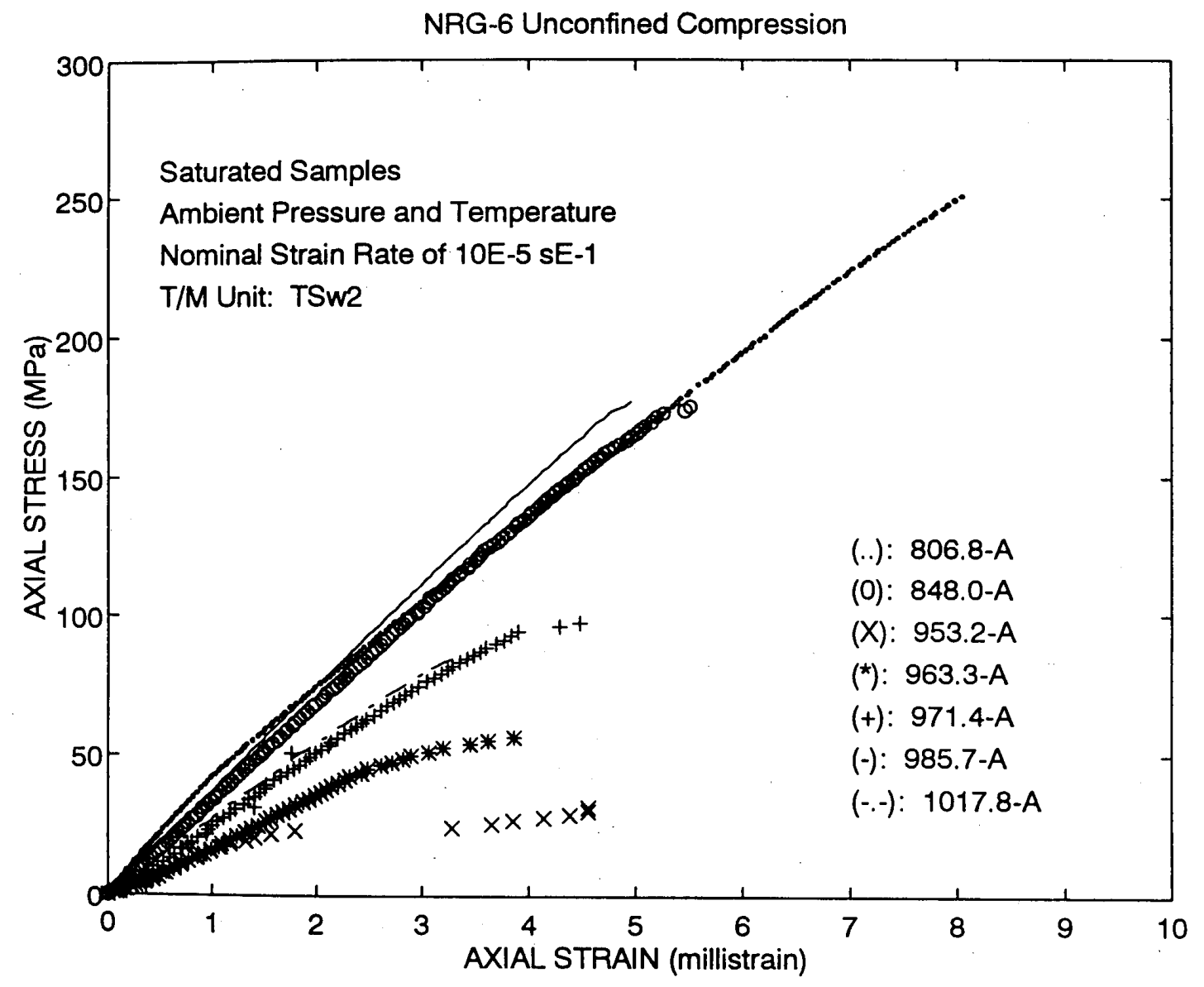

Figure 2-4 Stress-strain showing typical linear elastic stress-strain behavior and brittle failure for unconfined TSw2 welded tuff

\subsubsection{Joint Properties}

The properties of rock joints dominate rock mass deformation at all stress levels expected to occur in the repository. Large-scale mechanical tests (e.g., Zimmerman et al. [1986b]) have shown this to be true at stresses representing pre-excavation rock mass conditions at Yucca Mountain. Joint properties depend on the frictional and strength properties of the rock and on the geometry of joint surfaces. These factors are related to the cause of jointing, the nature of healing or mineral alteration, and the history of previous deformation.

Although joint-deformation response is scale-dependent due to scale-roughness and persistence considerations, it is possible to evaluate joint properties using drill core. Olsson $(1987,1988)$ found that the strength of a joint may increase with the time of stationary contact and that joint properties are dependent on stress history. He indicated that the latter area needs to be investigated further. Wibowo et al. (1993), and Olsson and Brown $(1994,1996)$ conducted laboratory experiments on fractures and joints in tuff to examine slip behavior and fracture surface damage during shear. 
Data on the effect of environmental variables (e.g., temperature, moisture content, and stress history) on joint properties are limited. In one study, seven specimens of TSw2 welded tuff from borehole SD-7 and one specimen from ESFTMA-MPBX-3 containing natural fractures were tested in rotary shear at $175^{\circ} \mathrm{C}$ (SNL, 1996). Fractures were sheared at constant normal stress levels between 2.5 and $15 \mathrm{MPa}$, in the "as-received" room-air dry condition, first at $20^{\circ} \mathrm{C}$, then at $175^{\circ} \mathrm{C}$. Values for fracture cohesion and friction coefficient increased slightly at the higher temperature, and the between-sample variability decreased slightly. Differences in average properties at the two temperatures may not have been significant. The differences in variability were interpreted to possibly represent more uniform sample conditioning by desiccation.

An ongoing laboratory investigation has evaluated the mechanical response, to normal loading at temperatures to $85^{\circ} \mathrm{C}$, of natural fractures in a $0.5-\mathrm{m}$ scale block of Topopah Spring welded tuff (Blair and Berge, 1996b). A block of tuff measuring $64 \times 32 \times 25 \mathrm{~cm}$ was oriented so that several fractures were sub-perpendicular to the loading axis. The block was instrumented for measurement of temperature, deformation of the fracture and the intact rock, and compressional wave ultrasonic velocity. It was subjected to a series of one-day loading cycles at various temperatures over a two-month period. An example of fracture deformation response to normal loading is shown in Figure 2-5.

Axial stress was cycled between 5 and $8.5 \mathrm{MPa}$ three times, at nominal temperatures of 50 and $85^{\circ} \mathrm{C}$ and again after cooling to ambient temperature. Blair and Berge (1997a) summarized the stress-strain behavior as follows:

- Compressive strain occurred while the block was heated under axial load.

- Deformation modulus decreased as temperature increased. Measurements over the complete height of the block indicated that the loading/ unloading modulus decreased from $19 \mathrm{GPa}$, for the unheated case, to 10 $\mathrm{GPa}$, for the load cycle at $90^{\circ} \mathrm{C}$.

- Young's modulus for the rock matrix decreased as temperature increased. At one measurement point, the matrix modulus decreased from 54 to 32 $\mathrm{GPa}$ in response to heating from $23^{\circ}$ to $90^{\circ} \mathrm{C}$.

Permanent deformation was evident when the sample was unloaded to zero after cooling. The block became shorter and broader during the series, but the lateral expansion was caused at least in part by slabbing of the sides during the test. 


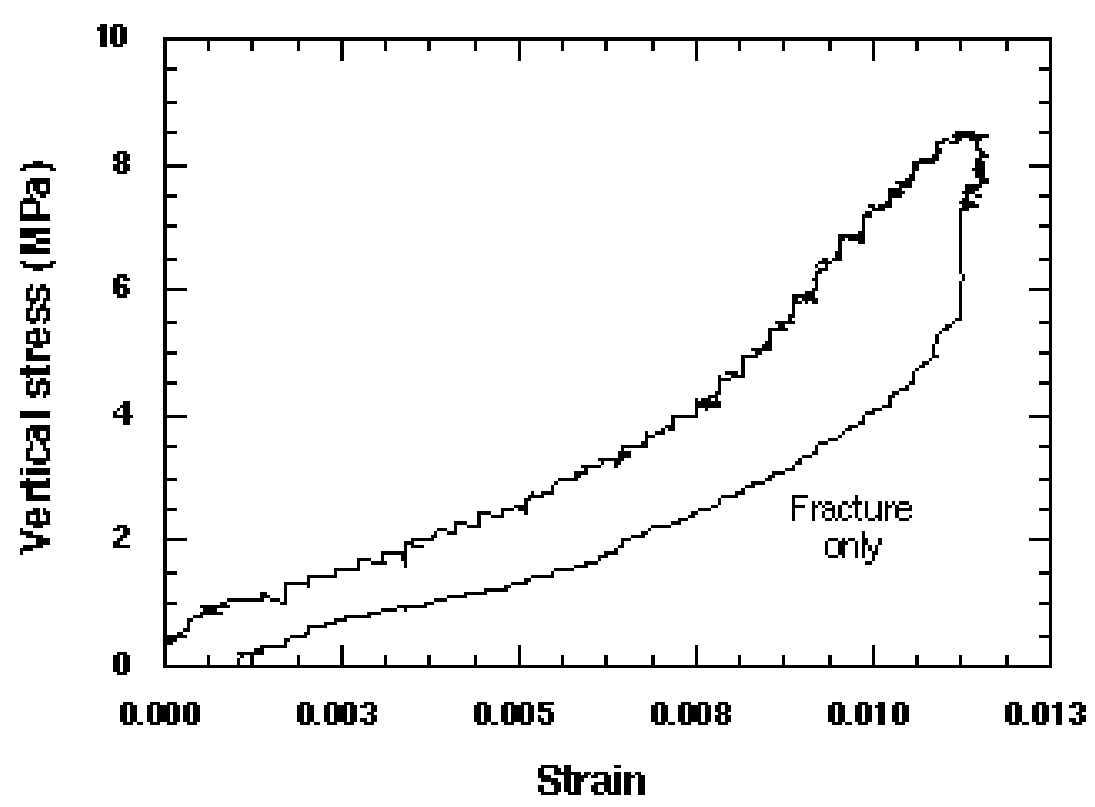

Figure 2-5 Stress-strain curve for deformation of a fracture in a 0.5-m scale block of Topopah Spring welded tuff, subjected to normal loading in the laboratory by Blair and Berge (1996a)

\subsubsection{Creep}

Laboratory measurements of thermal creep in welded tuff from the Topopah Spring (TSw2) unit at Busted Butte were performed by Martin et al. (1995c). The authors summarized the state of knowledge of creep in brittle silicate rocks. The strength of such rocks depends on the state of stress, saturation and pore pressure, temperature, and strain rate. Sample size is also important, as reported by Price et al. (1987), who concluded that the strength of the TSw 2 tuff is a function of size for core diameters less than $23 \mathrm{~cm}$.

Constant stress creep tests were conducted on cylinders $5.08 \mathrm{~cm}$ in diameter and $10.16 \mathrm{~cm}$ long of saturated TSw2 welded tuff (Martin et al., 1995c). The samples were jacketed and confined at $5 \mathrm{MPa}$ with argon during testing. Axial load was increased in steps of $10 \mathrm{MPa}$ until the strain rate exceeded $10^{-9} \mathrm{sec}^{-1}$, at which point load was held constant until the sample failed or the test was terminated. High temperature creep was investigated using the same procedure at $250^{\circ} \mathrm{C}$. Constant strain-rate-loading was also performed on some samples.

At more than approximately one-half the compressive strength, the predominant creep mechanism is opening and growth of axial cracks. There was a tendency for cracks to grow along curved trajectories until they were parallel to the direction of maximum compression. At both ambient and elevated temperatures, creep deformation in TSw2 welded tuff was observed, especially at stress levels greater than $90 \%$ of the compressive strength (Martin et al., 1995c). The strength of tuff under constant strain-rate-loading varied by a factor of 2 among the tested samples from the TSw2 unit. As the strain rate decreased from 
$10^{-5}$ to $10^{-9} \mathrm{sec}^{-1}$, the strength decreased to a moderate degree. Data were limited for evaluating the temperature dependence of creep, but indicated decreasing strength with increasing temperature. At a nominal strain rate of $10^{-5} \mathrm{sec}^{-1}$, the strengths ranged from 100 to $160 \mathrm{MPa}$, while at $10^{-9} \mathrm{sec}^{-1}$, strengths ranged from 45 to $108 \mathrm{MPa}$. The change of strength with strain rate was interpreted to be approximately $28 \%$ per thousandfold change in strain rate.

When applying the stress-corrosion model for crack growth in glass, quartz, and other silicates, the rate of steady crack growth is controlled by the rate of hydration at the crack tip (Martin, 1972; Martin and Durham, 1975). Growth occurs when covalent $\mathrm{Si}-\mathrm{O}$ bonds are altered to $\mathrm{Si}-\mathrm{OH}$ or van der Waals bonding, with a volume increase that enhances further diffusion of water to the crack tip. According to this model, the rate of crack growth in TSw2 tuff depends on the applied stress, the temperature, and the activity of water.

Martin et al. (1995c) argued that dilatancy observed in low-porosity crystalline silicate rocks is not characteristic of the TSw2 tuff. The interaction of large numbers of microcracks that produce a nonlinear increase in radial strain transverse to the loading axis, above approximately half of the unconfined compressive strength, is not operative in welded tuff. They identified axial cracks that developed during loading and propagated without coalescing until the ultimate strength was nearly achieved. They recognized that dilatancy may occur late in the loading history. Because of the linear elastic nature of tuff deformation at stress levels approaching the ultimate strength, pore-crushing did not appear to obscure the effects of dilatancy. Martin et al. (1995c) concluded from their review of the state of knowledge that TSw2 creep behavior is different from that of low-porosity crystalline rocks, and it is possible that creep strain may not be as pronounced while time to failure is still controlled by temperature, saturation, and stress.

\subsubsection{Ultrasonic Velocity}

Measurements of the elastic wave velocities provide a convenient means to evaluate changes in fracture abundance and apertures, liquid saturation, and mechanical anisotropy. Laboratory measurements provide the basis for designing field experiments and for interpreting the results.

Martin et al. (1994 and 1995b) measured compressional and shear wave velocities on samples of TSw2 welded tuff under saturated and dry conditions at ambient temperature. Compressional wave velocities were about 4.5 to $4.7 \mathrm{~km} / \mathrm{sec}$ for both dry and saturated samples from Busted Butte. The NRG borehole samples from Yucca Mountain had similar velocities, except that a few were as low as 4.0 to $4.3 \mathrm{~km} / \mathrm{sec}$ (Martin et al., 1994 and 1995b). These velocities are in agreement with compressional wave velocities measured at ambient temperature and pressure conditions for a block of Topopah Spring tuff at the 0.5-m scale (Blair and Berge, 1996a). 
Shear wave velocities for the Busted Butte samples were about 2.5 to $2.8 \mathrm{~km} / \mathrm{sec}$ for the saturated case and 2.7 to $2.8 \mathrm{~km} / \mathrm{sec}$ for the dry case (Martin et al., 1993). Similar results were obtained for the borehole samples, although fewer values were obtained (Martin et al., 1994 and 1995b).

Martin et al. (1993) used the velocity measurements to estimate dynamic Young's modulus and Poisson's ratio for the Busted Butte samples. They found values of about 41 to 44 GPa for dynamic Young's modulus in the dry case and of about 39 to $45 \mathrm{GPa}$ for the saturated case. The Poisson's ratio estimates were about 0.20 to 0.22 in the dry case and about 0.23 to 0.28 for the saturated case. The dynamic Young's modulus values were slightly higher than the measured static values for the Busted Butte samples (about $34 \mathrm{GPa}$ ). For these measurements, saturation had a greater effect on Young's modulus than the ultrasonic frequency.

Martin et al. (1992) evaluated anisotropy for TSw2 welded tuff and reported that velocity measurements exhibited transverse anisotropy, with the symmetry axis perpendicular to bedding; this was the same as the static linear compressibility. The compressional wave velocity anisotropy was approximately $2 \%$.

The effects of temperature on seismic velocities have not been experimentally evaluated for Topopah Spring welded tuff. With the Grouse Canyon tuff in G-Tunnel, velocities were found to decrease with temperature in laboratory studies (Board et al., 1984) and to decrease with temperature in the G-Tunnel Heated Block Test (Zimmerman et al., 1986b). Temperature increases are associated with greater deformability and growth of cracks, both of which cause velocities to decrease.

\subsection{Chemical Properties}

\subsubsection{Tuff Minerals Important to Near Field Performance}

The currently used geologic/lithologic stratigraphic nomenclature is detailed in the RIB (1.12, Revision 4). The upper Topopah Spring vitrophyre consists of subzones rv1 and rv2 and of the upper part of the TSw1 thermomechanical unit of Ortiz et al. (1985). The candidate host rock consists of the middle nonlithophysal zone pmn) and the upper part of the lower lithophysal (pll) units, both of which lie within the TSw2 thermomechanical unit. The lower Topopah Spring vitrophyre consists of subzones pv2 and pv3, which make up the TSw3 thermomechanical unit. The geologic/lithologic stratigraphy has been mapped directly to hydrogeologic units by Flint (1996).

\subsubsection{Alteration in the Upper Vitrophyre of the Topopah Spring Unit}

The portion of Yucca Mountain most likely to be significantly altered by repository induced conditions consists of the Topopah Spring Tuff and the underlying Calico Hills nonwelded (CHn) unit. The thin (3-7 m) upper vitrophyre is a unit of the Topopah Spring Tuff that lies above the repository, beneath the Paintbrush Tuff nonwelded (PTn) unit, and is probably the most 
effective barrier to downward recharge from the surface into the unsaturated zone (Flint et al., 1993). An important feature of this vitrophyre is the extent of alteration, which indicates how it has been affected by 12 Myr of exposure to infiltration. The upper vitrophyre is composed primarily of unaltered volcanic glass, with as much as $11 \%$ smectite in the glassy portions. Sampling in borehole UZ-16 showed that the upper vitrophyre was altered significantly, with as much as $18 \%$ smectite and $18 \%$ clinoptilolite-group zeolite.

Whereas heulandite formation in the basal vitrophyre (below the repository horizon) is found at the contact with the overlying devitrified tuff, heulandite occurrence in the upper vitrophyre affects two vitric zones (welded and overlying nonwelded) with different porosity and hydrologic properties. It is possible that heulandite occurrence in this upper zone was produced by perched water that accumulated on the underlying upper vitrophyre. Whatever the reason for heulandite formation, most of the upper vitrophyre is substantially unaltered, indicating little water/rock interaction in this relatively impermeable interval since tuff emplacement.

\subsubsection{Topopah Spring Host Rock}

The candidate repository horizon extends from below the zone of abundant $(>15 \% \mathrm{v} / \mathrm{v})$ lithophysal cavities in the upper Topopah Spring tuff down to the basal vitrophyre at the bottom of the Topopah Spring (Bish et al., 1996). The Topopah Spring tuff is chemically homogeneous, but varies with respect to the relative abundances of silica polymorphs (quartz, cristobalite, and tridymite). Within the repository block, there is little variation in mineralogy, and more than $98 \%$ of the mineral content of the rocks can be ascribed to tridymite, cristobalite, quartz, and alkali feldspar. The abundance of feldspar varies between about $55 \%$ and $65 \%$, with the remainder consisting of variable proportions of crystalline silica polymorphs. Hematite and smectite are common minor phases, and $\mathrm{Mn}$-oxides are common fracture coatings in the upper part of the interval.

The total abundance of silica polymorphs is nearly constant, although the proportion of each varies (Bish et al., 1996). Recent analysis of samples from the ESF indicates that the ratio of total crystalline silica polymorphs to alkali feldspar is $0.75 \pm 0.03$ within the host rock. Cristobalite is the dominant silica polymorph at $23 \% \pm 5 \%$, with quartz at $12 \% \pm 5 \%$ and tridymite at $4 \% \pm 1 \%$. X-ray diffraction analyses indicate a general decrease in cristobalite and increase in quartz with depth, beginning near the middle nonlithophysal zone. Silica polymorphs are important because the least stable of them (cristobalite and tridymite) can elevate the aqueous silica activity. They provide a source of silica for dissolution, transport, and deposition under repository thermal conditions. Cristobalite is particularly abundant at the candidate repository horizon (Bish et al., 1984) and is also important in the near field because it undergoes a displacive-phase transformation at about $220^{\circ} \mathrm{C}$, with an associated $5 \%$ volume increase (Peacor, 1973). 
Alteration reactions in the tuffs involving zeolites and smectite are quite sensitive to the aqueous silica activity (Bish et al., 1996; Chipera et al., 1995). The lower portion of the Topopah Spring devitrified zone generally contains all three of the crystalline silica polymorphs. Small amounts of tridymite ( $0 \%$ to $6 \%)$ and larger amounts of cristobalite (10\% to $20 \%$ ) occur throughout the rhyolitic portion of the Topopah Spring tuff. Thus, cristobalite and usually tridymite are present throughout the repository block to provide relatively soluble silica for dissolution, transport, and deposition under repository thermal conditions.

Apart from volcanic glass, opal-CT is the least stable form of silica present in Yucca Mountain cores (Bish et al., 1996; Chipera et al., 1995). The occurrence of this phase is strongly correlated with stratified occurrence of zeolites (clinoptilolite/mordenite), where it averages $18 \%$ of zeolitic rocks, and with the lower vitrophyre of the Topopah Spring tuff, where it averages $10 \%$ of glassy rocks.

\subsection{Alteration of Topopah Spring Tuff at Experimental Conditions}

Static hydrothermal alteration experiments were performed using outcrop samples (Knauss and Beiriger, 1984) and drill core (Oversby, 1984a, 1984b, 1985). Polished wafers were reacted either fully submerged or in water-saturated air, in Teflon ${ }^{\mathrm{TM}}$ autoclaves, for as long as 120 days, at temperatures of $90^{\circ}, 120^{\circ}$, and $150^{\circ} \mathrm{C}$. Periodic quench samples were acquired, and solutions were analyzed for anions, cations, and $\mathrm{pH}$. Air-dried samples were evaluated for weight loss and examined by scanning electron microsopy (SEM).

For the fully submerged experiments, systematic changes were observed in water composition. The major change was an increase of dissolved $\mathrm{Si}$, which was apparently controlled by cristobalite. Based on experiments, the equilibrium Si concentration due to dissolution of cristobalite in the near-field environment was predicted to reach $122 \mathrm{ppm}$ at $150^{\circ} \mathrm{C}$. Minor increases of $\mathrm{Al}, \mathrm{K}, \mathrm{Na}$, and the anions were observed, possibly due, in part, to dissolution of minor evaporite phases. There was no detectable source of anions in the rock at temperatures as great as $150^{\circ} \mathrm{C}$. An increase in $\mathrm{pH}$ was attributed to escape of volatiles (e.g., $\mathrm{CO}_{2}$ ) through the Teflon (in later experiments, the Teflon vessels were replaced with Dickson-type gold-bag autoclaves, which eliminated escape of gases). Changes associated with the saturated-air experiments were less significant than those in the fully submerged experiments. Other changes indicated that the minor, readily soluble evaporite component of the rock samples was dissolved by refluxing water.

The authors concluded that hydrothermal interaction with Topopah Spring welded, devitrified tuff with water present in the near-field environment will produce small changes from the starting water composition. Effects on the rock itself were minor over the 120-day duration of the experiments.

Nine short-term (<67 days) experiments using polished wafers of Topopah Spring welded tuff were run at temperatures of $90^{\circ}, 150^{\circ}$, and $250^{\circ} \mathrm{C}$ and at pressures of 50 and 100 bars (Knauss et al., 1985a). Secondary phases were 
dominated by clays, gibbsite, and cristobalite. In a longer-term experiment run for 303 days under otherwise identical conditions, zeolites precipitated in minor amounts. Comparison of EQ3/ 6 reaction-path calculations with experimental evaluation of secondary minerals showed better agreement at $150^{\circ} \mathrm{C}$ than $250^{\circ} \mathrm{C}$. At the higher temperature, more clinoptilolite was precipitated than was predicted. The zeolites dachiardite and mordenite were produced in one experiment at $250^{\circ} \mathrm{C}$, but not in any experiments at $150^{\circ} \mathrm{C}$ (thermodynamic data for dachiardite are not available for modeling with EQ3/6).

Experiments using crushed Topopah Spring welded tuff were reported by Knauss et al. (1985a). Five experiments were run at temperatures of $90^{\circ}, 150^{\circ}$, and $250^{\circ} \mathrm{C}$ and at pressures of 50 and 100 bars. The comparison of results using crushed tuff with previous studies of polished wafers supported the objective to assess "accelerated" testing based on different surface area/volume and temperature criteria. The crushed tuff samples had measured surface area/volume about 10 to 15 times greater than corresponding wafer samples (BET). After two weeks, the crushed-tuff experiments reached the same Si concentration (140 ppm) as eventually developed in the wafer experiments over much longer time periods. As the aqueous phase became supersaturated with respect to various aluminosilicates, the initial mineral assemblage tended to be dominated by minerals with the highest growth rates. These may be metastable, although they can exist in the natural environment for hundreds of years. Trends, with time, in solution composition were consistent at all three temperatures. The main effect of temperature was an apparent increase in the rate at which trends developed. However, it was not clear that the reaction products would ultimately be the same at all temperatures.

Longer-term (304-day) experiments were run on crushed Topopah Spring welded tuff at temperatures of $90^{\circ}$ and $150^{\circ} \mathrm{C}$ and with a pressure of 50 bars. Rates of reaction at $90^{\circ} \mathrm{C}$ were so slow that the results depended primarily on surface area/volume ratio differences between experiments. It was apparent that steadystate conditions had not been achieved after a year. The results indicated that there is kinetic inhibition in the precipitation of zeolite.

Similar experiments were also done on wafers of vitric Topopah Spring tuff from Yucca Mountain (Knauss, 1987; Knauss and Peifer, 1986). Borehole G-4 samples were taken of the basal, moderately welded vitric tuff below the Topopah Spring lower vitrophyre. Water from well J-13 was used in two 64-day experiments: at $150^{\circ} \mathrm{C}$ and at $250^{\circ} \mathrm{C}$. Liquid-phase chemical evolution was periodically subsampled and analyzed for anions, cations, $\mathrm{pH}$, and $\mathrm{CO}_{2}$. The BET gas adsorption surface area was determined before and after each run. Selected samples were removed at the end of the run, rinsed, air-dried, and carbon-coated for SEM analysis.

Solution compositions were used to calculate, using EQ3/6, chemical affinities for various clays, zeolites, and silica polymorphs (Wolery, 1992a, 1992b). The species with the highest affinities shifted from clays to zeolites during each run. At $250^{\circ} \mathrm{C}$, the final mineralogical development was consistent with the zeolite 
development indicated by affinity calculations. At $150^{\circ} \mathrm{C}$, the reaction progress was significantly retarded compared to that of the $250^{\circ} \mathrm{C}$ run and relative to the calculated reaction path.

\subsubsection{Topopah Spring Basal Vitrophyre}

The effects of thermal alteration by hot emplaced waste may be most pronounced in the basal vitrophyre closely underlying the potential repository horizon. The extent of alteration of this vitrophyre varies across Yucca Mountain, with heulandite formation probably caused by syn-depositional devitrification of the Topopah Spring unit penetrating the irregular upper surface (Levy and O'Neil, 1989).

The zeolite interval I of Bish et al. (1984) occurs at the top of the basal vitrophyre. This interval is $2-5 \mathrm{~m}$ thick and typically contains $30 \%$ clinoptilolite-heulandite and $45 \%$ smectite. Alteration is gradational in the upper and lower margins of the basal vitrophyre, and smaller amounts of other zeolites (e.g., erionite) invade the margins, usually in fractures. The zeolite interval I is potentially important to repository performance because it represents the first occurrence of highly sorptive minerals in significant quantity beneath the repository horizon, and these minerals are particularly sensitive to changes in temperature and/or watervapor pressure.

The basal vitrophyre itself is 10-30 m thick and consists primarily of densely welded glass $(40 \%-90 \%)$, with smaller amounts of feldspar, quartz, and opal-CT. Perlitic fractures in the vitrophyre are lined with smectite or zeolites. The glass is impermeable, and, although fractured, it is reactive so that fractures tend to seal with alteration products when exposed to moisture.

Knauss and Copenhaver (1995) reported an experiment that examined alteration of polished wafers of the Topopah Spring vitrophyre when exposed to J-13 water at $90^{\circ}, 150^{\circ}$, and $250^{\circ} \mathrm{C}$ for 2 months. The starting material was densely welded and essentially unaltered glass. Because of limited surface area, the reaction of these samples was much slower than it was with previous samples of airfall tuff with similar composition. At the highest temperature only $\left(250^{\circ} \mathrm{C}\right)$, smectite clay formed at first, then clinoptilolite formed as the run progressed. Only glass dissolution was observed at the lower temperatures.

Another experiment examined the alteration of naturally zeolitized samples of the same vitrophyre when exposed to J-13 water at $90^{\circ}$ and $150^{\circ} \mathrm{C}$ for 2 months. The starting material was mostly heulandite, with some smectite. The material appeared stable to alteration, with evidence for cation substitution at $150^{\circ} \mathrm{C}$.

\subsubsection{Thermodynamic Properties of Minerals Important to Performance}

The Topopah Spring welded, devitrified tuff comprises mostly feldspar and silica polymorphs that are relatively stable at elevated temperatures. Temperature effects on the dissolution and precipitation rates for some of these major phases are discussed in a later section of this report. Further hydrous minerals are 
present as minor phases in the tuff matrix and as major fracture-lining minerals (Carlos et al., 1995) and are more sensitive to elevated temperature in the range anticipated for the host rock. The following paragraphs discuss what is known about dehydration/hydration of common zeolites and smectites in the Topopah Spring welded tuff.

\subsubsection{Clinoptilolite, Heulandite, and Analcime}

Clinoptilolite is the most abundant zeolite in the candidate host rock at Yucca Mountain. Hydration and dehydration of clinoptilolite may have significant consequences in the near-field environment. Dehydration will alter clinoptilolite to less hydrous assemblages (albite and analcime), releasing significant amounts of water. Dehydration could have a significant effect on the thermal budget and cause porosity changes due to changes in molar volume. Experimental data needed to assess these factors have been measured or estimated (Bish, 1995; Bish et al., 1996; Carey and Bish, 1996a).

The equilibrium water content of clinoptilolite-as a function of temperature $\left(25^{\circ}-250^{\circ} \mathrm{C}\right)$, water vapor pressure $(0-35 \mathrm{mbar})$, and exchangeable cations $\left(\mathrm{Na}^{+}, \mathrm{K}^{+}\right.$, and $\mathrm{Ca}^{2+}$ - -was determined by Carey and Bish (1996b). These experiments were conducted by gravimetrically determining the equilibrium mass of clinoptilolite at a measured temperature and water-vapor pressure. They showed that clinoptilolite dehydration/hydration is reversible at temperatures of at least $215^{\circ} \mathrm{C}$, depending on the exchangeable cation. Equilibration is relatively rapid for dehydration/hydration of powders; therefore, kinetics apparently will not be limiting for repository conditions. The water content of clinoptilolite in experiments is a smooth function of temperature and pressure, with no discontinuity at the boiling point of water. Clinoptilolite retains substantial water at temperatures in excess of $150^{\circ} \mathrm{C}$, even in a nominally dry atmosphere.

Clinoptilolite hydration and dehydration energetics have been measured by Carey and Bish (1996a) using immersion calorimetry. In these experiments Na-, $\mathrm{K}-$, and Ca-exchanged clinoptilolite samples were partially dehydrated, sealed in evacuated ampoules, which were submersed and reacted in a calorimeter, where the heat of immersion was measured. The observed enthalpies of hydration increased with decreasing water content in clinoptilolite, demonstrating that the energetic cost of dehydration increases as dehydration proceeds. Dehydration and hydration of clinoptilolite can affect the temperature and relative humidity in the near-field environment, depending on factors such as the rate of water released by clinoptilolite relative to the local fluxes of heat, water, and vapor.

The molar volume of clinoptilolite is a sensitive function of temperature, exchangeable cations, and hydration state (Bish, 1984, 1995). Changes in molar volume may be important in the zeolitized Calico Hills unit, where clinoptilolite constitutes $50 \%$ to $70 \%$ of the rock. Bish (1984) observed that decreases in molar volume on heating to $300^{\circ} \mathrm{C}$ ranged from $1.6 \%$ to $3.6 \%$ to $8.6 \%$ for $\mathrm{K}-$, Ca-, and 
Na-exchanged samples, respectively. Bulk volume is relatively constant; thus, in a rock with $50 \%$ clinoptilolite, an $8 \%$ volume decrease could result in the development of $4 \%$ additional rock porosity.

The equilibrium water content of clinoptilolite as a function of temperature (to $\left.250^{\circ} \mathrm{C}\right)$, water-vapor fugacity, and exchangeable cation $\left(\mathrm{Na}^{+}, \mathrm{K}^{+}\right.$, and $\left.\mathrm{Ca}^{2+}\right)$ was investigated by Carey and Bish (1996b). At temperatures greater than $100^{\circ} \mathrm{C}$, the degree of dehydration increased significantly. Clinoptilolite retained some water in dry environments even at temperatures greater than $150^{\circ} \mathrm{C}$. In a moist environment, clinoptilolite dehydrated with increasing temperature, even in the presence of an aqueous phase.

An equation of state for clinoptilolite was given by Bish et al. (1996) and used to discuss dehydration and rehydration of clinoptilolite in the near-field environment. They concluded that the latent energetics of hydration could dramatically lower the temperature, over a time frame of years, at locations where zeolities are abundant. One such location is the altered interval of the Topopah Spring vitrophyre below the repository horizon. Similar energetics can be inferred for other zeolites (e.g., mordenite, analcime, heulandite).

Barnes and Wilkin (1995) reported solubility measurements from $25^{\circ}$ to $265^{\circ} \mathrm{C}$ on a Na-clinoptilolite. The Gibbs free energy of formation of Na-clinoptilolite calculated from the measured solubility products was almost linear in temperature (Figure 2-6). The thermodynamic properties of clinoptilolite and heulandite have been investigated by modeling, calorimetry, and solution chemistry. The various experimental results can be difficult to compare because of varying $\mathrm{Si} / \mathrm{Al}$ ratios of samples and the presence of difference exchangeable cations.

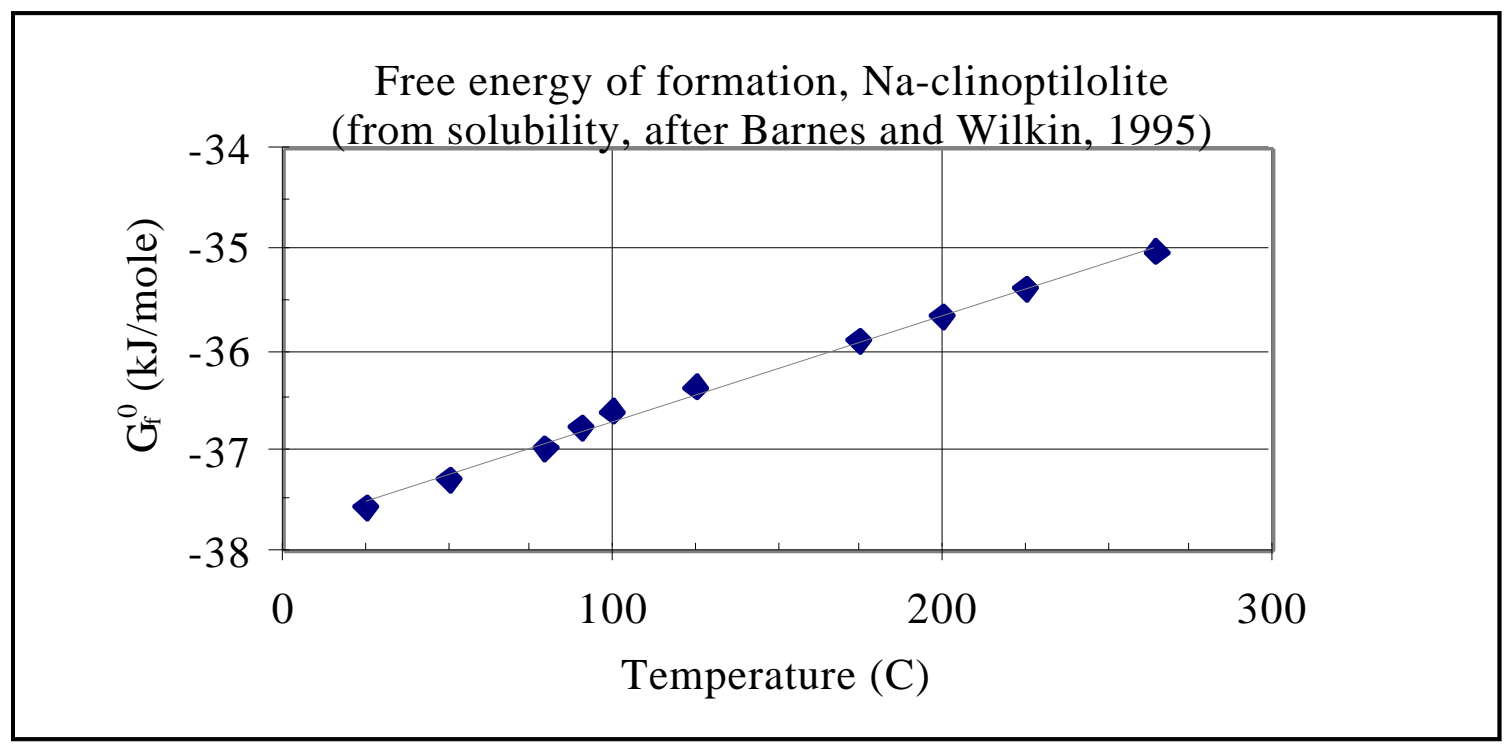

Figure 2-6 Gibbs free energy of Na-clinoptilolite determined experimentally as a function of temperature (after Barnes et al. [1995]). The trend line is a least-squares fit to the data points for $25^{\circ}$ to $265^{\circ} \mathrm{C}$. 
Experimental results for clinoptilolite are energetically similar to those for mordenite and intermediate between strongly (analcime) and weakly (cordierite) hydrating forms (Bish et al., 1996). The similarity of values for hydration of mordenite and clinoptilolite suggests that, in the absence of additional thermodynamic data, the hydration energetics of mordenite may be approximated by those of clinoptilolite. Note that the energetics of hydration are significantly greater than enthalpy change due to condensation of water vapor on a molar basis.

Thermodynamic data for analcime at elevated temperature were obtained by Barnes and Wilkin (1995) using solubility data at temperatures between $25^{\circ}$ and $300^{\circ} \mathrm{C}$. The Gibbs free energy of formation of analcime was calculated from these data. Additional high-temperature data include heat capacity measurements of analcime between $25^{\circ}$ and $350^{\circ} \mathrm{C}$ (Johnson et al., 1992).

\subsubsection{Smectites}

Hydration and dehydration reactions in smectite have a significant effect on stability and molar volume due to swelling/collapse of the aluminosilicate layers. These reactions may also affect pore-water saturation, fracture filling, and the osmotic swelling capacity (Bish, 1988). The hydration and dehydration behavior of smectites exhibits strong hysteresis in molar volume and water content. Although the behavior of smectites is a significant component in modeling the effects of repository-induced heating on the repository water budget, the reversible nature of these reactions suggests that the long-term effects on rock properties may be minor.

One important phenomenon observed during heating of smectites is the dramatic decrease in osmotic swelling ability after only short-term heating under steam conditions (Couture, 1985). The temperature in the near-field environment (as great as $200^{\circ} \mathrm{C}$ ) will be sufficient to suppress osmotic swelling in smectites. Reversibility and the implications for smectites formed as a result of near-field thermohydrologic processes are unknown. Effects of exposure of fracture-lining minerals to steam are discussed in a later section of this report.

\subsubsection{Thermochemical Properties of Selected Aqueous Species}

The effect of temperature on the composition of J-13 water (used as the reference composition for waters at equilibrium with Topopah Spring tuff) has been found to vary little between $25^{\circ}$ and $100^{\circ} \mathrm{C}$ (Glassley, 1996). The principal changes are increases in dissolved $\mathrm{Si}$ and slight decreases, from carbonate precipitation, in dissolved $\mathrm{Mg}, \mathrm{Ca}$, and carbonate.

The temperature-dependent speciation and solubility of several elements of interest to near-field performance was reviewed by Wruck and Palmer (1997). The following summary of solubility relationships was abstracted primarily from this source. Other sources of information include a review of background literature on radionuclide solubility by Rard (1996) and a review of actinide aqueous complex stability constants by Tait et al. (1996). 
Limited experimental data are available for actinide species at $\mathrm{pH}$, temperature, Eh, and other chemical conditions that are representative of near-field conditions. The complexes considered in these reviews primarily were hydroxides, carbonates, sulfates, and fluorides with the metal ions. (These were reviews, not qualified chemical data bases.) Some of the major points, and particularly those involving experimental data at elevated temperature, are as follows:

- Nickel is soluble in J-13 water, with $\mathrm{Ni}(\mathrm{OH})_{2}$ as a solubility-controlling solid phase. Published experimental data indicate that nickel speciation does not change significantly over the temperature range $20^{\circ}$ to $100^{\circ} \mathrm{C}$.

- Zirconium solubility in J-13 water is strongly limited by precipitation of $\mathrm{ZrO}_{2}$ (or a hydrated equivalent). Experimental data on $\mathrm{Zr}$ complexation with carbonate and phosphate are not available; thus such constants must be estimated from tetravalent actinides. The predominant species in J-13 water are probably $\mathrm{Zr}(\mathrm{OH})_{4}$ and $\mathrm{Zr}(\mathrm{OH})_{5}^{-}$. No experimental data are available on the solubility of hydroxyl-Zr complexes, but indications are that solubility remains low to $100^{\circ} \mathrm{C}$.

- Technetium is highly soluble in J-13 water as pertechnetate, which is probably the only Tc species of importance to transport. Redox behavior of Tc is important over the range of conditions reported for Yucca Mountain waters. In reducing conditions such as encountered in well USW H-3, total Tc is strongly limited by the solubility of $\mathrm{TcO}_{2} \cdot \mathrm{H}_{2} \mathrm{O}$. Few experimental data are available that describe the temperature dependence of Tc complexation.

- Uranium is sparingly soluble in $\mathrm{J}-13$ water at $25^{\circ} \mathrm{C}$, and its behavior is relatively well known. The solubility of the important uranium mineral $\mathrm{UO}_{2} \mathrm{CO}_{3}$ (rutherfordine) has been investigated to $200^{\circ} \mathrm{C}$. Stability constants for $\mathrm{UO}_{2} \mathrm{CO}_{3}(\mathrm{aq})$ were recently measured by Wruck et al. (1996), who found a small temperature effect. The complex was slightly more stable (factor of $\sim 2$ ) at $50^{\circ} \mathrm{C}$ than at $25^{\circ}$ or $75^{\circ} \mathrm{C}$, in a 0.1 -m percholorate medium. Carbonate complexes probably remain the predominant dissolved species over the temperature range $25^{\circ}$ to $100^{\circ} \mathrm{C}$ (in the repository, concrete may tend to keep the partial pressure of $\mathrm{CO}_{2}$ low, limiting carbonate complexation). Enthalpy values or elevated temperature-stability constants are also available for U(VI) hydroxyl-, sulfate, and fluoride complexes.

- Neptunium solubility in J-13 waters is thought to be limited at high concentrations (e.g., 0.1 to 2.0 millimolal) by a $\mathrm{NaNpO}_{2} \mathrm{CO}_{3} \cdot \mathrm{xH}_{2} \mathrm{O}$ phase that is presently under investigation. Aqueous speciation was predominantly $\mathrm{NpO}_{2}{ }^{+}(\sim 90 \%)$ and $\mathrm{NpO}_{2} \mathrm{CO}_{3}^{-}(\sim 10 \%)$. $\mathrm{Np}(\mathrm{IV})$ may be important at moderately reducing conditions $($ Eh $<-300 \mathrm{mV}$ ) that would substantially decrease Np mobility as a dissolved species (but experimental data for this behavior are lacking). Solubility studies, calorimetric studies, and near-infrared absorption spectroscopy have produced some conflicting 
data regarding solubility of $(\mathrm{Na}, \mathrm{K}) \mathrm{NpO}_{2} \mathrm{CO}_{3}$ and $\mathrm{NpO}_{2} \mathrm{OH}$. Study of spiked $\mathrm{J}-13$ water indicated that the neptunyl carbonate complex is important at elevated temperatures.

- Plutonium is sparingly soluble in J-13 water. Aqueous speciation is complicated by the redox chemistry of $\mathrm{Pu}$, for which there is limited data. Complexes include $\mathrm{PuO}_{2} \mathrm{CO}_{3}$ and $\mathrm{PuO}_{2}\left(\mathrm{CO}_{3}\right)_{2}{ }^{2-}$; by analogy to $\mathrm{U}(\mathrm{VI})$ carbonate complexes, the Pu carbonate complexes should be important up to $100^{\circ} \mathrm{C}$. $\mathrm{Pu}(\mathrm{VI})$ apparently predominates in some tuff groundwaters and has been reported to be important at intermediate temperatures (e.g., $\left.60^{\circ} \mathrm{C}\right)$ (Tait et al., 1996). Plutonium(V) readily disproportionates to $\mathrm{Pu}(\mathrm{IV})$ and $\mathrm{Pu}(\mathrm{VI})$ at elevated temperatures, but the behavior of $\mathrm{PuO}_{2} \mathrm{CO}_{3}{ }^{2-}$ may analogous to $\mathrm{NpO}_{2} \mathrm{CO}_{3}^{-}$. In addition, no data are available for $\mathrm{Pu}(\mathrm{IV})$ carbonate complexation at elevated temperatures, but they may be analogous to those of U(IV). Study of spiked J-13 water indicated that total $\mathrm{Pu}$, introduced as $\mathrm{Pu}(\mathrm{IV})$, decreased approximately an order of magnitude from $25^{\circ}$ to $90^{\circ} \mathrm{C}$ although $\mathrm{Pu}(\mathrm{V})$ and $\mathrm{Pu}(\mathrm{VI})$ were present.

- Americium solubility in J-13 water is limited by the solubility of solid phase $\mathrm{AmOHCO}_{3}$. Predominant aqueous species include $\mathrm{AmCO}_{3}{ }^{+}$and $\mathrm{AmOH}_{2}{ }^{+}$. Stability of the $\mathrm{AmCO}^{3+}$ complex was analyzed experimentally by Wruck et al. (1996) at temperatures of $25^{\circ}, 50^{\circ}$, and $75^{\circ} \mathrm{C}$ in a $0.1-\mathrm{m}$ percholorate medium. Stability increased by a factor of approximately 10 as temperatures increased from $25^{\circ}$ to $75^{\circ} \mathrm{C}$.

While experimental studies with J-13 water summarize the effects of various chemical reactions that determine the solubility of particular radioelements, there is an important limitation to the approach. The complexes or precipitates determining the total solubility of each radioelement are not exhaustively determined, and the results are specific to a particular chemical system (i.e., J-13 water). The results are therefore not generally applicable to predicting repository performance if aqueous-phase chemistry deviates significantly from that present in the experiments.

\subsubsection{Behavior of Spiked Groundwater at Elevated Temperature}

Nitsche (1991) reported a total of 27 solubility experiments to measure solution concentrations of $\mathrm{Pu}^{4+}, \mathrm{NpO}_{2}{ }^{+}$and $\mathrm{Am}^{3+}$ in J-13 water at $\mathrm{pH}$ values 6, 7, and 8.5 and at temperatures of $25^{\circ}, 60^{\circ}$, and $90^{\circ} \mathrm{C}$. Conditioned spikes were added to J-13 water, and precipitation and speciation reactions were monitored for as long as 150 days. The solution phase was sampled by filtration through 4.1-nm, preconditioned membrane filters. Solution composition was analyzed and reported as total elemental concentrations.

Americium and neptunium solutions precipitated carbonate phases, indicating that solubility decreased with higher $\mathrm{pH}$. There were no clear trends of solubility variation with temperature. X-ray diffraction analysis indicated that the $\mathrm{AmOHCO}_{3}$ precipitate changed from hexagonal to orthorhombic structure between $25^{\circ} \mathrm{C}$ and $60^{\circ} \mathrm{C}$. Plutonium solubility decreased with elevated 
temperature reportedly because of increasing stability of a " $\mathrm{Pu}(\mathrm{IV})$ polymer phase" (Nitsche, 1991). Although the J-13 water was spiked with $\mathrm{Pu}^{4+}$, the principal solution complexes were $\mathrm{PuO}_{2}{ }^{+}$and $\mathrm{PuO}_{2}{ }^{2+}$, which could not be explained by disproportionation and speciation equilibria.

Lemire and Garisto (1989) produced a review of solubility data for $\mathrm{U}, \mathrm{Np}, \mathrm{Pu}, \mathrm{Th}$, and Tc at conditions representative of the disposal vault for a crystalline rock repository. Complexation data were provided for carbonate, chloride, fluoride, phosphate, sulfate, and aquo-complexes of the elements, with exceptions for data availability. Temperature dependence was calculated in terms of heat capacities computed by the method of Criss and Cobble (1964a, 1964b).

According to Meike and Wittwer (1993), the stability of radionuclide-organic complexes with temperature also needs to be investigated. Experimental difficulties have limited the available information about the behavior of organic or inorganic colloids and the mechanisms of sorption and formation over time. Analogs are an important source of information. A few references exist for humic substances (Avogadro and de Marsily, 1984; Petersson et al., 1990). Polymerization and reduction in carbonyl content during diagenesis were also inferred to cause a reduction in solubility of humic substances (Longworth and Ivonovich, 1990). Colloid desorption has been observed also in long-term experiments (Anderson et al., 1985).

\subsubsection{Introduced Materials}

The number, identity, and significance of potential thermally driven, coupled interactions involving artificial materials in a geologic repository have not been determined. However, chemical processes involving concrete and a few other materials at repository conditions have been investigated.

Prior to aging, cement consists primarily of a gel phase composed of calcium, silicon, and water $\left(\mathrm{Ca}-\mathrm{Si}-\mathrm{H}_{2} \mathrm{O}\right)$. Upon aging (generally accelerated by heating), the gel converts to various hydrated Ca-silicates, including tobermorite, afwillite, hillebrandite, foshagite, xonolite, reyerite, gyrolite, and truscottite (Bruton et al., 1993b). Conversion increases the crystallinity of the $\mathrm{Ca}-\mathrm{Si}-\mathrm{H}_{2} \mathrm{O}$ phases while expelling water. As discussed by Meike (1996):

The fate of $\mathrm{Ca}-\mathrm{Si}-\mathrm{H}_{2} \mathrm{O}$ and the cement minerals and their interaction with the aggregate are a function of time, temperature, solid and aqueous solution compositions, and the availability of water. Of particular chemical concern is whether the concrete is exposed to air, $\mathrm{CO}_{2}$ or water, the aluminate and ferrite content of the cement, and the activities of carbonate and sulfate in the water. The oxidation of rebar creates a chemical environment that increases the degradation rate of concrete. Examples of this effect can be seen in many major bridges and thoroughfares, but knowledge of these processes remains qualitative.... 
The preferred rheology of the cement at the time of emplacement dictates the quantity of water added to the dry cement mix and usually exceeds that required for complete hydration. Therefore, extra water is expected in any situation in which wet grout is emplaced. Physical properties, such as interconnected porosity and permeability, can regulate the rate of long-term susceptibility to chemical attack. Porosity is affected by initial water:cement ratios and thus potentially by the method of emplacement. Leaching will preferentially dissolve some minerals such as portlandite and thus increase permeability, which will, in turn, influence the rate of degradation. Sufficiently high activities of sulfate or $\mathrm{CO}_{2}$ can react with concrete. At elevated temperatures, residual portlandite reacts with carbonates to form calcite (Milestone et al., 1987).

Disintegration and dissolution of cementitious materials may change the $\mathrm{pH}$ of water to values as high as 11.5 at $100^{\circ} \mathrm{C}$. Tobermorite $(14 \AA)$ forms in water at temperatures below $80^{\circ} \mathrm{C}$ (Fujii and Kondo, 1983). This phase begins to lose interlayer water at $70^{\circ} \mathrm{C}$ in dry $\mathrm{CO}_{2}$-free air to give $11 \AA$ tobermorite (Taylor, 1987). Sulfate-resistant cements (Soo and Milian, 1989) are formulated to have a relatively low aluminum content so as to minimize the possibility of forming ettringite after the cement has set. Minimization of the volume of portlandite in the set cement controls the reaction of $\mathrm{Ca}(\mathrm{OH})_{2}$ with sulfate to form gypsum. The large volume increases associated with both ettringite and gypsum formation cause cracking and increase the surface area exposed to degradation.

Ancient Roman concretes often incorporated pyroclastics, including acidic tuffaceous material that may be applicable to modern Portland cements in the sense that similar aggregate is being considered for use in the repository. Examination of these ancient materials demonstrates that low-permeability cements, and particularly pozzolanic cements, have the greatest durability (Roy and Langton, 1983 and 1989).

The presence of cementitious material may greatly alter the geochemistry of the repository by providing a large reservoir of unstable Ca-silicate phases which will dissolve and reprecipitate at the rock-water interface. Chemical interactions between water and nonthermally treated grout at 20 to $60^{\circ} \mathrm{C}$ may well be dominated by the dissolution kinetics of the unstable amorphous and crystalline phases, and precipitation kinetics of the metastable or stable phases (e.g., Atkins et al. [1991]). This type of low temperature interaction has received much attention in the international literature.

It is likely that the $\mathrm{Ca}-\mathrm{Si}-\mathrm{H}_{2} \mathrm{O}$ materials will dehydrate and transform to more crystalline minerals, of which many are possible at elevated temperatures (Meike, 1996). As a consequence of their appearance in cements exposed to 
elevated temperatures, chemical reactions involving these recrystallized phases can affect not only water chemistry, but also the relative humidity of the nearfield environment if it contains significant amounts of cement.

Other physico-chemical mechanisms are known to occur in cementitious materials over time and will also contribute to mechanical degradation, which, in turn, will increase the surface area available for chemical alteration (Meike, 1996). In principle, these mechanisms are accelerated by elevated temperatures. They include chloride attack, the alkali silica reaction, and delayed ettringite formation:

- Chloride attack involves transport of chloride-bearing water through cracks or permeable matrix to contact and corrode the metal reinforcement (rebar). The rate of reaction depends on the rate of chloride transport by permeating fluid and on the rate of reaction with metal. Expansion of the rebar due to product formation causes the cementitious materials to crack and spall. A potentially important source of chloride attack in a Yucca Mountain repository is the use of aggregate from desert climates that may contain evaporated salts (Taylor, 1990).

- Alkali silica reaction occurs when silica-bearing aggregate reacts with alkali impurities in the cement paste. As with chloride attack, expansion occurs due to formation of product phases, which causes cracking (Taylor, 1990).

- Delayed ettrigite formation (DEF) is also a cracking process due to the late formation of sulfate-bearing phases (Taylor, 1990). There is still much debate about the causes of this mechanism, but some significant DEF has been related to the heat-curing of sulfate-bearing cements. A phenomenon similar to DEF occurs through the formation of thaumasite, a sulfatecarbonate mineral (Crammond, 1996).

Meike (1996) concluded, from the available literature and experimental studies conducted to date, that cementitious materials significantly increase the uncertainty in chemical performance assessment. Interaction of Portland cement with water at ambient temperature produces waters with high $\mathrm{pH}$, and similar behavior can be expected at elevated temperatures. Interaction of cementitious materials with factors such as elevated temperature and microbiology are known to be complex and are not well characterized. Finally, for cementitious materials there is an important difference between the mechanical lifetime and the chemical lifetime. Large surface area partly determines the effectiveness of a sorbent, and a degraded cementitious material could offer extensive, reactive surface area for radionuclide sorption.

Experiments and modeling have suggested that the $\mathrm{pH}$ of fluids passing through concretes at ambient temperatures would be expected to remain very high for tens of thousands to hundreds of thousands of years (Atkinson et al., 1989). However, the $\mathrm{pH}$, sorptive capacity, and ability of the hydrothermally altered material to sequester radionuclides could be significantly different from that of unaltered concrete. 
Radionuclide partition coefficients measured for cements appear quite favorable in comparison to coefficients for Yucca Mountain devitrified tuffs, especially for $\mathrm{U}$ and $\mathrm{Np}$. It is possible that the measured partition coefficients for $\mathrm{U}$ (and possibly $\mathrm{Np}$ ) in cement reflect precipitation of a relatively insoluble phase in addition to sorption (Atkins et al., 1988). Distribution coefficients for $\mathrm{Pu}, \mathrm{Np}$, and other elements were measured for several cement compositions by Allard et al. (1984) and found to be in the range $10^{3}$ to $10^{4} \mathrm{ml} / \mathrm{g}$ and to increase during longduration (>100 day) experiments.

Metals that will be used for construction in the near-field environment, and possibly for waste-package-corrosion allowance material, will probably be mostly iron and iron alloys. These can degrade through several mechanisms, including oxidation. The rates and products of metal oxidation reactions are strongly dependent upon the local Eh and $\mathrm{pH}$. Studies of metal artifacts exposed to environmental attack have identified phases that rarely occur naturally and that could, therefore, not be predicted through the use of a current geochemical database. Development of some phases appears to be mediated by the activity of microorganisms (McNeil et al., 1990). That diffusion-controlled (and thus temperature-dependent) phenomena should be expected over time periods of at least 2000 years is apparent from investigation of corrosion phenomena in ancient bronzes (Scott, 1985).

\subsubsection{Colloid Formation}

The aqueous phase partitioning of $\mathrm{Pu}, \mathrm{Am}$, and $\mathrm{Cm}$ may be increased by three orders of magnitude by formation of pseudocolloids (i.e., sorption of these elements onto colloidal particles of materials such as silica, iron oxides, and clay). Colloids may result from natural or introduced materials as a result of various processes, including temperature-dependent chemical reactions, aggregation, or microbial activity. Iron could be a relatively abundant introduced material. The point-of-zero-charge for ferrihydrite is sensitive to temperature and age as well as to solution chemistry. Metal adsorption onto oxydroxides is generally sensitive to surface properties that depend on solution chemistry and temperature. The state of knowledge of temperature dependence of colloidal transport in the near field of a Yucca Mountain repository is described by Meike and Wittwer (1993):

The effect of a thermal pulse (on colloidal transport) due to the emplacement of waste is unknown. Reduction of solubility with temperature appears to be responsible for increased sorption, but the behavior of radionuclides is also dependent on the type of species and the temperature range (Boggs et al., 1985). For example, the possible soluble oxidized species of $\mathrm{Pu}, \mathrm{Tc}$, and $\mathrm{Np}$ can form at high temperature (Avogadro and de Marsily, 1984). On the other hand, a temperature decrease associated with a return to natural conditions 
could cause hydrolysis and precipitation of a colloidal phase. Colloid stability also depends on physical adhesion to the medium, which is found to increase over time for some substances (Dabros and deVen, 1982).

\subsubsection{Diffusion}

Where sorption occurs by ion exchange or surface complexation, retardation of dissolved radionuclides depends to some extent on diffusion into sorbent structures. Any sorptive phase will generally have restricted availability to the mobile phase. The effects of diffusion in sorbents, on radionuclide transport, are similar to the widely recognized matrix-diffusion mechanism, in which retardation occurs because of mobile-immobile phase-diffusive transfer (Grisak and Pickens, 1981; Neretnieks, 1980). The process is temperature-controlled because, to a first approximation, rates of molecular diffusion are proportional to the square root of absolute temperature. This type of matrix diffusion has been investigated in clinoptilolite, smectite, and the matrix porosity of TSw2 welded tuff.

\subsubsection{Diffusion in Smectite and Clinoptilolite}

Although not abundant in the TSw2, smectite and clinoptilolite line fractures that will be the pathways for flow and transport (Carlos, 1985). The retardation of radionuclides due to interaction with these minerals via cation exchange will be less than expected if the cation exchange reaction is limited by the rate of intracrystalline diffusion (Viani, 1996a).

Experiments were performed to examine Cs diffusion into Ca clinoptilolite at ambient temperature and at $90^{\circ} \mathrm{C}$ and to examine $\mathrm{Sr}$ diffusion into $\mathrm{Ca}$ clinoptilolite at ambient temperature (Roberts et al., 1996). Penetration of marker ions $(\mathrm{Cs}, \mathrm{Sr})$ into the structures was detected using secondary ion mass spectrometry (SIMS). The shapes of the concentration profiles with depth were not consistent with a model using a single diffusion coefficient, so a binary interdiffusion model, in which the effective coefficient depended on the composition of the exchange sites, was used. At $30^{\circ} \mathrm{C}$, the diffusion coefficients for Cs and Sr were on the order of $10^{-17}$ and $10^{-22} \mathrm{~m}^{2} / \mathrm{sec}$, respectively. At $90^{\circ} \mathrm{C}$, the penetration rate was much greater, apparently exceeding the depth to which ion penetration was investigated using SIMS.

Viani (1996a) described several additional points:

- Using a binary interdiffusion model, the ambient temperature diffusion of Cs was adequately modeled.

- The diffusion of $\mathrm{Cs}$ into the Ca clinoptilolite at $90^{\circ} \mathrm{C}$ was rapid enough to increase the Cs content several orders of magnitude above background to a depth of at least $35 \mu \mathrm{m}$ (the maximum depth probed) over a 12-day exposure. 
- The experimental data indicated that diffusion of $\mathrm{Cs}$ and $\mathrm{Sr}$ into clinoptilolite is not rapid enough to allow the assumption of local cationexchange equilibrium for situations in which groundwater flow is relatively rapid and clinoptilolite crystal size is relatively large (i.e., in fractures).

\subsubsection{Diffusion in the Topopah Spring Welded Tuff Matrix}

Viani (1996a) reported the use of SIMS to evaluate solute diffusion in wafers of Topopah Spring welded tuff:

Analysis of polished wafers that were exposed to radionuclide-bearing solutions showed that diffusion was bimodal. Long-term exposures of the tuff samples to radionuclide-tracer solutions $\left(180 \mathrm{~d} @ 90^{\circ} \mathrm{C}\right)$ yielded concentration profiles that could be modeled assuming a single [effective] diffusion coefficient on the order of $10^{-20} \mathrm{~m}^{2} / \mathrm{sec}$ (McKeegan et al., 1989; Phinney et al., 1987). After shorter exposures $\left(8 \mathrm{~h} @ 25^{\circ} \mathrm{C}\right)$ concentration profiles could not be modeled using a single diffusion coefficient. Elevated levels of tracer ( 3 to 40 times background) were observed at depths of 10 to $15 \mu \mathrm{m}$, indicating that fast paths allowed a portion of the diffusing species to be transported at rates approaching that in solution (McKeegan et al., 1989). These fast paths may not be identifiable optically as pores or by scanning electron microscopy. The resulting distribution of diffusing species was nonuniform and probably represented the distribution of fast paths. Pore size distribution measurements (Buchholtz-ten Brink et al., 1992; Klavetter and Peters, 1986) and direct measurement of elemental tracer concentration profiles in TSw2 samples exposed to actinidebearing solutions (McKeegan et al., 1989; Phinney et al., 1987) are in agreement. (See Figure 2-7.)

The authors suggested that both fast and slow paths will have to be accounted for to realistically predict retardation of radionuclides due to matrix imbibition.

By contrast, Rundberg (1987) inferred that diffusion in the tuff is relatively rapid $\left(10^{-10} \mathrm{~m}^{2} / \mathrm{sec}\right)$, but mass transport in smectite and zeolite solids is limited by relatively slow $\left(10^{-18} \mathrm{~m}^{2} / \mathrm{sec}\right)$ intracrystalline diffusion. This inference was based on an experiment that monitored the $\mathrm{Cs}$ and $\mathrm{Sr}$ tracer concentrations in a solution that was contacting wafers of Yucca Mountain tuff. Rundberg (1987) was not able to model diffusion of actinide tracers using this approach, presumably because they were excluded from cation exchange. 


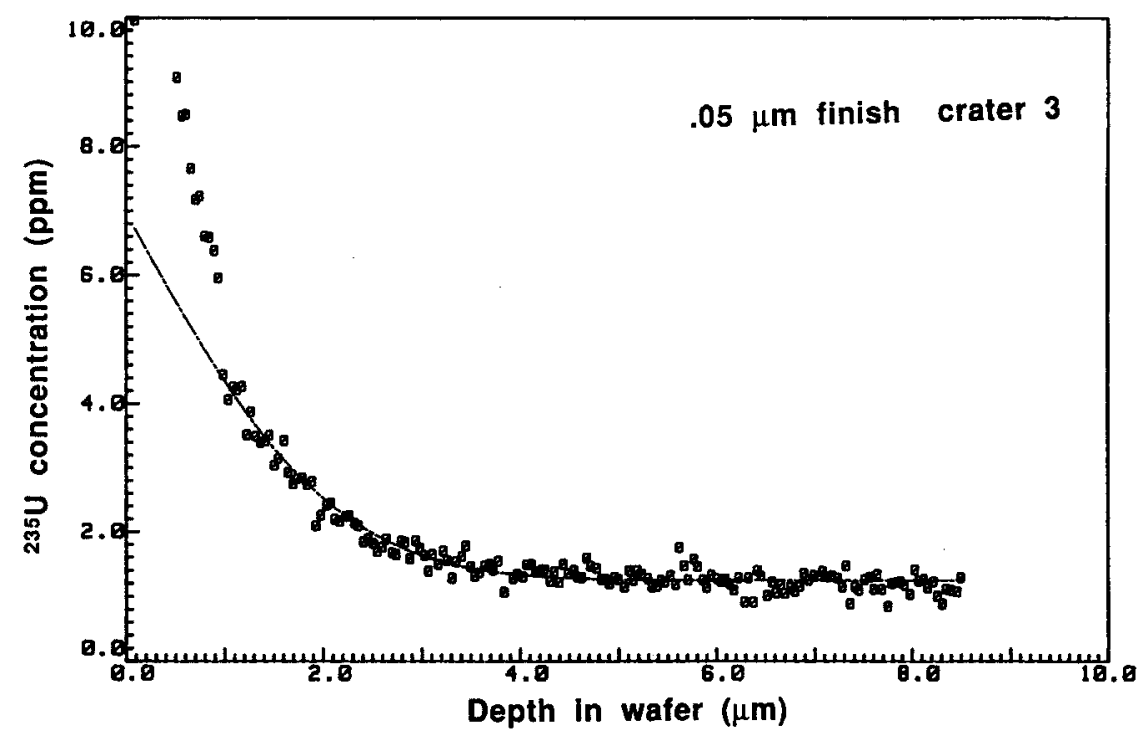

Figure 2-7 Concentration of ${ }^{235} \mathrm{U}$ diffused into the $0.05-\mu \mathrm{m}$ polished surface of a wafer of Topopah Spring welded, devitrified tuff (after McKeegan et al. [1989]). The wafers were saturated and soaked in spiked J-13 groundwater for $8 \mathrm{hr}$ at ambient temperature. The error-function linear diffusion model is fitted to the microprobe analyses as shown.

\subsubsection{Sorption}

Possible sorption mechanisms include ion exchange, surface precipitation, and surface complexation. In geologic media with cation-deficient silicates, ion exchange is relatively well understood but is substantially limited to cations. Surface complexation reactions are important for retardation of actinides and Tc, which are likely to be anionic in oxidizing groundwater. Surface precipitation, as described by Dzombak and Morel (1990) and Farley et al. (1985), involves coordination of surface complexes and will be important at the high contaminant concentrations possible in the near-field environment. Studies of surface precipitation are much less common in the literature than are studies of surface complexation, and emphasis is given to the latter in the following discussion.

A literature review of the sorption of $\mathrm{Pu}$ and other constituents of spent-fuel waste on cement, bentonite, silica, and other materials of geologic origin is provided by Paviet-Hartmann and Triay (1997). Their reviews of experimental investigations are limited to ambient-temperature studies.

\subsubsection{Cation Exchange}

Cation-exchange models are particularly effective for calculating the sorption of trace elements such as Cs and Sr (Viani and Bruton, 1991, 1992). On the other hand, spent-fuel waste constituent elements $\mathrm{U}, \mathrm{Np}, \mathrm{Pu}$, and Tc typically form oxyanions, or anionic carbonato-complexes, which dominate speciation at groundwater chemical conditions. The minerals accessible to pore water in 
silicate rocks are mostly cation exchangers. Therefore, Tc and the actinides generally do not participate in cation exchange because of their charge and the large size of polyatomic ions.

Cation-exchange behavior in Yucca Mountain is dominated by the presence of zeolites and smectites to a lesser degree. Cation-exchange predictions have been made with relative accuracy for zeolitized tuff from Yucca Mountain (Viani and Bruton, 1991, 1992). The data required to simulate cation exchange using the EQ3/6 model are as follows:

1. The type of cation exchanger and the binary exchange energies for cation pairs of interest

2. The initial composition of the exchanger

3. The quantity of exchanger in contact with water

\subsubsection{Surface Complexation}

Surface complexation models describe adsorption onto surfaces of metal oxides (including $\mathrm{SiO}_{2}$ ) and oxyhydroxides, over ranges of $\mathrm{pH}$, with different background electrolytes and with competing species (Dzombak and Morel, 1990). Experiments and modeling of hydrous ferric oxide (HFO) surface chemistry have shown that metal oxyhydroxides can serve as significant $\mathrm{pH}$-dependent sources and sinks for cations and anions (e.g., Bruton and Viani [1996]). A variety of cations (e.g., $\left.\mathrm{H}^{+}, \mathrm{Ca}^{2+}, \mathrm{Sr}^{2+}, \mathrm{Ba}^{2+}\right)$ and anions $\left(\mathrm{HCO}_{3}{ }^{-}, \mathrm{SO}_{4}{ }^{2-}, \mathrm{HPO}_{4}{ }^{-}\right)$are known to sorb onto $\mathrm{HFO}$ at $25^{\circ} \mathrm{C}$.

The surface of Fe-oxyhydroxide has a range of binding sites with strengths that may vary over an order of magnitude (Benjamin and Leckie, 1981; Dzombak and Morel, 1990). As the surface density of the sorbed species increases, a greater proportion of sorbate is bound to weaker, more readily reversible sites. When desorption occurs, these may dissociate first, and sorption on the strongest sites may be irreversible. Complete reversibility on a time scale of hours has been observed for uranyl complexation on HFO in response to decreasing $\mathrm{pH}$ in carbonate-free systems (Ho and Doern, 1985; Hsi and Langmuir, 1985). This was caused by increasing acidity that decreased the binding strength of all sites. On the other hand, batch experiments using U-free washes at sorption conditions have shown very limited desorption from natural Fe-oxyhydroxide and synthetic hematite, and irreversibility was inferred at $U$ concentrations less than $\sim 1 \mathrm{mg}$ $\mathrm{U} / \mathrm{g}$ sorbent (Ho and Doern, 1985).

Milton and Brown (1987) reported that most sorption of uranyl to natural Fe-oxyhydroxide in batch studies took place within a few hours, but that only a minor fraction desorbed in the same time after 2 years. Hysteresis in rates of sorption/desorption is common and may be caused by gradual conversion to stronger bonding (e.g., multidentate complexes) or by deposition of interfering phases such as silica (Davis and Kent, 1990). Laboratory sorption studies have generally been done at higher $U$ concentrations than those that exist naturally, so the observations may be affected more by weaker sites; in situ partitioning 
behavior could be stronger and more irreversible than reported results. Also, the simple chemical systems studied in the laboratory have fewer competitive effects and are more chemically homogeneous.

Studies of natural and synthetic HFO (Ho and Doern, 1985; Milton and Brown, 1987) have shown that, compared to other natural sorbents in simple carbonate systems, these forms have high affinity for uranyl. In one study (Ames et al., 1983) amorphous synthetic FeOOH was found to be 100 times more sorptive for uranyl than were several crystalline solids, including clinoptilolite and mineral standard clays. In oxidizing bicarbonate waters the soluble actinide species tend to be carbonate anions that have little affinity for cation-exchanging clays, opal, and zeolites. Sorption on silica gel was less hindered by bicarbonate complexation than was sorption on opal. Milton and Brown (1987) investigated uranyl sorption to natural Fe-oxyhydroxide, chlorite, and calcite in natural groundwater. The Fe-oxyhydroxide was about 100 times more sorptive than chlorite, which was more sorptive than calcite. Zielinski (1980) coprecipitated uranyl with colloidal silica from a bicarbonate solution resembling natural groundwater, producing partition coefficients comparable to the results of Ames et al. (1983) for reagent silica gel.

\subsection{Surface Complexation of Radionuclides to Devitrified Tuff}

The following discussion is abstracted from Ong et al. (1995), who investigated the sorption of uranyl onto powdered tuff, from G-Tunnel, and mineralogically pure albite at $25^{\circ} \mathrm{C}$. Surface complexation is described by reactions between dissolved solutes and surface functional groups. Hydrous oxide minerals and natural organic matter contain amphoteric (protolyzable) functional groups. Aluminosilicates are also amphoteric and can be categorized as those with permanent structural charge, and consequent ion-exchange capacity, and those without. Devitrified Topopah Spring tuff contains all three types of minerals and thus exhibits behavior that is a weighted average of the constituent reaction sites.

A series of experiments conducted by Ong et al. (1995) examined uranyl sorption onto devitrified tuff, in a $\mathrm{CO}_{2}$-free $\mathrm{NaCl}$ solution. An "unweathered" tuff suspension was prepared by agitating in $0.1 \mathrm{M} \mathrm{NaCl}$ for 35 days, resulting in a final (closed system) $\mathrm{pH}$ of 10.3. A "weathered" suspension was prepared at the same time, but was centrifuged and decanted every 5 days, and the liquid fraction replaced, resulting in a final (open system) pH of 7.2. The "unweathered" suspension was used directly in sorption experiments without changing the supernatant. A uranyl spike was added after the suspension equilibrated for 5 to 28 days at initial sorption conditions. Uranyl sorption was monitored over time in separate experiments, and most results were reported after $24 \mathrm{hr}$ equilibration time. Batches were titrated from $\mathrm{pH} 3$ to 10 and reverse titrated in some cases.

The results were interpreted by comparison to surface complexation studies of single minerals. An adsorption edge (i.e., sharp transition in sorption behavior) was observed over 2 to $3 \mathrm{pH}$ units, for both tuff and albite suspension, with maximum sorption at $\mathrm{pH} 7$ in all batches regardless of tuff pretreatment. The 
adsorption edge was similar to that observed in previous single-mineral experiments (Ong et al., 1995) (see Figure 2-8). Sorption declined sharply with increasing $\mathrm{pH}$ above 7 , except for the weathered sample. Application of these results to the near-field environment requires extension to elevated temperature and inclusion of $\mathrm{CO}_{2}$ in the chemical system.

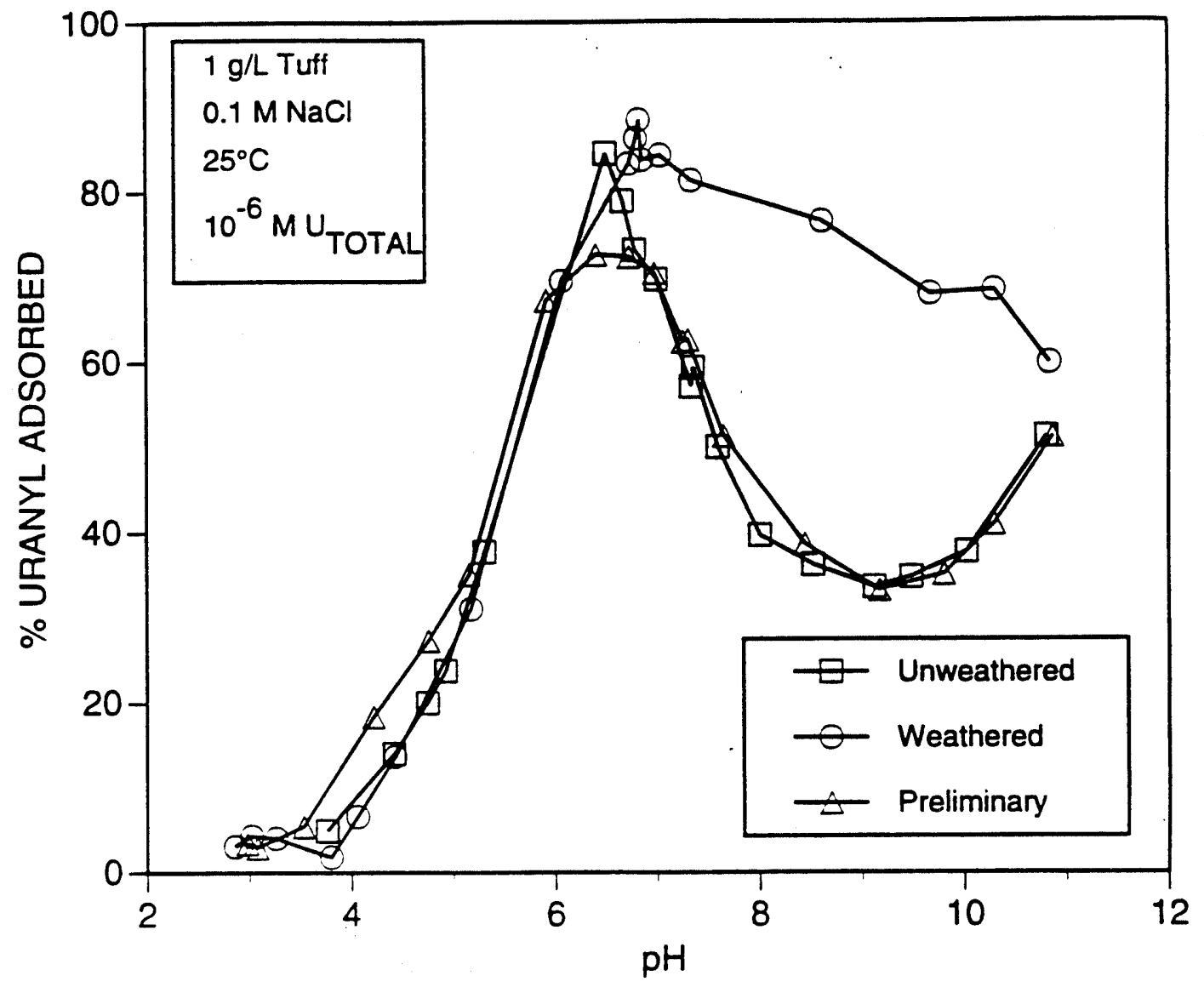

Figure 2-8 Comparison of urayl sorption to tuff in suspension, prepared by different methods, as described in text (after Ong et al. [1995])

\subsection{Temperature Dependence of Surface Complexation}

There are very few data available on actinide sorption at elevated temperatures. Interpretation of surface-complexation experiments, to obtain values for intrinsic equilibrium constants, has generally invoked mass action for postulated sorption mechanisms. Temperature dependence and calorimetry of complexation mechanisms generally have not been investigated. Surface-complexation mechanisms are likely to vary as speciation varies in solution in response to temperature changes. Thus, an aqueous system such as $\mathrm{UO}_{2}-\mathrm{H}_{2} \mathrm{O}-\mathrm{CO}_{2}$ may exhibit predictable speciation of aquo- and carbonato-complexes in solution, in response 
to temperature and $\mathrm{P}_{\mathrm{CO} 2}$ boundary conditions, but sorptive interaction of different dissolved species with surface complex sites would be difficult to predict accurately without experimental verification.

Ho and Miller (1986) measured sorption of uranyl onto hematite particles at $25^{\circ}$ and $60^{\circ} \mathrm{C}$. Synthetic hematite particles were equilibrated with a $1 \mathrm{mM}$ solution of sodium bicarbonate at $\mathrm{pH}$ values between 6 and 9 and contacted with a uranyl spike in sealed vessels for $16 \mathrm{hr}$. The percentage of $\mathrm{U}$ adsorbed decreased from approximately $80 \%$ to $25 \%$ in the $\mathrm{pH}$ range 6 to 9 . Importantly, the percentage adsorbed was only slightly greater at the higher temperature. The $\mathrm{pH}$ dependence was probably due to increased stabilization of uranyl carbonate complexes at higher $\mathrm{pH}$. The use of sealed vessels probably ensured that total carbon was similar at both temperatures. If this notion is correct, the data show that temperature dependence of the sorptive equilibrium was small (i.e., resulted in small changes to the sorption ratio).

In the near-field environment, the gas phase $\mathrm{CO}_{2}$ fraction will determine the equilibrium level for total dissolved carbon at a given $\mathrm{pH}$ and temperature. The $\mathrm{CO}_{2}$ fugacity in the near-field environment will probably be less than in the experimental conditions of Ho and Miller (1986) because these experiments were conducted with a solution of $\mathrm{Na}$ bicarbonate, thus decreased carbonate complexation and increased sorption might be expected. (Silica concentrations will increase markedly at elevated temperatures, which will have some effect on U speciation.)

Studies of U (VI) sorption onto synthetic goethite in J-13 water, at ambient and elevated temperatures, are currently underway.

\subsubsection{Variation of Reaction Rates with Temperature}

The significance of THC coupled processes depends critically on the rates of water-rock interactions that affect fracture permeability and transport characteristics. Properties of the rock matrix, backfill, and other engineered components may also be affected. Discussed in the following subsections are rates of reaction for different types of reactions: dissolution/precipitation, sorption, cation exchange, and surface complexation.

\subsubsection{Mineral Dissolution and Precipitation}

Mineral dissolution and precipitation rates are usually measured by observing mass transfer between dissolved components and a given mass of solid material of known surface area. The studies are conducted either in batch mode with evolving solution composition (e.g., Murphy et al. [1996]) or in flow-through devices with relatively constant solution composition (e.g., Nagy et al.[1991]). Table 2-8 shows a summary of kinetic data from different sources for minerals discussed in the following sections. 
Table 2-8 Kinetic data for dissolution of various phases important to near-field performance, including clinoptilolite and analcime, at $25^{\circ} \mathrm{C}$ (after Bish et al. [1996]); based on Lasaga et al. [1994b])

\begin{tabular}{|c|c|c|c|}
\hline Mineral & $\begin{array}{c}\log _{10} k_{\text {diss }} \\
\left(\mathrm{moles} / \mathrm{m}^{2} \text {-sec }\right)\end{array}$ & $\begin{array}{l}\log _{10} \mathrm{k} \text { Normalized to Two } \\
\text { Structural Oxygens }\end{array}$ & $\begin{array}{l}\text { Molar Volume } \\
\left.\text { (cm } \mathrm{cm}^{3} / \mathrm{mole}\right)\end{array}$ \\
\hline Analcime $^{a}$ & -11 & -11.5 & 97 \\
\hline Gibbsite & -11.5 & -11.6 & 32 \\
\hline Sanidine & -12.0 & -12.6 & 109 \\
\hline Albite & -12.3 & -12.9 & 100 \\
\hline Prehnite & -12.4 & -13.2 & 140 \\
\hline Microcline & -12.5 & -13.1 & 109 \\
\hline Epidote & -12.6 & -13.4 & 139 \\
\hline Na-clinoptilolite ${ }^{a}$ & -13.2 & -14.2 & 421 \\
\hline Amorphous silicab $^{b}$ & -12.2 & -12.2 & 29 \\
\hline$\beta$-Cristobalite ${ }^{b}$ & -12.3 & -12.3 & 27.4 \\
\hline Muscovite & -13.1 & -13.9 & 141 \\
\hline Kaolinite & -13.3 & -13.9 & 100 \\
\hline$\alpha$-Cristobalite $^{b}$ & -12.8 & -12.8 & 25.7 \\
\hline Quartz & -13.4 & -13.4 & 22.7 \\
\hline Na-clinoptilolite ${ }^{c}$ & -15.6 & -17.2 & 1263 \\
\hline
\end{tabular}

${ }^{a}$ Murphy et al. (1996)

${ }^{\mathrm{b}}$ Rimstidt and Barnes (1980)

${ }^{\mathrm{c}}$ MacInnis et al. (1995)

The following discussion draws heavily from the work of Bish et al. (1996). For background, they presented the model of Nagy et al. (1991) as an example of the interpretation of experimental data using transition state theory. The conditional rate of dissolution or precipitation was expressed as

$$
\text { rate }\left[\frac{\text { mole }}{\mathrm{m}^{2} \mathrm{sec}}\right]=-\mathrm{k}_{\text {diss }}\left(1-\frac{\mathrm{IAP}}{\mathrm{K}_{\mathrm{eq}}}\right)
$$

The ratio of the ion activity product (IAP) to the equilibrium constant $\left(\mathrm{K}_{\mathrm{eq}}\right)$ expresses the degree of saturation, and $\mathrm{k}_{\text {diss }}$ is the conditional rate constant for the dissolution reaction. The parameter $\mathrm{k}_{\text {diss }}$ is not an intrinsic rate parameter, but may depend on $\mathrm{pH}$ and other adsorbed species (Nagy et al., 1991). Equation 2-1 indicates that the rate of dissolution reaches a constant value $\left(\mathrm{k}_{\mathrm{dis}}\right)$ for increasing undersaturation, but the rate of precipitation is unbounded for increasing supersaturation and for constant solution composition. 


\subsection{Reaction of Clinoptilolite and Analcime}

The study of MacInnis et al. (1995) is the only data source for dissolution rates of clinoptilolite at elevated temperatures $\left(50^{\circ}, 80^{\circ}\right.$, and $\left.125^{\circ} \mathrm{C}\right)$. According to Bish et al. (1996), the dissolution rate obtained for clinoptilolite using a flow-through apparatus appears to be anomalous with respect to other minerals and is not in agreement with the batch study of Murphy et al. (1996). The experimental results of MacInnis et al. were fitted by the empirical expression

$$
\text { rate }=-\mathrm{k}_{\mathrm{o}} \exp \left(\frac{-\mathrm{E}_{\mathrm{a}}}{\mathrm{RT}}\right) \mathrm{a}_{\mathrm{H}}^{-0.54}\left(\frac{\mathrm{IAP}}{\mathrm{K}_{\mathrm{eq}}}\right)
$$

where $\mathrm{k}_{\mathrm{o}}=2 \pm 27 \times 10^{5} \mathrm{~mole} / \mathrm{m}^{2}$-sec; $\mathrm{E}_{\mathrm{a}}=35.1 \pm 9.2 \mathrm{kcal} / \mathrm{mole}$; and the experiments were conducted at $\mathrm{pH} 7.5$ to 9.0. They did not observe a constant dissolution rate at significant undersaturation, but they showed data indicating a linear relationship between rate and undersaturation (Eq. 2-2). Consequently, the dissolution process they observed may be distinct from that modeled by transition state theory (Equation 2-1).

There is no single study providing rate data for analcime at more than one temperature. Lasaga et al. (1994a) determined the dissolution of analcime at $80^{\circ} \mathrm{C}$ with flow-through methods. Their empirical rate equation was similar to Equation 2-2:

$$
\mathrm{R}=-10^{-12.4} \mathrm{a} \frac{-0.27}{\mathrm{Al}(\mathrm{OH})_{4}}-\left(\mid \mathrm{G}, \mathrm{kcal} \text { mole }{ }^{-1}\right)^{1.05}
$$

where the measurements were made at $\mathrm{pH} 8.6$ to 8.9 , and the degree of saturation is represented by the Gibbs free energy of the dissolution reaction. Typical values for this expression, which constitute the net dissolution rate constant, were $\sim 10^{-11}$ mole $/ \mathrm{m}^{2}$-sec. According to Bish et al. (1996), these values do not agree well with the batch study values of Murphy et al. (1996).

In summary, the available kinetic data for both analcime and clinoptilolite are poorly constrained and reflect the incomplete status of kinetic data measurement for these minerals. Different investigators have applied different interpretation strategies, and there is apparent disagreement between measurements made with batch vs. flow-through methods. Based on existing data, the dissolution of clinoptilolite appears to be slower than that of analcime by a factor of about 100 .

\subsection{Reaction of Silica Polymorphs}

A classic study of the dissolution/precipitation kinetics of silica polymorphs was published by Rimstidt and Barnes (1980). A series of experiments was run, using various materials, at temperatures from $18^{\circ}$ to $305^{\circ} \mathrm{C}$. Silica sand with a highly homogeneous grain size was used in the experiments with distilled water. The experiments were run in Barnes rocking autoclaves or in reactors that circulated hydrothermal fluid. Samples of the aqueous phase were withdrawn for analysis at convenient intervals. 
Rates of reaction were calculated from experimental equilibrium data. The ratelimiting step for silica-water reactions was assumed to be breaking of strong Si-O bonds. Because the activated complex was assumed to be the same, one value for the precipitation-rate constant was used for quartz, cristobalite, and amorphous silica. For dissolution reactions, a limiting transport step was assumed. A simple rate equation was derived by assuming that the reaction rate was proportional to the ratio of reacting solid area to fluid mass. The resulting equation was integrated analytically to express, as a function of time, the degree of silica saturation in solution. Linear regression of experimental data was used to estimate dissolution-rate constants. By using equilibrium constant values extracted from the literature for quartz, $\alpha$ - and $\beta$-cristobalite, and amorphous silica, precipitation-rate constants were computed from dissolution constants assuming microscopic reversibility.

Calculating actual rates of reaction using this model required estimates for the ratio of reactive surface area to mass of water. Time constants were computed as the inverse of the dissolution-rate constant. For area:mass ratios of 100 to $10^{4}$, the time constant varied from 1 day to 10 yr. Reaction rates for precipitation/ dissolution varied by 1 to 2 orders of magnitude for each $100^{\circ} \mathrm{C}$ temperature change.

Predicted precipitation rates increased with temperature to a maximum that depended on the silica concentration in solution. Upon cooling a saturated solution of silica, decreasing solubility caused increased supersaturation, while the rate constant for precipitation decreased, producing a maximum precipitation rate at a temperature $25^{\circ}$ to $50^{\circ} \mathrm{C}$ below the saturation temperature. The authors observed that silica can be quenched into solution by slow reaction rates, which contributes to the basis for the quartz geothermometer.

An Arrhenius rate equation was developed for dissolution/precipitation reactions and was used to evaluate the kinetic mechanism for experimental data. Values of the activation energies for different phases were obtained from linear regression of the measured dissolution-rate constant values vs. reciprocal temperature.

A more recent investigation of dissolution kinetics for quartz was published by Knauss and Wolery (1988). The mechanism of quartz dissolution at $\mathrm{pH}$ less than 6 was zero order in hydrogen ion activity. Above $\mathrm{pH} \sim 6$, the mechanism changed to -0.5 order in hydrogen ion activity. The latter reaction mechanism was postulated to involve formation of chemi-sorbed silicic acid on the hydroxylated quartz surface, which served as the activated complex.

At $70^{\circ} \mathrm{C}$ and $\mathrm{pH}$ 6, the quartz dissolution rate was approximately $10^{-15.3}$ $\mathrm{mol} / \mathrm{cm}^{2}$. sec, which was close to the rate reported by Rimstidt and Barnes (1980). The rate reported by Rimstidt and Barnes for $25^{\circ} \mathrm{C}$ was approximately $10^{-17.4}$ $\mathrm{mol} / \mathrm{cm}^{2}$. sec. Thus, to a first approximation, quartz dissolved faster by a factor of 300 at $70^{\circ} \mathrm{C}$ compared to at $25^{\circ} \mathrm{C}$ for neutral to alkaline $\mathrm{pH}$. These data were 
developed for the quartz-distilled water system (with $\mathrm{pH}$ buffers). Solution conditions were undersaturated so that interfering precipitates did not form. In this sense, the reported dissolution rates were upper bounds for this system.

Precipitation rates for amorphous silica were investigated experimentally by Carroll et al. (1996). Reagent grade silica gel was placed in Dickson gold-bag stationary reactors and observed at $100^{\circ} \mathrm{C}$. The solution $\mathrm{pH}$ was buffered to 3.0 and 5.0 in two experiments and unbuffered in another. All three experiments were equilibrated with amorphous silica at $120^{\circ} \mathrm{C}$ and 70 bars pressure, then cooled to $100^{\circ} \mathrm{C}$ and observed. Dissolved silicon concentrations in all three declined within a few days to equilibrium with amorphous silica at the new temperature. The unbuffered experiment rapidly stabilized at $\mathrm{pH}$ 6. Upon disassembly of the experiments and mineralogical examination of the solid phase, no evidence was found for precipitation of silica polymorphs such as cristobalite. The authors indicated that the presence of undissolved amorphous silica in the reactors prevented the precipitation of other silica phases.

\subsection{Reaction of Albite}

The dissolution rate of albite was measured experimentally by Knauss and Wolery (1986c) using a single-pass, flow-through experiment at $25^{\circ}$ and $70^{\circ} \mathrm{C}$ with $\mathrm{pH}$ buffered in the range 4 to 10 and test duration of 50 days. Feldspar samples were analyzed petrographically and by $x$-ray diffraction. Selected material was crushed and milled and treated by repeated rinsing and sonication, which avoided fluorination effects from the use of hydrofluoric acid. Despite the care given to mechanical preparation, dissolution rates typically did not stabilize for 10 to 20 days into the experiments.

Speciation calculations with the computer code EQ3NR (Wolery, 1992b) were based on elemental analysis of the discharge and showed that the experiments were consistently undersaturated with respect to secondary minerals.

A surface reaction mechanism was inferred from microscopic (SEM) examination that revealed etching pits characteristic of site-specific, intrinsically limited dissolution. Transport control associated with secondary phases was avoided through the use of a flow-through experiment. At $25^{\circ} \mathrm{C}$ and near-neutral $\mathrm{pH}$, the surface showed no indication of etching. Etching pits were apparent at low and high $\mathrm{pH}$ and in all experiments at $70^{\circ} \mathrm{C}$.

The experimental data were generally consistent with the transition state theory of Helgeson et al. (1984). Activation enthalpy values derived from experimental dissolution rates were comparable, although some differences remained. Limiting dissolution rates increased by a factor of approximately 30 , from $25^{\circ}$ to $100^{\circ} \mathrm{C}$ in the $\mathrm{pH}$ range 3 to 8 . 


\subsubsection{Sorption Reactions}

\subsection{Surface Complexation}

Surface complexation may be regarded as a rate process, and hours or days may be required for batch studies to achieve sorptive equilibrium. A significant source of error in measurements of sorptive equilibria is the lack of provision of sufficient equilibration time for batch experiments. Surface complexation processes have been identified with two reaction steps: fast and slow (Dzombak and Morel, 1990). Together they account for macroscopic equilibrium, but not necessarily in the same proportion for every ion-sorbent pairing, nor for different values of $\mathrm{pH}$, sorbate concentration or background electrolyte. The fast step takes place in minutes to hours, whereas the slow step can take several days for some sorbents.

In their compilation of surface complexation data for hydrous ferric oxide, Dzombak and Morel (1990) reviewed factors that could influence the equilibration time required for laboratory measurements. High ionic strength tends to retard the rate of sorption and increase the relative importance of the second, slower step. High sorbate concentration has a similar effect, probably from involvement of different site types with less affinity such that the first sites to be occupied are the fastest. Available data also indicate that cation adsorption is faster at higher $\mathrm{pH}$, and anion sorption is faster at lower $\mathrm{pH}$. Competing-ion effects may impact sorption kinetics, as in the case of anion sorption in the presence of sulfate or bicarbonate. Exclusion of $\mathrm{CO}_{2}$ is an important control in experimental investigation of surface complexation. It is noteworthy that only one experimental study reviewed by Dzombak and Morel (1990) pertaining to Co sorption, involved measurement of equilibria outside the range $20^{\circ} \mathrm{C}$ to $30^{\circ} \mathrm{C}$.

Fuller et al. (1993) examined the time-dependent sorption of arsenate onto synthetic ferrihydrite at $25^{\circ} \mathrm{C}$. An initial period of rapid sorption was followed by a gradually decreasing sorption rate over several days. The time variation was consistent with a model of a diffusion-limited rate process. If the ferrihydrite was aged prior to the experiment, the overall availability of sorption sites decreased because of crystallization, but the time dependence remained. Partitioning was greater for coprecipitation of arsenate with $\mathrm{FeOOH}$, relative to sorption on $\mathrm{FeOOH}$, and was not diffusion-limited. After coprecipitation, As was released for approximately one month as further crystallization proceeded.

Plutonium exhibits different sorption rates depending on its oxidation state (Paviet-Hartmann and Triay, 1997). Sorption of $\mathrm{Pu}(\mathrm{IV})$ on goethite reached equilibrium in one hour; $\mathrm{Pu}(\mathrm{V})$ did not reach equilibrium for 20 days. Whereas the concentration of $\mathrm{Pu}(\mathrm{V})$ in solution remained stable, it was inferred that the sorbed $\mathrm{Pu}(\mathrm{V})$ was gradually reduced to $\mathrm{Pu}(\mathrm{IV})$ at the interface and subsequently sorbed.

In contrast to reporting of studies in which adsorption or desorption increases with time and approaches equilibrium, Ong et al. (1995) reported steadily decreasing sorption of uranyl on mineralogically pure albite. The effect was 
observed over a nominal $\mathrm{pH}$ range from 6 to 9, in $\mathrm{CO}_{2}$-free $100 \mathrm{mM} \mathrm{NaCl}$ solution at $25^{\circ} \mathrm{C}$. It was attributed by the authors to slight $\mathrm{pH}$ drift, to which equilibrium is quite sensitive when sorption conditions are at the adsorption edge.

\subsection{Hydrological Properties}

Sensitivity of hydrologic properties to stress and temperature conditions has been the subject of investigation for different geologic media for many years. An important factor distinguishing different types of laboratory tests is whether the sample is isothermal or if permeant is conducted along a temperature gradient. Isothermal studies are discussed in the following section; temperature gradient experiments are discussed in a subsequent section of this report.

\subsubsection{Matrix Porosity}

Flint (1996) reported the most numerous set of matrix porosity measurements available for the TSw2 welded tuff and other rock units at Yucca Mountain. Average matrix porosity of the hydrostratigraphic interval corresponding to the TSw2 welded tuff was reported to be $11 \%$. Drying procedure was shown to impact measured porosity depending on the relative abundance of hydrated minerals such as clays and zeolites (Figure 2-1).

Mercury porosimetry measurements (Buchholtz-ten Brink et al., 1992; Klavetter and Peters, 1987) have shown that the large majority (>95\%) of pores in the matrix of TSw2 welded tuff are on the order of several tens of nanometers. A small component of porosity, which appears to be associated with microfractures, is contained in pores on the order of one to several microns. These observations are consistent with microscopic examination and solute diffusion studies reported by McKeegan et al. (1989), who found two populations of pores in the same size ranges.

\subsubsection{Matrix Permeability (Hydraulic Conductivity)}

A series of matrix hydrologic property measurements was performed, by Pacific Northwest Laboratory under contract to Sandia National Laboratory, on tuff samples from 48 locations in Yucca Mountain (Peters et al., 1984). Some of the results from these tests as summarized by the authors are as follows:

The measured saturated hydraulic conductivities for welded tuff samples were low, ranging from $10^{-10}$ to $10^{-14} \mathrm{~m} / \mathrm{sec}$. Most of the nonwelded, zeolitized samples exhibited low conductivities similar to those of welded samples. The nonwelded, nonzeolitized samples exhibited conductivities ranging from $10^{-6}$ to $10^{-10} \mathrm{~m} / \mathrm{sec}$, values that compare with silts and clay-type soils. 
The fracture-saturated conductivity was significantly higher than the matrix conductivity on all samples tested, and flow through all fractured and unfractured samples was reduced at elevated effective pressure. The degree of welding of the matrix and the fracture surface characteristics influenced the response of fractured samples to elevated pressure.

Flint (1996) reported a geometric mean matrix conductivity of $1.5 \times 10^{-11} \mathrm{~m} / \mathrm{sec}$, based on 266 sample measurements for the TMN hydrogeologic unit. This corresponds to the Tptpmn stratigraphic unit (RIB 1.12, Rev. 4) and the TSw2 thermomechanical unit. The equivalent intrinsic matrix permeability is approximately $1.5 \mu \mathrm{d}$.

Anderson (1992a) measured water permeability on core plugs taken from vertical and horizontal orientations in boreholes GU-3/G-3 and G-4 at Yucca Mountain. The horizontal-vertical sample pairs were also evaluated for correlation of grain density and porosity. Permeability was found to decrease, by a factor of 10 or more, with time during flow testing for several different permeants, including distilled water and J-13 water. Possible causes for this, including plugging by particles in the supplied permeant, were not investigated.

Early investigations of temperature and pressure effects on water permeability of TSw2 welded tuff were reported by Morrow et al. (1984) and Moore et al. (1985, 1986). Water permeability was measured on six samples from the Topopah Spring welded tuff (sampling locations not specified). Core samples were prepared with a small-diameter axial hole. The apparatus produced radial flow (either divergent or convergent), and the sample could be heated by a resistance element in the central hole. The flow direction was parallel to the rock fabric in four of the tests and was perpendicular to fabric in the two others. The observed range in permeability at room temperature was 0.8 to $64 \mu \mathrm{d}$. According to the authors, the permeability of a given sample was only slightly affected by heating to maximum temperatures between $90^{\circ} \mathrm{C}$ and $250^{\circ} \mathrm{C}$ during experiments of as long as 5 weeks duration. Between-sample variability was much greater than permeability variations associated with temperature changes, flow direction relative to rock fabric, and convergent vs. divergent flow.

Another investigation of temperature effect on permeability was performed by Reda (1985a). Water permeability was measured, over a range of temperature while maintaining confining pressure at $15.2 \mathrm{MPa}$, on a single sample of Topopah Spring welded tuff. Pore water flowed continually through the sample over a 3-month period during which temperature was systematically increased to $90^{\circ} \mathrm{C}$, then decreased, in increments of $15^{\circ} \mathrm{C}$. Time at each temperature step was approximately 170 hours. Permeability was measured using a transient-decay method. Water permeability of the sample was $0.3 \mu \mathrm{d} \pm 10 \%$ independent of temperature. The author concluded that thermal expansion and geochemical effects do not affect the matrix permeability of Topopah Spring welded tuff. Chemical comparison of effluent vs. influent elemental constituents at $90^{\circ} \mathrm{C}$ showed significantly increased concentrations of $\mathrm{Si}, \mathrm{Ca}, \mathrm{Na}, \mathrm{K}$, and $\mathrm{Sr}$. 
Lin and Daily (1984) measured water permeability of an intact sample of Topopah Spring tuff at various times during a series of three dehydration and rehydration cycles. The sample was maintained at a confining pressure of $5 \mathrm{MPa}$ and temperatures from $20^{\circ}$ to $140^{\circ} \mathrm{C}$. The water permeability of the intact tuff sample was independent of temperature, time, and dehydration/rehydration cycles. Initially, the permeability was $0.34 \mu \mathrm{d}$ at ambient temperature. After drying at $98^{\circ} \mathrm{C}$, the permeability was $0.32 \mu \mathrm{d}$; upon increasing the temperature to $140^{\circ} \mathrm{C}$, the permeability was $0.31 \mu \mathrm{d}$. After three subsequent drying/rewetting cycles, the measured permeability was $0.35 \mu \mathrm{d}$ at $98^{\circ} \mathrm{C}$.

Water permeability of an intact core sample of Topopah Spring welded tuff from the site of the Large Block Test was measured by Lin and Roberts (1996). The water permeability was again independent of temperature and ranged from 0.09 to $0.67 \mu \mathrm{d}$.

Later investigations showed that the permeability of fractured samples responds to elevated temperature in a fundamentally different way than it does with intact samples, and those studies are discussed in a later section of this report.

\subsubsection{Unsaturated Matrix Permeability}

The following discussion is taken from Hudson and Flint (1997). The simplest way to evaluate the effects of elevated temperature on hydraulic conductivity is to examine the effect on the properties of water. The hydraulic conductivity $\mathrm{K}$ for water (for any saturation) is related to the intrinsic permeability $\mathrm{k}$ of a porous medium by

$$
\mathrm{K}(\theta)=\frac{\mathrm{k}(\theta) \mathrm{g}}{\mathrm{v}}
$$

where $\theta$ is the volumetric moisture content, $g$ is the acceleration of gravity, and $v$ is the kinematic viscosity of water. Between $20^{\circ} \mathrm{C}$ and $60^{\circ} \mathrm{C}$, the kinematic viscosity decreases by $52 \%$, resulting in a commensurate increase in conductivity. (The upper limit of $60^{\circ} \mathrm{C}$ is a function of the apparatus available for measuring unsaturated conductivity and is not critical to the discussion.) Experimental results typically show greater temperature dependence of unsaturated hydraulic conductivity, principally from changes in the surface tension of water, than is predicted from viscosity alone (e.g., Hopmans and Dane [1986]). Other effects that have been discussed in the literature include changes in the volume of entrapped air and changes in the volume of the continuous water phase (Chahal, 1964 and 1965; Liu and Dane, 1993; Philip and Vries, 1957). For water-retention behavior, as temperature increases, the water potential decreases (becomes closer to zero). For unsaturated hydraulic conductivity, as temperature increases, the conductivity increases beyond the effect that would be predicted from the viscosity of water.

There are few data available for unsaturated conductivity of Yucca Mountain tuffs. Conca and Wright (1992) measured the conductivity of a single core sample of Topopah Spring welded tuff to J-13 water using an ultracentrifuge. The core 
contained an axial fracture with an aperture of approximately $200 \mu \mathrm{m}$. With the sample rotating at $7500 \mathrm{rpm}$, and at $88 \%$ average saturation (flow rate of 2 $\mathrm{mL} / \mathrm{hr}$ ), water moved only through the tuff matrix. The corresponding value of hydraulic conductivity was on the order of $4 \times 10^{-11} \mathrm{~m} / \mathrm{sec}$. A few minutes after the flow rate was increased (to $5 \mathrm{~mL} / \mathrm{hr}$ ), there was sudden drainage of accumulated water from the matrix to the fracture. At this stage, the fracture walls were wetted to a depth of $1 \mathrm{~mm}$ or less. The only other reported measurements on Yucca Mountain tuffs are for single samples of vitric and zeolitized nonwelded tuff (Conca and Triay, 1992), for which the hydraulic conductivity values were $2.5 \times 10^{-10}$ and $1.2 \times 10^{-10} \mathrm{~m} / \mathrm{sec}$ at saturation values of $62 \%$ and $53 \%$, respectively.

For numerical simulations of unsaturated zone thermohydrology (i.e., water movement in response to repository heating), the hydraulic conductivity function $\mathrm{K}(\theta)$ is usually estimated, using the van Genuchten-Mualem model, from the measured saturated conductivity and water retention function (Mualem, 1976; van Genuchten, 1980). This approach has been widely applied to soils but has not been verified experimentally for any indurated rock such as welded tuff.

\subsubsection{Enhanced Vapor Diffusion}

Soil scientists have long recognized that moisture transport in soils is enhanced in the presence of a temperature gradient (i.e., exceeds that predicted from Fick's first law of diffusion) except in very dry soils. In the presence of water and a temperature gradient, vapor diffusion occurs in the connected gas phase at partial saturation. Enhanced vapor diffusion occurs when tortuous paths through the connected gas phase are shortcut by mass transfer directly through islands of liquid water at constrictions in the pore structure. Accordingly, enhanced vapor diffusion is most significant at some intermediate saturation that is medium-specific.

The importance of enhanced vapor diffusion to the near-field environment has been explored by Buscheck (1996a) using numerical simulation. Enhanced diffusion was investigated by varying the value of $\tau_{\text {eff }}=\tau \eta$ in a modeling study using the effective continuum implementation of the NUFT code (Nitao, 1993). A major effect of enhanced diffusion, as reported by Buscheck (1996a), is on the rate of rewetting of the near-field environment as the host rock cools and the consequent increase relative humidity at the waste packages. Buscheck (1996a) summarized the results of simulations, with respect to the effects of enhanced vapor diffusion, as follows:

In general, enhanced vapor diffusion enhances rewetting rate only where the advective liquid-phase rewetting rate is relatively slow to begin with (i.e., for hydrologic properties that produce slow liquidphase rewetting rates and at the center of the repository). Enhanced vapor diffusion reduces the overall rewetting rate where the advective liquid-phase rewetting rate is fastest (i.e., depending on 
hydrologic properties and at the edge of the repository). Therefore, enhanced vapor diffusion, if it actually exists, may be thought to function as an "equalizer" of thermal-hydrological conditions in the near-field environment, countering some of the effects of heating variability and natural system heterogeneity.

This is evident from the range of temperatures projected to occur with and without enhanced vapor diffusion at the time when relative humidity of $70 \%$ first occurs in the near-field environment. Comparison calculations were made for a repository with circular layout, using a reference hydrologic model and areal mass loading of $150 \mathrm{MTU} /$ acre. Temperatures were calculated at circular contours enclosing different fractions of the repository area. Without enhanced diffusion $\left(\tau_{\text {eff }}=0.2\right)$, temperatures ranged from $49^{\circ}$ to $83^{\circ} \mathrm{C}$ between the $50 \%$ to $97 \%$ location contours (corresponding to elapsed times from 38.5 to $6.1 \mathrm{kyr}$, for $\mathrm{RH}=$ $70 \%$ ). With enhanced diffusion ( $\tau_{\text {eff }}=2.0$ ), the temperature range was only $63^{\circ}$ to $74^{\circ} \mathrm{C}$ (corresponding to elapsed times of 25.8 to $8.0 \mathrm{kyr}$ for $\mathrm{RH}=70 \%$ ).

Theoretical and experimental investigations have been undertaken to quantify the enhanced vapor diffusion effect (Carey, 1979; Cass et al., 1984; Jury and Letey, 1979; Parikh et al., 1979; Philip and DeVries, 1957). A version of Fick's first law states that the mass flux density of water vapor is given by

$$
\mathrm{J}_{\mathrm{v}}=-\mathrm{D} \nabla \rho
$$

where $\mathrm{D}$ is the vapor diffusion coefficient for water vapor in air, and $\nabla \rho$ is the water vapor density gradient. This law is modified for porous media to

$$
\mathrm{J}_{\mathrm{v}}=-\tau \theta \Delta \mathrm{D} \nabla \rho
$$

where $\tau$ and $\theta$ are the tortuosity and porosity. Expressing the gradient as an equivalent temperature gradient:

$$
\mathrm{J}_{\mathrm{v}}=-\tau \theta \mathrm{D}(\mathrm{d} \rho / \mathrm{dT}) \nabla \mathrm{T}
$$

gives the "simple" expression for Fickian vapor diffusion under a temperature gradient (Philip and DeVries, 1957). An enhancement factor $\eta$ is incorporated to account for experimental data:

$$
\mathrm{J}_{\mathrm{v}}=-\eta \tau \theta \mathrm{D}(\mathrm{d} \rho / \mathrm{dT}) \nabla \mathrm{T}
$$

or alternatively,

$$
\mathrm{J}_{\mathrm{v}}=-\beta \mathrm{D}(\mathrm{d} \rho / \mathrm{dT}) \nabla \mathrm{T}
$$

where $\eta$ has a value of unity for Fickian diffusion, or greater than unity for enhanced diffusion. The parameter $\beta$ includes the effects of tortuosity and porosity, which are properties of the solid medium. $\beta$ is proportional to $\eta$, and both are strongly dependent on saturation. 
Cass et al. (1984) summarized the soil science literature pertaining to the physical meaning of $\beta$ and proposed a method for laboratory measurement based on a derived analytical dependence between the effective thermal conductivity and the total pressure. They wrote the heat flux density in a soil under a temperature gradient as the sum of contributions from conduction and vapor transport:

$$
\begin{aligned}
& \mathrm{J}_{\mathrm{h}}=-\left(\mathrm{k}_{\mathrm{c}}+\mathrm{k}_{\mathrm{v}}\right) \nabla \mathrm{T} \\
& \mathrm{k}_{\mathrm{v}}=\mathrm{HD} \beta \mathrm{h}\left(\mathrm{d} \rho^{*} / \mathrm{dT}\right)
\end{aligned}
$$

where $\mathrm{H}$ is the heat of vaporization, $\mathrm{h}$ is relative humidity, and $\left(\mathrm{d} \rho^{*} / \mathrm{dT}\right)$ is the temperature dependence of the saturation vapor density. Differentiating with respect to reciprocal pressure, $\mathrm{P}_{\mathrm{r}}$ yielded

$$
\left(\mathrm{dk}_{\mathrm{v}} / \mathrm{dP}_{\mathrm{r}}\right)=\operatorname{Hh} \beta \mathrm{D}_{\mathrm{va}}\left(\mathrm{d} \rho^{*} / \mathrm{dT}\right)
$$

where $D_{v a}$ is the binary diffusion coefficient of water vapor in air. This expression shows that the pressure dependence of the effective thermal conductivity $\left(\mathrm{k}_{\mathrm{c}}+\right.$ $\mathrm{k}_{\mathrm{v}}$ ) is proportional to the enhancement factor $\beta$. Implicit in this derivation are the assumptions of gas-phase ideality, the separability of tortuosity effects from enhanced diffusion, and invariance of capillarity and water-adsorption effects over the range of temperature represented by $\nabla \mathrm{T}$.

Cass et al. (1984) measured thermal conductivity of two soil mixtures in the laboratory, as a function of total pressure, to measure $\beta$. Fixing sample temperature and moisture content, thermal conductivity was measured at various values of total pressure, saturation, and temperature. Relative humidity was calculated from moisture retention curves for the material. Thermal conductivity measurements were made at total pressures from 1 to 12 bars, at three saturations from 0.021 to 0.190 , and at three (isothermal) temperatures from $3.5^{\circ} \mathrm{C}$ to $32.5^{\circ} \mathrm{C}$ (Figure 2-9). The results were sensitive to pressure, indicating vapor diffusion (shown by the positive slopes in Figure 2-9). The relative magnitude of vapor diffusion increased at higher temperatures (greater slopes). Temperature dependence of vapor diffusion was attributed to more effective transfer of latent heat at greater values of absolute humidity. The approach of Cass et al. (1984) is the basis of an ongoing laboratory investigation of enhanced vapor diffusion in TSw2 welded tuff. 


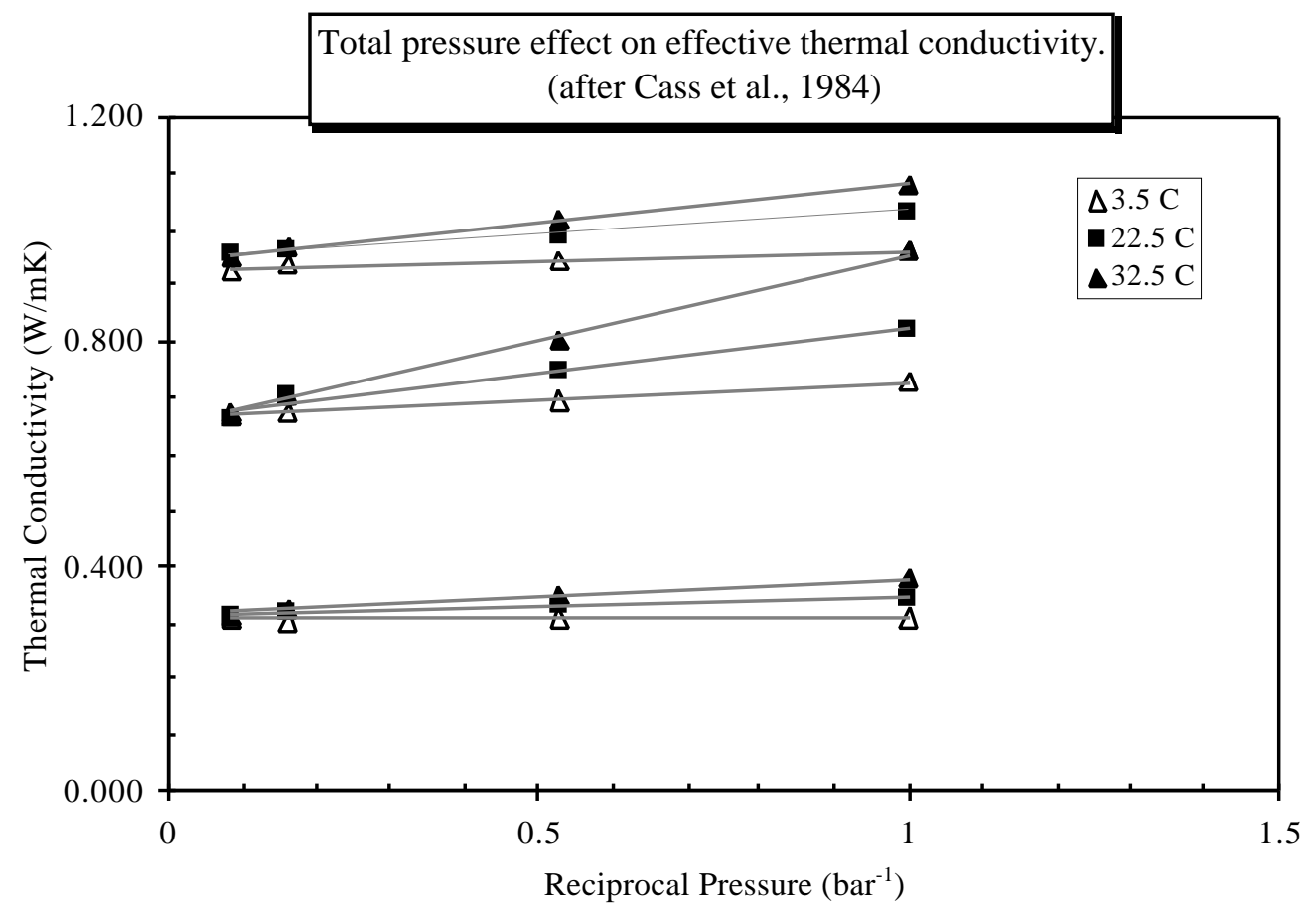

Figure 2-9 Measured thermal conductivity $k_{c}+k_{v}$ for three identical sand columns at different water contents $(\theta)$ and different temperatures $(T)$

\subsubsection{Knudsen Diffusion}

Whenever the mean free path of a gas approaches the scale of the medium in which the gas flows, noncontinuum gas dynamics result and "slip" phenomena are encountered (Klinkenberg, 1941). The effect can be studied by performing gas permeability measurements at different values of absolute pressure because the mean free path is inversely proportional to the gas density (Atkins, 1990). Reda (1985b) measured the permeability of a sample of Topopah Spring member welded tuff to nitrogen at ambient temperature, varying the average pressure from 0.1-13.1 MPa. Gas permeability varied by more than an order of magnitude over this pressure range. The difference between liquid and gas permeability was used to calculate the Knudsen diffusion coefficient, from which the average pore diameter was calculated to be $8 \mathrm{~nm}$, assuming a tortuosity of $\tau=5$. This compares with the mean free path calculated for water vapor at experimental conditions. This experiment suggests that gas permeability of the TSw2 rock matrix could be a factor of 2 or more greater than liquid permeability at repository conditions.

Reda (1985b) used this result to infer the mobility of water vapor. The Knudsen diffusion coefficient for nitrogen was converted to a diffusion coefficient for water vapor $\left(3.2 \times 10^{-7} \mathrm{~m}^{2} / \mathrm{sec}\right)$, which is less than the Fickian diffusion coefficient for water vapor into air at $20^{\circ} \mathrm{C}\left(2.4 \times 10^{-5} \mathrm{~m}^{2} / \mathrm{sec}\right)$. The difference in magnitude indicates that Knudsen diffusion does not have a significant role in vapor diffusion. 


\subsubsection{Water-Retention Characteristics}

Measurement of capillary-water potential as a function of rock-matrix saturation is needed to determine the extent of dryout or rewetting in response to specified changes in temperature or humidity. Wetting of the tuff matrix occurs differently because of the distribution of liquid water in the pore structure, so that drying/wetting hysteresis results. At moisture thermodynamic equilibrium, the pore-water potential is equivalent to the vapor fugacity in the gas phase. Thus, for a given moisture content and temperature, moisture-retention characteristics of the rock matrix will determine the relative humidity of air in contact with waste packages. Humidity is a key determinant of corrosion rates for some prospective waste package materials.

Where measured unsaturated matrix permeability data are unavailable, moisture-retention curves are used with saturated hydraulic conductivity measurements to predict unsaturated conductivity parameters. Flint (1996) measured moisture-retention curves for this purpose, at ambient temperature, for hydrogeologic units at Yucca Mountain, including the candidate host rock (Figure 2-10). The water-potential measurements were made by determining the moisture content of tuff samples gravimetrically, then equilibrating them with the air in a test volume containing a chilled-mirror psychrometer. The moistureretention curves (Figure 2-10) were generated using a curve fitting algorithm (van Genuchten et al., 1991) to fit the model of van Genuchten (1980). 

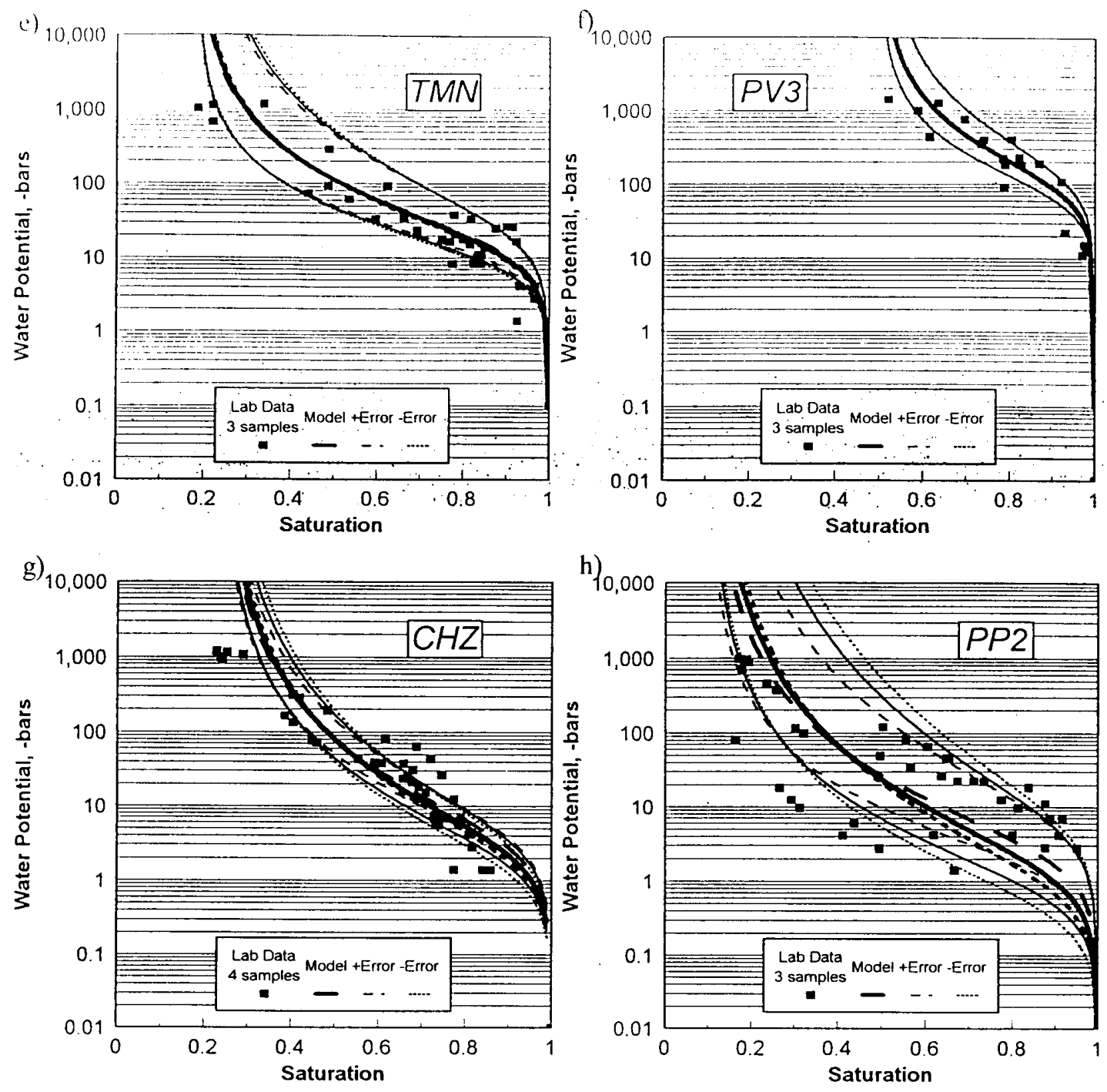

Figure 2-10 Moisture-retention curves developed by Flint (1996) for Yucca Mountain hydrogeologic units, including the middle nonlithophysal Topopah Spring unit (TMN), Calico Hills zeolitized unit $(\mathrm{CHz})$, Topopah Spring basal vitrophyre (PV3), and Prow Pass welded devitrified tuff (PP2) (based on fitting the van Genuchten (1980) model to measured data)

Daily and Lin (1991) performed gravimetric analysis of tuff samples from Fran Ridge and borehole $\mathrm{H}-1$ at $20^{\circ} \mathrm{C}$ and $70^{\circ} \mathrm{C}$. The samples were initially dried at $35^{\circ} \mathrm{C}$, then equilibrated under conditions of controlled humidity. Both wetting and drying curves were determined at each temperature. Saturation was attained by submerging the samples and pressurizing to $0.7 \mathrm{MPa}$. The Kelvin equation was used to calculate moisture potential from temperature and humidity measurements. Sample mass varied from 8 to $114 \mathrm{~g}$, and the duration of the test series was approximately 5 months. In general, for a given saturation represented by gravimetric moisture content, the water potential was greater (more suction) 
at $70^{\circ} \mathrm{C}$ than it was at $20^{\circ} \mathrm{C}$. Hysteresis was directly observed for samples at $20^{\circ} \mathrm{C}$, but there was a lack of measurable hysteresis at $70^{\circ} \mathrm{C}$. Considerable variation from sample to sample was observed. Similar moisture-retention curves for wetting only were obtained for 12 samples of Topopah Spring tuff from borehole G-4 (Roberts and Lin, 1994b).

The series of matrix property measurements reported by Peters et al. (1984) on tuff samples from 48 locations in Yucca Mountain included measurements of water retention. Moisture-retention curves were produced at ambient temperature and exhibited typical hysteresis. The curves were replicated by mercury intrusion measurements on similar samples. (Mercury intrusion measures the pressure required to overcome capillarity, on a volumetric basis, as the medium is permeated with a nonwetting, incompressible fluid.)

Measurements of moisture-retention characteristics indicate that high relative humidity can be reached with small moisture content in the rock matrix. The present saturation of the candidate host rock is about 0.85 (Flint, 1996); thus, without substantially drying out the host rock, the relative humidity will remain close to $100 \%$. According to moisture-retention data described here, the saturation will have to be less than about 0.10 to maintain an environment that is effectively dry (i.e., less than $65 \%$ relative humidity). Water-retention curves are steep for saturation less than about $20 \%$, so rewetting is potentially rapid. However, if a substantial mass of the host rock is dried out by heating, the rate of rewetting will be limited by transport of water.

\subsubsection{Imbibition Diffusivity}

Imbibition diffusivity describes the rate of movement of a wetting fluid into a porous medium under capillary pressure (Handy, 1960), which is the same problem as fracture-matrix flow coupling in the unsaturated zone at Yucca Mountain. Experimental data are readily generated and show that the rate of imbibition into a uniformly unsaturated porous sample is inversely proportional to the square root of elapsed time. Analytical models for this type of behavior can be derived assuming either diffusive or piston flow (Handy, 1960). The piston-flow concept is similar to the Green and Ampt infiltration model widely used in soil science (de Marsily, 1986). Assuming that water displaces air in piston flow, and ignoring gravity forces, Handy (1960) derived an expression for the time dependence of the total imbibed volume:

$$
\mathrm{Q}_{\mathrm{w}}^{2}=\left(\frac{2 \mathrm{P}_{\mathrm{c}} \mathrm{k}_{\mathrm{w}} \theta \mathrm{A}^{2} \mathrm{~S}_{\mathrm{w}}}{\mu_{\mathrm{w}}}\right) \mathrm{t}
$$

where $P_{c}$ is capillary pressure, $\theta$ is porosity, $A$ is the cross-sectional area, $S_{w}$ is water saturation behind the saturation front, $\mathrm{k}_{\mathrm{w}}$ is water permeability behind the front, and $\mu_{\mathrm{w}}$ is the kinematic water viscosity. Handy (1960) evaluated the dependence of imbibition diffusivity on temperature. The capillary pressure $P_{c}$ represents the pore-water potential ahead of the saturation front and depends on 
the air-water-surface tension and the contact angle (air-water-mineral). The effects of elevated temperature on water viscosity and surface tension are relatively well known, but the effect on contact angle is not.

Handy (1960) reported a series of measurements on sandstone cores, which showed that linearity of $Q_{w}{ }^{2}$ vs. $t$ is preserved at elevated temperature, but the slope steepens. Assuming that $\mathrm{P}_{\mathrm{c}}$ is proportional to surface tension and dividing each slope by the ratio of viscosity to surface temperature, the same values, to within experimental error (for the same core sample), were obtained for different temperatures. Thus, the variation of imbibition diffusivity with temperature was completely described by viscosity and surface-tension changes, if contact angle effects do not vary with temperature. The rate of imbibition actually increased moderately at elevated temperatures.

A series of sorptivity measurements was made at ambient temperature on Grouse Canyon tuff samples by Flint et al. (1994). Sorptivity is a parameter developed by Philip (1957) to describe the rate of water imbibition, under the impetus of capillarity without gravitational effects, into a porous medium. The imbibed volume of fluid is given as a function of time:

$$
\mathrm{I}=\mathrm{St}^{1 / 2}+\mathrm{At}
$$

where $S$ is sorptivity $\left(\mathrm{cm} / \mathrm{hr}^{1 / 2}\right)$, $\mathrm{t}$ is time $(\mathrm{hr})$ and $\mathrm{A}$ is a constant $(\mathrm{cm} / \mathrm{hr})$. Sorptivity is equivalent to the square root of imbibition diffusivity. If the value of $\mathrm{A}$ is negligible for early stages of infiltration, $\mathrm{S}$ can be measured by linear regression of total imbibition on the square root of time. Measured sorptivity varies as a function of initial saturation.

Flint et al. (1994) measured sorptivity on cores samples with diameters of 3.2 and $6.1 \mathrm{~cm}$. Total imbibition was monitored gravimetrically as water imbibed into core samples that had been equilibrated to in situ saturation levels. Twenty-two core samples (12 welded, 10 nonwelded zeolitized) were analyzed. For welded tuff, sorptivity increased in a linear manner from zero at full saturation to approximately $0.15 \mathrm{~cm} / \mathrm{hr}^{1 / 2}$ at zero saturation. Imbibition behavior at elevated temperature is of interest, but there are no experimental data for Yucca Mountain tuff.

\subsection{Electrical Properties}

Laboratory measured electrical properties are of interest for two reasons:

- Resistivity and electromagnetic transmission properties can be used to noninvasively image the distribution of moisture and temperature.

- Electrical potentials produced by thermally driven coupled processes might produce stray currents that accelerate corrosion processes in the near field. 


\subsubsection{Resistivity}

Electrical resistivity tomography (ERT) is a geophysical method that can image the distribution of resistivity in a two- or three-dimensional region. Resistivity can then be interpreted in terms of the distribution of moisture or temperature. Laboratory measurements of electrical resistivity over ranges of temperature and moisture conditions are the basis for interpretation. In addition, the variation of frequency-dependent impedance with moisture content can provide information about pore-scale wetting and drying processes in rock (Roberts and Lin, 1996a).

Laboratory resistivity measurements on the Topopah Spring welded tuff as a function of water saturation and temperature have been reported by Roberts and Lin (1994a, 1994b, 1996a, 1997). The measurement techniques were described in Roberts and Lin (1994a, 1994b). Briefly, a two-electrode method was used on thin disc-shaped samples that had sputtered gold electrodes backed by gold foil. Samples were placed in holders to control loss of moisture. Four samples of each rock type, each with a different thickness but with diameter-to-length ratios of approximately 10 or greater, were measured. Measurements were made over a range of frequencies from $10^{-3}$ or $10^{2} \mathrm{~Hz}$ up to $10^{5} \mathrm{~Hz}$ and included impedance magnitude and phase, resistance, and capacitance. Resistivity values were reported at $1 \mathrm{kHz}$.

Measurements were made at $23^{\circ}, 40^{\circ}$, and $95^{\circ} \mathrm{C}$ using J-13 water and distilled water as pore fluids (Roberts et al., 1994a, 1994b, 1996a, 1997a). Water was added to the samples incrementally, and saturation at each step was determined gravimetrically. Saturation of $2 \%$ to $4 \%$ was achieved by equilibrating the samples with air, $5 \%$ to $15 \%$ was achieved in a humidity chamber with relative humidity of $20 \%$ to $98 \%$, and saturation of $85 \%$ to $99 \%$ was achieved by directly adding or submersing in water. Resistivity was monitored at each step until a constant value was reached, which generally required 4 to 6 hours but depended on saturation and the relative sample area to which water was added. Drying behavior was investigated by air-drying or drying in an oven at $35^{\circ} \mathrm{C}$ and by equilibrating the samples in similar steps. For measurements at $40^{\circ} \mathrm{C}$, the samples were saturated or dried and equilibrated in an oven.

Figure 2-11 shows variation of resistivity with saturation at room temperature for a typical sample of Topopah Spring welded tuff from borehole G-4. Dry and saturated resistivities differed by more than four orders of magnitude. Resistivity during drying was typically greater than that that measured during wetting. For all samples, the resistivity was most sensitive to water saturation below a saturation of $20 \%$. Figure $2-11$ shows three regimes that describe moisture behavior. In region I, the change in resistivity was due to water adsorption; in region II, electrolytic conduction through a bulk water phase began to occur; and, region III, substantially all conduction took place through the water phase and further saturation served mainly to decrease the gas-filled porosity (Roberts and Lin, 1997a). 


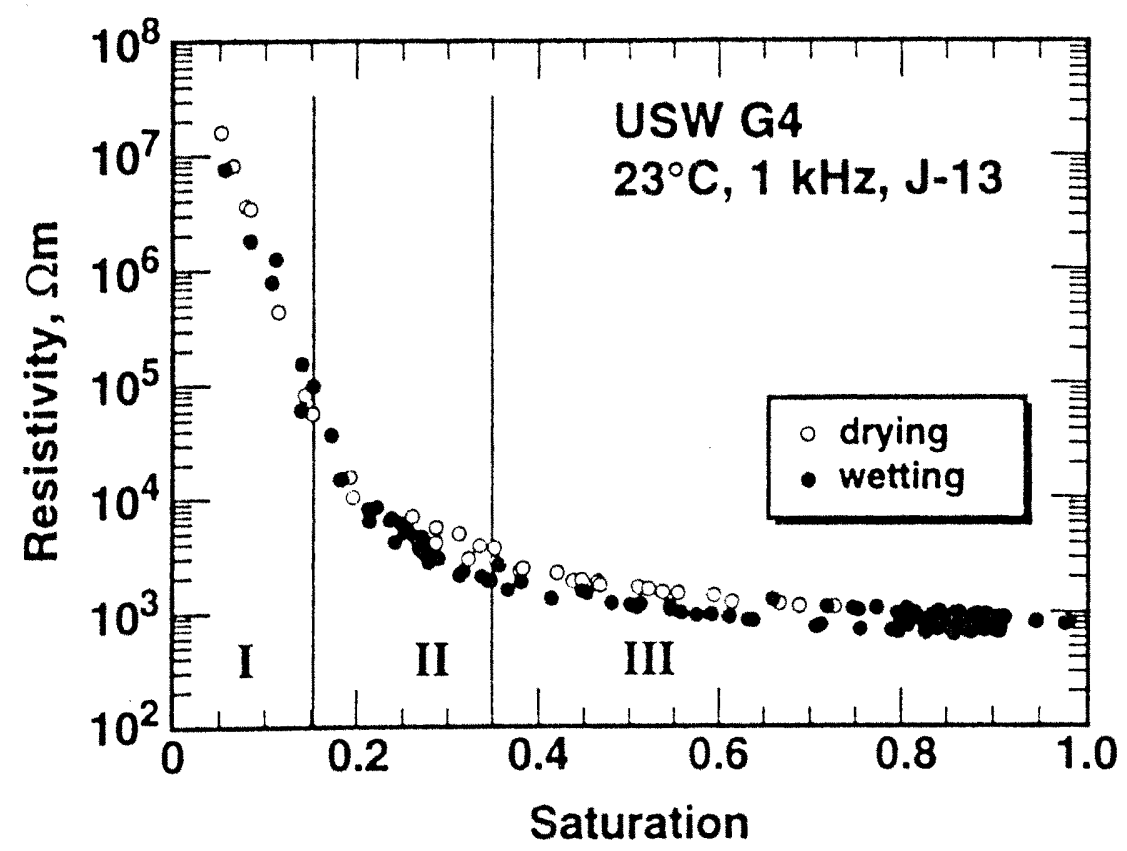

Figure 2-11 Plot of measured resistivity vs. saturation at room temperature for a sample of Topopah Spring welded tuff from borehole G-4 (after Roberts et al. [1997])

The three regimes were confirmed from analysis of the frequency-dependent impedance measurements. As different conduction mechanisms emerged, conduction regimes were signified by modes of magnitude and phase variation (impedance arcs) that changed with saturation.

As expected, resistivity decreased with increasing temperature. The temperature effect was small when the water saturation was less than $10 \%$. The maximum rate of decrease in resistivity with temperature increase occurred in the saturation range $20 \%$ to $40 \%$, which is also a range where resistivity is especially sensitive to saturation. Above $40 \%$ saturation, the temperature effect was greater than the saturation effect because resistivity was dominated by the pore-water electrolyte. On average, resistivity decreased by a factor of 3 to 4 from $23^{\circ} \mathrm{C}$ to $95^{\circ} \mathrm{C}$ at intermediate values of saturation.

Based on these results, the authors concluded that using electrical resistivity to determine the distribution of moisture in Topopah Spring tuff is most effective when the water saturation is less than $40 \%$. For water saturation greater than $50 \%$, relative permittivity (dielectric constant) may be more sensitive to water saturation than is resistivity (Roberts and Lin, 1994a). However, whereas the permittivity of dry silicate rocks does not vary significantly from $20^{\circ}$ to $100^{\circ} \mathrm{C}$, the permittivity of liquid water may decrease by as much as $40 \%$ depending on frequency (Daily and Ramirez, 1989). This tends to decrease the sensitivity of the electromagnetic tomography to changes in moisture content. 
Using paired vertical and horizontal core plugs cut from drill core (borehole GU3/G-3), Anderson (1992b) investigated resistivity anisotropy along with other rock properties. The results for saturated samples forming a profile through the unsaturated zone at Yucca Mountain are shown in Figure 2-12. Horizontal and vertical plugs were oriented parallel and perpendicular to bedding, respectively. Horizontal resistivity was less than vertical resistivity for the majority of pairs, but the degree of anisotropy was limited to a factor of 2 or 3 . Roberts and Lin (1994a) also reported that the electrical resistivity in USW G-4 was only slightly anisotropic.

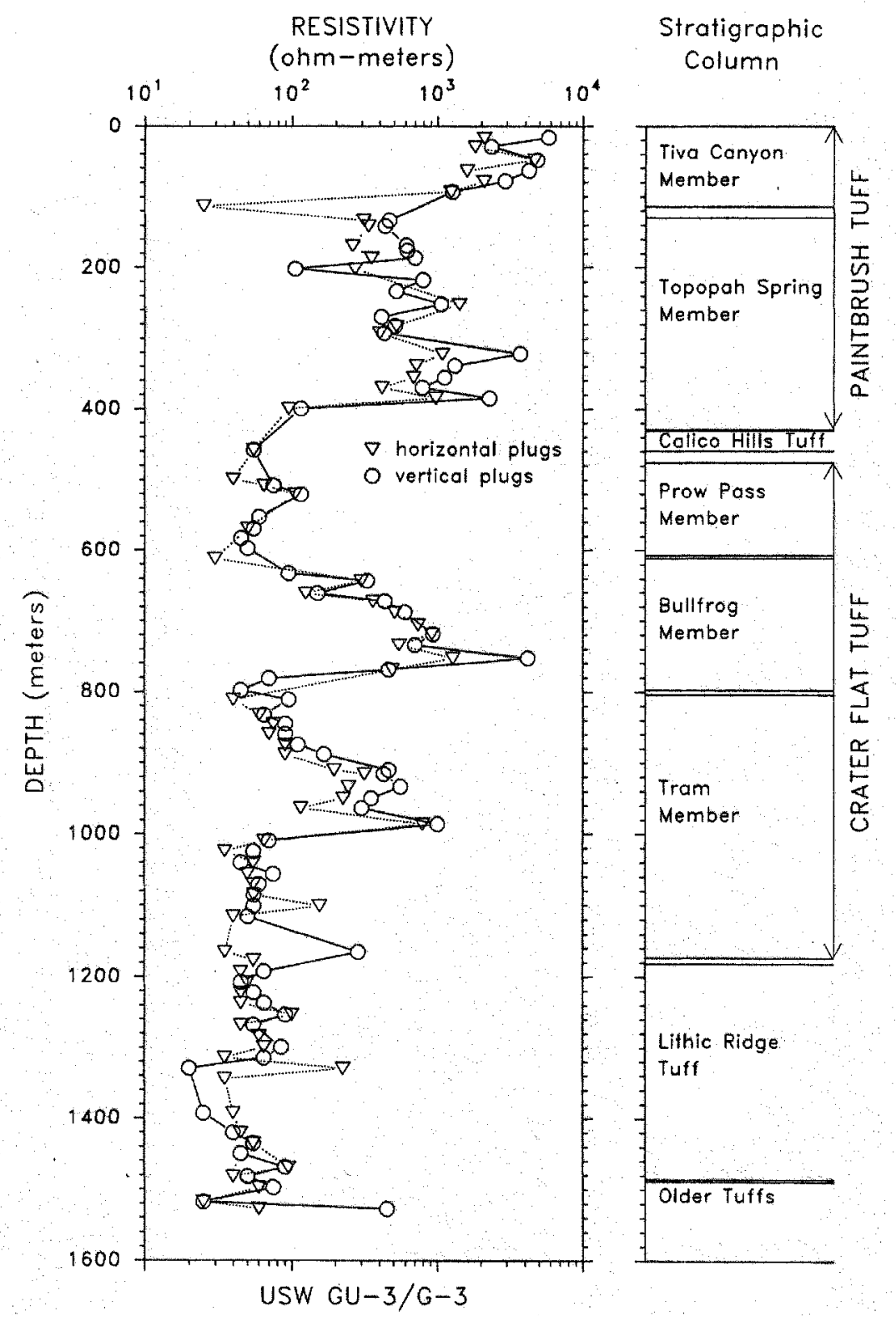

Figure 2-12 Resistivity values measured for horizontally and vertically oriented samples, plotted as a function of depth in borehole GU-3/G-3 (after Anderson [1992b]) 


\subsubsection{Self-Potential}

Potential differences of as much as $800 \mathrm{mV}$ have been observed between electrodes in the SHT electrode array installed for electrical resistance tomography (Ramirez, 1997). These were passive potential measurements, which may be directly associated with the effects of heating on the rock mass or may represent an instrument response. Naturally occurring electrical potentials are associated with geologic contacts where there are temperature and pressure gradients in underground fluids (thermoelectric and streaming potentials) or where there are gradients in electrolyte concentrations in groundwater (electrochemical potential). These effects are described subsequently, based on the discussion of Ramirez (1996).

When two phases are placed in contact, a difference in potential between them generally develops. If one of the phases is a polar liquid such as water, its molecules will tend to be oriented in a particular direction at the interface, generating a potential difference. If there are ions or excess electrons in one or both phases, the electrical charges will tend to distribute themselves nonuniformly at the interface. When liquid moves through a capillary or a porous medium under a pressure gradient, excess charges near the wall are carried along by the liquid, and their accumulation downstream causes the buildup of an electrical field, which drives an electrical current back (by ionic conduction through the liquid) against the direction of liquid flow (Hunter, 1981). The measured potential difference is the streaming potential.

Ishido et al. (1983) reported that, in rock-water systems, the streaming potential coefficient increases exponentially with decreasing hydraulic radii $<10^{-6} \mathrm{~m}$. This would suggest that the streaming potential effect for Topopah Spring tuff is relatively strong because of its fine pores, but the effect may be limited because of low flow velocities associated with low permeability, particularly at partial saturation. The streaming potential coefficient has not been established for welded tuff.

Temperature gradients give rise to thermoelectric potentials in rock-water systems (Telford et al., 1976). Nourbehecht (1963) reported that the thermoelectric coefficient for rock can be as great as $1 \mathrm{mV} /{ }^{\circ} \mathrm{C}$, with average values of about 0.2 to $0.4 \mathrm{mV} /{ }^{\circ} \mathrm{C}$. For an average thermoelectric coefficient of $0.3 \mathrm{mV} /{ }^{\circ} \mathrm{C}$ and a temperature difference of $100^{\circ} \mathrm{C}$, the calculated thermoelectric potential is $30 \mathrm{mV}$. This is much smaller than the apparent self-potential magnitude of as much as $800 \mathrm{mV}$ observed in conjunction with the SHT.

Electrochemical potentials arise when diffusion of ions occurs in groundwater. This potential can be attributed to any one of several causes:

- The difference in mobilities of various ions in solutions of different concentration (diffusion potential)

- The potential that develops when two electrodes are immersed in the same electrolyte but at different concentrations (Nernst potential)

- The separation of certain anions and cations by ion exclusion 
Each of these effects is capable of generating self-potentials on the order of hundreds of millivolts or more under certain conditions, but no measurements have been made at ambient or elevated temperature in welded tuff.

Another statement can be made concerning the effects on waste package corrosion of self-potentials generated in the host rock. Starting with dryout and extending well into the rewetting of the near-field environment, the host rock near the emplacement drifts will be relatively dry. As discussed previously (Figure 2-11), the electrical resistivity of TSw2 welded tuff increases steeply for saturation less than approximately 20\%. Laboratory tests (Roberts and Lin, 1997a) showed that resaturating from vapor could achieve maximum saturations on the order of $15 \%$. Therefore the host rock will remain highly resistive, even when the relative humidity rises to levels that support waste-package corrosion $(\mathrm{RH}>70 \%)$. The host rock will remain highly resistive until permeated by a significant quantity of water, thus limiting the impact of self-potential on corrosion processes.

\subsection{Microbiological}

Biotic processes that could affect repository performance include microbially induced corrosion (MIC) of the waste package or construction materials and alteration of the chemical environment that controls transport of radionuclides. Various bacteria normally inhabit the deep subsurface, and nonindigenous bacteria will be introduced. Microbes can survive and adapt to extreme temperatures, desiccation, and high radiation. The effects of microorganisms on their surroundings depend on the presence of adequate nutrients and moisture to maintain at least a minimum level of activity.

Most microorganisms generally require water activity values of 0.9 or higher for active metabolism (corresponding to $60 \%$ to $80 \%$ soil saturation); therefore, dry environments reduce total microbial activity. However, soil microorganisms may have aspects that support activity in desiccated environments, such as biofilm development, that maintain local water activity. Also, in desiccated environments, fungi may be more active and have been associated with cement corrosion (Horn and Meike, 1995).

It is generally accepted that the upper temperature boundary for bacterial activity is $120^{\circ}$ to $150^{\circ} \mathrm{C}$ (Horn and Meike, 1995). Spore-forming organisms may sporulate at lower temperatures, but the spores remain viable after exposure to higher temperatures. After cessation of microbiological activity in the near-field environment due to extreme conditions, dormant cells or spores can revive, or the region may be repopulated by migration when conducive conditions return.

Microbes can utilize a wide range of organic compounds to serve as sources of carbon for synthesis of cellular materials; autotrophic organisms can even fix carbon dioxide gas. Energy can be derived from either reduced organic or inorganic compounds. Hydrogen gas, nitrogen gas, ammonia, nitrite, ferrous iron, and reduced sulfur, for example, can all be used as energy sources by 
various microbial groups. Similarly, oxygen or a wide array of other inorganic compounds may be utilized as electron acceptors. Bacteria can also bind metals, secrete metal-complexing compounds, and transform metal ions to altered speciation states. These capabilities may enable the transport of radionuclides from the near-field environment. Nutrient supply and the composition of the repository community will govern the specific types of metabolic activity that occur.

\subsubsection{Indigenous and Introduced Microbial Species}

As a first step in investigating these possibilities, native and introduced bacteria were obtained from postconstruction Yucca Mountain rock and were isolated under varying conditions, including elevated temperature, low nutrient availability, and the absence of available oxygen (Meike, 1996). Isolates were screened for characteristics associated with MIC of metals. Preliminary determination of growth rates of whole Yucca Mountain microbial communities under varying conditions was also undertaken (Horn et al., 1996).

Samples of Topopah Spring welded tuff collected from a mined Fran Ridge outcrop and rock excavated during tunnel construction at Yucca Mountain were collected aseptically. Microorganisms were isolated both aerobically and anaerobically from whole and aseptically crushed $(1.7-2.4 \mathrm{~mm})$ rock samples at room temperature by plating onto low-nutrient R2 agar. Organisms that survived nutrient-depletion at $50^{\circ} \mathrm{C}$ were isolated from crushed samples $(1.0 \mathrm{~g})$ using low-nutrient $\mathrm{R} 2$ broth. The resulting whole microbial communities were grown for extended periods (aerobic incubation, $72 \mathrm{~h}$; anaerobic incubation, 17 days) at room temperature and at $50^{\circ} \mathrm{C}$. After extended cultivation, samples were incubated on R2 agar at the temperature of previous growth. Representative morphologically distinct isolates were prepared by repeated streaking of single colonies. Isolates were identified primarily through the use of fatty-acid analysis. The growth of microbes that possess sulfate-reducing and iron-oxidizing capabilities was encouraged from crushed rock samples using other specialized growth media.

Growth rates were determined by adding 10-gm crushed rock samples to $50 \mathrm{~mL}$ of R2 broth. Samples were incubated aerobically by shaking in covered flasks at ambient temperature, $30^{\circ} \mathrm{C}$, and $50^{\circ} \mathrm{C}$. Sterile controls were prepared by repeated cycles of autoclaving and incubation. Growth was monitored by periodic live plating of appropriate dilutions on R2 agar. Crude screening procedures were used to identify individual strains that exhibited the strongest MIC-related capabilities. Acid producers were identified after growth of individual isolates in $\mathrm{R} 2$ broth containing $\mathrm{pH}$ indicators. Production of hydrogen sulfide was detected by the ability to precipitate ferrous iron after growth in various media. Generation of exopolysaccharide capsular material was assessed after gross examination of colony morphology. Ferrous iron was assayed calorimetrically using ferrozine reagent. 
A multiplicity of microbial types was detected from whole and crushed Yucca Mountain rock on R2 media. In general, the greatest diversity of those microorganisms that could be cultured on R2 arose from plated rock samples grown under aerobic conditions at room temperature, although 17 anaerobic strains were purified from rock samples incubated at ambient temperature under anoxic conditions. Extended growth at room temperature and at $50^{\circ} \mathrm{C}$ showed a low diversity of microbial forms (one or two cell types). However, high cell numbers were reached after extended growth under aerobic conditions $\left(10^{8}\right.$ to $10^{9}$ cells $/ \mathrm{mL}$ ), while anaerobic conditions produced low cell densities (e.g., 140 cells $/ \mathrm{mL}$ ), and no growth was evident after extended anaerobic incubation at $50^{\circ} \mathrm{C}$. In total, more than 60 isolates were preserved for further study. After one month, growth of iron oxidizers and sulfate reducers was not evident in specialized media, although efforts continued to isolate these types of organisms.

Growth rates in low nutrient $\mathrm{R} 2$ broth of whole communities of microorganisms derived from Yucca Mountain depended on the temperature of incubation. While communities grown at room temperature or at $30^{\circ} \mathrm{C}$ showed an average mean doubling time of $1.8 \mathrm{hr}$, those growing at $50^{\circ} \mathrm{C}$ demonstrated doubling times of $3.2 \mathrm{hr}$. All cultures demonstrated significant increases in cell numbers, ranging to more 20,000 cells $/ \mathrm{mL}$ of media after a 10 -hr growth period. Preliminary screening of more than 60 isolates showed that $27 \%$ produced enough acid under aerobic conditions to decrease the $\mathrm{pH}$ of the growth media $\mathrm{pH}$ 5.3), and five of these strains produced acid when incubated at $50^{\circ} \mathrm{C}$. For anoxic conditions, $44 \%$ of those examined generated acid. Several isolates demonstrated marked production of capsular exopolysaccharide material.

Sulfide and metal sulfides have been identified as likely corrosive products, associated with sulfate-reducing organisms, of microbial activity. The distribution of sulfate reducers in samples from Yucca Mountain was not ubiquitous, and another pathway for microbial sulfide production was explored. Many of the isolates discussed by Meike (1996) were found to have the capacity to make sulfides through desulfurization of sulfur-containing amino acids; this process occurred under both anaerobic and aerobic conditions when a supplementary source of amino acids was provided. Preliminary experiments showed sulfide increased quickly to $0.5 \mathrm{ppm}$, then decreased most probably due to other culture conditions.

In a related investigation, diverse bacteria were found by aseptic sampling of ashfall tuffs underground at Rainier Mesa, on the Nevada Test Site (Haldeman and Amy, 1993; Haldeman et al., 1993). Sampling was undertaken using a mechanized mining machine to expose fresh, uncontaminated rock for hand sampling. Dust present in the excavation was found to have the same microbiota as the rock samples and to have fungal spores related to the presence of colonies on the tunnel wall rock.

In one experiment, nitrogen-fixing and denitrifying bacteria were found to be viable in measurable numbers. In another experiment, 19 samples acquired from specific locations within a $21 \mathrm{~m}^{3}$ test volume were typed and analyzed for spatial 
trends, but no definitive trend was identified. The spatial distribution of microorganism types within the test volume was strongly heterogeneous. The diversity was attributed to niches within the rock which supported different types of microbiota. The origin of the bacteria was attributed to the original depositional environment or to past hydrologic conditions that could have transported the bacteria from the surface.

\subsubsection{Behavior of Microbes Under Anticipated Repository Conditions}

The samples analyzed by Horn and Meike (1996b) probably included both native and introduced microorganisms. The study examined the portion of the Yucca Mountain community capable of growth on R2 media under the conditions specified. The findings demonstrated that microbes present are capable of survival and growth under conditions approaching those predicted for the nearfield environment. Some grew in the absence of oxygen and at temperatures greater than $50^{\circ} \mathrm{C}$. The community probably includes spore-forming organisms that can survive repeated exposure to $120^{\circ} \mathrm{C}$. Depleted nutrient conditions favor the growth of only a select group of organisms, but these can reach high cell densities under aerobic conditions, even at $50^{\circ} \mathrm{C}$. For anaerobic isolates capable of growth on R2 media, the combination of elevated temperature and nutrient depletion was deleterious to growth. Initial studies demonstrated that Yucca Mountain microorganisms can produce acidic conditions and biofilm-generating materials. Other microbial activities identified with MIC are being assessed, and isolates that demonstrated the highest rates of MIC-related activities will be used to assess the MIC resistance of candidate waste-package materials.

Related studies have been done to evaluate microbial growth in clay buffer materials that would surround a waste package, as envisaged for the Canadian and Swedish repository programs. Lucht and Stroes-Gascoyne (1996) investigated the coupled effects of heat and gamma radiation, using cultures obtained from natural buffer materials and various pure cultures. In the course of these investigations, a highly radiation-resistant organism was isolated. Organisms present in natural buffer materials were sensitive to total dose, but not to dose rate within the range studied. The same organisms were sensitive to temperature at $90^{\circ} \mathrm{C}$ but not at $60^{\circ} \mathrm{C}$ or $30^{\circ} \mathrm{C}$. Combined heat and radiation exposure produced bimodal survival responses indicating two different subpopulations. The first subpopulation exhibited a decrease in radiation resistance with increasing temperature, and the second exhibited increased radiation resistance with increasing temperature.

Stroes-Gascoyne et al. (1996) analyzed microbial activity in the buffer material used in the Buffer/Container Experiment (BCE) carried out at the Canadian Underground Research Laboratory. The BCE was conducted using electrical heaters for $2.5 \mathrm{yr}$ to examine the performance of compacted buffer material in a single emplacement borehole under simulated repository conditions. When the bentonite buffer material was installed, the water content was $18 \%$ and 
homogeneous. The material and the method of installation were aerobic. The water content at which free water is available in this 1:1 sand-clay mixture is estimated to be $15 \%$ (Pedersen et al., 1995).

Samples of buffer material were taken during decommissioning to determine if the naturally present microbiota in the buffer material survived compaction, heat, and desiccation. Samples were analyzed for total viable aerobic and anaerobic heterotrophs at $25^{\circ}$ and $50^{\circ} \mathrm{C}$, sulfate-reducing bacteria, methanogens, fermenters, fungi, sulfur-oxidizing bacteria, iron-related bacteria, and slime formers. The results were reported as follows (Stroes-Gascoyne et al., 1996):

Results showed an almost universal disappearance of viable microorganisms (both heterotrophic and specialized bacteria) in the samples taken from the heater surface, where the moisture content was low $(<15 \%)$ and the temperature was high (up to $60^{\circ} \mathrm{C}$ ). The microbial activity measurements confirmed the lack of viable organisms with very weak or no activity measured in most of these samples. Generally, aerobic heterotrophic culture conditions gave the highest mean CFU [colony forming units] values at both $25^{\circ}$ and $50^{\circ} \mathrm{C}$.

Statistical evaluation of all culture data demonstrated clearly that the water content, and not the temperature, was the variable limiting the viability of the bacteria present. The water content below which viable bacteria could not be detected on culture media was about $15 \%(w / w)$. Calculations have shown that the activity of water for buffer material with a $15 \%$ moisture content is approximately 0.96 . This is at the limit where most Gram negative bacteria cease to grow, although some groups of bacteria such as Pseudomonas, sulfate-reducing bacteria, and Vibrio are still able to grow. Virtually no viable bacteria were found in the samples of buffer material that contained less than $15 \%$ water.

In wetter regions of the backfill, relatively large numbers of aerobic, mesophillic bacteria were detected (Pedersen et al., 1995).

\subsubsection{Significance to Yucca Mountain}

The reactions actually mediated by bacteria are determined by both innate metabolic ability and the conditions to which they are exposed. Presumably, native microbes have adequate resources for continued growth under ambient conditions, but heat and desiccation will alter local activity that resumes when near-field environmental conditions become less severe. It is likely that organisms that thrive at high temperatures and those that form spores under adverse conditions already exist at Yucca Mountain (Meike, 1996). Growth of microorganisms introduced through repository construction and operation will likewise depend on nutrient supplies and metabolic adaptation and will be altered by repository conditions. 
Thermohydrologic models have shown that rewetting of tuff and backfill in the near-field environment will occur first by vapor diffusion and result in rock saturation below that which has been associated with microbial growth. Whereas biofilm "slimes" could facilitate growth even at a very low relative humidity, for such organisms to significantly affect corrosion before the reentry of liquid water, they would have to survive the near-field environment in situ. Eventually the near-field environment may become repopulated with native biota through reentry of liquid water carrying both nutrients and microbes.

Once growth resumes, microbial activity may acidify and otherwise alter the pore-water chemistry of the near-field repository environment and may directly affect the corrosion of repository waste packages. The rates of microbial growth processes observed in vitro were very rapid when compared to the long duration of repository performance. Given adequate nutrients, microbial products increased to their highest levels within days or weeks. Thus, the period required for these organisms to reach their greatest corrosive potential, given the required conditions, is insignificant.

Ongoing investigations seek to identify these conditions and whether they are likely to occur in the near-field environment. Establishing conditions for microbial activity in the context of a radioactive-waste repository requires information beyond that which is presently available in the literature. As a first step, organisms collected from the ESF have been cultured and assembled into a Yucca Mountain library. These microbes were grown in low-nutrient media with various amendments and screened for modalities of significance to waste isolation in the near-field environment. These microbes have been used in estimating the required conditions for MIC and to optimize conditions for accelerated testing of candidate barrier alloys.

\subsection{Summary of Laboratory Properties Measurements}

The following comments summarize some of the findings on temperature dependence of laboratory-measured properties found in the reports compiled for this review. These comments do not include some topics for which few data are available and for which experimental work is in progress (e.g., microbially induced corrosion). Additional information and source citations are provided in the preceding sections.

- Physical properties porosity and grain density-For the TSw2 welded tuff, these properties change little from ambient temperature up to at least $180^{\circ} \mathrm{C}$. Changes expected for the welded, devitrified tuff matrix in the altered zone are minor and will probably be caused mainly by mineral phase transitions (e.g., $\alpha \Rightarrow \beta$ cristobalite) and dehydration of hydrous phases such as clinoptilolite and smectites. Of these, dehydration of hydrous fracture-lining minerals has greater potential to affect alteredzone performance. 
- Thermal conductivity-Laboratory measurements of thermal conductivity have been performed on samples from the Exploratory Studies Facility (ESF), in conjunction with field-scale thermal testing (Brodsky et al., 1996). There is a slight increase of conductivity with temperature for the Topopah Spring welded tuff. These data are summarized by parameter values in the Reference Information Base (Rev. 0 ; [DOE, 1995]). Similar results were obtained when the samples were systematically oven-dried or water-saturated before measurement. Water saturation increases thermal conductivity of the TSw2 welded tuff by approximately $50 \%$. Thermal conductivity has been defined to not include transport of latent heat by advective or diffusive transport of water vapor. A small pressure effect in other rock types, whereby conductivity increases with confining stress, has been observed and is probably caused by closing of microcracks. Pressure effects on thermal conductivity have not been examined for Yucca Mountain tuffs.

- Heat capacitance-When measured on dried samples, the heat capacitance of the TSw2 welded tuff increases about $20 \%$ from ambient temperature to $200^{\circ} \mathrm{C}$ (Brodsky et al., 1996). The available data are summarized in the Reference Information Base (Rev. 0; [DOE, 1995]). Behavior at temperatures greater than $150^{\circ} \mathrm{C}$ is affected by mineral phase transitions, notably that of cristobalite, which apparently occurs over a temperature range of $20^{\circ}$ to $50^{\circ} \mathrm{C}$.

- Thermal expansion-The coefficient of thermal expansion for TSw2 welded tuff increases with temperature because of mineral-phase transitions and dilatancy caused by heterogeneous thermal expansion of different minerals. Linear expansion measurements have been reported for ambient pressure, temperatures to $300^{\circ} \mathrm{C}$, and several saturation states (Brodsky et al., 1996). Measured thermal expansion for samples of TSw2 welded tuff varied by a factor of five. Average values summarizing the data from this study are used in the Reference Information Base (Rev. 0; [DOE, 1995]). Thermal expansion is relatively insensitive to saturation. Hysteresis becomes apparent at temperatures greater than $200^{\circ} \mathrm{C}$, probably because the factors causing increased expansivity produce irreversible changes in rock fabric.

- Mechanical properties-Few data are available for evaluating the variation of laboratory-measured compressive strength or Young's modulus with temperature or saturation for the TSw2 welded tuff. Laboratory measurements (Board et al., 1984) for the Grouse Canyon welded tuff indicated that variations in compressive strength due to temperature and saturation are smaller than the variations between samples. For the Topopah Spring welded tuff, long-term (3.5- to 6-month) changes in the mechanical properties of three samples were investigated at temperatures of $80^{\circ}, 120^{\circ}$, and $180^{\circ} \mathrm{C}$ (Blacic et al., 1986). Similar results were produced (i.e., temperature effects on mechanical properties were smaller than those between samples). More recently, a 0.5-m scale block of 
Topopah Spring welded tuff was subjected to uniaxial loading at temperatures as great as $93^{\circ} \mathrm{C}$ (Blair and Berge, 1997). Young's modulus for the tuff matrix at several locations in the block decreased significantly as temperature increased. These results indicate a tendency for joints, while loaded by in situ stress, to close in response to heating.

- Compressive strength vs. saturation-It has been reported that a significant decrease in compressive strength could be associated with increased saturation (Nimick and Schwartz, 1987). This observation was based on early studies that may have been affected by different methods used to control sample saturation (Boyd et al., 1994).

- Rock creep-The rheological properties of Topopah Spring welded tuff depend, just as with other materials, on stress level and sample size. Recent creep properties data for Yucca Mountain tuffs are available (Martin et al., 1995c)). In the reported experiments with core samples of welded tuff, the predominant creep mechanism was growth of axial cracks, which is different from creep deformation in other silicate crystalline rocks. There was some evidence that the ultimate strength at a given strain rate decreased with increased temperature. Significant creep occurred only when samples were stressed to at least $50 \%$, and in some cases more than $90 \%$, of their ultimate strength. Such stress conditions may be uncommon in the near-field environment, occurring only at fracture asperity contacts. These results also indicate a tendency for fractures in the host rock to close in response to heating and subsequently open in response to cooling.

- J-13 water-Groundwater from this well is widely regarded as being representative of the chemical composition of water in equilibrium with the Topopah Spring welded tuff. Changes in the chemistry of J-13 water in contact with welded tuff on heating from $25^{\circ}$ to $100^{\circ} \mathrm{C}$ were evaluated using EQ3/6 (Wolery, 1992a, 1992b) and found to be minor (Glassley, 1996). The major differences calculated to result from heating were increased dissolved Si and precipitation of a minor amount of carbonates. Modeling results depend strongly on the postulated behavior of volatile constituents such as $\mathrm{CO}_{2}$. Qualified models and thermodynamic data are available for predicting the chemistry of the aqueous phase in contact with many minerals, including those that make up the major constituents of the Topopah Spring tuff (Wolery, 1992a and 1992b; Wolery et al., 1992).

- Behavior of radionuclides in J-13 water-Experimental data on the speciation and solubility of important radionuclides at elevated temperature are limited. Investigation of spiked J-13 water at temperatures as great as $100^{\circ} \mathrm{C}$ indicated that $\mathrm{Pu}$ solubility decreased, but $\mathrm{U}, \mathrm{Np}$, and $\mathrm{Am}$ remained soluble or increased (Nitsche, 1991). Carbonate complexes appeared to be important to the solubility of $\mathrm{U}, \mathrm{Np}$, and Am at elevated temperature. A recent review of what is known about complexation and solubility of $\mathrm{Ni}, \mathrm{Zr}, \mathrm{Tc}, \mathrm{U}, \mathrm{Np}, \mathrm{Pu}$, and $\mathrm{Am}$ in J-13 water at elevated temperature has been published (Wruck and Palmer, 1997). 
- General vs. analog approaches to chemical systems-Although experimental studies with J-13 water summarize the effects of various chemical reactions that are important to repository performance, the approach has an important limitation. The complexes or precipitates determining the total solubility of each radioelement are not exhaustively determined, and the results are specific to a particular chemical system (i.e., J-13 water). The experiment is therefore an analog, and the results are not generally applicable to predicting repository performance if aqueousphase chemistry deviates significantly from that present in the experiments.

- Hydrothermal tuff alteration-Batch studies of hydrothermal alteration of wafers of Topopah Spring welded, devitrified tuff have been performed at temperatures from $90^{\circ}$ to $250^{\circ} \mathrm{C}$ and for durations to 120 days (Knauss, 1987; Knauss and Beiriger, 1984; Knauss et al., 1987, 1986; Knauss and Peifer, 1986; Oversby, 1984a, 1984b, 1985). They showed that changes in the composition of water in contact with the tuff were moderate at temperatures as great as $150^{\circ} \mathrm{C}$, with slight alteration of the tuff over a few months. At higher temperatures, similar alteration products were produced, but reaction rates increased significantly. Accelerated experiments on crushed tuff at temperatures greater than $150^{\circ} \mathrm{C}$ produced more extensive alteration, including metastable phases. The temperature of matrix pore water in the "dryout zone" of the near-field environment could approach $150^{\circ} \mathrm{C}$ if the permeability of the tuff matrix is low enough to produce "throttling" (Buscheck, 1996b).

- Alteration of vitric and zeolitized tuff-The upper and basal Topopah Spring vitrophyre units contain glass and secondary minerals that are quite reactive and potentially important to repository performance. In particular, the zeolite interval I of Bish (1984) represents the first natural occurrence of highly sorptive minerals found in significant abundance beneath the repository horizon; these minerals are sensitive to changes in temperature and humidity. The basal vitrophyre below the repository horizon is as much as $30 \mathrm{~m}$ thick and consists primarily of densely welded glass. The glass is impermeable, and, although fractured, it is reactive so that fractures tend to seal with alteration products when exposed to water. One reported test (Knauss and Copenhaver, 1995) examined alteration of polished wafers of the unaltered, densely welded basal vitrophyre. Only glass dissolution was observed at temperatures as great as $150^{\circ} \mathrm{C}$, but alteration at $250^{\circ} \mathrm{C}$ was significantly faster. Another experiment examined the alteration of naturally zeolitized samples of the same vitrophyre (Knauss and Copenhaver, 1995). The starting material was mostly heulandite, with some smectite, and it appeared stable to alteration at temperatures as great as $250^{\circ} \mathrm{C}$. Thus, the reaction of vitric tuff with water is significantly slower at temperatures up to $150^{\circ} \mathrm{C}$ than it is at $250^{\circ} \mathrm{C}$, and hydrologically important alteration minerals are relatively stable to alteration (although dehydration may occur). 
- Energetics of zeolite dehydration-Zeolites could have a significant effect on the heat and water balance where they are abundant because zeolite dehydration is more energetic than evaporation of water on a molar basis (Bish, 1995; Bish et al., 1996; Carey and Bish, 1996b). Zeolite hydration is apparently reversible (at dehydration temperatures as great as $215^{\circ} \mathrm{C}$ for clinoptilolite), so complementary effects will occur during repository cooldown. Altered units above and below the repository horizon contain a large fraction of zeolites; the data produced by these studies indicate that dehydration will cause some amount of shrinkage that increases porosity and probably also increases permeability. This could affect the waterperching behavior at altered zones associated with the upper and lower Topopah Spring vitrophyres.

- Effect of steam on fracture-lining alteration minerals-Hydrous minerals, including zeolites and smectites, are common in fractures, and their dehydration behavior is important for predicting transport of moisture and released radionuclides in the near-field environment. In particular, hydrous phases could exhibit similar behavior to a bentonite:sand mixture, which was shown to shrink dramatically when exposed to steam (Couture, 1985). The behavior of actual fracture-lining mineral assemblages at conditions anticipated for the near-field environment has not been directly investigated.

- Effect of hydrothermal alteration on flowpaths-Plug-flow reactor studies involving flow-through reaction of J-13 water with crushed tuff at $240^{\circ} \mathrm{C}$ resulted in significant dissolution of alkali feldspar and cristobalite (DeLoach et al., 1997)). This experiment produced significantly different results from those of batch reactor studies at similar temperatures (i.e., predominantly dissolution instead of alteration). The two approaches span the range of conditions likely to exist in the near-field environment: stagnant vs. flowing water in the tuff matrix or fractures. Future plug-flow experiments will extend the temperature ranges and types of samples investigated.

- Limitations of available kinetic data-The available kinetic data for dissolution of mineral phases that may be important to repository performance are limited and reflect the general incomplete nature of kinetic data. Different investigators have used various interpretation strategies, and there is apparent lack of agreement between measurements made with batch methods and those made with flow-through methods.

- Kinetics of silica dissolution and precipitation-Reaction rates for dissolution of quartz and silica polymorphs, and precipitation of amorphous silica, are key parameters in estimating the extent and magnitude of thermohydrochemical coupled effects in the host rock. Dissolution will be strongly expressed in heat-pipe zones where refluxing water is at approximately $100^{\circ} \mathrm{C}$. Mineral dissolution will occur in heat pipes, then silica will be deposited as amorphous silica where the reflux water evaporates or boils. A boiling front will expand outward but 
eventually reverse because of diminished heat generation. Depending on how fracture hydraulics are affected by precipitated silica, fracture flow during cooldown may be channeled toward or away from wasteemplacement areas.

- Experimental data for silica kinetics-Dissolution rates are key parameters in estimating the extent and magnitude of thermohydrochemical coupled effects in the host rock. In a classic study, the dissolution rate for silica polymorphs increased by 2 orders of magnitude for each $100^{\circ} \mathrm{C}$ temperature increase, with a factor of 300 increase in the dissolution rate between $25^{\circ}$ and $70^{\circ} \mathrm{C}$ (Rimstidt and Barnes, 1980). In addition, upon cooling a saturated silica solution, decreasing solubility caused supersaturation, while the rate constant for precipitation decreased, producing a maximum precipitation rate at a temperature $25^{\circ}$ to $50^{\circ} \mathrm{C}$ less than the saturation temperature. A more recent investigation of quartz dissolution kinetics at $70^{\circ} \mathrm{C}$ (Knauss and Wolery, 1988) produced dissolution rate data that were similar, at neutral to mildly alkaline $\mathrm{pH}$, to rates predicted for quartz by the classic model.

- Cement alteration-The $\mathrm{Ca}-\mathrm{Si}-\mathrm{H}_{2} \mathrm{O}$ constituents of cement will dehydrate on exposure to elevated temperatures and will transform to more crystalline minerals. Chemical reactions involving these recrystallized phases can affect not only water chemistry, but also the relative humidity of the near-field environment if it contains significant amounts of cement. In addition, water in contact with Portland cement typically develops high $\mathrm{pH}$. Other degradation mechanisms are known to occur in cementitious materials over time and will increase the surface area available for chemical alteration. Degraded concrete in the near-field environment could be beneficial to radionuclide retardation, as indicated by laboratory comparison with crushed tuff. Preliminary studies on chemical interactions for various candidate cementitious materials are underway.

- Interaction of radionuclides with alteration products of introduced materials-Surface complexation reactions will be important for retardation of actinides, and possibly pertechnetate, in the near-field environment. Introduced materials including the waste-package corrosion-allowance material, will be important sources for potential high-affinity sorbents, which may form colloidal particles on which radionuclides can sorb and be transported. Sorption on these materials (e.g., goethite, silica polymorphs, thermally transformed Ca-Si- $\mathrm{H}_{2} \mathrm{O}$ minerals) has not been evaluated at elevated temperature nor generally in chemical systems that represent the near-field environment and include $\mathrm{CO}_{2}$ and silica. Sorption of $\mathrm{U}(\mathrm{VI})$ on goethite at ambient and elevated temperatures is the subject of ongoing investigation. 
- Matrix diffusion effects-Diffusion of radionuclides into minerals, and into the tuff matrix, is an important temperature-dependent retardation mechanism. The tuff matrix has been shown to contain ubiquitous nanopores that support slow diffusion and a few connected paths through which diffusion is orders of magnitude faster but limited in extent. Effective diffusion coefficients have been estimated for uranium migration into polished wafers of Topopah Spring tuff at ambient temperature (Viani, 1996a). Relative diffusivities of actinide and Tc species have been compared at $90^{\circ} \mathrm{C}$ using "tuff cup" experiments (Buchholtz-ten Brink et al., 1991). Effective diffusion parameters for migration of $\mathrm{Sr}$ and Cs ions in clinoptilolite have been estimated (Roberts et al., 1996). These data generally indicate that the rate of diffusion in the tuff matrix and sorbent minerals is significantly enhanced at elevated temperatures. The performance implications of increased diffusivity at elevated temperatures in the host rock have not been established.

- Matrix permeability-Variations associated with temperature changes have been found to be much less than variations between samples in matrix permeability of the Topopah Spring welded tuff. This conclusion was reached in several studies, including a long-term flow test lasting three months (Lin et al., 1984 and 1996; Moore et al., 1985 and 1986; Morrow et al., 1984; Reda, 1985a). Permeability of the welded tuff matrix to steam was also investigated (Lin and Daily, 1984) and found to be comparable to the water permeability.

- Unsaturated hydraulic conductivity-Virtually no measurements have been made of unsaturated conductivity in Yucca Mountain tuffs. Using semi-empirical methods such as that of van Genuchten (1980), this important parameter has been estimated for hydrologic and thermohydrologic models. Conca and Wright (1992) measured the conductivity of a single core sample of Topopah Spring welded tuff to J-13 water using an ultracentrifuge. The only other reported measurements for tuffs were for single samples of vitric and zeolitized nonwelded tuff (Conca and Triay, 1994). Changes in the properties of water at elevated temperature (viscosity and surface tension) suggest that unsaturated conductivity may increase by as much as an order of magnitude from $20^{\circ}$ to $100^{\circ} \mathrm{C}$. The viscosity effect is already taken into account in thermohydrologic simulations, but the surface-tension effect is not. In addition, changes in the water-rock-air contact angle at elevated temperature are difficult to predict and can also influence unsaturated conductivity.

- Enhanced vapor diffusion-This effect has been observed in soils and may be significant in the Topopah Spring welded tuff matrix for a range of saturation in which contiguous gas-phase pathways are partially blocked by islands of pore water. In thermohydrologic simulations, it has the effect of equalizing the rates of rewetting in regions of the repository subject to spatial heterogeneity of rock properties and to different hydrologic 
conditions caused by repository geometry (Buscheck, 1996a). Diffusion of water vapor under a temperature gradient has been observed to increase several fold in soils (Cass et al., 1984), but there are no known measurements in rocks. An experiment to evaluate enhanced vapor diffusion in welded tuff is underway.

- Knudsen diffusion-This effect could mean that gas permeability is several times greater than water permeability in Topopah Spring welded tuff (Reda, 1985b). The gas permeability of one sample of Topopah Spring welded tuff was measured at ambient temperature and found to vary by more than an order of magnitude over a range of average pressure from 0.1 to $13.1 \mathrm{MPa}$. Enhanced gas permeability results when the size of pores is comparable to the molecular mean free path, which is approximately true for Topopah Spring welded tuff. This study shows that Knudsen diffusion and its possible variation with temperature are potentially important for Yucca Mountain tuffs.

- Rewetting behavior-Limited testing has indicated that water-retention hysteresis varies at elevated temperature (Lin and Roberts, 1996). The wetting/drying hysteresis typically observed in saturation, vs. water potential functions at ambient temperature, was reversed at $90^{\circ} \mathrm{C}$ and was virtually nonexistent at $78^{\circ} \mathrm{C}$. Other experiments (Daily and Lin, 1985) measured wetting and drying curves using vapor saturation and also detected a lack of measurable hysteresis at $70^{\circ} \mathrm{C}$ when compared to $20^{\circ} \mathrm{C}$. This effect is probably related to changes in surface tension and the rockwater-air contact angle at elevated temperature. It has not been explained nor further investigated.

- Self-potential-Naturally occurring electrical potentials are associated with geologic contacts where there are temperature or fluid pressure gradients (thermoelectric and streaming potentials) or gradients in electrolyte concentrations (electrochemical potential). Potential differences observed in the SHT in the ESF are large enough to be considered a factor in electrochemical corrosion predictions, but the source of these potentials and its current generating capacity have not been investigated.

- Microbiology-Investigations have established that a variety of subsurface microbes, including natural organisms and those introduced during construction, exists in the Topopah Spring host rock. Survival of some species at elevated temperatures has been observed. Some species produce metabolic products that could be important in determining the rates of predominant corrosion processes and radionuclide transport in the nearfield environment. Further testing is required to support prediction of microbial processes in the repository.

The just listed comments indicate that supporting laboratory data for evaluating thermally coupled processes are relatively complete in some topical areas and sparse in others. Variation of thermal and thermomechanical properties with temperature is relatively well understood, and qualified data are available. The dependence of rheological properties, including deformation modulus and creep, 
is less well known, and there are few qualified data. For hydrologic matrix properties, there are fundamental temperature effects that may be important but that have not been investigated experimentally. For certain types of chemical reactions such as surface complexation, reaction rates and equilibria at elevated temperature are poorly known and are likely to be based on non-Q data and experimental results with simplified chemical systems that may not be representative of the near-field environment. Reaction rates are generally poorly understood except for a few systems such as dissolution and precipitation of silica polymorphs, and qualified data are sparse.

Qualified data are defined as having been collected and reported as part of a scientific activity that was planned and implemented in accordance with a QA program that was approved by the current Yucca Mountain Site Characterization Project QA system. Qualified data were identified as such during the planning process prior to review, approval, and implementation of the activity plans. The conclusions given in this subsection are based on qualified and on "existing" data, the latter of which are defined as not qualified based on when, how, or by whom the data were collected. For conclusions that are based on measured data, qualification status is summarized in Table 2-9. (This table does not address studies in progress nor findings that additional data are needed in certain areas to support further understanding.)

Table 2-9 Quality assurance status of conclusions reported in Chapter 2

\begin{tabular}{|l|l|l|}
\hline \multicolumn{1}{|c|}{ Section } & \multicolumn{1}{|c|}{ Description of conclusion } & \multicolumn{1}{c|}{ Principal support } \\
\hline \hline $\begin{array}{l}\text { 2.2 Physical } \\
\text { Properties }\end{array}$ & $\begin{array}{l}\text { Thermal effects on physical properties (e.g., } \\
\text { porosity and grain density) may be irreversible at } \\
100^{\circ} \mathrm{C} \text { and are related to the abundance of clay } \\
\text { and zeolite. }\end{array}$ & Qualified data: (Flint, 1996) \\
\cline { 2 - 4 } & $\begin{array}{l}\text { Previous studies showed the tuff is unaffected by } \\
\text { elevated temperatures as great as } 180^{\circ} \mathrm{C} .\end{array}$ & $\begin{array}{l}\text { Existing (non-Q) data: (Blacic } \\
\text { et al., 1986) }\end{array}$ \\
\hline $\begin{array}{l}\text { 2.3.1 Thermal } \\
\text { Conductivity }\end{array}$ & $\begin{array}{l}\text { Thermal conductivity remains constant or } \\
\text { increases slightly from } 25^{\circ} \text { to 300 } \mathrm{C} .\end{array}$ & $\begin{array}{l}\text { Qualified data: (Brodsky, } \\
1996 a \text { and 1997a; Brodsky et } \\
\text { al., 1997 and 1996) }\end{array}$ \\
\cline { 2 - 4 } & $\begin{array}{l}\text { Earlier studies of the Climax granite, in a different } \\
\text { rock type, produced somewhat different results. }\end{array}$ & $\begin{array}{l}\text { Existing (non-Q) data: } \\
\text { (Durham and Abey, 1981) }\end{array}$ \\
\cline { 2 - 4 } & $\begin{array}{l}\text { Thermal conductivity of the Grouse Canyon } \\
\text { welded tuff is isotropic, and thermal resistance of } \\
\text { a rejoined sawcut is negligible. }\end{array}$ & $\begin{array}{l}\text { Existing data: (Moss et al., } \\
1982)\end{array}$ \\
\hline $\begin{array}{l}\text { 2.3.2 Heat } \\
\text { Capacitance }\end{array}$ & $\begin{array}{l}\text { Heat capacitance increases with temperature in a } \\
\text { way that is related to mineral phase changes. }\end{array}$ & $\begin{array}{l}\text { Qualified data: (Brodsky, } \\
\text { 1996a and 1997a; Brodsky et } \\
\text { al., 1997 and 1996) }\end{array}$ \\
\cline { 2 - 4 } & $\begin{array}{l}\text { The phase transitions are evidently reversible, } \\
\text { with considerable hysteresis. }\end{array}$ & $\begin{array}{l}\text { Existing (non-Q) data: (Meike } \\
\text { and Glassley, 1989) }\end{array}$ \\
\hline
\end{tabular}




\begin{tabular}{|c|c|c|}
\hline Section & Description of conclusion & Principal support \\
\hline \multirow[t]{6}{*}{$\begin{array}{l}\text { 2.4 Thermal } \\
\text { Expansion }\end{array}$} & $\begin{array}{l}\text { Thermal expansion of Topopah Spring welded } \\
\text { tuff increases with temperature, with significant } \\
\text { between-sample variability. }\end{array}$ & $\begin{array}{l}\text { Qualified data: (Brodsky, } \\
\text { 1996a and 1997a; Brodsky et } \\
\text { al., 1997 and 1996) and } \\
\text { (Martin et al., 1996) }\end{array}$ \\
\hline & $\begin{array}{l}\text { Available expansion data are biased toward } \\
\text { nonlithophysal tuff. }\end{array}$ & $\begin{array}{l}\text { Existing (non-Q) data: (Blair } \\
\text { and Berge, 1996a) }\end{array}$ \\
\hline & $\begin{array}{l}\text { Between-sample variability of thermal expansion } \\
\text { is attributable to differences in cristobalite } \\
\text { abundance. }\end{array}$ & $\begin{array}{l}\text { Existing (non-Q) data: (Bish } \\
\text { and Vaniman, 1985; Nimick } \\
\text { and Schwartz, 1987) }\end{array}$ \\
\hline & $\begin{array}{l}\text { No correlation between thermal expansion and } \\
\text { mineralogy was observed. }\end{array}$ & $\begin{array}{l}\text { Existing (non-Q) data: } \\
\text { (Schwartz and Chocas, 1992) }\end{array}$ \\
\hline & $\begin{array}{l}\text { Correlation between thermal expansion and } \\
\text { mineralogy is not clear. }\end{array}$ & $\begin{array}{l}\text { Qualified data: (Brodsky et al., } \\
\text { 1997) }\end{array}$ \\
\hline & $\begin{array}{l}\text { Phase-transition effects and associated dilatancy } \\
\text { occur especially at temperatures great than } \\
\sim 200^{\circ} \mathrm{C} \text {. Expansion is mostly reversible, but } \\
\text { permanent elongation occurs in some samples. }\end{array}$ & $\begin{array}{l}\text { Qualified data: (Brodsky, } \\
\text { 1996a and 1997a; Brodsky et } \\
\text { al., 1997 and 1996) }\end{array}$ \\
\hline \multirow[t]{5}{*}{$\begin{array}{l}2.5 .1 \\
\text { Strength and } \\
\text { Deformability }\end{array}$} & $\begin{array}{l}\text { Variation of the compressive strength, due to } \\
\text { temperature and saturation, of the Grouse } \\
\text { Canyon welded tuff matrix is smaller than variation } \\
\text { between samples. }\end{array}$ & $\begin{array}{l}\text { Existing (non-Q) data: (Board } \\
\text { et al., 1984) }\end{array}$ \\
\hline & $\begin{array}{l}\text { Variation in deformability of the Topopah Spring } \\
\text { welded tuff due to temperature is smaller than } \\
\text { variation between samples. }\end{array}$ & $\begin{array}{l}\text { Existing (non-Q) data for } \\
\text { three samples (Blacic et al., } \\
\text { 1986) }\end{array}$ \\
\hline & $\begin{array}{l}\text { In Young's modulus for the Topopah Spring } \\
\text { welded tuff matrix, measurements showed a clear } \\
\text { decrease with increasing temperature. }\end{array}$ & $\begin{array}{l}\text { Existing (non-Q) } \\
\text { measurements on a single, } \\
\text { large sample (Blair and Berge, } \\
\text { 1997) }\end{array}$ \\
\hline & $\begin{array}{l}\text { Saturation may lower the compressive strength } \\
\text { and increase between-sample variability. }\end{array}$ & $\begin{array}{l}\text { Existing (non-Q) data } \\
\text { (Karakouzian and Hudyma, } \\
\text { 1996) }\end{array}$ \\
\hline & $\begin{array}{l}\text { Young's modulus and compressive strength of } \\
\text { Topopah Spring welded tuff do not change } \\
\text { significantly with temperature, but compressive } \\
\text { strength may decrease with increased saturation. }\end{array}$ & $\begin{array}{l}\text { Review of existing (non-Q) } \\
\text { data (Nimick and Schwartz, } \\
\text { 1987) }\end{array}$ \\
\hline $\begin{array}{l}2.5 .2 \text { Joint } \\
\text { Properties }\end{array}$ & $\begin{array}{l}\text { Permanent, compressive strain occurred while } \\
\text { the block was heated under axial load. Fracture } \\
\text { deformability increased significantly as } \\
\text { temperature increased. }\end{array}$ & $\begin{array}{l}\text { Existing (non-Q) data (Blair } \\
\text { and Berge, 1997) }\end{array}$ \\
\hline 2.5.3 Creep & $\begin{array}{l}\text { Data are limited for evaluating the temperature } \\
\text { dependence of creep, but they indicate } \\
\text { decreasing strength with increasing temperature. } \\
\text { TSw2 creep behavior is different from that of low- } \\
\text { porosity crystalline rocks; creep strain may not be } \\
\text { as pronounced, while time-to-failure is still } \\
\text { controlled by temperature, saturation, and stress. }\end{array}$ & $\begin{array}{l}\text { Qualified data (Martin et al., } \\
\text { 1997; 1995a; 1995c) }\end{array}$ \\
\hline
\end{tabular}




\begin{tabular}{|c|c|c|}
\hline Section & Description of conclusion & Principal support \\
\hline $\begin{array}{l}\text { 2.5.4 Ultrasonic } \\
\text { Velocity }\end{array}$ & $\begin{array}{l}\text { For the Grouse Canyon welded tuff, } \\
\text { compressional velocity decreases with } \\
\text { temperature in laboratory measurements, and the } \\
\text { G-Tunnel Heated Block Test elevated } \\
\text { temperature is associated with greater } \\
\text { deformability and growth of cracks. }\end{array}$ & $\begin{array}{l}\text { Existing (non-Q) data (Board } \\
\text { et al., 1984; Zimmerman et al., } \\
\text { 1986b) }\end{array}$ \\
\hline $\begin{array}{l}\text { 2.6.1.2 Topopah } \\
\text { Spring Host } \\
\text { Rock }\end{array}$ & $\begin{array}{l}\text { Silica polymorphs are important because the least } \\
\text { stable of them (cristobalite and tridymite) can } \\
\text { elevate the aqueous silica activity. They provide a } \\
\text { source of silica for dissolution, transport, and } \\
\text { deposition under repository thermal conditions. }\end{array}$ & $\begin{array}{l}\text { Review of qualified and } \\
\text { existing (non-Q) data: (Bish et } \\
\text { al., 1984) }\end{array}$ \\
\hline \multirow[t]{3}{*}{$\begin{array}{l}2.6 .1 .2 .1 \\
\text { Alteration of } \\
\text { Topopah Spring } \\
\text { Tuff at } \\
\text { Experimental } \\
\text { Conditions }\end{array}$} & $\begin{array}{l}\text { At temperatures of } 150^{\circ} \mathrm{C} \text { and greater, the } \\
\text { equilibrium Si concentration is controlled by } \\
\text { cristobalite dissolution in batch experiments with } \\
\text { Topopah Spring welded tuff. }\end{array}$ & \multirow[t]{3}{*}{$\begin{array}{l}\text { Existing (non-Q) data: } \\
\text { (Knauss, 1987; Knauss and } \\
\text { Beiriger, 1984; Knauss et al., } \\
\text { 1985a, 1987, 1985b; Knauss } \\
\text { and Peifer, 1986; Oversby, } \\
\text { 1984a, 1984b, 1985) }\end{array}$} \\
\hline & $\begin{array}{l}\text { No leaching of anions from the rock is detectable } \\
\text { at temperatures as great as } 150^{\circ} \mathrm{C} \text {. }\end{array}$ & \\
\hline & $\begin{array}{l}\text { In accelerated experiments using crushed tuff, } \\
\text { the main effect of temperature is increased rates } \\
\text { of reaction. Rates at } 90^{\circ} \mathrm{C} \text { were so slow, steady } \\
\text { state conditions were not achieved after a year. }\end{array}$ & \\
\hline \multirow[t]{2}{*}{$\begin{array}{l}\text { 2.6.1.3 Topopah } \\
\text { Spring Basal } \\
\text { Vitrophyre }\end{array}$} & $\begin{array}{l}\text { Knauss and Copenhaver (1995) reported } \\
\text { reaction of wafers of the unaltered Topopah } \\
\text { Spring vitrophyre with } \mathrm{J}-13 \text { water at } 90^{\circ}, 150^{\circ} \text {, and } \\
250^{\circ} \mathrm{C} \text { for } 2 \text { months. At } 250^{\circ} \mathrm{C} \text {, smectite and } \\
\text { clinoptilolite formed; only glass dissolution was } \\
\text { observed at } 90 \text { and } 150^{\circ} \mathrm{C} \text {. }\end{array}$ & \multirow[t]{2}{*}{$\begin{array}{l}\text { Existing (non-Q) data: } \\
\text { (Knauss and Copenhaver, } \\
\text { 1995) }\end{array}$} \\
\hline & $\begin{array}{l}\text { Naturally zeolitized samples from the same } \\
\text { vitrophyre were relatively stable to dissolution or } \\
\text { alteration at } 90^{\circ} \text { and } 150^{\circ} \mathrm{C} \text { for } 2 \text { months. }\end{array}$ & \\
\hline \multirow[t]{2}{*}{$\begin{array}{l}2.6 .2 .1 \\
\text { Clinoptilolite, } \\
\text { Heulandite, and } \\
\text { Analcime }\end{array}$} & $\begin{array}{l}\text { Clinoptilolite dehydration/hydration is reversible } \\
\text { up to } 215^{\circ} \mathrm{C} \text { or higher depending on the } \\
\text { exchange cation. Equilibration is relatively rapid } \\
\text { for dehydration/ hydration of powders, so kinetics } \\
\text { will apparently not be limiting for repository } \\
\text { conditions. }\end{array}$ & \multirow[t]{2}{*}{$\begin{array}{l}\text { Qualified data: (Carey and } \\
\text { Bish, 1996a) }\end{array}$} \\
\hline & $\begin{array}{l}\text { Dehydration of clinoptilolite is energetically similar } \\
\text { to that of mordenite. The energetics of hydration } \\
\text { are significantly greater than enthalpy change } \\
\text { due to condensation of water vapor. }\end{array}$ & \\
\hline $\begin{array}{l}2.6 .2 .2 \\
\text { Smectites }\end{array}$ & $\begin{array}{l}\text { Hydration/dehydration of smectite exhibits strong } \\
\text { hysteresis in molar volume. Smectite is significant } \\
\text { to the repository heat/water budget, but } \\
\text { reversibility nature suggests that the long-term } \\
\text { effects may be minor. }\end{array}$ & $\begin{array}{l}\text { Interpretation of existing } \\
\text { (non-Q) data (Bish, 1988) }\end{array}$ \\
\hline
\end{tabular}




\begin{tabular}{|c|c|c|}
\hline Section & Description of conclusion & Principal support \\
\hline \multirow[t]{3}{*}{$\begin{array}{l}2.6 .3 \\
\text { Thermochemical } \\
\text { Properties of } \\
\text { Selected } \\
\text { Aqueous } \\
\text { Species }\end{array}$} & $\begin{array}{l}\text { The effect of temperature on the composition of } \\
\mathrm{J}-13 \text { water was calculated to vary little between } \\
25^{\circ} \text { and } 100^{\circ} \mathrm{C} \text {. The principal changes from } \\
\text { precipitation are increases in dissolved } \mathrm{Si} \text { and } \\
\text { slight decreases in } \mathrm{Mg}, \mathrm{Ca} \text {, and carbonate. }\end{array}$ & $\begin{array}{l}\text { Analysis of qualified data } \\
\text { (Glassley, 1995) }\end{array}$ \\
\hline & \multirow{2}{*}{$\begin{array}{l}\text { Review of temperature dependence of } \\
\text { speciation and solubility relationships for } \mathrm{Ni}, \mathrm{Zr} \text {, } \\
\mathrm{Tc}, \mathrm{U}, \mathrm{Np}, \mathrm{Pu} \text {, and } \mathrm{Am}\end{array}$} & $\begin{array}{l}\text { Non-Q review of existing } \\
\text { (Wruck and Palmer, 1997) }\end{array}$ \\
\hline & & $\begin{array}{l}\text { Qualified review of existing } \\
\text { (non-Q) and qualified data } \\
\text { (Rard, 1996) }\end{array}$ \\
\hline $\begin{array}{l}\text { 2.6.3.1 Behavior } \\
\text { of Spiked } \\
\text { Groundwater at } \\
\text { Elevated } \\
\text { Temperature }\end{array}$ & $\begin{array}{l}\text { Solubility experiments are reported using } \mathrm{Pu}^{4+} \text {, } \\
\mathrm{NpO}_{2}^{+} \text {and } \mathrm{Am}^{3+} \text { in } \mathrm{J}-13 \text { water at } \mathrm{pH} \text { values } 6,7 \text {, } \\
\text { and } 8.5 \text { and at temperatures of } 25^{\circ}, 60^{\circ} \text {, and } \\
90^{\circ} \mathrm{C} \text {. Solubility data for } \mathrm{U}, \mathrm{Np}, \mathrm{Pu}, \mathrm{Th} \text {, and Tc are } \\
\text { reviewed for conditions relevant to waste disposal } \\
\text { in crystalline rock. }\end{array}$ & $\begin{array}{l}\text { Existing (non-Q) data (Lemire } \\
\text { and Garisto, 1989; Nitsche, } \\
\text { 1991) }\end{array}$ \\
\hline \multirow[t]{5}{*}{$\begin{array}{l}2.6 .4 \text { Introduced } \\
\text { Materials }\end{array}$} & $\begin{array}{l}\text { It is likely that the Ca-Si- } \mathrm{H}_{2} \mathrm{O} \text { materials will } \\
\text { dehydrate and transform to more crystalline } \\
\text { minerals, of which many are possible at elevated } \\
\text { temperatures. Chemical reactions involving the } \\
\text { recrystallized phases can affect water chemistry } \\
\text { and the relative humidity of the near-field } \\
\text { environment if it contains significant amounts of } \\
\text { cement. }\end{array}$ & \multirow[t]{3}{*}{$\begin{array}{l}\text { Review of existing (non-Q) } \\
\text { and qualified data: (Meike, } \\
\text { 1996) }\end{array}$} \\
\hline & $\begin{array}{l}\text { Other physico-chemical mechanisms are known } \\
\text { to occur in cementitious materials over time: alkali } \\
\text { silica reaction and delayed ettringite formation. }\end{array}$ & \\
\hline & $\begin{array}{l}\text { Interaction of Portland cement with water at } \\
\text { ambient temperature produces waters with high } \\
\mathrm{pH} \text {, and similar behavior can be expected at } \\
\text { elevated temperatures. }\end{array}$ & \\
\hline & $\begin{array}{l}\text { Results indicate that the pH of fluids passing } \\
\text { through concretes at ambient temperatures } \\
\text { would be expected to remain very high for tens of } \\
\text { thousands to hundreds of thousands of years. }\end{array}$ & $\begin{array}{l}\text { Existing (non-Q) data: } \\
\text { (Atkinson et al., 1989) }\end{array}$ \\
\hline & $\begin{array}{l}\text { Distribution coefficients for } \mathrm{Pu}, \mathrm{Np} \text {, and other } \\
\text { elements measured for several cement } \\
\text { compositions were in the range } 10^{3} \text { to } 10^{4} \mathrm{ml} / \mathrm{g} \\
\text { and increased during long duration ( }>100 \text { day) } \\
\text { experiments. }\end{array}$ & $\begin{array}{l}\text { Existing (non-Q) data: (Allard } \\
\text { et al., 1984) }\end{array}$ \\
\hline
\end{tabular}




\begin{tabular}{|c|c|c|}
\hline Section & Description of conclusion & Principal support \\
\hline \multirow{2}{*}{$\begin{array}{l}\text { 2.6.5.1 Diffusion } \\
\text { in Smectite and } \\
\text { Clinoptilolite }\end{array}$} & $\begin{array}{l}\text { Diffusion of Cs and Sr into clinoptilolite is strongly } \\
\text { temperature-dependent. }\end{array}$ & $\begin{array}{l}\text { Existing (non-Q) data: } \\
\text { (Roberts et al., 1996) }\end{array}$ \\
\hline & $\begin{array}{l}\text { When groundwater flow is relatively rapid and } \\
\text { clinoptilolite crystal size is relatively large (i.e., in } \\
\text { fractures), diffusion of Cs and Sr into clinoptilolite } \\
\text { is not rapid enough to allow the assumption of } \\
\text { local cation-exchange equilibrium. }\end{array}$ & $\begin{array}{l}\text { Existing (non-Q) data: } \\
\text { (Roberts et al., 1996; Viani, } \\
\text { 1996a) }\end{array}$ \\
\hline $\begin{array}{l}\text { 2.6.5.2 Diffusion } \\
\text { in the Topopah } \\
\text { Spring Welded } \\
\text { Tuff Matrix }\end{array}$ & $\begin{array}{l}\text { Diffusion in tuff nanopores is consistent with a } \\
\text { linear } 1-D \text { diffusion model, especially with } \\
\text { increasing exposure time and elevated } \\
\text { temperature. }\end{array}$ & $\begin{array}{l}\text { Existing (non-Q) data: } \\
\text { (McKeegan et al., 1989; } \\
\text { Phinney et al., 1987) }\end{array}$ \\
\hline $\begin{array}{l}\text { 2.6.6.1 Cation } \\
\text { Exchange }\end{array}$ & $\begin{array}{l}\text { Cation exchange predictions for zeolitized tuff are } \\
\text { made, using the EQ3/6 mode, with relative } \\
\text { accuracy. }\end{array}$ & $\begin{array}{l}\text { Analysis of existing (non-Q) } \\
\text { data: (Viani and Bruton, } 1991 \\
\text { and 1992) }\end{array}$ \\
\hline \multirow[t]{4}{*}{$\begin{array}{l}\text { 2.6.7.1.2 } \\
\text { Reaction of Silica } \\
\text { Polymorphs }\end{array}$} & $\begin{array}{l}\text { Predicted precipitation rates for silica polymorphs } \\
\text { increase with temperature to a maximum that } \\
\text { depends on the silica concentration. }\end{array}$ & \multirow[t]{2}{*}{$\begin{array}{l}\text { Existing (non-Q) data: } \\
\text { (Rimstidt and Barnes, 1980) }\end{array}$} \\
\hline & $\begin{array}{l}\text { Upon cooling a saturated solution, decreasing } \\
\text { solubility causes supersaturation while the rate } \\
\text { constant for precipitation decreases such that the } \\
\text { maximum precipitation rate occurs at a } \\
\text { temperature } 25^{\circ} \text { to } 50^{\circ} \mathrm{C} \text { below the saturation } \\
\text { temperature. }\end{array}$ & \\
\hline & $\begin{array}{l}\text { Investigation of quartz dissolution produced a } \\
\text { rate comparable to that of Rimstidt and Barnes } \\
\text { (Rimstidt and Barnes, } 1980 \text { ). To an } \\
\text { approximation, quartz was a factor of } 300 \text { more } \\
\text { soluble at } 70^{\circ} \mathrm{C} \text { than at } 25^{\circ} \mathrm{C} \text { for neutral-to-alkaline } \\
\text { pH in a distilled water system. }\end{array}$ & $\begin{array}{l}\text { Existing (non-Q) data: } \\
\text { (Knauss and Wolery, 1988) }\end{array}$ \\
\hline & $\begin{array}{l}\text { Precipitation of amorphous silica occurs in } \\
\text { laboratory batch reactors with characteristic time } \\
\text { on the order of hours or days. The presence of } \\
\text { amorphous silica in solid form apparently prevents } \\
\text { the precipitation of other silica polymorphs. }\end{array}$ & $\begin{array}{l}\text { Existing (non-Q) data: (Carroll } \\
\text { et al., 1996) }\end{array}$ \\
\hline \multirow[t]{2}{*}{$\begin{array}{l}2.6 .7 .1 .3 \\
\text { Reaction of } \\
\text { Albite }\end{array}$} & $\begin{array}{l}\text { Microscopic examination revealed etching pits } \\
\text { characteristic of site-specific, intrinsically limited } \\
\text { dissolution. At } 25^{\circ} \mathrm{C} \text { and nearly neutral } \mathrm{pH} \text {, there } \\
\text { was no etching, but it was apparent at low and } \\
\text { high pH and in all experiments at } 70^{\circ} \mathrm{C} \text {. }\end{array}$ & \multirow[t]{2}{*}{$\begin{array}{l}\text { Existing (non-Q) data: } \\
\text { (Knauss and Wolery, 1986c) }\end{array}$} \\
\hline & $\begin{array}{l}\text { In the } \mathrm{pH} \text { range } 3 \text { to } 8 \text {, limiting dissolution rates for } \\
\text { albite increased by a factor of approximately } 30 \\
\text { from } 25^{\circ} \text { to } 100^{\circ} \mathrm{C} \text {. }\end{array}$ & \\
\hline
\end{tabular}




\begin{tabular}{|c|c|c|}
\hline Section & Description of conclusion & Principal support \\
\hline \multirow[t]{3}{*}{$\begin{array}{l}\text { 2.7.2 Matrix } \\
\text { Permeability } \\
\text { (Hydraulic } \\
\text { Conductivity) }\end{array}$} & $\begin{array}{l}\text { Pore water flowed continually through one } \\
\text { sample of Topopah Spring welded tuff for three } \\
\text { months at (isothermal) temperatures as great as } \\
90^{\circ} \mathrm{C} \text {. Thermal expansion and geochemical } \\
\text { effects apparently did not affect the matrix } \\
\text { permeability. }\end{array}$ & $\begin{array}{l}\text { Existing (non-Q) data: (Reda, } \\
\text { 1985a) }\end{array}$ \\
\hline & $\begin{array}{l}\mathrm{J}-13 \text { water flowed intermittently through one } \\
\text { sample of Topopah Spring welded tuff, at } \\
\text { (isothermal) temperatures up to } 140^{\circ} \mathrm{C} \text {. } \\
\text { Permeability was independent of temperature, } \\
\text { time and of dehydration or rehydration. }\end{array}$ & $\begin{array}{l}\text { Existing (non-Q) data: (Lin } \\
\text { and Daily, 1984; Lin et al., } \\
\text { 1985) }\end{array}$ \\
\hline & $\begin{array}{l}\text { In an intact core sample of Topopah Spring } \\
\text { welded tuff, water permeability was independent } \\
\text { of temperature. }\end{array}$ & $\begin{array}{l}\text { Existing (non-Q) data: (Lin } \\
\text { and Daily, 1991) }\end{array}$ \\
\hline \multirow[t]{2}{*}{$\begin{array}{l}2.7 .2 .1 \\
\text { Permeability to } \\
\text { Steam }\end{array}$} & $\begin{array}{l}\text { Matrix permeability of a single sample of Topopah } \\
\text { Spring welded tuff to steam was approximately six } \\
\text { times the water permeability at the same } \\
\text { temperature. }\end{array}$ & $\begin{array}{l}\text { Existing (non-Q) data: (Lin } \\
\text { and Daily, 1984) }\end{array}$ \\
\hline & $\begin{array}{l}\text { Permeability of bentonite-sand mixtures } \\
\text { increased by orders of magnitude after moderate } \\
\text { exposure to steam. }\end{array}$ & $\begin{array}{l}\text { Existing (non-Q) data: } \\
\text { (Couture, 1985) }\end{array}$ \\
\hline \multirow[t]{2}{*}{$\begin{array}{l}\text { 2.7.5 Water- } \\
\text { Retention } \\
\text { Characteristics }\end{array}$} & $\begin{array}{l}\text { Hysteresis was directly observed for samples of } \\
\text { Topopah Springs welded tuff at } 20^{\circ} \mathrm{C} \text {, but there } \\
\text { was a lack of measurable hysteresis at } 70^{\circ} \mathrm{C} \text {. }\end{array}$ & $\begin{array}{l}\text { Qualified data: (Daily and Lin, } \\
\text { 1991) }\end{array}$ \\
\hline & $\begin{array}{l}\text { To maintain an environment that is effectively dry, } \\
\text { matrix saturation must be less than approximately } \\
10 \% \text { or less than } 65 \% \mathrm{RH} \text {. }\end{array}$ & Qualified data: (Flint, 1996) \\
\hline 2.8.1 Resistivity & $\begin{array}{l}\text { The temperature effect for the Topopah Spring } \\
\text { welded tuff matrix is relatively small for saturation } \\
\text { less than } 10 \% \text {. The maximum rate of decrease } \\
\text { with increasing temperature occurs in the } \\
\text { saturation range of } 20 \% \text { to } 40 \% \text {. On average, } \\
\text { resistivity decreases, at intermediate values of } \\
\text { saturation, by a factor of } 3 \text { to } 4 \text { from } 23^{\circ} \text { to } 95^{\circ} \mathrm{C} \text {. }\end{array}$ & $\begin{array}{l}\text { Existing (non-Q) data: } \\
\text { (Roberts and Lin, 1994a, } \\
\text { 1996a, and 1997a) }\end{array}$ \\
\hline
\end{tabular}




\begin{tabular}{|c|c|c|}
\hline Section & Description of conclusion & Principal support \\
\hline \multirow[t]{6}{*}{$\begin{array}{l}2.9 .1 \\
\text { Indigenous and } \\
\text { Introduced } \\
\text { Microbial } \\
\text { Species }\end{array}$} & $\begin{array}{l}\text { Microbes present in Yucca Mountain tuff are } \\
\text { capable of survival and growth under conditions, } \\
\text { including temperatures greater than } 50^{\circ} \mathrm{C} \text { and the } \\
\text { absence of oxygen, that approach those } \\
\text { predicted for the near-field environment. }\end{array}$ & \multirow[t]{3}{*}{$\begin{array}{l}\text { Existing (non-Q) data: (Horn } \\
\text { et al., 1996; Horn and Meike, } \\
1995 \text { and 1996) and analysis } \\
\text { (Meike, 1996) }\end{array}$} \\
\hline & $\begin{array}{l}\text { Spore-forming organisms that can survive } \\
\text { repeated exposure to } 120^{\circ} \mathrm{C} \text { probably exist. }\end{array}$ & \\
\hline & $\begin{array}{l}\text { Yucca Mountain microorganisms can produce } \\
\text { acidic conditions and biofilm-generating materials. }\end{array}$ & \\
\hline & $\begin{array}{l}\text { The distribution of microorganism types within a } \\
21-\mathrm{m}^{3} \text { test volume of nonwelded Rainier Mesa tuff } \\
\text { was strongly heterogeneous. The diversity was } \\
\text { attributed to niches supporting different types of } \\
\text { microbiota (analogous to Yucca Mountain tuffs). }\end{array}$ & $\begin{array}{l}\text { Existing (non-Q) data: } \\
\text { (Haldeman and Amy, 1993; } \\
\text { Haldeman et al., 1993) }\end{array}$ \\
\hline & $\begin{array}{l}\text { Combined heat and radiation exposure produced } \\
\text { bimodal survival responses indicating two } \\
\text { different subpopulations. }\end{array}$ & \multirow[t]{2}{*}{$\begin{array}{l}\text { Existing (non-Q) data: } \\
\text { (Stroes-Gascoyne et al., } \\
\text { 1996) }\end{array}$} \\
\hline & $\begin{array}{l}\text { Water content, and not the temperature, in clay- } \\
\text { sand mixtures limits the viability of the bacteria. }\end{array}$ & \\
\hline
\end{tabular}




\section{Laboratory-Scale Process Studies}

This section describes recent or ongoing laboratory research into the nature and effects of thermally coupled processes with emphasis on the near-field environment. Much of the work discussed here involved observation of processes at elevated temperatures. A few studies conducted at ambient temperature are discussed as background information or where they represent the state of knowledge in a subject area that is potentially important to repository performance.

\subsection{Drying and Rewetting}

Lin and Roberts (1996) described an experiment showing that the uptake of water during rewetting in a $100 \%$ relative humidity environment is quite different from that achieved by immersion, although the water potential is zero in both cases (zero potential implies thermodynamic equilibrium with free water). Five samples of the Grouse Canyon welded tuff were held at 100\% humidity for more than $917 \mathrm{hr}$, then removed and submersed in water. At 100\% humidity, saturation was limited to $20 \%$, but when the samples were submersed, the saturation increased to more than $70 \%$. This implies that, after the liquid water has been driven off by thermal loading from waste emplacement, the saturation level will not increase to more than about $20 \%$ until liquid water can return to the near-field environment. The authors did not interpret the vapor-rewetting behavior as a transport-limited process controlled by vapor diffusion and heat flow in the tuff matrix.

During the G-Tunnel heater experiments, rehydration took place much more slowly than did dehydration, supporting the observation that saturation levels do not increase without liquid water (Ramirez et al., 1991b).

Water saturation at a constant matric potential generally decreases with increasing temperature. Hysteresis between the drying and wetting phases exists at most of the temperatures. Roberts and Lin (1996b) measured water potential in wafer samples of Topopah Spring tuff taken from the site of the Large Block Test $(\mathrm{N}=36)$ and from borehole $\mathrm{G}-4$ core $(\mathrm{N}=12)$. Water potential was assumed equal to matric potential (osmotic potential zero). They used the humidity-chambermethod aqueous solutions of known water activity to control the moisture content of tuff samples between approximately $40 \%$ and full saturation. Typical wetting/drying hysteresis was observed at ambient temperature $\left(25^{\circ} \mathrm{C}\right)$ whereby, for a given saturation, the magnitude of the water potential was smaller on drying than on rewetting (Figure 3-1).

A reversal in the usual hysteresis relationship was observed when the experiment temperature was increased. At $78^{\circ} \mathrm{C}$, there was little hysteresis, and at $94^{\circ} \mathrm{C}$, the hysteresis was reversed so that the magnitude of the water potential was greater (as shown toward the left in Figure 3-1) on drying than on rewetting. 
A complete series of drying/rewetting measurements was completed at $94^{\circ} \mathrm{C}$, then repeated at $78^{\circ} \mathrm{C}$ on the same samples. The extent of the hysteresis effect at $94^{\circ} \mathrm{C}$ was similar, though opposite in sign, to that at ambient temperature. The cause of the reversal was not established.

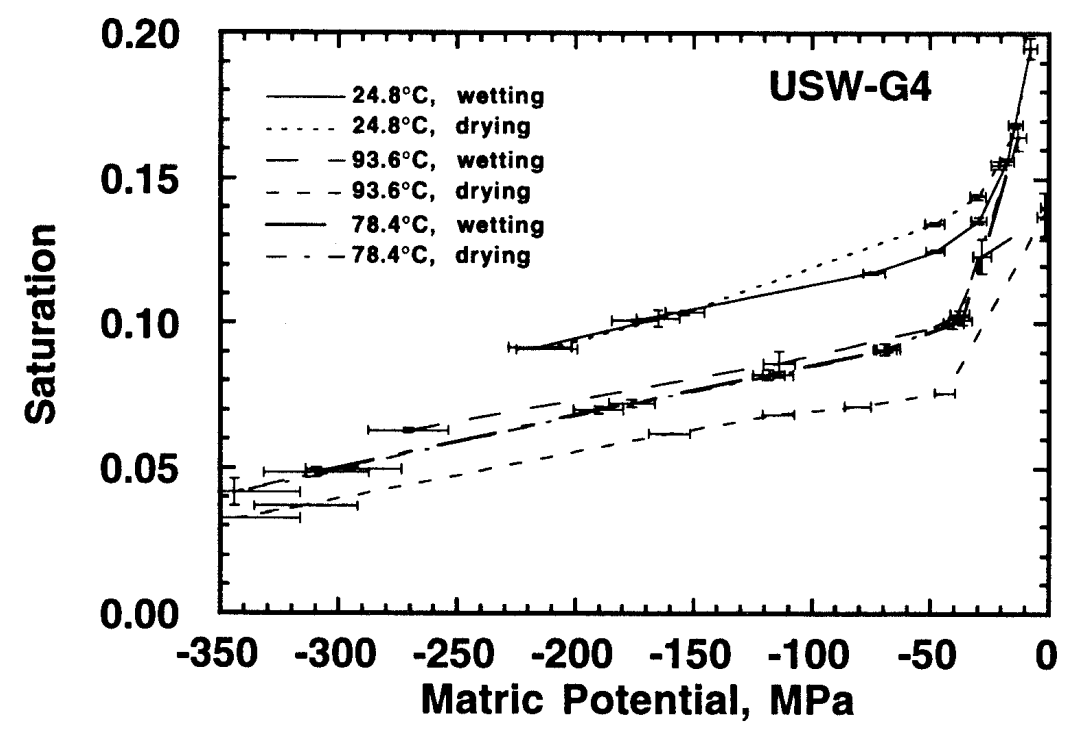

Figure 3-1 Experimentally determined moisture-retention curves for samples of Topopah Spring welded tuff at $25^{\circ}, 78^{\circ}$, and $94^{\circ} \mathrm{C}$ (from Roberts and Lin [1996b])

\subsection{Permeability Reduction}

\subsubsection{Matrix Permeability of Yucca Mountain Tuff and Other Rocks}

Permeability variation with temperature has been of interest since the inception of research and development for geologic disposal and prior to that for the study of hydrocarbon reservoir rocks at in situ conditions. Results from a few core samples of Topopah Spring welded tuff have shown that matrix permeability changes are minor as long as temperature differences within the sample are not significant (i.e., the sample is isothermal) (Lin et al., 1984, 1985, and 1996; Moore et al., 1985 and 1986; Morrow et al., 1984; Reda, 1985a). Welded tuff matrix permeability under isothermal, elevated temperature conditions was discussed in a previous section of this report. The following discussion pertains to permeability measurements in the presence of a temperature gradient.

Vaughan (1985) analyzed permeability tests reported by Moore et al. (1983) and Morrow et al. (1981) for Westerly granite. In these tests, permeability reduction resulted from flow in the direction of a temperature gradient. Permeability was measured in response to radial flow of water in a core sample, down a temperature gradient from $300^{\circ} \mathrm{C}$ at the centerline to $92^{\circ} \mathrm{C}$ at the outer surface. 
This gradient of temperature $\left(\sim 80^{\circ} \mathrm{C} / \mathrm{cm}\right)$ is probably 2 orders of magnitude greater than the largest gradient that could be expected in the repository host rock. The observed reduction in permeability over 2 to 3 weeks was $96 \%$. Scanning electron microscopy indicated that mineral precipitation in microfractures was the cause of permeability reduction. Rate equations for dissolution and precipitation of quartz were used to model the concentration of silica in pore fluid flowing in the sample and in the effluent. The estimated ratio of reactive surface area to mass of water was a parameter in these equations. The calculated maximum decrease in porosity was $8 \%$, which was converted to a $22 \%$ reduction in permeability assuming spatially homogeneous precipitation. Underprediction of permeability reduction indicated that either 1) precipitation was inhomogeneous, or 2) other minerals besides quartz participated in the reactions.

A similar series of permeability measurements was reported by Morrow et al. (1984). The change in permeability with time for core samples of granite, quartzite, anorthosite, and gabbro was measured while these rocks were subjected to a temperature gradient. The highest temperature (at the centerline heat source) was $250^{\circ} \mathrm{C}$, while low temperatures ranged from $60^{\circ}$ to $111^{\circ} \mathrm{C}$, depending on the rock type. Permeability reductions of as many as two orders of magnitude were observed, with the greatest reactions occurring in the quartzite. These changes were thought to be caused by dissolution of minerals at high temperatures and redeposition of the dissolved material at lower temperatures. Quartz appeared to be an important mineral in this process.

The described testing methodology for crystalline rocks was extended to Topopah Spring welded tuff (Moore et al., 1985; Morrow et al., 1984). Water permeability was measured on six samples from the Topopah Spring welded tuff (sampling locations unspecified). Core samples were prepared with a small-diameter axial hole. The apparatus produced radial flow (either divergent or convergent), and the sample was heated by a resistance element in the central hole. The flow direction was parallel to the rock fabric in four tests and perpendicular to fabric in the others.

The observed range in permeability of Topopah Spring samples at room temperature was 0.8 to $64 \mu \mathrm{d}$. The authors stated that the permeability of a given sample was only slightly affected by heating to maximum temperatures between $90^{\circ} \mathrm{C}$ and $250^{\circ} \mathrm{C}$ during experiments of as many as 5 weeks duration. Betweensample variability was much greater than permeability variations associated with temperature changes, flow direction relative to rock fabric, or convergent vs. divergent flow. 


\subsubsection{Laboratory Studies of Fracture Permeability in Tuff}

\subsubsection{Water Permeability}

Permeability of fractured samples responds to elevated temperature in a fundamentally different way than it does in intact samples. Lin and Daily (1984, 1985) tested three core samples of Topopah Spring welded tuff obtained from Fran Ridge and borehole G-1. The samples were permeability-tested in an axial permeameter with $5 \mathrm{MPa}$ hydrostatic confinement, pore pressure of 0.1 to 2.5 $\mathrm{MPa}$, and uniform temperature in the range $20^{\circ}$ to $140^{\circ} \mathrm{C}$. The apparatus was heated externally, and the sample temperature was uniform. Water from well J13 was flowed through the samples for steady-state permeability measurement, and the fractures remained saturated but static at other times.

The effects of dehydration were investigated by venting the pore pressure at $140^{\circ} \mathrm{C}$, while monitoring, using electrical resistance measurements between electrodes fixed to the sides of the sample. The samples were then rehydrated by introducing water at $2.5 \mathrm{MPa}$, while monitoring the permeant flow rate. Steam permeability was measured by introducing permeant at $0.2 \mathrm{MPa}$ pore pressure to a dehydrated sample at $140^{\circ} \mathrm{C}$, which was open to the atmosphere at the other end. One of the Fran Ridge samples was intact (unfractured), and the results were discussed in a previous section.

For one of the naturally fractured samples, permeability decreased by 3 orders of magnitude after multiple dehydration/rehydration cycles at $140^{\circ} \mathrm{C}$ (Figure 3-2). The decreased permeability was similar in magnitude to that of intact tuff. The other fractured sample was kept saturated to inhibit formation, of precipitates in the fracture, due to dehydration. The permeability of this sample decreased by an order of magnitude after uniform heating to $96^{\circ} \mathrm{C}$ while fully saturated. After this initial permeability decrease, further changes were small and uncorrelated with time or temperature. The initial decrease in permeability was not recovered when the sample was cooled.

Microscopic examination of the fracture surfaces showed deposition of silica. The authors concluded that fracture healing was caused by water transport of minerals, mainly silica. In naturally fractured samples (which initially contained siliceous precipitates), healing began when water at temperatures greater than $90^{\circ} \mathrm{C}$ flowed through the sample. Further healing occurred when samples were dehydrated as water moved from the matrix to boiling sites in the fracture. 


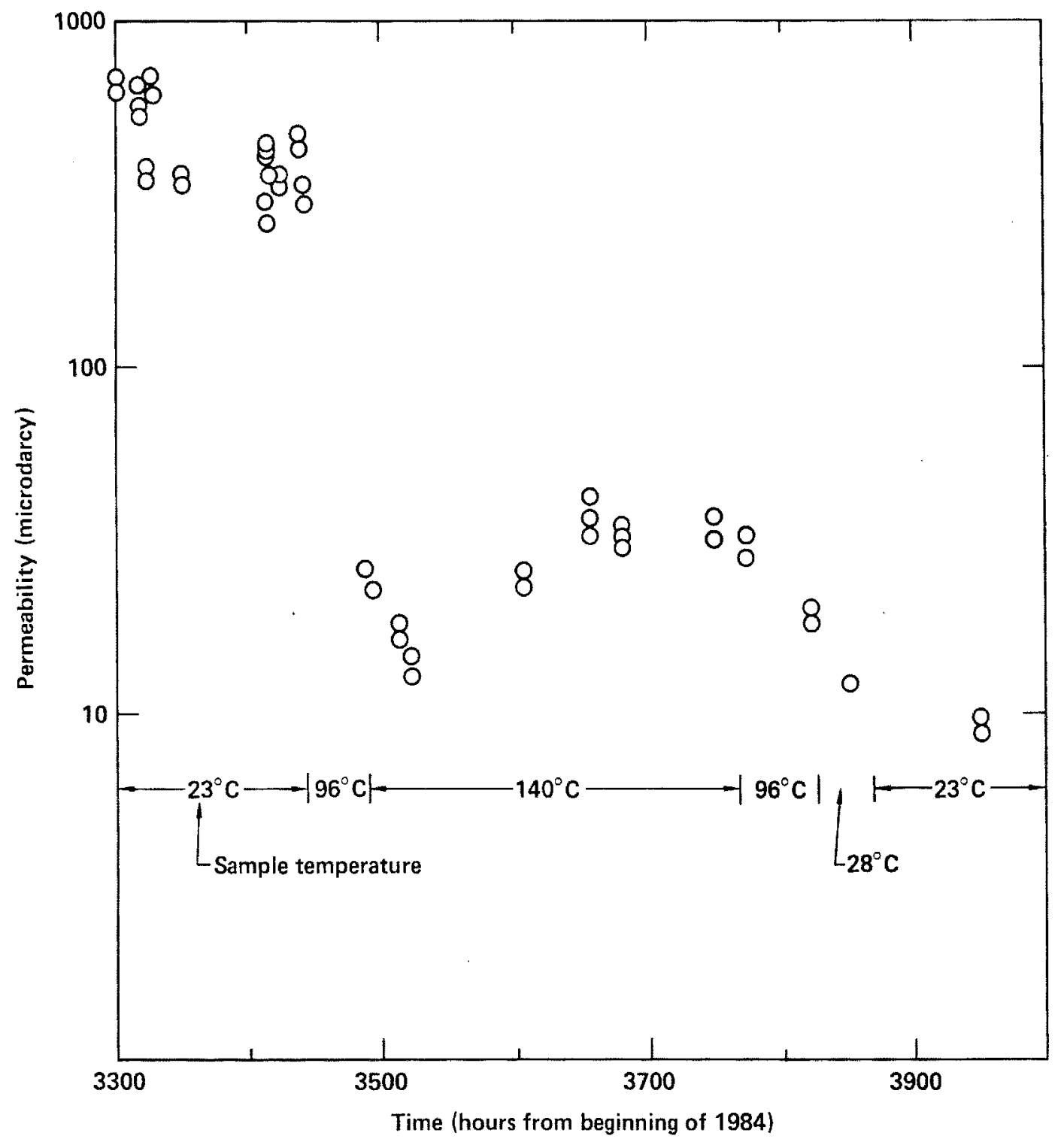

Figure 3-2 Permeability of a naturally fractured core sample of Topopah Spring welded tuff, as a function of temperature and time. The sample remained saturated at all times, but water flowed only during permeability measurements (after Lin et al. [1984]).

Daily et al. (1987) reported water-permeability testing of a naturally fractured core sample, approximately $10 \mathrm{~cm}$ long and $8 \mathrm{~cm}$ in diameter, of Topopah Spring welded tuff from borehole H-6. The sample fracture was naturally healed and was broken and reassembled prior to the test. Water from well J-13 was used as permeant. The sample was confined at $5 \mathrm{MPa}$ and isothermally heated in stages to a maximum temperature of $140^{\circ} \mathrm{C}$ over a duration of 6 months. 
Permeability of the fractured sample decreased by approximately three orders of magnitude over the course of testing. The largest decrease in apparent permeability (from 900 to $100 \mu \mathrm{d}$ ) occurred as the temperature was increased from ambient to $90^{\circ} \mathrm{C}$. The authors interpreted this behavior as silica redistribution, associated with dissolution caused by small variations in species concentration, $\mathrm{pH}$, or temperature. Initial opening of the naturally healed fracture may have dislodged siliceous material, which formed asperities and increased permeability. Such asperities would have presented greater surface area and subsequently dissolved, leading to closing of the fracture under confining pressure.

Lin and Daily (1989) reported additional testing of naturally fractured and saw-cut samples and a tensile fracture. Temperature was increased in steps to a maximum of approximately $150^{\circ} \mathrm{C}$. Permeability of fractured samples decreased by as much as three orders of magnitude over the course of the experiments. The first major permeability decrease for each naturally fractured sample was observed when the temperature increased to $90^{\circ} \mathrm{C}$ while the samples were saturated with water. After that, the permeability decreased gradually with time, independently of other conditions such as dehydration/rehydration.

Permeability changes were not recovered when the samples returned to ambient temperature. Permeability changes for the saw-cut and tensile fracture occurred at approximately $150^{\circ} \mathrm{C}$ instead of at $90^{\circ} \mathrm{C}$. During the heat-up period for most samples, the concentration of silica in the effluent from these tests was similar to the value for water at equilibrium with cristabolite. At elevated temperatures $\left(90^{\circ}\right.$ to $\left.150^{\circ} \mathrm{C}\right)$, the silica concentration increased to approximately the value for equilibrium with amorphous silica. During and after cool-down, the silica concentration indicated equilibrium with amorphous silica.

The results were interpreted to represent dissolution of fracture asperities and permeability decrease by reduction of aperture. SEM examination of fracture surfaces showed that spherical structures present at the beginning of testing were dissolved. There was evidence of silica redeposition on the fracture surfaces, possibly influenced by small-scale variations in flow rate, temperature, and water chemistry.

Lin and Daily (1989) summarized some of the results from this test series as follows:

At temperatures below about $100^{\circ} \mathrm{C}$, silica concentration was approximately that for water in equilibrium with cristobalite, while at higher temperatures, the fluid was saturated with respect to amorphous silica. At $150^{\circ} \mathrm{C}$, the silica concentration was even greater than that expected for water in equilibrium with amorphous silica. As temperature dropped, the fluid remained approximately saturated with respect to amorphous silica. It is interesting to note that most of the permeability decrease in the saw-cut sample occurred when temperature was above $125^{\circ} \mathrm{C}$. The silica concentrations in the water that flowed through the thermal gradient sample (from cold to hot regions), when the hot zone temperature was about $150^{\circ} \mathrm{C}$, were very 
close to amorphous silica saturation. This indicates that dissolution of silica has occurred on the fracture surfaces. The dissolution may begin at the contact points on the fracture, where stress concentration may increase the solubility of minerals. The dissolution of silica may also be affected by other conditions such as surface roughness, concentration of other minerals, etc. The dissolution of silica at the contact points of a fracture will smooth the asperities of the fracture surfaces .... Silica may migrate within the matrix itself due to the silica solubility variation related to thermal gradients, which may have happened to our [thermal gradient] sample, but ... permeability was dominated by the fracture. All other samples were under isothermal conditions, therefore the thermal gradient induced chemical potential gradient was not applicable.

\subsubsection{Permeability to Dry Gas and Steam}

To compare with permeability reduction in water-saturated fractures, fracture permeability studies just described were repeated with dry gas and steam (Lin, 1990). The dry-nitrogen permeability of a dried, naturally fractured sample was independent of temperature. The water permeability measured before and after heating to $150^{\circ} \mathrm{C}$, with no flow of water, also did not change significantly. Flowing steam at $\sim 127^{\circ} \mathrm{C}$ decreased the permeability by about 1 order of magnitude. The results were interpreted to show that fracture healing requires 1) dissolution/decomposition of fracture-lining minerals, as under the influence of stress concentration at fracture asperities, and 2) transport of silica by fracture flow. Flowing steam and flowing water had similar effects on fracture permeability.

\subsubsection{Effect of Confining Pressure}

A core sample with a longitudinal natural fracture was flow-tested in an axial permeameter with control of hydrostatic confinement, average pore pressure, and differential pore pressure (Roberts and Lin, 1995). The permeant was J-13 water, bio-inhibited by the addition of sodium azide. The test was conducted at constant differential pore pressure with a duration of 4200 hours, during which confining pressure and temperature were varied systematically. The results are summarized in Figure 3-3.

Increasing confining pressure from 1 to $5 \mathrm{MPa}$ at ambient temperature decreased the permeability, with nearly full recovery on unloading to $1 \mathrm{MPa}$. Increasing the temperature to $155^{\circ} \mathrm{C}$ caused an irreversible permeability decrease of about $50 \%$. Lowering the average pore pressure at elevated temperature produced steam flow, with little effect on subsequent permeability to water. After cooling, the confining pressure was raised to $2 \mathrm{MPa}$, and another temperature excursion to $155^{\circ} \mathrm{C}$ was performed, further lowering the residual permeability to about $20 \%$ of 
the original value. After cooling, the confining pressure was raised again to 3 $\mathrm{MPa}$, and a final temperature excursion was performed, causing a minor decrease in the residual permeability.
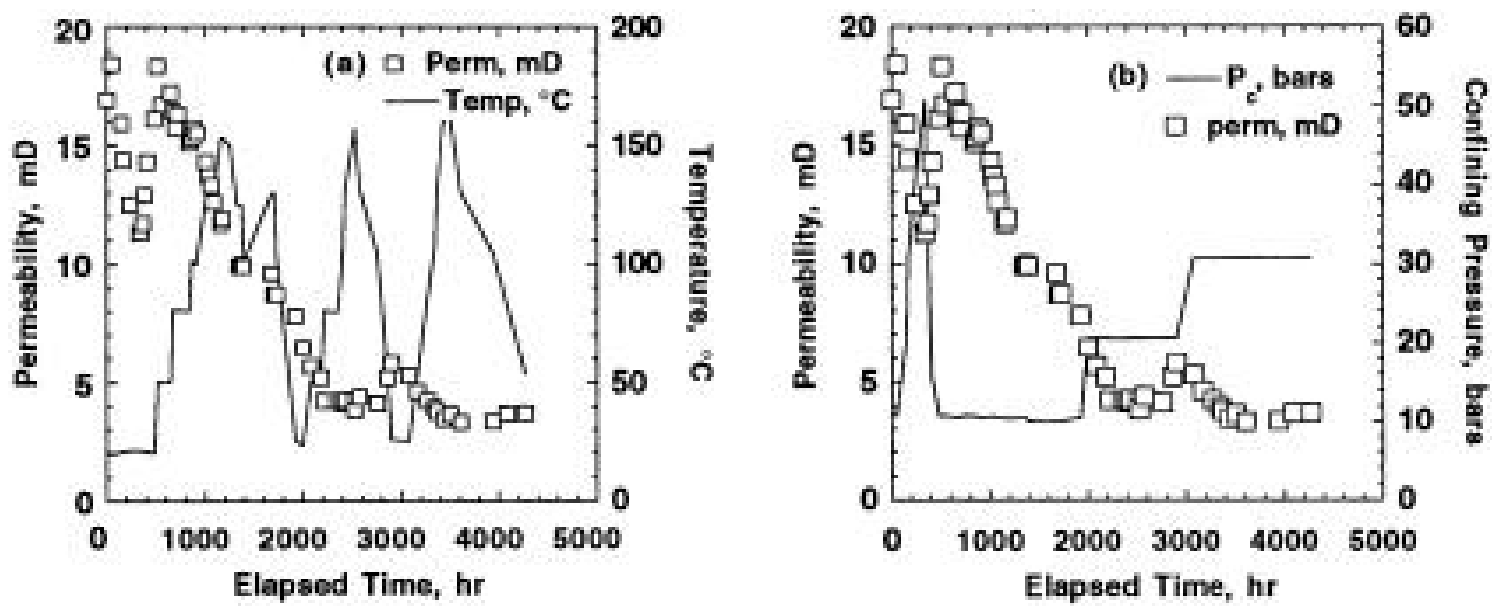

Figure 3-3 Permeability of a single fracture in a core sample of Topopah Spring welded tuff, which varied as a function of time and exposure to flowing water. Temperature and confining pressure variation during the test series are plotted for comparison (after Roberts et al. [1995]).

Lin and Daily (1988) measured water permeability of a naturally fractured sample of Topopah Spring welded tuff in a temperature gradient. The fracture had been naturally healed, and was reopened and refitted prior to the start of testing. The sample was jacketed and confined by a hydrostatic pressure of $5 \mathrm{MPa}$. It was heated at one end, and J-13 water was introduced as permeant at the other. The sample was subjected to dehydration and rehydration at the maximum temperature $\left(\sim 160^{\circ} \mathrm{C}\right.$ at the hot end). For rehydration, J-13 water was introduced at the cold end $\left(60^{\circ} \mathrm{C}\right)$ while elevated temperature and pressure conditions were maintained.

Temperature was measured by several thermocouples embedded in the sample, and moisture distribution was monitored by an array of electrodes used for electrical impedance tomography. For permeability calculation a temperature correction for the permeant viscosity was based on measured sample temperature. Permeant flow was usually directed in the cold-to-hot direction. Similar permeability values were obtained by reversing the flow, but the reversal was of limited duration. There was little correspondence between permeability and average pore pressure. 


\title{
3.3 Fracture-Matrix Flow Coupling
}

The following section (3.3.1) is taken verbatim (with permission) from the published report of Roberts and Lin (1997b).

\subsubsection{X-Ray Radiography of Fracture Flow and Matrix Imbibition in Topopah Spring Tuff Under a Thermal Gradient}

\author{
Jeffery J. Roberts and Wunan Lin \\ Lawrence Livermore National Laboratory
}

Note: Video presentations of selected results from the investigation described in Section 3.3.1 is provided in digital format.

\subsubsection{Abstract}

A method of imaging the flow of liquid in fractures and matrix imbibition in tuff using x-ray radiography has been developed and a formulation for the calculation of saturation in the matrix based on x-ray radiography is presented. Experiments were performed using different thermal gradients and hydrostatic heads. The distance that liquid penetrates the boiling region was found to be dependent on hydrostatic head: during the highest-head experiment, liquid water penetrated the entire fracture and continued to pass through the boiling region. For experiments where flow stopped at the boiling region, $x$-ray images indicate crystal deposition along the fracture. In some cases, when the sample was cooled, fracture flow resumed, and in other cases the fractures were sealed and flow did not continue.

\subsubsection{Keywords}

Fracture flow, Fluid flow, Temperature effects, Rock properties, Radioactive waste, Laboratory tests, Transport properties, Permeability

\subsubsection{Introduction}

Understanding and predicting the performance of a high-level nuclear waste repository requires knowledge of how water flows through heated, unsaturated, fractured rock. Several strategies and models for the isolation of waste packages and containment vessels from infiltrating liquid water and condensate from steam have been proposed (e.g., Buscheck and Nitao [1992]). These strategies depend to some degree on flow in fractures under thermal gradients and the effect of matrix imbibition on fracture flow (Wilder, 1996b). The distance that water can travel during gravity driven fracture flow is controlled by several factors, including the saturation of the matrix, the fracture aperture, the capillary properties of the matrix, and the temperature of the rock (Nitao and Buscheck, 1991). Flow in fractures is potentially slowed by imbibition into the matrix that is driven by capillary suction. A theoretical investigation of liquid flow and infiltration into heated rock has been reported by Phillips (1994 and 1996). 
Phillips shows that the depth of penetration of liquid fingers into superheated rock is dependent on several factors including flux, thermal conductivity of the rock mass and the temperature gradient. In the present work, a series of experiments has been performed to investigate fracture flow and fracture-matrix interactions under a thermal gradient using $\mathrm{x}$-ray radiography to image some of the above factors and processes.

\subsubsection{Experimental Methods}

Tabular blocks $(23 \times 15 \times 2.6 \mathrm{~cm})$ of densely welded Topopah Spring tuff were prepared from outcrop samples from Fran Ridge, Nevada Test Site. The matrix porosity as determined by mercury injection and by gravimetric methods was $\sim 10 \%$. Tensile fractures were induced in the middle of the samples, oriented so that the plane of the fracture was parallel to the direction of $x$-ray transmission, which is parallel to the smallest dimension (Figure 3-4 on page 3A-1). These fractures were held open with $0.5 \mathrm{~cm} \times 1 \mathrm{~cm} \times 25 \mu \mathrm{m}$ thick gold shims evenly spaced along the fracture in order to control the fracture aperture. These shims show up as highly attenuating lines in the normal radiographs (Figure 3-5 on page 3A-1).

Samples were coated with a silicon moisture barrier on all vertical sides, and mounted in an aluminum frame. At the top and bottom of the sample were chambers for ponding and collection of water. Three heaters were mounted on an aluminum plate in thermal contact with the bottom of the sample. Channels were machined in the aluminum plate to enable water flowing the length of the fracture to exit the sample to a lower collection chamber. Each heater had a separate power supply so that by varying the power to each heater an even temperature distribution could be achieved. Thermocouples (Type J) were placed near the heaters, on top of the rock near the fracture, and inserted into the rock to monitor temperature. The thermocouples placed in the rock entered the sample from the side, out of the way of the detector, and penetrated a distance of $3.8 \mathrm{~cm}(\sim 3.7 \mathrm{~cm}$ from the fracture). Two experiments will be described here: FR5 and FR6 (Table 3-1). The difference between these two experiments is that FR6 had four additional heaters on the sides of the sample. This was done to create a lower temperature gradient from the top to the bottom of the sample. FR5 had a temperature of $\sim 111^{\circ} \mathrm{C}$ at the bottom and $\sim 28^{\circ} \mathrm{C}$ at the top, and FR6 had a temperature $\sim 148^{\circ} \mathrm{C}$ at the bottom and $\sim 80^{\circ} \mathrm{C}$ at the top. The boiling region $\left(\mathrm{T}>100^{\circ} \mathrm{C}\right.$ ) extended 2 to $3 \mathrm{~cm}$ into FR5 (from the bottom) while FR6 had a much larger boiling region extending $6-7 \mathrm{~cm}$ into the sample (from the bottom). Two experiments were performed on FR6, one with a hydrostatic head of $\sim 0.26 \mathrm{~m}$, and another with the head approximately $0.46 \mathrm{~m}$. The head on FR5 was quite small, only 1-2 cm, which was the chamber height where the water ponded on top of the sample. Note that the measurement of head is not exact because of the translation of the stage and the lack of a large reservoir at the top of the water column. A calibrated burette was used to measure the amount of water that entered the sample. Between radiographs, water level readings were taken and the burette filled as needed. After the first experiment on FR6, distilled water was 
permitted to flow the length of the fracture in an attempt to eliminate any KI crystals that may have been deposited during the previous boiling event. The second experiment was performed in an attempt to test the effect of head on penetration of liquid into the boiling region.

X-ray radiographs were taken periodically to image water movement into the fracture and rock matrix by translating the sample vertically through a $160 \mathrm{kV}$ linear $\mathrm{x}$-ray source (tungsten target and a $41 \mu \mathrm{m} \mathrm{Cu}$ filter). X-rays passing through the sample were converted to a digital signal by a photo-diode linear array detector and stored by computer. Water (doped with KI to enhance contrast, 10\% by weight) was ponded on the top of the upper fracture surface and allowed to flow down the fracture while x-ray radiographs were periodically taken to image water movement in the fracture and matrix. For these two sets of experiments, water entered the sample only through the top fracture area (the rest of the sample tops were sealed). X-ray images were generally analyzed in two different ways, by simple difference imaging and by saturation calculation (vida infra). The difference image method consists of taking background radiographs of the sample in an initial known state (typically dry or fully saturated). After imposing some change on the sample such as liquid flow, or heating or cooling, changes from the initial state can be observed by subtracting the initial image from the subsequent images. Difference imaging permits the qualitative imaging of spatial and temporal variations of saturation in the matrix. More quantitative evaluations of saturation are performed by a similar procedure described below. Most flow and imbibition phenomena and processes can be observed through difference imaging.

Table 3-1 Experimental Parameters

\begin{tabular}{|l||c|c|c|c|}
\hline Sample/Run & Number of Heaters & $\begin{array}{c}\text { Bottom } \\
\text { Temperature, C }\end{array}$ & $\begin{array}{c}\text { Top Temperature, } \\
\text { C }\end{array}$ & $\begin{array}{c}\text { Water Column } \\
\text { Height, } \mathbf{m}\end{array}$ \\
\hline \hline FR5 & 3 (bottom heat only) & 111 & 28 & 0.02 \\
\hline FR6 & 7 (four side heaters) & 148 & 80 & 0.26 \\
\hline FR6b & 7 (four side heaters) & 148 & 80 & 0.46 \\
\hline
\end{tabular}

\subsection{Calculation of Saturation}

The first step in the quantitative calculation of saturation is the normalization of the radiographs. Normalization corrects for small variations in equipment performance such as power output, x-ray energy, and detector efficiency, and is accomplished through the use of wedge-shaped aluminum standards (both stepped and continuous). After normalization, $x$-ray attenuation through the standards is the same for all radiographs.

The equation that describes the absorption of $\mathrm{x}$-rays in a material, assuming a monochromatic source, is:

$$
\mathrm{dI} / \mathrm{I}=-\mu \rho \mathrm{d} x,
$$


where I is the intensity, $\mu$ is the mass absorption coefficient, $\rho$ is the density, and $\mathrm{x}$ is the thickness of the material through which the $\mathrm{x}$-rays pass. The integrated form of (3-1) is

$$
\mathrm{I}=\mathrm{I}_{\mathrm{o}} \exp [-\mu \rho \mathrm{x}] \text {, }
$$

where $I_{o}$ is the intensity of the incident beam, and I the intensity of the transmitted beam. For our work, we have the initial image (dry image) and all subsequent (more saturated) images. For the dry case,

$$
I_{d}=I_{o} \exp \left[-\left(\mu_{r} \rho_{r} x_{r}+2 \mu_{c} \rho_{c} x_{c}\right)\right] \text {, }
$$

where the subscripts $\mathrm{c}$ and $\mathrm{r}$ represent the chamber and rock, respectively. For later, partially saturated images, we have

$$
I_{S W}=I_{o} \exp \left[-\left(\mu_{r} \rho_{r} x_{r}+2 \mu_{c} \rho_{c} x_{c}+\mu_{1} \rho_{1} x_{1}\right)\right],
$$

where the subscript 1 represents the liquid that has imbibed into the pore space. We assume the pore space filled with air is negligible with respect to $x$-ray attenuation. Dividing (3-4) by (3-3) and solving for saturation yields

$$
S_{w}=\frac{\ln \left(\frac{I_{x S w}}{I_{x d}}\right)}{-\left(\rho_{l} \mu_{l} x \phi\right)} .
$$

This formulation differs from that of Tidwell and Glass (1994) in that there is no requirement to perform radiography of both the dry and the saturated medium; however, it is necessary to know the porosity of the sample and assume that when averaged over the thickness of the sample the porosity is uniform. The calculation of saturation will fail at the fracture (edge-on to x-rays, porosity not known), in anomalously high or low porosity regions, and in regions where KI crystals are deposited as a result of prolonged boiling.

Cores of tuff were prepared for the specific purpose of evaluating the above method. The cores were machined into right cylinders approximately $1.9 \mathrm{~cm}$ diameter and $2.3 \mathrm{~cm}$ length. Five cores of approximately the same porosity $(10.5 \pm$ $0.2 \%$ ) were selected from a larger population. Radiographs were taken of the nominally dry cores $\left(<1.5 \% \mathrm{~S}_{\mathrm{w}}\right)$, with the cylinder axis parallel to the $\mathrm{x}$-rays for a thickness similar to that of the tuff thickness in the flow experiments. Sample saturations were measured gravimetrically immediately prior and subsequent to radiography of cores pre-saturated to known water contents (approximately $0.5 \%$, $22 \%, 49 \%, 74 \%$, and $81 \%$ ). During the radiography there was some water loss or gain, depending on whether or not samples were relatively dry or wet. Figure 3-6 (page 3A-2) shows the calculated saturation of each core as a function of normalized $x$-ray attenuation coefficient. The actual saturations are also shown. This plot demonstrates (1) that the saturation/attenuation coefficient relationship is linear, and (2) that the calculation of $S_{w}$ using equation 5 above is fairly accurate. For the samples greater than $40 \% S_{w}$, the calculated $S w$ is between the two gravimetrically determined saturations. Therefore, the error in 
calculated $S_{w}$ is smaller than the range of saturations measured before and after the radiography. For the two lower saturated samples, the calculated saturations are higher than the gravimetrically determined saturations. At the lowest saturation the error is $\sim 10 \% \mathrm{~S}_{\mathrm{w}}$.

\subsubsection{Results and Discussion}

\subsection{Results of Previous Experiments}

A series of experiments similar to those described above was performed earlier on several samples under a variety of conditions (Roberts and Lin, 1996c). Sample sizes and initial conditions may have been different, as well as the sample holder design. The general results of those experiments are described here briefly. These experiments included: (1) Fracture flow and imbibition with nominal normal stress on an unshimmed fracture $\left(23^{\circ} \mathrm{C}\right.$, sample initially dry, water ponded on top); (2) Fracture flow and imbibition with shims of $25 \mu \mathrm{m}$ thickness placed in the fracture $\left(23^{\circ} \mathrm{C}\right.$, sample dried after [1], water ponded on top); (3) Dehydration of the sample after (2) under a thermal gradient created by imposing temperatures of $\sim 95^{\circ} \mathrm{C}$ at the bottom and $\sim 33^{\circ} \mathrm{C}$ at the top.

Imbibition occurred chiefly through the matrix for the unshimmed fracture experiment, and primarily horizontally from the fracture to the matrix during the shimmed fracture experiment. A roughly V-shaped wetting front was observed for the unshimmed case, and after more than 2017 hours of ponding, water still had not flowed the length of the fracture. During the shimmed fracture experiment, water flowed the fracture length after only $\sim 0.15$ hours. Different (lateral) imbibition rates were observed in different regions of the sample, demonstrating the heterogeneous properties of the rock. Enhanced imbibition appeared to be controlled by the presence of lithic fragments that contain small microfractures. A significant difference in the two series of experiments is that water imbibed laterally into the matrix (from the fracture) at a much higher rate when the fracture was shimmed open. For the shimmed experiment, after 1000 hours a large portion of the sample was highly saturated.

The dehydration experiment (3) began after no more imbibition into the matrix was observed (shimmed experiment, $>1200$ hours of imbibition). Dryout along the fracture was observed and was most pronounced between 4.5 and 23 hours after heating was initiated. At longer times dryout along the fracture was not apparent, and at times greater than $\sim 215$ hours the fracture was highly attenuating. Possible explanations include: (1) the fracture increased in saturation at times greater than 215 hours, or (2) evaporation of water continuously along the fracture resulted in the crystallization of salt (KI) that attenuates the x-rays. Another feature was the development of a horizontal band of high attenuation approximately $1.5-2 \mathrm{~cm}$ from the bottom of the sample. This band appeared initially at about 0.5 hours after heating, and became more pronounced with time. At about 25 hours after heating, two such bands were observed, again near the bottom of the sample. 


\subsection{Fracture Flow Under a Thermal Gradient}

Results for experiment FR5 are shown in Figure 3-7 (page 3A-3). These images are difference radiographs, and for the images shown here, darker shades indicate higher attenuation, and hence, indicate the presence of water. Figure 37a shows the progress of the wetting front in the matrix and the fracture after 1.7 hours since water was ponded on the top surface. The fracture is near the center of the image. The flow reached $\sim 13 \mathrm{~cm}$ down the fracture relatively quickly, and then stopped. The most likely reason for the stopped flow is the presence of a relatively high-porosity clast that is intersected by the fracture. As time progressed, this more porous region became more saturated until flow proceeded around or through the region. During this time there was significant lateral imbibition into the matrix from the fracture. The extent of this can be seen in Figure $3-7 \mathrm{~b}$, taken 73.5 hours after ponding. Figure $3-7 \mathrm{~b}$ still shows the highly attenuating spot where flow stopped and another highly attenuating region near the bottom of the sample. After flow continued past the highly porous region, the shape of the wetting front was less sharp and more rounded. This wetting front stopped $\sim 2.6 \mathrm{~cm}$ from the bottom of the sample. A very narrow neck of high attenuation extended downward from this section to the lowermost highly attenuating region at the bottom of the sample. In this sample the lowermost 1 to $2 \mathrm{~cm}$ are above boiling. Our interpretation is that the highly attenuating spot at the very bottom of the fracture is a region where KI crystals may have deposited because of continued boiling. For this experiment, liquid water never penetrated the entire fracture length. After nine days the heaters were turned off and water still did not flow through the fracture. Post-experiment examination of the fracture surface revealed small crystals in this region.

Figure 3-8 (page 3A-4) shows two difference images for experiment FR6 and FR6b. These two experiments were similar to FR5 except that FR6 was hotter, had less of a thermal gradient, and the column of water used to pond the sample was higher (refer to Table 3-1 for details). Figure 3-8a is an image of FR6 7.2 hours after ponding. Features indicated are rapid flow down the fracture that stops, development of a highly attenuating region, and the development of a narrow neck that is highly attenuating. Liquid water penetrated about $3 \mathrm{~cm}$ into the boiling region. The highly attenuating neck extending below the boiling region is unexplained. What is different about this experiment compared to FR5 is that flow continued down the length of the fracture after the heaters were turned off and the sample cooled. This is explained by either the increased head, or the lack of complete sealing of the fracture by crystal deposition.

Figure $3-8 b$ shows an image of FR6b about 0.67 hours after flow was initiated. This sample had almost twice the head of FR6. The thermal gradient was the same, but in this case water flowed the entire length of the fracture within minutes and continued to flow through the boiling region. Thus we conclude that hydraulic head directly affects the distance liquid water can penetrate into the boiling region. 
One interesting observation made for FR6 was the effect of fracture flow on the temperatures measured near the fracture. The ponded water was initially room temperature $\left(\sim 25^{\circ} \mathrm{C}\right)$. Thermocouples $(\mathrm{TC})$ placed along the fracture $(\sim 3.7 \mathrm{~cm}$ away from fracture) measured temperature decreases as flow progressed through the fracture. Typically, temperature decreased rapidly (within $~ 150$ seconds), reached a minimum, and rebounded to a subsequent value. If we disregard the top two thermocouples because of their closeness to the ponded water, we find that the largest temperature decrease was observed by TC9, which dropped by $\sim 6$ ${ }^{\circ} \mathrm{C}$. The change in temperature decreased down the fracture until TC4 (the lowermost TC in the rock), which dropped by $\sim 1^{\circ} \mathrm{C}$. In general, the thermocouples reached a steady temperature within $1-2^{\circ} \mathrm{C}$ of the initial value after approximately 4500 seconds of flow. Theoretical work investigating infiltration of liquid fingers into hot rock (Phillips, 1996) predicts that the time to approach steady state temperatures is $\tau=1^{2} / \kappa$, where 1 is the penetration distance and $\kappa$ is the thermal diffusivity. For the current experiment this predicts a value of $\kappa$ of $\sim 1.5 \times 10^{-7} \mathrm{~m}^{2} \mathrm{~s}^{-1}$. Future work will include more carefully measured thermal histories in an attempt to determine how matrix saturation affects thermal properties.

\subsubsection{Conclusions}

We are able to visualize phenomena related to fracture flow and matrix imbibition during fracture flow experiments at a variety of conditions and to quantitatively calculate saturation within the matrix. Results indicate that under some conditions it is difficult for water to penetrate the region where temperatures are above boiling, but that water can penetrate this region upon cooling. Additional experiments where head was increased indicate penetration of the boiling region. Fracture flow stopped or slowed significantly when a region of higher porosity than the surrounding matrix was encountered. Heating a nearly saturated rock/fracture sample drove water out of the fracture on a very short time scale. These results provide important input needed for understanding coupled thermal-hydrological-chemical processes and models of repository-design-based performance. Directions for future work include measurement of temperature closer to the fracture and experiments with variable fracture aperture.

\subsubsection{Acknowledgments}

D. Rikard, D. Ruddle, and D. Fletcher provided technical support. We thank Dan Schneberk for valuable discussions and ideas. This work was supported by the Yucca Mountain Site Characterization Project. Work performed under the auspices of the U.S. D.O.E by Lawrence Livermore National Laboratory under contract W-7405-ENG-48. 


\subsubsection{Fracture Coatings}

A key determinant of fracture flow and transport processes in the near-field environment, and throughout the unsaturated zone at Yucca Mountain, is the nature of interaction with the adjacent matrix porosity. Water and solute that are transferred to the rock matrix become immobilized. Fracture-matrix interaction may be hindered if fracture walls are coated or if the tuff matrix is altered at the fracture wall. Fractures at Yucca Mountain are generally coated or filled to some extent at all depths, down to and below the water table. The mineralogy, thickness, and coverage of fracture coatings are highly variable. Typical coatings in the Topopah Spring welded tuff include manganese oxides, iron oxides and oxyhydroxides, silica polymorphs, zeolites, smectites, and carbonates (Gallegos et al., 1992).

Gallegos et al. (1992) investigated fracture-matrix coupling using four samples of natural fractures acquired from tuff formations in southern Nevada. Capillary imbibition was measured through the coatings and through uncoated surfaces. Small $(1 \mathrm{~cm})$ cubes were sawed with one face being the undisturbed fracture surface. Capillary uptake through the fracture surface was compared to that through the opposite face of each cube. Mineral coatings generally inhibited imbibition and virtually eliminated imbibition in one sample. The potential impact of fracture coatings on fracture flow in porous media was explored using a 1-D fracture-matrix interaction model, which assumed piston flow in a parallel plate fracture, with initially dry conditions in the matrix. Using measured fracture-matrix coupling parameters, the authors showed that low permeability coatings can have a significant impact on penetration depth and travel time of water flowing down fractures.

Chekuri et al. (1994) investigated fracture coatings on outcrop samples of the Tiva Canyon welded tuff at Yucca Mountain. Sorptivity (Philip, 1957) was used as the conceptual basis for measuring matrix imbibition and is related to permeability. Fracture coatings for this study consisted of desert varnish with little or no carbonate in evidence. Sorptivity was measured on fracture surfaces using a modified sorptivity cell. The sample was then broken and sorptivity measured on the exposed tuff matrix. For many of the samples tested, sorptivity of coated surfaces was greater than for uncoated surfaces. Properties of desert varnish coatings and the effects of weathering were not compared with fracture coatings that occur in the subsurface. Statistical interpretation was not attempted with the small number of samples tested.

The temperature dependence of fracture-matrix interaction depends on that of capillary imbibition, which was discussed in a previous section of this report. In addition, hydrothermal alteration of fracture surfaces in the near-field environment is likely to change the nature of fracture-matrix coupling. 


\subsection{Flow Channeling}

Geller et al. (1996) described a series of flow visualization studies of water percolation through transparent fracture replicas. Unsaturated flow was produced in the replicas under the impetus of gravity. The experiments were isothermal and conducted at ambient temperature, but they effectively demonstrated the complex phenomenology of flow in partially saturated fractures.

The authors described physical model flow-visualization studies using a $21 \times 33$ $\mathrm{cm}$ epoxy cast of a natural fracture in granite from the Stripa mine in Sweden plus parallel plates of acrylic plastic or glass. The epoxy casts allowed visual indication of flow, and dyed water was used to enhance visibility. Epoxy differs from rock in that imbibition is nil, and there may be mismatch between replica halves that affects the distributions of asperity contacts and fracture aperture. However, similar complications may occur with rock-fracture specimens.

Differences in surface texture and surface chemistry between rock and epoxy affect the wetting properties. Impermeable surfaces generally are less wetted. The authors investigated contact-angle behavior and observed, with air as the second fluid, water-drop behavior on surfaces of epoxy, glass, and rock. The contact angle for water on epoxy was found to be closer to the contact angle of water on granite than it was to the contact angle of water on glass.

These experiments were intended to extend the understanding, achieved by previous investigators (e.g., Nicholl et al. [1994]), of unsaturated flow at ponded inlet conditions. Water was introduced, using a capillary siphon, at the upper boundary at negative potential. An additional series was performed using a patented endcap to control flow volume and water potential. The gravitational potential gradient was varied by changing the inclination angle of the replica, which ranged from subhorizontal to subvertical. Miscible displacement experiments were conducted by switching to dyed water after establishing the flow field with undyed water.

Regions of stagnant water formed in the fracture, then flow occurred in strips that would flow intermittently, "snap off," and reform (Figure 3-9 and Figure 310). The rate at which snap-off occurred increased when the replica inclination was closer to vertical. The flowing strips were narrower, and "snap-off" more frequent, for strong wetting behavior (e.g., water on glass) than for weak wetting behavior (e.g., water on acrylic plastic; see Figure 3-10). Existence of stagnant regions was indicated by the slow rate of miscible displacement.

Key findings of the study included 1) the localized, nonuniform flow paths produced and 2) the unsteady or intermittent nature of flow as saturated regions drained through connecting "threads" that snapped off and reformed (Geller et al., 1996). The authors pointed out that intermittent flow behavior must decrease the effective fracture area through which fracture-matrix interaction can occur. Some other general observations included the following: 
- Regions of penetration by initial flow can be bypassed by subsequent flow throughout the experiment.

- "Snap-off" behavior tended to occur at more vertical inclination angles.

- Flow patterns were sensitive to conditioning of the fracture replica surface (effect of the gas/water/solid contact angle).

Predictive models of near-field thermohydrologic response are based on continuum approximations to flow behavior in systems of fractures. The results reported by Geller et al. (1996) showed that such processes are actually nonuniform, which was widely recognized, and also unsteady, which is a new perspective. Thus the predictions of continuum models apply to both spatially and temporally averaged behavior.

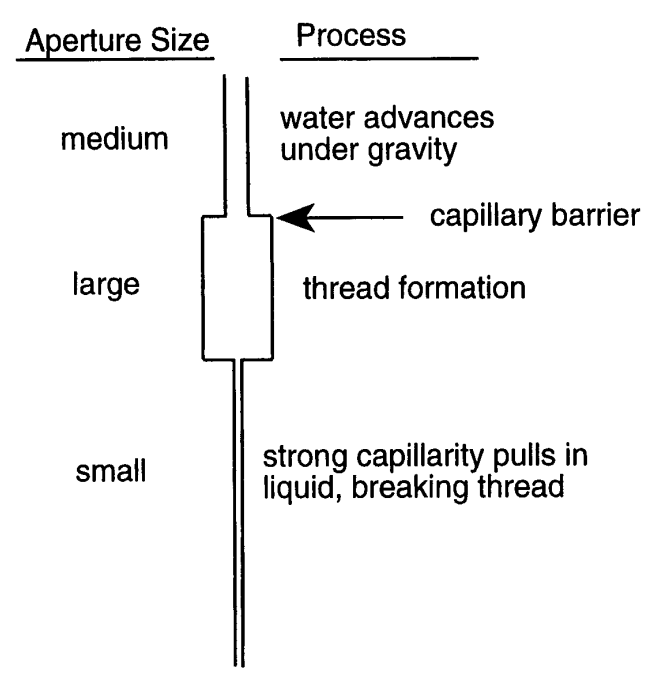

(a) Aperture sequence hypothesized as giving rise to flow intermittency.
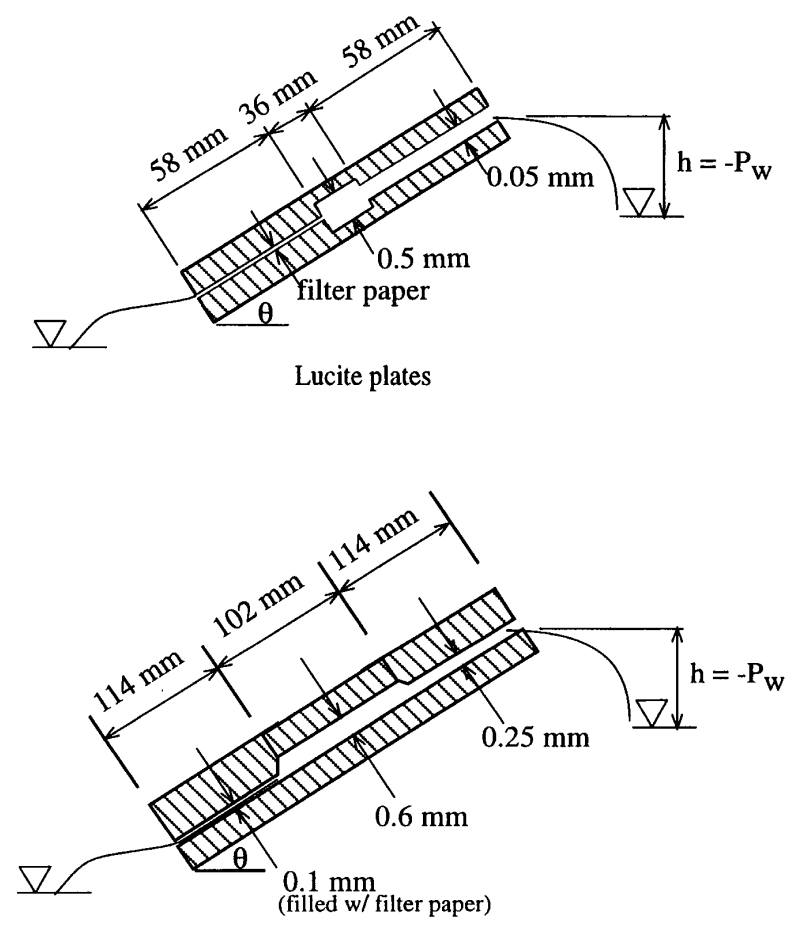

Glass plates

(b) Cross sections of lucite and glass plate cells used in Series 3 experiments

Figure 3-9 Conceptual fracture aperture model developed to explain fingering and "snap-off" (after Geller et al. [1996]) 

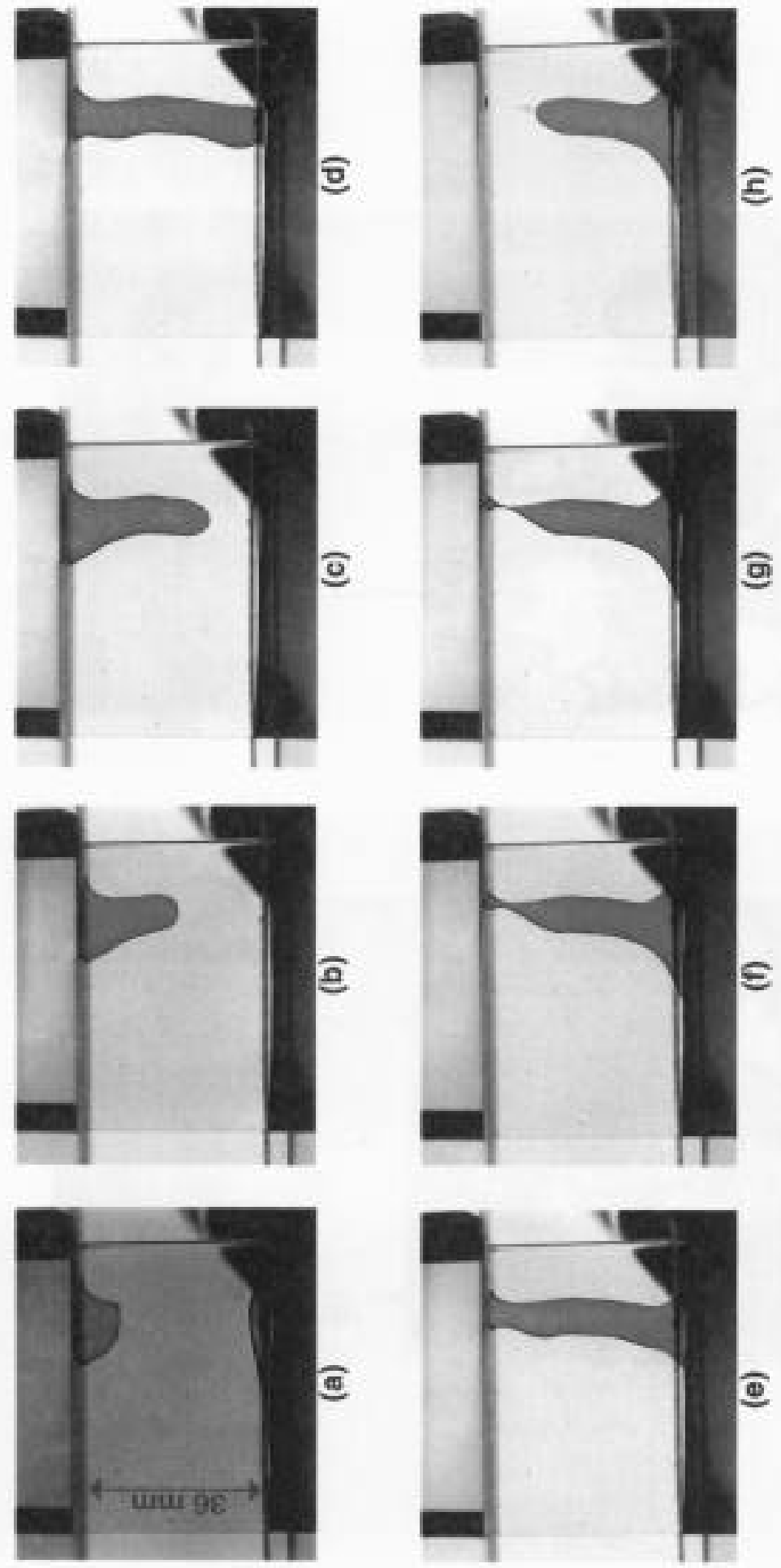

Figure 3-10 Physical model of water flow in an unsaturated fracture consisting of parallel plates of acrylic plastic. Fracture aperture varies in zones, and the middle zone has the largest aperture (from Geller et al. [1996]). 


\title{
3.5 Creation of Heat Pipes and Refluxing Zones
}

The following section (3.5.1) is taken verbatim (with permission) from the published report of Kneafsey and Pruess (1997).

\subsubsection{Preferential Flow Paths and Heat Pipes: Results from Laboratory Experiments on Heat-Driven Flow in Natural and Artificial Rock Fractures}

\author{
Timothy J. Kneafsey \\ Karsten Pruess \\ Earth Sciences Division \\ Lawrence Berkeley National Laboratory
}

Note: A video presentation of selected results from the investigation described in Section 3.5.1 is provided in digital format.

\subsubsection{Abstract}

Water flow in fractures under the conditions of partial saturation and thermal drive may lead to fast flow along preferential localized pathways and heat pipe conditions. Water flowing in fast pathways may ultimately contact waste packages at Yucca Mountain and transport radionuclides to the accessible environment. Sixteen experiments were conducted to visualize liquid flow in glass fracture models, a transparent epoxy fracture replica, and a rock/replica fracture assembly. Spatially resolved thermal monitoring was performed in seven of these experiments to evaluate heat-pipe formation. Depending on the fracture apertures and flow conditions, various flow regimes were observed including continuous rivulet flow for high flow rates, intermittent rivulet flow and drop flow for intermediate flow rates, and film flow for low flow rates and wide apertures. These flow regimes were present in both fracture models and in the replica of a natural fracture. Heat-pipe conditions indicated by low thermal gradients were observed in five experiments. Conditions conducive to heat-pipe formation include an evaporation zone, condensation zone, adequate space for vapor and liquid to travel, and appropriate fluid driving forces. In one of the two experiments where heat pipe conditions were not observed, adequate space for liquid-vapor counterflow was not provided. Heat pipe conditions were not established in the other, because liquid flow was inadequate to compensate for imbibition and the quantity of heat contained within the rock.

\subsubsection{Introduction}

Heat released from high-level nuclear waste packages in a partially saturated environment can have major impacts on moisture distribution and migration. The tuff formations in the unsaturated zone at Yucca Mountain contain from 40 to $80 \%$ or more liquid water in the pore space, which will be vaporized as formation temperatures approach and exceed the boiling point at prevailing pressures. This will cause pressurization of the gas phase, which will drive vapor 
away from the heat source. In a fractured medium, the vapor is expected to flow primarily in the fractures. Condensation will take place as the vapor invades cooler rock, which will generate mobile water in the fractures. The water will flow under the combined action of gravity and capillary forces. It may, in part, return to the vicinity of the waste packages where it would again be subject to vaporization (Buscheck and Nitao, 1993). Mathematical modeling studies have indicated that vaporization may not be complete. Water flowing down (sub-) vertical fractures may partially escape vaporization, and may migrate considerable distances through fractured rock that is at above-boiling temperatures (Pruess, 1997). This raises the obvious concern that flowing condensate may contact waste packages, and provide a pathway for the transport of water-soluble radionuclides.

The amount of water that could be generated by vaporization-condensation cycles is potentially very large. From the data given by Pruess and Tsang (1994) one can deduce that a single multipurpose canister can generate condensate at an average rate of several cubic meters per year over a 10,000-year period. For a nominal thermal loading of $57 \mathrm{~kW} /$ acre, this translates into an average equivalent percolation flux from condensate of $23.1 \mathrm{~mm} / \mathrm{yr}$ over 1,000 years, and $5.2 \mathrm{~mm} /$ yr over 10,000 years. These numbers are comparable to or larger than current estimates of net infiltration at Yucca Mountain (Flint et al., 1996). The condensate would be generated in the immediate vicinity (meters) of the waste packages, so that its impact on waste package and repository performance is likely to be larger than the impact of a similar amount of water introduced at the land surface.

These considerations suggest that thermally driven flow processes induced by repository heat may well be as important or even more important for repository performance than natural infiltration (Buscheck and Nitao, 1993; Pruess and Tsang, 1994). A combined program of field, laboratory, and theoretical studies is needed to gain an understanding of these processes, so that they may be properly taken into account for waste package and repository design, and for repository performance evaluation. Key issues include the potential development of fast preferential water flow paths, migration of transient water pulses through heated regions, and the development of heat pipe conditions. There is a long track record of mathematical modeling studies devoted to thermally driven processes in the Yucca Mountain project, see for example the references given in the review article by Pruess and Tsang (1994). In situ heater tests are underway at the ESF facility (CRWMS M\&O, 1997).

The present report summarizes first results from a laboratory experimental program, started in December, 1996, on vaporizing water flow in hot fractures. We present and discuss results of a limited number of laboratory experiments to visualize and study thermally driven liquid flow phenomena, including preferential liquid flow paths in fractures and the development of heat pipes. These mechanisms could give rise to fast transport of radionuclides. Two types of experiments have been performed. The first type investigates the thermally 
driven movement of liquid in a fractured, partially saturated medium at elevated temperatures. The second type of experiment examines the likelihood that heat pipe conditions can develop in fractures.

\subsubsection{Setup for Flow Visualization Experiments}

Sixteen experiments were performed in fracture models and fracture replicas. Fracture models were composed of various assemblies of sandblasted obscure (non-flat) and flat glass plates. Transparent epoxy fracture replicas were cast from molds taken from natural fracture faces. In the experiments, regions of fracture models and replicas were subjected to temperatures exceeding the boiling point of the liquid.

Fracture models were prepared using ordinary $1 / 4$ inch thick flat plate glass and 3/16-inch-thick P516 obscure glass. The obscure glass has a random pattern of rounded projections and depressions, with an estimated amplitude on the order of 100 microns, and a projection-to-projection spacing of about $2 \mathrm{~mm}$.

Sandblasting was used to roughen many of the glass plates resulting in small pits covering the entire surface. Two sizes of aluminum oxide grit (80 and 240) were used on different pieces of glass to impart different roughnesses. The 80 grit left pits estimated to be on the order of 10 microns deep. The 240 grit left smaller pits resulting in a smoother surface. Large sheets of flat glass may vary from being truly flat by up to 150 microns; however, the glass plates used in these experiments appeared flat. Fracture models were assembled by clamping together clean plates of glass sized $21.6 \times 33 \mathrm{~cm}$ with or without shims, and applying epoxy to the bottom, side, and top edges, leaving three approximately evenly spaced 1.5 $\mathrm{cm}$ openings on the top (Figure 3-11 on page 3A-5). Transparent fracture replicas are epoxy casts (Eccobond 27, W.R. Grace Co., Canton, MA) made from a silicone mold (Silpak R2230, Silpak Inc., Pomona CA) of the fracture surfaces. Both the silicone mold and the epoxy cast are cured at room temperature. Details of the replica-making procedure, originally developed by Gentier (1986), are described in Su (1995) and Persoff and Pruess (1995).

Pentane was used instead of water as the working fluid because the lower boiling point $\left(36.1^{\circ} \mathrm{C}\right.$ at one atmosphere pressure) simplifies the experimental setup. This also allows for a more accurate portrayal of expected boundary conditions because the pentane boiling point is closer to the ambient laboratory temperature thus producing lower temperature gradients more akin to what would be expected in heating geologic media. The combined use of pentane and fracture models and replicas allows for direct visualization of liquid behavior in the void space and a visual investigation of preferential flow path development without the addition of dyes. Some properties of pentane and water relevant to flow and boiling which will be important in scaling efforts to be conducted in FY 98 are presented in Figure 3-12 (page 3A-6) (surface tensions and vapor pressures [Lide, 1990]; enthalpy of vaporization [Wark, 1977; and Vargaftik 1975]; kinematic viscosity, calculated from Lide [1990]); steam kinematic viscosity calculated from Welty et al. [1984] and Meyer et al. [1993]; pentane vapor kinematic viscosity 
calculated from Vargaftik [1975]). The surface tension of water is greater than that of pentane, thus capillary forces will be stronger in similar systems containing water. Water has a much higher enthalpy of vaporization, thus water fingers and films would likely penetrate much further into a boiling region than pentane under similar conditions. The kinematic viscosities of liquid water and liquid pentane are similar near boiling temperatures, as are vapor pressures. The kinematic viscosity of steam is an order of magnitude higher than that of pentane vapor, which will result in water vapor being more difficult to force through fractures than pentane under similar conditions.

A summary of the experiments performed is presented in Table 3-2. In Table 3-2, the experiment number is followed by the designations that describe the two fracture model or replica faces. The designations include SOG for sandblasted obscure glass, SFG for sandblasted flat glass, and FG for flat glass. Thus, SOG/FG designates a fracture model with one face sandblasted obscure glass, and the other face flat glass. Some fracture models were used in several experiments.

Table 3-2 Summary of experiments and major observations

\begin{tabular}{|c|c|c|}
\hline Experiment & Conditions/Estimated Aperture & Major Observations \\
\hline $1 \mathrm{SOG} / \mathrm{FG}^{*}$ & $\begin{array}{l}\text { Aperture varies from near zero to } \\
\text { an estimated few hundred } \\
\text { microns with random pattern of } \\
\text { narrow/wide apertures spaced } \\
\text { about } 1 \mathrm{~mm} \text { apart. Sandblasted } \\
\text { with } 80 \text { grit aluminum oxide for } \\
\text { coarse surface roughness. } \\
\text { Partially submerged fracture } \\
\text { model. Temperature increasing, } \\
\text { then decreasing, then increasing. }\end{array}$ & $\begin{array}{l}\text { Film flow penetrating warmed region. } \\
\text { Finger flow penetrating warmed region. } \\
\text { Film and finger lengths decreased with } \\
\text { increasing bath temperature. } \\
\text { Rapid evaporation events (REEs**) } \\
\text { observed. }\end{array}$ \\
\hline 2 SOG/FG & $\begin{array}{l}\text { Partially submerged fracture } \\
\text { model. Temperature increasing. } \\
\text { Pentane entirely contained within } \\
\text { warmed region at startup. } \\
\text { Sandblasted with } 80 \text { grit aluminum } \\
\text { oxide for coarse surface } \\
\text { roughness. }\end{array}$ & $\begin{array}{l}\text { Film flow penetrating warmed region. } \\
\text { Finger flow penetrating warmed region. Film } \\
\text { and finger lengths decreased with increasing } \\
\text { bath temperature. } \\
\text { Large REE during dryout. }\end{array}$ \\
\hline 3 SFG/FG & $\begin{array}{l}\text { Aperture varies from near zero to } \\
\text { an estimated hundred microns } \\
\text { with pattern of narrow/wide } \\
\text { apertures due to sandblasting } \\
\text { spaced about } 2 \mathrm{~cm} \text { apart. } \\
\text { Sandblasted with } 80 \text { grit aluminum } \\
\text { oxide for coarse surface } \\
\text { roughness. Partially submerged } \\
\text { fracture model. Temperature } \\
\text { increasing, then decreasing. }\end{array}$ & $\begin{array}{l}\text { Film flow penetrating warmed region. } \\
\text { Finger flow penetrating warmed region. Film } \\
\text { and finger lengths decreased with increasing } \\
\text { bath temperature. }\end{array}$ \\
\hline
\end{tabular}




\begin{tabular}{|c|c|c|}
\hline Experiment & Conditions/Estimated Aperture & Major Observations \\
\hline 4 SOG/SOG & $\begin{array}{l}\text { More variable than the SOG/FG } \\
\text { model with an aperture varying } \\
\text { from near zero to an estimated } \\
\text { several hundred microns with } \\
\text { random pattern of narrow/wide } \\
\text { apertures spaced about } 1 \mathrm{~mm} \\
\text { apart. Sandblasted with } 80 \text { grit } \\
\text { aluminum oxide for coarse surface } \\
\text { roughness. Partially submerged } \\
\text { fracture model. Temperature } \\
\text { increasing, then decreasing. }\end{array}$ & $\begin{array}{l}\text { Film flow penetrating warmed region. } \\
\text { Finger flow penetrating warmed region. Film } \\
\text { and finger lengths decreased with increasing } \\
\text { bath temperature. } \\
\text { REEs observed. }\end{array}$ \\
\hline 5 SOG/SOG & $\begin{array}{l}\text { Partially submerged fracture } \\
\text { model. Temperature increasing, } \\
\text { then decreasing. Two infiltration } \\
\text { events. Sandblasted with } 80 \text { grit } \\
\text { aluminum oxide for coarse surface } \\
\text { roughness. }\end{array}$ & $\begin{array}{l}\text { Film flow penetrating warmed region. } \\
\text { Finger flow penetrating warmed region. Film } \\
\text { and finger lengths decreased with increasing } \\
\text { bath temperature. } \\
\text { REEs observed. }\end{array}$ \\
\hline 6 SFG/SFG & $\begin{array}{l}\text { More variable than the SFG/FG } \\
\text { model with aperture varying from } \\
\text { near zero to an estimated few } \\
\text { hundred microns with a vertical } \\
\text { pattern of narrow/wide apertures } \\
\text { spaced about } 2 \mathrm{~cm} \text { apart. } \\
\text { Sandblasted with } 80 \text { grit aluminum } \\
\text { oxide for coarse surface } \\
\text { roughness. Partially submerged } \\
\text { fracture model. Temperature } \\
\text { increasing, then decreasing. }\end{array}$ & $\begin{array}{l}\text { Finger flow penetrating warmed region. } \\
\text { Finger lengths decreased with increasing } \\
\text { bath temperature. } \\
\text { Frequent, violent REEs observed affecting } \\
\text { location of saturated islands and film } \\
\text { thicknesses in the condensation halo. }\end{array}$ \\
\hline $\begin{array}{l}7 \text { SOG/SOG } \\
\text { Circular Heated } \\
\text { Regions }\end{array}$ & $\begin{array}{l}\text { Circular warmed disks attached to } \\
\text { model. Sandblasted with } 80 \text { grit } \\
\text { aluminum oxide for coarse surface } \\
\text { roughness. }\end{array}$ & $\begin{array}{l}\text { Stable, dry region in warmed region beneath } \\
\text { the warmed disks except when large } \\
\text { pentane seepage occurred, causing fingers } \\
\text { to flow into warmed region. }\end{array}$ \\
\hline $\begin{array}{l}8 \text { SOG/FG } \\
\text { Finger Location } \\
\text { Repeatability }\end{array}$ & $\begin{array}{l}\text { Fracture sequentially submerged } \\
\text { to different depths in a constant } \\
\text { temperature bath warmer than the } \\
\text { boiling point, and sequentially } \\
\text { raised to the same depths. } \\
\text { Sandblasted with } 80 \text { grit aluminum } \\
\text { oxide for coarse surface } \\
\text { roughness. }\end{array}$ & $\begin{array}{l}\text { Major fingers formed in approximately the } \\
\text { same location when submersion depth was } \\
\text { the same; however, the same number of } \\
\text { fingers did not always form. }\end{array}$ \\
\hline
\end{tabular}




\begin{tabular}{|c|c|c|}
\hline Experiment & Conditions/Estimated Aperture & Major Observations \\
\hline $\begin{array}{l}9 \text { SFG/SFG Wall } \\
\text { Thickness/ } \\
\text { Heat Pipe } \\
\text { Development }\end{array}$ & $\begin{array}{l}\text { Partially submerged fracture } \\
\text { model. Temperature increasing, } \\
\text { then decreasing. Two glass } \\
\text { thicknesses. Sandblasted with } 80 \\
\text { grit aluminum oxide for coarse } \\
\text { surface roughness. } \\
\text { Infrared temperature monitoring of } \\
\text { region above warmed region } \\
\text { performed. }\end{array}$ & $\begin{array}{l}\text { Frequent, violent REEs with thinner glass. } \\
\text { Fewer, less violent REEs with thicker glass. } \\
\text { Longer, wider fingers with thicker glass. } \\
\text { Finger lengths decreased with increasing } \\
\text { bath temperature. } \\
\text { Heat pipe regions of similar size and shape } \\
\text { for thin and thick glass. }\end{array}$ \\
\hline $\begin{array}{l}10 \text { SFG/SFG } \\
\text { Non-uniform } \\
\text { Heating }\end{array}$ & $\begin{array}{l}\text { Partially submerged fracture } \\
\text { model. Temperature increasing, } \\
\text { then decreasing. } 1.9 \times 2.5 \mathrm{~cm} \\
\text { Lexan strips placed across model } \\
\text { to alter heat flow. Sandblasted } \\
\text { with } 80 \text { grit aluminum oxide for } \\
\text { coarse surface roughness. }\end{array}$ & $\begin{array}{l}\text { On warming, Lexan strips hindered heat flow } \\
\text { into model in warmed region and impeded } \\
\text { heat flow out of model in non-warmed } \\
\text { region. On cooling the Lexan hindered heat } \\
\text { flow out of the model in both regions. These } \\
\text { heat flow heterogeneities altered } \\
\text { condensation halo location, finger location } \\
\text { and length. } \\
\text { Finger lengths decreased with increasing } \\
\text { bath temperature. }\end{array}$ \\
\hline
\end{tabular}




\begin{tabular}{|c|c|c|}
\hline Experiment & Conditions/Estimated Aperture & Major Observations \\
\hline $\begin{array}{l}11 \text { SOG/SOG } \\
\text { Impermeable } \\
\text { Barriers }\end{array}$ & $\begin{array}{l}\text { More variable than the SOG/FG } \\
\text { model, with an aperture varying } \\
\text { from near zero to several hundred } \\
\text { microns, with random pattern of } \\
\text { narrow/wide apertures spaced } \\
\text { about } 1 \mathrm{~mm} \text { apart. Partially } \\
\text { submerged fracture model. } \\
\text { Temperature increasing, then } \\
\text { decreasing. Impermeable epoxy } \\
\text { barriers placed to form a funnel } \\
\text { and focus flow. Sandblasted with } \\
80 \text { grit aluminum oxide for coarse } \\
\text { surface roughness. } \\
\text { Infrared temperature monitoring of } \\
\text { region above warmed region } \\
\text { performed. }\end{array}$ & $\begin{array}{l}\text { Condensation halo and fingers initially } \\
\text { formed below barrier. Later, pentane pooled } \\
\text { in the funnel center, and pentane vapors } \\
\text { traveled upward on the outside of the } \\
\text { funnel. Longer fingers were present from } \\
\text { the funnel center than other locations. } \\
\text { Number of fingers under notch was not } \\
\text { constant. Higher gas pressure present } \\
\text { below the barriers. } \\
\text { Finger lengths decreased with increasing } \\
\text { bath temperature. } \\
\text { Regions of low temperature gradient } \\
\text { indicating vapor-liquid counterflow (heat- } \\
\text { pipe behavior) were present outside of the } \\
\text { barrier region. }\end{array}$ \\
\hline $\begin{array}{l}12 \text { SFG/SFG } \\
\text { Wide Aperture }\end{array}$ & $\begin{array}{l}\text { Nominal aperture of } 0.76 \mathrm{~mm} \text { with } \\
\text { a vertical pattern of variable } \\
\text { surface roughness spaced about } \\
2 \mathrm{~cm} \text { apart. Sandblasted with } 80 \\
\text { grit aluminum oxide for coarse } \\
\text { surface roughness. Partially } \\
\text { submerged fracture model. } \\
\text { Temperature increasing, then } \\
\text { decreasing. } \\
\text { Infrared temperature monitoring of } \\
\text { region above warmed region } \\
\text { performed. }\end{array}$ & $\begin{array}{l}\text { Stable films occurred until enough pentane } \\
\text { was added such that films were present to } \\
\text { the top of the model. Pentane condensing } \\
\text { on the model top resulted in drops which } \\
\text { rapidly fell through the model. } \\
\text { Region of low temperature gradient } \\
\text { indicating vapor-liquid counterflow (heat- } \\
\text { pipe behavior) was present throughout the } \\
\text { condensation halo region. }\end{array}$ \\
\hline $\begin{array}{l}13 \text { SOG/SOG } \\
\text { Fine Surface } \\
\text { Roughness }\end{array}$ & $\begin{array}{l}\text { More variable than the SOG/FG } \\
\text { model with an aperture varying } \\
\text { from near zero to an estimated } \\
\text { several hundred microns with } \\
\text { random pattern of narrow/wide } \\
\text { apertures spaced about } 1 \mathrm{~mm} \\
\text { apart. Sandblasted with } 240 \text { grit } \\
\text { aluminum oxide for fine surface } \\
\text { roughness. Partially submerged } \\
\text { fracture model. Temperature } \\
\text { increasing, then decreasing. } \\
\text { Open side at top right. } \\
\text { Infrared temperature monitoring of } \\
\text { region above warmed region } \\
\text { performed. }\end{array}$ & $\begin{array}{l}\text { Finger flow penetrating warmed region. } \\
\text { Finger length decreasing with increasing } \\
\text { bath temperature. } \\
\text { The size of the condensation halo was } \\
\text { somewhat limited by the location of the side } \\
\text { vent. } \\
\text { Flow-formed saturated islands contained } \\
\text { numerous voids, condensation-formed } \\
\text { islands were completely filled. } \\
\text { Region of low temperature gradient } \\
\text { indicating vapor-liquid counterflow (heat pipe } \\
\text { behavior) was present in the condensation } \\
\text { halo region. }\end{array}$ \\
\hline
\end{tabular}




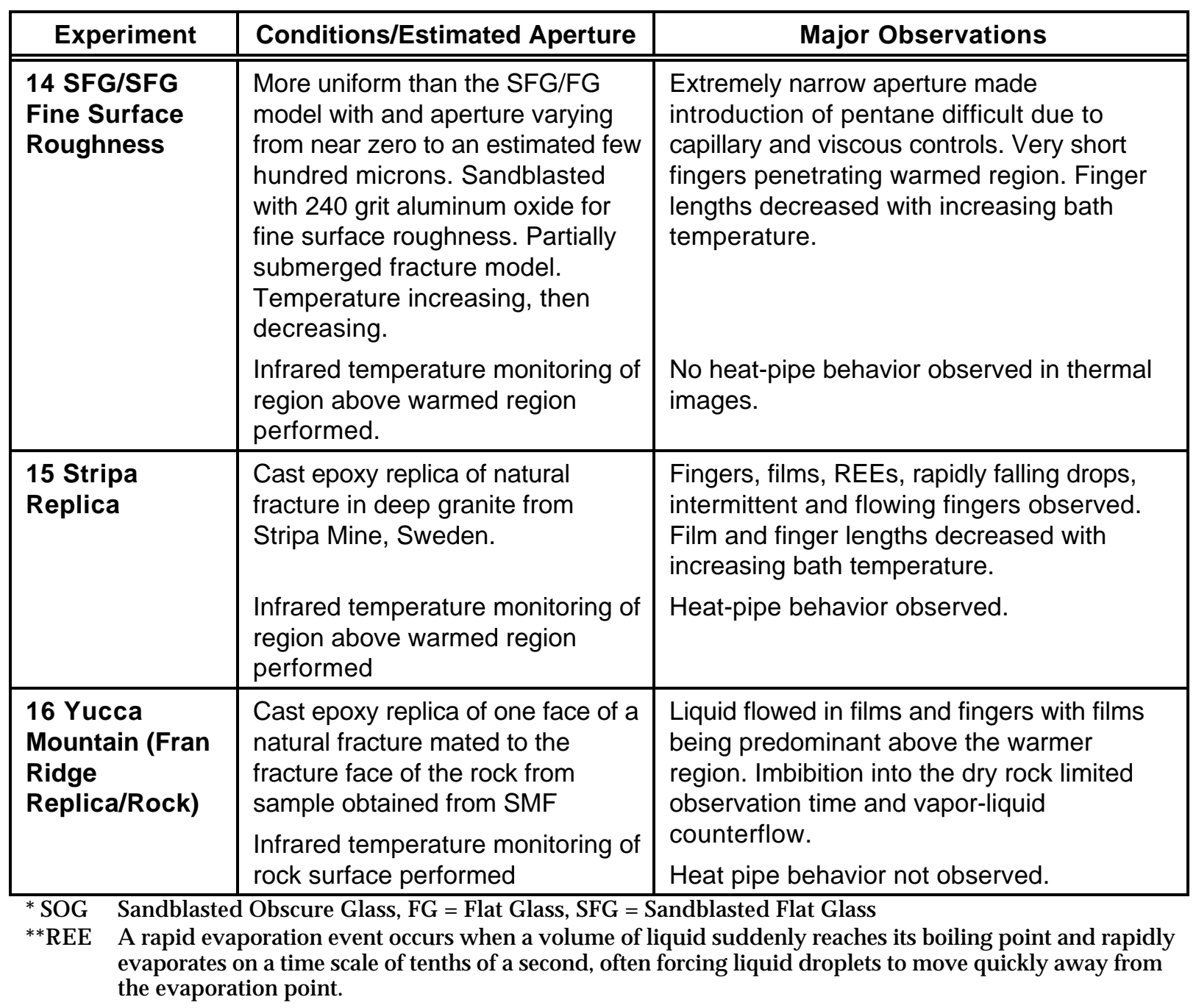

These experiments were conducted by introducing pentane into the aperture of the fracture model or replica and applying heat to a portion of the model or replica. A light source was placed behind the model to allow for direct visualization of the liquid pentane in the fracture (Figure 3-13 on page 3A-7) in Experiments 1 - 15. In Experiment 16, the light source was placed in front of the replica to illuminate the fracture. Experiments were video taped using a JVC KYF55BU camera with a JVC HZ-610MDU $6-60 \mathrm{~mm}$ motorized zoom lens with a Kenko No. 2 Close-Up filter and recorded on a Sony SVHS SVO-5800 video recorder with time coding providing temporal resolution of $1 / 30 \mathrm{~s}$. Pentane wets the air-glass and air-epoxy interface, in the same manner that water is generally assumed to wet air-mineral interfaces. Light is more easily transmitted through the fracture models and replicas where the surface is wet with the brightest regions occurring where the aperture is saturated with pentane. Two additional brightness levels are often visible in glass fracture models between the brightness level of the dry roughened glass (darkest) and the saturated aperture. These occur where films of pentane are present, and the different brightness levels may represent different pentane film thicknesses suited to multimodal surface 
roughness; hence, different liquid saturations can be visually observed. Cases were also observed where different brightness levels occurred when a film was present on only one fracture face. In epoxy replicas, brighter regions also occur where films of pentane are present, however, no brightness differences in films have been distinguished.

Because of the transmission of light, flow patterns were directly observable without the addition of dye in transparent replicas and models. Flow patterns were established in the fracture models in a time frame that did not require completely sealing the model. Observations of flow path formation were made on several spatial scales, including the model scale (tens of centimeters), the finger scale (centimeters), and the finger structure scale (fractional centimeters).

\subsubsection{Observed Flow Behavior}

In Experiments 1 through 6,10 and 11, and 13 through 15, the fracture models and replicas were partially submerged in a glass tank into which temperaturecontrolled water was constantly supplied. The temperature of the water was set near but below the pentane boiling point at the beginning of the experiment and the model allowed to equilibrate with the water. After equilibration, pentane was introduced into the fracture model or replica aperture. The pentane seeped downwards, influenced by gravity, viscosity, and capillarity. In Figure 3-14 (page $3 \mathrm{~A}-8$ ), pentane seeps primarily downward, indicating the influence of gravitational force. When the pentane reaches the warmed region, even if the bath temperature is somewhat below the boiling point, a condensation halo may form in the cooler region above the heated bath. The temperature of the bath is increased over time to above the pentane boiling point to observe the drying out of the warmed region. In many cases, dry-out proceeds with liquid pentane in the warmed region evaporating out and condensing in the condensation halo. In the condensation halo, the pentane begins to travel downwards, either in films along the fracture wall or in intermittent or continuously flowing fingers that saturate the aperture (Figure 3-15 on page 3A-9). As the temperature of the warmed region approaches the pentane boiling point, pentane gas bubbles (formed by boiling) struggle to escape the bounds of saturated regions. Often this is relatively uneventful; however, rapid evaporation events (REEs) (Figure 3-16 on page 3A-10) have been frequently observed. In Figure 3-16, the encircled finger undergoes a REE. In a REE, a volume of pentane vaporizes quickly as it suddenly reaches its boiling point, rapidly expelling droplets of remaining pentane in many directions. In one case (Experiment 2), a rather large REE occurred during dry-out, sending a visible cloud of pentane upwards at a rate of about $30 \mathrm{~cm} / \mathrm{sec}$. Rate measurements were made from images captured from the time-coded video recordings.

Experiment 7 was conducted by attaching transparent disks to the fracture model through which water from the temperature controller could flow (Figure 3-17 on page 3A-11). The circular warmed regions were heated to well above the pentane boiling point, and pentane was introduced to the top of the system. This setup 
was designed to model, in an idealized fashion, the (partial) dry-out processes that are expected in the vicinity of emplacement drifts at Yucca Mountain. As the pentane reached the warmed region of the fracture model surrounding the heated disks, a condensation halo appeared surrounding the warmed region. Upon rapid introduction of pentane, pentane fingers seeped deeply into the warmed region (Figure 3-17). Following large seepage events, liquid flow occurred primarily by film drainage that did not penetrate deeply into the warmed region. When cooled to below the pentane boiling point, pentane films flowed through the warmed region.

Experiment 8 was conducted to determine whether the location of fingers was repeatable. The fracture model containing pentane was sequentially lowered into a constant temperature bath exceeding the pentane boiling point to predetermined locations and maintaining it at these locations for some time and recording the location of the fingers. The model was then sequentially raised to the same locations, again allowing some time at each location to observe where fingers formed. Major fingers formed in the same locations when the model was set at a particular height; however, the same number of fingers did not always form. Smaller fingers formed in different locations when the model was set to the same height. The amount of pentane in the system was not constant throughout the duration of the experiment due to evaporative loss. Pentane was added at intermittent intervals to replace the lost pentane. This loss and replenishment could have contributed to the different numbers of fingers.

In Experiment 9, the fracture model was allowed to equilibrate with warmed water exceeding the pentane boiling point prior to the introduction of pentane. Figure 3-18 (page 3A-12) shows that although pentane is introduced through the middle port, capillary forces draw the pentane horizontally to the left, after which a pathway downwards is encountered. Pentane is not as readily drawn to the right either because not as great a capillary pressure gradient exists in that direction, or because the aperture is more narrow towards the right than the left and viscous forces are comparatively greater. When the pentane penetrates the warmed region, it begins to boil and a condensation halo quickly forms above the warmed region. Fingers of the condensing pentane from this halo then formed in locations that were previously dry. The experiment was repeated with $1 / 2 \mathrm{in}$. glass plates on either side of the fracture model to reduce the rate of heat transfer from the water bath to the fluid in the fracture. Fingers penetrated farther into the warmed region and were broader when the heat transfer was reduced (Figure 3-19 on page 3A-13). Thicker glass may tend to model more accurately the heat transfer through fractured rock where large rock masses exist between fractures. Temperature measurements of the portion of the fracture model above the water bath were made with an infrared camera (Inframetrics PM 200 Thermacam, SN 8954, 256 x 256 pixels) and will be discussed in the "Heat Pipe Development" section below.

Experiment 10 was conducted by placing $1.9 \times 2.5 \mathrm{~cm}$ Lexan strips at an angle across both sides of the fracture model (Figure 3-20 on page 3A-14). These strips reduced the rate of heat transfer between the thermal bath and the fracture 
model and from the fracture model to the atmosphere, and were intended to model rock thermal property heterogeneities. On heating, the region between the Lexan strips (Labeled "Region A" in Figure 3-20) was cooler than the surrounding model in the warmed region. Condensation occurred in this region, and fingers formed from the condensation. The apparent finger on the right side was not the result of this condensation, but of capillary flow from the bottom upwards. The region between the Lexan strips above the warmed region was warmer than the surrounding area, thus condensation rates were reduced. As the experiment progressed, the heating heterogeneity caused shortening of one finger which had formed in previous experiments (Figure 3-21 on page 3A-15), and lengthening of an adjacent finger. This lengthening is not visible in Figure 3-21. On cooling, the Lexan strips caused Region A to remain warmer than the surroundings, thus hindering condensation and film flow (Figure 3-22 on page 3A-16).

The fracture model used in Experiment 11 was constructed using sandblasted (80grit) obscure glass. Epoxy barriers were placed on one face of the glass at an angle of about 20 degrees from horizontal to form funnel-like structures and the plates were pressed together and cemented around the edges leaving vents on the top as in previous experiments. Funnel-like structures are of interest because they have been observed in soils (Kung, 1990a; 1990b) and are capable of focusing flow into localized preferential paths. Seepage through the model was impacted by the presence of these barriers (Figure 3-23 on page 3A-17). A condensation halo formed under the right barrier and in vertical regions outside the funnel from which fingers formed. Pentane saturated the aperture in the center of the funnel obstructing vertical gas flow, forcing gas to flow in pathways outside of the funnel structure. The longest fingers flowed from the pathway between the lower barriers (Figure 3-24 on page 3A-18). Temperature measurements made of the upper part of the fracture model are discussed in the "Heat Pipe Development" section below.

The fracture model used in Experiment 12 was composed of two sheets of sandblasted (80-grit) flat glass cemented together with three thicknesses of 0.254$\mathrm{mm}$ brass shims around the edges, providing a nominal aperture of $0.76 \mathrm{~mm}$. This models a wide vertical fracture with a few contact points. Upon introduction, pentane flowed straight downwards rapidly to the model bottom. The warmed region of the model was near the pentane boiling point, and a condensation halo appeared soon after injection. Because of the wide aperture, pentane was held in films on the fracture faces; no saturated islands formed. Following the evaporation of all of the pooled pentane in the warmed region, steady films flowing downwards into the warmed region were observed (Figure 3-25 on page 3A-19). Additional volumes of pentane were added resulting in the condensation halo extending further both vertically upwards and downwards. When enough pentane was added so that the films covered the entire nonwarmed region, drops of pentane condensed on the model top and fell downwards with speeds on the order of $50 \mathrm{~cm} / \mathrm{s}$, slowing in the dry, warmed region, but frequently reaching the model bottom. 
Experiment 13 was conducted with a model composed of two sheets of sandblasted (240-grit) obscure glass. A region 12 centimeters long on the right side, $5.5 \mathrm{~cm}$ above the warmed region, was left open. This caused a rapid loss of pentane (compared with other experiments) and tended to keep the height of the condensation halo below the vent. Longer fingers formed on the right side near the vent. This is likely due to pentane vapors being forced under a pressure gradient from their point of evaporation towards the atmospheric pressure boundary at the side vent. Condensation of this vapor would occur as the pentane moved towards the vent resulting in the longer fingers.

Experiment 14 was conducted with a model composed of two sheets of sandblasted (240-grit) flat glass. This model had the narrowest aperture of all models investigated, and thus viscous flow resistance was the highest and capillary effects strongest. After the boiling temperature of pentane was reached, very short fingers penetrated the warmed region. Saturated islands of pentane were present throughout the upper region, with flow-formed islands having a porous structure, and condensation formed islands being completely filled.

Experiment 15 was conducted using an epoxy fracture replica with dimensions $21.8 \times 30.3 \times \sim 3.7 \mathrm{~cm}$, made from both faces of a natural fracture in a granite core obtained from the Stripa mine in Sweden. This particular fracture and replicas thereof have also been used in a series of isothermal water flow experiments at ambient temperatures (Geller et al., 1996). The replica faces were mated and sealed together with epoxy like the fracture models, leaving three vents on the top (Figure 3-26 on page 3A-20). When releasing the confining pressure used in gluing the faces together, the faces came apart on the right and bottom sides. These were re-glued without applying confining pressure thus the aperture towards the right and bottom is likely to be generally larger than at the top and left. All phenomena observed in the glass fracture models were observed in this experiment, including film flow, continuous rivulet flow, intermittent rivulet flow, REEs, drops falling rapidly through the fracture, and the development of a heat pipe. Finger and film length also decreased with increasing temperature. The falling drops occurred on the right side where the aperture was greater, with condensation occurring higher in the replica, presumably at a location of contact or small aperture. A feature referred to as a microfracture intersected the plane of the warmed region at an angle. Downward flow in the location of the microfracture was altered if the flow was slow. Rapidly moving drops passed the microfracture with their course unaltered. On the left side, where the aperture was narrower, a cell of boiling pentane existed in the warmed region, fed by pentane flowing down the microfracture and by a continuously and later intermittently flowing finger from a saturated island above the cell. This boiling cell was present at bath temperatures well above the pentane boiling point. The thermal conductivity of epoxy is much less than that of glass $\left(0.2 \mathrm{Wm}^{-1} \mathrm{~K}^{-1} \mathrm{vs} .1 .4\right.$ $\mathrm{W} \mathrm{m}^{-1} \mathrm{~K}^{-1}$ ), perhaps more accurately modeling heat transfer in large fractured rock masses. 
Experiment 16 was conducted using a replica of one fracture face and the corresponding rock face from a natural fracture from a sample obtained from Fran Ridge (near Yucca Mountain). The replica was made by attempting to saturate the rock with water prior to making a mold with the RTV compound to prevent imbibition of the RTV into the matrix. Saturating with water was done instead of using a mold release compound in an attempt to provide a more accurate impression of surface roughness, and to leave the rock surface topography and chemistry as pristine as possible. Saturation was not complete, however, and some RTV imbibed into the rock, altering its wetability from initially very water wetting to water repelling. Visual inspection suggests that the replica has approximately the same roughness as the rock surface.

Prior to the introduction of pentane, the rock was heated using heating tapes set at between 65 and $100^{\circ} \mathrm{C}$. After six hours, temperature measurements indicated that only small portions of the rock face exceeded the pentane boiling temperature, so for about 20 minutes a heat gun was used in addition to the heating tape. Temperature measurements then indicated that a large area of the rock fracture face was above the pentane boiling point. The epoxy face was affixed to the warm rock and allowed to equilibrate for 8 minutes (Figure 3-27 on page 3A-21), after which the replica was removed and a thermal image of the rock surface was obtained. The epoxy face was replaced, and eight 1- to 3- milliliter volumes of pentane were introduced with two additional disassemblies, rock temperature measurements, and observations made. Due to evaporation and imbibition attributed to the large size and dryness of the rock $(\sim 130 \mathrm{~kg})$ and the amount of heat added, each addition of pentane was visible for only about one minute. This may be representative only of small flows in heated, very dry fractures such as intermittent flows very near the heat source, and is not considered to be representative of all liquid flow in heated fractures where flow rates, water content, and relative humidity may be much greater. Better matching of liquid volumes to rock size and heat content will be attempted in future experiments.

\subsubsection{Heat Pipe Development}

Of the sixteen experiments listed in Table 3-2, thermal imaging of the fracture model or replica above the warmed region was performed in seven. Thermal imaging of the portion of the model submerged in the water has not been performed. Spatially resolved near-aperture (model or replica surface) temperatures were monitored using an infrared camera. The temperatures recorded by the infrared camera are of the front glass or epoxy surface. These temperatures are indicative of the temperatures within the aperture, but somewhat lower due to convective heat loss to the atmosphere. Liquid-vapor counterflow (heat-pipe conditions) is indicated by regions of low temperature gradient. Thermal images are presented in Figures 3-28-3-34. In these figures, temperatures are represented by colors, with a scale presented underneath. The scales are unfortunately sparse due to the data acquisition method; however, low temperature gradients, shown as uniform color regions or slowly changing 
colors indicative of heat-pipe conditions, are clearly visible in the images. The temperature scale corresponding to each image is different to account for high and low temperatures perceived by the camera. Heat-pipe conditions were observed in five of the seven experiments in which near-aperture temperatures were monitored.

The initial temperature distributions in all these experiments with no pentane in the aperture show a steep temperature gradient near the interface between the warmed and ambient regions (Figure 3-28 on page 3A-22). This steep gradient is expected for heat transfer from an extended surface or fin, where in the limit of an infinite one-dimensional fin, the normalized excess temperature goes as $\mathrm{e}^{-\mathrm{mx}}$, where $\mathrm{x}$ is distance and $\mathrm{m}$ is a function of the relative importance of conductive and convective heat transfer (Incropera and DeWitt, 1981). With pentane in the aperture and the bath temperature exceeding the boiling point, large regions of low temperature gradient have been observed, indicating the formation of a heat pipe. An example is shown in Figure 3-29 (page 3A-23).

The shape of the heat pipe region is strongly affected by the structure of the aperture. In Figure 3-29, the green protrusions on the left and right sides indicate vertical pentane vapor pathways in these locations. The photo image to the left shows corresponding conduits free from saturated islands of pentane in these locations. Towards the center and adjacent to these conduits are saturated islands of pentane, indicated in the thermal image by the darker green and cyan (cooler). The central bright green region contains darker green spots that correspond to the locations of pentane islands saturating the aperture. In Experiment 11, heatpipe development was strongly affected by the impermeable barriers (Figure 3-30 on page 3A-24). Pentane vapor was forced to travel vertically on the left and right sides of the model due to the impermeable barriers and liquid saturation in the center of the funnel structure. These warmed regions are indicated by the brighter green color. In the center, the model is cooler, indicating that liquid flow is predominant there. The shape of the heat-pipe region in Experiment 13 was influenced by the presence of the large vent on the upper right side (Figure 3-31 on page 3A-25). Newly vaporized pentane in this experiment was pushed towards the right boundary where the pressure was ambient, producing a bulge in the condensation halo and longer fingers on the right. The most uniform heat-pipe region was found in Experiment 12 (Figure 3-32 on page 3A-26). Due to the wide aperture, pentane was present only in films on the fracture walls. The orange region shows a very nearly constant temperature. The size of the heatpipe region was larger when more pentane was present in the model. In Experiment 14, the aperture was very narrow which severely restricted liquid and vapor flow and limited heat pipe development (Figure 3-33 on page 3A-27). An uneven heat pipe formed in the Stripa fracture replica (Experiment 15) that was much more predominant on the right side. This is because the aperture was wider there providing less viscous resistance to flow (Figure 3-34 on page 3A-28). 
No heat pipe was observed in rock/replica Experiment 16. Insufficient liquid was present in the system for the partial rock saturation needed to investigate this phenomenon. Thermal images indicate some rock cooling where the pentane evaporation occurred, however, thermal conductivity heterogeneities may also explain the observed temperature distributions.

\subsubsection{Discussion}

\subsection{Liquid Flow in Fractures Under Conditions of Partial Saturation and Thermal Drive: Implications for Fast Liquid Flow Paths}

Three types of liquid flow have been visually observed and are distinguishable in the fracture models. These are described here as continuous rivulet flow, intermittent rivulet and drop flow, and film flow. In the laboratory experiments, continuous rivulet flow occurred during the initial rapid introduction of pentane into the models and replicas. In this flow, the gravitational forces greatly exceed the capillary and viscous forces, which would tend to stabilize the pentane in the fracture. The direction of flow responds to the gravitational and capillary forces controlled by aperture heterogeneity. Continuous rivulet flow would occur in geologic media in locations where a constant supply of water was present, either due to infiltration or to the confluence of many, smaller flows at a heterogeneity. Intermittent rivulet flow occurs when there is only a slight imbalance between the stabilizing capillary forces and the destabilizing gravitational forces. These events occur when liquid is held in saturated islands, which are roughly in equilibrium with destabilizing forces. When additional fluid is added to these saturated islands, the destabilizing forces exceed the stabilizing capillary forces, and liquid from the saturated island flows in response to the imposed forces. This flowing liquid may contact other saturated islands and destabilize them, adding volume to the flow. Intermittent rivulet flow will likely occur in geologic media any time the rate of water seepage into a region exceeds the capacity for the water to flow onwards via film flow. Drop flow is an extreme example of intermittent rivulet flow. This occurs when liquid accumulates at a contact point above a wide aperture. When a sufficient volume collects such that gravitational force exceeds the capillary force, a drop breaks off and falls. In wide vertical apertures, it is conceivable that liquid may fall freely without contacting the fracture walls. Film flow occurs when the aperture is large. The films discussed here are on the order of tens of microns thick (Tokunaga and Wan, 1997); much thicker than thin adsorbed water films which are on the order of tens to a hundred angstroms thick (Gee et al., 1990). These thick films move on the fracture walls in response to gravitational forces and capillary forces imposed by the surface roughness. This type of flow may be the slowest of the three observed types and seems to be incompatible with rivulet flow when the fracture wall temperature exceeds the boiling temperature. Film flow may be the dominant flow mechanism transporting condensate to saturated islands, and dominant under low flow conditions where the amount of water 
present exceeds the amount that would be present due to sorption and capillaryheld water in equilibrium with groundwater. All of these conditions may be present at Yucca Mountain.

In all experiments performed, fingers penetrated some distance into the warmed region. In some experiments, films also penetrated into the warmed regions, primarily in wider aperture regions of fractures. The depth of penetration of both films and fingers decreased with increasing temperature of the water bath (Figures 3-35-3-37 on pages 3A29-31). The average finger length and the variability of the finger length are displayed in Figures 3-36 (page 3A-30) and 3-37 (page 3A-31) for Experiments 9 (thick glass) and 10. No theoretical analysis has yet been developed to attempt to scale finger and film penetration information determined under experimental conditions to conditions expected at Yucca Mountain. Development of these theoretical analyses and scaling relationships is expected to be a priority in FY 1998.

Because of the somewhat friable nature of the welded tuff within the ESF and the mining techniques used, fracture samples from the ESF large enough for experimentation purposes are not presently available. Fractured Topopah Spring Tuff samples recently obtained from Fran Ridge are suitable for experimentation purposes, and experiments are currently being conducted on these samples and their replicas. The natural surface roughness of fractures within the ESF ranges from nearly table-top smooth to roughly half-centimeter steps. This roughness range was experimentally accounted for by heterogeneities in fracture models due to imperfections in the glass manufacture, manufactured heterogeneities in obscure glass, and heterogeneities imparted by uneven sandblasting. Large-scale surface roughness was modeled by using two different roughnesses of glass: flat and obscure glass. Two sandblasting grits were used to provide different smallscale surface roughness. Impermeable barriers were placed in a fracture model to observe the effects of focusing flow, and uneven heating was used to simulate heterogeneous heat transfer. Experiment 15 was performed using a replica of a natural fracture from the Stripa Mine in Sweden. The variability in fracture features within this replica induced all the phenomena observed in the experiments using glass models. Experiment 16 was conducted using an epoxy replica of one fracture face mated to the actual opposing rock-fracture face of a sample from Fran Ridge near Yucca Mountain. Heterogeneities and boiling conditions influenced flow and liquid imbibition into the rock. The high degree of small-scale surface roughness caused rapidly spreading pentane films on both the epoxy replica and the rock surface.

Pentane has been introduced into vertical fracture models containing regions both above and below the pentane boiling point, and all regions below the pentane boiling point. The temperature ranges used in the experiments generally bracketed the pentane normal boiling point $\left(36.1^{\circ} \mathrm{C}\right)$ by several degrees. This allowed for observation of phenomena across this range. Water has not been used as the working fluid, and hence the effect of ionic strength has not been investigated. The relative importance of gravity has been investigated by using fracture models with different apertures rather than by inclining the model. 
Drop flow in subvertical fractures would be different than in vertical fractures, but other phenomena observed are more strongly influenced by viscosity due to narrow apertures, and would likely be similar. In horizontal fractures, only minimal vapor-liquid counterflow would be expected, which would reduce the heat pipe effect. This was modeled by a fracture model with a very narrow aperture. Other effects due to subvertical inclinations are not expected to be large in narrow aperture fractures, due to the high capillary and viscous forces encountered. These effects may be more pronounced in wider aperture fractures and will be considered in future experiments.

Parameters such as the enhanced diffusion coefficient and the magnitude of buoyant gas flow have not been quantified in this work. In this work, it is believed that advection is the predominant gas flow mechanism under the conditions investigated because of the rapid evaporation of pentane (local production of pentane gas). Measurement of both buoyant gas flow and enhanced diffusion would require advection to be relatively unimportant. The enhanced binary diffusion coefficient is poorly understood in porous media where it has been studied for more than 40 years (Cass et al., 1984). The conditions for which it exists in a partially saturated fracture have not yet been identified.

\subsection{Conditions Conducive to Forming Heat Pipes}

The general conditions necessary for heat pipe formation include (1) a region at a temperature exceeding the liquid boiling point (evaporation zone), (2) adequate space for vapor and liquid counterflow, (3) a region cooler than the liquid boiling point (condensation zone), and (4) a driving force for liquid return to the evaporation zone. In all of these experiments, the driving force for liquid return is gravity. Horizontal flow was observed in some cases within the condensation halo due to capillary forces, but the liquid was ultimately returned to the warm region by gravity. In one of the five experiments where heat pipes were observed (Experiment 12), liquid return was in films, in the other four experiments, liquid return to the evaporation zone was primarily in fingers. Within the condensation halo (condensation zone), fingers and films were responsible for liquid flow. Large horizontal capillary pressure gradients present within fractures and on fracture surfaces due to dryout may contribute in the long run to the amount of water present above the heated drifts available for reflux and flow in fast paths.

In Experiment 12 (Figure 3-32 on page 3A-26), good heat pipe conditions exist, and the condensation halo is uniform. The wide aperture provides for minimal interference between the liquid and vapor, and the liquid return is due to gravity. In Experiment 11 (Figure 3-30 on page 3A-24), gas flow is hindered by the impermeable barriers and liquid saturation in the model center. Similarly, the liquid flow through the funnel center was hindered by the increased pressure in 
the model bottom. Saturated islands, such as those in Figure 3-29 (page 3A-23), may act like impermeable barriers to the vapor transport, while at the same time the liquid may be flowing.

No heat pipe was observed in Experiment 14. In this experiment, the aperture was small, and viscous resistance controlled liquid flow. The rate at which pentane flowed into the warmed region, evaporated and condensed, was not large enough such that thermal images registered significant deviation from the original condition. The condition for adequate space for vapor-liquid counterflow was not met in this experiment.

\subsubsection{Conclusions}

Emplacement of heat-generating nuclear waste packages in a partially saturated environment such as Yucca Mountain is expected to give rise to complex twophase (liquid-gas) flow phenomena with phase change (boiling and condensation). Of particular interest are heat-driven flows in fractures, which could cause "fast" migration of water and solutes along localized-preferential pathways. The objective of the current project is to obtain a better understanding of the relevant phenomena through laboratory-scale experimentation under controlled and monitored conditions.

We have studied thermally driven flows in a variety of laboratory fracture specimen, using glass plates of different small- and large-surface roughness, an epoxy replica of a natural rock fracture, and an actual rock fracture. The typical scale of the experiments was $20-30 \mathrm{~cm}$. Pentane, with a boiling point of $36.1^{\circ} \mathrm{C}$, was used as volatile fluid instead of water to facilitate the experiments. Flow behavior was observed visually, and spatially-resolved temperature monitoring was performed. Our initial experiments have demonstrated the following phenomena: boiling and condensation; formation of dry-out zones; flow funneling, focusing, and bypassing; localized-preferential flow of liquid in nominally superheated regions; capillary-driven flow; and film flow. The presence of heat-pipe processes (vapor-liquid counterflow) was inferred from observations of extended regions with very nearly isothermal conditions.

The project is continuing. Future work will attempt to explore flow in a broader variety of fracture specimen, with special emphasis on actual rock fractures from Yucca Mountain. Different flow geometries will be explored, including nonvertical fractures. An effort will be made to not only use pentane, but to also set up experiments with water as the working fluid. Quantitative analysis of fluid flow and heat-transfer mechanisms will be made, and issues of scale-up to conditions at Yucca Mountain will be considered. Close integration will be sought with ongoing in situ heater experiments at Yucca Mountain, and with mathematical modeling studies of thermo-hydrologic behavior. 


\subsubsection{Data Collected}

In order to record visible phenomena, all laboratory experiments have been video taped, thus, data have been collected in video form. Video and "TGRAM" format recording of thermal images have also been made for Experiments 9 and 11 - 16. Table 3-3 provides a catalogue of recordings made. These recordings are considered preliminary at this time, and planning is underway for editing and producing a video for distribution. Production of the video is expected to be completed in FY 1998. Film penetration depth data displayed in Figure 3-35 (page 3A-29) were submitted on 14 April with data tracking number

LB970400123122.001. Finger length data displayed in Figure 3-36 (page 3A-30) and Figure 3-37 (page 3A-31) are included with data tracking numbers LB970600123122.001 and LB970600123122.002.

Table 3-3 Laboratory experiments and video recordings

\begin{tabular}{|c|c|}
\hline Experiment & Video Recording ID \\
\hline $1 \mathrm{SOG} / \mathrm{FG}$ & 1/29/97 SOG/FG \\
\hline $2 \mathrm{SOG} / \mathrm{FG}$ & SOGFG 1/30/97 \\
\hline 3 SFG/FG & FGxSFG 1/30/97 \\
\hline 4 SOG/SOG & 2/4/97 SOGXSOG \\
\hline 5 SOG/SOG & 2/11/97 SOG/SOG \\
\hline 6 SFG/SFG & SFGxSFG 2/27/97 \\
\hline $7 \mathrm{SOG} / \mathrm{SOG}$ & SOG/SOG Circular 2/28/97 \\
\hline 8 SOG/FG Finger Location Repeatability & 3/20/97 Repeatability \\
\hline $\begin{array}{l}9 \text { SFG/SFG Wall Thickness/Heat Pipe } \\
\text { Development }\end{array}$ & $\begin{array}{l}\text { 3/26/97 SFGxSFG w/ Temperatures } \\
\text { 3/27/97 SFG/SFG Thick } \\
\text { Thermal Tape ID: } \\
\text { 3/26 SFG/SFG Thin Temps } \\
\text { 3/27/97 SFG/SFG Thick Temps }\end{array}$ \\
\hline 10 SFG/SFG Non-uniform Heating & 4/15/97 SFG/SFG w/LEXAN \\
\hline 11 SOG/SOG Impermeable Barriers & $\begin{array}{l}\text { 4/17/97 SOG/SOGII Heterogeneous } \\
\text { Thermal Tape ID: } \\
\text { 4/17 SOG/SOGII Heterogeneities Temps }\end{array}$ \\
\hline 12 SFG/SFG Wide Aperture & $\begin{array}{l}\text { 5/12/97 Wide Aperture SFG/SFG } \\
\text { Thermal Tape ID: } \\
\text { 5/12/97 Wide Aperture SFG/SFG temps }\end{array}$ \\
\hline 13 SOG/SOG Fine Surface Roughness & $\begin{array}{l}\text { 5/13 SOG/SOG } 240 \text { uneven } \\
\text { Thermal Tape ID: } \\
\text { 5/13 SOG/SOG } 240 \text { uneven temps }\end{array}$ \\
\hline
\end{tabular}




\begin{tabular}{|l|l|}
\hline \multicolumn{1}{|c|}{ Experiment } & \multicolumn{1}{c|}{ Video Recording ID } \\
\hline \hline 14 SFG/SFG Fine Surface Roughness & $\begin{array}{l}\text { 5/13/97 SFG/SFG240 } \\
\text { Thermal Tape ID: }\end{array}$ \\
\cline { 2 - 2 } & $5 / 13 / 97$ SFG/SFG240 temps \\
\hline 15 Stripa Replica & $\begin{array}{l}5 / 30 / 97 \text { Stripa Replica } \\
\text { Thermal Tape ID: }\end{array}$ \\
\cline { 2 - 2 } & 5/30/97 Stripa temps \\
\hline 16 Yucca Mountain (Fran Ridge Replica) & $\begin{array}{l}\text { 6/5/97 Fran Ridge II } \\
\text { Thermal Tape ID: }\end{array}$ \\
& 6/5/97 Fran Ridge II temps \\
\hline
\end{tabular}

\subsubsection{Quality Assurance Status}

Data collected and referenced herein were collected under the Yucca Mountain Project (YMP) Quality Assurance Program. They are recorded in scientific notebooks YMP-LBNL-TJK1 and YMP-LBNL-TJK2 and associated images. Calibration data for the infrared camera are contained in YMP-LBNL-JSW-1.2. Data used to compile Figure 3-12 come from recognized sources (see page 4 of this report) and as existing data do not need to be qualified. Conclusions drawn from this work are based on qualified data.

\subsubsection{Acknowledgments:}

This work was supported by the Director, Office of Civilian Radioactive Waste Management, U.S. Department of Energy, through the Memorandum Purchase Order EA9013MC5X between TRW Environmental Safety Systems, Inc. and the Ernest Orlando Lawrence Berkeley National Laboratory, under Contract No. DEAC03-76SF00098.

The technical reviews by Yvonne Tsang and Ardyth Simmons and the quality assurance review by Don Mangold and Vivi Fissekidou were greatly appreciated.

\subsection{Alteration of Minerals and their Distribution}

\subsubsection{Fracture Healing}

In laboratory fracture-healing experiments, reduction in fracture permeability has been associated with precipitation and bonding together of opposing fracture walls. In one typical sample, the fracture initially contained a white siliceous precipitate before testing (Lin and Daily, 1985). After repeated dehydration/rehydration at elevated temperatures, which resulted in 3 orders of magnitude decrease in permeability, SEM examination revealed booklets of precipitated silica deposited on the fracture surfaces and filling the aperture. The concentration of dissolved $\mathrm{Si}$ in fracture effluent at elevated temperatures indicated equilibrium with amorphous silica, while crystalline forms were 
observed on SEM inspection. The authors reported that, from SEM examination of fracture samples before and after flow testing, naturally occurring spherical silica structures were dissolved and replaced by siliceous particles.

Tensile strength of the bonded fracture measured by the indirect Brazilian loading technique was approximately half that of the intact tuff (Lin and Daily, 1985). Subsequent testing of another naturally fractured sample showed that less reduction of permeability occurred if there was no dehydration. These results indicate separate mechanisms for silica precipitation under saturated conditions and under dehydrating (boiling) conditions.

\subsubsection{Changes in Water Chemistry}

\subsubsection{Water Chemistry in Fracture Flow Experiments}

Roberts and Lin (1994b) monitored major dissolved chemical constituents $\mathrm{K}, \mathrm{Na}$, $\mathrm{Ca}, \mathrm{B}, \mathrm{Si}, \mathrm{Al}$, and $\mathrm{Fe}$ in the effluent from a fracture-healing study. A naturally healed fracture was tested at constant differential pore pressure for a duration of 4200 hours. During this time, the confining pressure and temperature were varied systematically. The permeant was J-13 water, bio-inhibited by addition of sodium azide. Changes in fracture permeability in this experiment were discussed previously (Figure 3-3).

No Fe or Al was detected above the limits of 0.02 and $0.06 \mathrm{mg} / \mathrm{l}$, respectively (Roberts and Lin, 1994b). The concentration of $\mathrm{K}$ in the effluent closely tracked the temperature history, with a maximum value of $13 \mathrm{mg} / \mathrm{l}$, whereas the concentration of sodium increased to approximately $700 \mathrm{mg} / 1$ and never declined (Figure 3-38). Silicon and boron concentrations increased with elevated temperature, responding erratically to temperature cycles between $20^{\circ}$ and $150^{\circ} \mathrm{C}$ and reaching maximum concentrations of $\sim 100$ and $0.5 \mathrm{mg} / \mathrm{l}$, respectively.

Calcium exhibited maximum concentration peaks of about $40 \mathrm{mg} / 1$ at $20^{\circ} \mathrm{C}$ and minimum concentrations at elevated temperatures, suggesting the influence of the retrograde solubility of calcite (as one candidate among possible precipitates that could exhibit retrograde solubility). 

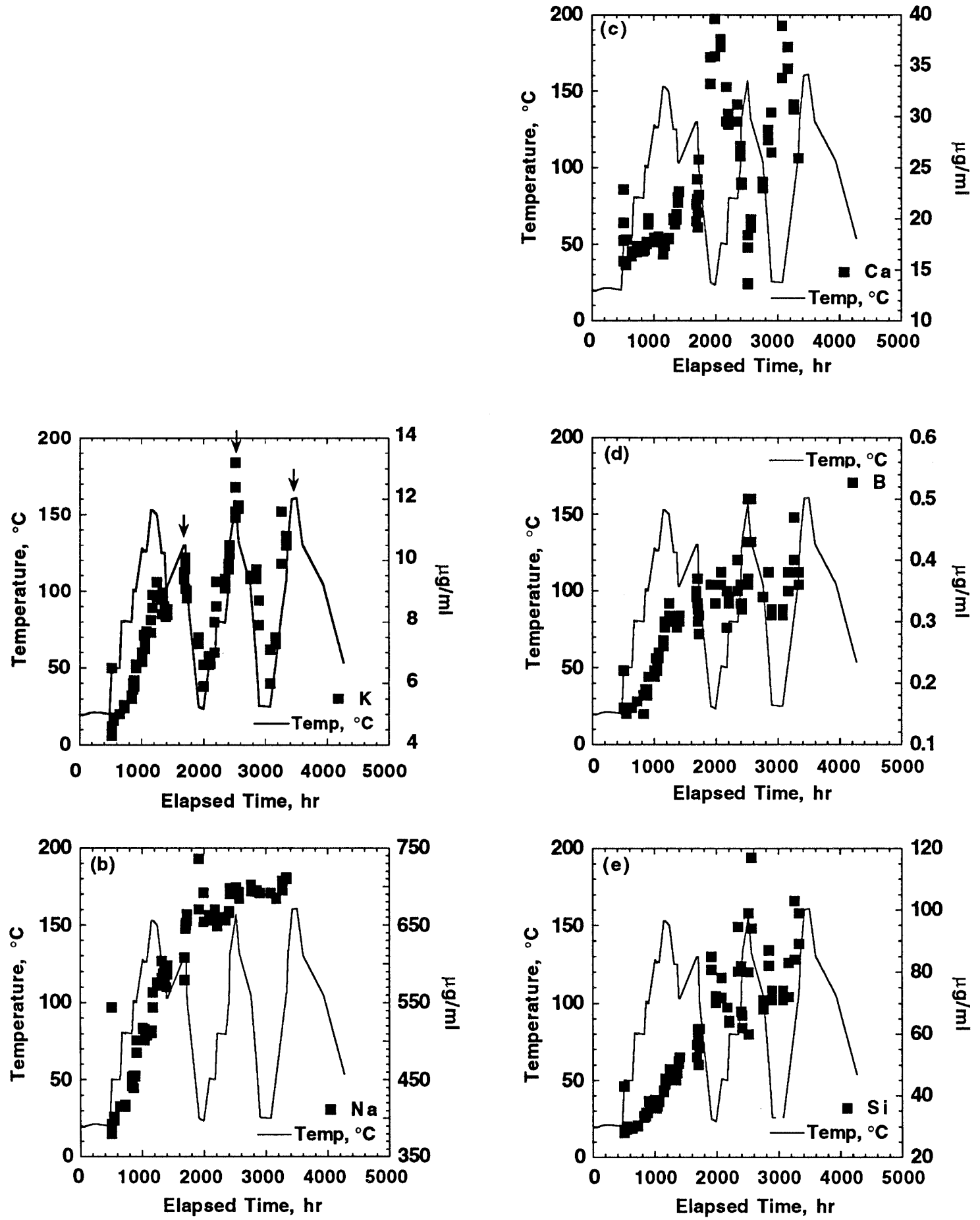

Figure 3-38 Partial chemical analyses of major constituents in water effluent from flow testing of a natural fracture (after Roberts et al. [1994b]). Potassium, Na, $\mathrm{Ca}, \mathrm{B}$, and Si were determined for the composited effluent from flow tests, which were performed periodically during the $4200-\mathrm{hr}$ experiment. 
Viani and Carman (1996) conducted fracture-flow experiments on a saw-cut core sample of Topopah Spring welded tuff. Representative chemical analyses for concentrations of major cations and silica, for flow tests at $23^{\circ} \mathrm{C}$ and $92^{\circ} \mathrm{C}$, are shown in Table 3-4. Major observations were 1) positive correlation of dissolved $\mathrm{Si}$ with temperature and 2) negative correlation of $\mathrm{Si}, \mathrm{Ca}$, and $\mathrm{Mg}$ with flow rate $\left(\right.$ at $92^{\circ} \mathrm{C}$ ). The Si concentrations observed in the $0.2 \mathrm{~mL} / \mathrm{h}$ runs at both $23^{\circ} \mathrm{C}$ and $92^{\circ} \mathrm{C}$ indicated slight supersaturation with respect to quartz, but significant undersaturation with respect to cristobalite. The authors noted that, if the length of the core were longer or the flow rate were slower, the concentration of $\mathrm{Si}$ in the effluent could have approached saturation with cristobalite. Preliminary calculations based on fracture surface area and water residence time were consistent with laboratory-derived rates of quartz dissolution (Viani and Carman, 1996). The lower Si concentration at $92^{\circ} \mathrm{C}$ and a flow rate of $2.0 \mathrm{ml} / \mathrm{hr}$ indicated kinetically limited dissolution when compared with the previous test at $0.2 \mathrm{ml} / \mathrm{hr}$.

Table 3-4 Concentrations (mg/l) of selected elements analyzed in effluent splits from selected flow tests with a saw-cut fracture (after Viani et al. [1996])

\begin{tabular}{|c|c|c|c|c|c|c|c|c|c|c|}
\hline \multirow[b]{2}{*}{ Elem. } & \multirow[b]{2}{*}{$\begin{array}{c}\mathrm{J}-13 \\
\text { Water }\end{array}$} & \multicolumn{3}{|c|}{$\begin{array}{l}\text { Test: FT041495 } \\
23^{\circ} \mathrm{C}, 0.2 \mathrm{~mL} / \mathrm{hr}\end{array}$} & \multicolumn{3}{|c|}{$\begin{array}{l}\text { Test: FT080695 } \\
92^{\circ} \mathrm{C}, 0.2 \mathrm{~mL} / \mathrm{hr}\end{array}$} & \multicolumn{3}{|c|}{$\begin{array}{l}\text { Test: FT081495 } \\
92^{\circ} \mathrm{C}, 2.0 \mathrm{ml} / \mathrm{hr}\end{array}$} \\
\hline & & Pre- & $\begin{array}{c}\text { Tracer } \\
\text { test }\end{array}$ & Post- & Pre- & $\begin{array}{c}\text { Tracer } \\
\text { test }\end{array}$ & Post- & Pre- & $\begin{array}{c}\text { Tracer } \\
\text { test }\end{array}$ & Post- \\
\hline $\mathrm{Ca}$ & 0.05 & 2.05 & 4.67 & 4.54 & 3.30 & 4.13 & 3.62 & 3.71 & 2.95 & 2.46 \\
\hline $\mathrm{Mg}$ & $<0.01$ & 0.46 & 1.09 & 1.08 & 0.74 & 0.85 & 0.83 & 0.83 & 0.60 & 0.53 \\
\hline $\mathrm{Na}$ & 33 & 36 & 43 & 37 & 35 & 38 & 34 & 34 & 32 & 31 \\
\hline $\mathrm{K}$ & $<0.01$ & 0.2 & 0.4 & 0.4 & 1.5 & 2.2 & 1.7 & 1.6 & 1.6 & 1.2 \\
\hline Si & 0.08 & 0.49 & 2.75 & 2.65 & 18.74 & 20.92 & 22.49 & 23.24 & 8.54 & 6.91 \\
\hline $\mathrm{Sr}$ & $<0.02$ & 0.07 & 0.13 & 0.12 & 0.07 & 0.03 & 0.09 & 0.08 & 0.3 & 0.06 \\
\hline
\end{tabular}

Experiments such as these demonstrate the types of reactions that can be expected in the near-field environment. Data in Table 3-4 clearly show that dissolution reactions involving $\mathrm{Si}$ are rate-limited. The test conditions involved intermittent flow, which complicates the interpretation of rate behavior. Although useful, experiments such as these are not directly applicable to predicting field-scale chemical responses. Solution and solid phase compositions are rate- and reaction-path-dependent; because temporal and spatial scales for near-field/altered-zone phenomena will be different from those of laboratory experiments, different reactions may prevail, resulting in different solution and solid phase compositions. For predictive purposes, it is necessary to identify and quantify the rates for possible reactions in the near-field/altered-zone environment. 


\subsubsection{Water Chemistry in Matrix-Flow Experiments}

Following the early investigations of temperature and pressure effects on water permeability of TSw2 welded tuff (discussed previously), Moore et al. (1985) performed similar tests with chemical analysis of the effluent water. Radially convergent or divergent flow of J-13 water was parallel to a thermal gradient produced by an axial heater. Pore fluid within the sample was static for periods of time (typically 1 day) between flow tests from which fluid samples were collected. Fluid samples collected immediately after resumption of flow generally had compositions different from those of samples collected at the end of the flow tests, thus indicating rate-dependent and path-dependent dissolution behavior. Effluent fluids were generally dilute, with near neutral $\mathrm{pH}$. The $\mathrm{pH}$ declined gradually during testing, from slightly alkaline to near neutral.

Concentrations of $\mathrm{Si}$, major cations ( $\mathrm{Na}, \mathrm{K}, \mathrm{Ca}$ ), and major anions (sulfate, chloride, bicarbonate) increased significantly on initial exposure to rock at elevated temperatures, then approached the influent concentrations during 10 to 14 days of daily permeability testing. During the first few days, the concentration of $\mathrm{Si}$ increased to 40 to $50 \mathrm{mg} / \mathrm{l}$, suggesting equilibrium with a polymorph such as cristobalite (or precipitation of amorphous silica in the "cold" part of the sample or apparatus). Fracture-flow experiments at elevated temperatures yielded $\mathrm{Si}$ concentrations of approximately $100 \mathrm{mg} / \mathrm{l}$, which may represent equilibrium with amorphous silica. Magnesium declined significantly from the J-13 water concentration.

\subsubsection{J-13 Water Chemistry Changes Associated with Evaporation and Boiling}

Numerical simulations of J-13 water evaporation using the EQ3 / 6 code (Wolery, 1992a and 1992b; Wolery et al., 1992) were reported by Glassley (1995). These calculations showed that carbonates, phosphate, Al-silicates, and Si polymorphs become saturated at very low degrees of evaporation $(<10 \%)$. However, the only precipitates that develop in significant abundance, even at relatively high degrees of evaporation (70\% to $90 \%$ ), are carbonates and Si-polymorphs. For greater evaporation, chloride salts can precipitate; however, as evaporation approaches $100 \%$, brines will tend to form in fine pores and persist to temperatures greater than the boiling point.

As pointed out by Glassley (1995), the chemical effects of evaporation may be different from those of boiling, depending on the behavior of dissolved gases. Based on a modeling exercise using EQ3/6, evaporation of J-13 water without controls on the composition of coexisting gases produced water with near neutral $\mathrm{pH}$ and Eh that was slightly oxidizing. The most abundant precipitates predicted were calcite and silica polymorphs. When the coexisting gas phase was fixed at atmospheric $\mathrm{O}_{2}$ and $\mathrm{CO}_{2}$ fugacities, fluid evolution was significantly different with respect to $\mathrm{pH}, \mathrm{Eh}, \mathrm{Ca}$, and $\mathrm{Si}$. The $\mathrm{pH}$ was more alkaline (>9), and the Eh was more oxidizing at low temperature but became more reducing at high 
temperatures. When compared to effects in the case with uncontrolled fugacites, these effects led to much greater $\mathrm{Ca}$ and $\mathrm{Si}$ concentrations in solution. The concentrations of other major ions were unchanged.

\subsubsection{Flow-Reactor Experiments}

The following description is abstracted from DeLoach et al. (1997). Chemical interaction of hot water with tuff samples has been investigated experimentally for comparison to model predictions. Hot water moving through fractured tuff in the near-field environment will cause dissolution and precipitation of mineral phases and will create a chemically and hydrologically altered zone encompassing each emplacement drift. Reactive transport models for these processes rely on thermodynamic data for mineral stability and water composition and on mineral dissolution and precipitation rate laws for determining rates of change for mineral abundances and hydrologic properties. Plug-flow reactor experiments have been designed to produce data for direct comparison to model predictions.

In the experiment, the reactor consisted of an inert reaction vessel approximately $0.66 \mathrm{~cm}$ in diameter, into which reactive material of known mineralogy, grain size, and surface area was placed. The vessel was placed in a furnace and maintained at constant temperature. Water of known composition was pumped through the vessel at measured flow rates and at pressures high enough to prevent boiling. At completion of the experiment, the solid material was removed, mapped according to its position along the flow path, and examined using x-ray diffraction (XRD), SEM, and electron microprobe methods of instrumental analysis.

Crushed TSw2 welded tuff was tested at $240^{\circ} \mathrm{C}$ and $8.4 \mathrm{MPa}$. Deionized water flowed through the sample at $25 \mathrm{ml} /$ day for 36 days. The thermochemical model EQ3/6 (Wolery, 1992a; Wolery and Daveler, 1992) was used to identify likely aqueous species and secondary phases; the reactive transport simulator code OS3D/GIMRT (Steefel and Yabusaki, 1995) incorporated that information to predict the observables: effluent-water composition, mineral dissolution, and secondary mineral development. Effluent-water composition was monitored during the experiment for comparison to predictions, and the kinetic parameters were adjusted for better fit. By the end of the experiment, model predictions indicated that cristobalite abundance would be substantially decreased, and albite would be completely dissolved. Predicted changes in other mineral phases, both primary and secondary, were relatively minor (a few percent of the total).

Examination of the solid phase showed that cristobalite decreased in abundance within a few centimeters of the inlet by about $11 \%$ to $13 \%$ (w/w total)-close to the $12 \%$ predicted. Feldspar abundance exhibited scatter and could not be quantified precisely ( $\pm 20 \%$ was typical); nowhere in the sample, however, was albite completely dissolved. In accordance with predictions, there was no detectable change in the abundance of other mineral phases. A bladelike mineral, typically 1 to $2 \mathrm{~mm}$ in length, was noted from SEM examination. Iron was 
observed qualitatively to be present wherever the blades occurred, and the authors concluded that the blades were remnant hematite exposed after the silicate matrix was dissolved around them.

Except for silica spheres, run products from the experiment were not clearly identified. Silica spheres were 10 to $30 \mathrm{~mm}$ in diameter and had been observed in previous hydrothermal alteration studies on this rock type (Knauss et al., 1985a and 1985b). In addition, a tentative identification of micron-sized clay grains was made in one sample.

The model predictions and test series provided evidence that major aspects of mineral dissolution and precipitation in the repository altered zone can be predicted. More precise agreement between model predictions and observations depends on modeling of solid solutions, particularly alkali feldspar.

\subsection{Near-Field Radionuclide Transport}

\subsubsection{Waste Package/Waste Form Releases}

Radionuclide releases from the waste package and waste form depend on a number of thermally coupled processes. Corrosion mechanisms are driven by free energy changes and depend also on other temperature-controlled rate processes, including thermohydrology in the near field, transport, galvanic effects, and rheology of waste-package materials. Should waste-package failure occur during the initial period when spent fuel temperatures are highest, oxidation of the $\mathrm{UO}_{2}$ waste form is likely to disrupt the cladding and accelerate eventual releases. Once water accumulates in failed waste packages, the rates of spent fuel or waste-glass dissolution, and the solubility of radionuclides, will depend on temperature. The processes that determine the rate of water movement into and out of failed waste packages, and thus the release rates and conversely the performance of partially failed packages, will also be temperature dependent.

Description of laboratory studies to examine the nature and rates of these processes is beyond the scope of this report but may be found in other reports, namely the Waste Form Characteristics Report (Stout, 1996 and 1997) and the Engineered Materials Characterization Report (McCright, 1996 and 1997).

\subsubsection{Radionuclide Retardation}

\subsubsection{Discussion of Extant Sorption and Solubility Data}

The extant experimental data for radionuclide sorption on welded tuff, hydrous ferric oxide, zeolites, and other sorbents was discussed in a previous section. Ion exchange onto zeolites can be calculated for elevated temperatures, but the mechanism is significant only for certain cations (e.g., Cs and Sr). Mineral solubility calculations can be extrapolated to elevated temperatures with uncertainty that varies according to the assumptions and approximations used to 
develop and apply the thermodynamic database. Available surface complexation data are predominantly from experiments at ambient temperature. In general, surface complexation mechanisms may change at elevated temperatures depending on the complexation thermodynamics and the speciation in solution. The status of presently available thermodynamic data has benefited from review and interpretation of many years of accumulated laboratory work. Investigation of radionuclide sorption onto cementitious materials at ambient and elevated temperatures is currently underway.

\subsubsection{Matrix Diffusion}

A series of flow tests was performed (Viani and Carman, 1996) for a single core sample at three temperatures $\left(23^{\circ}, 59^{\circ}\right.$, and $\left.92^{\circ} \mathrm{C}\right)$ and two flow rates $(0.2$ and 2.0 $\mathrm{mL} / \mathrm{h}$ ). Bromide and iodide were used as tracers. The average permeability at $23^{\circ} \mathrm{C}$ was on the order of 0.06 millidarcy (md) and was independent of the flow rate and average pore pressure. At $59^{\circ} \mathrm{C}$, the average permeability was slightly larger $(\sim 0.1 \mu \mathrm{d})$ and also appeared to be independent of the flow rate and average pore pressure. At $92^{\circ} \mathrm{C}$, the average permeability varied between $0.08 \mathrm{md}$ and 2.34 md depending on the average pore pressure.

A dilute $\mathrm{Na}-\mathrm{Cl}-\mathrm{HCO}_{3}$ solution containing bromide and iodide tracers was eluted through the core under constant flow conditions. Following a period of flow of the standard feed solution (dilute $\mathrm{NaCl}, \mathrm{NaHCO}_{3}, \mathrm{pH} \sim 7.5$ ), a $560 \mu \mathrm{l}$ pulse of either $\mathrm{NaBr}$ or $\mathrm{NaI}$ tracer solution $(0.75$ millimolal) was injected upstream from the core. The tracers were detected using ion-specific electrodes. Recoveries were within experimental error of $100 \%$.

The tracers eluted slightly sooner (in terms of volume eluted) and exhibited less tailing at lower flow rates. Slight retardation and tailing at greater injection pressures may have resulted from increased fracture-matrix interaction. Temperature also affected the initial breakthrough and the extent of tailing in the tracer pulse. The volumetric elution of the tracer occurred earlier at elevated temperatures, and tailing was less pronounced. Physical retardation associated with fracture-matrix interaction apparently decreased at elevated temperatures.

\subsection{Multiply Coupled Processes}

Testing of multiply coupled processes has involved elevated temperatures, control of water or moisture conditions, and control of mechanical or chemical effects. Useful results depend on control of boundary conditions such as temperature, moisture potential, stress or displacement, and fluxes of heat or mass. Some of the experiments described in previous sections have involved multiply coupled processes; additional studies are discussed subsequently. A discussion of field-scale test results is given in Chapter 4 of this report. 


\subsubsection{Nominal 0.5-m Scale Laboratory Experiments}

Blair and Berge (1997a) describe recent preliminary results of laboratory testing of 0.5-m scale block samples of Topopah Spring welded tuff. At this scale, on a sample large enough to contain natural fractures, known boundary and environmental conditions can be imposed. Reported results include deformation and elastic wave velocity measurements in conjunction with uniaxial loading of the block at temperatures as great as $85^{\circ} \mathrm{C}$.

Deformation results were discussed in a previous section of this report. Changes in ultrasonic compressional wave velocity corresponded with changes in temperature. Parts of the block at higher temperature also exhibited faster velocities. Increased velocity was attributed to closure of cracks (Blair and Costantino, 1997). The edges of the block had slower velocities as well as cooler temperatures. Blair and Berge (1996b) summarized the results from this phase of testing:

Preliminary analysis indicates that cycling of compressive stress in 1day tests produced nonlinear, but repeatable behavior in the $0.5-\mathrm{m}$ scale block with most of the deformation occurring across cracks, vugs, and fractures. Imposing low levels of compressive stress for periods of a few days caused time-dependent, unrepeatable behavior to occur for cracks oriented both parallel and perpendicular to the applied stress. Under long-term loading, cracks or vugs oriented perpendicular to the applied stress showed significant closure beyond that observed in the 1-day tests. In addition, long-term loading caused pre-existing hairline cracks oriented in the direction parallel to the applied stress to open, which significantly reduced velocities in this direction. Increasing temperature caused closure of some of the vertical cracks, which increased horizontal velocities. Increasing temperature also caused softening of the mechanical response in the direction of loading.

These results have significant implications for flow and transport properties in the near-field environment because they indicate that some important properties of the rock mass may become increasingly anisotropic with time. For instance, if cracks, vugs, and fractures oriented parallel to the maximum principal stress undergo timedependent closure, permeability in this direction will be reduced, and the deformation modulus will increase. Moreover, opening of preexisting hairline cracks that occur near the drift wall and are oriented parallel to it will increase the permeability in this direction and will change the geochemical environment by exposing different mineral assemblages.

A second phase of testing involved flow testing of the predominant, throughgoing fracture in the same block of Topopah Spring welded tuff (Blair and Costantino, 1997). Flow was produced by a small source in the center of the fracture. The perimeter of the fracture was divided into 38 intervals at which fluid flow was monitored. At zero applied load, substantially all of the flow was 
collected at 8 of the 38 intervals. No flow-through outside of the fracture plane was observed (although the top and bottom faces were not visible). The flow was apparently dominated by paths in one direction; this is clearly related to fracture geometry and may be a result of previous stress conditions or fracture deformation.

\subsection{Microbial Effects}

Potential microbial effects on near-field performance were discussed in a previous section, and new tests are underway as discussed in the Engineered Materials Characterization Report (McCright, 1997). Corrosion testing in the presence of microbes is underway to evaluate the potential for microbially induced corrosion of candidate waste-package materials. Microbial strains isolated from Yucca Mountain samples are being screened for survival and growth characteristics and for environmental modifications, such as acid or sulfide production and polysaccharide formation, that may be important to waste-package performance.

\subsubsection{Biofouling of Fracture Flow}

Viani (1996a) reported laboratory testing, at elevated temperatures, of saw-cut fractures in Topopah Spring welded tuff that were affected by biofouling. This section summarizes results of flow and tracer tests using core samples. Experiments were undertaken using cylindrical cores measuring $5-\mathrm{cm}$ in diameter by $5-\mathrm{cm}$ in length. A longitudinal saw-cut was made and propped open with two 3.2-mm strips of 25-micron-thick gold foil. The core sample was mounted in an axial permeameter that controlled confining pressure, pore pressure, and temperature. Confining pressures were maintained between 3.5 and $5 \mathrm{MPa}$, and pore pressure varied between 0.01 and $0.5 \mathrm{MPa}$. Details of the apparatus and the sample treatment were given in Viani and Martin (1993 and 1994).

To prevent the growth of bacteria during the flow test, the fractured core sample was sterilized by autoclaving. Filtered, deionized water (milli-Q water $0.05-$ micron filtered) was pumped through the core for two permeability tests lasting approximately 6 weeks each.

For the initial tests, the flow rate and permeability declined substantially, apparently as a result of bacterial fouling of the fracture aperture. In one test, permeability was correlated with differential pressure. The observed flow behavior suggested that the fracture gradually clogged and that, by increasing the differential pressure, the clogging material dispersed. Samples of the effluent fluid were analyzed using transmission and SEM to determine the presence of particles that could account for the permeability decrease. The most abundant particles appeared to be rod-shaped bacteria (1 to 1.5 microns long). Although no obvious source of carbon was introduced into the system, it is apparent that bacterial growth was sufficient to clog the 25- micron fracture aperture. 
Later tests used an isocratic pump, and clogging was not observed, although bacterial growth almost certainly occurred. Apparently the bacteria were continuously eluted from the fracture with a constant permeant flow rate. Bacterial growth in the subsurface could significantly impact the path that fluids will take in the fractured flow-path components of the engineered barrier system/near-field environment.

\subsection{Summary of Laboratory-Scale Study of Thermally Coupled Processes}

The following comments, on the laboratory investigation of thermally coupled processes, summarize some of the findings in the reports compiled for this review. These comments do not include some topics for which few data are available and for which experimental work is in progress. Additional information and source citations are provided in the preceding sections.

- Rewetting behavior-Testing of wafers of welded tuff has indicated (Lin and Roberts, 1996), that water-retention hysteresis varies at elevated temperatures. Typical wetting/drying hysteresis at ambient temperature was nearly zero at $78^{\circ} \mathrm{C}$ and reversed at $94^{\circ} \mathrm{C}$. Similar results were reported in a previous study (Daily and Lin, 1991). The effect is probably related to changes in surface tension and the rock-water-air contact angle at elevated temperatures. Hysteresis behavior is generally ignored, for computational expediency, in thermohydrologic models, and this may be defensible. The effects of negative hysteresis have not been considered. Rewetting hysteresis at elevated temperatures has not been explained nor further investigated.

- Vapor resaturation-Tuff matrix rewetting due to the presence of saturated water vapor $(100 \% \mathrm{RH})$ has a different result than rewetting by liquid at the same zero potential. Experimental data (Lin et al., 1996) show that rewetting of dry tuff in the presence of water vapor occurs much more slowly than does rewetting by imbibition of liquid water. This effect is incorporated in thermohydrologic models by adjusting the matric potential-vs.-saturation relationship so that matrix saturation of $30 \%$ to $40 \%$ or greater corresponds to relative humidity of nearly $100 \%$. The vapor resaturation effect strongly influences the timing of rewetting in the repository (Buscheck, 1996a) and tends to increase the relative humidity calculated at waste packages during cooldown.

- Fracture healing-An understanding of fracture-permeability reduction has been developed, and observations reported in the literature can be explained by three mechanisms:

1) Dissolution of fracture asperities by flowing water and consequent aperture reduction under the influence of confining stress

2) Dissolution/precipitation reactions that clog porosity by redistributing silica or by creating alteration products with greater molar volume 
3) Heating the rock matrix, which causes flow of matrix pore water toward fractures where the pressure is lower and evaporation or boiling occurs, clogging fractures or matrix porosity

Experiments have shown that flowing water or steam is required for permeability reduction, and the effect is strongest at temperatures greater than $90^{\circ} \mathrm{C}$ (Lin and Daily, 1985; Lin et al., 1995). To distinguish among these mechanisms, additional experiments are needed in which fracture aperture changes are measured directly, flow conditions are closely controlled, effluent chemistry is monitored, and the mass and distribution of fracture precipitates are evaluated.

- Permeability reduction by steam-Permeability reduction by flowing steam has been investigated in non-Q laboratory experiments (Lin, 1990), and the effects are similar to those of flowing water. The mechanism for silica transport (e.g., dissolved in water droplets) has not been verified.

- Fracture-matrix coupled-flow visualization-Laboratory studies (Roberts and Lin, 1996c) have physically demonstrated the relationship between fracture-matrix coupling in welded tuff and the fracture pressure gradient or flow velocity. When the experiment was repeated with a thermal gradient, a different flow regime resulted, with localized precipitation of the solute tracer. These experiments can be simulated, using equivalent continuum models (ECM) and dual permeability models (DKM), to evaluate whether the flow phenomenology and thermal coupling are handled appropriately by both approaches. Additional experiments are needed to relate saturation data with accumulation of fracture precipitates and to examine the distribution of solute that results when the matrix is initially saturated and then dehydrates through the fracture.

- Flow channelization-Visualization experiments (Geller et al., 1996) showed, among other findings, that fracture transport in response to constant boundary conditions can be unsteady and associated with intermittent rivulets that "snap off" and reform periodically. These ambient-temperature experiments demonstrated that parallel plate fractures and epoxy casts of natural fractures can produce unsteady, episodic fracture flow in response to constant upstream boundary conditions. Similar flow can be expected in the fractures of a heat-pipe zone. These data have important implications for fracture-matrix interaction, especially in areas of the fracture traversed by the unsteady flow and where the contact time available for matrix imbibition is limited. The authors related the average repetition rate for episodic flow, with fracture aperture and wetting properties, and the inclination of the models to gravity.

- Physical models of heat pipes-Fracture thermohydrology visualization studies by Kneafsey and Pruess (Kneafsey and Pruess, 1997) examined conditions (e.g., fracture saturation, temperature difference, and fracture dimensions) that support heat-pipe development. Heat pipes were observed in parallel plate fractures containing obstacles, heat sources, and 
vents. Film flow as well as meniscal flow were observed to produce heat pipes. Unsteady rivulet-flow behavior, analogous to episodic fracture flow at ambient temperature, was observed (Geller et al., 1996). Rapid evaporation events occurred when "islands" of fluid became superheated and suddenly boiled, constituting another mechanism for unsteady flow with the potential to rapidly disperse solute. A few of these observations were repeated with a half-cast model incorporating welded tuff as one fracture wall. Ongoing investigations will evaluate other types of models and compare the physical model observations with numerical simulations.

- Potential for episodic reflux-Flow visualization results (Kneafsey and Pruess, 1997) indicate that there is the potential for large-scale episodic reflux flow into emplacement drifts. Condensate liquid islands can coalesce and flow rapidly, analogous to the intermittent-rivulet behavior observed in the physical models. Fracture water could penetrate the dryout zone and possibly the emplacement drifts, depending on the velocity, flow rate, and thermal response. The unsteady behavior observed with pentane in simulated fractures could be enhanced with stronger wetting behavior (e.g., water in natural fractures). Alternatively, fracture surface heterogeneity and matrix imbibition may moderate the unsteady behavior. These issues can be addressed through further testing.

- Water-rock interaction-Chemical analyses of effluent water from matrix and fracture flow experiments indicated water-rock interaction. When J-13 water was flowed through an intact core sample, the concentration of most major anions and cations first increased, then approached influent concentrations (Moore et al., 1985). Anions such as chloride and sulfate were leached in quantities that may be significant to waste-package degradation. Other reported data for similar tests (Roberts and Lin, 1994b) included chemical analyses of water that flowed through a healed, natural fracture at elevated temperatures. Leaching of soluble salts from the tuff matrix and fracture-lining minerals could be an important factor in the chemistry of waters that eventually reenter the waste-emplacement drifts. Accumulation of soluble salts in a heat-pipe zone has not been evaluated by either physical or numerical simulation.

- Alteration of flow paths-Plug-flow reactor experiments have produced results that compare with reactive transport calculations (DeLoach et al., 1997). Additional experiments will evaluate sensitivity to test conditions, such as flow rate and temperature, and will test more reactive materials, such as vitric tuff. The same modeling approach will be used to predict mineral alteration along potential waste-migration pathways through the altered zone. Comparison to observations obtained from field-scale testing is planned for model validation purposes.

- Matrix diffusion-Matrix diffusion was investigated using conservative tracer-transport through a core sample with a saw-cut fracture (Viani and Carman, 1996). Complete recovery of chloride and bromide tracers was 
achieved, but the breakthrough time and tailing behavior were sensitive to temperature. Matrix diffusion was apparently less effective at elevated temperatures. This is the only investigation of matrix diffusion behavior in tuff and is contrary to the expected result that diffusion increases with temperature. Replication of the experiment with direct before-and-after measurement of changes in matrix permeability of the fracture walls has not been done.

- Laboratory scale block test-Uniaxial loading of a fractured, 0.5-m scale block at elevated temperatures has shown that fractured tuff becomes more deformable at elevated temperature (Blair and Berge, 1997). Also, permanent deformation occurred as the block temperature was elevated to $\sim 85^{\circ} \mathrm{C}$ while under compressive load. Much of the deformation of the block occurred at the fractures. These results indicate that fractures in the host rock will close in response to thermal loading and will possibly reopen in response to cooling. The authors also interpreted test results to indicate that fractures will develop in the host rock proximal and parallel to the drift walls. Additional testing of the block will examine transport behavior under similar temperature and loading conditions.

Additional testing is needed to investigate gaps in the current understanding of thermally coupled processes and their relevance to repository performance.

Qualified data are defined as having been collected and reported as part of a scientific activity that was planned and implemented in accordance with a QA program that was approved by the current Yucca Mountain Site Characterization Project QA system. Qualified data were identified as such during the planning process prior to review, approval, and implementation of the activity plans. The conclusions given in this section were based on both qualified and "existing" (non-Q) data, which is defined as not qualified based on when, how, or by whom the data were collected. For conclusions that were based on measured data, qualification status is summarized in Table 3-5. (This table does not address studies in progress nor findings that additional data are needed in certain areas to support further understanding.) 
Table 3-5 Quality assurance status of conclusions reported in Chapter 3

\begin{tabular}{|c|c|c|}
\hline Section & Description of conclusion & Principal support \\
\hline \multirow[t]{2}{*}{$\begin{array}{l}\text { 3.1 Drying and } \\
\text { Rewetting }\end{array}$} & $\begin{array}{l}\text { In laboratory experiments, after the liquid water } \\
\text { has been driven off by thermal loading from waste } \\
\text { emplacement, the saturation level does not } \\
\text { increase to more than about } 30 \% \text { to } 40 \% \text { until } \\
\text { contacted by liquid water. }\end{array}$ & $\begin{array}{l}\text { Existing (non-Q) data: (Lin } \\
\text { and Roberts, 1996) }\end{array}$ \\
\hline & $\begin{array}{l}\text { Reversal in the usual wetting/drying water- } \\
\text { potential hysteresis relationship occurs when the } \\
\text { experiment temperature is increased from } \\
\text { ambient to } 96^{\circ} \mathrm{C} \text {. }\end{array}$ & $\begin{array}{l}\text { Existing (non-Q) data: } \\
\text { (Roberts and Lin, 1996b) }\end{array}$ \\
\hline \multirow{3}{*}{$\begin{array}{l}\text { 3.2.1 Matrix } \\
\text { Permeability of } \\
\text { Yucca Mountain } \\
\text { Tuff and Other } \\
\text { Rocks }\end{array}$} & $\begin{array}{l}\text { Matrix permeability changes at elevated } \\
\text { temperatures are minor as long as temperature } \\
\text { differences within the sample are not significant } \\
\text { (i.e., the sample is isothermal). }\end{array}$ & \multirow{3}{*}{$\begin{array}{l}\text { Existing (non-Q) data: (Lin et } \\
\text { al., } 1984 \text { and 1996; Moore et } \\
\text { al., } 1985 \text { and 1986; Morrow et } \\
\text { al., 1984; Reda, 1985a) } \\
\text { Qualified data: (Lin and Daily, } \\
\text { 1991) }\end{array}$} \\
\hline & & \\
\hline & $\begin{array}{l}\text { Permeability of a given sample in the direction of a } \\
\text { thermal gradient is only slightly affected by } \\
\text { heating at temperatures as great as } 250^{\circ} \mathrm{C} \text {. } \\
\text { Variations between samples are much greater } \\
\text { than variations associated with temperature } \\
\text { changes. }\end{array}$ & \\
\hline \multirow[t]{4}{*}{$\begin{array}{l}\text { 3.2.2.1 Water } \\
\text { Permeability in } \\
\text { Fractures }\end{array}$} & $\begin{array}{l}\text { Fracture healing is caused by water transport of } \\
\text { minerals, mainly silica, at temperatures greater } \\
\text { than } 90^{\circ} \mathrm{C} \text {. Further healing occurs when samples } \\
\text { are dehydrated as water moves from the matrix to } \\
\text { boil in the fracture. }\end{array}$ & $\begin{array}{l}\text { Existing (non-Q) data: (Lin } \\
\text { and Daily, } 1984 \text { and 1985) }\end{array}$ \\
\hline & $\begin{array}{l}\text { Fracture asperity contacts present greater surface } \\
\text { area and dissolve, leading to closing of the } \\
\text { fracture under confining pressure. }\end{array}$ & $\begin{array}{l}\text { Existing (non-Q) data: (Daily } \\
\text { et al., 1987) }\end{array}$ \\
\hline & $\begin{array}{l}\text { During heat-up, permeability changes for saw-cut } \\
\text { and tensile fractures occur at } \sim 150^{\circ} \mathrm{C} \text { instead of at } \\
90^{\circ} \mathrm{C} \text {, and effluent silica concentration represents } \\
\text { equilibrium with cristabolite. At } 90^{\circ} \text { to } 150^{\circ} \mathrm{C} \text {, and } \\
\text { during and after cool-down, the silica } \\
\text { concentration represents equilibrium with } \\
\text { amorphous silica. }\end{array}$ & $\begin{array}{l}\text { Existing (non-Q) data: (Lin } \\
\text { and Daily, 1989) }\end{array}$ \\
\hline & $\begin{array}{l}\text { Fracture healing requires } 1 \text { ) dissolution of } \\
\text { fracture-lining minerals and } 2 \text { ) transport of silica by } \\
\text { fracture flow. Flowing steam and flowing water } \\
\text { have similar effects on fracture permeability. }\end{array}$ & $\begin{array}{l}\text { Existing (non-Q) data: (Lin } \\
\text { and Daily, 1991) }\end{array}$ \\
\hline
\end{tabular}




\begin{tabular}{|c|c|c|}
\hline Section & Description of conclusion & Principal support \\
\hline \multirow[t]{2}{*}{$\begin{array}{l}\text { 3.3.1 X-ray } \\
\text { Radiography of } \\
\text { Fracture Flow } \\
\text { and Matrix } \\
\text { Imbibition }\end{array}$} & $\begin{array}{l}\text { Under some conditions, fracture flow does not } \\
\text { readily penetrate a region at temperatures greater } \\
\text { than boiling, but penetration is possible upon } \\
\text { cooling. }\end{array}$ & \multirow[t]{2}{*}{$\begin{array}{l}\text { Existing (non-Q) data: } \\
\text { (Roberts and Lin, 1996c) }\end{array}$} \\
\hline & $\begin{array}{l}\text { Heating a nearly saturated fracture-matrix system } \\
\text { readily drives out the water through the fracture }\end{array}$ & \\
\hline \multirow[t]{2}{*}{$\begin{array}{l}\text { 3.3.2 Fracture } \\
\text { Coatings }\end{array}$} & $\begin{array}{l}\text { Mineral coatings from various tuff formations } \\
\text { generally inhibited imbibition and virtually } \\
\text { eliminated imbibition in one sample. }\end{array}$ & $\begin{array}{l}\text { Existing (non-Q) data: (Daily } \\
\text { and Ramirez, 1989) }\end{array}$ \\
\hline & $\begin{array}{l}\text { Sorptivity of desert varnish surfaces can be } \\
\text { greater than that of uncoated surfaces. }\end{array}$ & $\begin{array}{l}\text { Existing (non-Q) data: } \\
\text { (Chekuri et al., 1994) }\end{array}$ \\
\hline \multirow[t]{3}{*}{$\begin{array}{l}\text { 3.4 Flow } \\
\text { Channeling }\end{array}$} & $\begin{array}{l}\text { Intermittent, episodic flow occurs when liquid } \\
\text { islands drain through connecting "threads" that } \\
\text { snap off and reform. }\end{array}$ & \multirow[t]{3}{*}{$\begin{array}{l}\text { Existing (non-Q) data: (Geller } \\
\text { et al., 1996) }\end{array}$} \\
\hline & $\begin{array}{l}\text { Intermittent flow behavior decreases the effective } \\
\text { area through which fracture-matrix interaction can } \\
\text { occur. }\end{array}$ & \\
\hline & $\begin{array}{l}\text { Regions penetrated by initial flow can be } \\
\text { bypassed by subsequent flow. "Snap-off" } \\
\text { behavior tends to occur at low inclination angles, } \\
\text { and flow patterns are sensitive to the } \\
\text { gas/water/solid contact angle. }\end{array}$ & \\
\hline \multirow[t]{3}{*}{$\begin{array}{l}3.5 .1 \\
\text { Preferential Flow } \\
\text { Paths and Heat } \\
\text { Pipes }\end{array}$} & $\begin{array}{l}\text { Conditions for heat-pipe formation are a boiling } \\
\text { zone, space for counterflow, a condensation } \\
\text { zone, and a reflux driving force. Hydraulic } \\
\text { conditions must be such that significant vapor and } \\
\text { liquid flows occur. }\end{array}$ & \multirow[t]{3}{*}{$\begin{array}{l}\text { Qualified data: (Kneafsey and } \\
\text { Pruess, 1997) }\end{array}$} \\
\hline & $\begin{array}{l}\text { Heat pipes can be produced by reflux as film flow } \\
\text { or as episodic rivulet flow, depending on the rate. }\end{array}$ & \\
\hline & $\begin{array}{l}\text { Rapid evaporation events occur when liquid } \\
\text { islands become superheated and disperse } \\
\text { permeant at relatively high velocities. }\end{array}$ & \\
\hline \multirow[t]{2}{*}{$\begin{array}{l}\text { 3.6.1 Fracture } \\
\text { Healing }\end{array}$} & $\begin{array}{l}\text { The concentration of dissolved Si in fracture } \\
\text { effluent at elevated temperature may suggest } \\
\text { equilibrium with amorphous silica, but crystalline } \\
\text { forms have been observed on SEM inspection. }\end{array}$ & \multirow[t]{2}{*}{$\begin{array}{l}\text { Existing (non-Q) data: (Lin } \\
\text { and Daily, 1989) }\end{array}$} \\
\hline & $\begin{array}{l}\text { Naturally occurring spherical siliceous structures } \\
\text { are dissolved and replaced by tabular crystalline } \\
\text { precipitates in laboratory experiments. }\end{array}$ & \\
\hline $\begin{array}{l}\text { 3.6.2.2 Water } \\
\text { Chemistry in } \\
\text { Matrix-Flow } \\
\text { Experiments }\end{array}$ & $\begin{array}{l}\text { During matrix flow, effluent } \mathrm{pH} \text { declines gradually } \\
\text { from slightly alkaline to nearly neutral. } \\
\text { Concentrations of } \mathrm{Si} \text {, major cations ( } \mathrm{Na}, \mathrm{K}, \mathrm{Ca}) \text {, } \\
\text { and major anions (sulfate, chloride, bicarbonate) } \\
\text { increase significantly then approach the influent } \\
\text { (J-13) concentrations, on initial exposure to rock }\end{array}$ & $\begin{array}{l}\text { Existing (non-Q) data: (Moore } \\
\text { et al., 1985) }\end{array}$ \\
\hline
\end{tabular}




\begin{tabular}{|c|c|c|}
\hline Section & Description of conclusion & Principal support \\
\hline & at elevated temperatures. & \\
\hline $\begin{array}{l}\text { 3.6.2.3 Changes } \\
\text { in J-13 Water } \\
\text { Chemistry from } \\
\text { Evaporation and } \\
\text { Boiling }\end{array}$ & $\begin{array}{l}\text { The only precipitates that develop in significant } \\
\text { abundance, even at relatively high degrees of } \\
\text { evaporation ( } 70 \% \text { to } 90 \%) \text {, are carbonates and } \mathrm{Si}- \\
\text { polymorphs. For greater evaporation, brines will } \\
\text { form, and chloride salts can precipitate. }\end{array}$ & $\begin{array}{l}\text { Existing (non-Q) data: } \\
\text { (Glassley, 1995) }\end{array}$ \\
\hline $\begin{array}{l}\text { 3.6.3 Flow } \\
\text { Reactor } \\
\text { Experiments }\end{array}$ & $\begin{array}{l}\text { Reaction of crushed tuff with deionized water in a } \\
\text { flow-through reactor at } 240^{\circ} \mathrm{C} \text { was dominated by } \\
\text { dissolution of cristobalite and albite. }\end{array}$ & $\begin{array}{l}\text { Existing (non-Q) data: } \\
\text { (DeLoach et al., 1997) }\end{array}$ \\
\hline $\begin{array}{l}\text { 3.7.2.2 Matrix } \\
\text { Diffusion }\end{array}$ & $\begin{array}{l}\text { Physical retardation from fracture-matrix } \\
\text { interaction apparently decreased at elevated } \\
\text { temperatures. }\end{array}$ & $\begin{array}{l}\text { Qualified data: (Viani and } \\
\text { Carman, 1996) }\end{array}$ \\
\hline $\begin{array}{l}\text { 3.8.1. Nominal } \\
0.5-\mathrm{m} \text {-Scale } \\
\text { Laboratory } \\
\text { Experiments }\end{array}$ & $\begin{array}{l}\text { Long-term loading opened pre-existing cracks } \\
\text { oriented parallel to the maximum (uniaxial) stress, } \\
\text { and increased temperature caused some of these } \\
\text { cracks to close. }\end{array}$ & $\begin{array}{l}\text { Existing (non-Q) data: (Blair } \\
\text { and Berge, 1997) }\end{array}$ \\
\hline
\end{tabular}


Appendix 3A

Figures for Section 3.3.1 and Section 3.5.1 

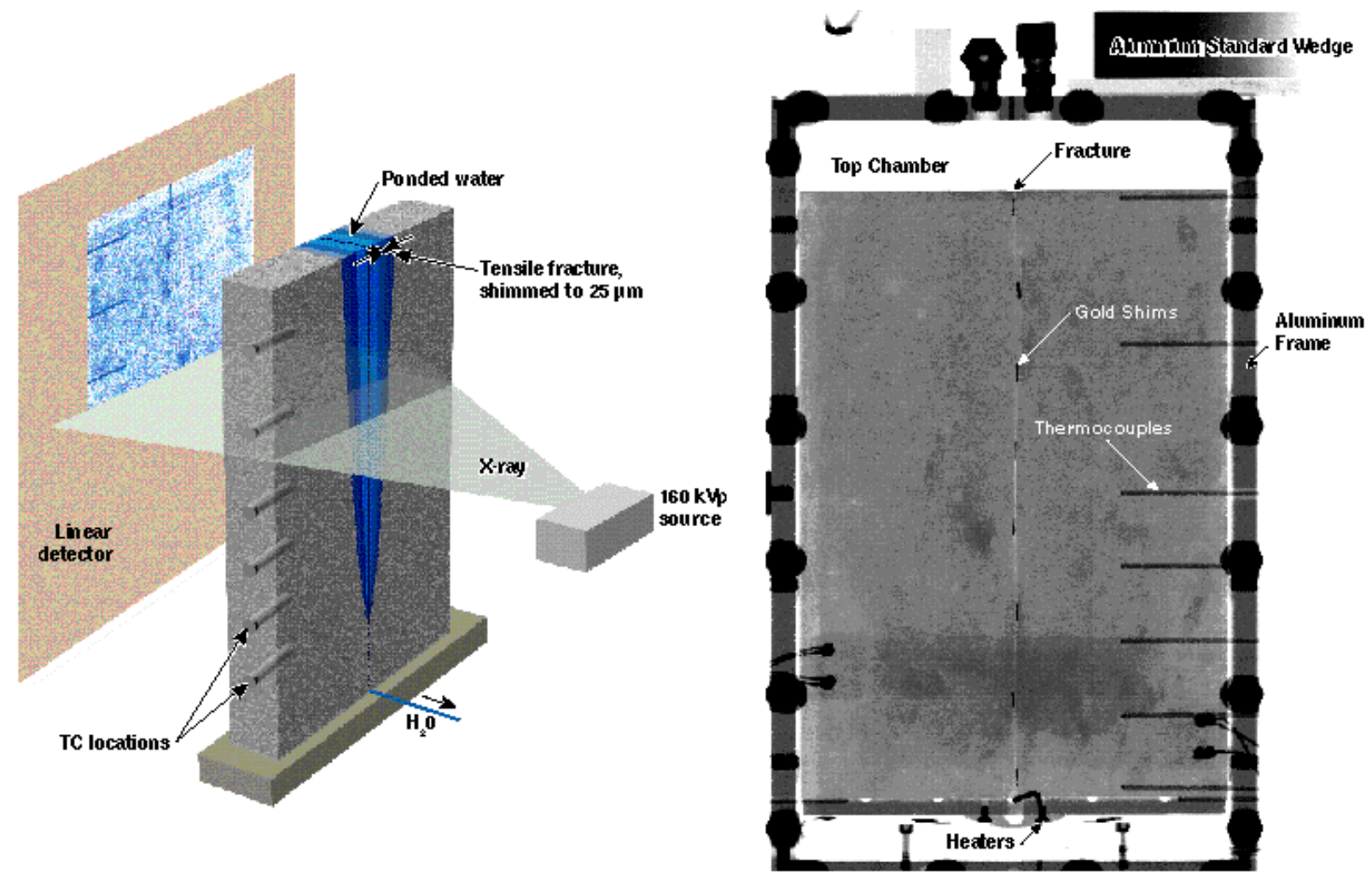

Figure 3-4. Schematic of $x$-ray radiograph system. Sample translates vertically through the $160 \mathrm{kVp}$ linear source. Detector stores digital data, line by line. One scan takes between one and two minutes, depending on sample height.

Figure 3-5. Radiograph of sample and assembly. Sample dimensions are $23 \times 15 \times 2.6 \mathrm{~cm}$. 


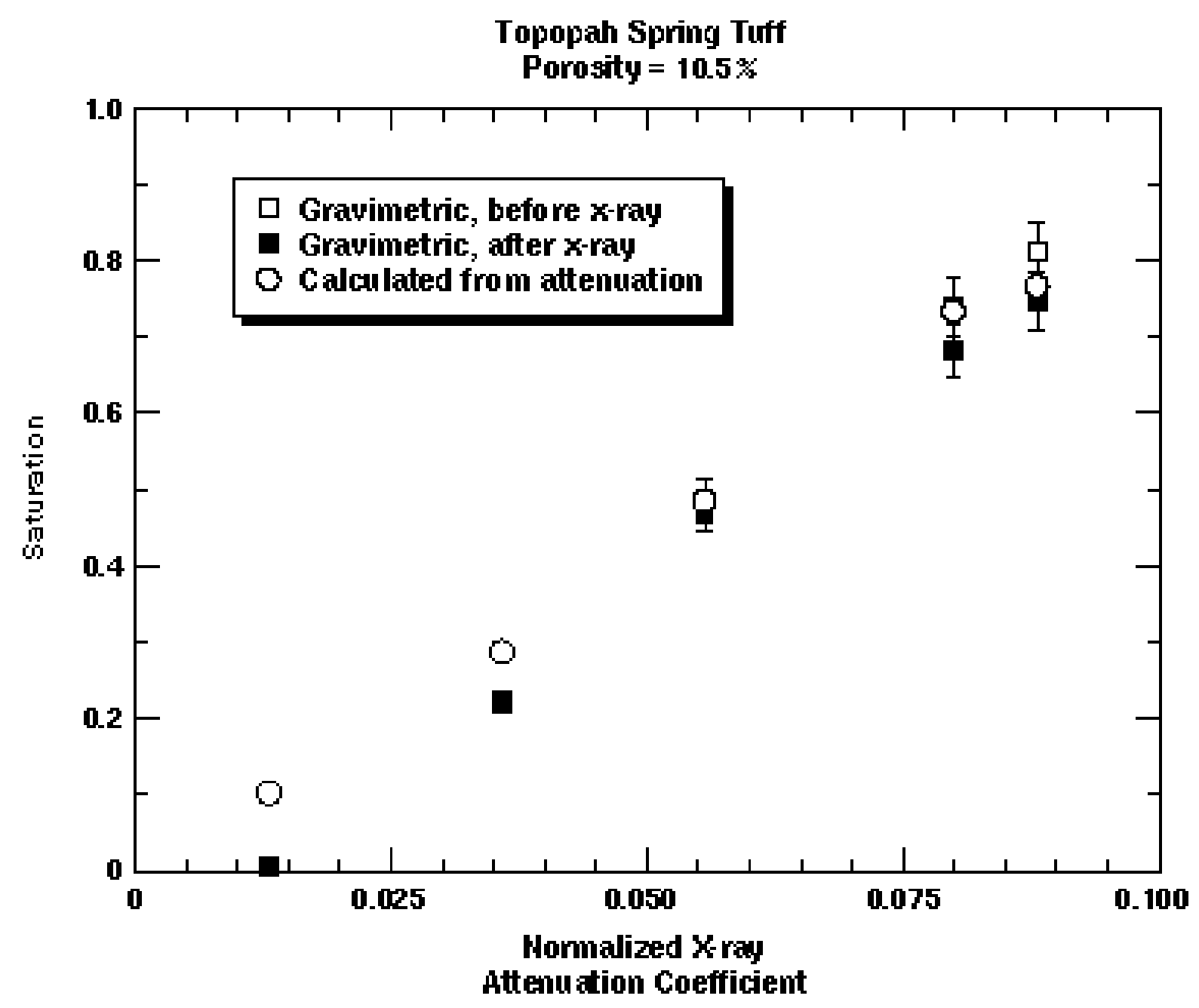

Figure 3-6. Saturation as a function of normalized x-ray attenuation coefficient for five samples of Topopah Spring tuff. The average porosity of the tuff is $10.5 \pm 0.1 \%$. Samples were prepared to specific saturations that were redetermined gravimetrically before and after radiography (open and filled squares). Open circles indicate saturation calculated from radiographs using Equation 5. 

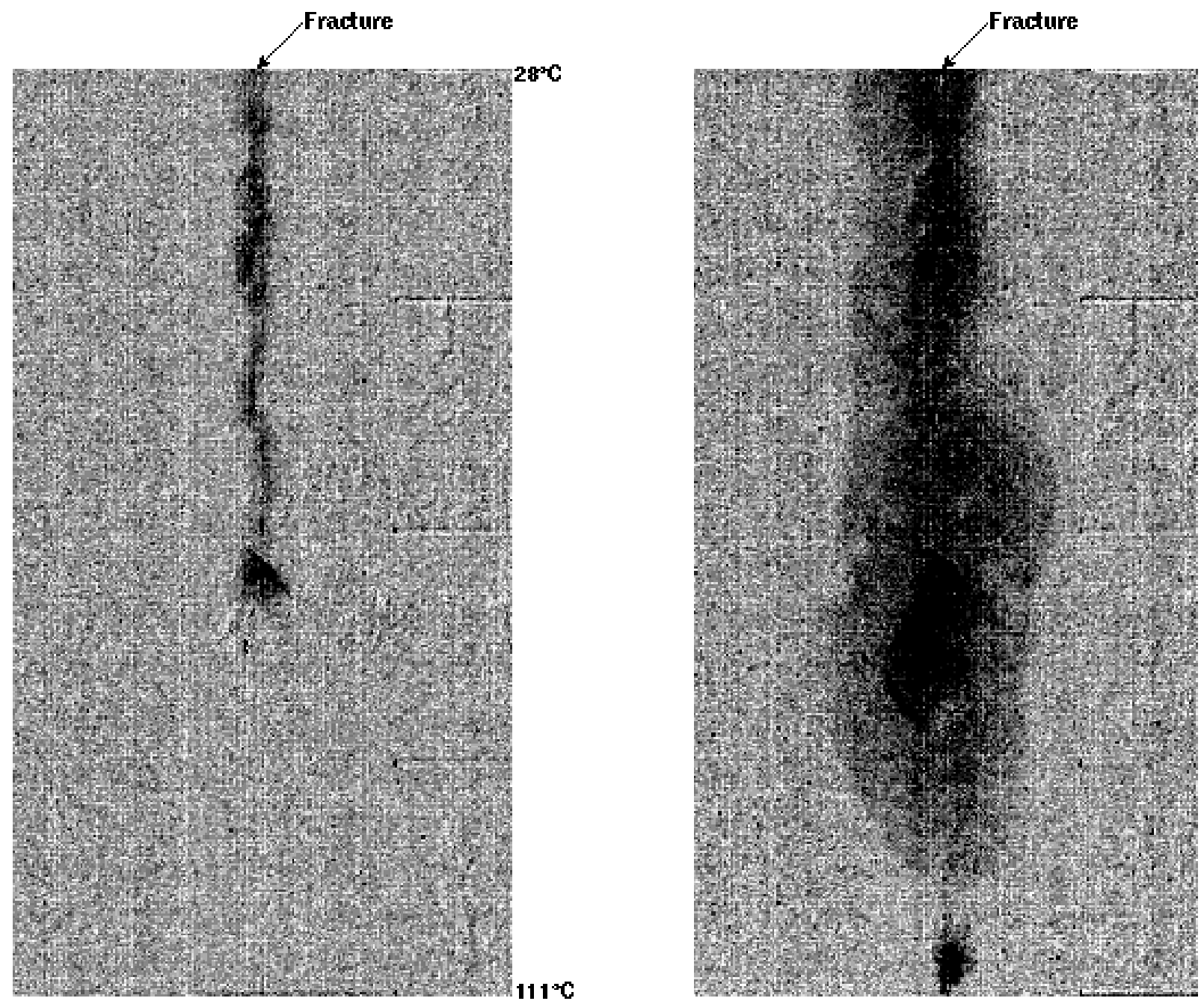

Figure 3-7. Difference radiographs of FR5. Darker shades indicate increased x-ray attenuation compared to the initial image and, hence, increased saturation. Images were taken 1.7 (a) and 73.5 (b) hours after flow was initiated. The first image shows a stoppage of flow along the fracture that was caused by the presence of a relatively porour region intersected by the fracture. The second image shows progression of the watting front past the highlyporous region to the boiling zone. See text for futher discussion. 

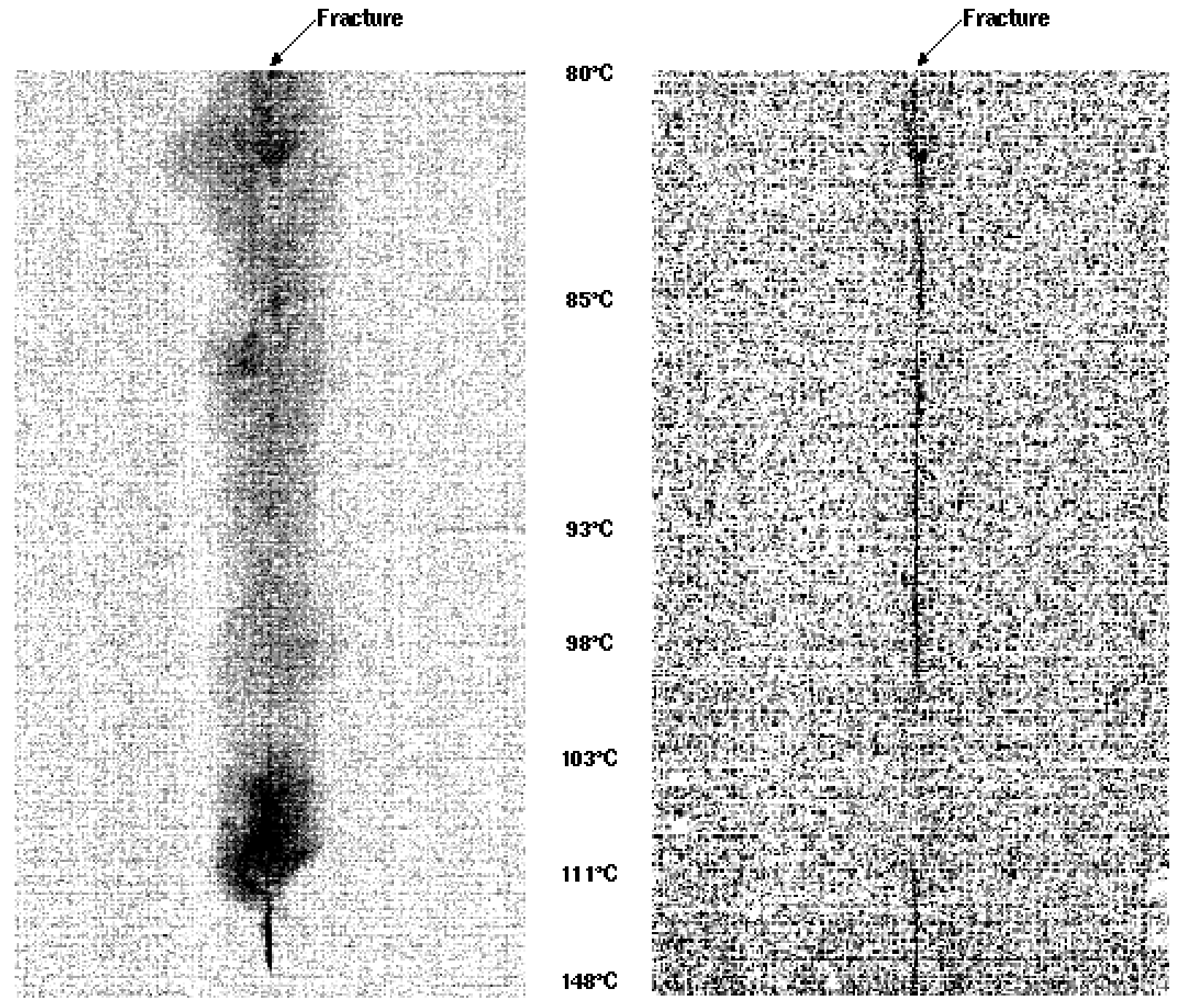

Figure 3-8. Difference images of FR6 (a) and FR6b (b), 7.2 and 0.67 hours after flow was initiated. thermal gradient is indicated between the figures. The difference between these two experiments was the height of the water column, 0.26 and $0.46 \mathrm{~m}$ for FR6 anf FR 6b, respectively. The difference in head was large enough to force flow through the boiling region during FR $6 \mathrm{~b}$. 


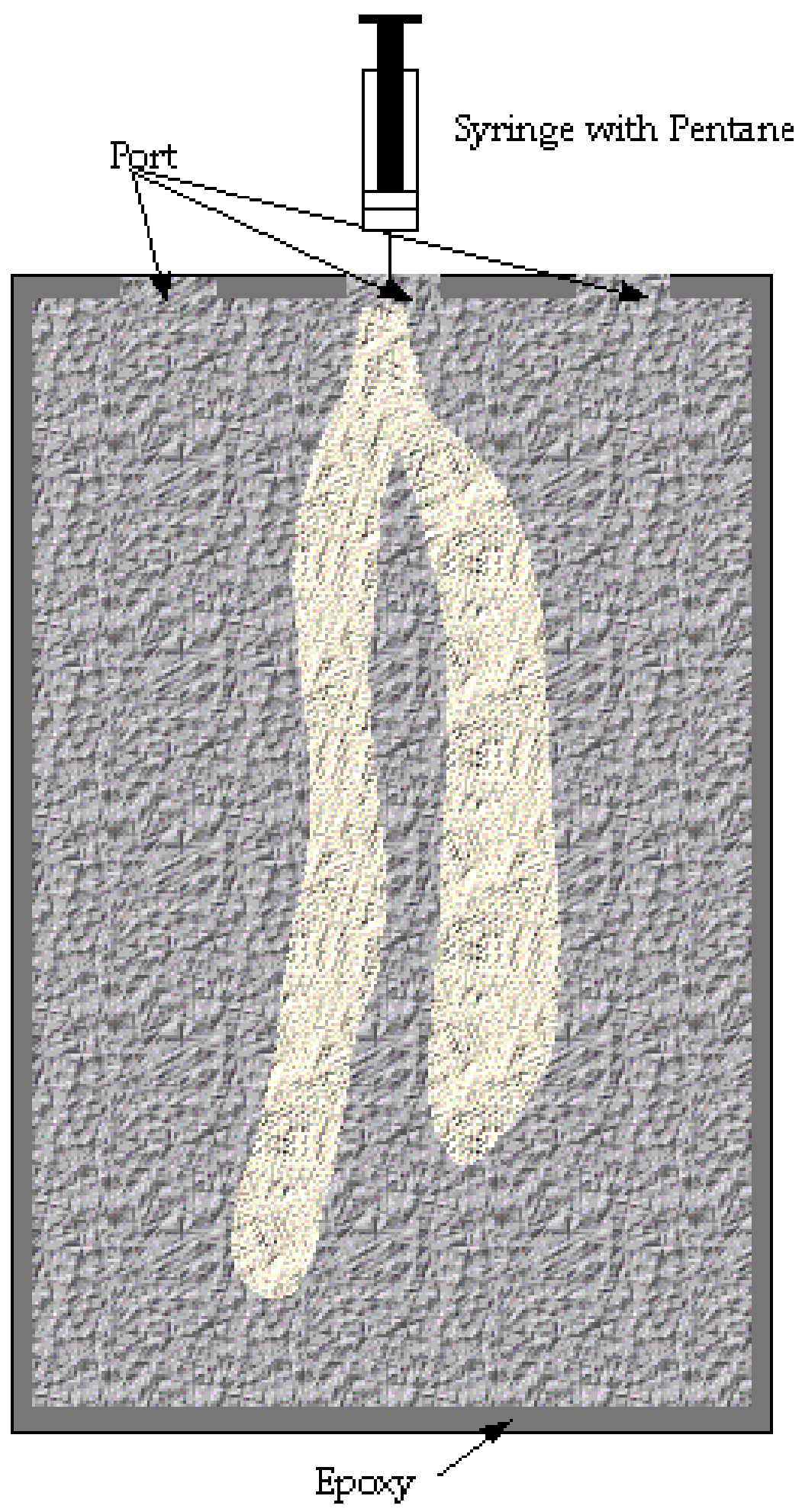

Figure 3-11. Glass fracture model 

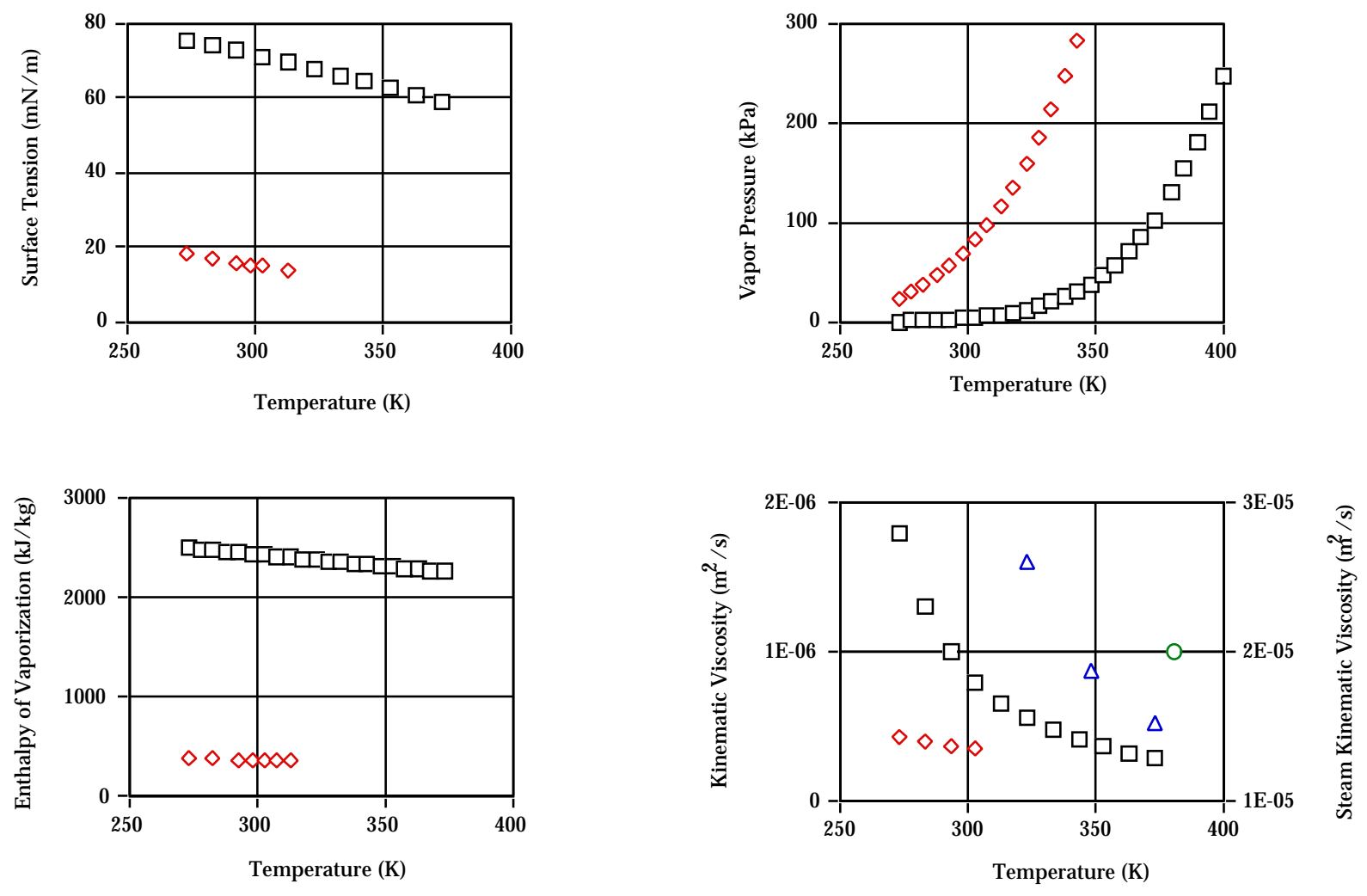

\begin{tabular}{|c|c|c|c|c|c|c|c|}
\hline$\square$ & Water & $\diamond$ & Pentane & 0 & Steam & $\Delta$ & Pentane Vapor \\
\hline
\end{tabular}

Figure 3-12. Water and pentane properties 


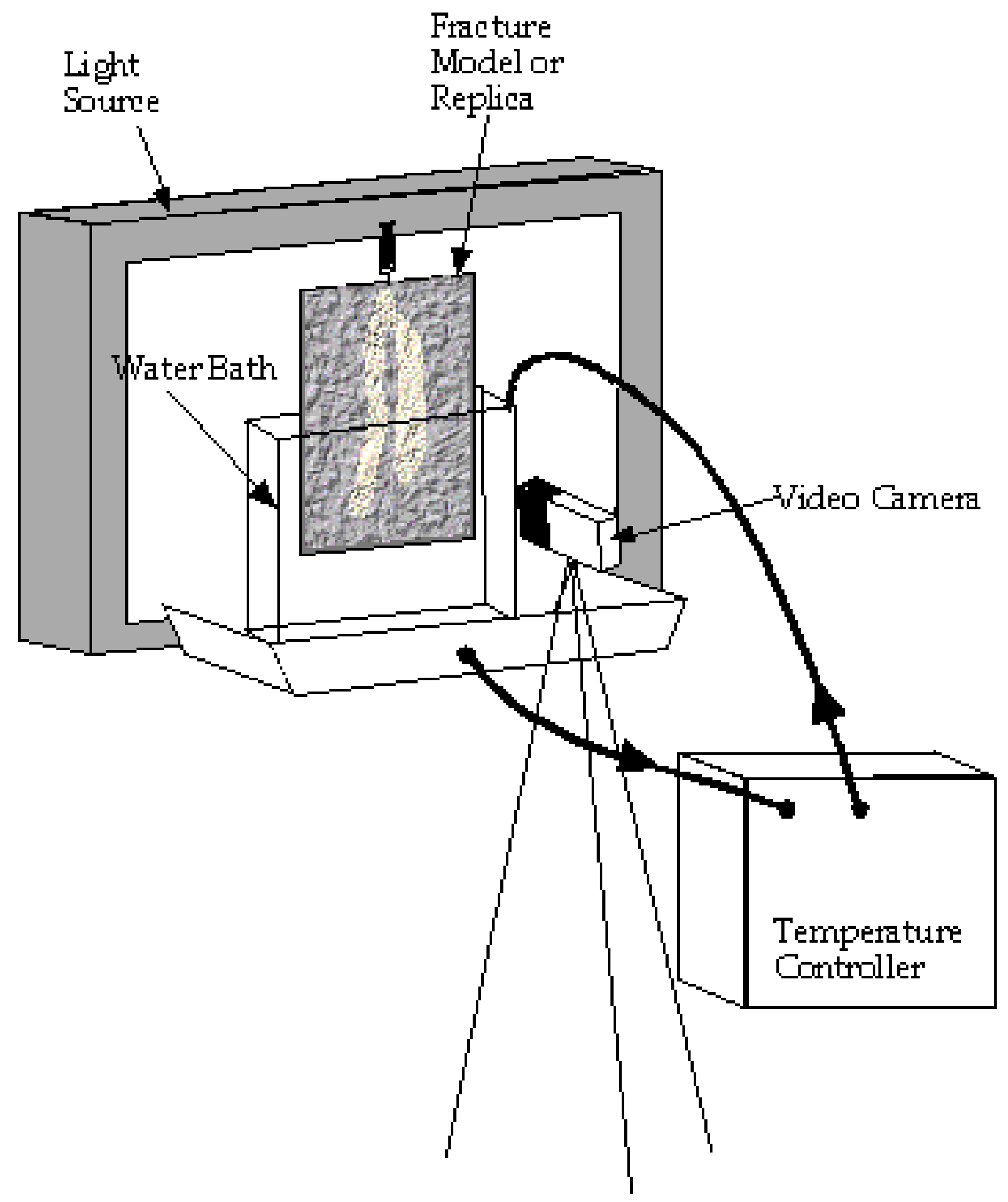

Figure 3-13. Experiment setup 



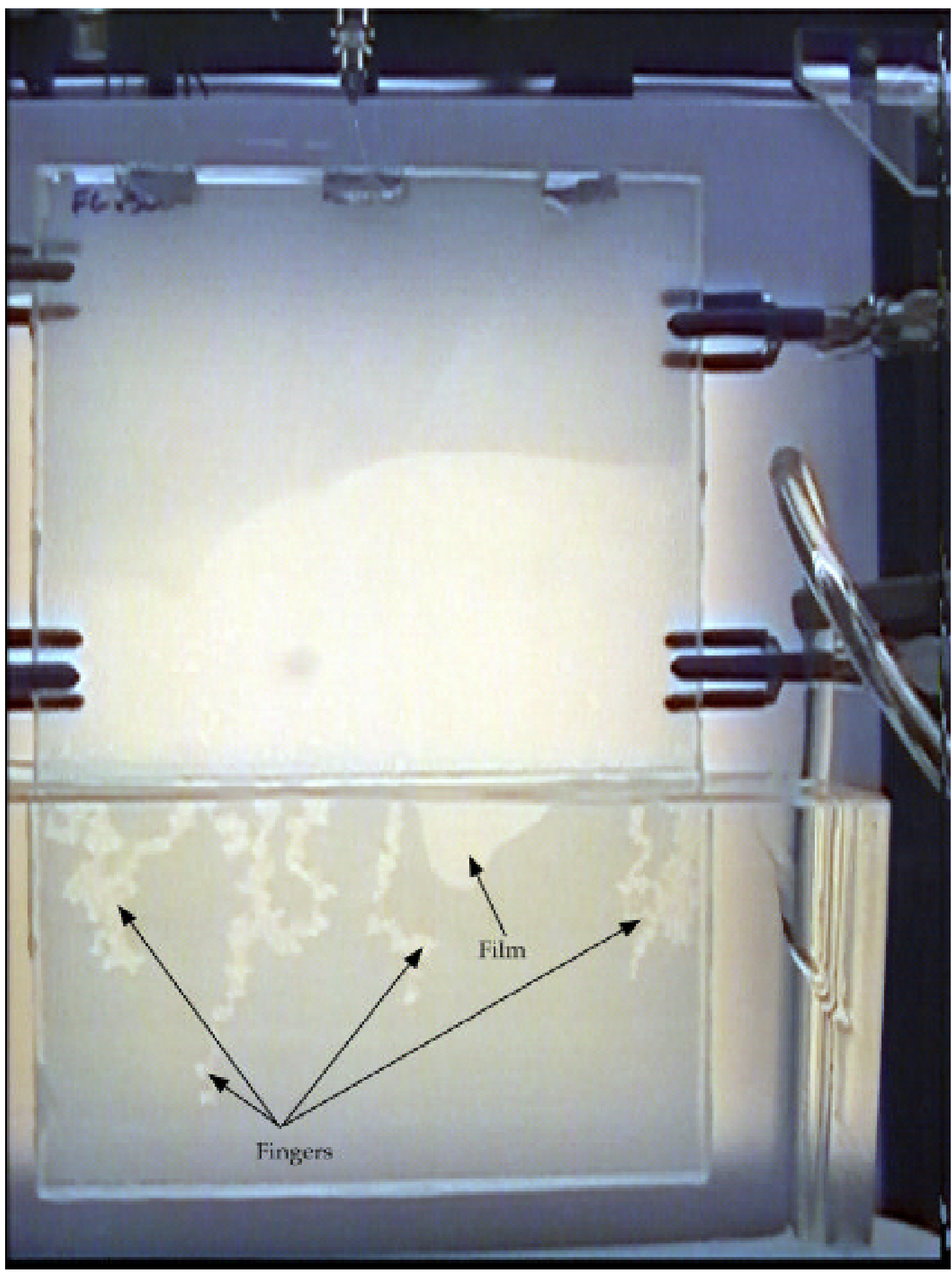

Figure 3-15. Fingers and films. Experiment $1: 37.2^{\circ} \mathrm{C}<\mathrm{T}_{\text {bath }}<27.6^{\circ} \mathrm{C}$ 

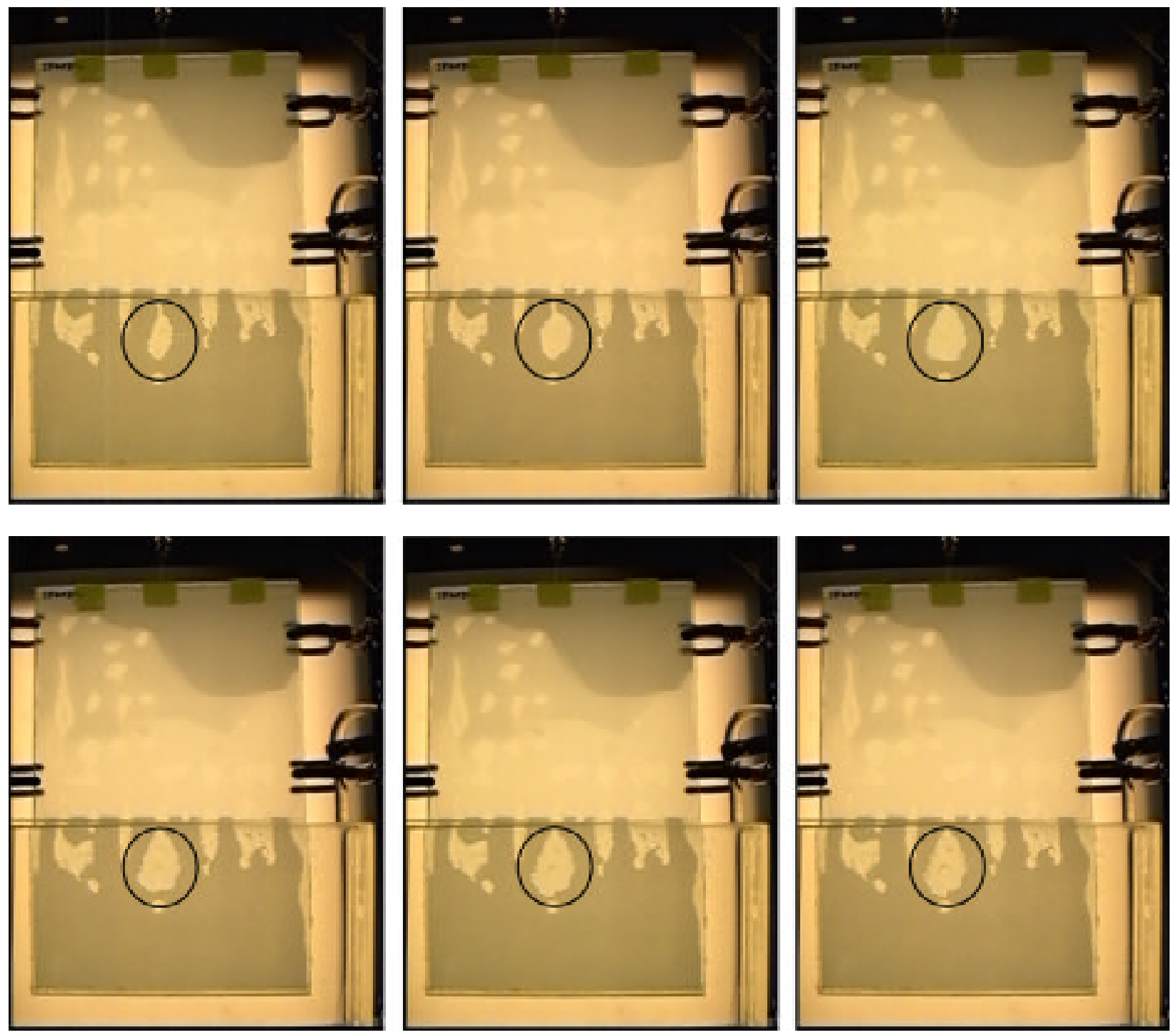

Figure 3-16. Fingers and rapid evaporation event. Experiment 6: 1/30 second between frames, $\mathrm{T}_{\text {bath }}=37.4^{\circ} \mathrm{C}$ 


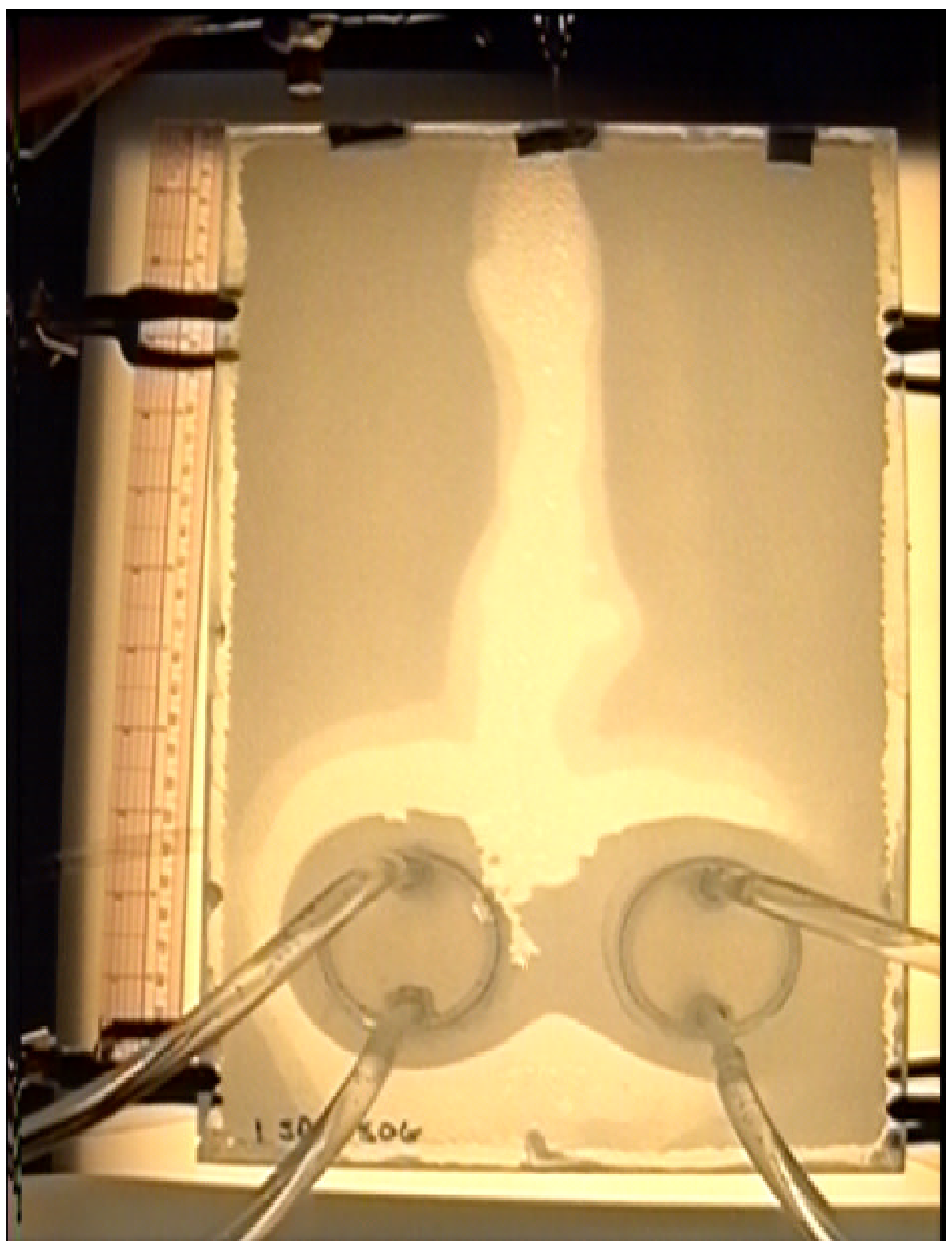

Figure 3-17. Finger between and through warmed circles. Experiment 7: $\mathrm{T}_{\text {reg }}=50.6^{\circ} \mathrm{C}$ 


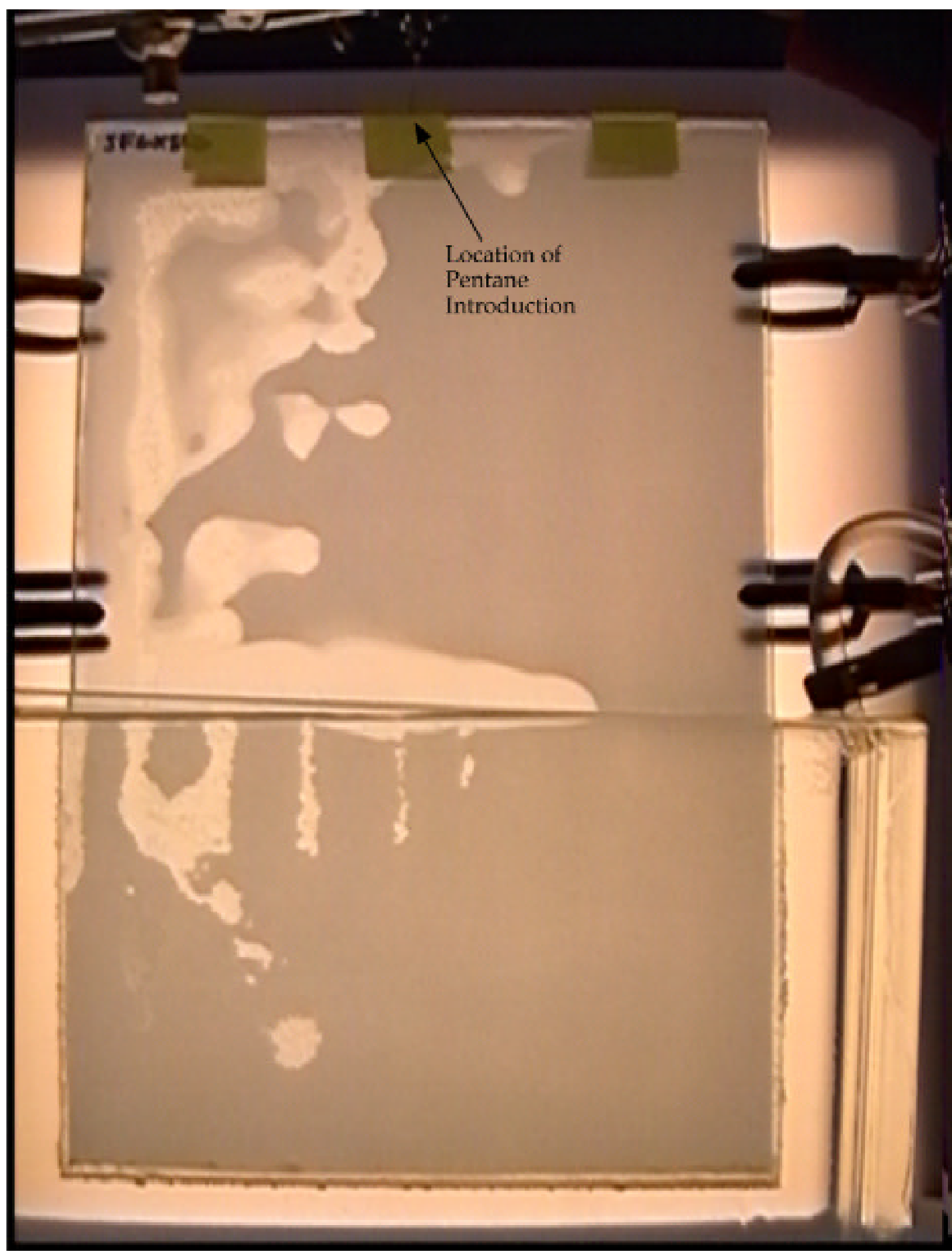

Figure 3-18. Infiltration and condensation halo formation. Experiment 9: $\mathrm{T}_{\text {bath }}=36.5^{\circ} \mathrm{C}$ 

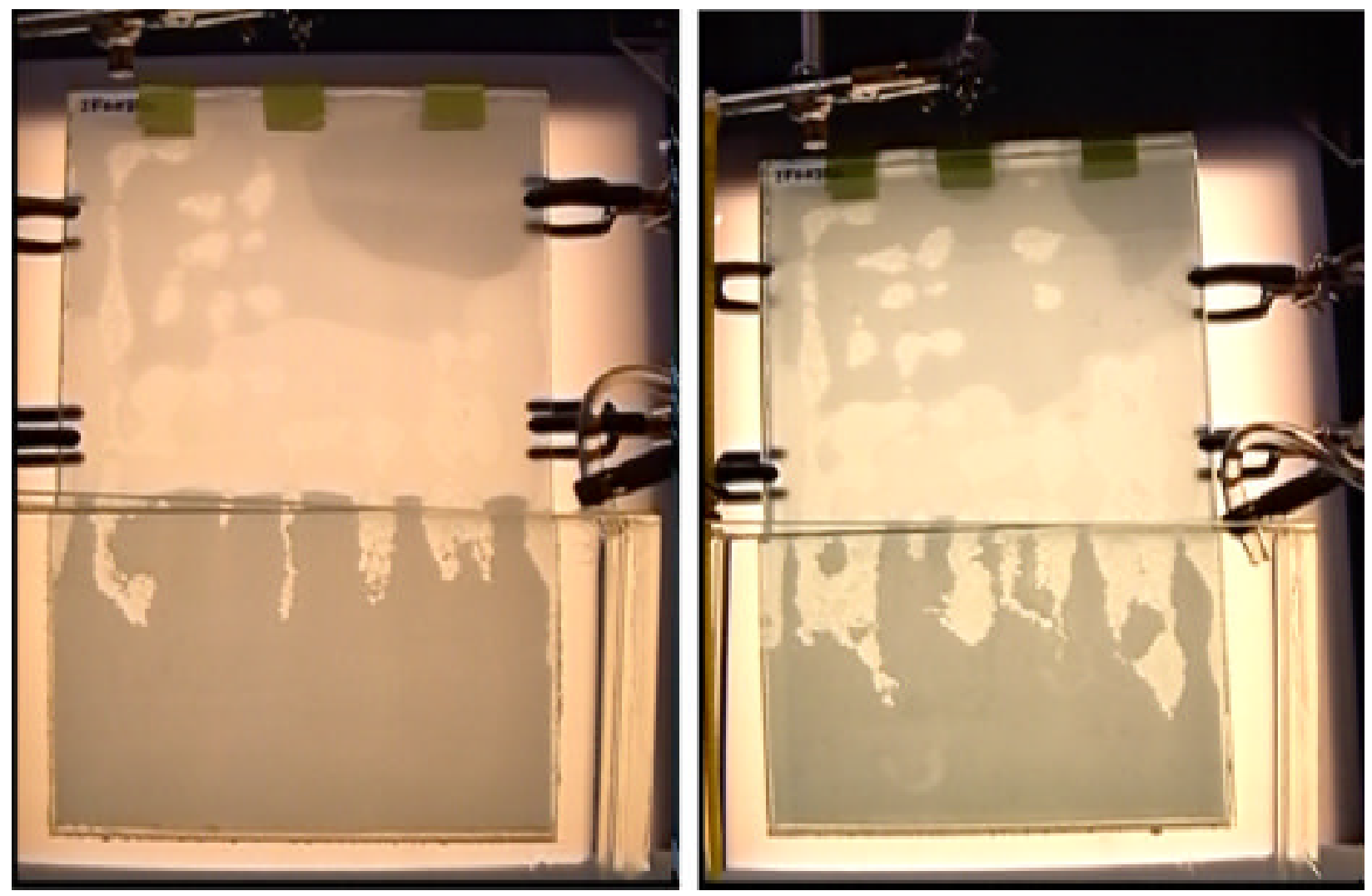

Figure 3-19. Finger length and width. Experiment 9: thin glass (left); thick glass (right); $\mathrm{T}_{\text {bath }}=38.8^{\circ} \mathrm{C}$ 


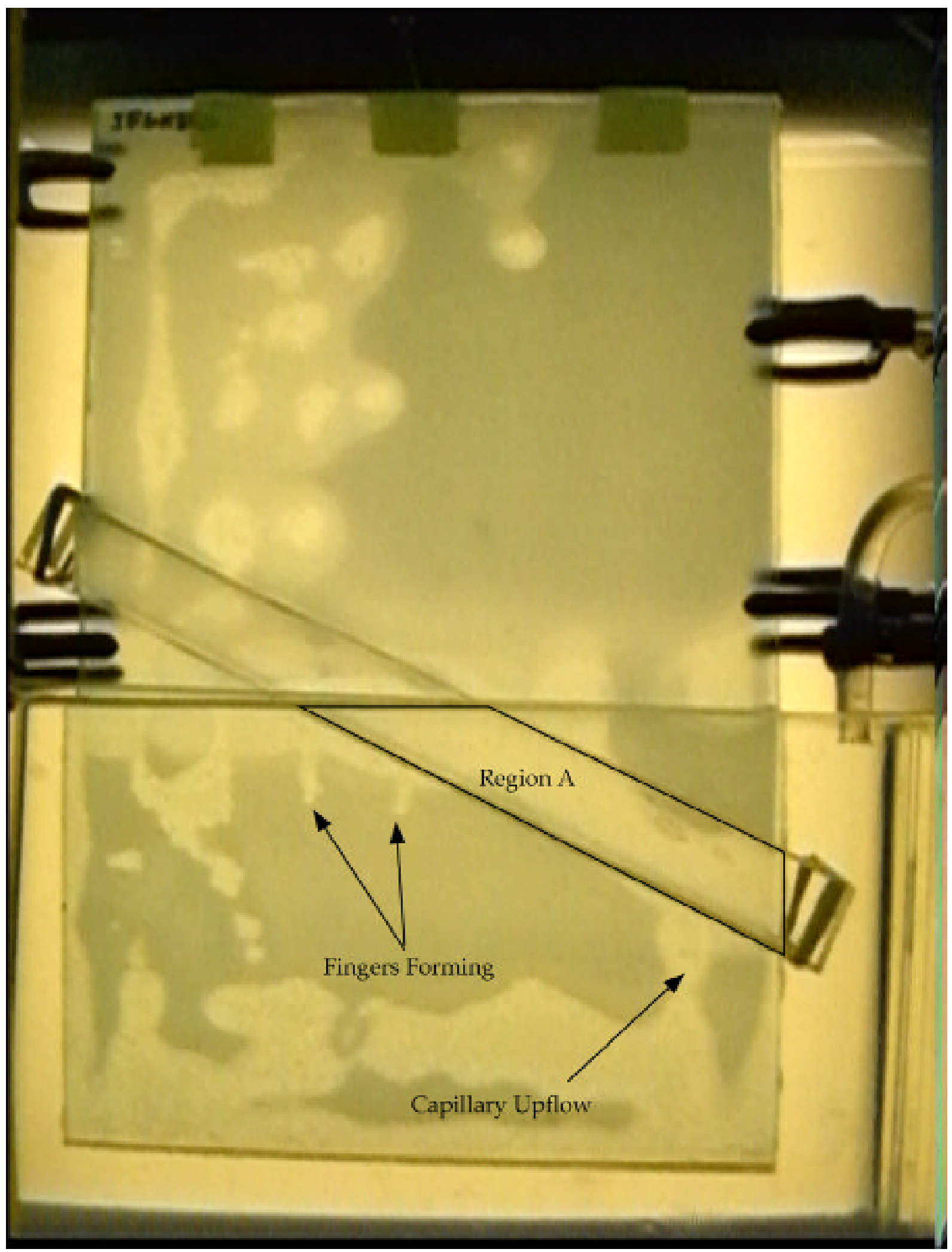

Figure 3-20. Fingers forming in model with Lexan strips on heating. Experiment 10: $35.6^{\circ} \mathrm{C}<\mathrm{T}_{\text {bath }}<36.4^{\circ} \mathrm{C}$ 


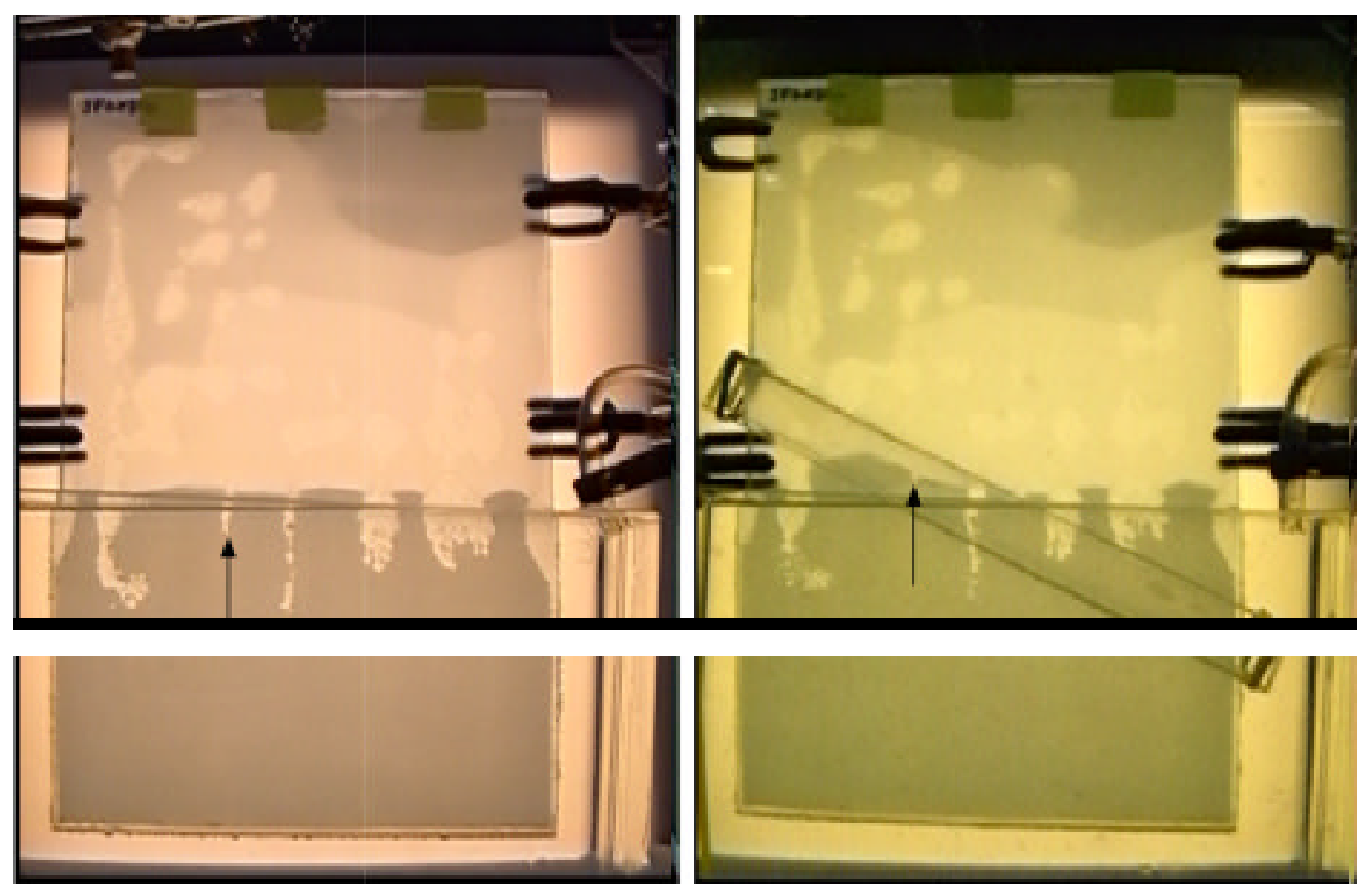

Figure 3-21. Finger length altered by heterogeneous heat transfer. Experiments 9 and 10: $\mathrm{T}_{\text {bath }}=39.6^{\circ} \mathrm{C}, 39.8^{\circ} \mathrm{C}$ 


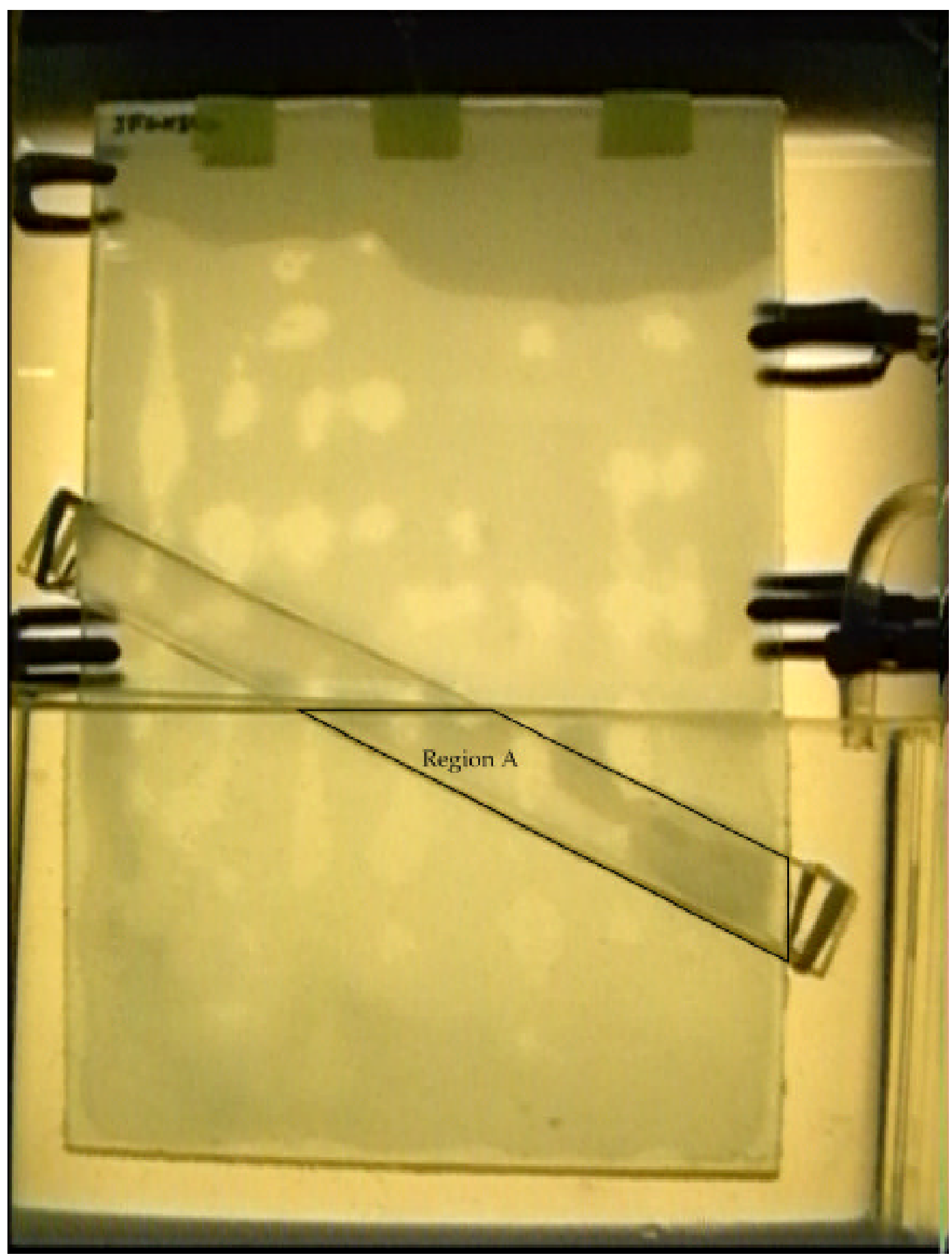

Figure 3-22. Film development and hindered flow in Region A. Experiment 10: Tbath = $35.2^{\circ} \mathrm{C}$ 


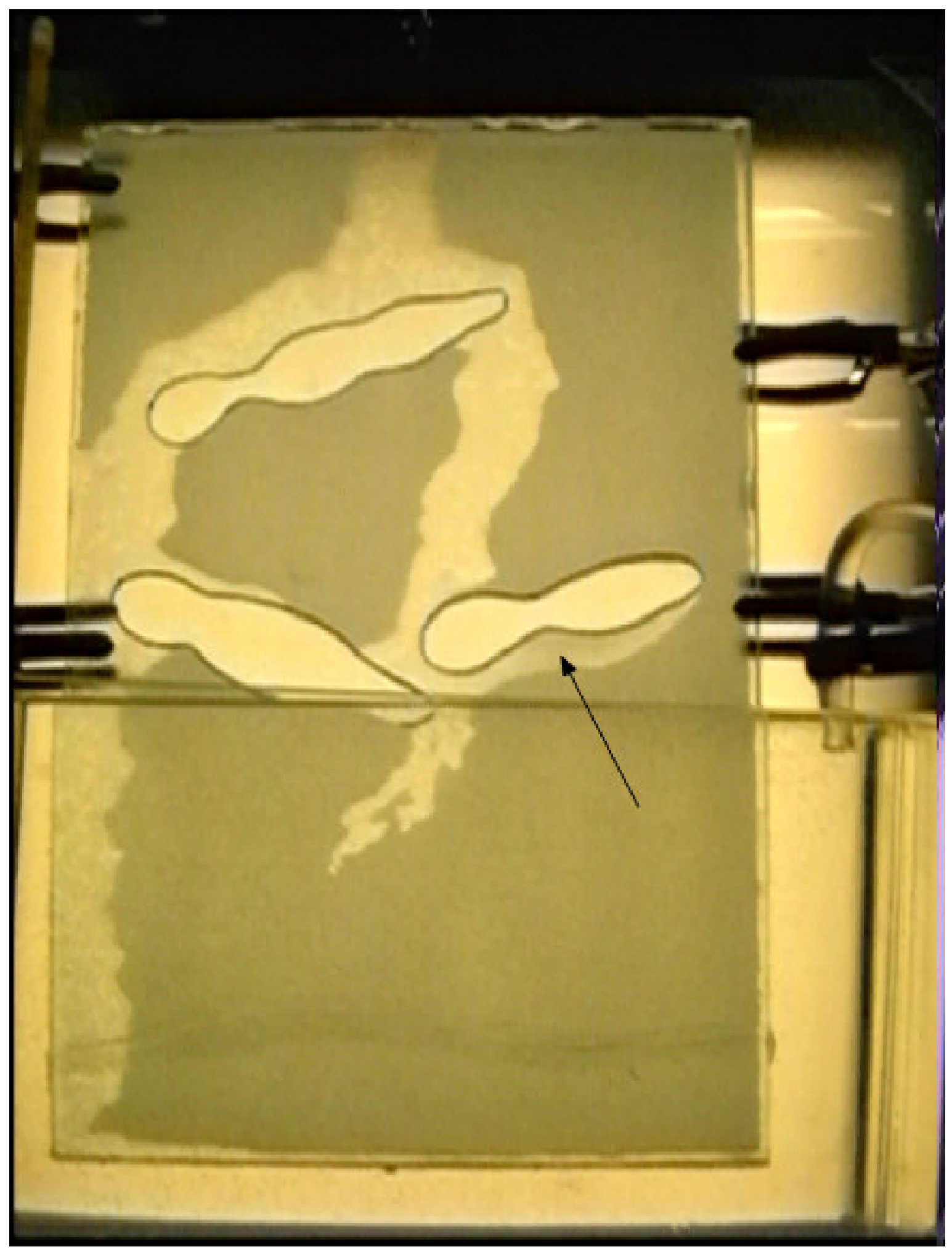

Figure 3-23. Seepage through model with impermeable barriers. Condensation halo is identified with an arrow. Experiment 11: $\mathrm{T}_{\text {bath }}=35.3^{\circ} \mathrm{C}$ 


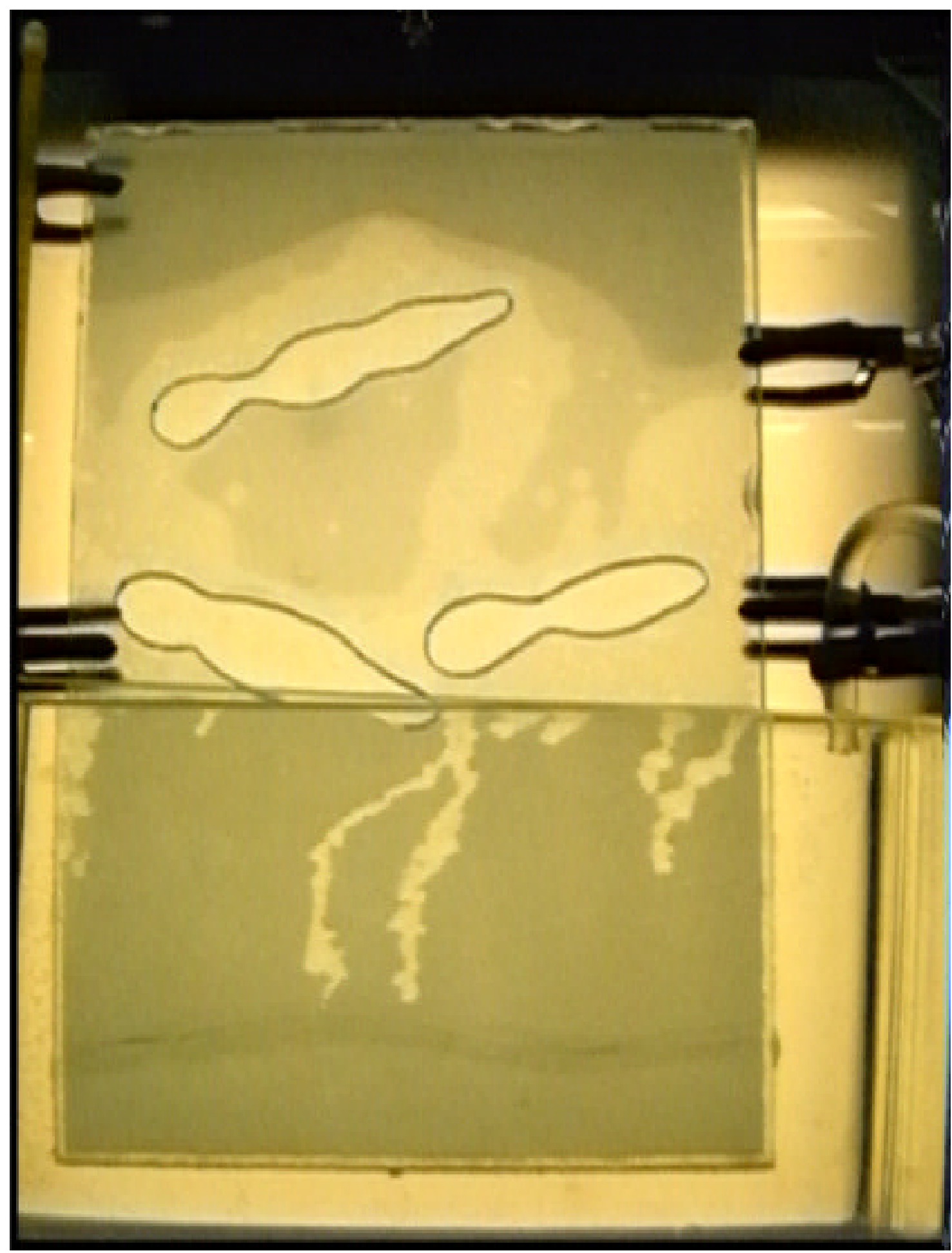

Figure 3-24. Longer fingers through model center. Experiment 11: $\mathrm{T}_{\text {bath }}=37.1^{\circ} \mathrm{C}$ 


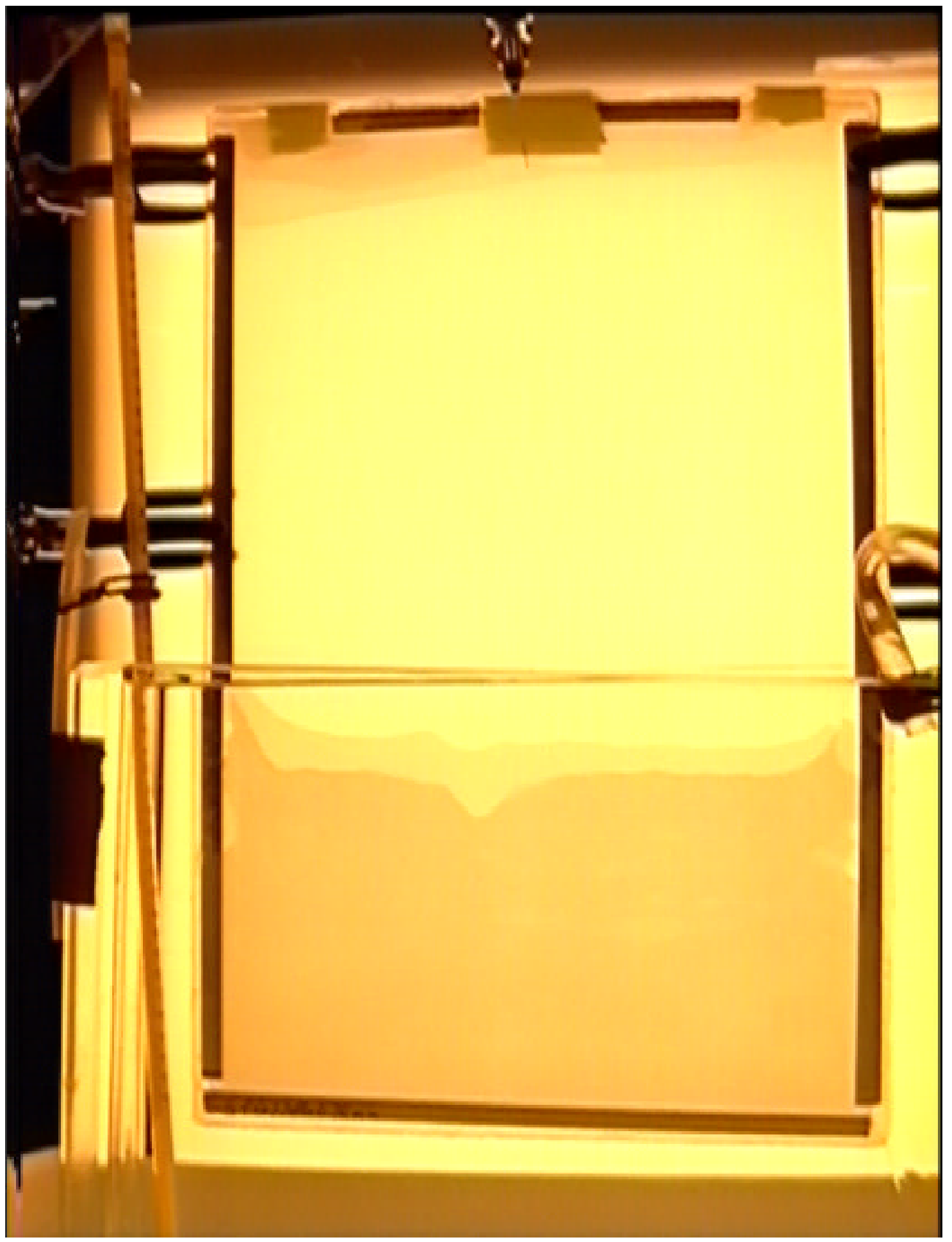

Figure 3-25. Pentane films. Experiment $12: 38.6^{\circ} \mathrm{C}<\mathrm{T}_{\text {bath }}<38.8^{\circ} \mathrm{C}$ 


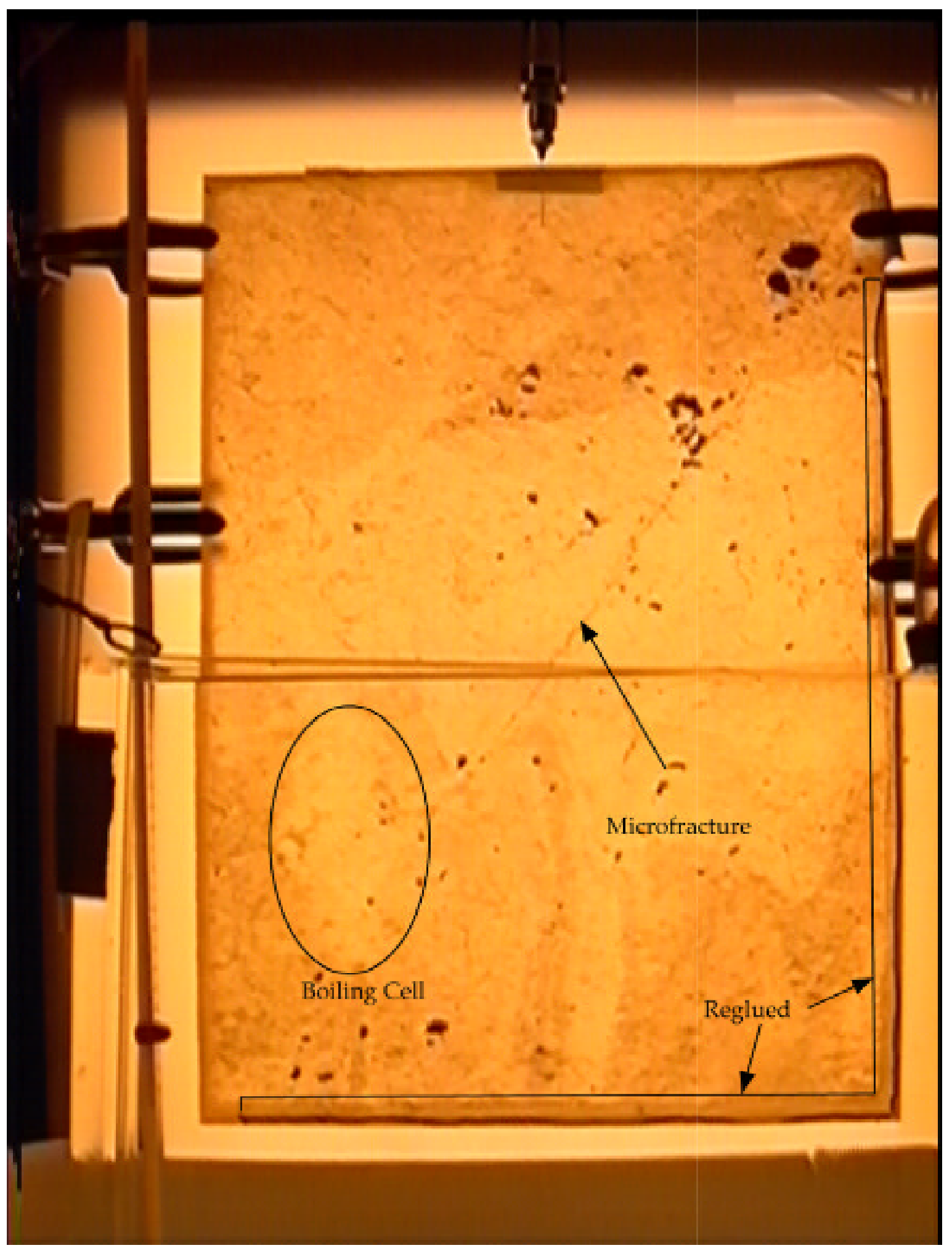

Figure 3-26. Films and fingers. Experiment $15: \mathrm{T}_{\text {bath }}=39.0^{\circ} \mathrm{C}$ 


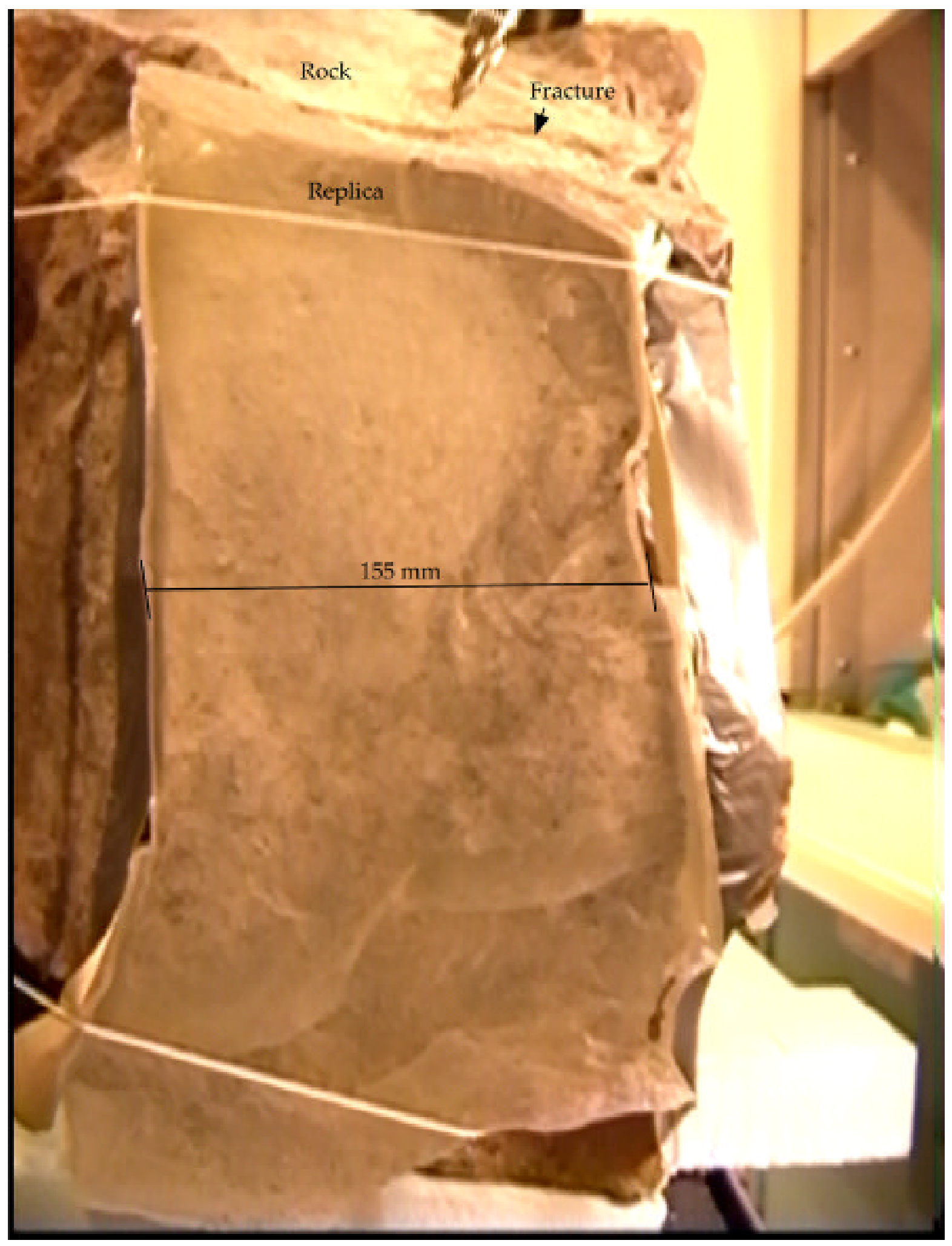

Figure 3-27. Rock-replica setup. Experiment 16 


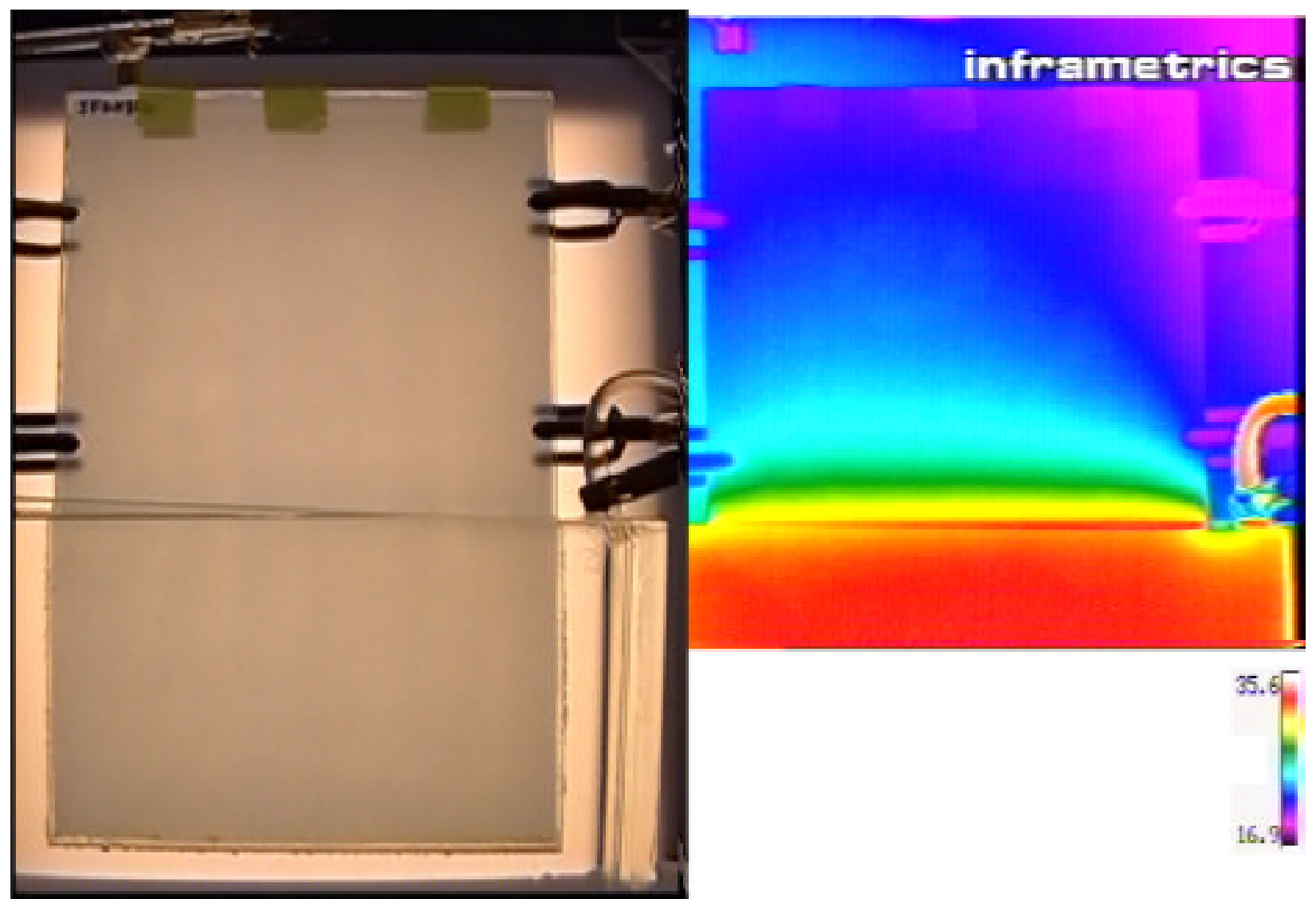

Figure 3-28. Initial model condition and temperature distribution. Note steep temperature gradient near water bath. Experiment 9: $\mathrm{T}_{\text {bath }}=36.4^{\circ} \mathrm{C}$ 

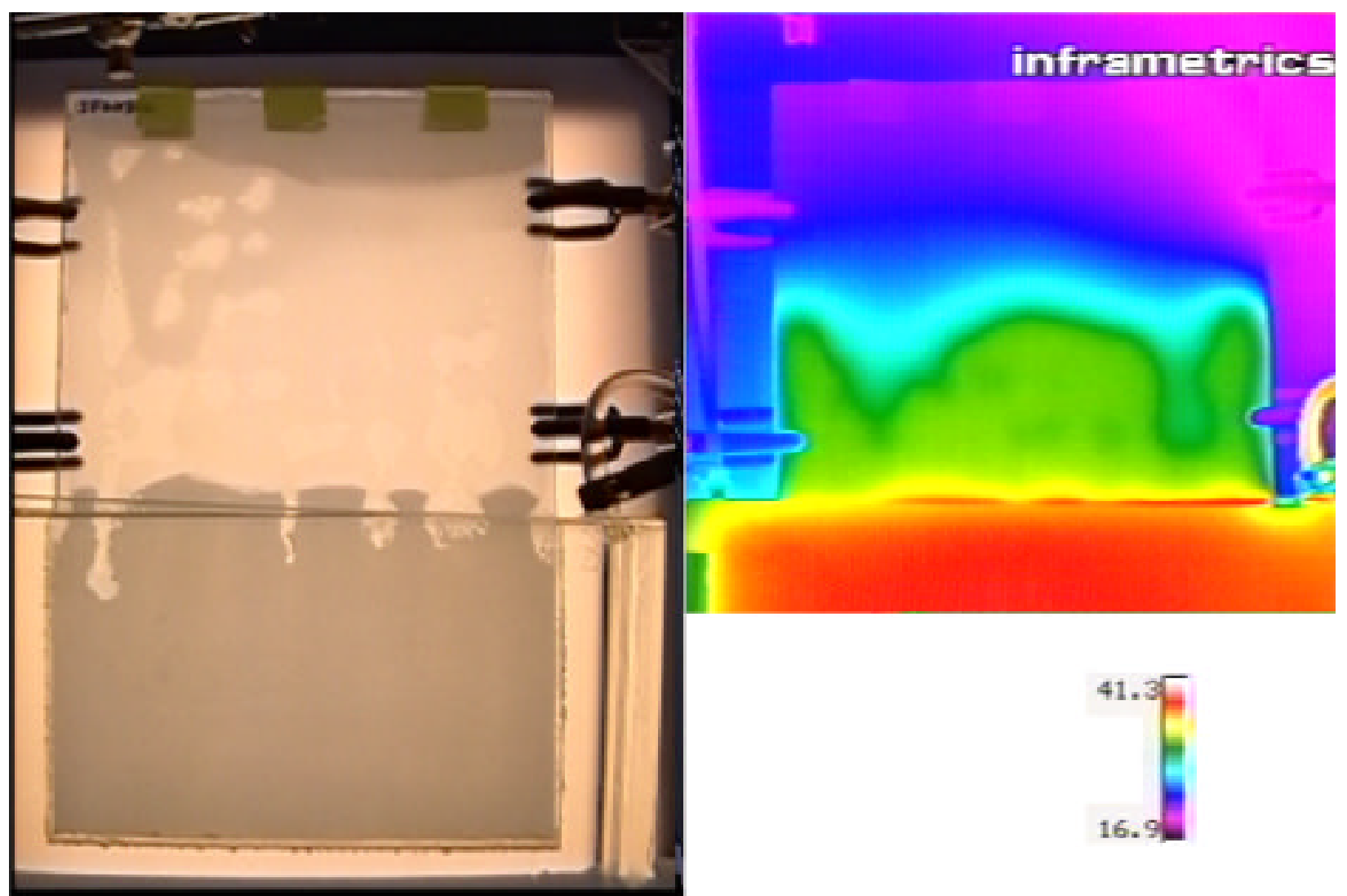

Figure 3-29. Pentane and temperature distribution showing heat pipe. Experiment 9: $\mathrm{T}_{\text {bath }}=42.4^{\circ} \mathrm{C}$ 


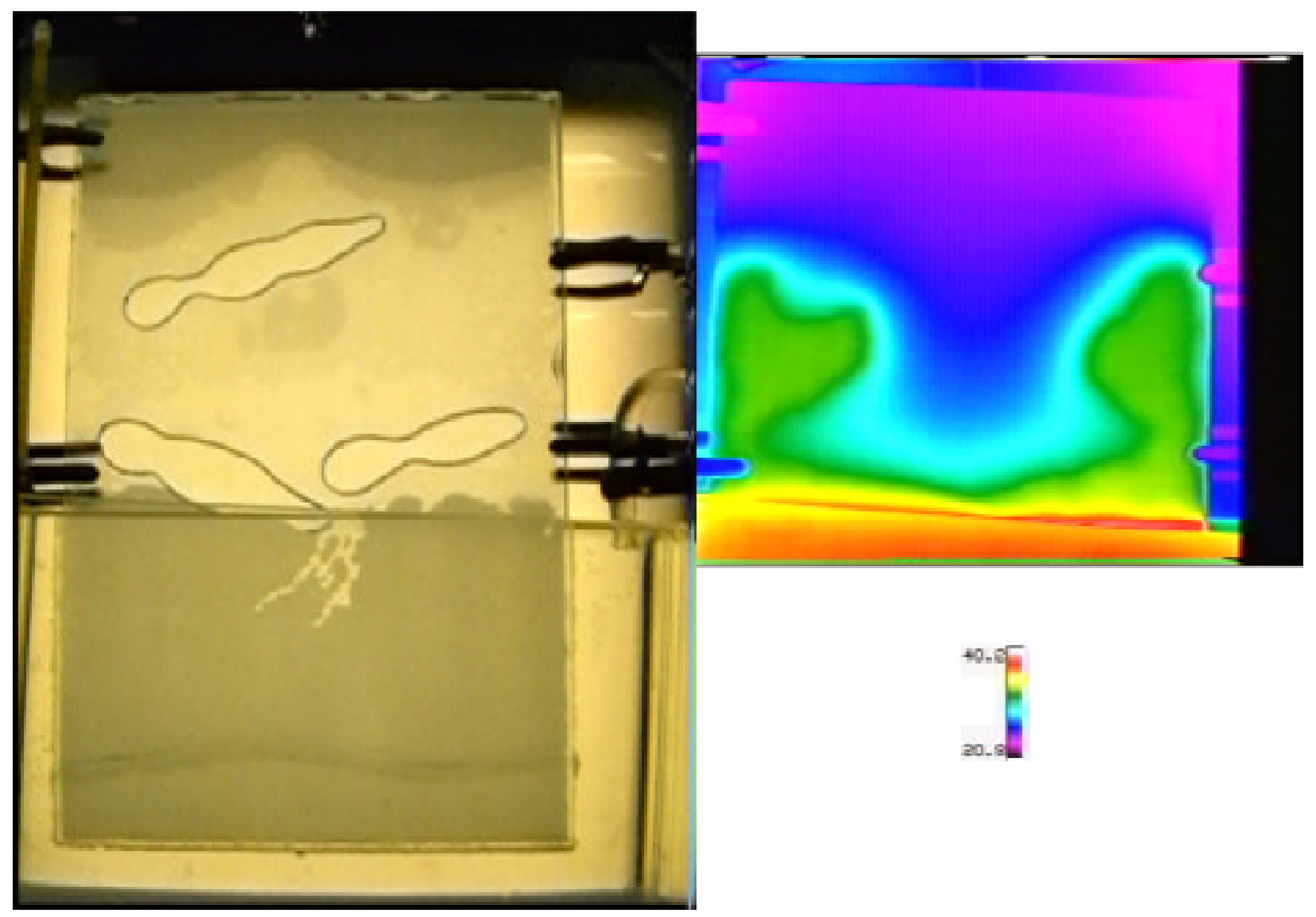

Figure 3-30. Pentane and temperature distributions showing heat pipes on left and right sides. Experiment 11: $\mathrm{T}_{\text {bath }}=41.3^{\circ} \mathrm{C}$ 


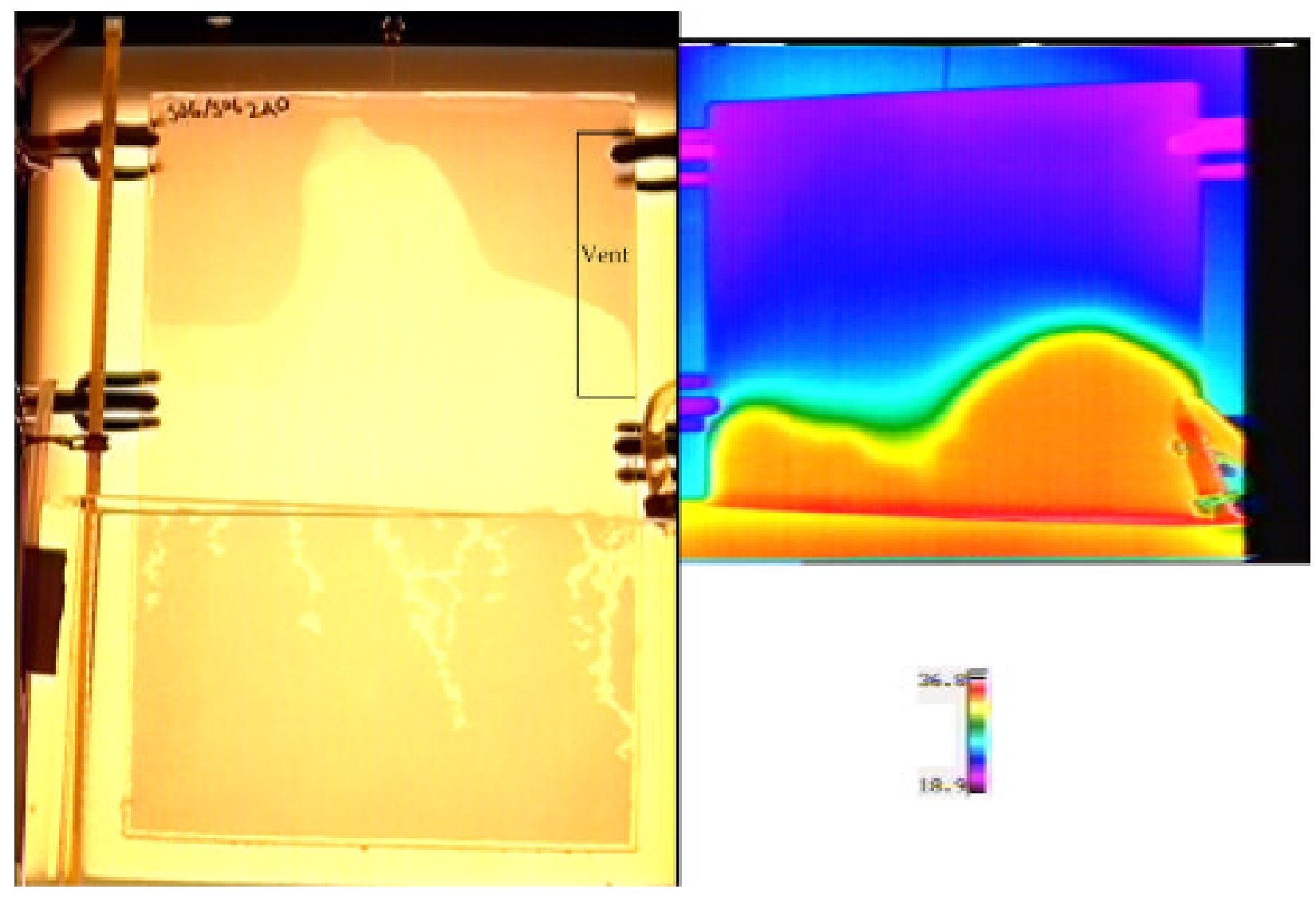

Figure 3-31. Pentane and temperature distribution. Experiment 13: $37.2^{\circ} \mathrm{C}<\mathrm{T}_{\text {bath }}$ $<37.8^{\circ} \mathrm{C}, 37.2^{\circ} \mathrm{C}$ 


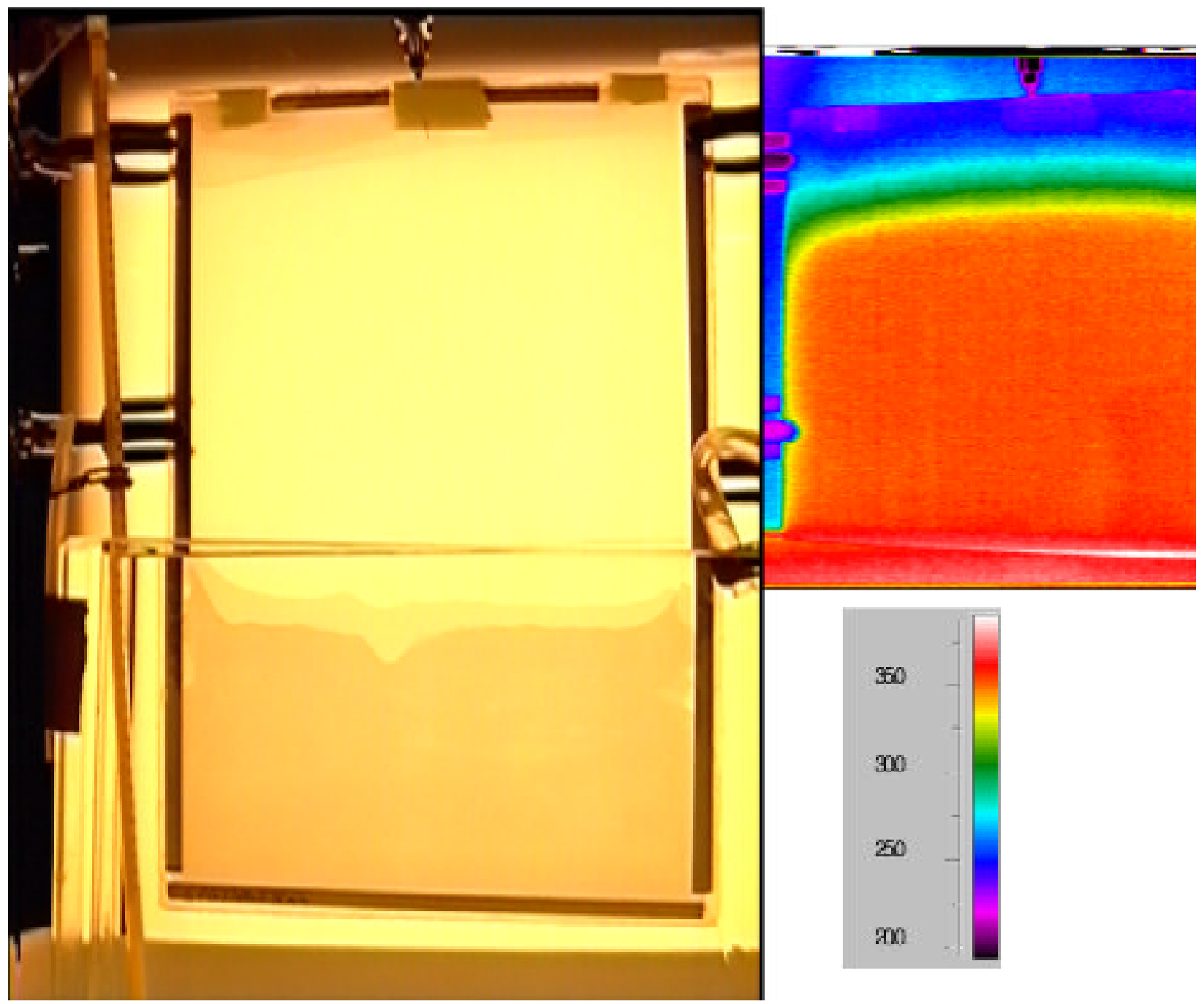

Figure 3-32. Pentane and temperature distributions showing heat pipe. Experiment 12: $38.6^{\circ} \mathrm{C}<\mathrm{T}_{\text {bath }}<38.8^{\circ} \mathrm{C}$ 


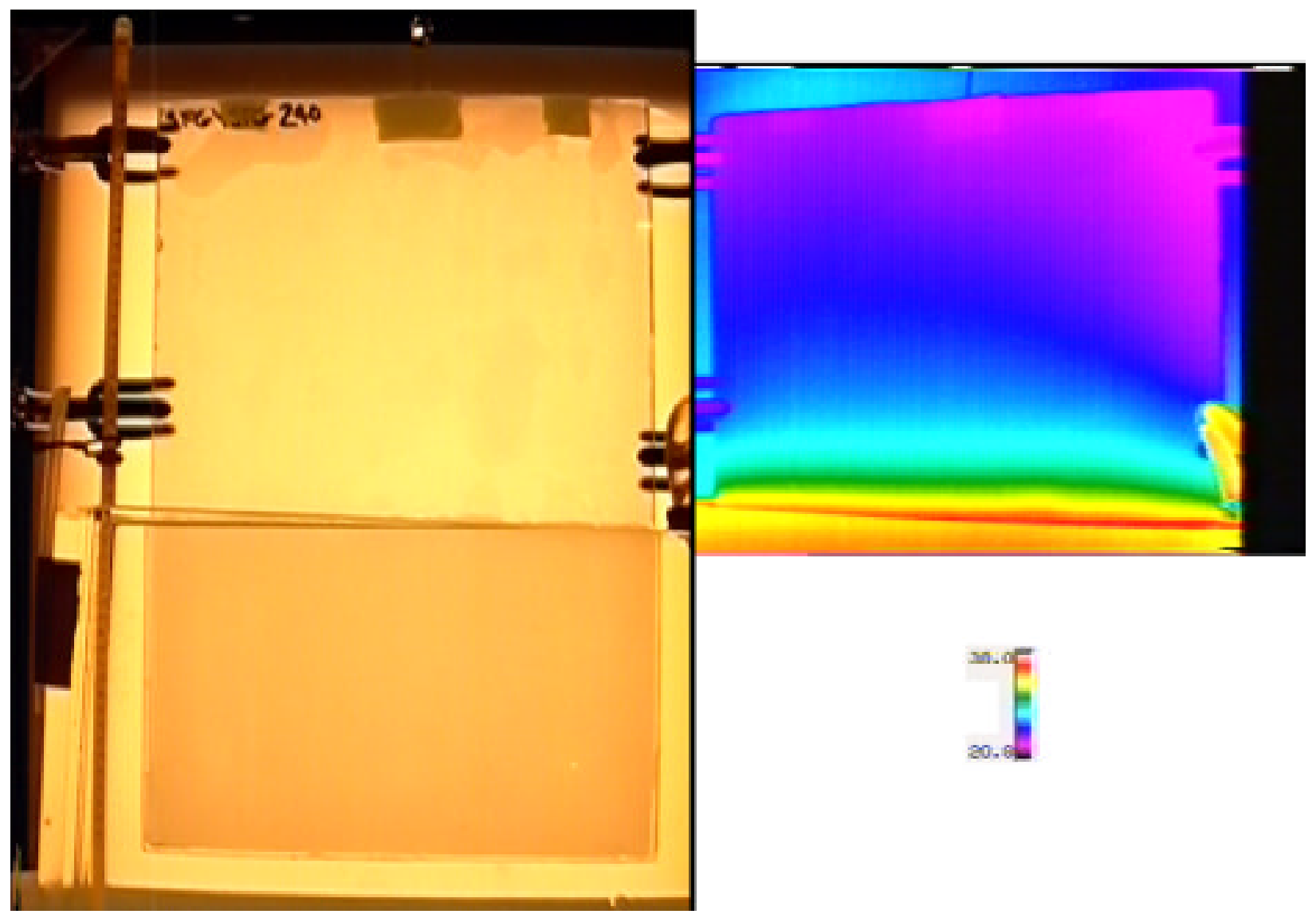

Figure 3-33. Pentane and temperature distribution. Experiment 14: $\mathrm{T}_{\text {bath }}=38.3^{\circ} \mathrm{C}$ 


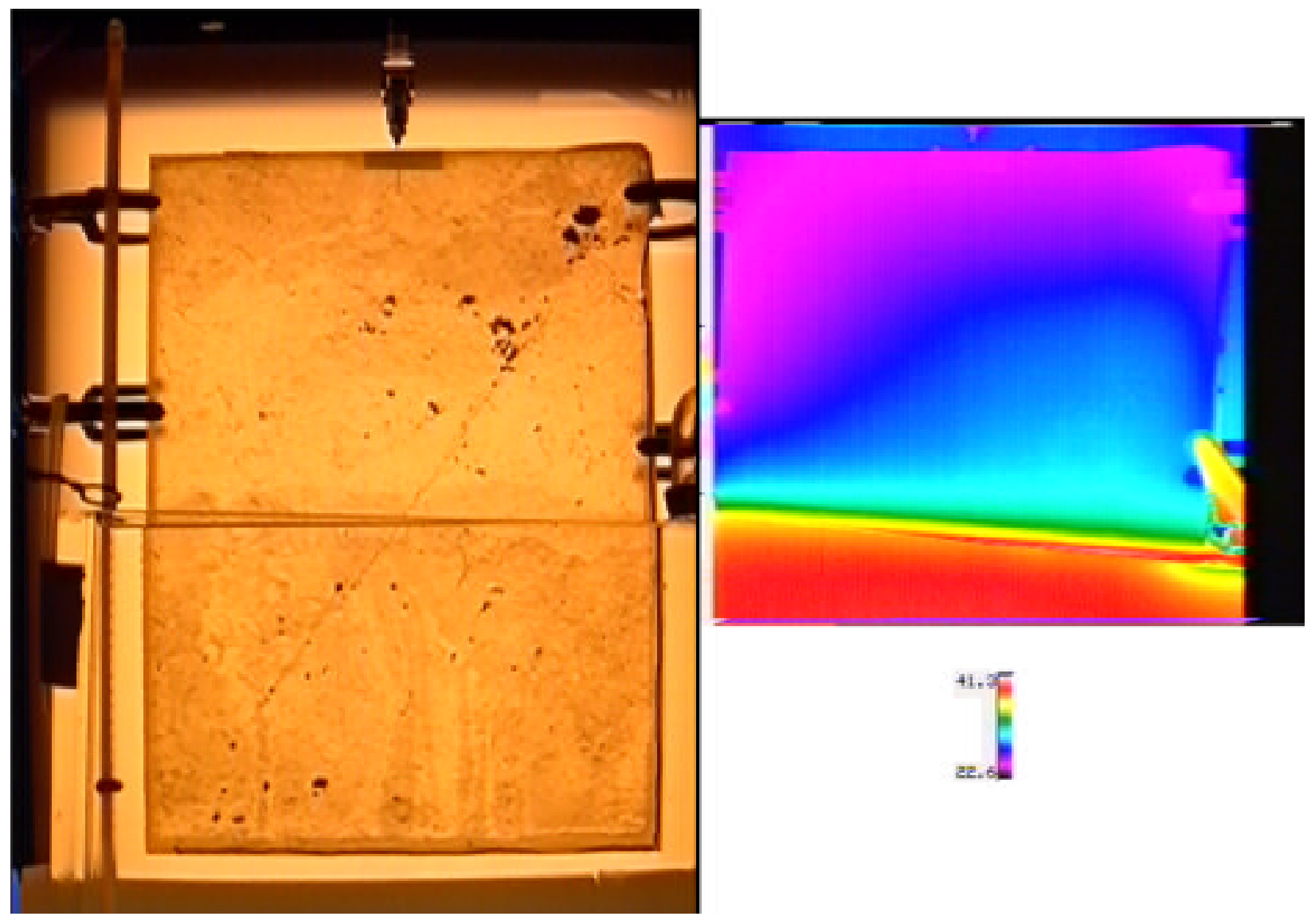

Figure 3-34. Pentane and temperature distributions. Experiment 15: $42.2^{\circ} \mathrm{C}<\mathrm{T}_{\text {bath }}$ $<42.4^{\circ} \mathrm{C}$ 


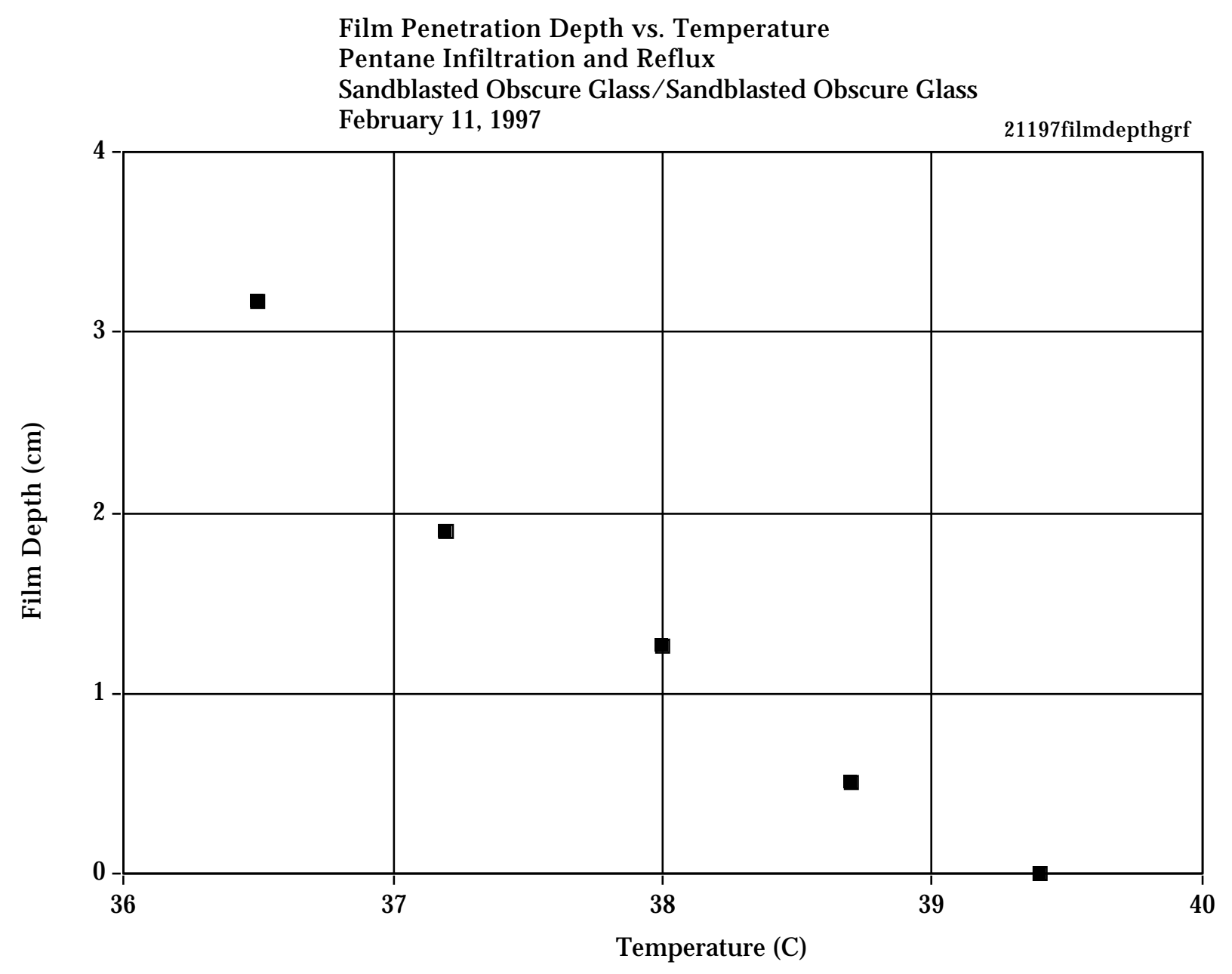

Figure 3-35. Film penetration depth vs. temperature: Experiment 5 


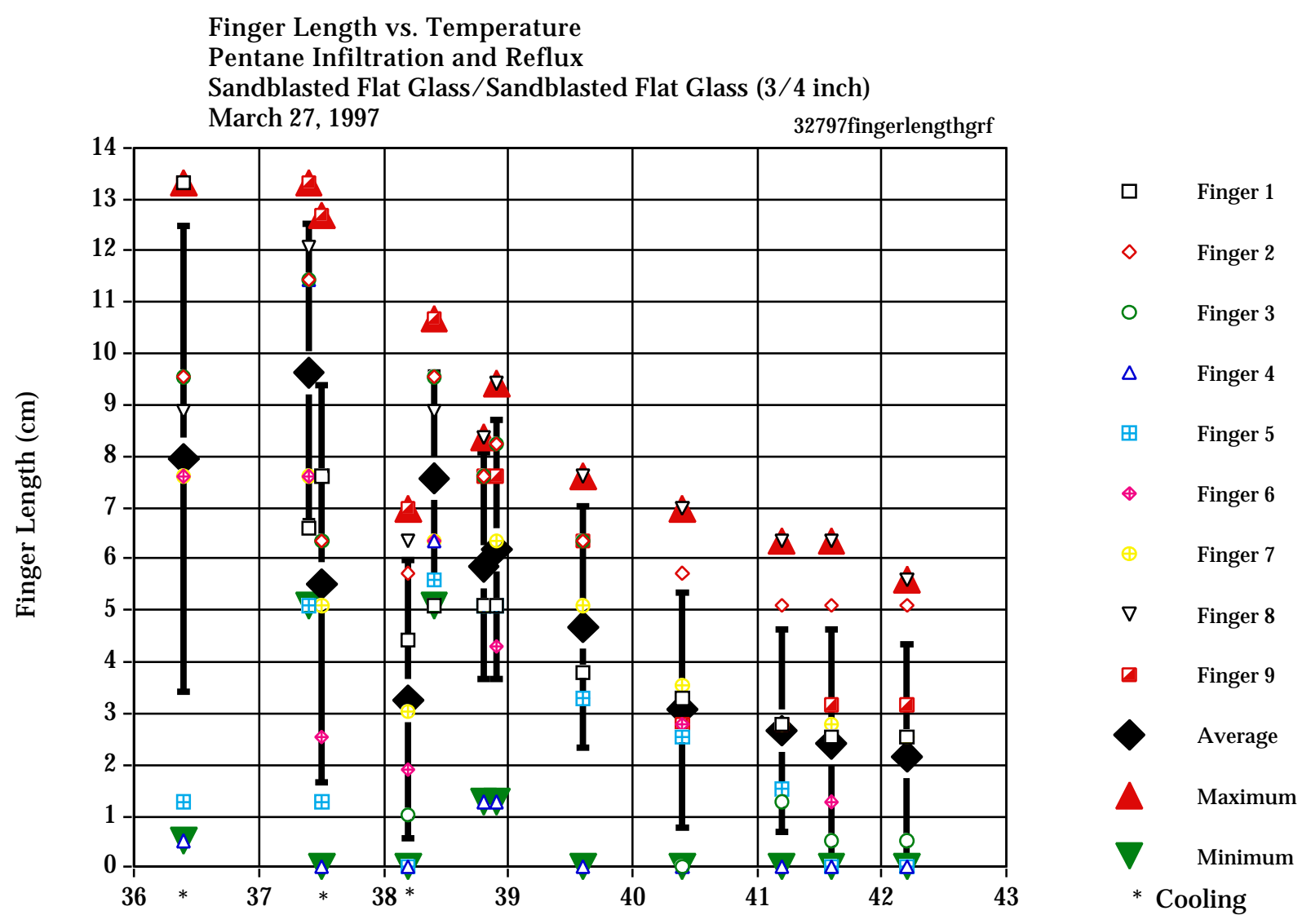

Figure 3-36. Finger length vs. temperature. Experiment 9: (3/4-inch glass plates); error bars represent 1 standard deviation. 


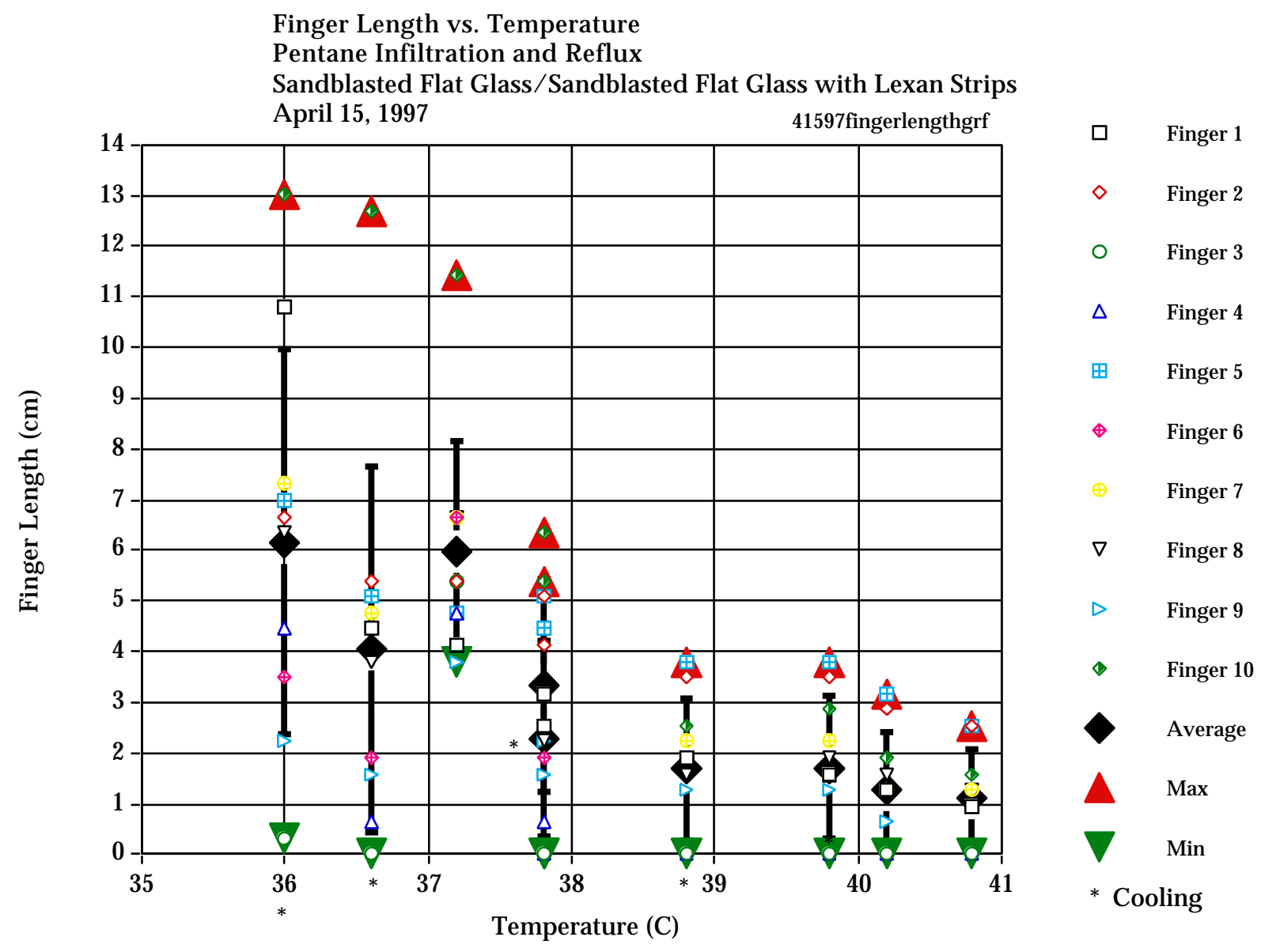

Figure 3-37. Finger length vs. temperature. Experiment 10: error bars represent 1 standard deviation. 


\section{Field-Scale Experiments and Observations of Thermally Driven Coupled Processes}

An adequate understanding of the response of Yucca Mountain to repository heat requires consideration of spatial and temporal scales that are larger than can be investigated in the laboratory. This chapter describes a number of field-scale experiments and natural processes having some features in common with processes expected at Yucca Mountain. Emphasis is given to thermally driven processes; however, in some cases, such as fracture clogging by carbonate precipitates resulting from the injection of lime water at a site in Sweden, a potentially relevant result was observed at ambient temperature.

Some experiments have been and are being performed specifically for the Yucca Mountain project, and others have been part of the research and development (R\&D) efforts for spent fuel and high-level waste (HLW) disposal outside the United States. International efforts are reviewed briefly to indicate how coupled processes are investigated in other countries. A more comprehensive review of international $R \& D$ for nuclear waste disposal is given by Witherspoon (1996).

In addition to work performed specifically for high-level radioactive waste disposal, thermally-driven coupled processes (particularly simultaneous heat and mass transport, with or without chemical reactions) play an important role in the exploitation of geothermal reservoirs and in enhanced recovery of heavy oil and tar. Both of these applications have stimulated a large amount of literature on laboratory measurements, field operations, and computer simulation involving thermally coupled processes. Although there are obvious differences in such parameters as temperature, pressure, and the magnitudes of driving forces, there is enough similarity to Yucca Mountain to warrant systematic investigation. This report presents a few promising sources and considers their potential relevance to Yucca Mountain.

Except for the Large Block Test at Fran Ridge and the heater tests currently underway in the Exploratory Studies Facility (ESF), none of the investigations discussed in this chapter was performed under a QA program approved by the current Yucca Mountain Project.

\subsection{Yucca Mountain Project}

\subsubsection{Spent-Fuel Test-Climax}

The Spent-Fuel Test (SFT) was designed to obtain technical data for qualification of granite as a high-level waste disposal medium and to detect any unanticipated processes attendant to geologic disposal of HLW. Using only a few fuel assemblies and electrical heaters, the SFT simulated the effects of many canisters (Patrick, 1985). The test was designed to emphasize waste-handling and 
monitoring of disposal conditions. Monitoring of waste emplacement during the preclosure operation of a permanent repository will serve to check on the analyses and projections made on the basis of short-term tests.

Drift geometry for the test was chosen to simulate the waste emplacement layout that might be used in a repository (Patrick, 1985). Electrical heaters were designed and positioned to simulate a large array of heat sources. Facilities and methods for handling live waste were developed for the test. A total of $1570 \mathrm{~m}$ of granite core was obtained from instrumentation and heater holes. In situ testing conducted before the main experiment (Heuze et al., 1982; Montan and Bradkin, 1984) included stress measurements (by overcoring), radon background measurements, geologic mapping, water collection from seeps, two types of seismic measurements (accelerometry during mining blasts and wideband seismic monitoring), and in situ heater tests for determination of rock-mass thermal properties.

Spent-fuel canisters were lowered in a drilled shaft, $0.76 \mathrm{~m}$ in diameter and 426 $\mathrm{m}$ deep, which was intersected by the canister drift. This shaft was functionally separate from the men and materials shaft. Earth shielding was used when lowering and raising the spent-fuel container, thus lightening the package and reducing the hoisting capacity required for safe handling. The canister emplacement holes measured $0.61 \mathrm{~m}$ in diameter and $5.2 \mathrm{~m}$ deep and were situated $3 \mathrm{~m}$ apart. Eleven fuel canisters and six electrical simulators were used. All of these holes were lined with 0.46-m diameter carbon steel casing.

Duration of the spent-fuel portion of the test was about $3 \mathrm{yr}$, including fuel exchanges, ventilation tests, and auxiliary heater power tests (Wilder and Yow, 1987). The last fuel was retrieved 1083 days after the first fuel was emplaced. Results of the test include the following (Patrick, 1985):

- Acoustic emissions responded to the rate of thermal energy production and may be useful for monitoring the stability of a repository.

- No significant changes in mineralogy or microfracturing occurred, as a result of heat or irradiation, near the electrical heaters or spent-fuel canisters.

- Post-test analyses provided data on corrosion of metals. Nitric acid formed by radiolysis of atmospheric nitrogen accelerated corrosion of the carbon steel liners. Corrosion was also observed in stainless steel, Inconel 600, and super-Invar.

From the perspective of rock mechanics, much interest in the long-term monitoring related to the influence of structural features and to the return of post-test conditions to pre-test conditions (Wilder and Yow, 1987). Once the waste was emplaced and the heaters were switched on, displacements were nonuniform, and the response from structural features appeared to be complex.

Wilder and Yow (1987) stated that "the rock mass deformations during cooling were dominated at first by the release of a thermal stress regime that had overridden any local variation in stress associated with geologic structure; 
however, as cooling continued, the anisotropy of the field stress and the presence of discontinuities may have increasingly affected observed response." During the entire experiment, including heating and cool-down, monitoring recorded permanent displacements on the order of 0.1 to $1 \mathrm{~mm}$.

Joints influenced gross behavior by reducing rock-mass stiffness. Fracture deformation was not stick-slip, but was more uniform. Displacements parallel to fracture dip were generally larger, and those along strike were quite small. The sense of displacement was consistent with the regional extensional tectonic regime. Displacements normal to fractures ranged from -0.15 to $+0.05 \mathrm{~mm}$ during heating. Some observed displacements had the same sense during both cooling and heating.

The heating phase of the SFT was monitored for velocity and amplitude of emitted and controlled-source P- and S-waves. A 15-station network with $1-10 \mathrm{kHz}$ bandwidth was operated to detect and locate seismic emissions and to characterize source mechanisms. Daily pulsing of a reference source was used to measure changes in transmission characteristics. Temperatures in the monitored region of the rock mass reached $80^{\circ} \mathrm{C}$, with abundant associated acoustic emission events and large changes in S-wave amplitudes. P-wave velocities and amplitudes were not affected by heating or cooling (Majer and McEvilly, 1985).

\subsubsection{Edgar Mine, Colorado School of Mines (CSM)}

The heated-block-test concept was evaluated in 1980 at the Edgar experimental mine (Hardin et al., 1981 and 1985). The concept was to measure large-scale deformation modulus, thermal properties, and the flow behavior of a single fracture as a fractured block was subjected to biaxial and uniaxial stress over a range of temperature. The block was isolated from the rock mass so that loading conditions could be controlled in addition to, and independent of, the temperature. By separating the boundary conditions, it was possible to distinguish the effects of each on various responses of the rock, including deformability, thermal expansion, thermal conductivity, and fracture permeability.

A 2-m cube of rock in the floor of a test room in fractured gneiss was isolated on the top and sides by line-drilling. Flatjacks were installed to a depth of $2 \mathrm{~m}$ in the slots, and boreholes were drilled for heaters and emplacement of various stress and displacement-measuring instruments.

Biaxial and uniaxial stress magnitudes of $7 \mathrm{MPa}$ were achieved in this test. Rock mass modulus was generally about $50 \%$ of the intact modulus. The effects of loading/displacement history on mechanical response were observed, and the displacements of individual joints were measured. Heating caused significant reductions in deformation modulus and in the permeability of a test fracture. 


\subsubsection{G-Tunnel, Nevada Test Site}

G-Tunnel is located within Rainier Mesa and was used for nuclear testing for about 30 yr. In the early 1980s, the tunnel complex was made available for underground testing in connection with high-level nuclear waste disposal. Most testing was performed in the welded Grouse Canyon Member of the Belted Range Tuff, which is about $20 \mathrm{~m}$ thick and sandwiched between thicker, nonwelded tuff units.

\subsubsection{In Situ Water Migration/Borehole Heater Test}

A borehole heater test was performed in nearly saturated, fractured welded tuff of the Grouse Canyon tuff exposed in G-Tunnel. The heater borehole was oriented 20; upward, above the horizontal, so that condensate could be collected at the borehole collar. Water was also collected in another borehole $0.5 \mathrm{~m}$ vertically below the heater midpoint. Some $61.7 \mathrm{~L}$ of water, most of which came from the heater borehole, was collected during heating. The recovery rate was highest in the first three days.

The original water migration/heater experiment reported by Johnstone, et al. (1992) was modeled by Ho and Eaton (1995). The original experiment appeared to show that liquid water migrated toward the heater and against a temperature gradient. Modeling was undertaken to interpret the results in a manner consistent with thermohydrologic principles. A 2-D model was developed to represent a $2 \times 2-\mathrm{m}$ region of the vertical plane that included the heater borehole. The borehole itself was assigned hydrologic properties representing a cavity. A heater test consisting of 10 days heating at $1 \mathrm{~kW}$ was simulated. The results showed that, at 10 days, vapor movement was mostly directed away from the heater as expected. Some liquid counterflow was projected along a saturation gradient toward the heater. Liquid water movement in the rock matrix was apparently deflected toward the borehole collar by gravity.

\subsubsection{G-Tunnel Small Diameter Heater Tests}

A series of small-diameter heater tests at the G-Tunnel underground laboratory was described by Zimmerman and Finley (1987). These tests were done in unsaturated welded tuff, in both vertical and horizontal orientations, to investigate moisture behavior. A similar test was performed in nonwelded tuff for comparison. The tests produced liquid-vapor counterflow in the rock near the heaters and in the heater borehole, as evidenced from asymmetry in the temperature field.

The observed temperature increases due to vertical heater tests in welded and nonwelded G-Tunnel tuffs could be reproduced with a thermal conduction model, using laboratory-measured values for thermal properties, and an "empirical description" of the heat-transfer properties (Blanford and Osnes, 1987). Boiling behavior was inferred from temperatures measured within the heater borehole, but the effects were assumed to have been limited to the 
immediate vicinity and not to have significantly influenced measured temperatures. Hydrothermal phenomena observed in the three G-Tunnel smalldiameter heater tests are summarized as follows:

- In the vertical heater test in welded tuff, a small amount of water collected at the bottom of the heater hole at the onset of heating, then vaporized when the temperature in this region exceeded $94^{\circ} \mathrm{C}$.

- In the vertical heater test in nonwelded tuff, no liquid water was observed in contact with the rock, but $0.5 \mathrm{~L}$ water condensed in a heater-handling tube that had an opening $1.2 \mathrm{~m}$ above the top of the heater.

- In the horizontal heater test in welded tuff, for the first 29 days of heating, small amounts of water collected in the heater borehole and wetted a thermocouple located immediately under the heater.

- The gaseous-phase environment of the heater boreholes was similar for all three tests. Relative humidity approached saturation within hours after the start of heating. Total pressures remained at ambient.

Neutron probe measurements of moisture content in the heated rock showed that significant changes occurred in the temperature range $70^{\circ} \mathrm{C}$ to $120^{\circ} \mathrm{C}$. Dewatering apparently began at temperatures less than boiling. The neutron probe was calibrated at elevated temperatures (Zimmerman et al., 1986a).

\subsubsection{G-Tunnel Heated-Block Test}

Preparation of the G-Tunnel heated-block test was similar to that of the earlier CSM block test (Hardin et al., 1985). A 2-m cube of fractured Grouse Canyon tuff was isolated in place by line-drilling (Figure 4-1). A single fracture within the block was selected for flow-testing. Various measurement methods and instruments were used to monitor the condition of the block throughout the testing period: neutron moisture probes, ultrasonic compressional wave velocity, thermal conductivity probe, strain and displacement measurements, borehole piezometers, and electrical impedance tomography. One important difference from previous tests was that the block was maintained at a minimum, uniform biaxial stress throughout the test matrix to simulate stress conditions in the unexcavated rock mass. 


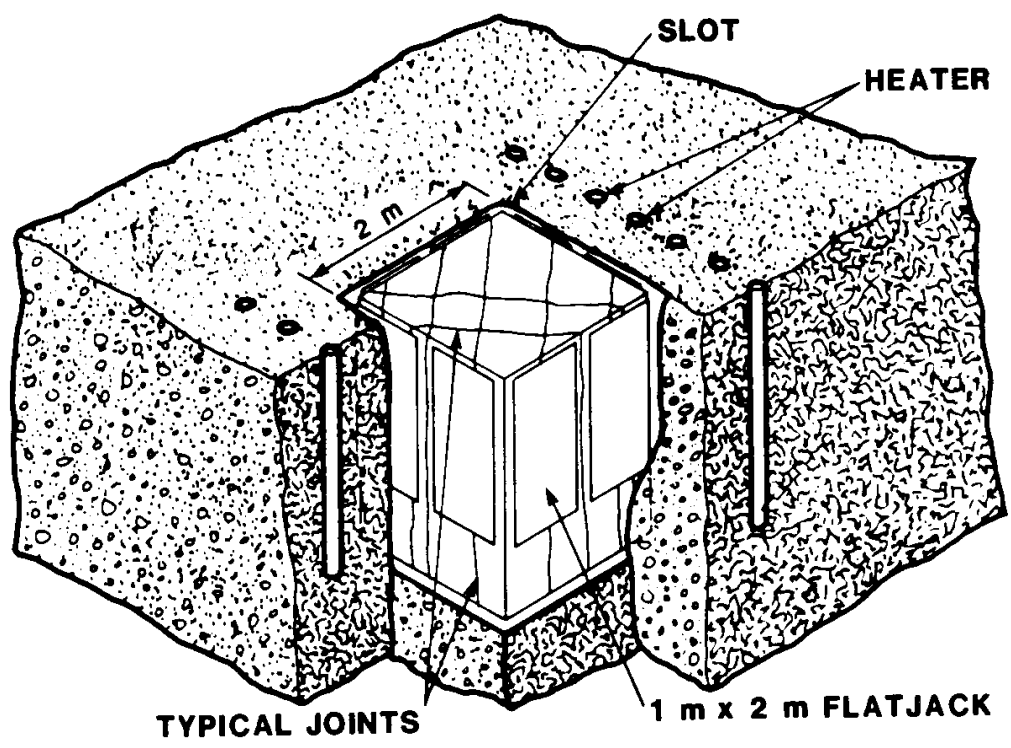

Figure 4-1 Schematic of G-Tunnel heated-block test (after Zimmerman et al. [1986b])

The objectives of the G-Tunnel heated block test series and the relevant findings were summarized by Zimmerman et al. (1986b) as follows:

1. Measure rock mass mechanical and thermomechanical properties under controlled thermal and stress loading conditions.

The block was subjected to maximum temperatures ranging from 76 to $130^{\circ} \mathrm{C}$ depending on location, and equal biaxial stresses with magnitudes up to $10.6 \mathrm{MPa}$. The effective modulus of deformation ranged from 0.4 to 0.83 times the intact rock measurements, depending on the number of joints included and their apertures. A slight dependence of modulus on stress was indicated, but no significant temperature effects on modulus were identified. Thermal expansion behavior of the heated block was well represented by measurements on intact rock samples.

2. Determine the effects of excavation, stress, and temperature changes on the permeability of a single joint."

Permeability of a single, near-vertical fracture was measured using three vertical boreholes in a linear array. The largest changes in permeability were associated with excavation of the block (at ambient temperature) when the apparent permeability increased from 76 to $758 \mu \mathrm{d}$. Subsequent compressive loading decreased the permeability, but did not exactly reverse the unloading conditions, and the apparent permeability ranged from 252 to $332 \mu \mathrm{d}$ over a stress range of 3.1 to $10.6 \mathrm{MPa}$. Increased temperature (under biaxial confinement) decreased the fracture aperture, lowering the apparent permeability from 234 to $89 \mu \mathrm{d}$ during heating. 
3. Determine the shear strength properties of the welded tuff so that field and laboratory measurements can be compared.

Three uniaxial tests were performed at ambient temperature, to stress magnitudes of 5.5, 8.25, and $11.0 \mathrm{MPa}$. The maximum secondary horizontal compressive stress magnitudes during these loading cycles were $0.4,1.4$ and $2.3 \mathrm{MPa}$, respectively. These data were consistent with calculations for a jointed medium, using laboratory measured mechanical properties.

4. Evaluate hydrologic-based measurements and obtain thermohydrologic data that can be used to further develop measurement techniques for site characterization testing at Yucca Mountain.

Neutron moisture monitoring indicated that the saturation declined from 60 to $80 \%$ down to approximately $15 \%$ as a result of heating, in steps corresponding to the increasing maximum temperature for successive cycles. Rehydration upon cooling was not significant on a time scale of weeks. A thermal conductivity probe installed near the block surface showed a decline from 1.61 to $1.53 \mathrm{~W} / \mathrm{mK}$ over the test series, which was associated with drying at elevated temperature.

\subsubsection{G-Tunnel Prototype Engineering Barrier System Field Test}

A single-heater test called the prototype engineered barrier system field test (PEBSFT) was conducted in the Grouse Canyon welded tuff that was exposed in the wall of G-Tunnel (Ramirez et al., 1989). A section of a horizontal borehole was heated at $3.3 \mathrm{~kW}$ for 128 days, then ramped down in a series of 20 steps over 67 days. The surrounding rock mass was monitored for changes in temperature, moisture content, and air permeability (Figure 4-2). 


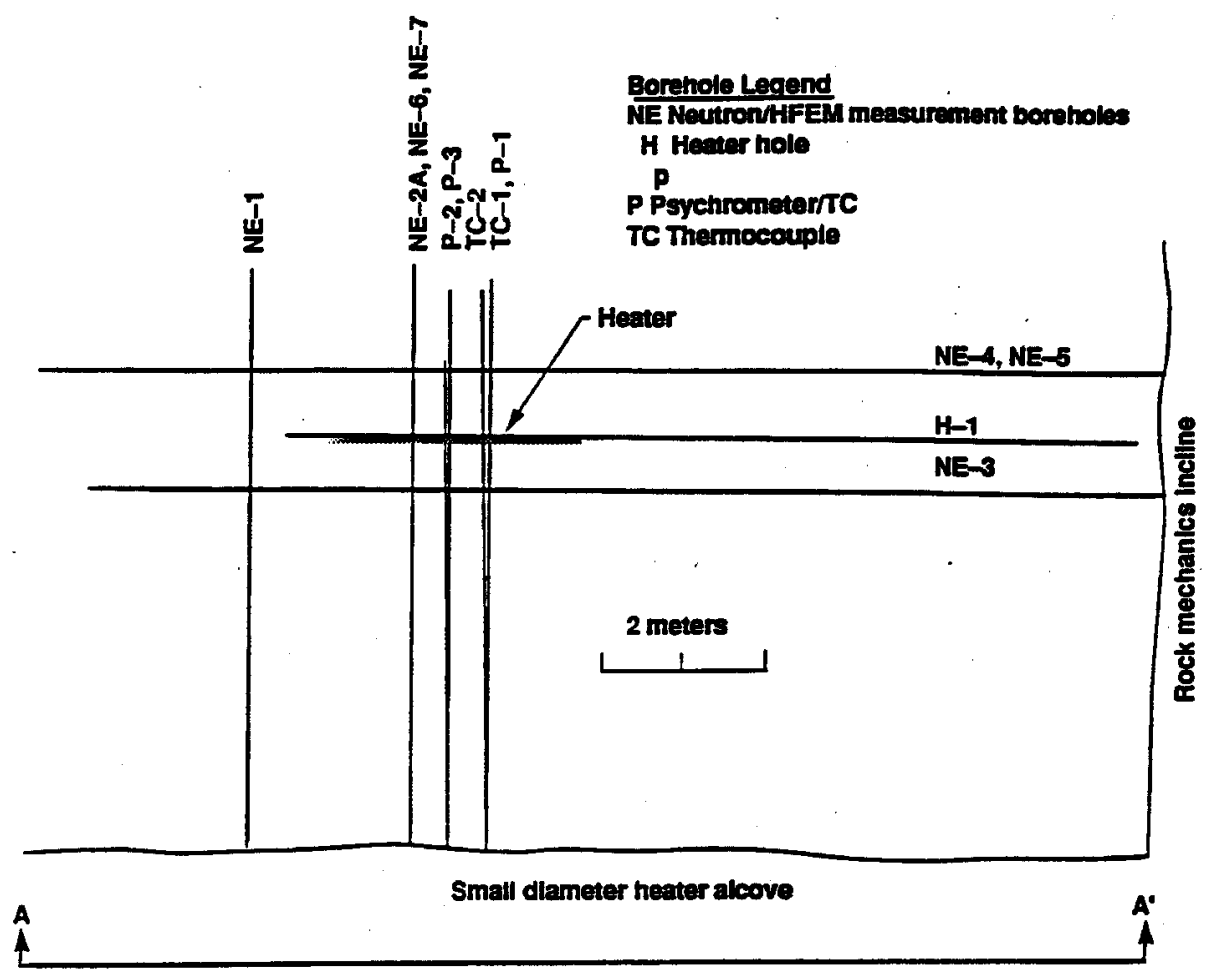

Figure 4-2 Plan view schematic of the PEBSFT showing heater and monitoring borehole locations (after Lin et al. [1991])

Temperature measurements were analyzed qualitatively and compared to thermohydrologic predictions (Lin et al., 1991). The rock immediately above the heater reached a temperature approximately $30 ; \mathrm{C}$ greater than the temperature below. Evidence for boiling was observed at thermocouples within approximately $0.7 \mathrm{~m}$ of the heater, the inferred extent of the boiling front. Temperature time-series showed flattening at $96^{\circ}$ to $100^{\circ} \mathrm{C}$, which lasted several weeks at some locations (Figure 4-3). (The boiling temperature of distilled water at this location was approximately $93^{\circ} \mathrm{C}$.) Flattening of the curves was typically preceded by accelerated heating at these thermocouple locations, which was interpreted as resulting from movement of heated condensate along fractures. 


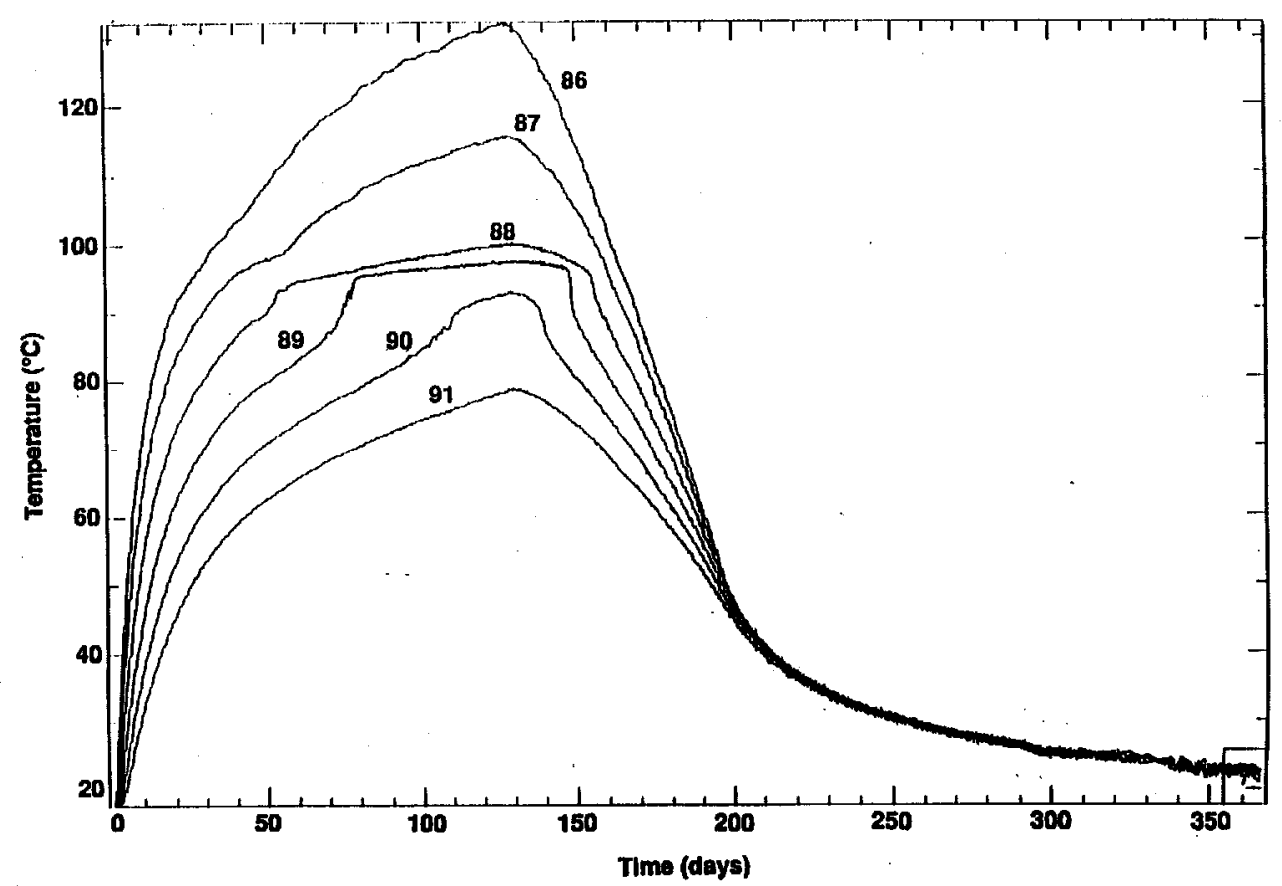

Figure 4-3 Temperature vs. time at six thermocouples installed near the heater in the PEBSFT (after Lin et al. [1991]): behavior in the vicinity of $96^{\circ} \mathrm{C}$ indicated thermohydrologic heat-pipe effects.

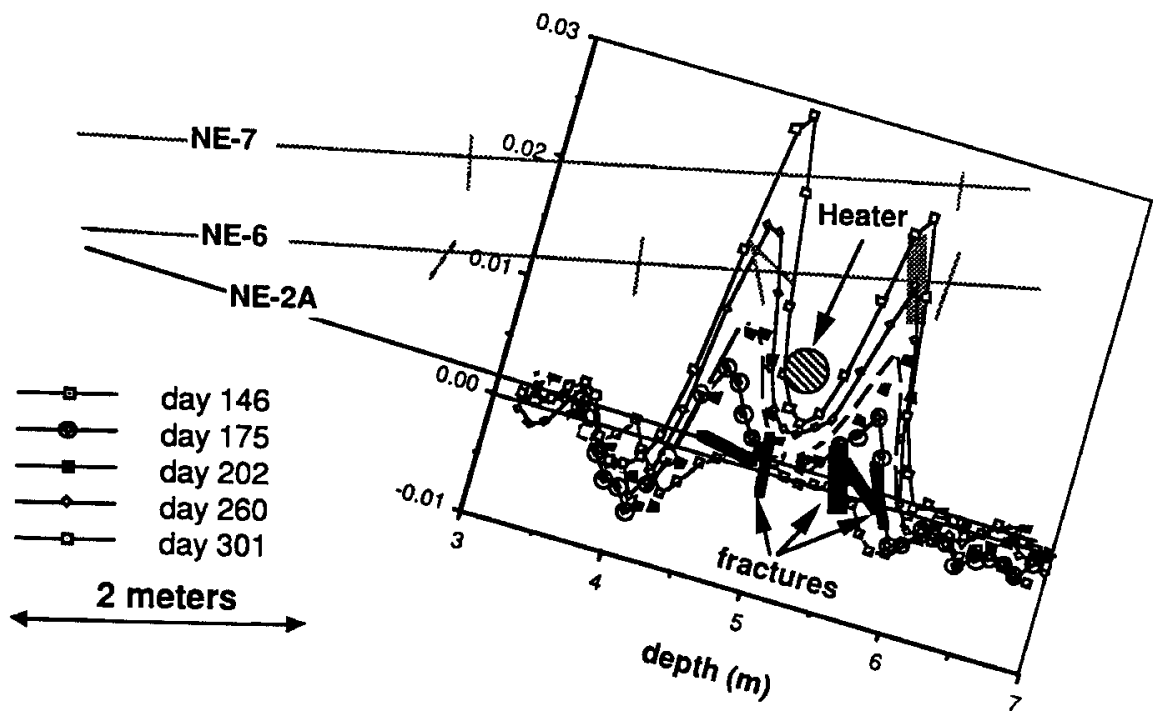

Figure 4-4 Changes in moisture content, measured with a neutron moisture probe, along borehole NE-2A in the PEBSFT in G-Tunnel (after Ramirez et al. [1991b]). The heater and nearby boreholes are projected in a vertical plane. The borehole was oriented perpendicular to the heater and passed beneath it. Values are indicated as absolute changes in volumetric moisture content and are positive for wetting and negative for drying. 
Moisture logging with a neutron probe confirmed thermohydrologic effects (Figure 4-4) that were similar to those predicted from numerical simulation. The following qualitative conclusions were reported (Ramirez et al., 1991a and 1991b):

- The drying front penetrated more rapidly along fractures during the maximum heating power phase. Rewetting occurred more rapidly near fractures during the ramping down and cooling phases. Reduction in volumetric moisture content by as much as 0.15 (proportion of total volume occupied by water) occurred in the vicinity of the observation boreholes, which approached to approximately $0.5 \mathrm{~m}$ from the heater (Figure 4-4).

- The boiling zone acted as an "umbrella," shielding rock below the heater from drainage of condensate generated above the heater. Water vapor that condensed above the heater drained downward through fractures. Much of this flow was reboiled, and some of the reboiling occurred on the flanks of the heater.

- Water vapor that condensed below the heater drained away from the boiling zone. Significant asymmetry of drying and rewetting behavior was noted above and below the heater. The rock below the heater dried out faster than it did above the heater (at equal radial distances). During the ramping down and cooling phases, rewetting above the heater occurred slightly faster than it did below the heater.

The presence of fractures, which were pneumatically tested prior to heating, was indicated by fluctuations in the temperature time-series measured at some locations. Condensate was collected from an aluminum sleeve installed in the collar of the heater hole. The water collection rate increased, to the maximum of approximately $100 \mathrm{ml} /$ day, within approximately 25 days. Decline in the watercollection rate started after 50 days, and the rate diminished to less than 0.10 of the maximum at 100 days. However, the partial pressure of water vapor within the heater borehole was fixed at about 0.3 bar during the interval of declining water collection, a fact that was not explained.

Pneumatic permeability measurements were made in boreholes before and after the PEBSFT (Lee and Ueng, 1991). Pseudo-steady state, single-well-injection tests were conducted in the heater hole at various spacings. Observed permeability was highly heterogeneous, varying over a factor of approximately 1500. After heating and cooling back to ambient temperature, measured permeability increased by 10 to $1800 \%$. The increase was greatest in intervals with the smaller values of preheating permeability. This was attributed to formation of microfractures proximal to the heater. Microfractures in high-permeability intervals would not be expected to produce a measurable increase in permeability within that interval. The maximum temperature of the heater borewall during heating was $242^{\circ} \mathrm{C}$.

Electromagnetic tomography at $200 \mathrm{MHz}$ was used to map the moisture redistribution (Daily and Ramirez, 1989). In laboratory studies, the relative real permittivity of tuff matrix increased by a factor of 2 as the volumetric water 
content increased from 0 to $13.8 \%$. The relative permittivity of water decreased from approximately 80 at $20^{\circ} \mathrm{C}$ to 48 at $100^{\circ} \mathrm{C}$. Electromagnetic measurements were made between horizontal boreholes, which were drilled perpendicular to the horizontal heater borehole from an intersecting drift. The boreholes defined two planes for tomography: a $1 \times 2-\mathrm{m}$ vertical plane perpendicular to the heater, and a $1 \times 2-\mathrm{m}$ horizontal plane that was approximately parallel to and $0.5 \mathrm{~m}$ below the heater. Alterant tomography was used, in which the pre-test distribution of relative real permittivity was subtracted from data sets acquired during the heater test.

The electromagnetic-tomography method was also tested using a heater test separate from the one just described but at the same location. The borehole heater was operated at $1 \mathrm{~kW}$ for 34 days during which time the measurement boreholes were unsealed, allowing water-vapor transport. After 30 days of heating, $473 \mathrm{~L}$ of water was injected, for 4 days, into a borehole approximately $1 \mathrm{~m}$ above the heater. The heater was then turned off and the rock mass monitored during cooling. Near the heater, drying proceeded rapidly during the heating period and resulted in substantial changes in moisture content. During cooldown, rewetting was much more gradual and involved comparatively small changes in moisture content. The tomograms showed a thermal front expanding into the rock mass. Anomalies indicative of drying coincided approximately in location and orientation with fractures mapped along the boreholes. On cooling, anomalies indicating rewetting also coincided with fractures.

\subsubsection{Large Block Test}

Currently underway at Fran Ridge, the Large Block Test (LBT) was designed to investigate rock mass behavior in response to controlled boundary conditions, with a rationale similar to that for the heated-block tests discussed previously. The LBT will study moisture refluxing in a thermal gradient, enhanced vapor diffusion, fracture displacement, water-rock interaction, response of microbiota, and rewetting response after cooling. Laboratory studies of smaller blocks are also underway, as discussed in a previous section of this report, to further extend the test conditions, particularly with the use of uniaxial loading.

A block of fractured Topopah Spring welded tuff, measuring $3 \mathrm{~m} \times 3 \mathrm{~m}$ in plan and $4.5 \mathrm{~m}$ high, was isolated in place at the surface of Fran Ridge. An array of boreholes was drilled into a test volume of rock exposed at the surface (Figure 4-5), and initial characterization investigations were performed. Four slots were cut with a large bar cutter, thus isolating the sides of the block from the adjacent rock, which was subsequently removed by excavation. Additional heater and instrument boreholes were then drilled into the sides of the block. 


\section{Thermally Driven Coupled Processes}

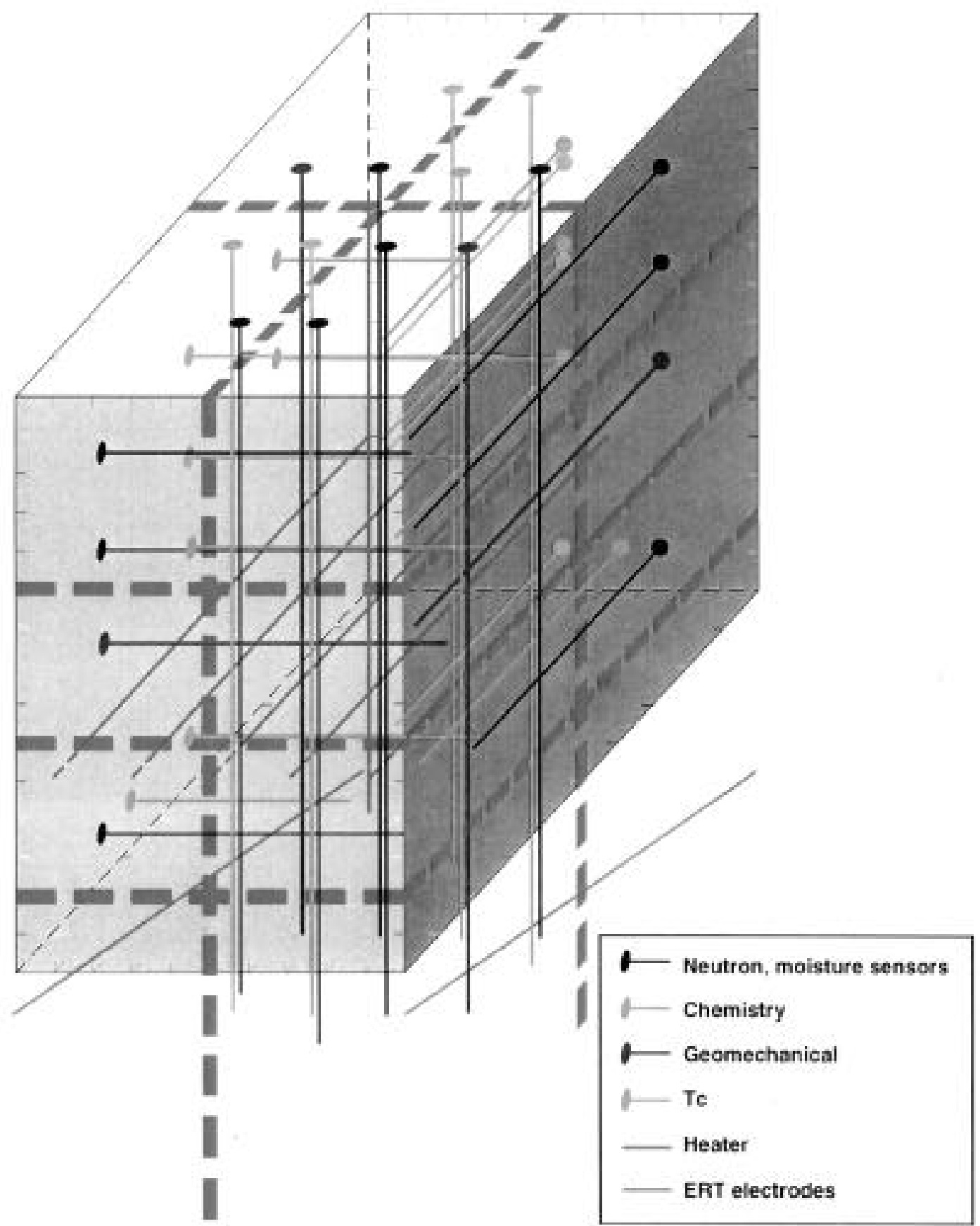

Figure 4-5 Schematic of LBT borehole array (after Lin et al. [1995])

Pre-test characterization included neutron moisture logging and measurement of the borehole air injectivity before and after isolating the block by cutting slots. Instruments were installed in the boreholes, which were subsequently sealed to inhibit moisture migration. The following responses are measured on a continuous or intermittent basis: temperature, displacement, moisture content, thermal conductivity and diffusivity, and pore-gas pressure. Microbiological and corrosion coupon samples were installed within the block for later recovery and 
analysis. The sides of the block were covered with an impervious membrane and thermal insulation to promote 1-D transport of heat and moisture. A heat exchanger with a separate temperature bath was installed on the top surface to control the upper boundary temperature during heat-up.

The block is presently being heated by borehole heaters in a horizontal array at the heater midplane. The objective is to achieve a steady state temperature of $140^{\circ} \mathrm{C}$ at the heater midplane while a temperature of $60^{\circ} \mathrm{C}$ is maintained at the top surface. The block will then cool naturally, which will take approximately six months.

\subsubsection{Thermohydrologic Response to Thermal Perturbation}

Recent temperature data from the LBT revealed a transient event in which downward water movement cooled a substantial portion of the midsection of the block (Lin, 1997a). Time series temperature data are plotted for a period of 450 $\mathrm{hr}$ in Figure 4-6. The time interval plotted is approximately 19 days, beginning after 98 days of heating. The locations TT1- 8 to -18 bracket the heater midplane in borehole TT1. Vertical temperature profiles for boreholes TT1 and TT2 are shown in Figure 4-7 and compare two dates that bracket the data time interval plotted in Figure 4-6.

At approximately $2500 \mathrm{hr}$, the equipment that maintains the top surface of the block at $60^{\circ} \mathrm{C}$ failed, allowing the surface to cool for several days. The upper part of the block cooled by about $10 ; \mathrm{C}$, as shown by measurement TT1-27 in Figure 4-6. At about $2525 \mathrm{hr}$, the temperature in borehole TT1 near the heater midplane decreased by $15{ }_{i} \mathrm{C}$ in less time than the temperature sampling interval of $1 \mathrm{hr}$, while smaller temperature changes occurred simultaneously at other measurement locations mostly above the heater midplane. The event at $2525 \mathrm{hr}$ was also observed at other temperature-measurement points located in horizontal boreholes. It is significant that the largest decreases in temperature were observed at locations where the initial temperature (before $2525 \mathrm{hr}$ ) was greater than $96^{\circ} \mathrm{C}$ (i.e., where boiling occurred in response to the reflux event).

These temperature changes occurred when the rate of condensation increased, causing a rapid increase of saturation in the tuff matrix and fractures and culminating in a fracture reflux episode. For each cubic meter of saturated tuff that was cooled by $15 ; \mathrm{C}$, simple calculations show that approximately $30 \mathrm{~L}$ water was vaporized. A similar amount of heat was apparently reabsorbed in the upper block due to condensation of the steam produced near the heater midplane. Therefore it is likely that several tens of liters of water refluxed during the event. For comparison, if the fracture porosity is $10^{-3}$, the void volume of fractures above the heater plane is approximately $25 \mathrm{~L}$. Changes in moisture content will also be examined by alterant electrical resistance tomography (ERT) and neutron logging, which are currently underway. 


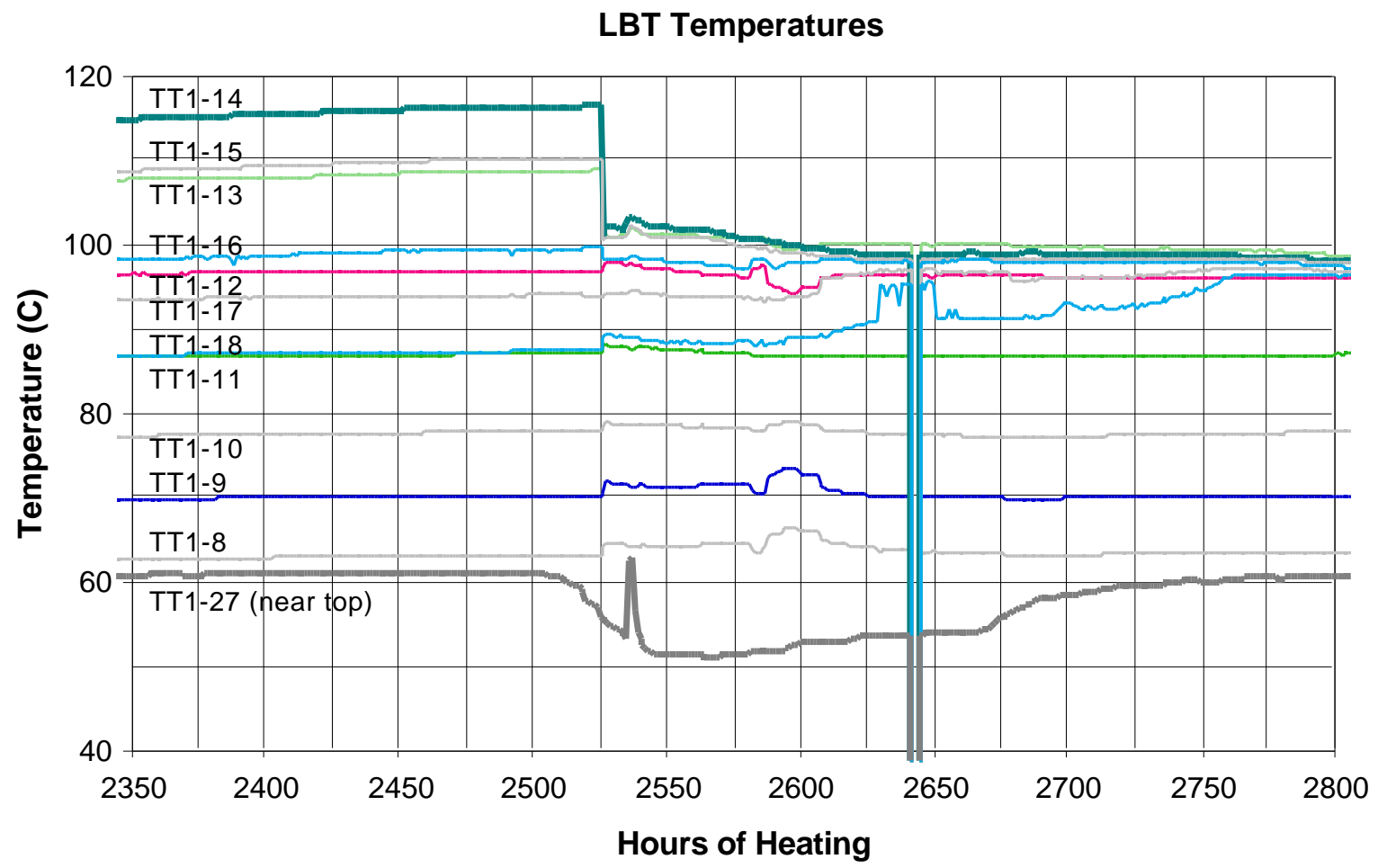

Figure 4-6 Time series temperature fluctuations in the LBT in response to transient cooling of the top surface (data from Lin [1997a]) 

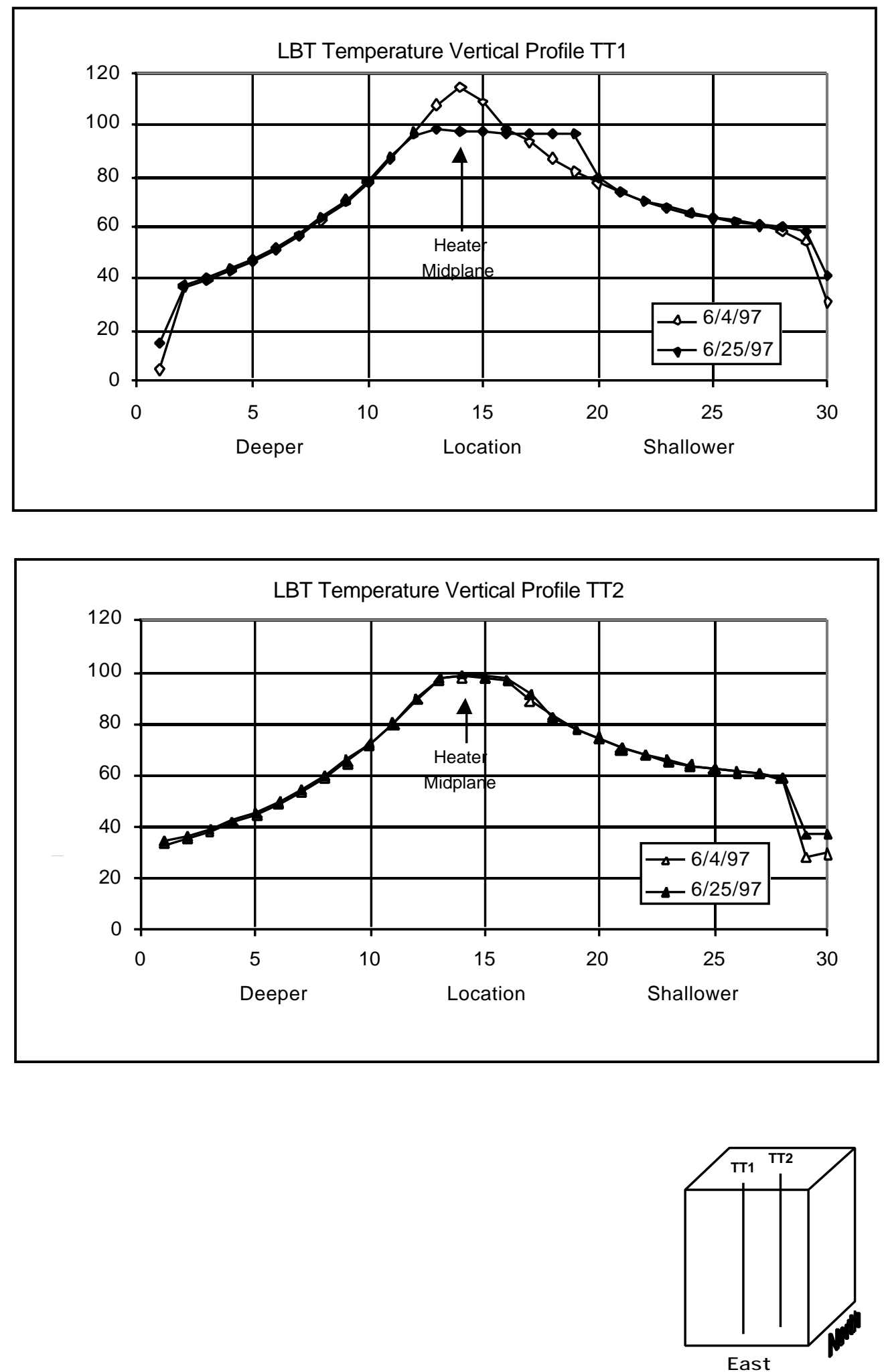

Figure 4-7 Vertical temperature profiles through the large block for June 4 and June 25, showing development of a heat-pipe zone (data from Lin [1997a]) 


\subsubsection{Yucca Mountain Exploratory Studies Facility}

\subsubsection{Single Heater Test}

The Single Heater Test (SHT) is an ongoing experiment located in the ESF at the repository horizon in the Topopah Spring welded tuff. The SHT is intended to provide information on rock mass thermal and thermomechanical processes, information on ground-support performance at elevated temperature, and preliminary information on thermal, hydrologic, geochemical, and mechanical coupled processes (SNL, 1997). The emphasis of the SHT is thermomechanical because the small size and limitations on access to the rock mass have made the test inadequate for complete study of coupled processes (Lin, 1997b).

The test is located in a large pillar exposed on three sides by drifts (Figure 4-8). Mechanized mining methods were used for excavation, thus limiting excavation damage. Boreholes were drilled for the heater, borehole extensometers and other instruments; neutron logging; hydrologic packer testing; borehole jack measurements; chemical sampling; ERT electrode arrays; and rock bolt testing. A 5-m long horizontal heater was operated for 9 months at an average power level of $3.8 \mathrm{~kW}$.

Temperature measurements during the SHT showed that the dryout region $\left(>100^{\circ} \mathrm{C}\right)$ extended to approximately $0.9 \mathrm{~m}$ from the heater in the vertical plane through the heater midpoint (Lin, 1997b). The isotherms were generally circular, and the temperature variation with distance was fitted to a function of the form: $\mathrm{r}^{-1 / 2}$ (SNL, 1997). Similar behavior was observed for temperature variation in the direction of the heater axis. These results are similar to the predictions made by Lee (1996) for 9 months of heating, except that the dryout region was less extensive than predicted. The predictions were made for low- and highpermeability cases using the NUFT code (Nitao, 1993) incorporating the equivalent continuum approximation. 


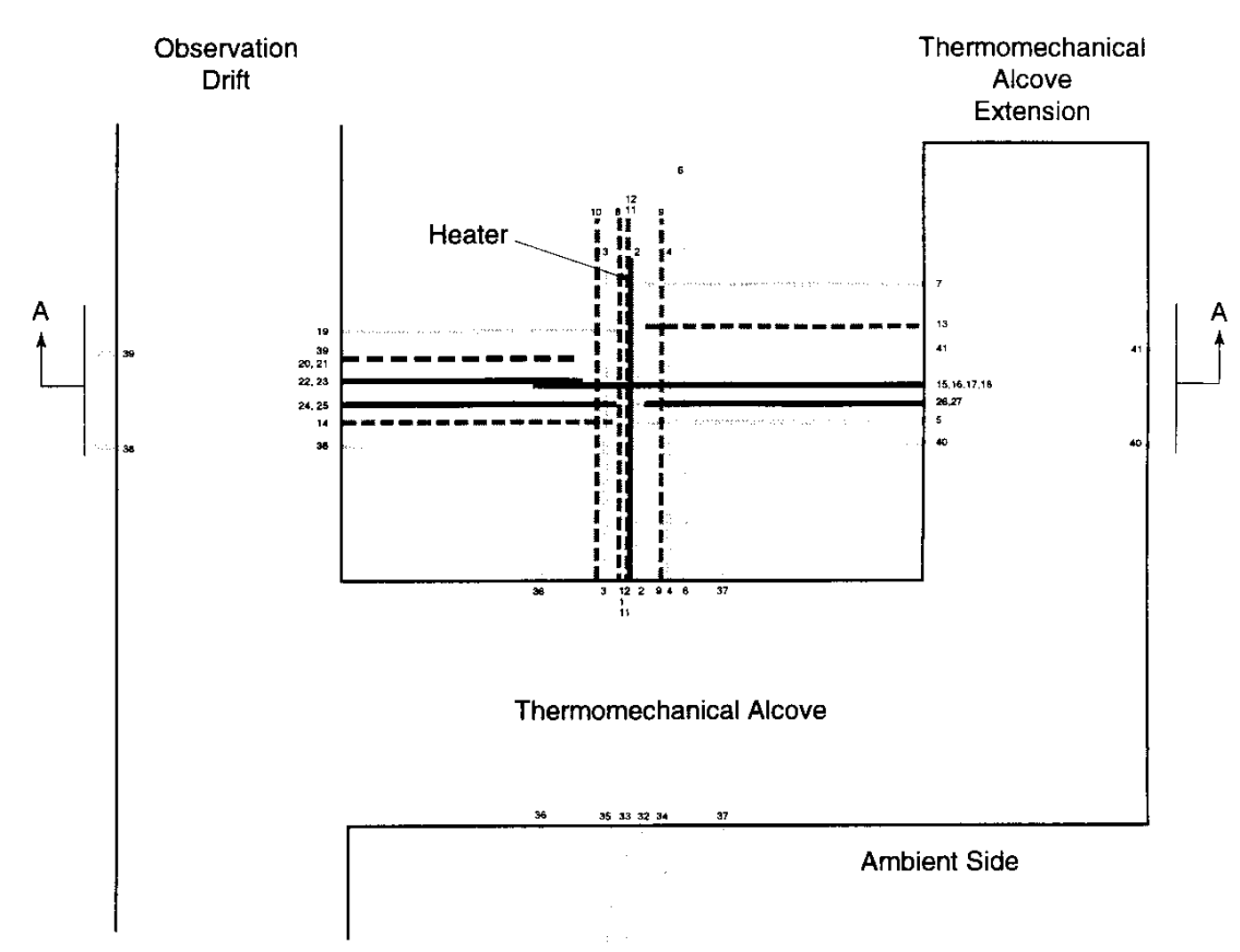

Reference Only

(Not to Scale)

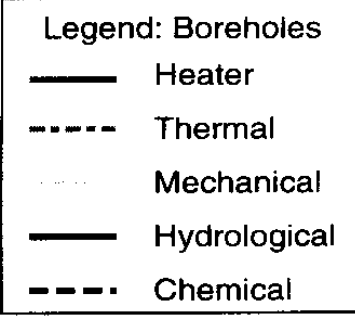

Figure 4-8 Single Heater Test layout, in plan view, showing borehole locations (after SNL [1997]).

Thermohydrologic processes were monitored using neutron logging, ERT, relative humidity measurements, and periodic retesting with borehole packers. Ramirez et al. (1996) reported using ERT to create images of changes in the rock mass in the vicinity of the heater. Thirty electrodes were installed in four boreholes framing a 2-D tomographic window perpendicular to the heater and centered on its midpoint.

ERT images of rock mass resistivity acquired at several stages during the heat-up phase are presented in Figure 4-9. Resistivity decreased by as much as $45 \%$, distributed similarly to the temperature field but displaced approximately $1.5 \mathrm{~m}$ downward. The decrease in resistivity can be attributed to temperature effects plus the redistribution of moisture in fractures and other macropores. The distribution of resistivity changes was centered approximately on the heater, but 
the shape appeared to be controlled by heterogeneities in the rock mass (Lin, 1997b). Early in the heat-up phase, the distribution of resistivity changes was strongly influenced by resistivity decreases associated with warming of pore waters, with no indication of dewatering of matrix or fractures. Conversion of resistivity to apparent saturation is reported by Lin (1997b). Later in the test series, drying was indicated by higher resistivity propagated upward, and the rock was apparently drier above the heater than it was below the heater (Lin, 1997b). This is consistent with previous results for a horizontal heater test in G-Tunnel reported by Ramirez et al. (1991b); in these results, neutron logging showed a zone of increased saturation below and to each side of the heater.

Pre-test pneumatic tests to characterize the rock mass were completed and found the air permeability of the test region to be very heterogeneous. Measured air permeability values varied by more than two orders of magnitude. The inner portion of the block was more permeable than was the outer portion of the block, except where the rock was highly fractured immediately adjacent to the excavations. The observation of fractures in a borehole was uncorrelated with the permeability in that hole. Retesting during the heat-up phase (with correction for elevated temperature properties of air) indicated that the permeability did not change, or decreased slightly, possibly from thermomechanical effects or changes in water saturation (Lin, 1997b).

Relative humidity was monitored by Humicap sensors installed in packed-off intervals within boreholes. High relative humidity was observed during the heat-up phase at sensors that were believed to be isolated, and low humidity was observed where pneumatic communication with the drift was most likely (Lin, 1997b). Relative humidity generally increased when the heater was turned off. Gas pressure measured in isolated intervals was less than the drift pressure at some locations and was greater at other locations (Lin, 1997b). The magnitude of positive and negative pressures was on the order of 0.5 psig. Pressure changes at each location during the test were limited to long-term changes with magnitudes of less than 0.1 psig.

Changes in water saturation observed by neutron logging were consistent with the temperature measurements (i.e., lower saturations were indicated at higher temperatures). The overall degree of drying of the intact tuff was limited. Changes, based on neutron logging, in the pre-test saturation extended approximately $2 \mathrm{~m}$ from the heater. No changes in saturation were detected in the first month of cooling (Lin, 1997b). 

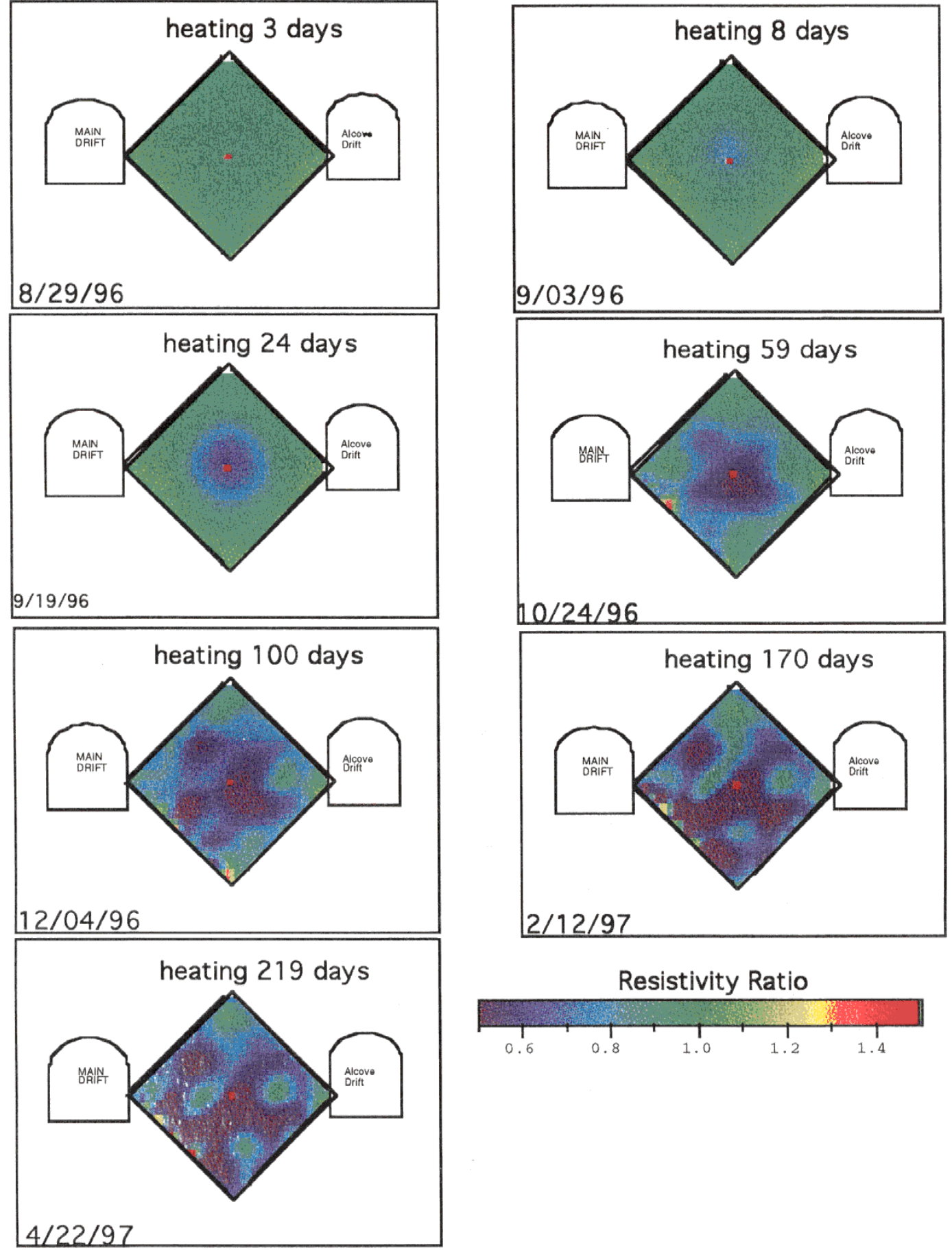

Figure 4-9 ERT changes during heating phase of SHT (after Ramirez and Daily [1997]) 


\subsection{Chemical Analysis of Collected Water Sample}

Water was trapped in one of the packed-off intervals in one of the SHT uncased boreholes. Water samples were collected from Zone 4 of borehole 16-4, which extends from $1.23 \mathrm{~m}$ to $3.36 \mathrm{~m}$ from the heater. Samples were collected on three dates: November 25, 1996 (yielding 5.5 L); February 4, 1997 (yielding 5.5 L); and February 27, 1997 (yielding 1.5 L) (Lin, 1997b). Chemical analyses for the first two of these samples are given in Table 4-1. As indicated, the major ion chemistry is comparable to J-13 water and other tuffaceuous groundwaters from the Yucca Mountain region. The SHT water samples are more dilute than J-13 water, except that $\mathrm{Ca}$ is present at about the same concentration. This may indicate that the water was condensed in fractures and flowed through fractures to the borehole and that fracture lining minerals are a source of $\mathrm{Ca}$. 
Table 4-1 Chemical analyses of water samples collected from borehole SHT-16-4, compared with other water compositions (after Glassley and DeLoach [1997])

\begin{tabular}{|c|c|c|c|c|}
\hline & $\begin{array}{c}16-4 \\
\text { LLNL }\end{array}$ & $\begin{array}{c}16-4 \\
\text { LANL }\end{array}$ & $\begin{array}{c}16-4 \\
\text { USGS }\end{array}$ & $J-13^{a}$ \\
\hline $\mathrm{Na}(\mathrm{mg} / 1$ & 16 & & & 45.8 \\
\hline $\mathrm{Si}(\mathrm{mg} / 1)$ & 16.8 & & & 28.5 \\
\hline $\mathrm{Ca}(\mathrm{mg} / \mathrm{l}$ & 13 & & & 13 \\
\hline $\mathrm{K}(\mathrm{mg} / \mathrm{l})$ & 2.5 & & & 5 \\
\hline $\mathrm{Mg}(\mathrm{mg} / \mathrm{l})$ & 1.63 & & & 2.01 \\
\hline $\mathrm{pH}$ & 6.2 & & & 7.4 \\
\hline $\mathrm{HCO}_{3}{ }^{-}\left(\mathrm{mg} / \mathrm{l}^{\mathrm{b}}\right.$ & 84.4 & & & 129 \\
\hline $\mathrm{F}(\mathrm{mg} / \mathrm{l})$ & 0.44 & & & 2.18 \\
\hline $\mathrm{Cl}(\mathrm{mg} / \mathrm{l})$ & 2.54 & 2.1 & & 7.1 \\
\hline $\mathrm{S}(\mathrm{mg} / \mathrm{l})$ & 0.71 & & & \\
\hline $\mathrm{SO}_{4}^{2-}(\mathrm{mg} / \mathrm{l})$ & 1.83 & 1.5 & & 18.4 \\
\hline $\mathrm{PO}_{4}{ }^{3-}(\mathrm{mg} / \mathrm{l})$ & $<0.03$ & & & $<10$ \\
\hline Nitrite $(\mathrm{mg} / \mathrm{l})$ & $<0.01$ & & & \\
\hline $\mathrm{NO}_{3}^{-}(\mathrm{mg} / \mathrm{l})$ & 1.1 & & & 8.8 \\
\hline $\mathrm{Li}(\mathrm{mg} / \mathrm{l})$ & $<0.03$ & & & 0.048 \\
\hline $\mathrm{B}(\mathrm{mg} / \mathrm{l})$ & 0.37 & & & 0.134 \\
\hline $\mathrm{Al}(\mathrm{mg} / \mathrm{l})$ & $<0.06$ & & & 0.02 \\
\hline $\mathrm{Fe}(\mathrm{mg} / \mathrm{l})$ & 0.74 & & & \\
\hline $\mathrm{Sr}(\mathrm{mg} / \mathrm{l})$ & 0.2 & & 0.0022 & 0.04 \\
\hline $\mathrm{Br}(\mathrm{mg} / \mathrm{l})$ & $<0.02$ & 0.008 & & \\
\hline$\delta \mathrm{D}$ & & & & -98 \\
\hline$\delta^{18} \mathrm{O}$ & & & & -13 \\
\hline Tritium (TU) & $\begin{array}{r}0.44 \\
+0.19 \\
\end{array}$ & & & \\
\hline${ }^{87} \mathrm{Sr} /{ }^{86} \mathrm{SR}$ & & & 0.7124 & \\
\hline
\end{tabular}

${ }^{\mathrm{a}}$ Harrar et al. (1990)

${ }^{\mathrm{b}}$ Calculated using laboratory-measured $\mathrm{pH}$

Water entered the hole much more quickly than could be expected from matrix flow; hence, it is considered to have drained through fractures intersecting the packed-off interval (Glassley and DeLoach, 1997). The authors observed that "the low $\mathrm{pH}$ of this water, the relative abundance of the major ions, and the time period over which it formed require that the coexisting $\mathrm{CO}_{2}$ partial pressure must have been elevated, relative to ambient atmospheric values, by approximately 


\section{Thermally Driven Coupled Processes}

two orders of magnitude. Analyses in progress suggest that this is consistent with the expected evolution of the gas phase coexisting with ambient pore waters interacting with tuff during heating to ca. 120 to $150^{\circ} \mathrm{C} . "$

\subsection{Thermoelectric Potential}

Self-potential (SP) surveys were performed, using a simple digital voltmeter connected to the ERT electrodes, before heating started and during the heating period (Ramirez, 1997). The electrodes are installed in boreholes located in a plane perpendicular to the heater and passing through the midpoint. SP voltages measured on August 22, 1996, before heating, were very close to zero $\mathrm{mV}$. The heater was turned on August 26, 1996, and three SP surveys were collected after heating started. Changes as great as $800 \mathrm{mV}$ developed at the same time after the heater was turned on, and the voltages across some electrode pairs continued to increase over time. The signals are DC, and repeatable readings were obtained with the heater power and instruments turned off briefly.

SP measurements made over geothermal reservoirs indicate that signals of a volt or more are present. Possible mechanisms were discussed in a previous section of this report and may occur in the repository near-field environment.

Differences in SP measurements from electrode pairs above and below the heater were spatially correlated with changes observed in ERT tomographs, which showed that resistivity below the heater decreased more than did that above (Ramirez, 1997). The SP response may be associated with condensate accumulation or with movement around the heater. The SP observations at the SHT are poorly understood, as are the implications for accelerated pitting corrosion of waste packages.

\subsubsection{Drift Scale Test}

The DST is the larger of two in-situ heater tests (the smaller is the SHT) to be conducted underground at Yucca Mountain and is scheduled to begin in early FY98. The SHT had one 4-kW heater that was $5 \mathrm{~m}$ long and was operated for 9 months; the DST will have 9 canister heaters, each with a maximum power of $7.5 \mathrm{~kW}$, placed in a drift with a heated length of $47.5 \mathrm{~m}$ and flanked by 25 borehole "wing" heaters in each wall that can be operated at a total maximum power of $143 \mathrm{~kW}$. The anticipated duration of the DST heat-up period is $4 \mathrm{yr}$ (Birkhozer and Tsang, 1997). The drift wall temperature will approach $200^{\circ} \mathrm{C}$ during the test.

Various types of sensors will be installed in more than 80 instrument boreholes to monitor the thermal, mechanical, hydrologic, and geochemical changes that result from heating and subsequent cooling. Preparations for the DST are underway. A schematic of the test layout is shown in Figure 4-10. Approximately half the instrument boreholes have been drilled from a parallel observation drift, which will permit monitoring during the test by such means as neutron 
moisture probes, electrical resistance tomography, chemical sampling, and pneumatic packer testing. Baseline measurements will be acquired prior to the start of heating.

\section{Plan View}

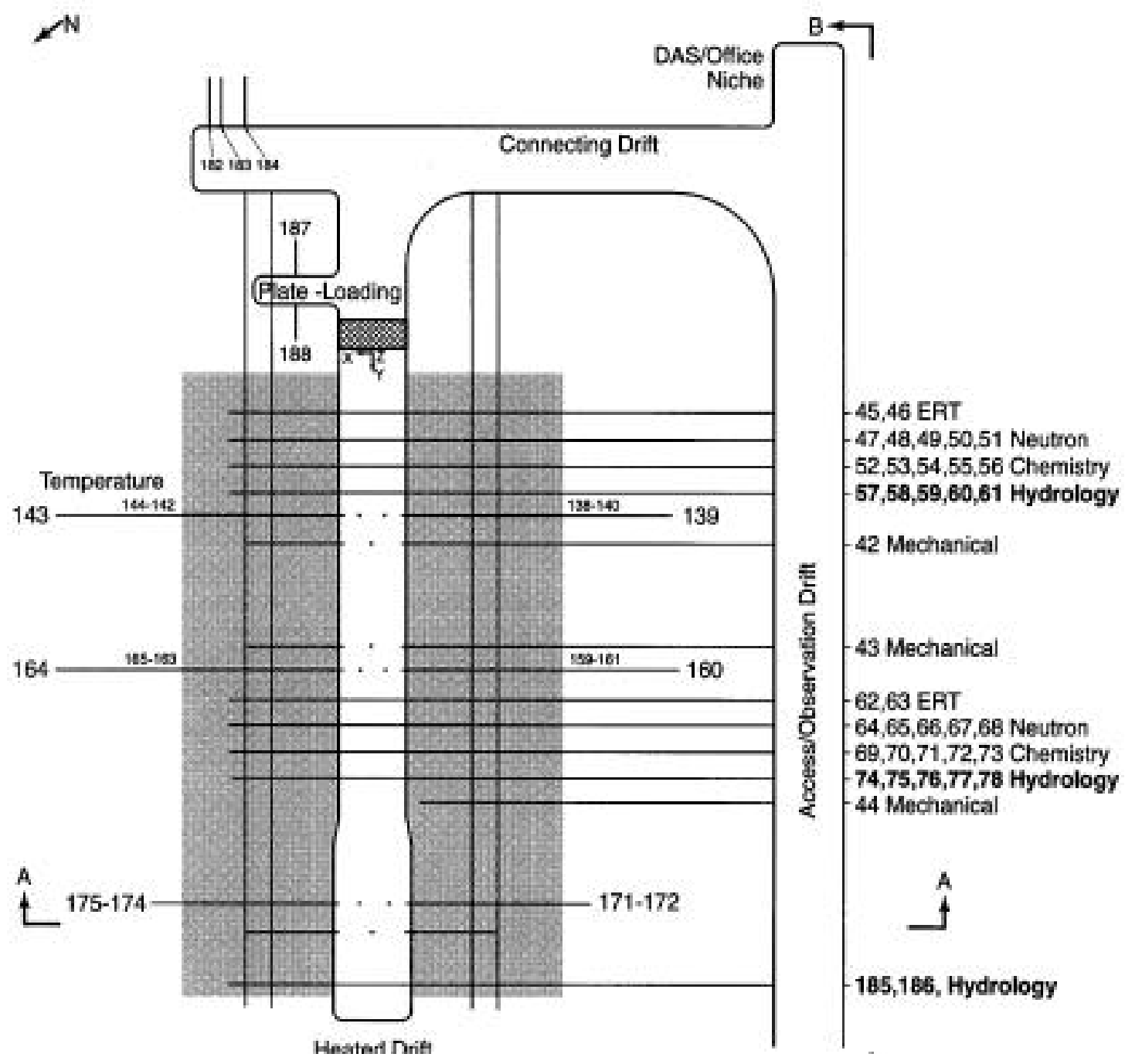

Figure 4-10 Schematic plan view of DST layout (after Birkhozer et al. [1997]).

Boreholes from observation drift incline above or below the heated drift. (Borehole identifying numbers are shown.)

A comparative thermohydrologic analysis was performed to establish research hypotheses for the DST and features of an appropriate test design to evaluate them. Numerical analysis of test size and thermal loading supported the selection of the test design, as described by Buscheck (1996b):

With the V-TOUGH code, we modeled and evaluated a range of heater test sizes, heating rates, and heating durations under a range of plausible hydrological conditions to help optimize an in situ thermal 
test design that provides sufficient (and timely) information to determine the following:

- The dominant mode(s) of heat flow.

- The major thermal-hydrological (T-H) regime(s) and the thermalhydrological-geomechanical-geochemical (T-H-M-C) processes that determine the magnitude and direction of vapor and condensate flow.

- The influence of heterogeneous properties and conditions on the flow of heat, vapor, and condensate.

Perhaps the single most important purpose of the ESF thermal tests is to determine which of three major decay-heat-driven $\mathrm{T}-\mathrm{H}$ flow regimes will govern the magnitude and direction of vapor flow (and the resulting condensate flow) leading to advective rock dryout:

- Throttled, nonbuoyant, advective rock dryout: the regime in which $\mathrm{k}_{\mathrm{b}}$ (bulk permeability) is low enough ( $<1$ millidarcy) to significantly throttle the rate of boiling-driven rock dryout. The threshold $\mathrm{k}_{\mathrm{b}}$ at which rock dryout is throttled decreases with increasing areal mass loading (AML) of heat-generating water..

- Unthrottled, nonbuoyant, advective rock dryout: the regime in which $\mathrm{k}_{\mathrm{b}}$ is high enough ( $>1$ millidarcy) not to significantly throttle the rate of boiling-driven rock dryout, but not large enough ( $<5$ darcy) to allow buoyant gas-phase convection to dominate the direction of vapor flow.

- Unthrottled, buoyant, advective rock dryout: the regime in which $\mathrm{k}_{\mathrm{b}}$ is high enough not to throttle the rate of boiling-driven rock dryout and is also large enough ( $>5$ darcy) to allow buoyant gas-phase convection to determine the direction of vapor flow.

How these major $\mathrm{T}-\mathrm{H}$ regimes influence the flow of heat, vapor, and condensate depends in part on whether vapor diffusion is substantially enhanced. Therefore, another major purpose of the thermal tests is to determine the importance of enhanced vapor diffusion.

We evaluated the following cases: 1) thermal test sizes of 50, 270, 490, 1475 , and $5077 \mathrm{~m}^{2} ; 2$ ) three heating schedules, including 1-, 2-, and 4-yr full-power heating periods; and 3$)$ three heating rates $(122,177$, and $236 \mathrm{~W} / \mathrm{m}^{2}$ ). We then determined a minimum thermal test size, minimum heating duration, and a preferred heating rate based on the following criteria: 1) the ability of the test to discriminate between the major T-H regimes; 2) the rock dryout volume; 3) peak rock temperatures; 4) duration of refluxing conditions; 5) ability to observe the influence of heterogeneity; and 6) ability to observe whether heat conduction is able to overwhelm the effects of heterogeneity. 
We evaluated the single-drift thermal test (without wing heaters) and found that the substantial lateral heat flow necessitated very high peak temperatures in order to create a thick enough dryout zone; moreover, the test does not promote enough condensate perching to generate significant refluxing. We then evaluated a number of singledrift, winged thermal tests and determined that an optimal configuration consists of a row of drift heaters that generates 0.8 $\mathrm{kW} / \mathrm{m}$ along the drift axis, flanked by wing heater arrays generating an areal power density (APD) of $105 \mathrm{~W} / \mathrm{m}^{2}$ averaged over the interval $4<|\mathrm{x}|<9 \mathrm{~m}$ and $157.5 \mathrm{~W} / \mathrm{m}^{2}$ over the interval $9<|\mathrm{x}|<14 \mathrm{~m}$. This configuration (called the reference case) generates an APD of 122 $\mathrm{W} / \mathrm{m}^{2}$ averaged over the heated area.

We then evaluated the reference single-drift, winged thermal test and found that a 2-yr full-power heating period is required to provide clear and unambiguous information about all three major $\mathrm{T}-\mathrm{H}$ regimes and about whether enhanced vapor diffusion is significant. We also found that a 4-yr full-power test provides an earlier determination than the 2 -yr full-power test of the degree of vapor diffusion enhancement and of whether buoyant gas-phase convection of humid air significantly increases the rate at which the dryout zone rewets to humid conditions.

For determining the dominant $\mathrm{T}-\mathrm{H}$ regime(s) and dominant heat flow mode(s), we found that the most diagnostic measurements are the following:

- Vertical temperature distributions.

- Vertical gas-phase pressure distributions.

- Gas-phase pressure history in the drift during heat-up.

- Relative humidity (RH) history in the drift during heat-up.

For determining the degree of vapor diffusion enhancement, we found that the most diagnostic measurement is the RH history in the drift during cool-down.

We found that the influence of heterogeneity will be observable within the first 1 to $2 \mathrm{yr}$ of the test (after a sufficiently large boiling zone has developed). The effects of heterogeneity are quite apparent in the temperature distribution. We found that a full-power heating period of at least $6 \mathrm{yr}$ might be required to determine whether heat conduction is able to overwhelm the effects of heterogeneity on the temperature and liquid saturation distributions near the heater horizon.

For determining the influence of heterogeneity on the flow of heat, vapor, and condensate, we found the most diagnostic measurements are the following: 
- Horizontal temperature distributions.

- Horizontal liquid saturation (or RH) distributions.

- RH history in the drift during heat-up.

We also evaluated whether the tests provide for refluxing conditions of sufficient duration and over a large enough volume to allow for observations of potentially important coupled $\mathrm{T}-\mathrm{H}-\mathrm{C}$ processes. We found that the 4-yr full-power test was far more likely to promote conditions necessary to make these observations than the 1- or 2-yr full-power tests.

We then evaluated heating rate and made a preliminary determination that the $177 \mathrm{~W} / \mathrm{m}^{2} 2$-yr full-power test has virtually all of the advantages of the $122 \mathrm{~W} / \mathrm{m}^{2}$ 4-yr full-power test. We plan to conduct additional analyses of the $177 \mathrm{~W} / \mathrm{m}^{2} 2$-yr full-power test to determine whether we can recommend it for the first ESF thermal test.

Pretest analyses of the thermohydrochemical effects of heating in the DST have also been completed (Glassley and DeLoach, 1997).

\subsection{International High Level Nuclear Waste Programs}

The following sections describe a selection of tests that have been performed at underground laboratories internationally.

\subsubsection{Tests in the Boom Clay near Mol, Belgium}

The CERBERUS experiment is a long-term investigation in the Boom clay to evaluate the effects of heat and radiation from a HLW canister on the near-field. In a clay repository, the formation of steam must be avoided because it would lead to enhanced permeability of the clay, possible hydraulic fracturing, and increased corrosion of the waste packages (Neerdael, 1996). The process of heating and cooling produces changes in the mechanical properties of clay backfill. Also, the natural clay contains relatively large amounts of natural organic matter and soluble salts (e.g., nitrates and sulfates) that affect the stability of the clay and the mobility of the waste nuclides. Nitrates can make the environment more oxidizing, and high concentration of salts can decrease sorption of radionuclides. High concentrations of sulfate could stimulate the growth of sulfate-reducing bacteria, leading to the production of corrosive $\mathrm{H}_{2} \mathrm{~S}$.

A HLW canister was simulated by a ${ }^{60} \mathrm{Co}$ source combined with electrical heaters and emplaced in the floor of a test drift. Instrumentation in the near-field clay environment measured temperature, pore pressure, swelling (total) pressure, $\mathrm{pH} / \mathrm{Eh}$, and radiation dose. The experiment has been ongoing for approximately $5 \mathrm{yr}$, and further exposure of the clay is planned before the experiment is cooled and disassembled. Some potential chemical effects have been identified. The near-field $\mathrm{pH}$ decreased by approximately one unit, and the Eh increased slightly; 
thus, the environment is still reducing even in the presence of gammahydrolysis. Thiosulfate compounds, which can accelerate corrosion, and oxalate, which can act as a complexing agent for radionuclides, were observed (Neerdael, 1996).

\subsubsection{Underground Tests at Stripa, Sweden}

The Stripa underground laboratory was located in a granite pluton and was accessed from an adjacent inactive iron mine. The first heater test at Stripa used a single heater $3 \mathrm{~m}$ long and having $6 \mathrm{~kW}$ power (Carlsson, 1978). The heater was placed in the bottom of a 10-m borehole. Stress and temperature changes were monitored in other boreholes at distances as great as approximately $3 \mathrm{~m}$. The heaters were operated for 69 days; maximum rock temperature was $102^{\circ} \mathrm{C}$, measured at radial distance of $0.85 \mathrm{~m}$. Fractures did not appear to cause thermal anisotropy (i.e., heat was conducted uniformly in all directions). Measured thermal stresses were smaller, by a factor of 3 to 8 , than predictions based on core properties. Heating appeared to have no effect on the rock deformability measured using borehole dilatometers.

Two full-scale heater tests were performed at Stripa during the SwedishAmerican Cooperative phase (Cook and Hood, 1978; IAEA, 1987; Robinson, 1985) to investigate short-term near-field effects from thermal loading. Two heaters, each $0.3 \mathrm{~m}$ in diameter and $3 \mathrm{~m}$ long, were emplaced in vertical boreholes.

Heater power levels were $5 \mathrm{~kW}$ and $3 \mathrm{~kW}$, and an array of eight 1-kW peripheral heaters was installed around the 5-kW heater at a radial distance of $0.9 \mathrm{~m}$. Instrumentation and tests included borehole extensometers, boreholedeformation gauges, rigid-inclusion stressmeters, hydraulic-flow tests, and ultrasonic crosshole-velocity surveys.

The peripheral heaters were activated 204 days after the central heater and had the effect of increasing the near-field temperature by approximately $100^{\circ} \mathrm{C}$, with a corresponding increase in stress; the borewall compressive stress soon exceeded the strength. Borewall temperatures reached $300^{\circ}$ to $350^{\circ} \mathrm{C}$ during this period. Spalling of the heater borehole started within a few days and increased with time.

A time-scaled heater test was also performed at Stripa to investigate long-term thermomechanical response to thermal loading (Robinson, 1985). The test was designed, using dimensionless analysis, with the timescale for repository simulation compressed by 10:1. Linear scales (e.g., distance, power) were compressed by the ratio of the linear distance to the square root of the product of time and thermal diffusivity. Eight 1-kW heaters, each $1 \mathrm{~m}$ long, were installed below the floor of the drift in vertical boreholes sufficiently deep to be away from the thermal and mechanical effects of the test-room floor.

Analysis showed that, in the full-scale and time-scale heater tests, heat flow conformed to linear conduction theory and was not affected by fractures or other discontinuities. Thermal properties extracted from the data were only slightly higher than laboratory measured values (Jeffry et al., 1979). Thermoelastic 
deformation of the rock mass was nonlinear and less than expected. During the first weeks, measured displacements were much less than predicted by linear thermoelasticity (Hood, 1979). Later in the tests, the displacements increased uniformly, but in fixed proportion to predicted levels. A likely explanation was closing of fractures in response to thermal expansion. Fracture closure was confirmed by observation of diminished water inflow to the heater and instrument boreholes (Nelson et al., 1981) and by increased ultrasonic compressional wave velocity during heating (King and Paulsson, 1981).

As part of the Stripa Project, Makurat et al. (1990) performed a block test on a single fracture. The block test was part of a series of tests at different scales with the objective of developing scale relationships for fracture parameters as described by Barton and Choubey (1977). The test series was part of the site characterization and validation (SCV) experiment to characterize the relationship between in situ stress and fracture hydraulics in the SCV block. A 1$\mathrm{m}$ block was excavated in place by line drilling slots for installation of flatjacks. The mechanical aperture of the joint increased during drilling of the slots. During flatjack loading to $10 \mathrm{MPa}$, not all of this deformation was recovered. Once the baseline in situ stress had been applied, hydraulic testing of the joint was quite insensitive to applied load. This result was similar to that from the GTunnel block test.

\subsubsection{Berfeforsen Power Dam, Sweden}

Lime water was injected into the foundation of the Berfeforsen power dam, an earthen structure $400 \mathrm{~m}$ long and $35 \mathrm{~m}$ high. The bedrock consists of a crystalline gneiss intruded by dikes of carbonated alkali peridotite, which weathers by reaction of $\mathrm{CaCO}_{3}$ with $\mathrm{CO}_{2}$ and water. Preferential weathering of the dikes by seepage from the impoundment was prevented by injection of grout, bitumen, and water in which dry-slaked lime had been dissolved. The purpose of limewater injection was not precipitation of calcite, but protection of the carbonaceous dikes from chemical attack.

The lime water was a $98 \%-100 \%$ saturated solution at $6^{\circ}-7^{\circ} \mathrm{C}$. The solution was prepared at or below $8^{\circ} \mathrm{C}$ by adding $4 \mathrm{~kg} \mathrm{CaO} / \mathrm{m}^{3}$ water. The solution was filtered to prevent clogging and injected, at low head under the impetus of gravity, through 4-cm boreholes $1 \mathrm{~m}$ apart in a row between two rows of grout-injection holes. Approximately 100 boreholes, for total length of approximately $1500 \mathrm{~m}$, were used for lime-water injection.

According to annual measurements, consumption of lime water declined about $80 \%$, at a uniform rate from 1955 to 1961. To examine for possible clogging, some injection holes were brushed with no effect on injectivity. Additional boreholes were drilled between the original holes, but lime-water consumption was only slightly greater, suggesting a decrease in rock permeability at a scale of $\sim 0.5 \mathrm{~m}$. 
Core-drilling investigations performed after $3 \mathrm{yr}$ of injection showed that calcite was precipitating in fractures, but very near the injection holes. The farthest distance, observed in a crushed zone, from an injection hole to calcite precipitate was $1 \mathrm{~m}$. The estimated total of precipitated calcite was $1400 \mathrm{~kg}$, or approximately $1 \%$ of the total injected.

\subsubsection{Underground Tests at Grimsel, Switzerland}

\subsubsection{Grimsel Heater Test}

This test investigated thermal, mechanical, and hydraulic responses to thermal loading. Of particular interest was the deformation response of a major fracture zone crossing the test field (Lieb, 1988). Electrical heaters were placed in two boreholes in the floor of the test drift; the heaters spanned a depth range from 12 to $18 \mathrm{~m}$ (Schneefuß et al., 1989). Power output for each heater was variable up to $24 \mathrm{~kW}$. One of the heaters was situated in intact rock adjacent to the fracture zone, and the other was situated entirely within the zone.

Inclinometers and extensometers were used to measure deformation. Pressure cells (flatjacks) were used to monitor stress changes in the rock. Water inflow to heater and instrument boreholes was monitored, an acoustic emission detection array was installed, and temperature sensors were installed in most of the boreholes. The heater tests were monitored for about 18 months without heating ("zero state"). The heater power was controlled so that temperature at the rock wall remained just below the boiling point $\left(90^{\circ} \mathrm{C}\right)$ for more than a year. Radial stresses developed around the heaters, reaching $10 \mathrm{MPa}$ at a distance of $0.5 \mathrm{~m}$. Measured thermal stresses were within an order of magnitude of predictions, and no significant perturbation of pre-test hydraulic conditions was observed even in the intersected dike (Lieb, 1988).

The Grimsel heater test did not reproduce the Stripa observation of water inflow correlated to heater power changes (Schneefuß et al., 1989). However, at Stripa, the heater power and rock temperatures were much greater, and the rock was more fractured and wet. Transient pore-pressure changes were observed in the Grimsel test, but only close to the heater.

\subsubsection{Grimsel Ventilation Test}

The Grimsel ventilation test was a large-scale hydraulic-properties test similar to the macropermeability test at Stripa (Brewitz et al., 1988). A drift $74 \mathrm{~m}$ long and $3.5 \mathrm{~m}$ in diameter was tested to measure bulk hydraulic conductivity. Large, airfilled bladders were used as ventilation bulkheads. Hydraulic head was measured in the vicinity of the drift using piezometers installed in radial boreholes at 32 isolated intervals situated $2.75 \mathrm{~m}$ and $5.25 \mathrm{~m}$ from the axis of the drift (Schneefuß et al., 1989). 
Water inflow in the Grimsel pluton was limited to structural zones, and the tunnel section selected for testing had one main water bearing zone. Inflow of 1.6 $1 /$ hr was observed over the entire test period, independent of ventilation conditions and relative humidity (Schneefuß et al., 1989). Numerical simulation was done to deduce whether the fracture zone was fed from the surface or from the surrounding rock mass; the result was that the $1.6 \mathrm{l} / \mathrm{hr}$ can be readily supplied from storage in the granite massif. Fracture-zone conductivity of $2 \times 10^{-}$

${ }^{10}$ to $5 \times 10^{-9} \mathrm{~m} / \mathrm{sec}$ was needed to explain the behavior modeling the zone as a single planar feature extending to the surface (Brewitz et al., 1988).

Observation-borehole piezometric heads did not change during the ventilation test (Schneefuß et al., 1989). Conductivity values interpreted from this test were $10^{-11} \mathrm{~m} / \mathrm{sec}$ for the rock matrix and $10^{-9}$ for the fractured zones (Schneefuß et al., 1989).

Ventilation air temperature was adjusted to $13^{\circ}, 17^{\circ}$, and $23^{\circ} \mathrm{C}$ in a series of tests. This caused the rock temperature to increase by $2^{\circ}$ to $5 \mathrm{C}^{\circ}$, except in the fracture zone, where less change was observed (Schneefuß et al., 1989). Each test was terminated when relatively constant temperature was observed over the temperature-measurement array.

An infrared temperature-scanning device was used to scan the drift wall during the test (Schneefuß et al., 1989). Surface-temperature resolution on the order of $0.1^{\circ} \mathrm{C}$ was obtained. The temperature distribution indicated channeling processes and selective flow associated with fracture surfaces and planes of schistosity (Brewitz et al., 1988). Eight temperature profiles over the full length of the test drift were acquired as part of each scan, with the infrared camera rotated azimuthally by $45^{\circ}$ for each profile.

\subsubsection{Uranium Migration Investigation, Grimsel}

One interesting observation from the Grimsel facility was uranium-containing residue, which fluoresced green in ultraviolet light, on the tunnel walls (Frick et al., 1988). The phenomenon was caused by pore-water transport along a capillary gradient, toward an evaporation interface at the tunnel wall. Fluorescent residues were found in different areas in the Grimsel tunnels, and they were always linked to hydrothermal alteration or other geological disturbance of the wall rock. The deposits were observed along lamprophyre dikes, aplite lenses, and shear zones.

A pore-water extraction and capillary-pressure experiment was performed by cementing a small vacuum chamber to a specially prepared surface on the tunnel wall (Frick et al., 1988). Both aplitic granite (hard, impermeable, and dry) and hydrothermally altered granite (near a tension joint) were tested. Water was extracted from the hydrothermal granite using a 0.1-bar vacuum. The extracted water had high uranium concentration, lower $\mathrm{pH}$, and increased $\mathrm{CO}_{2}$ content than did typical Grimsel water. Extraction rate was a linear function of the vacuum used, and $10^{-9} \mathrm{~m} / \mathrm{sec}$ was the inferred saturated hydraulic conductivity. This water contained from 1 to 10 ppm inorganic colloids, but no radiocolloids. 
Water could not be removed from the aplite even with 0.8-bar vacuum; it could, however, be removed by evaporation (Frick et al., 1988). Using about $800 \mathrm{l} / \mathrm{hr}$ of dry air, and silica gel for water recovery, approximately $6 \mathrm{dl}$ water was obtained in several months. A tiny bit of uranium was left behind on the rock surface. The evaporation rate dropped during the course of the experiment to approximately $10 \%$ of the initial value.

Rock samples were taken from the tunnel wall, including the fluorescing zones, and leached in the laboratory. Most of the uranium could be mobilized from the cores. The origin of the observed uranium is unknown, but it appears to have resided in microfractures and along grain boundaries, where it could come into contact with pore water.

\subsubsection{Russia and FSU}

A cooperative project has been initiated with the authorities at the Krasnoyarsk nuclear facility in Siberia (Gupalo, 1996). Three large nuclear reactors were operated $300 \mathrm{~m}$ underground in crystalline gneiss for production of plutonium and cogeneration of electrical power and steam. Further, chemical reprocessing plants were operated underground, and the resulting mixed wastes are stored in underground tanks. The facility has many features that are relevant to Yucca Mountain repository performance, including concrete exposed to radiation and hot water and a very large volume of rock heated to temperatures of $70^{\circ} \mathrm{C}$ or greater. The fate of radioactive spills may also be of practical interest. The scientific work will be performed by Russian scientists and will include archive research and resampling of key locations within the facility. Funding will be provided through the Organization for Economic Cooperation and Development/Nuclear Energy Agency (OECD/NEA).

\subsection{Geothermal Fields}

A survey of geothermal literature pertaining to coupled thermohydrologic processes at Yucca Mountain was conducted by Simmons and Bodvarsson (Simmons and Bodvarsson, 1997). The authors maintained that the magnitude of the average percolation flux will determine the extent to which heat-pipe effects develop in the host rock. They generalized that heat-pipe effects involving reflux of liquid water will prevail in the near-field environment if the ambient percolation flux is greater than 4 to $5 \mathrm{~mm} / \mathrm{yr}$. At lower values for the ambient flux, development of heat-pipe effects will depend more on rock mass heterogeneity. Buscheck (1996b) also reported that dryout of the near-field environment was suppressed by high ambient percolation flux (e.g., $5 \mathrm{~mm} / \mathrm{yr}$ ). Repository heat production will, at first, be more than sufficient to boil off ambient flux of $5 \mathrm{~mm} / \mathrm{yr}$ or more. Declining heat production will eventually allow return to wetter conditions, which happens sooner with greater ambient flux. The magnitude of the ambient flux does not affect the development of heat pipes if the flux is greater than $\sim 0.05 \mathrm{~mm} / \mathrm{yr}$; however, it may do so strongly when heat pipes form in the near-field environment. 
The existence of a heat pipe is manifested by a temperature gradient that is small relative to heat transfer by conduction and by temperatures close to the boiling point, which depend on the local pressure. Geothermal systems in which heat pipes occur may be categorized as vapor- or liquid-dominated.

Vapor-dominated geothermal systems are generally underpressured in comparison to adjacent, cooler rock that is liquid-saturated. Vapor-dominated systems occur in fractured rock with low matrix permeability (Pruess and Narasimhan, 1982; Simmons and Bodvarsson, 1997). The few known vapordominated systems include The Geysers, California; Larderello, Italy; and Matsukawa, Japan. In a typical vapor-dominated system, the temperature is $240^{\circ} \mathrm{C}$ over a depth interval of as much as $2000 \mathrm{~m}$, and the vapor-phase pressure is relatively constant because the vapor has low density. Liquid water must be present throughout the heat-pipe zone to sustain the uniformity of vapor-phase pressure. Pathways for water return tend to be clogged by precipitates, creating a low-permeability aureole around the heat-pipe zone and limiting the rate of infiltration and, hence, cooling of the system. Within the vapor-dominated heatpipe zone, the fracture permeability must remain relatively high to support convective heat transfer. Overlying the heat-pipe zone is a cap of liquid condensate supported by pressure in the underlying vapor-dominated zone. The gradient of total pressure in the liquid cap must be directed outward.

Most geothermal reservoirs are liquid-dominated (Simmons and Bodvarsson, 1997), and the pressure increases hydrostatically with depth; heat pipe effects are caused by upward and downward flowing water in the same zone. In hotter liquid-dominated zones, the temperature may controlled by boiling so that the vapor pressure is approximately equal to the hydrostatic pressure. Upwardcirculating water cools by conduction, which causes precipitation that maintains a low permeability cap.

Compared to the heat pipes in geothermal systems discussed by Simmons and Bodvarsson (1997), heat pipes in the repository host rock will be vapordominated but will not be confined. A liquid cap will develop and tend to move outward with time. Heat-pipe zones in the repository host rock will be transient features compared to those of geothermal systems, and the host rock will be free draining, with natural percolation flux impinging from above. The development of a liquid cap above the repository may involve episodic counterflow that would not be expected from the apparent stability of natural systems.

The hydrologic properties of the repository host rock are consistent with conditions that promote heat-pipe development in geothermal systems (Bjornsson and Bodvarsson, 1990; Simmons and Bodvarsson, 1997). The matrix is permeable enough to allow steam from boiling to flow into fractures without excessive pressure buildup that would greatly increase the boiling temperature. The fracture network is permeable enough to allow for liquid-vapor counterflow to remove all repository-generated heat. Simmons and Bodvarsson (1997) confirmed that the observations of Ramirez et al. (1991b) and Lin et al. (1991b) from a heater test at G-Tunnel resulted from heat-pipe activity. In this test, a 
boiling front was detected, and measured temperatures in the vicinity of the heater tended to stabilize at the boiling point as the boiling front expanded. Simmons and Bodvarsson (1997) concluded that, if the natural percolation flux in the repository host rock is greater than about $10 \mathrm{~mm} / \mathrm{yr}$ (on a local or average basis, with duration that is significant compared to repository heating), heat-pipe conditions are very likely to predominate in the near field, and no dryout zone will develop. They further noted that heat-pipe mechanisms will depend locally on heterogeneity of thermohydrologic properties, particularly gas permeability.

\subsubsection{The Geysers}

The Geysers geothermal field is operated by Unocal (1997). The project, located about $65 \mathrm{~km}$ north of Santa Rosa, California, currently has a developed area of 59 $\mathrm{km}^{2}$. It produces dry steam (slightly superheated) from 246 production wells at an average depth of $2410 \mathrm{~m}$. The deepest well reaches $3872 \mathrm{~m}$. The Geysers also has 14 injection wells for injecting steam condensate back into the geothermal reservoir to extend the life of the project. Without injection, depletion of mass from this closed system would cause the steam-production rate to decline more rapidly. The first power plant came on line in September, 1960, with an installed capacity of $12 \mathrm{MW}$. In 1994, the project produced 4.5 million MW-hours of electricity, making it the largest commercial geothermal power-generating installation in the world.

A comprehensive assessment of the subsurface geology, geophysics, reservoir performance, and well-construction practices was published by Stockton et al. (1984). Considerable work to understand this important resource and other geothermal areas continues to the present; much of it can be accessed through the Internet at http:/ / doegeothermal.inel.gov (U.S. Department of Energy) and http:/ / ekofisk.stanford.edu/geoth (Stanford University). These web sites also contain links to others with extensive information on geothermal projects worldwide.

Stockton et al. (1984) stated that temperature profiles above the steam zone in two wells are almost linear with depth from the surface and that extrapolation of these measured profiles to the depth at the top of the steam reservoir gives an estimate of $240^{\circ} \mathrm{C}$ for the steam temperature, compared with measured steam temperatures of $238^{\circ}$ to $245^{\circ} \mathrm{C}$. Based on the measured gradients above the steam zone and estimates for the thermal conductivity of the rock, the heat flux is calculated to be between 314 and $389 \mathrm{~mW} / \mathrm{m}^{2}$.

Reservoir steam pressure and temperature generally closely follow the saturation curve for water: in one survey presented by Stockton et al., pressure at the top of the producing interval was about 35 bar, and the temperature was $245^{\circ}$ $\mathrm{C}$, at a depth of slightly more than $1000 \mathrm{~m}$. The deepest zone from which steam entered this well was approximately $2000 \mathrm{~m}$, with a measured temperature of $248^{\circ} \mathrm{C}$ and a pressure of $36 \mathrm{bar}$. This relatively constant temperature and pressure 
over a depth interval of $2000 \mathrm{~m}$ is strong evidence of a gravity-driven heat pipe in which steam rises by buoyancy and condenses at the top of the reservoir, and the resulting liquid drains back counter to the steam flow.

Assuming that the conductive heat flux ( 314 to $389 \mathrm{~mW} / \mathrm{m}^{2}$ ) leaving the top of the steam reservoir is supplied by the latent heat of condensing steam, the steady-state evaporation/condensation flux is estimated to be 4 to $5 \mathrm{~mm} / \mathrm{yr}$, in qualitative agreement with the conclusions of Simmons and Bodvarsson (described previously). According to Stockton et al. and references cited therein, there is no infiltration into The Geysers geothermal steam reservoir. Hence, evaporation and condensation flux must balance.

The situation at Yucca Mountain is quite different. For the advanced conceptual design (ACD) thermal load, the heat flux would be $22,300 \mathrm{~mW} / \mathrm{m}^{2}$, or 50 to 70 times the heat flux at The Geysers. This large heat flux could evaporate more than $290 \mathrm{~mm} / \mathrm{yr}$, not just the $10 \mathrm{~mm} / \mathrm{yr}$ estimated by Simmons and Bodvarsson. Locally, during the transient stages of heating around the emplacement drifts, much higher heat and evaporation fluxes would occur, especially in the lineload strategy investigated by Buscheck (1996b). It is entirely possible that proper management of the thermal load can minimize the contact of water with waste packages and waste forms for thousands of years.

Future study of the literature on The Geysers and other geothermal areas will produce additional insights into the complex coupled processes driven by decay heat at Yucca Mountain, and these processes may be one of the more promising ways to improve the credibility of thermohydrologic modeling. This chapter should be considered a preliminary survey into this topical area.

\subsubsection{New Zealand}

The geothermal systems of the Taupo Volcanic Zone (TVZ) were selected for field-scale application of geochemical models such as EQ3/6 (Bruton et al., 1993a). The rocks of the TVZ are silicic volcanics similar in composition to Yucca Mountain tuffs. Temperatures in the accessible parts range from $25^{\circ}$ to $300^{\circ} \mathrm{C}$, producing a variety of secondary minerals similar to those anticipated from repository effects at Yucca Mountain. Water chemistry has changed little over the $30-y r$ life of geothermal energy production in the TVZ.

Hydrothermal conditions in the TVZ are comparable to the regimes identified by Glassley et al. (1993), based on the analysis of Buscheck and Nitao (1993). Regime A was designated as sub-boiling and partially saturated with evaporation taking place; regime $\mathrm{B}$ is at the boiling temperature and is associated with heat-pipe effects; regime $\mathrm{C}$ is above boiling temperature and is dried out except for trapped or closely held water; and regime $\mathrm{D}$ represents rock that is below the boiling temperature but was altered at higher temperatures. The TVZ is fully saturated and therefore does not represent regime $A$; however, extensive regions of the rock mass are subjected to temperatures in the range $20^{\circ}$ to $100^{\circ} \mathrm{C}$. The effects of boiling are observed and represent regime B, except the overall proportion of water that is boiled is less than expected for the repository host rock. 
Long-term dissolution and corrosion testing has begun-testing for which samples of rock, minerals, and manufactured materials were placed in natural thermal features. Manufactured materials such as steel and concrete have been used extensively in geothermal energy production. Rates of silica precipitation from thermal fluids have been analyzed and compared with laboratory-derived rate data (Carroll et al., 1995). Microbially influenced corrosion of concrete used in the energy production facilities is also being investigated (Bruton et al., 1995).

\subsubsection{Mineral Equilibrium Calculations}

Initial work at the TVZ focused on testing, at temperatures encountered in TVZ boreholes, the EQ3/ 6 code package for the analysis of solution compositions and mineral assemblages (Bruton et al., 1993a; 1994). Chemical affinity for mineral dissolution or precipitation reactions was calculated for water compositions from geothermal wells in the TVZ. Affinity was defined as $A=R T \ln (Q / K)$ where $R$ is the gas constant, $\mathrm{Q}$ is the ion activity product for the reaction under consideration, and $\mathrm{K}$ is the equilibrium constant at the absolute temperature, $\mathrm{T}$. Calculated affinities represent the free energy change associated with a reaction such as dissolution or precipitation. The use of equilibrium calculations to interpret mineral assemblages is justified by the expectation that aqueous systems at temperatures greater than $200^{\circ} \mathrm{C}$ are at chemical equilibrium (Bruton et al., 1995). Water compositions were corrected, using the measured downhole temperatures, for evaporation loss during sampling. The downhole $\mathrm{H}_{2} \mathrm{~S}$ concentration was estimated from solution equilibrium with pyrite, and the in situ redox state was assumed to be represented by the $\mathrm{SO}_{4} / \mathrm{H}_{2} \mathrm{~S}$ couple. The downhole $\mathrm{Al}$ concentration was fixed by assuming equilibrium with albite.

Mineral assemblages predicted for two geothermal wells on the basis of chemical affinity (ignoring possible kinetic controls) were compared with observed assemblages in feeder zones sampled by drilling. Major phases such as quartz and calcite were calculated to be at near-equilibrium, in accordance with observations. Other phases such as wairakite and epidote were not predicted as accurately because of 1) kinetic considerations, 2) adequacy of thermodynamic data, 3) solid solution effects, 4) influence of boiling on dissolution/precipitation, and 5) assumptions, including steady-state conditions in situ, redox state, and Al concentration.

\subsubsection{Silica Precipitation Kinetics}

Most of the kinetic data available for silica concern dissolution rates and were obtained with laboratory experiments. Comparison of laboratory and field data for amorphous silica precipitation has shown that significant discrepancies exist between results obtained with different test conditions (Carroll et al., 1995). Field measurements of amorphous silica precipitation rates were made in natural hydrothermal waters at the TVZ and compared with rates measured in the laboratory using similar techniques (Carroll et al., 1996). The importance of silica precipitation kinetics was introduced as follows (Carroll et al., 1995): 
It is very common in geothermal systems to observe an impermeable layer of silica-rich rock capping the zone of convective fluid and heat flow. Heat flow through the silica cap is mainly conductive. The initial circulation pattern of a geothermal system evolves to this configuration regardless of the rock-permeability distribution. The fundamental cause is that silica becomes less soluble during cooling and precipitates along the fluid migration pathways, reducing permeability. Similar behavior is observed in laboratory simulations of fluid flow, including flow in unsaturated hydrologic systems designed to simulate conditions in a repository at Yucca Mountain; (Rimstidt et al., 1989).... The kinetics of silica precipitation may change due to the presence of other aqueous species such as $\mathrm{Na}^{+}$and $\mathrm{Al}^{3+}$ and are also important because of the potential for radionuclide transport on silica pseudocolloids.... Precipitation kinetics depends on the reactive solid surface area, which is relatively unknown.

For field precipitation experiments, the authors used a fluidized bed reactor to control reactive surface area. A fluidized bed apparatus was loaded with sorted, $99 \%$ pure quartz sand and connected directly to a supply of geothermal water at temperatures as great as $130^{\circ} \mathrm{C}$ and at 2 bars pressure. An equilibration time of 2 to $4 \mathrm{hr}$ was allowed before the reactor was disassembled for sample evaluation. Sand samples were preserved with $\mathrm{HCl}$ and analyzed for monomeric (amorphous) and total silica.

Laboratory experiments (described in Section 2.6.7.1.2) were conducted in Dickson gold bag autoclaves with ports for sampling in situ (Carroll et al., 1996).

Geothermal water and reagent silica gel were reacted at $120^{\circ} \mathrm{C}$ until the aqueous phase was at equilibrium with amorphous silica; the temperature then was lowered to $100^{\circ} \mathrm{C}$, and precipitation was inferred from the decrease in the aqueous-phase concentration over time. Changes in aqueous silica were observed over time in experiments with and without addition of solid amorphous silica (Figure 4-11). Precipitation rates on the order of $3 \times 10^{-7}$ $\mathrm{mol} / \mathrm{m}^{2}$-day were obtained, which is within an order of magnitude of the rate predicted using the approach recommended by Rimstidt and Barnes (1980). Similar results were obtained at buffered $\mathrm{pH}$ values of 3,5 and 6 with slower precipitation at lower $\mathrm{pH}$ (Carroll et al., 1995). The $\mathrm{pH}$ dependence was similar to that observed by Knauss and Wolery (Knauss and Wolery, 1988). Precipitation was more rapid in the presence of amorphous silica, indicating that the reaction rate was controlled at the solid-solution interface, rather than by nucleation in the aqueous phase. 

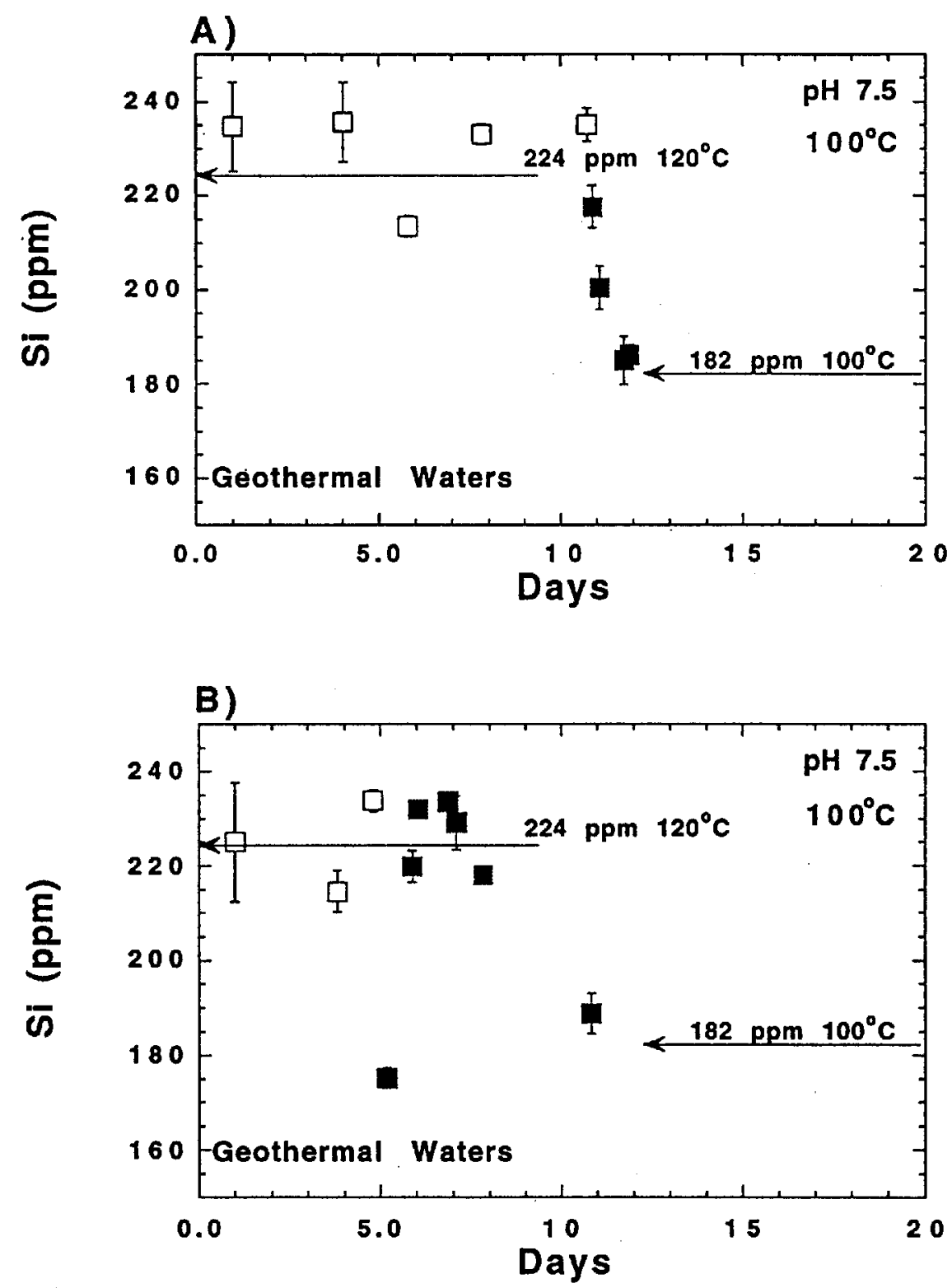

Figure 4-11 Concentration of aqueous silica vs. time in laboratory measurements of silica precipitation rates (after Carroll et al. [1995]). The plots compare results from batches of geothermal water: a) with amorphous silica added, and b) without silica added. Response to a temperature change from $120^{\circ}$ to $100^{\circ} \mathrm{C}$ was monitored over approximately 6 to 12 days. Open and filled symbols represent silica concentrations at $120^{\circ}$ and $100^{\circ} \mathrm{C}$, respectively. The arrows refer to the concentration of total silica at equilibrium at the specified temperatures.

Rates measured in the field were 400 times faster than those obtained in laboratory measurements. Differences between the laboratory and field results were attributable to several possible causes (Carroll et al., 1995). The solid phase for field tests was quartz, whereas amorphous silica was used in the laboratory 
tests, raising the possibility of different precipitates. Previous investigators (Rimstidt and Barnes, 1980) argued, but without supporting empirical data, that precipitation rates for all silica polymorphs are identical because the molecular mechanism is the same. Differences in catalyzed precipitation by other elements in solution were considered unlikely because the same geothermal water was used in laboratory and in field experiments. The authors discussed possible differences in the effective surface area available for precipitation. Another possible cause is that the laboratory experiments (Carroll et al., 1996; Rimstidt and Barnes, 1980) measured transient adjustments by a closed system, whereas the field test measured a steady-state process with nearly constant solution-phase composition. These results indicate that assumptions used in previous studies (Rimstidt and Barnes, 1980) are not generally applicable to silica precipitation in situ.

\subsection{Thermal Oil Recovery}

Thermal oil recovery is a general term for heating a petroleum reservoir to increase the production rate of oil; this is especially useful when the oil is extremely viscous at initial reservoir conditions. Because the viscosity of crude petroleum decreases very rapidly with increasing temperature, raising the average reservoir temperature by even a few 10s of degrees Celsius can increase the production rate by a factor of 10 or more. Although various schemes with different types of borehole heaters have been tried over many decades, significant enhancement of oil recovery requires heating a substantial portion of the reservoir volume, not just a small region near the well bore.

Heating such large volumes of rock in a time period short enough to be commercially successful requires the injection of hot fluids (steam or hot water) or of compressed air to burn some of the oil in situ. Heat produced at the combustion front in the latter processes raises the rock and fluid temperatures downstream from the front and also produces combustion gases that help displace oil. Clearly, a good understanding of thermally coupled processes of heat and mass transfer, reactive transport, and so on is required to profitably develop field-scale thermal oil-recovery projects. These processes are even more complex than those of direct interest to the Yucca Mountain Project. The heavy-oilrecovery process of most interest the Yucca Mountain Project is steam injection because it involves similar temperatures, albeit normally at much higher pressures.

As in the case with vapor-dominated geothermal reservoirs, there are important differences between thermal oil-recovery processes and the thermally coupled processes of interest to the Yucca Mountain Project. Extensive amounts of literature exists, much of which can be accessed on the Internet (e.g., http:/ / ekofisk.stanford.edu/geoth). In both the production of steam from geothermal reservoirs and the injection of steam into heavy-oil reservoirs, the mass-flow rates dominate the energy transfer; i.e., advection driven by an imposed pressure gradient between a well and the reservoir is the major 
mechanism for heat transfer in the rock. Conduction is responsible for heat losses from the system but is only a small fraction of the overall rate of heat transfer. At Yucca Mountain, the dominant mode of heat transfer is conduction, and the mass flux is driven by heat and gravity.

A typical rate for steam flooding is about 7 tons of dry steam injected per hour per well into a pattern area of 5 to 10 acres; the average steam-production rate per well at The Geysers is about 37 tons per hour. These correspond to heat transfer rates of approximately $5 \mathrm{MW}$ and $28 \mathrm{MW}$, respectively. At Yucca Mountain, the entire initial heat load, based on a 700-acre emplacement footprint, is approximately $63 \mathrm{MW}$, and the total initial mass evaporation rate is approximately 90 tons per hour.

Although the heat and mass flow rates per unit area are different by more than an order of magnitude, the rock and fluid properties that control overall behavior are very similar, as is the temperature range. Hence, one could expect to make use of property measurements and measurement techniques developed for thermal oil recovery. This will be systematically explored in a future revision of this report.

\subsection{Summary}

Field-scale thermohydrologic coupling has been observed in several experiments, including the G-Tunnel heater tests (PEBSFT), Large Block Test (LBT), and Single Heater Test (SHT). Thermohydrologic coupling was apparent from the first heater test in G-Tunnel (Johnstone et al., 1985), in which a prodigious amount of condensate was collected in a short time. Additional heater tests in G-Tunnel also produced thermohydrologic coupling, redistributing moisture around the heaters in a manner reasonably consistent with calculated models.

It is interesting to compare certain details of some of the heater tests that have been conducted in welded tuff:

- In the original water-migration experiment (Johnstone et al., 1985), water was produced from upward-oriented boreholes. A 3-m-long heater was operated at $1 \mathrm{~kW} / \mathrm{m}$ for 10 days, during which more than $60 \mathrm{~L}$ of water was collected at several points near the heater. The radius of the dryout zone was not investigated, but was much less than $0.5 \mathrm{~m}$. The volume collected is equal to the amount of water within a $0.25-\mathrm{m}$ radius, assuming $10 \%$ initial water content by volume.

- For the PEBSFT (Lin et al., 1991; Ramirez et al., 1989 and 1991b), moisture redistribution was observed using several boreholes spaced as closely as 0.5 $\mathrm{m}$; the maximum radius of the dryout zone was determined to be approximately $0.7 \mathrm{~m}$. The configuration of the dryout zone was circular and shifted downward relative to the heater axis. Evidence for shedding of condensate to the sides of the heater was observed. A 3-m-long heater was operated at $1 \mathrm{~kW} / \mathrm{m}$ for 128 days. Areal power density at the limit of the 
dryout zone was $160 \mathrm{~W} / \mathrm{m}^{2}$, considerably greater than the initial thermal power density of $22.3 \mathrm{~W} / \mathrm{m}^{2}$ (used for the ACD). No water accumulation was observed in any borehole.

- In the SHT (Lin, 1997b), moisture redistribution was also observed on a scale of $1 \mathrm{~m}$ or less. The dryout zone was apparently more centered on the heater than it was in the G-Tunnel tests. Water was collected after 70 days and twice more during heating. A 5-m-long heater was operated at $4 \mathrm{~kW}$ for approximately 270 days. Approximately $2000 \mathrm{~L}$ of water was boiled from the dryout zone, which had a maximum radius of approximately $0.9 \mathrm{~m}$. At this radius, the areal power density was $100 \mathrm{~W} / \mathrm{m}^{2}$. Hence, both the PEBSFT and the ESF SHT were strongly "overdriven" (i.e., heat fluxes were about five times higher than the maximum average heat flux for the $A C D)$. The effects of overdriving these tests on long-term predictions remains to be determined during preclosure monitoring. During the heatup phase of the SHT, about $12 \mathrm{~L}$ of water were recovered from borehole 164 (Glassley and DeLoach, 1997).

Thermohydrologic processes observed in field-scale tests have mobilized significant amounts of water as fracture flow. In the PEBSFT, drying fronts proceeded along fractures during heating, and rewetting occurred near fractures during cooling. In the LBT, a reflux event lasting a short time $(<1 \mathrm{hr})$ involved a quantity of water sufficient to change the temperature of much of the block; this can only have occurred by fracture flow. In the SHT, water was collected in borehole 16-4 at a rate exceeding, by nearly an order of magnitude, the vertical hydraulic conductance of the tuff matrix intercepted by the borehole. This water was flowing in fractures and became trapped in the borehole.

An important determinant of heat-pipe behavior in field-scale tests is dimensionality. Single-heater experiments have permitted shedding of condensate around the edge of the heated zone so that much of the condensate does not flow back to the boiling zone. This has tended to suppress heat-pipe effects, artificially resulting in a larger dryout zone. The LBT represents an attempt to investigate heat-pipe effects with restricted dimensionality approaching a planar heat zone. Indications of heat-pipe behavior observed so far in the LBT have been spatially and temporally heterogeneous; this is similar to the intermittent behavior identified in laboratory physical model studies. Both the laboratory and field studies show that water reflux is intermittent; however, when it occurs, a strong flow forms from coalescing liquid "islands." The enhanced flow rate and velocity cause liquid flow to penetrate the boiling zone and contact the heated region of the test. The implication for a Yucca Mountain repository is that reflux events will be episodic and are potentially capable of penetrating to the emplacement drifts.

Review of the geothermal literature suggests that heat pipes are possible on a large or small scale, associated with surface-measured heat flow as low as 5 to 10 high flow units (HFU; $1 \mathrm{HFU}=41 \mathrm{~mW} / \mathrm{m}^{2}$ ). The maximum rate of repository heating will be approximately $250 \mathrm{HFU}$, which is comparable to the average 
heating rate in thermal oil recovery. The duration of repository heating and the total heat energy introduced into the rock will be intermediate between humancaused perturbations (e.g., thermal oil recovery) and natural systems (e.g., geothermal systems).

Heat pipes at a Yucca Mountain repository will bear some resemblance to vapordominated geothermal systems such as The Geysers. The geothermal systems are naturally sealed on the top and sides; otherwise the steam would escape or the vapor-dominated zone would be flooded by groundwater. The required lowpermeability cap is thought to form, when the geothermal system is young and still liquid-dominated, in response to solubility changes in a liquid convection system.

A cap of liquid condensate forms lower-at the top of the vapor-dominated zone. Condensate in this zone flows laterally to some extent, and similar lateral flow will probably occur above the heat-pipe zone at Yucca Mountain. Shedding of condensate around emplacement drifts has been reported in thermohydrologic simulations (Buscheck, 1996b), and similar behavior has been observed in borehole heater tests (Ramirez et al., 1991b). This liquid cap could be supported by various types of vapor-liquid interaction with the vapor-dominated region below. However, support of a liquid cap above the repository could be limited because the host rock-fracture porosity is likely to remain in communication with the atmosphere.

Another potential important geothermal effect that has been observed is the stability of wells that have been quenched by the accumulation of water (i.e., once a steam well inadvertently fills with water, it tends to remain filled). The coupling between heat and mass flow, which is caused by changes in the relative permeability associated with saturation, means that wet pathways receive less heat and therefore tend to remain wet. This has obvious indications for a Yucca Mountain repository because it implies that some waste packages could be exposed to refluxing water or higher humidity while others remain dry.

Discrepancy between field and laboratory measured precipitation rates for amorphous silica in geothermal waters (Carroll et al., 1995) indicates dependence on boundary conditions of aqueous silica concentration and on possible rate control by boundary layer transport. Silica precipitation in a heat-pipe zone at Yucca Mountain could exhibit rate behavior covering the range between laboratory and field experiments. Experimental precipitation-rate data could be interpreted to mean that precipitation will be strongly limited in heat-pipe zones at Yucca Mountain if liquid water travel time is on the order of minutes or hours. It should be noted that the experimental conditions were isothermal, whereas water reflux in a heat-pipe zone travels up a thermal gradient. A more realistic approach for further experimentation might involve nonisothermal conditions and variation of boundary conditions such as flow velocity.

Qualified data are defined as having been collected and reported as part of a scientific activity that was planned and implemented in accordance with a QA program approved by the current Yucca Mountain Site Characterization Project 
QA system. Qualified data were identified as such during the planning process prior to review, approval, and implementation of the activity plans. The conclusions given in this section are based on both qualified and "existing" data, the latter of which is defined as not qualified based on when, how, or by whom the data were collected. For conclusions, from Chapter 4 , that were based on measured data, qualification status is summarized in Table 4-2. (This table does not address studies in progress nor findings that additional data are needed in certain areas to support further understanding.) Major field tests in the Exploratory Studies Facility and the Large Block Test at Fran Ridge are currently in progress, and discussion in this report is limited to preliminary or interim results. 
Table 4-2 Quality assurance status of conclusions reported in Chapter 4

\begin{tabular}{|c|c|c|}
\hline Section & Description of conclusion & Principal support \\
\hline \multirow[t]{3}{*}{$\begin{array}{l}\text { 4.1.1 Spent Fuel } \\
\text { Test-Climax }\end{array}$} & $\begin{array}{l}\text { Acoustic emissions responded to the rate of } \\
\text { thermal energy production and may be useful for } \\
\text { monitoring the stability of a repository. }\end{array}$ & $\begin{array}{l}\text { Existing (non-Q) data: (Majer } \\
\text { and McEvilly, 1985) }\end{array}$ \\
\hline & $\begin{array}{l}\text { No significant changes in mineralogy or } \\
\text { microfracturing occurred, as a result of heat or } \\
\text { irradiation, near the electrical heaters or spent-fuel } \\
\text { canisters. }\end{array}$ & \multirow[t]{2}{*}{$\begin{array}{l}\text { Existing (non-Q) data: (as } \\
\text { reported by Viani and } \\
\text { Carman, 1996) }\end{array}$} \\
\hline & $\begin{array}{l}\text { Nitric acid formed by radiolysis of atmospheric } \\
\text { nitrogen accelerated corrosion of the carbon steel } \\
\text { emplacement hole liners. Corrosion was also } \\
\text { observed in alloys such as stainless steel, Inconel } \\
600 \text {, and super-Invar. }\end{array}$ & \\
\hline $\begin{array}{l}\text { 4.1.2 Edgar } \\
\text { Mine, Colorado, } \\
\text { School of Mines } \\
\text { Block Test }\end{array}$ & $\begin{array}{l}\text { Heating of a fractured gneiss caused significant } \\
\text { reductions in the loading and unloading moduli } \\
\text { and reductions in the permeability of a test } \\
\text { fracture. The largest permeability change } \\
\text { occurred during excavation. Compressive loading } \\
\text { reduced the permeability, but the permeability } \\
\text { does not return to the pre-excavation condition. } \\
\text { Permeability reduction at elevated temperatures } \\
\text { was smaller in magnitude than was the effect of } \\
\text { excavation. }\end{array}$ & $\begin{array}{l}\text { Existing (non-Q) data: (Hardin } \\
\text { et al., 1981) }\end{array}$ \\
\hline \multirow[t]{3}{*}{$\begin{array}{l}\text { 4.1.3.2 } \\
\text { G-Tunnel Small- } \\
\text { Diameter Heater } \\
\text { Tests }\end{array}$} & $\begin{array}{l}\text { For the first month of heating in the horizontal } \\
\text { heater test in welded tuff, small amounts of water } \\
\text { collected in the heater borehole and wetted a } \\
\text { sensor located immediately under the heater. }\end{array}$ & \multirow[t]{3}{*}{$\begin{array}{l}\text { Existing (non-Q) data: } \\
\text { (Zimmerman and Finley, } \\
\text { 1987) }\end{array}$} \\
\hline & $\begin{array}{l}\text { The gaseous-phase environments of the heater } \\
\text { boreholes were similar for all three tests. Relative } \\
\text { humidity approached saturation within hours after } \\
\text { the start. Total pressures remained at ambient. }\end{array}$ & \\
\hline & $\begin{array}{l}\text { Neutron-probe measurements of moisture } \\
\text { content in the heated rock showed that significant } \\
\text { changes occurred in the temperature range } 70^{\circ} \text { to } \\
120^{\circ} \mathrm{C} \text {. Dewatering apparently began at } \\
\text { temperatures less than boiling. }\end{array}$ & \\
\hline
\end{tabular}




\begin{tabular}{|c|c|c|}
\hline Section & Description of conclusion & Principal support \\
\hline \multirow[t]{3}{*}{$\begin{array}{l}4.1 .3 .3 \\
\text { G-Tunnel } \\
\text { Heated Block } \\
\text { Test }\end{array}$} & $\begin{array}{l}\text { A slight dependence of modulus on stress was } \\
\text { indicated, but there was no significant } \\
\text { temperature effect. Thermal expansion behavior } \\
\text { of the heated block was well represented by } \\
\text { measurements on intact rock samples. }\end{array}$ & \multirow[t]{3}{*}{$\begin{array}{l}\text { Existing (non-Q) data: } \\
\text { (Zimmerman et al., 1986b) }\end{array}$} \\
\hline & $\begin{array}{l}\text { The largest changes in permeability of a test } \\
\text { fracture were associated with excavation. } \\
\text { Subsequent compressive loading and increased } \\
\text { temperature lowered the apparent permeability of } \\
\text { a test fracture. }\end{array}$ & \\
\hline & $\begin{array}{l}\text { Saturation declined, in steps corresponding to } \\
\text { successive cycles, from } 60 \% \text { to } 80 \% \text { and down to } \\
\text { approximately } 15 \% \text { as a result of heating. } \\
\text { Rehydration upon cooling was not significant on a } \\
\text { time scale of weeks. }\end{array}$ & \\
\hline \multirow{3}{*}{$\begin{array}{l}4.1 .3 .4 \\
\text { G-Tunnel } \\
\text { Prototype } \\
\text { Engineering } \\
\text { Barrier System } \\
\text { Field Test }\end{array}$} & $\begin{array}{l}\text { The drying front penetrated most rapidly along } \\
\text { fractures, and rewetting occurred most rapidly } \\
\text { near fractures during the ramping down and } \\
\text { cooling phases }\end{array}$ & \multirow[t]{2}{*}{$\begin{array}{l}\text { Existing (non-Q) data: } \\
\text { (Ramirez et al., } 1989 \text { and } \\
1991 \text { b) }\end{array}$} \\
\hline & $\begin{array}{l}\text { Water vapor that condensed below the heater } \\
\text { drained away from the boiling zone, and rock } \\
\text { below the heater dried out more quickly than it did } \\
\text { above the heater. During cooling, rewetting } \\
\text { above the heater occurred slightly more quickly } \\
\text { than it did below the heater. }\end{array}$ & \\
\hline & $\begin{array}{l}\text { After heating and cooling back to ambient } \\
\text { temperature, measured permeability in the heater } \\
\text { borehole increased by } 10 \% \text { to } 1800 \% \text {. }\end{array}$ & $\begin{array}{l}\text { Existing (non-Q) data: (Lee } \\
\text { and Ueng, 1991) }\end{array}$ \\
\hline $\begin{array}{l}\text { 4.1.4 Large } \\
\text { Block Test }\end{array}$ & $\begin{array}{l}\text { During heating of the block, several tens of liters } \\
\text { of water refluxed during a rapid event that initiated } \\
\text { a period of heat-pipe activity. The amount of water } \\
\text { involved was of the same order as rough } \\
\text { estimates for fracture porosity. }\end{array}$ & Qualified data: (Lin, 1997a) \\
\hline
\end{tabular}




\begin{tabular}{|c|c|c|}
\hline Section & Description of conclusion & Principal support \\
\hline \multirow[t]{4}{*}{$\begin{array}{l}\text { 4.1.5.1 Single } \\
\text { Heater Test }\end{array}$} & $\begin{array}{l}\text { The temperature field was similar to the } \\
\text { predictions made using the effective continuum } \\
\text { model approximation, except that the dryout } \\
\text { region was less extensive than predicted. }\end{array}$ & \multirow[t]{3}{*}{ Qualified data: (Lin, 1997b) } \\
\hline & $\begin{array}{l}\text { High relative humidity was observed during } \\
\text { heatup at sensors that were believed to be } \\
\text { isolated, and low humidity was observed where } \\
\text { there was pneumatic communication with the drift. } \\
\text { Relative humidity increased when the heater was } \\
\text { turned off. }\end{array}$ & \\
\hline & $\begin{array}{l}\text { Gas pressure was less than the drift air pressure at } \\
\text { some locations and greater at others. The } \\
\text { magnitude of positive and negative pressures } \\
\text { was on the order of } 0.5 \text { psig or less, and pressure } \\
\text { changed slowly at each measurement location. }\end{array}$ & \\
\hline & $\begin{array}{l}\text { The chemistry of sampled fracture water was } \\
\text { comparable to } \mathrm{J}-13 \text { water. Solution equilibrium } \\
\text { modeling indicated gas phase } \mathrm{CO}_{2} \text { fugacity } \\
\text { approximately two orders of magnitude greater } \\
\text { than atmospheric. }\end{array}$ & $\begin{array}{l}\text { Existing (non-Q) data: } \\
\text { (Glassley and DeLoach, } \\
\text { 1997) }\end{array}$ \\
\hline $\begin{array}{l}4.2 .2 \\
\text { Underground } \\
\text { Tests at Stripa, } \\
\text { Sweden }\end{array}$ & $\begin{array}{l}\text { Fracture closure in response to heating was } \\
\text { confirmed by observation of diminished water } \\
\text { inflow to heater and instrument boreholes. }\end{array}$ & $\begin{array}{l}\text { Existing (non-Q) data: } \\
\text { (Nelson et al., 1981) }\end{array}$ \\
\hline \multirow[t]{2}{*}{$\begin{array}{l}4.3 \text { Geothermal } \\
\text { Fields }\end{array}$} & $\begin{array}{l}\text { Heat pipes in the repository will be short-lived, } \\
\text { transient features compared to geothermal } \\
\text { systems; the development of a liquid cap above } \\
\text { the repository may involve episodic counterflow. }\end{array}$ & $\begin{array}{l}\text { Analysis of existing data; this } \\
\text { report. }\end{array}$ \\
\hline & $\begin{array}{l}\text { The hydrologic properties of the repository host } \\
\text { rock are consistent with the hydrologic conditions } \\
\text { associated with vapor-dominated heat pipes in } \\
\text { geothermal systems. }\end{array}$ & $\begin{array}{l}\text { Existing data and analysis: } \\
\text { (Bjornsson and Bodvarsson, } \\
\text { 1990; Simmons and } \\
\text { Bodvarsson, 1997) }\end{array}$ \\
\hline \multirow[t]{3}{*}{$\begin{array}{l}\text { 4.3.1 The } \\
\text { Geysers }\end{array}$} & $\begin{array}{l}\text { The pressure and temperature of a vapor- } \\
\text { dominated geothermal heat-pipe zone plot along } \\
\text { the liquid-vapor phase boundary for water, } \\
\text { whereas the repository host rock will be free- } \\
\text { draining, and the pressure of refluxing water will } \\
\text { be constrained at } \sim 1 \text { atm. }\end{array}$ & \multirow[t]{3}{*}{$\begin{array}{l}\text { Existing (non-Q) data and } \\
\text { analysis: (Buscheck, 1996b; } \\
\text { Stockton et al., 1984); this } \\
\text { report }\end{array}$} \\
\hline & $\begin{array}{l}\text { The maximum heat flux from the repository will be } \\
50 \text { to } 70 \text { times that calculated for The Geysers. }\end{array}$ & \\
\hline & $\begin{array}{l}\text { Therefore, the calculated reflux magnitude at The } \\
\text { Geysers ( } 4 \text { to } 5 \mathrm{~mm} / \mathrm{yr} \text { ) does not imply that there } \\
\text { will be no dryout zone above the repository. } \\
\text { However, heat-pipe activity may involve the } \\
\text { repository near field during cooldown (based on } \\
\text { analysis of existing data). }\end{array}$ & \\
\hline
\end{tabular}



Thermally Driven Coupled Processes

\begin{tabular}{|l|l|l|}
\hline \multicolumn{1}{|c|}{ Section } & \multicolumn{1}{|c|}{ Description of conclusion } & \multicolumn{1}{c|}{ Principal support } \\
\hline \hline $\begin{array}{l}\text { 4.3.2.1 Mineral } \\
\text { Equilibrium } \\
\text { Calculations TVZ } \\
\text { natural analog) }\end{array}$ & $\begin{array}{l}\text { In accordance with observations, major phases } \\
\text { such as quartz and calcite were calculated to be at } \\
\text { near-equilibrium. Other phases were not } \\
\text { predicted as accurately for several possible } \\
\text { reasons: 1) kinetics, 2) adequacy of } \\
\text { thermodynamic data, 3) solid-solution effects, and } \\
\text { 4) influence of boiling. }\end{array}$ & $\begin{array}{l}\text { Existing (non-Q) data: (Bruton } \\
\text { et al., 1993a and 1994) }\end{array}$ \\
\hline $\begin{array}{l}\text { 4.3.2.2 Silica } \\
\text { Precipitation } \\
\text { Kinetics }\end{array}$ & $\begin{array}{l}\text { Differences between precipitation rates } \\
\text { measured in the laboratory and those measured } \\
\text { in the field were observed. An earlier study } \\
\text { (Rimstidt and Barnes, 1980) argued that } \\
\text { precipitation rates for silica polymorphs are the } \\
\text { same, but this is unsupported by empirical data. }\end{array}$ & $\begin{array}{l}\text { Existing (non-Q) data: (Carroll } \\
\text { et al., 1995) }\end{array}$ \\
&
\end{tabular}




\section{Summary and Conclusions}

Thermally driven coupled processes may have beneficial or adverse effects on the performance of a repository at Yucca Mountain. These effects are likely to occur because of the expected large amounts of water that will be redistributed by repository heating. This redistributed water will dominate seepage into emplacement drifts and will control environmental conditions at the waste packages for thousands of years. Adverse effects of seepage into drifts, however, could be mitigated by decreased fracture permeability caused by coupled thermohydrochemical alteration and precipitation processes.

Thermally coupled processes must be thoroughly evaluated and bounded to support credible assessment of total system performance. It is also important to understand how these processes interact with engineered components and operational controls to support selection among alternative designs and operating strategies.

Coupled processes can generally be classified as the Onsager-type, driven by gradients of thermodynamic state variables, or another type in which processes occur solely because of temperature-dependent changes in medium, fluid, or reactive properties. Many of the Onsager-type coupled processes are probably not significant to repository performance because the required potential gradients are nonexistent or the effects are overwhelmed by direct processes such as Darcy flow, Fickian diffusion, and electrical conduction. A few of the Onsager coupled processes-including chemical osmosis, electrophoresis, sedimentation current, and streaming current-cannot be eliminated from consideration given present knowledge about the near-field environment. Temperature-dependent changes in properties, and the processes which they control, are the major focus of investigation into coupled processes that could affect a repository at Yucca Mountain.

\subsection{Summary of Laboratory Property Measurements}

The supporting laboratory data for assessing matrix contributions to thermally coupled processes are adequate in some topical areas and sparse in others.

Because sample sizes are typically much smaller than the in situ fracture spacing, laboratory measurements generally provide properties of the rock matrix only and, hence, do not directly show the effects of thermally coupled processes on rock-mass behavior at the repository scale. These data provide only part of the input data required to model coupled processes. The properties of fracture networks are also needed and must be inferred from observations and measurements in the field. Variation of thermal and thermomechanical properties with temperature is relatively well understood, and qualified data are available. The dependence of the matrix and fracture rheology on temperature, including deformation modulus and creep properties, is less well known, and 
there are few qualified data at elevated temperatures. However, it is not clear how important this information would be for prediction of long-term repository performance. Further work in this topical area should carefully delineate what, if any, additional measurements are required.

For matrix hydrologic properties, there are fundamental temperature-dependent responses that may be important to thermohydrologic models but that have not been investigated experimentally. These include the temperature effect on hysteresis of wetting and drying characteristic curves, Knudsen diffusion, and the magnitude of enhanced vapor diffusion. Enhanced vapor diffusion has been shown to have significant effects on thermohydrologic predictions, particularly the timing of rewetting after the thermal pulse decays.

Chemical reactions are strongly temperature-dependent, but the effects of elevated temperature on chemical kinetics have not been determined experimentally for many important reactions. However, experimental kinetic data are not generally needed for reactions that can be satisfactorily modeled using qualified thermodynamic equilibrium and reaction-path models such as EQ3/ 6 and its associated chemical databases. The question of which reactions can be satisfactorily modeled using available, qualified data and computer codes is complicated by two uncertainties: whether reaction rates at $100^{\circ} \mathrm{C}$ and higher are sufficient to assure equilibrium and the difference between the time scales for laboratory and repository processes. Determination of which chemical processes in the repository can be modeled using thermodynamic equilibrium and reaction-path models will rely on results from laboratory and field-scale experiments.

Thermodynamic equilibrium data for many aqueous and mineral species have been measured or estimated and also reviewed for accuracy and consistency in preparation for use with qualified analyses. For certain other types of reactions (e.g., surface complexation), equilibrium conditions at elevated temperatures are unknown and must be estimated, relying chiefly on ambient temperature data for simplified chemical systems, including data which were not collected under approved QA programs with controls appropriate for qualified data.

Naturally occurring electrical potentials were observed in the Single Heater Test (SHT) and were large enough to be considered as a factor in waste-package corrosion analyses, but the source of these potentials and the amount of current generated have not been investigated.

Microbiology investigations have established that the natural microbes present in the unsaturated zone at Yucca Mountain, plus those introduced by excavation, include species that can survive exposure to desiccation and elevated

temperatures. Some species produced metabolic products that could be important in determining rates of corrosion and radionuclide transport in the near-field environment. Further testing is required to support predicting the effects of microbial processes in the repository. 
A more detailed summary of the temperature dependence of key laboratory measured properties was given in Section 2.10, which included a list of important findings compiled from review of project and external literature and identification of principal sources available to support these findings.

\subsection{Summary of Laboratory-Scale Process Studies}

Laboratory experiments have included comparison of vapor-phase and liquidphase rewetting, fracture healing, fracture-matrix coupling with flow into heated tuff, fracture flow visualization, heat-pipe formation, and rock-water interaction studies. These physical simulations of thermally coupled processes have advanced conceptual understanding and provided data for testing mathematical models.

Based on experimental data, a set of conditions has been identified that produces the fracture-healing response. Additional experiments have been suggested to isolate mechanical and chemical effects on fracture healing. Investigation of tuff dissolution and alteration in batch reactor studies and preliminary flow-through studies has indicated that the nature and rates of predominant reactions will depend on the local thermohydrology. Studies predicting changes in the altered zone are planned and will incorporate chemical and thermohydrologic constraints.

Flow-visualization experiments have shown that episodic fracture flow occurs even with constant boundary conditions, particularly in heat pipes. Prediction of the effects of episodic flow on fracture-matrix interaction and movement of refluxing water into the dryout zone around the repository has not been attempted.

Laboratory hydrologic experiments have revealed drying/wetting hysteresis effects at elevated temperatures. To date, these effects have not been systematically investigated in thermohydrologic analyses. Matrix diffusion as a retardation mechanism was evaluated in one laboratory experiment and was found to decrease at elevated temperature. This result is contrary to the expectation that diffusion increases with temperature and has not been replicated or further investigated.

Preliminary experiments have shown that soluble salts are leached from the tuff matrix and fracture-lining minerals and are likely to accumulate in heat-pipe zones where they can be remobilized during rewetting. Deposition of salts on the waste packages has the potential to adversely affect their lifetime. High concentrations of chloride and sulfate ions will be highly detrimental to the performance of the corrosion-resistant inner barrier in the waste packages and could require the use of more expensive materials. 
A more detailed summary of what has been learned was given in Section 3.10, which included a list of important findings compiled from review of project and external literature plus identification of principal sources available to support these findings.

\subsection{Summary of Field-Scale Experiments}

Field-scale thermohydrologic coupling has been observed in several experiments, including G-Tunnel heater tests, the Large Block Test (LBT), and the SHT. Field-scale tests have mobilized significant amounts of water as fracture flow. Observations of wetting and drying behavior are qualitatively consistent with predictive models, at least for the spatially and temporally averaged response to heating. Water movement apparently occurs along discrete fractures in welded tuff, and there is mounting evidence for strongly episodic behavior in heat-pipe zones that is not predicted from thermohydrologic simulations.

In the LBT, a heat-pipe zone was created after a region of the block centered on the heater plane attained a temperature greater than $100^{\circ} \mathrm{C}$. The block heated by conduction only at first; then a reflux event occurred in response to boundary temperature fluctuations. The event lasted less than one hour and involved sufficient water to change the temperature of much of the block by a few degrees. This was followed by repeated, smaller reflux events, which were rapid and can only have occurred by fracture flow.

In the SHT, water was collected in borehole \#16-4 at a rate that exceeded, by nearly an order of magnitude, the permeability of the tuff matrix. The water was flowing in fractures and became trapped in the borehole. Moisture was redistributed in a manner consistent with predictive models. Small temperature fluctuations were observed that may be evidence for heat pipe activity. The dimensionality of the SHT and similar borehole heater tests has permitted shedding of condensate around the heater so that much of the condensate has not flowed back to the boiling zone. This has resulted in larger dryout zones and tended to suppress heat-pipe effects.

Comparison of heater tests performed at G-Tunnel and Yucca Mountain indicates that they are very similar with respect to size, duration, and thermal loading. This is important because similar results have been achieved in separate tests conducted in different geologic units. However, these tests were so similar that they sampled a narrow range of spatial and temporal scales and have produced data that are not representative of expected repository conditions.

Both laboratory and field studies have shown that water reflux is intermittent. When it occurs, a strong flow forms from coalescing liquid islands. In the LBT, the enhanced flow rate and velocity caused liquid flow to penetrate the boiling zone and contact the heated region. The implication for a Yucca Mountain repository is that reflux events will be episodic and may be capable of penetrating to the emplacement drifts. 
Review of the geothermal literature suggests that heat pipes are possible on a large or small scale. Heat pipes in vapor-dominated geothermal reservoirs are associated with surface measured heat fluxes as low as 5 to 10 heat flow units (HFU). The currently expected initial heat flux from a potential repository at Yucca Mountain is about $250 \mathrm{HFU}$, or 25 to 50 times the flux in geothermal reservoirs. However, the rate of heat production from nuclear waste decreases rapidly with time after emplacement; although both the temporal and spatial scale of thermohydrologic effects on the repository host rock will be more limited, heat pipes at a Yucca Mountain repository are expected bear some resemblance to vapor-dominated geothermal systems such as The Geysers, California. The duration of thermohydrologic effects is expected to be intermediate between previous human-caused perturbations, such as thermal oil recovery, and the life cycle of geothermal reservoirs.

Vapor-dominated systems are naturally sealed, and similar processes may cause alteration of flow paths in repository host rock. Shedding of condensate around emplacement drifts may be analogous to the lateral movement of the liquid cap at the top of a vapor-dominated geothermal system.

Another potentially important geothermal effect observed is the stability of geothermal wells that have been quenched by the accumulation of water. Coupling between heat and mass flow, caused by permeability changes associated with saturation, means wet pathways receive less heat and therefore tend to remain wet. This implies that some waste packages in a Yucca Mountain repository may be exposed to refluxing water or higher humidity while others remain dry.

Silica precipitation in a repository heat-pipe zone at Yucca Mountain is likely to exhibit rate behavior covering the range of rates observed in laboratory and field experiments. If liquid-water travel time is on the order of minutes or hours, experimental precipitation-rate data can be interpreted to mean that precipitation will be rate-limited in heat-pipe zones.

A more detailed summary of key findings from review of field testing at Yucca Mountain and elsewhere and the geothermal literature was given in Section 4.5, which included identification of principal sources available to support these findings.

An important conclusion of this report is that thermohydrologic processes, and particularly transient behavior likely to be important to repository performance, are inherently difficult to simulate with the available numerical models and hydrologic parameters. Repository heat release is expected to cause significant redistribution of moisture with a complex, time-dependent spatial distribution of liquid and vapor movement in fractures, condensate zone formation, and heat pipes. Laboratory and field-scale experiments have shown that heat-pipe effects are inherently episodic and sensitive to spatial heterogeneity of material properties. Thermohydrologic simulators, on the other hand, have important limitations for predicting such effects: 
- Available data on hydrologic state variables (e.g., moisture potential) represent only the steady values that exist, at ambient temperature, between flow events.

- Parameter models (e.g., UZ site scale model) are based only on fitting steady state properties to available ambient temperature data.

- The equivalent continuum approximation is based on the assumption of local fracture-matrix equilibrium, which has a smoothing effect.

- Modeling a fracture network as a continuum has the effect of dispersing flow, damping the natural tendency for strongly variable fracture-matrix interaction under transient flow conditions.

- Unsaturated flow simulators are implicit "low-pass" operators that tend to produce smooth calculated fields and filter out transient events at time scales less than a few time steps.

Limitations on the available models and the parameters used to run them point to a need for continued experimentation, in both the laboratory and the field. This is true also when considering the effects of chemical processes coupled to thermohydrology. To investigate the effects of chemical alteration on fracture permeability and sorption in fractures requires simulation and experimentation over spatial and time scales that exceed any yet used for field scale tests at Yucca Mountain.

\subsection{Conclusion}

Three sets of coupled processes and properties have been discussed in this report: the first set includes thermal and thermomechanical properties for which temperature-dependent variation is relatively well understood.

A second set includes tuff rheology, hydrologic matrix properties, fracture healing, wetting/drying hysteresis, and the kinetics of key chemical reactions for which the temperature dependence has been identified in laboratory experiments, but which is not well understood. This set also includes potentially significant effects that have been inferred from the general literature, for which site-specific data are sparse or nonexistent. This set includes microbiological effects on the near-field environment, microbially induced corrosion, effects of introduced materials on transport of radionuclides, enhanced vapor diffusion, and surface complexation-reaction equilibria. The uncertainty is generally associated with understanding complex mechanisms for thermal coupling. Some or all of these coupled processes and properties could be important to repository performance, and further laboratory testing is an appropriate means for resolving uncertainty. The conclusions for each chapter of this report identify topical areas for which needed testing is already underway as well as areas for which no tests are currently planned. 
The third set consists of coupled processes and properties that are conceptually understood but that require additional field sampling and testing to evaluate their importance to repository performance. Visualization experiments performed in the laboratory have shown that fracture flow is temporally as well as spatially scale-dependent and that strongly episodic flow can be expected in heat-pipe zones. Thermohydrologic simulations have been used to study heatpipe behavior, but these models have inherent limitations. Similarly, thermohydrochemical processes have been inferred from geothermal observations, laboratory measurements, and chemical modeling. For scaledependent, multiply coupled processes, additional field-scale tests are required to evaluate whether the effects will be important for repository performance. These tests must be designed specifically to evaluate coupled processes. Most field tests conducted to date (except for Large Block Test currently underway and the Drift Scale Test in preparation) were designed with different or conflicting objectives, and it is likely that additional field-scale testing will be required in the future for the final resolution of repository and performance issues related to the effects of thermally coupled processes. 


\section{Acknowledgments}

We acknowledge the reviews of W.E. Glassley, Thomas J. Wolery, and Richard B. Knapp; the editorial assistance of Karen L. Lew; and the graphicdesign and CD-ROM support of Sabrina Danielle Fletcher. This work was performed under the auspices of the U.S. Department of Energy by the Lawrence Livermore National Laboratory under contract W-7405-ENG-48 and was supported specifically by the Yucca Mountain Site Characterization Project at LLNL.

We have described the work of many individuals and have freely quoted from their reports. We appreciate their support in meeting the objectives of this synthesis report.

\section{References}

Allard, B., L. Eliasson, S. Hoglund, and K. Andersson (1984). "Sorption of Cs, I and actinides in concrete systems." (SKB 84-15). Stockholm, Sweden: Swedish Nuclear Fuel and Waste Management Co.

Ames, L.L., J.E. McGarrah, and B.A. Walker (1983). "Sorption of trace constituents from aqueous solutions onto secondary minerals: 1 . Uranium." Clays $\mathcal{E}$ Clay Minerals 31(5):321-334.

Anderson, L.A. (1992a). “Water permeability and related rock properties measured on core samples from the Yucca Mountain USW GU3/G-3 and USW G-4 boreholes, Nevada Test Site, Nevada." Open File Report. (OFR 92-201). Denver, CO: U.S. Geological Survey.

Anderson, L.A. (1992b). “Water permeability and related rock properties measured on core samples from Yucca Mountain USW GU-3/G-3 and USW G-4 boreholes, Nevada Test Site, Nevada." (Open File Report 92-201). Denver, CO: U.S. Geological Survey.

Anderson, M.A., M.I. Tejedor-Tejedor, and R.R. Stanforth (1985). "Influence of Aggregation on the Uptake Kinetics of Phosphate by Goethite." Env. Sci. Tech. 19.

Atkins, M., A.N. Beckley, and F.P. Glasser (1988). "Influence of cement on the near field environment and its specific interactions with uranium and iodine." Radiochimica Acta 44/45:255-261.

Atkins, M., F.P. Glasser, A. Kindness, and D.E. Macphee (1991). Solubility Data for Cement Hydrate Phases $\left(25^{\circ} \mathrm{C}\right)$. Washington, DC: U.S. Department of Energy. (DOE/HMIP/RR/91/032). 
Atkins, P.W. (1990). Physical Chemistry. New York, NY: W.H. Freeman. (Fourth Edition).

Atkinson, A., N.M. Everitt, and R.M. Guppy (1989). "Time dependence of pH in a cemetitious repository." In proceedings from Scientific Basis for Waste Management. Materials Research Society. 127:439-446.

Avogadro, A., and G. de Marsily (1984). In proceedings from Scientific Basis for Nuclear Waste Management. Materials Research Society. 26.

Barnes, H.L., and R.T. Wilkin (1995). "Kinetic measurements on the silicates of the Yucca Mountain potential repository." Yucca Mountain Final Report for FY85 for the Civilian Radioactive Waste Management System Management and Operating Contractor, U.S. Department of Energy. Las Vegas, NV: Los Alamos National Laboratory.

Barton, N., and V. Choubey (1977). "The shear strength of rock joints in theory and practice." Rock Mechanics 10:1-54.

Benjamin, M.M., and J.O. Leckie (1981). "Multiple-site adsorption of Cd, Cu, Zn and $\mathrm{Pb}$ on amorphous iron oxyhydroxide." J. Colloid Inter. Sci. 79:209-221.

Birkhozer, J.T., and Y.W. Tsang (1997). "Pretest Analysis of the ThermalHydrological Conditions of the ESF Drift Scale Test." Milestone report for the CRWMS Management and Operating Contractor, U.S. Department of Energy. (SP9322M4). Berkeley, CA: Lawrence Berkeley National Laboratory.

Bish, D.L. (1984). "Effects of exchangeable cation composition on the thermal expansion/contraction of clinoptilolite." Clays \& Clay Minerals 32:444-452.

Bish, D.L. (1988). "Smectite dehydration and stability: Applications to radioactive waste isolation at Yucca Mountain." (LA-11023-MS). Las Vegas, NV: Los Alamos National Laboratory.

Bish, D.L. (1995). “Thermal behavior of natural zeolites." Natural Zeolites '93: Occurrence, Properties, and Use. D.W. Ming and F.A. Mumpton (eds.). Brockport, NY: Int. Comm. Natural Zeolites.

Bish, D.L., J.W. Carey, S.S. Levy, and S.J. Chipera (1996). "Mineralogy-Petrology Observations Regarding the Near-Field Environment." Near-Field Environment Report. Livermore, CA: Lawrence Livermore National Laboratory. (UCRL-LR-124998, Rev. 1).

Bish, D.L., A.E. Ogard, D.T. Vaniman, and L. Benson (1984). “Mineralogypetrology and groundwater geochemistry of Yucca Mountain tuffs." In proceedings from Scientific Basis for Waste Management. Materials Research Society. 26:283-291. 
Bish, D.L., and D.T. Vaniman (1985). "Mineralogic Summary of Yucca Mountain, Nevada." (LA-10543-MS). Las Alamos, NM: Los Alamos National Laboratory.

Bjornsson, G., and G.S. Bodvarsson (1990). "A survey of geothermal reservoir properties." Geothermics 19:17-27.

Blacic, J.D., D.T. Vaniman, D.L. Bish, C.J. Duffy, and R.C. Gooley (1986). “Effect of long-term exposure of tuffs to high-level nuclear waste repository conditions: Final report." (LA-9330-MS). Los Alamos, NM: Los Alamos National Laboratory.

Blair, S.C. (1996). "One table showing the results from the uniaxial tests on samples of Topopah Spring tuff, which provides the peak strength, Young's modulus, irradiation specification, and general comments on the behavior of the sample during testing." (DTN LL960201104243.006). Livermore, CA: Lawrence Livermore National Laboratory. (Non-Q).

Blair, S.C., and P.A. Berge (1996a). "Chapter 4: Geomechanics." Near Field Environment Report. Livermore, CA: Lawrence Livermore National Laboratory. (UCRL-LR-124998, Rev. 1).

Blair, S.C., and P.A. Berge (1996b). "Uniaxial compression behavior of small blocks of welded tuff." In proceedings from Seventh Annual International High Level Radioactive Waste Management Conference. American Nuclear Society, La Grange Park, IL. pp. 409411. (Also UCRL-JC-122733, Lawrence Livermore National Laboratory, Livermore, CA).

Blair, S.C., and P.A. Berge (1997). “Geomechanical Properties of Topopah Spring Tuff at the $0.5 \mathrm{~m}$ Scale: Preliminary Results of Compression Tests at Elevated Temperature." (UCRL-ID-125089). Livermore, CA: Lawrence Livermore National Laboratory.

Blair, S.C., and M.S. Costantino (1997). "Preliminary Results of a Coupled Fracture-Flow Test at the $0.5 \mathrm{~m}$ Scale." Milestone report for the CRWMS Management and Operating Contractor, U.S. Department of Energy. (SPLFA1M4). Livermore, CA: Lawrence Livermore National Laboratory.

Blanford, M.L., and J.D. Osnes (1987). "Numerical analysis of the G-Tunnel small-diameter heater experiments." (SAND85-7115). Albuquerque, NM: Sandia National Laboratories.

Board, M.P., M.L. Wilson, and M.D. Voegele (1984). “Laboratory Determination of the Mechanical, Ultrasonic and Hydrologic Properties of Welded Tuff from the G-Tunnel Heated Block Site." (SAIC-84/1734). Las Vegas, NV: Science Applications International Corp. 
Boggs, S., D. Livermore, and M.G. Seitz (1985). "Humic Substances in Natural Waters and their Complexation with Trace Metals and Radionuclides: A Review." (ANL-4-78). Argonne, IL: Argonne National Laboratory.

Boyd, P.J., R.J. Martin, and R.H. Price (1994). “An Experimental Comparison of Laboratory Techniques in Determining Bulk Properties of Tuffaceous Rocks." (SAND92-0119). Albuquerque NM: Sandia National Laboratories.

Boyd, P.J., R.H. Price, J.S. Noel, and R.J. Martin (1996). “Bulk and Mechanical Properties of the Paintbrush Tuff Recovered from Boreholes UE25 NRG-4 and -5: Data Report." (SAND94-2138). Albuquerque, NM: Sandia National Laboratories.

Brewitz, W., T. Brasser, H. Kull, and P. Hufschmeid (1988). “The Ventilation Test." Nagra Bulletin. 46-49. (Special Edition 1988 [English]).

Brodsky, N.S. (1996a). "Thermal Properties of Test Specimens from the Single Heater Test in the Thermal Testing Facility at Yucca Mountain, Nevada." August 15, 1996. Report for the CRWMS Management and Operations Contractor, U.S. Department of Energy. (SNL22080196001.001). Albuquerque, NM: Sandia National Laboratories.

Brodsky, N.S. (1996b). “Unconfined compression tests on specimens from the Single Heater Test area in the Thermal Testing Facility at Yucca Mountain, Nevada." August 22, 1996. Report for the CRWMS Management and Operating Contractor, U.S. Department of Energy. (SNL22080196001.002). Albuquerque, NM: Sandia National Laboratories.

Brodsky, N.S. (1997a). "Thermal expansion and thermal conductivity of test specimens from the Drift Scale Test Area of the Exploratory Studies Facility at Yucca Mountain, Nevada." Data report for the CRWMS Management and Operating Contractor, U.S. Department of Energy. (DTN SNL22100196001.001). Albuquerque, NM: Sandia National Laboratories.

Brodsky, N.S. (1997b). “Unconfined compression tests on specimens from the Drift Scale Test Area of the Exploratory Studies Facility at Yucca Mountain, Nevada." Data report for the CRWMS Management and Operating Contractor, U.S. Department of Energy. (DTN SNL02100196001.001). Sandia National Laboratories.

Brodsky, N.S., M. Riggins, and J. Connolly (1997). “Thermal Expansion, Thermal Conductivity, and Heat Capacity Measurements at Yucca Mountain, Nevada." Int. J. Rock Mech. Min. Sci. 34:3-4. (paper no. 40). 
Brodsky, N.S., M. Riggins, J. Connolly, and R. Ricci (1996). “Thermal Expansion, Thermal Conductivity, and Heat Capacity Measurements for Boreholes UE25 NRG-4, UE25 NRG-5, USW NRG-6, and USW NRG-7/7A." (SAND95-1955). Albuquerque, NM: Sandia National Laboratories.

Bruton, C.J., W.E. Glassley, and W.L. Bourcier (1993a). "Testing geochemical modeling codes using New Zealand hydrothermal systems." (UCRL-JC-114798). Livermore, CA: Lawrence Livermore National Laboratory.

Bruton, C.J., W.E. Glassley, and W.L. Bourcier (1994). “Field-based tests of geochemical modeling codes using New Zealand hydrothermal systems." (UCRL-ID-118009). Livermore, CA: Lawrence Livermore National Laboratory.

Bruton, C.J., W.E. Glassley, and A. Meike (1995). "Geothermal Areas as Analogues to Chemical Processes in the Near-field Altered Zone of the Potential Yucca Mountain, Nevada Repository." October 1995. (UCRL-ID-119842). Livermore, CA: Lawrence Livermore National Laboratory.

Bruton, C.J., A. Meike, B.E. Viani, S. Martin, and B.L. Phillips (1993b). "Thermodynamic and Structural Characteristics of Cement Minerals at Elevated Temperatures." In proceedings from Topical Meeting on Site Characterization and Model Validation: Focus '93. American Nuclear Society, La Grange Park, IL. (Also UCRL-JC114116, Lawrence Livermore National Laboratory, Livermore, CA).

Bruton, C.J., and B.E. Viani (1996). "Ion Sorption onto Hydrous Ferric Oxides: Effect on Major Element Chemistry at Aspo, Sweden." (UCRL-JC124329). Livermore, CA: Lawrence Livermore National Laboratory.

Buchholtz-ten Brink, M., S.I. Martin, B.E. Viani, D.K. Smith, and D. Phinney (1992). "Heterogeneities in radionuclide transport: Pore-size, particle-size, and sorption." J.F. McCathy (ed.). Concepts in Manipulating Groundwater Colloids for Environmental Restoration. Chelsea, MI: Lewis Publishers.

Buchholtz-ten Brink, M., D.L. Phinney, and D.K. Smith (1991). “Actinide Transport in Topopah Spring Tuff: Pore Size, Particle Size, and Diffusion." (UCRL-JC-104530). Livermore, CA: Lawrence Livermore National Laboratory.

Buscheck, T.A. (1996a). "Chapter 10: Altered Zone Environment." Near Field Environment Report. D. G. Wilder (ed.). Livermore, CA: Lawrence Livermore National Laboratory. (UCRL-124998, Rev. 1). 
Buscheck, T.A. (1996b). "Section 1.0: Hydrothermal Modeling." Near-Field and Altered-Zone Environment Report (Volume II). D. G. Wilder (ed.). Livermore, CA: Lawrence Livermore National Laboratory. (UCRLJC-124998).

Buscheck, T.A., and J.J. Nitao (1992). "The Impact of Thermal Loading on Repository Performance at Yucca Mountain." In proceedings from Third International High-Level Radioactive Waste Management. Las Vegas, NV. April 12-16, 1992. American Nuclear Society, La Grange, IL. (Also UCRL-JC-109232, Lawrence Livermore National Laboratory, Livermore, CA).

Buscheck, T.A., and J.J. Nitao (1993). "The analysis of repository-heat-driven hydrothermal flow at Yucca Mountain." In proceedings from Fourth International High Level Radioactive Waste Management. Las Vegas, NV. April 26-30, 1993. American Nuclear Society, La Grange, IL. (Also UCRL-JC-112444, Lawrence Livermore National Laboratory, Livermore, CA).

Carey, J.W. (1979). "Soil heat transducer and water vapor flow." Soil Sci. Soc. Am. J. 43:835-839.

Carey, J.W., and D.L. Bish (1996a). "Calorimetric measurement of the enthalpy of hydration of clinoptilolite." Clays and Clay Minerals. (Also CRWMS milestone report 3442: DTN LA000000000131.002). (Also Los Alamos National Laboratories, Technical Information Product \#LA-EES-1TIP-95-012).

Carey, J.W., and D.L. Bish (1996b). "Equilibrium in the clinoptilolite- $\mathrm{H}_{2} \mathrm{O}$ system." American Mineralogist. 81: 952-962.

Carlos, B. (1985). "Minerals in Fractures of the Unsaturated Zone from Drill Core USW-G4, Yucca Mountain, Nye County, Nevada." (LA-10415-MS). Los Alamos, NM: Los Alamos National Laboratory.

Carlos, B.A., S.J. Chipera, and D.L. Bish (1995). “Distribution and chemistry of fracture-lining zeolites at Yucca Mountain, Nevada." (LA-12977MS). Los Alamos, NM: Los Alamos National Laboratory.

Carlsson, H. (1978). "A pilot heater test in the Stripa granite." Swedish-American Cooperative (SAC) Technical Project Report \#6. Berkeley, CA: Lawrence Berkeley National Laboratory.

Carnahan, C.L. (1987). "Effects of Coupled Thermal, Hydrological and Chemical Processes on Nuclide Transport." (LBL-23186). Berkeley, CA: Lawrence Berkeley National Laboratory.

Carroll, S.A., M. Alai, and S. Copenhaver (1996). "Amorphous silica precipitation kinetics at $100^{\circ} \mathrm{C}$ and $\mathrm{pH} \mathrm{3,5}$, and 6." Milestone report for the CRWMS Management and Operating Contractor, U.S. Department of Energy. (MOL123, OL3ALIW). Livermore, CA: Lawrence Livermore National Laboratory. 
Carroll, S.A., E. Mroczek, W. Bourcier, M. Alai, and M. Ebert (1995). “Comparison of Field and Laboratory Precipitation Rates of Amorphous Silica from Geothermal Waters at $100^{\circ} \mathrm{C}$." Milestone report for the CRWMS Management and Operating Contractor, U.S. Department of Energy. (MOL207). Livermore, CA: Lawrence Livermore National Laboratory.

Cass, A., G.S. Campbell, and T.L. Jones (1984). "Enhancement of thermal vapor diffusion in soil." Soil Sci. Soc. Am. J. 48(1):25-32.

Chahal, R.S. (1964). "Effect of temperature and trapped air on the energy status of water in porous media." Soil Sci. Soc. Am. J. 98:107-112.

Chahal, R.S. (1965). "Effect of temperature and trapped air on matric suction." Soil Sci. Soc. Am. J. 100:262-266.

Chekuri, V.S., S.W. Tyler, and J.W. Fordham (1994). “The Role of Fracture Coatings on Water Imbibition into Unsaturated Tuff." In proceedings from Fifth Annual International Conference on High Level Radioactive Waste Management. Las Vegas, NV. American Nuclear Society, La Grange Park, IL. 4.

Chipera, S.J., D.L. Bish, and B.A. Carlos (1995). "Equilibrium modeling of the formation of zeolites in fractures at Yucca Mountain, Nevada." In proceedings from Natural Zeolites '93: Occurrence, Properties, and Use. D.W. Ming and F.A. Mumpton (eds.). pp. 565-577.

Conca, J.L., and I.R. Triay (1994). "Selenite transport in unsaturated tuff from Yucca Mountain." In proceedings from Sixth Annual International High Level Radioactive Waste Management Conference. American Nuclear Society, La Grange Park, IL. 4:1275-1282.

Conca, J.L., and J. Wright (1992). “Diffusion and flow in gravel, soil, and whole rock." Applied Hydrogeology 1:5-24.

Cook, N.G.W. (1985). "Coupled Processes in Geomechanics." International Symposium On Coupled Processes Affecting the Performance of a Nuclear Waste Repository. Berkeley, CA: Lawrence Berkeley National Laboratory. (LBL-21850).

Cook, N.G.W., and M. Hood (1978). “Full-scale and time-scale heating experiments at Stripa: Preliminary results." (LBL-7072). Berkeley, CA: Lawrence Berkeley National Laboratory.

Cooper, H.W., and G. Simmons (1977). "The Effects of Cracks on Thermal Expansion of Rocks." Earth and Planet. Sci. Lett. 36:404.

Couture, R.A. (1985). "Rapid increases in permeability and porosity of bentonitesand mixtures due to alteration by water vapor." Scientific Basis for Waste Management. Materials Research Society. 44:515-522. 
Crammond, N. (1996). "The thaumasite form of sulfate attack-discussion of possible reaction mechanisms." In proceedings from Gordon Research Conference. Plymouth, NH. July 1996.

Criss, C.M., and J.W. Cobble (1964a). “The thermodynamic properties of hightemperature aqueous solutions, IV. Entropies of the ions up to $200^{\circ} \mathrm{C}$ and the corresponding principle." Journal of the American Chemical Society 86:5385-5390.

Criss, C.M., and J.W. Cobble (1964b). "The thermodynamic properties of hightemperature aqueous solutions, $\mathrm{V}$. The calculation of ionic heat capacities up to $200^{\circ} \mathrm{C}$." Journal of the American Chemical Society 86:5390-5393.

CRWMS M\&O (1997). "Single Heater Test Interim Report." Yucca Mountain Site Characterization Project Milestone Report. (BABEAF000-0171769000001, Rev00). Las Vegas, NV: Civilian Radioactive Waste Management System, Management and Operating Contractor.

Dabros, T., and T.G.M.V. deVen (1982). "Kinetics of Coating by Colloidal Particles." J. Col. Int. Sci. 89.

Daily, W., and W. Lin (1991). "Laboratory Determined Suction Potential of Topopah Spring Tuff at High Temperatures." (UCRL-102127). Livermore, CA: Lawrence Livermore National Laboratory.

Daily, W., W. Lin, and T. Buscheck (1987). “Hydrological Properties of Topopah Spring Tuff-Laboratory Measurements." J. Geophys. Res. 92(B8):7854-7864. (Also UCRL-94363, Lawrence Livermore National Laboratory, Livermore, CA).

Daily, W., and A. Ramirez (1989). "Evaluation of electromagnetic tomography to map in situ water in heated welded tuff." Water Resources Research 25(6):1083-1096. (Also UCRL 96816, Lawrence Livermore National Laboratory, Livermore, CA).

Daily, W.D., and W. Lin (1985). “Laboratory-determined transport properties of Berea sandstone." Geophysics 50(5):775-784.

Davis, J.A., and D.B. Kent (1990). "Surface complexation modeling in aqueous geochemistry." M.F. Hochella, Jr., and A.F. White (eds.). MineralWater Interfacial Geochemistry, Reviews in Mineralogy. Washington, DC: Mineral. Soc. Am. (Volume 23).

de Marsily, G. (1986). Quantitative Hydrology: Academic Press, Inc.

DeLoach, L., W. Glassley, J. Johnson, and K. Knauss (1997). “Formation of Flow Barriers within the Altered Zone: Progress Report of Model Results." Milestone report for the CRWMS Management and Operating Contractor, U.S. Department of Energy. (SPL2AM4). Livermore, CA: Lawrence Livermore National Laboratory. 
Dennis, A.W. (1991). "Exploratory Studies Facility Alternatives Study: Final Report." (SAND91-0025/1). Sandia National Laboratories. (Volume 1: Executive Summary).

DOE (1995). "Yucca Mountain Project Reference Information Base, Version 4." (YMP/CC-0002). Las Vegas, NV: Yucca Mountain Site Characterization Project Office, U.S. Department of Energy.

Durham, W.B., and A.E. Abey (1981). "Thermal conductivity and diffusivity of Climax Stock quartz monzonite at high pressure and temperature." (UCRL-86619). Livermore, CA: Lawrence Livermore National Laboratory.

Dzombak, D.A., and F.M. Morel (1990). Surface Complexation Modeling: Hydrous Ferric Oxide. New York, NY: John Wiley \& Sons.

Farley, K.J., D.A. Dzombak, and F.M.M. Morel (1985). “A surface precipitation model for the sorption of cations on metal oxides." J. Colloid Inter. Sci. 106:226-242.

Flint, A., J.A. Hevesi, and L.E. Flint (1996). "Conceptual and numerical model of infiltration for the Yucca Mountain area, Nevada." Water Resources Investigation Report. (3GUT623M). Denver, CO: U.S. Geological Survey. (U.S.G.S. Survey Milestone Report).

Flint, A.L., L.E. Flint, and J.A. Hevesi (1993). "The influence of long term climate change on net infiltration at Yucca Mountain, Nevada." In proceedings from 4th Annual International High-Level Radioactive Waste Management. Las Vegas, NV. American Nuclear Society, La Grange Park, IL. pp. 152-159.

Flint, A.L., L.E. Flint, and K.A. Richards (1994). “Evaluation of Measurement Scale Using Imbibition Experiments in Volcanic Tuffs." Soil Science Soc. of Am. J. 58(1).

Flint, L.E. (1996). “Matrix Properties of Hydrogeologic Units at Yucca Mountain, Nevada." Review draft dated 9/20/96. Water Resources Investigations Report. (96-XX). Denver, CO: U.S. Geological Survey.

Frick, U., P. Baertschi, and E. Hoehn (1988). "Migration Investigations." Nagra Bulletin. 23-34. (Special Edition 1988 [English]).

Fujii, X., and W. Kondo (1983). "Estimation of thermochemical data for calcium silicate hydrate (C-S-H)." Am. Ceram. Soc. J. 66:C220-C221.

Fuller, C.C., J.A. Davis, and B.A. Waychunas (1993). "Surface chemistry of ferrihydrite: Part 2. Kinetics of arsenate adsorption and coprecipitation." Geochim. et Cosmochim. Acta 57:2271-2282. 
Gallegos, D.P., S.G. Thoma, and D.M. Smith (1992). "Impact of Fracture Coatings on the Transfer of Water Across Fracture Faces in Unsaturated Media." In proceedings from Third Annual International High Level Radioactive Waste Management. Las Vegas, NV. American Nuclear Society, La Grange Park, IL.

Gee, M.L., T.W. Healy, and L.R. White (1990). "Hydrophobicity effects in the condensation of water films on quartz." J. Colloid and Interface Science 140(2):450-465.

Geller, J.T., G. Su, and K. Pruess (1996). "Preliminary studies of water seepage through rough-walled fractures." (LBNL-38810). Berkeley, CA: Lawrence Berkeley National Laboratory.

Gentier, S. (1986). "Morphologie et comportement hydromèchanique d'une fracture naturelle dans un granite sous constrainte normale." France: Univ. D' Orlèans, Ph.D. Thesis.

Glassley, W.E. (1995). “Report on Near-Field Geochemistry: Water Composition Changes Due to Evaporation." Milestone report for the CRWMS Management and Operating Contractor, U.S. Department of Energy. (M0L206).

Glassley, W.E. (1996). “Equilibrium Bounds on Water Chemistry and Mineralogical Changes Produced by Near-Field Relative Humidity Changes." Near-Field Environment Report. Livermore, CA: Lawrence Livermore National Laboratory. (UCRL-124998, Rev. 1).

Glassley, W.E., C.J. Bruton, and W.L. Bourcier (1993). “Testing long-term predictions from hydro-geochemical models." In proceedings from Scientific Basis for Waste Management. Materials Research Society. 333:805-810.

Glassley, W.E., and L. DeLoach (1997). "Second Quarter Results of Chemical Measurements in the Single Heater Test." Milestone report for the CRWMS Management and Operating Contractor, U.S. Department of Energy. (SP9240M4). Livermore, CA: Lawrence Livermore National Laboratory.

Grisak, G.E., and J.F. Pickens (1981). "An analytical solution for solute transport through fractured media with matrix diffusion." J. Hydrology 52:47-57.

Gupalo, T. (1996). "All Russian Design and Research Institution of Production Engineering of Minatom of Russia (VNIPIPT)." Moscow: Project \#307-96: Development of quantitative criteria of suitability of rock mass for safe long-term storage of waste from Weapon Plutonium production illustrated by Krasnoyarsk Integrated Mining Chemical Plant. (Phase 1-Feasibility Study). 
Haldeman, D.L., and P.S. Amy (1993). "Bacterial Heterogeneity in Deep Subsurface Tunnels at Rainier Mesa, Nevada Test Site." Microb. Ecol. 25:183-194.

Haldeman, D.L., P.S. Amy, D. Ringelberg, and D.C. White (1993). "Characterization of the Microbiology Within a 21- $\mathrm{m}^{3}$ Section of Rock from the Deep Subsurface." Microb. Ecol. 26:149-159.

Handy, L.L. (1960). "Determination of effective capillary pressures for porous media from imbibition data." Society of Petroleum Engineers, Petroleum Transactions, AIME 219:75-80.

Hardin, E.L., N. Barton, R. Lingle, M. Board, and M.D. Voegele (1981). “A Heated Flatjack Test Series to Measure the Thermomechanical and Transport Properties of in situ Rock Masses." (ONWI-260). Columbus, OH: Office of Nuclear Waste Isolation, Battelle Memorial Institute.

Hardin, E.L., M.D. Voegele, M.P. Board, and H.R. Pratt (1985). “Development of a Test Series to Determine in situ Thermomechanical and Transport Properties." H.J. Pincus and E.R. Hoskins (eds.). Measurement of Rock Properties at Elevated Pressures and Temperatures. Philadelphia, PA: American Society for Testing and Materials. (ASTM STP 869).

Harrar, J., J.F. Carley, W.F. Isherwood, and E. Raber (1990). “Report of the committee to review the use of J-13 well water in Nevada nuclear waste storage investigations." (UCRL-ID-21867). Livermore, CA: Lawrence Livermore National Laboratory.

Helgeson, H.C., W.M. Murphy, and P. Aagard (1984). “Thermodynamic and kinetic constraints on reaction rates among minerals and aqueous solutions, II. Rate constants, effective surface area, and the hydrolysis of feldspar." Geochim. et Cosmochim. Acta 48:2405-2432.

Heuze, F., W. Patrick, T. Butkovich, J. Peterson, R.V. DelaCruz, and C.F. Voss (1982). "Rock Mechanics Studies of Mining in the Climax Granite." Intl. J. of Rock Mech. and Min. Sci. 19:167-183.

Ho, C.H., and D.C. Doern (1985). "The sorption of uranyl species on a hematite sol." Can. J. Chem. 63:1100-1104.

Ho, C.H., and N.H. Miller (1986). "Adsorption of uranyl species from bicarbonate solution onto hematite particles." J. Colloid Interface Sci. 110:165-171.

Ho, C.K., and R.R. Eaton (1995). "TOUGH2 Model of the G-Tunnel Heater Test." In proceedings from Sixth Annual International Conference on High-Level Radioactive Waste Management. American Nuclear Society, La Grange Park, IL. pp. 331-333. 
Hood, M. (1979). "Some results from a field investigation of thermomechanical loading of a rock mass when heaters are emplaced in the rock." Swedish-American Cooperative (SAC) Technical Information Report No. 26. (LBL-9392). Berkeley, CA: Lawrence Berkeley National Laboratory.

Hopmans, J.W., and J.H. Dane (1986). "Temperature dependence of soil hydraulic properties." Soil Sci. Sci. Am. J. 50:4-9.

Horn, J.M., B. Economides, A. Meike, and R.D. McCright (1996). “Initial Studies to Assess Microbial Impacts on Nuclear Waste Disposal." (UCRL-JC122587). Livermore, CA: Lawrence Livermore National Laboratory.

Horn, J.M., and A. Meike (1995). "Microbial Activity at Yucca Mountain." (UCRLID-122256). Livermore, CA: Lawrence Livermore National Laboratory.

Horn, J.M., and A. Meike (1996). "A Program to Assess Microbial Impacts on Nuclear Waste Containment." In proceedings from 1996 High-Level Radioactive Waste Meeting. Las Vegas, NV. (Also UCRL-JC-122732, Lawrence Livermore National Laboratory, Livermore, CA).

Hsi, C.-K., and D. Langmuir (1985). "Adsorption of uranyl onto ferric oxyhydroxides: Application of the surface complexation site-binding model." Geochim. et Cosmochim. Acta 49:1931-1941.

Hudson, D., and A. Flint (1997). "Re: Ideas for measuring the temperature effects on unsaturated conductivity using the U.S. Geological Survey's unsaturated flow apparatus (UFA)." Memo to D. Chesnut, July 15, 1997.

Hunter, R.J. (1981). Zeta Potential in Colloid Science: Principles and Applications. London: Academic Press.

IAEA (1987). In Situ Experiments for Disposal of Radioactive Waste in Deep Geological Formations: International Atomic Energy Agency. (TECDOC-446).

Incropera, F.P., and D.P. DeWitt (1981). Fundamentals of Heat Transfer. New York, NY: John Wiley \& Sons.

Ishido, T., H. Mizuanti, and K. Baba (1983). "Streaming Potential Observations, Using Geothermal Wells and In Situ Electrokinetic Coupling Coefficients under High Temperature." Tectonophysics 91(1-2):89-104.

Jamet, P., D. Fargue, and G. de Marsily (1991). "Coupled Processes in the Near Field." In proceedings from Technical Workshop on Near-Field Performance Assessment for High-Level Waste. P. Sellin, M. Apted, and J. Gago (eds.). Madrid, Spain. October 15-17, 1990. Swedish Nuclear Fuel and Waste Management Co. (TR 91-59). 
Jeffry, J.A., T. Chan, N.G.W. Cook, and P.A. Witherspoon (1979). “Determination of in situ thermal properties of Stripa granite, from temperature measurements in the full-scale heater experiments: method and preliminary results." Swedish-American Cooperative (SAC) Technical Information Report No. 24. (LBL-8423). Berkeley, CA: Lawrence Berkeley National Laboratory.

Johnson, G.K., I.R. Tasker, H.E. Flotow, P.A.G. O'Hare, and W.S. Wise (1992). "Thermodynamic studies of mordenite, dehydrated mordenite, and gibbsite." American Mineralogist 77:85-93.

Johnstone, J.R., G.R. Hadley, and D.R. Waymire (1985). "In-situ Tuff Water Migration/Heater Experiment: Final Report." (SAND81-1918). Albuquerque, NM: Sandia National Laboratories.

Jury, W.A., and J.L. Jr. (1979). "Water vapor movement in soil: reconciliation of theory and experiment." Soil Sci. Soc. Am. J. 43:823-827.

Karakouzian, M., and N. Hudyma (1996). "The effect of saturation on the mechanical properties of tuff at Yucca Mountain." In proceedings from Seventh Annual International High-Level Radioactive Waste Management. Las Vegas, NV. American Nuclear Society, La Grange Park, IL. pp. 407-408.

King, M.S., and B.N.P. Paulsson (1981). "Acoustic velocities in a heated block of granite subjected to uniaxial stress." Geoph. Res. Letters 8:669-702.

Klavetter, E.A., and R.R. Peters (1986). "Estimation of Hydrologic Properties of an Unsaturated, Fractured Rock Mass." (SAND-84-2642). Albuquerque, NM: Sandia National Laboratories.

Klavetter, E.A., and R.R. Peters (1987). “An Evaluation of the Use of Mercury Porosimetry in Calculating Hydrologic Properties of Tuff from Yucca Mountain, Nevada." (SAND86-0286-UC-70). Albuquerque, NM: Sandia National Laboratories.

Klinkenberg, L.J. (1941). “The permeability of porous media to liquids and gases." Drilling and Production Practice. American Petroleum Institute. pp. 200-213.

Knauss, K. (1987). “Zeolitization of Glassy Topopah Spring Tuff under Hydrothermal Conditions." In proceedings from Materials Research Society Symposium. 84:737-745. (Also UCRL-94664, Lawrence Livermore National Laboratory, Livermore, CA).

Knauss, K.G., and W.J. Beiriger (1984). "Report on Static Hydrothermal Alteration Studies of Topopah Spring Tuff Wafers in J-13 Water at $150^{\circ} \mathrm{C} . "$ (UCRL-53576). Livermore, CA: Lawrence Livermore National Laboratory. 
Knauss, K.G., W.J. Beiriger, and D.W. Peifer (1985a). "Hydrothermal Interaction of Crushed Topopah Spring Tuff and J-13 Water at 90, 150, and $250^{\circ} \mathrm{C}$ Using Dickson-Type, Gold-Bag Rocking Autoclaves." (UCRL52560). Livermore, CA: Lawrence Livermore National Laboratory.

Knauss, K.G., W.J. Beiriger, and D.W. Peifer (1987). "Hydrothermal Interaction of Solid Wafers of Topopah Spring Tuff with J-13 Water and Distilled Water at 90 and $150^{\circ} \mathrm{C}$ Using Dickson-Type, Gold-Bag Rocking Autoclaves: Long-Term Experiments." (UCRL-53722). Livermore, CA: Lawrence Livermore National Laboratory.

Knauss, K.G., W.J. Beiriger, D.W. Peifer, and A.J. Piwinskii (1985b).

"Hydrothermal Interaction of Solid Wafers of Topopah Spring Tuff with J-13 Water and Distilled Water at 90, 150, and $250^{\circ} \mathrm{C}$, Using Dickson-Type, Gold-Bag Rocking Autoclaves." (UCRL-53645). Livermore, CA: Lawrence Livermore National Laboratory.

Knauss, K.G., and S.A. Copenhaver (1995). "Progress Report on Hydrothermal Alteration of Vitric Tuff from Yucca Mountain." June 1955. Livermore, CA: Lawrence Livermore National Laboratory, Earth Sciences Division.

Knauss, K.G., J.M. Delany, W.J. Beiriger, and D.W. Peifer (1986). “Hydrothermal Interaction of Topopah Spring Tuff with J-13 Water as a Function of Temperature." In proceedings from Mat. Res. Soc. Symp. 44:539-546.

Knauss, K.G., and D.W. Peifer (1986). “Reaction of Vitric Topopah Spring Tuff and J-13 Ground Water Under Hydrothermal Conditions, Using Dickson-Type, Bold-Bag Rocking Autoclaves." (UCRL-53795). Livermore, CA: Lawrence Livermore National Laboratory.

Knauss, K.G., and T.J. Wolery (1986). “Dependence of albite dissolution kinetics on $\mathrm{pH}$ and time at $25^{\circ} \mathrm{C}$ and $70^{\circ} \mathrm{C}$." Geochim. et Cosmochim. Acta 50:2481-2497.

Knauss, K.G., and T.J. Wolery (1988). “The dissolution kinetics of quartz as a function of $\mathrm{pH}$ and time at $70^{\circ} \mathrm{C}$." Geochim. et Cosmochim. Acta 52(1). (Also UCRL-96071, Lawrence Livermore National Laboratory, Livermore, CA).

Kneafsey, T.J., and K. Pruess (1997). "Preferential Flow Paths and Heat Pipes: Results from Laboratory Experiments on Heat-Driven Flow in Natural and Artificial Rock Fractures." Milestone report for the CRWMS Management and Operating Contractor, U.S. Department of Energy. (SPL6A5M4). Berkeley, CA: Lawrence Berkeley National Laboratory.

Kung, K.-J.S. (1990a). "Preferential flow in a sandy vadose zone: 1. Field observation." Geoderma 46:51-58.

Kung, K.-J.S. (1990b). “Preferential flow in a sandy vadose zone: 2. Mechanisms and implications." Geoderma 46:59-71. 
Lasaga, A.C., J. Ganor, and I.N. MacInnis (1994a). "Progress report on the kinetic measurements of the reactions of the silicates at the Yucca Mountain potential repository site (August 1994)." Report for the CRWMS Management and Operating Contractor, U.S. Department of Energy. Los Alamos, NM: Los Alamos National Laboratory.

Lasaga, A.C., J.M. Soler, J. Ganor, T.E. Burch, and K.L. Nagy (1994b). “Chemical weathering rate laws and global geochemical cycles." Geochim. et Cosmochim. Acta 58:2361-2386.

Lee, K.H. (1996). "Forecast Thermo-Hydrologic Results of the Single Heater Test." Milestone report for the CRWMS Management and Operating Contractor, U.S. Department of Energy. (SP911M4). Livermore, CA: Lawrence Livermore National Laboratory.

Lee, K.H., and T.-S. Ueng (1991). "Air-Injection Field Test to Determine the Effect of a Heat Cycle on the Permeability of Welded Tuff." (UCRL-ID105163). Livermore, CA: Lawrence Livermore National Laboratory.

Lemire, R.J., and F. Garisto (1989). "The Solubility of U, Np, Pu, Th and Tc in a Geological Disposal Vault for Used Nuclear Fuel." (AECL-10009). Atomic Energy of Canada Limited.

Levy, S.S., and J.R. O'Neil (1989). "Moderate-temperature zeolitic alteration in a cooling pyroclastic deposit." Chemical Geology 76:321-326.

Lide, D.R. (1990). Handbook of Chemistry and Physics: CRC Press, Inc.

Lieb, W. (1988). “The Grimsel Test Site from 1983 to 1990-An Overview." Nagra Bulletin. 5-13. (Special Edition 1988 [English]).

Lin, W. (1990). "Variation of Permeability with Temperature in Fractured Topopah Spring Tuff Samples." (UCRL-JC-104765). Livermore, CA: Lawrence Livermore National Laboratory.

Lin, W. (1994). “Preliminary characterization data for the Large Block Test obtained primarily to support construction decisions. Includes permeability, fracture density and initial moisture content." (DTN LL940800804244.001). Livermore, CA: Lawrence Livermore National Laboratory. (Non-Q).

Lin, W. (1995). "Information on the porosity, moisture content, and permeability of samples taken from the Large Block Test." (DTN LL950102904244.003). Livermore, CA: Lawrence Livermore National Laboratory. (Non-Q).

Lin, W. (1996). "Table showing permeability measurements on an intact core sample from the Large Block Test." Near Field Environment Report. Livermore, CA: Lawrence Livermore National Laboratory. (UCRL-LR-124998; Non-Q). 
Lin, W. (1997a). "Data on Temperature of the Large Block Test (LBT)." Data report for the CRWMS Management and Operating Contractor, U.S. Department of Energy, Las Vegas, NV. (DTN LL970803004244.06). Livermore, CA: Lawrence Livermore National Laboratory.

Lin, W. (1997b). "Status report of the Single Heater Test: Chapter 4. Integrated analyses." Milestone report for the CRWMS Management and Operating Contractor, U.S. Department of Energy. (SP9266M4). Livermore, CA: Lawrence Livermore National Laboratory.

Lin, W., and W.D. Daily (1984). "Transport Properties of Topopah Spring Tuff." (UCRL-53602). Livermore, CA: Lawrence Livermore National Laboratory.

Lin, W., and W.D. Daily (1985). "Water Transport in Topopah Spring TuffImplications for a Nuclear Waste Repository in Tuff." (UCRL93382). Livermore, CA: Lawrence Livermore National Laboratory.

Lin, W., and W.D. Daily (1988). "Hydrological properties of Topopah Spring Tuff under a Thermal Gradient: Laboratory Results." Intl. J. Rock Mech. 27(5): 373-385. (Also UCRL-96926, Lawrence Livermore National Laboratory, Livermore, CA).

Lin, W., and W.D. Daily (1989). “Laboratory Study of Fracture Healing in Topopah Spring Tuff-Implications for Near Field Hydrology." In proceedings from Topical Meeting on Nuclear Waste Isolation in the Unsaturated Zone, Focus '89. Las Vegas, NV. September 17-21, 1989. American Nuclear Society, La Grange Park, IL. (Also UCRL100624, Lawrence Livermore National Laboratory, Livermore, CA).

Lin, W., and W.D. Daily (1991). "Variation of permeability with Temperature in Fractured Topopah Spring Tuff Samples." In proceedings from Second Annual International High Level Radioactive Waste Management. Las Vegas, NV. American Nuclear Society, La Grange Park, IL. 988-993. (Also UCRL-JC-104765, Lawrence Livermore National Laboratory, Livermore, CA).

Lin, W., A. Ramirez, and D. Watwood (1991). “Temperature Measurements from a Horizontal Heater Test in G-Tunnel." (UCRL-JC-106693). Livermore, CA: Lawrence Livermore National Laboratory.

Lin, W., and J.J. Roberts (1996). "Chapter 2: Laboratory Determined Hydrologic Properties and Processes." Near Field Environment Report. Livermore, CA: Lawrence Livermore National Laboratory. (UCRL124998, Rev. 1).

Lin, W., D. Wilder, J. Blink, P. Berge, S. Blair, V. Brugman, K. Lee, M. Owens, C. Radewan, A. Ramirez, N. Rector, J. Roberts, D. Ruddle, and J. Wagoner (1995). "A Progress Report on the Large Block Test." (UCRL-JC-119106-95). Livermore, CA: Lawrence Livermore National Laboratory. 
Liu, H.H., and J.H. Dane (1993). "Reconciliation between measured and theoretical temperature effects on soil water release curves." Soil Sci. Soc. Am. J. 57:1202-1207.

Longworth, G., and M. Ivonovich (1990). Manteo III: Concepts in Manipulating Groundwater Colloids for Environmental Restoration. Manteo, NC: U.S. Department of Energy.

Lucht, L.M., and S. Stroes-Gascoyne (1996). "Characterization of the Radiation and Heat Resistance of the Natural Microbial Population in Buffer Materials and Selected Pure Cultures." Technical report. (TR-744). Atomic Energy of Canada Limited.

MacInnis, I.N., R.T. Wilkin, M.A. Mercy, H.L. Barnes, and A.C. Lasaga (1995). “A rate law for clinoptilolite dissolution/precipitation at $50-125^{\circ} \mathrm{C}$ in basic solutions." Milestone report for the CRWMS Management and Operating Contractor, U.S. Department of Energy. (LA3445). Los Alamos, NM: Los Alamos National Laboratory.

Majer, E.L., and T.V. McEvilly (1985). "Acoustic Emission and Wave Propagation Monitoring at the Spent Fuel Test: Climax, Nevada." Int. J. Rock Mech. Min. Sci. E Geomech. 22(4):215-226.

Makurat, A.N., N. Barton, G. Vik, and L. Tunbridge (1990). "Site characterization and validation: Coupled stress-flow testing of mineralized joints of 200-mm and 1400-mm length in the laboratory and in situ, Stage 3." Stripa Project Report. (TR-90-07). Stockholm, Sweden: Swedish Nuclear Fuel and Waste Management Co.

Marovelli, R.L., and K.F. Vieth (1964). “Thermal Conductivity of Rock: Measurement by the Transient Line Source Method." (7939). Minneapolis, MN: U.S. Bureau of Mines.

Martin, R.J. (1972). "Time dependent crack growth in quartz and its application to the creep of rocks." J. Geophys. Res. 77:1406.

Martin, R.J., and W.B. Durham (1975). "Mechanisms of crack growth in quartz." J. Geophys. Res. 80:4837.

Martin, R.J., J.S. Noel, P.J. Boyd, and R.H. Price (1996). “Thermal expansion as a function of confining pressure for welded tuff from Yucca Mountain." In proceedings from Second Annual North American Rock Mechanics Symposium. Aubertin, Hassani, and Mitri (eds.). Montreal, Canada. June 19-21, 1996. Balkema, Rotterdam.

Martin, R.J., J.S. Noel, P.J. Boyd, and R.H. Price (1997). “Creep and Static Fatigue of Welded Tuff from Yucca Mountain, Nevada." Int. J. Rock Mech. Min. Sci 34:3-4. (paper no. 190).

Martin, R.J., J.S. Noel, R.H. Price, and P.J. Boyd (1995a). “Creep properties of the Paintbrush Tuff recovered from borehole NRG-7/7A." Data report. (SAND95-175). Albuquerque, NM: Sandia National Laboratories. 
Martin, R.J., R.H. Price, P.J. Boyd, and R.W. Haupt (1992). "Anisotropy of the Topopah Spring Member Tuff." (SAND91-0894). Albuquerque, NM: Sandia National Laboratories.

Martin, R.J., R.H. Price, P.J. Boyd, and J.S. Noel (1993). “Unconfined Compression Experiments on Topopah Spring Member Tuff at $22^{\circ} \mathrm{C}$ and a Strain Rate of $10^{-9} \mathrm{~s}^{-1}$." Data report. (SAND92-1810). Albuquerque, NM: Sandia National Laboratories.

Martin, R.J., R.H. Price, P.J. Boyd, and J.S. Noel (1994). “Bulk and Mechanical Properties of the Paintbrush Tuff Recovered from Borehole USW NRG-6: Data Report." (SAND93-4020). Albuquerque, NM: Sandia National Laboratories.

Martin, R.J., R.H. Price, P.J. Boyd, and J.S. Noel (1995b). “Bulk and Mechanical Properties of the Paintbrush Tuff Recovered from Borehole USW NRG-7/7A." (SAND94-1996). Albuquerque, NM: Sandia National Laboratories.

Martin, R.J., R.H. Price, P.J. Boyd, and J.S. Noel (1995c). "Creep in Topopah Spring Member Welded Tuff." (SAND94-2585). Albuquerque, NM: Sandia National Laboratories.

McCright, R.D. (1996). "Engineered Materials Characterization Report." (UCRLID-119564, Rev. 0). Livermore, CA: Lawrence Livermore National Laboratory.

McCright, R.D. (1997). "Engineered Materials Characterization Report." Milestone report for the CRWMS Management and Operating Contractor, U.S. Department of Energy. (TR251FB9, Rev. 1). Livermore, CA: Lawrence Livermore National Laboratory.

McKeegan, K.D., D. Phinney, V.M. Oversby, M.B.t. Brink, and D.K. Brink (1989). "Uranium transport in Topopah Spring tuff: An ion-microscope investigation." In proceedings from Scientific Basis for Waste Management. Materials Research Society. 127:813-821.

McNeil, M.B., D.W. Mohr, and B.J. Little (1990). “Correlation of laboratory results with observations on long-term corrosion of iron and copper alloys." In proceedings from Symposium on Materials Science in Archeology. Materials Research Society. (1990 Spring Meeting).

Meike, A. (1996). “Chapter 6.0: Introduced (Man-made) Materials.” Near Field Environment Report. Livermore, CA: Lawrence Livermore National Laboratory. (UCRL-124998, Rev. 1).

Meike, A., and W. Glassley (1989). "In-Situ Observation of the Alpha/Beta Cristobalite Transition Using High Voltage Electron Microscopy." (UCRL-101323). Livermore, CA: Lawrence Livermore National Laboratory. 
Meike, A., and C. Wittwer (1993). "Formation of Colloids from Introduced Materials in the Post-Emplacement Environment: A Report on the State of Understanding." In proceedings from Topical Meeting on Site Characterization and Model Validation: Focus '93. American Nuclear Society, La Grange Park, IL. (Also UCRL-JC-114782, Lawrence Livermore National Laboratory, Livermore, CA).

Meyer, C.A., R.B. McClintock, G.J. Silvestri, and R.C. Spencer Jr. (1993). ASME Steam Tables, Thermodynamic and Transport Properties of Steam: American Society of Mechanical Engineers. (Sixth Edition).

Milestone, N.B., T. Sugama, L.E. Kukacka, and N. Carciello (1987). “Carbonation of geothermal grouts-Part 3: $\mathrm{CO}_{2}$ attack on grouts containing bentonite." Cem. Concr. Res. 17:295-306.

Milton, G.M., and R.M. Brown (1987). "Adsorption of uranium from groundwater by common fracture secondary minerals." Can. J. Earth Sci. 24:1221-1328.

Montan, D.N., and W.E. Bradkin (1984). "Heater Test 1, Climax Stock Granite, Nevada." (UCRL-53496). Livermore, CA: Lawrence Livermore National Laboratory.

Moore, D.E., C.A. Morrow, and J.D. Byerlee (1983). “Chemical reactions accompanying fluid flow through granite held in a temperature gradient." Geochim. et Cosmochim. Acta 47:445-453.

Moore, D.E., C.A. Morrow, and J.D. Byerlee (1985). “Permeability and Fluid Chemistry Studies of the Topopah Spring member of the Paintbrush Tuff, Nevada Test Site: Part II." (UCRL-15667). Livermore, CA: Lawrence Livermore National Laboratory.

Moore, D.E., C.A. Morrow, and J.D. Byerlee (1986). "High-Temperature Permeability and Groundwater Chemistry of Some Nevada Test Site Tuffs." J. Geophys. Res. 91(B2):2163-2171.

Morrow, C.A., D. Lockner, D.E. Moore, and J.D. Byerlee (1981). "Permeability of granite in a temperature gradient." J. Geophys. Res. 86:3002-3008.

Morrow, C.A., D.E. Moore, and J.D. Byerlee (1984). “Permeability and Pore-Fluid Chemistry of the Topopah Spring Member of the Paintbrush Tuff, Nevada Test Site, in a Temperature Gradient-Application to Nuclear Waste Storage." In proceedings from Scientific Basis for Waste Management. Materials Research Society. 26.

Moss, M., J.A. Koski, G.M. Haseman, and T.V. Tormey (1982). "The Effects of Composition, Porosity, Bedding-Plane Orientation, Water Content and a Joint on the thermal Conductivity of Tuff." (SAND82-1164). Albuquerque, NM: Sandia National Laboratories.

Mualem, Y. (1976). "A new model for predicting the hydraulic conductivity of unsaturated porous media." Water Resources Res. 12:513-522. 
Murphy, W.M., R.T. Pabalan, J.D. Prikryl, and C.J. Goulet (1996). "Reaction kinetics and thermodynamics of aqueous dissolution and growth of analcime and Ma-clinoptilolite at $25^{\circ}$ C." Am. J. of Sci. 296:128-186.

Nagy, K.L., A.E. Blum, and A.C. Lasaga (1991). “Dissolution and precipitation kinetics of kaolinite at $80^{\circ} \mathrm{C}$ and $\mathrm{pH}$ 3: the dependence on solution saturation state." Am. J. of Sci. 291:649-686.

Neerdael, B. (1996). “Geological Radwaste Disposal in Belgium: Research Programme, Review and Objectives." P. Witherspoon. Geological Problems in Radioactive Waste Isolation, Second Worldwide Review. Berkeley, CA: Lawrence Berkeley National Laboratory. (LBNL-38915).

Nelson, P.H., R. Rachiele, J.S. Remer, and H. Carlsson (1981). "Water inflow into boreholes during the Stripa heater experiments." SwedishAmerican Cooperative (SAC) Technical Information Report No. 35. (LBL-12574). Berkeley, CA: Lawrence Berkeley National Laboratory.

Neretnieks, I. (1980). “Diffusion in the rock matrix: an important factor in radionuclide retardation?" J. Geophys. Res. 85(B8):4379-4397.

Nicholl, M.J., R.J. Glass, and S.W. Wheatcraft (1994). “Gravity driven infiltration instability in initially dry nonhorizontal fractures." Water Resources Res. 30(9):2533-2546.

Nimick, F.B. (1989). “Thermal Conductivity Data for Tuffs from the Unsaturated Zone at Yucca Mountain, Nevada." (SAND88-0624). Albuquerque, NM: Sandia National Laboratories.

Nimick, F.B. (1990a). "The Thermal Conductivity of Seven Thermal Mechanical Units at Yucca Mountain, Nevada." (SAND88-1387). Albuquerque, NM: Sandia National Laboratories.

Nimick, F.B. (1990b). "The Thermal Conductivity of the Topopah Spring Member at Yucca Mountain, Nevada." (SAND86-0090). Albuquerque, NM: Sandia National Laboratories.

Nimick, F.B., and J.R. Connolly (1991). "Calculation of heat capacities for tuffaceous units from the unsaturated zone at Yucca Mountain, Nevada." (SAND88-3050). Sandia National Laboratories.

Nimick, F.B., and B.M. Schwartz (1987). “Bulk, Thermal, and Mechanical Properties of the Topopah Spring Member of the Paintbrush Tuff, Yucca Mountain, Nevada." (SAND85-0762). Albuquerque, NM: Sandia National Laboratories.

Nitao, J.J. (1993). “The NUFT Code for Modeling Nonisothermal, Multiphase, Multicomponent Flow and Transport in Porous Media." In proceedings from EOS. Washington, DC. American Geophysical Union. Supplement 73:31. (Also UCRL-JC-107092 Abs, Lawrence Livermore National Laboratory, Livermore, CA). 
Nitao, J.J., and T.A. Buscheck (1991). "Infiltration of a Liquid Front in an Unsaturated, Fractured Porous Medium." Water Resources Res. 27:2099-2112. (Also UCRL-JC-121231, Lawrence Livermore National Laboratory, Livermore, CA).

Nitsche, H. (1991). "Solubility Studies of Transuranium Elements for Nuclear Waste Disposal: Principles and Overview." Radiochim. Acta 52/53:3-8.

Nourbehecht, B. (1963). "Irreversible Thermodynamic Effects in Inhomogeneous Media and their Applications in Certain Geoelectric Problems." Cambridge, MA: Massachusetts Institute of Technology, Ph.D. Thesis.

Olsson, W.A. (1987). “Rock Joint Compliance Studies." (SAND86-0177). Albuquerque, NM: Sandia National Laboratories.

Olsson, W.A. (1988). "Compliance and Strength of Artificial Joints in Topopah Spring Tuff." (SAND88-0660). Albuquerque, NM: Sandia National Laboratories.

Olsson, W.A., and S.R. Brown (1994). "Mechanical Properties of Seven Fractures from Drillholes NRG-4 and NRG-6 at Yucca Mountain Nevada." (SAND94-1995). Albuquerque, NM: Sandia National Laboratories.

Ong, C., G. Redden, and J.O. Leckie (1995). "Surface complexation of radionuclides to devitrified tuff." Milestone report for the CRWMS Management and Operating Contractor, U.S. Department of Energy. (3451). Los Alamos, NM: Los Alamos National Laboratory.

Ortiz, T.S., R.L. Williams, F.B. Nimick, B.C. Whittet, and D.L. South (1985). “A Three-Dimensional Model of Reference Thermal/Mechanical and Hydrologic Stratigraphy at Yucca Mountain, Southern Nevada." (SAND84-1076). Albuquerque, NM: Sandia National Laboratories.

Oversby, V.M. (1984a). "Reaction of the Topopah Spring Tuff with J-13 Water at $120^{\circ} \mathrm{C}$." (UCRL-53574). Livermore, CA: Lawrence Livermore National Laboratory.

Oversby, V.M. (1984b). "Reaction of the Topopah Spring Tuff with J-13 Well Water at $90^{\circ} \mathrm{C}$ and $150^{\circ} \mathrm{C} . "$ (UCRL-53552). Livermore, CA: Lawrence Livermore National Laboratory.

Oversby, V.M. (1985). "The Reaction of Topopah Spring Tuff with J-13 Water at $150^{\circ} \mathrm{C}$-Samples from Drill Cores USW G-1, USW GU-3, USW G-4, and UE-25h\#1." (UCRL-53629). Livermore, CA: Lawrence Livermore National Laboratory.

Papike, J.J., and M. Cameron (1976). "Crystal chemistry of silicate mineral of geophysical interest." Rev. of Geophys. and Space Phys. 14:37-80. 
Parikh, R.J., J.A. Havens, and H.D. Scott (1979). "Thermal diffusivity and conductivity of moist porous media." Soil Sci. Soc. Am. J. 43:1050-1052.

Patrick, W.C. (1985). “Operational and Technical Results from the Spent Fuel Test - Climax." (UCRL-53294). Livermore, CA: Lawrence Livermore National Laboratory.

Paviet-Hartmann, P., and I. Triay (1997). "Radionuclide species sorbed onto tuffaceous materials." Milestone report to the CRWMS Management and Operating Contractor, U.S. Department of Energy. (SP341EM4). Los Alamos, NM: Los Alamos National Laboratory.

Peacor, D.R. (1973). "High-temperature single-crystal study of the cristobalite inversion." Zeitschrift für Kristallographie 138:274-298.

Pedersen, K., M. Motamedi, and O. Karnland (1995). "Survival of bacteria in nuclear waste buffer materials: The influence of nutrients, temperature and water activity." (SKB 95-27). Stockholm, Sweden: Swedish Nuclear Fuel and Waste Management Co.

Persoff, P., and K. Pruess (1995). “Two-phase flow visualization and relative permeability measurement in natural rough-walled rock fractures." Water Resources Res. 31(5):1173-1186.

Peters, R.R., E.A. Klavetter, I.J. Hall, S.C. Blair, P.R. Heller, and G.W. Gee (1984). "Fracture and Matrix Hydrologic Characteristics of Tuffaceous Materials from Yucca Mountain, Nye County, Nevada." (SAND841471). Albuquerque, NM: Sandia National Laboratories.

Petersson, C., J. Ephraim, B. Allard, and H. Boren (1990). "Characterization of Humic Substances from Deep Groundwaters in Granitic Bedrock in Sweden." (SKB 90-29). Swedish Nuclear Fuel and Waste Management Co.

Philip, J.R. (1957). "Theory of infiltration: 1 . The infiltration equation and its solution." Soil Science 83:345-357.

Philip, J.R., and D.A. DeVries (1957). "Moisture Movement in Porous Materials under Temperature Gradients." Trans. Am. Geophys. Union 38(2):222-232.

Phillips, O.M. (1994). "Liquid Infiltration Through the Boiling-Point Isotherm in a Desiccating Fractured Rock Matrix." In proceedings from Fifth International High-Level Radioactive Waste Management. Las Vegas, NV.

Phillips, O.M. (1996). "Infiltration of a Liquid Finger Down a Fracture into Superheated Rock." Water Resources Research 32:1665-1670. 
Phinney, D.L., F.J. Ryerson, V.M. Oversby, W.A. Lanford, R.D. Aines, and J.K. Bates (1987). "Integrated testing of the SRL-165 glass waste form." In proceedings from Scientific Basis for Waste Management. Materials Research Society. 84:433-446.

Price, R.H. (1983). "Analysis of Rock Mechanics Properties of Volcanic Tuff Units from Yucca Mountain, Nevada Test Site." (SAND82-1315). Albuquerque, NM: Sandia National Laboratories.

Price, R.H. (1986). "Effects of Sample Size on the Mechanical Behavior of Topopah Spring Tuff." (SAND85-0709). Albuquerque, NM: Sandia National Laboratories.

Price, R.H., J.R. Connolly, and K. Keil (1987). “Petrologic and Mechanical Properties of Outcrop Samples of the Welded, Devitrified Topopah Spring Member of the Paintbrush Tuff." (SAND86-1131). Albuquerque, NM: Sandia National Laboratories.

Price, R.H., F.B. Nimick, J.R. Connolly, K. Keil, B.M. Schwartz, and S.J. Spense (1985). "Preliminary Characterization of the Petrologic, Bulk, and Mechanical Properties of a Lithophysal Zone Within the Topopah Spring Member of the Paintbrush Tuff." (SAND84-0860). Albuquerque, NM: Sandia National Laboratories.

Pruess, K. (1997). “On vaporizing water flow in hot sub-vertical rock fractures." Transport in Porous Media. (in press).

Pruess, K., and T.N. Narasimhan (1982). "On fluid reserves and the production of superheated steam from fractured, vapor-dominated geothermal reservoirs." J. Geophys. Res. 87(B11):9329-9339.

Pruess, K., and Y. Tsang (1994). “Thermal modeling for a potential high-level nuclear waste repository at Yucca Mountain, Nevada." (LBL-35381). Berkeley, CA: Lawrence Berkeley National Laboratory.

Ramirez, A. (1996). “Chapter 8: Electrical Potentials." Near-Field Environment Report. Livermore, CA: Lawrence Livermore National Laboratory. (UCRL-124998, Rev. 1).

Ramirez, A. (1997). "Electronic potential from the SHT." Lawrence Livermore National Laboratory: memorandum to E.L. Hardin, Lawrence Livermore National Laboratory, July 28, 1997.

Ramirez, A., T. Buscheck, R. Carlson, W. Daily, K. Lee, W. Lin, N. Mao, T. Ueng, H. Wang, and D. Watwood (1991a). "Prototype Engineered Barrier System Field Test (PEBSFT) Final Report." (UCRL-ID-106159). Livermore, CA: Lawrence Livermore National Laboratory. 
Ramirez, A., and W. Daily (1997). "Electrical resistivity monitoring of the thermomechanical heater test in Yucca Mountain." Milestone report for the CRWMS Management and Operating Contractor, U.S. Department of Energy. (SP9215M4). Livermore, CA: Lawrence Livermore National Laboratory.

Ramirez, A., W. Daily, M. Buettner, and D. LaBrecque (1996). “Electrical Resistivity Monitoring of the Thermomechanical Heater Test in Yucca Mountain." (UCRL-JC-126011). Livermore, CA: Lawrence Livermore National Laboratory.

Ramirez, A.L., T.A. Buscheck, R. Carlson, W. Daily, V.R. Latorre, K. Lee, W. Lin, N. Mao, D. Towse, T.S. Towse, and D. Watwood (1989). "Prototype Heater Test of the Environment Around a Simulated Waste Package." (UCRL-101693). Livermore, CA: Lawrence Livermore National Laboratory.

Ramirez, A.L., R.C. Carlson, and T.A. Buscheck (1991b). "In Situ Changes in the Moisture Content of Heated, Welded Tuff Based on Thermal Neutron Measurements." (UCRL-ID-104715). Livermore, CA: Lawrence Livermore National Laboratory.

Rard, J.A. (1996). "Potential for Radionuclide Immobilization in the EBS/NFE: Solubility Limiting Phases for Neptunium, Plutonium, and Uranium." Milestone report for the CRWMS Management and Operating Contractor, U.S. Department of Energy. (SPL3EM4). Livermore, CA: Lawrence Livermore National Laboratory.

Reda, D.C. (1985a). “Liquid Permeability Measurements on Densely Welded Tuff Over the Temperature Range $25^{\circ}$ to $90^{\circ} \mathrm{C}$." (SAND85-2482). Albuquerque, NM: Sandia National Laboratories.

Reda, D.C. (1985b). "Slip-flow experiments in welded tuff: The Knudsen diffusion problem." In proceedings from Int'l. Symp. on Coupled Processes Affecting the Performance of a Nuclear Waste Repository. Berkeley, CA. Sept. 18-20, 1985. Lawrence Berkeley National Laboratory. (LLBL-21850).

Rimstidt, J.D., and H.L. Barnes (1980). "The kinetics of silica-water reactions." Geochim. et Cosmochim. Acta 44:1683-1699.

Rimstidt, J.D., W.D. Newcomb, and J.L.S. Jr. (1989). “A vertical thermal gradient experiment to simulate conditions in vapor dominated geothermal systems, epithermal gold deposits, and high level radioactive repositories in unsaturated media." In proceedings from Water-Rock Interaction. Rotterdam. A.A. Balkema. 6:585-588. (D.L. Miles [ed.]).

Roberts, J.J. (1995). “Letter report on thermal-hydrological-chemical tests of small blocks in the laboratory." (DTN LL950812304244.006). Livermore, CA: Lawrence Livermore National Laboratory. (Non-Q). 
Roberts, J.J. (1996). "Figure of electrical resistivity of Large Block Test samples as a function of saturation with data table on disk that produced figure." (DTN LL960201404244.011). Livermore, CA: Lawrence Livermore National Laboratory. (Non-Q).

Roberts, J.J., and W. Lin (1994a). "Electrical properties of Topopah Spring tuff as a function of saturation." In proceedings from Fifth Annual International Conference on High-Level Radioactive Waste Management. Las Vegas, NV. American Nuclear Society, La Grange Park, IL. 2112-2120.

Roberts, J.J., and W. Lin (1994b). "Hydrological Property Measurements of Topopah Spring Tuff." (UCRL-ID-119033). Livermore, CA: Lawrence Livermore National Laboratory.

Roberts, J.J., and W. Lin (1995). "Permeability of Fractured Tuff as Functions of Temperature and Confining Pressure." In proceedings from Sixth Annual International High Level Radioactive Waste Management Conference. Las Vegas, NV. American Nuclear Society, La Grange Park, IL. 44-45. (Also UCRL-JC-119116, Lawrence Livermore National Laboratory, Livermore, CA).

Roberts, J.J., and W. Lin (1996a). “Electrical Properties of Partially Saturated Topopah Spring Tuff: Water Distribution as a Function of Saturation." (UCRL-JC-123763). Livermore, CA: Lawrence Livermore National Laboratory.

Roberts, J.J., and W. Lin (1996b). "Report on Laboratory Tests of Drying and Rewetting of Intact Rocks." (UCRL-ID-121513). Livermore, CA: Lawrence Livermore National Laboratory.

Roberts, J.J., and W. Lin (1996c). “X-ray Radiography of Fracture Flow and Matrix Imbibition." In proceedings from Seventh International High-Level Radioactive Waste Management. Las Vegas, NV. American Nuclear Society, La Grange Park, IL. 89-91. (Also UCRL-JC-122504, Lawrence Livermore National Laboratory, Livermore, CA).

Roberts, J.J., and W. Lin (1997a). “Electrical properties of partially saturated Topopah Spring tuff: Water distribution as a function of saturation." Water Resources Res. 33(4):577-587. (Also UCRL-JC123763, Lawrence Livermore National Laboratory, Livermore, CA).

Roberts, J.J., and W. Lin (1997b). "X-Ray Radiography of Fracture Flow and Matrix Imbibition in Topopah Spring Tuff Under a Thermal Gradient." Int. J. Rock Mech. E Min. Sci. 34:3-4. (paper no. 259; also UCRL-JC125612, Lawrence Livermore National Laboratory, Livermore, CA). 
Roberts, S., and B. Viani (1997). "Mineral abundances for samples from six chemistry (SEAMIST) boreholes in the Drift Scale Test (DST) area of the ESF." Milestone report for the CRWMS Management and Operating Contractor, U.S. Department of Energy. (SP9510M4). Livermore, CA: Lawrence Livermore National Laboratory.

Roberts, S.K., B.E. Viani, and D. Phinney (1996). "Intracrystalline Diffusion in Clinoptilolite: Implications for Radionuclide Isolation." In proceedings from Seventh Annual International High Level Radioactive Waste Management Conference. Las Vegas, NV. American Nuclear Society, La Grange Park, IL. (Also UCRL-JC122735, Lawrence Livermore National Laboratory, Livermore, CA).

Robinson, R.A. (1985). "Summary results and conclusions from the cooperative project at Stripa, between Sweden and the United States during 1977-1980." In proceedings from Second NEA/SKB Symp., International Stripa Project. Stockholm, Sweden. June 1985. . (organized by OECD/NEA).

Roy, D.M., and C.A. Langton (1983). "Characterization of Cement Based Ancient Building Materials in Support Seal Materials Study." (MI/ONWI523). Columbus, OH: Battelle Memorial Institute/Office of Nuclear Waste Isolation. (139 pp.).

Roy, D.M., and C.A. Langton (1989). "Studies of Ancient Concrete as Analogs of Cementitious Sealing Materials for a Repository in Tuff." (LA11527-MS). Los Alamos, NM: Los Alamos National Laboratory. (101 pp.).

Rundberg, R.S. (1987). "Assessment Report on the Kinetics of Radionuclide Adsorption on Yucca Mountain Tuff." (LA-11026-MS). Los Alamos, NM: Los Alamos National Laboratory.

Schneefuß, J., H. Kull, and T. Brasser (1989). "Stress and temperature effects on the permeability in granitic rock around a gallery excavated by continuous mining." In proceedings from OECD/NEA Workshop: Excavation Response in Geological Repositories for Radioactive Waste. Winnipeg, Canada.

Schwartz, B.M., and C.S. Chocas (1992). "Linear Thermal Expansion Data for Tuffs From the Unsaturated Zone at Yucca Mountain, Nevada." (SAND88-1581). Albuquerque, NM: Sandia National Laboratories.

Scott, D.A. (1985). "Periodic corrosion phenomena in bronze antiquities." Studies in Conservation 30:49-57.

Simmons, A.M., and G.S. Bodvarsson (1997). "Building Confidence in Thermohydrologic Models of Yucca Mountain Using Geothermal Analogues." Milestone Report for the CRWMS Management and Operating Contractor, U.S. Department of Energy. (SPLE1M4). Berkeley, CA: Lawrence Berkeley National Laboratory. 
SNL (1996). "Mechanical Properties of Fractures in Specimens from Drillhole USW SD-7 and ESF-TMA-MPBX-3 at Elevated Temperature." Data report for the CRWMS Management and Operating Contractor, U.S. Department of Energy. (MOL.19961002.0109). Albuquerque, NM: Sandia National Laboratories.

SNL (1997). "Evaluate measurements and analyze single heater test: First quarter results (8/26/96 through 11/30/96)." Milestone report for the CRWMS Management and Operating Contractor, U.S. Department of Energy. (SP9213M4/SP9233M4). Albuquerque, NM: Sandia National Laboratories.

Sobolik, S.R. (1997). "Pre-experimental thermal-hydrological-mechanical analyses for the ESF Single Heater Test—Phase 2." January 9, 1997. Letter report for the CRWMS Management and Operating Contractor, U.S. Department of Energy. (SLTR96-0005). Albuquerque, NM: Sandia National Laboratories. (Data tracking number SNF35110695001.002).

Soo, P., and L.W. Milian (1989). "Sulfate-attack resistance and gamma-irradiation resistance of some portland cement based mortars." (NUREG/ CR5279). U.S. Nuclear Regulatory Commission. (35 pp.).

Srivastava, R.C., and P.K. Avasthi (1975). "Non-equilibrium thermodynamics of thermo-osmosis of water through kaolinite." J. Hydrol. 24:111-120.

Steefel, C.I., and S.B. Yabusaki (1995). “OS3D/GIMRT: Software for modeling multicomponent-multidimensional reactive transport." Richland, WA: Pacific Northwest Laboratory, Battelle Memorial Institute.

Stockton, A.D., R.P. Thomas, R.H. Chapman, and H. Dykstra (1984). "A Reservoir Assessment of the Geysers Geothermal Field." J. Pet. Tech. pp. 2137-2159.

Stout, R.B. (1996). “Waste Form Characteristics Report.” (UCRL-ID-108314, Rev. 0). Livermore, CA: Lawrence Livermore National Laboratory.

Stout, R.B. (1997). “Waste Form Characteristics Report (Addendum, Rev. 1.2)." Milestone report for the CRWMS Management \& Operating Contractor, U.S. Department of Energy. (TR241FB2). Livermore, CA: Lawrence Livermore National Laboratory.

Stroes-Gascoyne, S., K. Pederson, S. Daumas, C.J. Hamon, S.A. Haveman, T.L. Delaney, S. Ekendahl, N. Jahromi, J. Arlinger, L. Hallbeck, and K. Dekeyser (1996). "Microbial Analysis of the Buffer/Container Experiment at AECL's Underground Research Laboratory." (AECL11436). Atomic Energy of Canada, Ltd.

Su, G. (1995). “Water Infiltration and Intermittent Flow in Rough-Walled Fractures." Berkeley, CA: University of California, Department of Civil Engineering. Masters Thesis. 
Tait, C.D., S.A. Ekberg, D.L. Clark, and P.D. Palmer (1996). “Temperature dependent $\mathrm{Pu}(\mathrm{VI})$ hydrolysis complexation." Milestone report for the CRWMS Management and Operating Contractor, U.S. Department of Energy. (4091). Los Alamos, NM: Los Alamos National Laboratory.

Taylor, H.F.W. (1987). "Bound water in cement pastes and its significance for pore solution compositions." In proceedings from Scientific Basis for Waste Management. Materials Research Society. 85:47-53.

Taylor, H.F.W. (1990). Cement Chemistry. London: Academic Press.

Telford, W.M., L.P. Geldart, R.E. Sheriff, and D.A. Keys (1976). Applied Geophysics. London: Cambridge University Press.

Thornton, E.C., and W.E.S. Jr. (1985). "Chemical and diffusional effects in a thermal gradient: Results of recent experimental studies and implications for seabed disposal of nuclear waste." In proceedings from International Symposium on Coupled Processes Affecting the Performance of a Nuclear Waste Repository. September 1985. Lawrence Berkeley National Laboratory. (LBL-21850).

Tidwell, V.C., and R.J. Glass (1994). “X-ray and Visible Light Transmission for Laboratory Measurement of Two-Dimensional Saturation Fields in Thin-Slab Systems." Water Resources Res. 30:2873-2882.

Tokunaga, T.K., and J. Wan (1997). "Water film flow along fracture surfaces of porous rock." Water Resources Res. 33(6):1287-1295.

Touloukian, Y.S., and C.Y. Ho (1981). Physical Properties of Rocks and Minerals. New York: McGraw-Hill.

TRW (1995). "Systems Study of Options for Characterizing the Calico Hills Nonwelded Hydrogeologic Unit at Yucca Mountain, Nevada." (B000000001717570500021REV00). TRW Environmental Safety Systems, Inc.

Tsang, C.-F., and D.C. Mangold (1984). "Panel Report on Coupled ThermoMechanical-Hydro-Chemical Processes Associated with a Nuclear Waste Repository." Berkeley, CA: Lawrence Berkeley National Laboratory. (LBL-18250).

Unocal (1997). "Geothermal and Power Operations." http:/ / www.unocal.com/geotherm/geysers.htm.

van Genuchten, M.T. (1980). “A closed form equation for predicting the hydraulic conductivity unsaturated soils." Soil Sci. Soc. Am. J. 44:892-898.

van Genuchten, M.T., F.J. Leij, and S.R. Yates (1991). "The RETC code for quantifying hydraulic functions of unsaturated soils." (EPA/600/291/065). Washington, DC: U.S. Environmental Protection Agency. (93 pp.). 
Vargaftik, N.B. (1975). Tables on the Thermophysical Properties of Liquids and Gases in Normal and Dissociated States. New York, NY: John Wiley \& Sons. (Second Edition).

Vaughan, P.J. (1985). "Analysis of Permeability Reduction During Flow of Heated, Aqueous Fluid Through Westerly Granite." In proceedings from Int'l. Symp. On Coupled Processes Affecting the Performance of a Nuclear Waste Repository. September 1985. Lawrence Berkeley National Laboratory. (LBL-21850).

Viani, B.E. (1996a). “Chapter 7: Integrated Testing, in: Near Field Environment Report." (UCRL-124998, Rev. 1). Livermore, CA: Lawrence Livermore National Laboratory.

Viani, B.E. (1996b). “Mineral abundances for nine samples from the thermal test area of the ESF." Data report for the CRWMS Management and Operating Contractor, U.S. Department of Energy. (DTN LL960810604244.016). Livermore, CA: Lawrence Livermore National Laboratory.

Viani, B.E. (1996c). "Mineral abundances for nine samples taken from the thermal test area of the ESF." Data report for the CRWMS Management and Operating Contractor, U.S. Department of Energy,. (DTN LL960810704244.017). Livermore, CA: Lawrence Livermore National Laboratory.

Viani, B.E. (1997). "Mineral abundances for samples used for thermal testing at SNL (boreholes in the Drift Scale Test [DST] area of the ESF)." Data report for the CRWMS Management and Operating Contractor, U.S. Department of Energy. (DTN LL970600304244.032). Livermore, CA: Lawrence Livermore National Laboratory.

Viani, B.E., and C.J. Bruton (1991). "Modeling Fluid-Rock Interaction at Yucca Mountain, Nevada." (UCRL-ID-109921). Livermore, CA: Lawrence Livermore National Laboratory.

Viani, B.E., and C.J. Bruton (1992). "Modeling ion exchange in clinoptilolite using the EQ3/6 geochemical modeling code." In proceedings from Seventh International Symposium on Water-Rock Interaction. Y. Kharaka and A. S. Maest (eds.). Brookfield, VT. A.A. Balkema. pp. 73-77. (Also UCRL-JC-109952, Lawrence Livermore National Laboratory, Livermore, CA).

Viani, B.E., and L. Carman (1996). "Transport of soluble species through tuff core." Milestone report for the CRWMS Management and Operating Contractor, U.S. Department of Energy. (SPL7A1M4). Livermore, CA: Lawrence Livermore National Laboratory. (MOL52). 
Viani, B.E., and S.I. Martin (1993). "Core-Flow Through Apparatus: Letter Report Documenting Testing Phase." Milestone report for the CRWMS Management and Operating Contractor, U.S. Department of Energy. (M0L06). Livermore, CA: Lawrence Livermore National Laboratory.

Viani, B.E., and S.I. Martin (1994). "Core Flow Experiment Protocol." Milestone Report for the CRWMS Management and Operating Contractor, U.S. Department of Energy. (M0L04). Livermore, CA: Lawrence Livermore National Laboratory.

Wang, J., and R. Suarez-Rivera (1997). “Laboratory test results of hydrological properties from dry drilled and wet drilled cores in the Drift Scale Test area and in the Single Heater Test area of the Thermal Test Facility." May 1997. Milestone report for the CRWMS Management and Operating Contractor, U.S. Department of Energy. (SP5130M4). Berkeley, CA: Lawrence Berkeley National Laboratory.

Wark, K. (1977). Thermodynamics: McGraw-Hill Book Company. (Third Edition).

Welty, J.R., C.E. Wicks, and R.E. Wilson (1984). Fundamentals of Momentum, Heat, and Mass Transfer. New York, NY: John Wiley \& Sons. (Third Edition).

Wibowo, J., B. Amadei, S. Sture, R.H. Price, and A.B. Robertson (1993). "Effect of Boundary Conditions on the Strength and Deformability of Replicas of Natural Fractures in Welded Tuff." (SAND92-1853).

Albuquerque, NM: Sandia National Laboratories.

Wilder, D.G. (1996a). Near Field Environment Report. Livermore, CA: Lawrence Livermore National Laboratory. (UCRL-LR-124998, Rev. 1).

Wilder, D.G. (1996b). “Near-Field and Altered-Zone Environment Report, Volume II." (UCRL-LR-124998). Livermore, CA: Lawrence Livermore National Laboratory.

Wilder, D.G., and J.L. Yow (1987). "Geomechanics at the Spent-Fuel TestClimax." (UCRL-53767). Livermore, CA: Lawrence Livermore National Laboratory.

Witherspoon, P.A. (1996). "Geological Problems in Radioactive Waste Isolation: Second Worldwide Review." (LBNL-38915). Berkeley, CA: Lawrence Berkeley National Laboratory.

Wolery, T.J. (1992a). “EQ3/6, A Software Package for Geochemical Modeling of Aqueous Systems: Package Overview and Installation Guide." (UCRL-MA-110662). Livermore, CA: Lawrence Livermore National Laboratory. (part 1). 
Wolery, T.J. (1992b). "EQ3NR, A Geochemical Program For Aqueous SpeciationSolubility Calculations: Theoretical Manual, User's Guide, and Related Documentation." (UCRL-MA-110662). Livermore, CA: Lawrence Livermore National Laboratory. (part 3).

Wolery, T.J., and S.A. Daveler (1992). “EQ6, A Computer Program for Reaction Path Modeling of Aqueous Geochemical Systems: Theoretical Manual, User's Guide, and Related Documentation (Version 7.0)." (UCRL-MA-110662). Livermore, CA: Lawrence Livermore National Laboratory. (part 4).

Wruck, D.A., and C.E.A. Palmer (1997). "Status Update on the Analysis of Elevated Temperature Data for Thermodynamic Properties of Selected Radionuclides." Milestone report for the CRWMS Management and Operating Contractor, U.S. Department of Energy. (SPL4B1M4). Livermore, CA: Lawrence Livermore National Laboratory.

Wruck, D.A., C.E.A. Palmer, and R.J. Silva (1996). “Stability quotients of actinide complexes at 25,50 , and $75^{\circ} \mathrm{C}$ by laser-induced photoacoustic spectroscopy." Milestone report for the CRWMS Management and Operating Contractor, U.S. Department of Energy. (MOL163, Rev. 1). Livermore, CA: Lawrence Livermore National Laboratory.

Yehaneh-Hari, A., D.J. Weidner, and J.B. Parise (1992). "Elasticity of a-Cristobalite: A Silicon Dioxide with a Negative Poisson's Ratio." Science 257:650-652.

Zielinski, R.A. (1980). “Uranium in secondary silica: A possible exploration guide." Economic Geology 75:592-602.

Zimmerman, R.M., M.L. Blanford, J.F. Holland, R.L. Schuch, and W.H. Barrett (1986a). "Final Report: G-Tunnel Small Diameter Heater Experiments." (SAND84-2621). Albuquerque, NM: Sandia National Laboratories.

Zimmerman, R.M., and R.E. Finley (1987). "Summary of geomechanical measurements taken in and around G-Tunnel Underground Facility, Nevada Test Site." (SAND86-1015). Albuquerque, NM: Sandia National Laboratories.

Zimmerman, R.M., R.L. Schuch, D.S. Mason, M.L. Wilson, M.E. Hall, M.P. Board, R.P. Bellman, and M.L. Blanford (1986b). "Final Report: GTunnel Heated Block Experiment." (SAND84-2620). Albuquerque, NM: Sandia National Laboratories. 